\title{
The Success of a Policy Model Irrigation Management Transfer in Mexico
}

Edwin Rap 


\section{Propositions}

1. T'm hopeful. I know there is a lot of ambition in Washington, obroiously. But I hope the ambitious realize that they are more likely to succeed with success as opposed to failure.' George W. Bush

Interview with Associated Press, January 18, 2001.

This thesis, Chapter 10

2. The Mexican policy of Irrigation Management Transfer is a success.

This thesis, Chapter 11

3. The privileged position of academic researchers enables them to follow the actors involved in policy processes, but not necessarily the current in which they drift. The outcome of such research is policy relevant; after all it is about policy, even when it is not cast in the form of policy recommendations.

4. Drinking is a form of irrigation of which the importance is hugely underestimated in the study of irrigation management performance.

5. In order to understand domination we have to turn away from an exclusive concern with social relations and weave them into a fabric that includes nonhuman actants, actants that offer the possibility of holding society together as a durable whole'.

From: 'Technology is society made durable' (Latour, 1991: 103)

6. Repetitive Strain Injury (RSI) is a contemporary Dutch consequence of a Calvinist work ethic. We cannot help it. It is our culture.

Insight generated in the process of writing this thesis

7. 'After one look at this planet any visitor from outer space would say,

"I want to see the manager".

William S. Burroughs

Propositions belonging to the thesis 'The Success of a Policy Model: Irrigation Maragement Transfer in Mexico'. To be defended by Edwin Rap on the $20^{\text {th }}$ of September, 2004. 


\section{THE SUCCESS OF A POLICY MODEL}

\section{IRRIGATION MANAGEMENT TRANSFER IN MEXICO}




\section{Promotor:}

Prof. Dr. N.E. Long

Hoogleraar in de ontwikkelingssociologie

Wageningen Universiteit

\section{Copromotor:}

Dr. J. K. van Donge

Universitair docent

Institute of Social Studies, Den Haag

Promotiecommissie:

Prof. Dr. S. Whiteford

Michigan State University, USA

Prof. Dr. F. Wilson

Roskilde University, Denmark

Prof. Dr. Ir. C. Leeuwis

Wageningen Universiteit

Dr. Ir. P. van der Zaag

Technische Universiteit Delft

Dit onderzoek is uitgevoerd binnen de onderzoekschool CERES. 


\title{
THE SUCCESS OF A POLICY MODEL
}

\section{IRRIGATION MANAGEMENT TRANSFER IN MEXICO}

\author{
Edwin Rap
}

Proefschrift ter verkrijging van de graad van doctor op gezag van de rector magnificus van Wageningen Universiteit prof. dr. ir. L. Speelman in het openbaar te verdedigen op maandag 20 september 2004 des namiddags te vier uur in de Aula

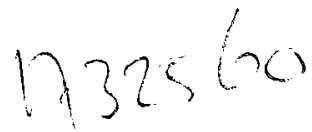


Edwin Rap

The Success of a Policy Model:

Irrigation Management Transfer in Mexico

Keywords: Irrigation Management, Policy, Organization, Bureaucracy, Political Culture, Public Administration, Ethnography, Irrigation Management Transfer, Mexico

ISBN: 90-8504-077-9

Copyright $(2004$ by Edwin Rap 
To my mother 



\section{Table of Contents}

Table of Contents vii

List of Figures ix

List of Tables $\quad$ ix

List of Boxes $\quad$ ix

List of Maps $\quad x$

List of Photos $\quad x$

List of Acronyms $\quad$ xi

Glossary $\quad$ xiii

Acknowledgements $\quad$ Xv

1 Introduction: A research journey 1

1.1 Introduction 1

1.2 Prelude $\quad 2$

1.3 The Research Proposal 4

1.4 The Course of the Research 11

1.5 Limitations of the Study 21

1.6 Outline of the Chapters 21

2 The Politics of Creating Commitment: Irrigation reforms and the reconstitution of the hydraulic bureaucracy in Mexico 25

2.1 Introduction $\quad 25$

2.2 The Construction Era (1926-1976) and the Formation of the Hydraulic Bureaucracy 27

2.3 Loss of Autonomy and the Emergence of Policy Ideas in the SARH Era (1976-1988) 34

2.4 Towards a Reform Package

2.5 The Creation of the CNA and Irrigation Management Transfer 47

2.6 Conclusions

3 Engineering a Policy Package: From the slow to the fast track

3.1 Introduction

3.2 Standardising the Transfer Package: Assembling Technologies of Governance

through Initiatives and Resistance on the Ground (1989-1991)

3.3 Over the Hill: Accelerated Transfer and Success (1992-1994)

3.4 The policy package in action

3.5 Conclusion

4. An Introduction to the Region: The Left Bank of the Santiago River 89

4.1 Introduction

4. 2 The Regional Landscape

4.3 Irrigated Agriculture

4.4 The Irrigation System in a Wider Perspective

108

4.5 Conclusion 
5 Following the Current: A situated case study of a canalero

5.1 Introduction

5.2 The Left Bank Canaleros $\quad 126$

5.3 Case Study Laguna $\quad 132$

$\begin{array}{ll}5.4 \text { Conclusion } & 146\end{array}$

6 The Client in a Political Group: The case and place of a canalero 153

6.1 Introduction 154

6.2 Diego as a Cultural Agent $\quad 157$

6.3 Privileged Support to Large Producers 164

6.4 Privileged Access Pérez $\quad 170$

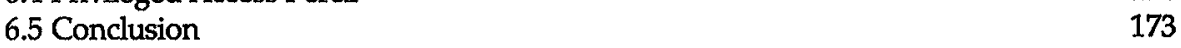

7 The Multiple Performances of Maintenance Machinery 179

$\begin{array}{ll}7.1 \text { Introduction } & 180\end{array}$

$\begin{array}{ll}\text { 7.2 Maintenance on the Left Bank } & 181\end{array}$

$\begin{array}{ll}\text { 7.3 The Organisation of Maintenance } & 189\end{array}$

7.4 The Socio-Material Practice of Maintenance 194

$\begin{array}{ll}7.5 \text { Conclusion } & 200\end{array}$

8 The Cultural Performance of an Election Rally: Using the WUA as a political platform

8.1 Introduction: Organisational Models of Resource Management and Politics 208

8.2 The Election Rally 223

8.3 Analysis 229

8.4 Conclusions 239

9 Accountability in Times of Financial Crisis 245

9.1 Introduction 246

9.2 Financial Accountability: The CNA and the WUA 248

9.3 Two Consecutive Delegate Assemblies 257

9.4 Analysis $\quad 270$

$\begin{array}{ll}9.5 \text { Conclusion } & 272\end{array}$

10 The Success of a Policy Model: Irrigation management transfer in Mexico 277

$\begin{array}{ll}\text { 10. } 1 \text { Introduction } & 277\end{array}$

10. 2 The Production and Promotion of a Policy Model 279

10.3 The Success of the Mexican Model 287

10.4 Conclusions $\quad 300$

11 Conclusions 303

11.1 The Practice of User Management and Outcomes of IMT 303

11.2 Discrepancy Between the Policy's Proclaimed Success and its Practice $\quad 305$

11.3 The Political Opportunities Opened Up by Neo-liberal Policy 308

11.4 An International Workshop 313

11.5 The Ethnography of Irrigation, Policy and Organisation 314

Epilogue on the Culture and Politics of the Gold Coast 
Appendices $\quad 335$

Appendix 1: Plan Nacional Hidráulico 335

Appendix 2: Details of World Bank Lending History from 1982

Appendix 3: The Pre-1989 Technologies of Governance and the IMT Package 339

Appendix 4: Steps Involved in First Phase of Transfer Progamme 341

Appendix 5: Nayarit 343

Appendix 6: Financial Data 344

Summary $\quad 347$

Resumen $\quad 350$

$\begin{array}{ll}\text { Samenvatting } & 353\end{array}$

$\begin{array}{ll}\text { Curriculum Vitae } & 357\end{array}$

\section{List of Figures}

Figure 1 Area transferred in the period 1989-1994 ......................................................... 72

Figure 2 Crop distribution in the $1997 / 98$ irrigation season .......................................107

Figure 3 Guttiérez' organisational chart............................................................................... 189

\section{List of Tables}

Table 1 Development of the CNA's income from water rights and fees.........................50

Table 2 Financial self-sufficiency levels of the CNA ......................................................51

Table 3 Sections 3 and 5 in Autumn-Winter 1999 ..................................................... 136

Table 4 Annual maintenance programme and report compared...................................... 184

Table 5 Historical overview financial balance of the Left Bank module..........................344

Table 6 Historical analysis of irrigation service fee recovery in the Left Bank's module and its payment for 'water in blocks' to the CNA-District................................345

Table 7 Monthly overview of irrigation service fee collection 1997-1998 .......................346

\section{List of Boxes}

Box 1 The multiple performances of a pick-up 


\section{List of Maps}

Map 1 Irrigation Districts in Mexico ……....................................................................6

Map 2 The regions of Nayarit....................................................................................91

Map 3 The course of the Great River of Santiago in Nayarit..................................... 93

Map 4 The Left Bank of the River Santiago Irrigation Module ................................. 103

Map 5 Municipalities in Nayarit..........................................................................110

Map 6 Operational sections of The Left Bank .........................................................128

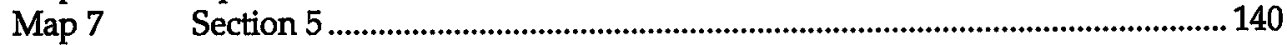

Map 8 Machine-operator movements....................................................................... 195

\section{List of Photos}

Photo 1 The beauty of an irrigated landscape ................................................................. xviii

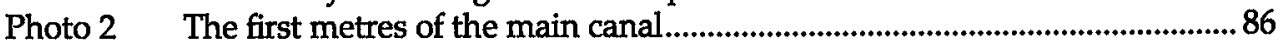

Photo 3 Santiago Ixcuintla from the Right Bank of the River Santiago .........................86

Photo 4 A fisherman repairing his net.........................................................................87

Photo 5 A cross-regulator from on top of a tobacco truck ............................................ 88

Photo 6 A sprinkler pump...............................................................................................119

Photo 7 A pipeline with sprinklers.................................................................................. 119

Photo 8 A bombero carrying pipes..............................................................................120

Photo 9 A tabaquero and his horse working the land .................................................. 120

Photo 10 The canalero and an irrigator closing an inlet.................................................150

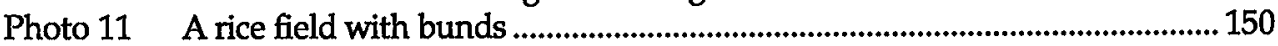

Photo 12 An irrigator working on an irrigation furrow................................................. 151

Photo 13 Canaleros distributing food ...........................................................................152

Photo 14 A neglected cross-regulator................................................................................ 177

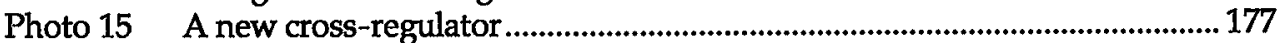

Photo 16 The podium at the annual assemblee of the WUA...........................................178

Photo 17 The water user delegates facing the podium....................................................178

Photo 18 The new bridge over the River Santiago............................................................204

Photo 19 A public work carried out with maintenance machinery ................................. 204

Photo 20 Ejido commissioners arriving at the rally .......................................................205

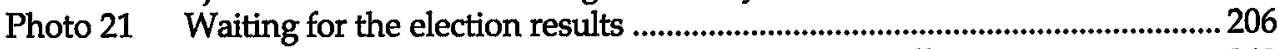

Photo 22 A CNA pick-up parked in front of the new WUA office................................. 243

Photo 23 An ejidatario in the office about to pay his irrigation fee..................................243

Photo 24 An assembly meeting from the back ................................................................ 244

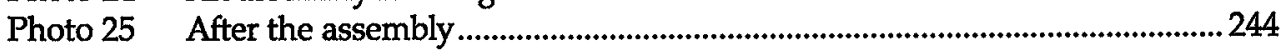

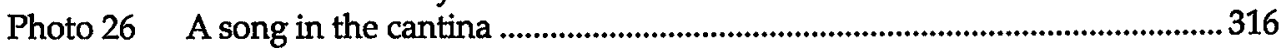

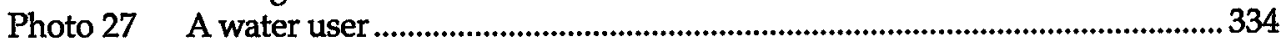

Photo 28 The Great River of Santiago turning towards the Pacific Ocean...................334 


\section{List of Acronyms}

ANUR

ARIC

BANRURAL

CFE

$\mathrm{CMC}$

CNA

$\mathrm{CNC}$

$\mathrm{CNI}$

CNOP

CONASUPO

CNPP/CNPR

CTM

DID

EDI

FAO

ICID

IMT

IMTA

IADB

IBRD

ICTD

IFPRI

IMF

IMTA

IMT

INPIM

IWMI

NAFTA
Asociación Nacional de Usuarios de Riego; National Association of Irrigation Users (ANUR)

Asociación Rural de Interés Colectioo; Rural Association of Collective Interest

Banco Nacional de Crédito Rural; National Bank for Rural Credit

Comisión Federal de Electricidad: Federal Electricity Commission

Comité Municipal de Campesinos; Municipal Peasant Committee

Comisión Nacional del Agua; National Water Commission

Confederación Nacional de Campesinos; National Peasant Confederation

Comisión Nacional de Irrigación; National Irrigation Commission

Confederación Nacional de Organizaciones Populares; National Confederation of Popular Organisations

Compañias Nacional de Subsistencias Populares; National Subsidised Staple Products Company

Confederación Nacional de Pequeños Propietarios', later changed to Confederación Nacional de Propietarios Rurales; National Confederation of Rural Proprietors

Confederación de Trabajadores de México; Confederation of Mexican Workers

Directorate of Irrigation Districts (CNA)

Economic Development Institute, the educational arm of the World Bank

Food And Agriculture Organization Of The United Nations International Commission on Irrigation and Drainage

Irrigation Management Transfer

Instituto Mexicano de Technologia del Agua; Mexican Institute of Water Technology

Inter-American Development Bank

International Bank for Reconstruction and Development

International Commission on Irrigation and Drainage

International Food Policy Research Institute

International Monetary Fund

Instituto Mexicano de Technología del Agua; Mexican Institute of Water Technology

Irrigation Management Transfer

International Network on Participatory Irrigation

Management

International Water Management Institute

North American Free Trade Agreement; Tratado de Libre Comercio 
NPM

O\&M

PAN

PIM

PNH

PPS

PRD

PRI

PROCAMPO

PRODERITH

PRONASOL

PT

SAG

SAGAR

SARH

SHINO

SPP

SRH

SRL

Tabamex

UNAM

WUA

WTO
New Public Management

Operation and Maintenance

Partido Acción Nacional; National Action Party

Participatory Irrigation Management

Plan Nacional Hidráulico: National Water Plan

Partido Popular Socialista; Popular Socialist Party

Partido de la Reoolución Democrática; Party of the Democratic Revolution

Partido Reoolucionario Institucional: Institutional Revolutionary Party

Programa de Apoyos Directos al Campo; Direct Agricultural Support Payments Programme

Programa de Desarrollo Rural Integrado del Tropico Húmedo; Programme for the Integrated Rural Development of the Humid Tropics

Programa Nacional de Solidaridad; National Solidarity Programme

Partido de Trabajo; Labour Party

Secretaría de Agricultura y Ganadería; Ministry of Agriculture and Livestock

Federal Ministry of Agriculture

Secretaría de Agricultura y Recursos Hidráulicos; Ministry of Agriculture and Water Resources

Sistema Hidraulico Interconectado del Noroeste: Northwestern Interconnected Hydraulic System

Secretaria de Programación y Presupuesto: Ministry of Programming and Budget

Secretaria de Recursos Hidráulicos; Ministry of Water Resources

Sociedad de Responsabilidad Limitada; Society of Limited Responsibility

Tabacos Mexicanos; tobacco parastatal

Universidad Nacional Autónoma de México; National National Autonomous University of Mexico

Water Users' Association

World Trade Organization 


\section{Glossary}

albures
banda
birria
bomberos
cacique
campesino
canaleros
comida politica
compadrazgo
concertación social
confianza
Costa de Oro
cuatismo
diputado

ejidatarios ejido

ejido commissioners

equipo

hacienda

headworks

hydraulic bureaucracy

hydrocracy

hydrocrat

informe

Irrigation District

lateral

licenciado

machine-operators

mariachi jokes with a double meaning and often a sexual undertone music played by a brass orchestra

a regional goat meat dish, particularly served during special celebrations and public gatherings

operators of pumps and sprinkler installations

regional strongman

peasant

water guards, who are responsible for the water distribution political meal

ritual co-parenthood between compadres and comadres

social consensus building or consultation

trust

Gold Coast

a Mexican form of male friendship

deputy; Every electoral district in a state elects a local deputy or MP to represent it in the state congress. Nayarit has eighteen such districts. Each state also has a number of federal deputies in the Federal Chamber of Deputies that is part of the national legislature.

members of ejidos

land reform communities created after the Mexican Revolution

president, secretary, and treasurer of an ejido committee and the president of the control committee

team of trusted collaborators

large landholding

hydraulic work that functions as the water source for an irrigation system, e.g. a dam

the various government agencies that were responsible for the allocation, distribution and use of the nation's waters and the construction and administration of hydraulic infrastructure

hydraulic bureaucracy

a contraction of hydraulic bureaucrats that is used to refer to engineers working in water bureaucracies

reporting

medium- to large-scale irrigation systems in Mexico, for the largest part constructed by the hydraulic bureaucracy

lateral or secondary canal

title of bachelor, used to address (among others) a lawyer, and expressing respect

composite entities of maintenance machines and operators executing maintenance work

popular music characteristic of Western Mexico 


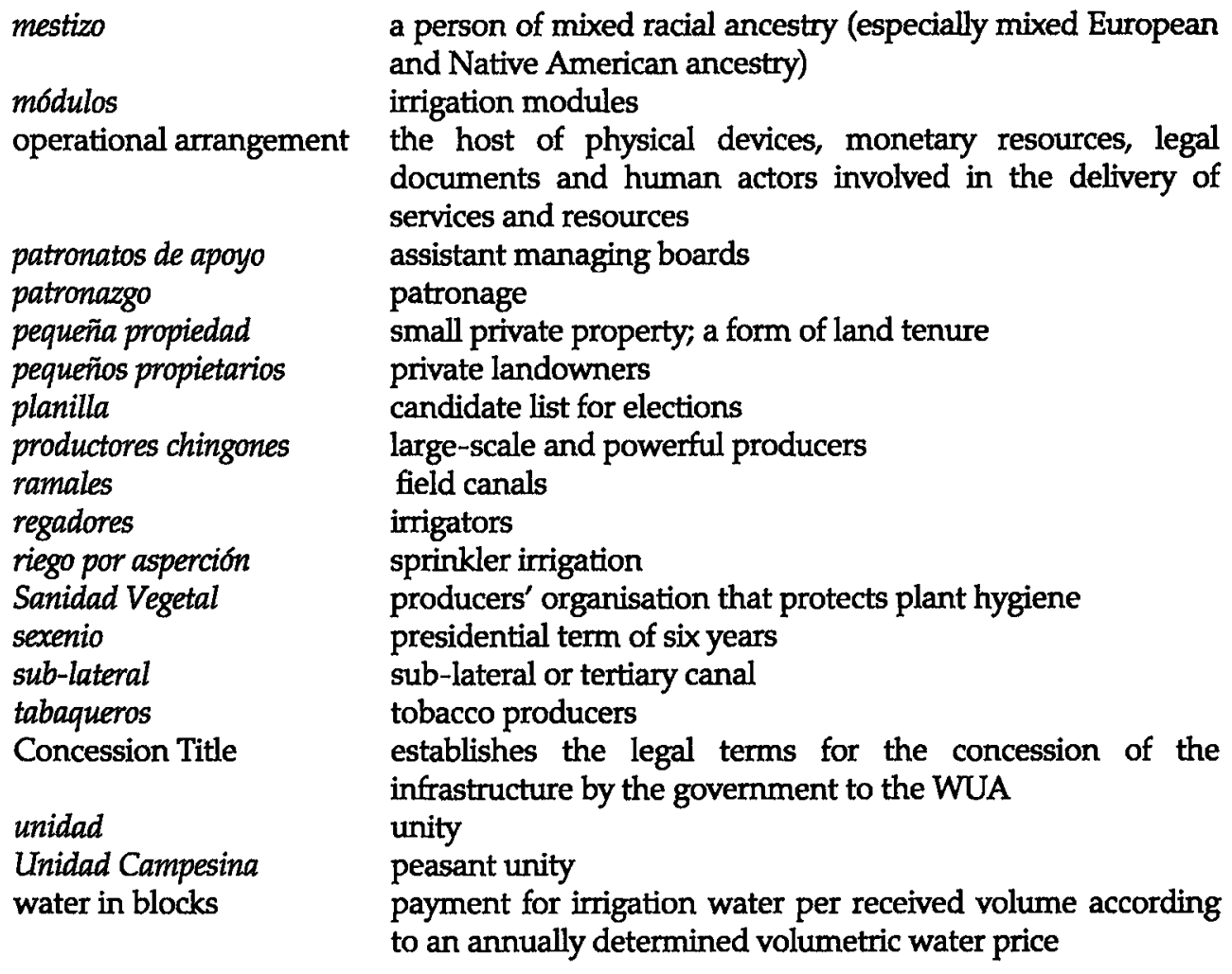




\section{Acknowledgements}

This $\mathrm{PhD}$ thesis is dedicated to my mother. It is in some way an unintended product of her perseverance to make sure her children got on in life, despite numerous setbacks. I inherited some of this from her and owe her a lot more, so I really would have liked her to see me defend it. That this will not be possible, indicates the most painful episode of the period that I am about to conclude. A seemingly minor but telling thing that she taught me at a young age was not to give up on a book with a slow start until I had read the first fifty pages. Often she was right, the book would catch my imagination after the first pages and become way too captivating to put aside. A larger lesson that I learned from this was not to give up too easily on something that you start.

Ethnographic research is such a schizophrenic process. After living and researching in Mexico for two years and enjoying every minute of the smells, tastes, people, and music that appear to make you a different person, you go back and sit behind a university computer to write about the experience for an even longer period. Disconnected from the world you try to communicate on paper, yet connected to the World Wide Web. It takes a long time to know what you should write and then how to write it. In the process, you go through several crises in terms of motivation, and physical and mental health. The triumphs are scarce and the journey is lonesome, as very few people really understand what you are doing. There is really not one sensible reason to embark upon such an activity. At the same time, it is also a most enriching experience with ample opportunity and freedom for your own formation. So now that I have finished it, I am proud and reckon that doing this was the best job in the world.

There are many people whom I would like to thank for helping me and making the process so much more pleasurable. In Mexico, I started working in the Colegio de Michoacán, a task in which Esteban Barragan and Brigitte Böhm were very helpful. There I developed a circle of friends who transformed Zamora into an exciting town - an achievement of considerable proportions - and with whom I had many discussions and organised several parties from which I learned a lot: Zulma, Blanca, Fransisco, Eduardo, Alma, and many others. With some romanticism, I remember the parties that took not much more than tequila, a table with food that we prepared ourselves, and an old cassette recorder that played the music to which I made my first timid attempts to dance a merengue. At the Colegio, Luz Nereida helped me to start up the research and discuss the findings.

At the Autonomous University of Nayarit in Tepic, I benefited a lot from the assistance of Omar Wicab and Emma Sifuentes. Not only did they help me to understand Nayarit, make contacts and undertake my research, they were also great friends who generously invited me into their home, whenever I was in Tepic. Talking with them about my fieldwork functioned as a necessary reflective exercise. At the university, there were numerous other people who assisted me to fill in parts of the puzzle. I am most thankful to them. I particularly remember a long, very instructive, conversation with Javier Castellon, who is from Santiago Ixcuintla and told me a lot about the region. I also want to thank Carmen who assisted me in finding information, books, and other materials. 
In Santiago Ixcuintla I developed a close friendship with Pepe and Gaby and their children. Pepe is a sociable person and a local English teacher who gathered a class of enthusiastic students around him whom I got to know very well and with whom I enjoyed spending time. Gaby is a generous human being and a great cook who often invited me to eat with them and feel at home in Santiago. Several local engineers introduced me to topics such as sprinkler irrigation and tobacco, as well as how to eat certain local dishes, which beer to drink, and which politicians or issues to follow.

When I found a nice house in a working-class neighbourhood, I got to know my neighbours the very first morning. At six or seven o' clock, the neighbour opposite started his day with a ritual that involved accelerating the motors of two old American cars for fifteen minutes in order to warm them up. If I am not mistaken, he left on foot that day. Besides myself, this exercise woke up his old neighbour who was over from Los Angeles. This former LA resident placed his cassette player in front of his house and started to play loud banda music, drink beer, and observe street life from a rocking chair. Later he told me that this was impossible in LA, where he would immediately be hit with a fine. Here, at least, he was not confined within walls, and he was free to do what he wanted an idea of freedom that surprised me. Quite innocently, I asked some of my female neighbours whether this was the local custom. They told me: We are cheerful people. We are born and we die with music'. In the process of living there I learned to love the people, their ways of expressing themselves and of accepting my Dutch presence in their neighbourhood. I have a fond memory of my farewell party. In the best tradition, everybody from the neighbourhood turned up without it being necessary for me to issue any invitations. The rumour of a party with food and drink was enough. A combo played whilst we were eating birria, a dish that you will encounter on several occasion in this book. Rigoletto, my singing teacher, sang a few romantic songs. Many people stayed until the beer was finished. Indeed, the people from the Northern Coast of Nayarit are, in spite of all their economic misfortune, the most cheerful and high-spirited bunch that I have known so far.

I am indebted to all the farmers, workers and managers who shared their working and private lives with me with very little in return. I have attempted to represent their lives as truly and in as nuanced a way as possible for me. I am also grateful to numerous CNA officials at different levels who enabled me to carry out my research or provided information. Although I do not always agree with individual opinions, I have much respect for the knowledge and experience within this institution. In Mexico City I have benefited from open conversations with several people from the academic, institutional, and political spheres. In particular, I would like to mention the researchers from the RISSA network who are trying to bring about an academic and informed public debate on water issues, from whom I learned a lot in recent years. When I started to work with Flip Wester, the research took a whole new turn. Interviewing and writing jointly with him was a most pleasant, instructive, and exciting enterprise. I thank the IWMI for their support of our work.

Back in The Netherlands, there is a long list of people whom I thank for making my work and life more agreeable. First of all, I would like to thank Jens Andersson, Alex Bolding, and Flip Wester, whom I consider to be not only my friends but also my intellectual kin. Jens and Judith were there for me at both difficult and cheerful moments, and I value 
Alex' intelligence and his friendship. Whilst I was working at the Department of Rural Development Sociology, one of the most interesting experiences was sharing a room, and often large parts of our lives, with people from around the globe, who then became good friends: Woldeab, Hamidul, Carla, Humberto, and others. Together with Jens, Flip and Gemma we re-initiated a regular seminar at the department at which people could present their papers in a constructive atmosphere, something that was indispensable for us PhDs. Of course, I want to thank Norman Long, my supervisor, who made it possible and stimulated me to do 'my own thing'. His presence has had a profound influence on the academic tradition of the department, and on myself, and he has fostered an appreciation for good fieldwork, which I value. I also want to thank the department members for supporting me in different ways. In particular, I would like to mention Monique Nuijten, from whom I learned a lot and whose seriousness in supervising and interacting with students I appreciate. Further, Jos Michel has helped me with too many things to remember all. Several of these and other people have read, commented upon, and improved my chapters. Gracias.

I am most thankful to The Netherlands Foundation of Tropical Research (WOTRO), which enabled this research by providing funds. I also want to thank the Section of International Development Studies of the Roskilde University, in particular Fiona Wilson and Christian Lund, for a fruitful stay of four months in their work place. Ben and Wolf accompanied me. The Department of Rural Development Sociology also supported me. During the last year I have benefited a great deal from the scholarship, experience, and generosity of Jan-Kees van Donge. As a result, this has become a more readable book without 'frenchisms', such as (in his words): The materiality made concrete by the mediation as embedded in the process of hegemonisation'. If you still find some, don't blame him, he has done his best. I am greatly indebted to his skilful and stimulating way of supervising me. Here I also want to mention Catherine O'Dea, who has edited the manuscript with admirable patience and empathy and hence contributed immensely to its readability. Then, I would like to thank Pim van Hengel, a great friend who helped me with the maps and Olivier Rijcken for designing the cover. Rob has helped me a lot with computers, and Yvonne was so sweet to make the photos ready.

Why not thank my band 'The Lahars', my housemates, and many other friends for not doing anything in relation to this thesis, which helped me to forget it when it was crucial. And last but not least my family: Mia, Lian, and the larger family, especially my brother Jan-Martijn and sister Daniëlle, to whom I am grateful for stimulating me and forgetting to ask me when 'it' would be finished. I see my mother and father reflected in them. 


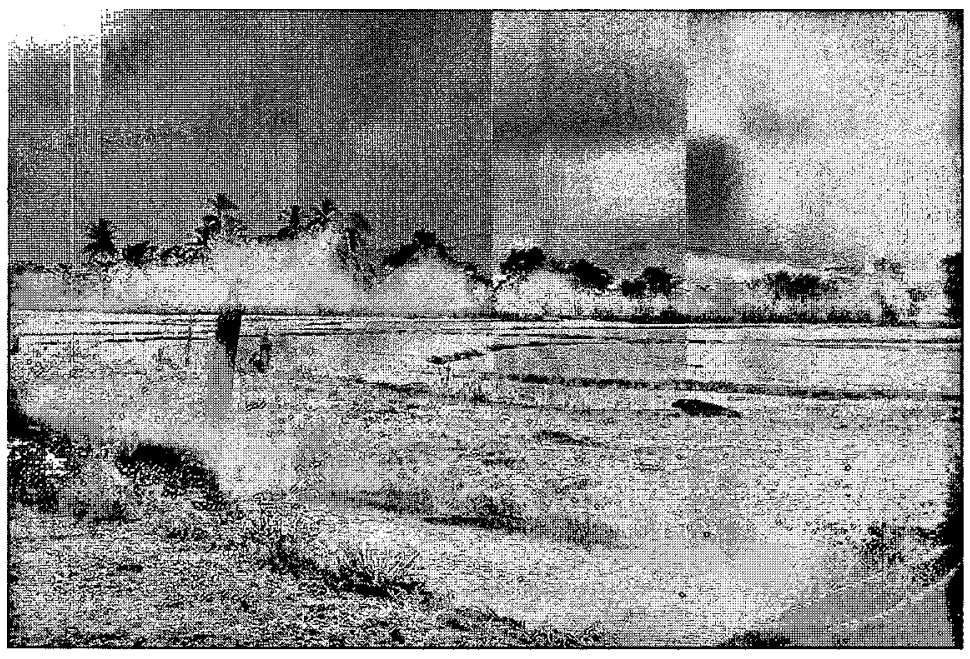

Photo 1 The beauty of an irrigated landscape 


\section{Introduction:}

\section{A research journey}

\subsection{Introduction}

This thesis examines the origin, process and outcomes of the Mexican policy of Irrigation Management Transfer (IMT). Under the influence of neo-liberal government policies, the transfer of government-managed irrigation districts to water users' associations (WUAs) has radically changed irrigation management in Mexico during the past fifteen years. Internationally, Mexico's IMT programme has been heralded as a success and has drawn widespread attention because of its rapid implementation. Consequently, it has been propagated as a model for other countries seeking to improve the performance of their public irrigation systems and cut burgeoning public expenditures (Groenfeldt, 1998). This study firstly critically examines the emergence of this policy model and its proclaimed success. Secondly, it discusses the impacts this has on everyday irrigation management.

Most studies that have appeared so far on the Mexican experience of management transfer have reproduced this appealing imagery of success and have not contested the ideological claims that underlie the Mexican IMT model. This occurs because, among other things, the currently dominant policy and management literature is based on a systems analysis that de-politicises policy implementation and irrigation management. This leads to two analytical flaws that are sustained by the false dichotomies between policy formulation and implementation and between politics and management. Firstly, the political process of policy making is not finished after the formulation of a policy. Secondly, policy implementation and irrigation management are not neutral and technical processes that can be reduced to a blackbox, in which inputs are transformed into logical and inevitable system outputs. This book aims to provide an alternative perspective on policy reform and irrigation management, by overcoming these flaws. My contribution to the study of policy and irrigation management is that I consistently analyse them as political practices that are also expressive of the cultural dimensions of human action and social ordeting. To do this, the book sets out in two directions.

On the one hand, the thesis offers a comprehensive analysis of the entire life cycle of the IMT policy. It traces the idea of transfer back to its bureaucratic roots and reviews how the idea gained political commitment as the result of a prolonged bureaucratic struggle. This shows that the IMT policy has a fascinating political history and that it is tied up with the past and the future of the hydraulic bureaucracy. Then, the thesis discusses how the assembling of a policy package that materialised the changes at the field level was still an intensely political process of policy making that, in the end, contributed to accelerated effectuation in Mexico's irrigation districts. Towards the end, I focus on how the Mexican IMT policy became an international policy model that was propagated as a huge success. This aspect of the book results in the understanding that policy is political 
throughout its life cycle and that policy making is a continuous and profoundly cultural undertaking.

On the other hand, this book takes a close look at the everyday organisational practices that have emerged in a WUA around the strategic resources of water, maintenance machinery and irrigation fees. It shows how a political group based in a WUA maintains a network of political and institutional relations by controlling this set of resources. The outcome of this process in this case is that the organisation becomes a platform to further the careers of the group's proponents and their ascendancy to important posts in the regional government. Central to the group's efforts is the organisation and cultural performance of a series of election events. This aspect of the book illustrates how the continuous political nature of IMT affects the outcomes of the policy and focuses attention on the cultural aspects of irrigation management and politics.

\subsection{Prelude}

Looking back at my research, I have made a journey that has led me along several passage points, critical moments through which new insights emerged, some of which were predictable and others most unexpected. They determined the further course that the research has taken, and therefore also the outcomes. In this chapter I take the reader through some of these points in time, so that you understand both the product and the path that led me to it.

The seed of this thesis was sown what seems like ages ago. For my MSc, I studied Tropical Land and Water use (Tropische Cultuurtechniek) at Wageningen University. I was part of a wave of irrigation students who tried to incorporate the social sciences in an attempt to arrive at an interdisciplinary understanding of irrigation management, something that later settled as the socio-technical approach of the Irrigation and Water Engineering Group (Mollinga, 1992; Bolding et al., 1995; Vincent, 1997; Oorthuizen, 2003). Because I inclined more towards the social sciences, I left the development of my engineering skills aside. However, the heated ideological and political debates with my fellow students and former professors shaped my perspective on the possibility of ordering and stabilising social and organisational life by means of irrigation technology.

Another influence that shaped me was the actor-oriented approach of Norman Long (Long, 2001), which centres human agency as the point of departure for analysing social life. The academic climate that he created in Wageningen triggered and nourished my skills and preference for ethnography as a means of analysis. Long's influence is notable throughout this study. To start with, in the choice of methods, of which many can be traced back to the Manchester School. I cannot imagine a better stimulus for conducting ethnographic research than familiarity with an extended case study such as that of the multiple enterprises and social networks of Romero in the Central Highlands of Peru (Long, 1979; Long, 2001). An aspect that I particularly value about the actor-oriented approach is that it opens up a perspective on actual social behaviour that is very productive for research, without providing a closed theoretical model that 'explains' things beforehand. Further, early on in my MSc. study I read the article Long wrote with van der Ploeg about 'de-mystifying planned intervention', which radically changed my 
understanding of policy and the role of social interfaces in generating a variety of outcomes (Long and van der Ploeg, 1989, 1995; Long 1989).

At the same time, I developed an interest in actor-network theory (Latour, 1987; Law, 1994). I found it most useful because it attempted to integrate the social, technological, and natural in the analysis of scientific research, without seeing them as separate domains, where one prevails over the others. I considered this also applicable to the analysis of irrigation, organisation, and policy.

Over the years, it has become my conviction that the actor-oriented approach and the actor-network approach can have a mutually enriching influence on each other. On the one hand, the actor-oriented approach opens up possibilities to study technology and materiality with a methodological sensibility for the cultural dimensions of social and material practices. On the other hand, the actor-network approach enables an understanding of the role of materiality in all forms of power, practices, and processes of social ordering.

The origin of my $\mathrm{PhD}$ research lies in an intensive four months of fieldwork in Mexico that I undertook towards the end of my MSc study. This final piece of research that combined Rural Development Sociology and Irrigation was a slightly unexpected reacquaintance with the field of irrigation, although now from a different angle, that of organisation studies. The research involved a detailed organisational study of the El Grullo Irrigation District in Jalisco (See map 1: 094), the first irrigation district in Mexico to be transferred to a water users' association - in 1989. An interesting aspect of this irrigation district was that it had been studied under government management by Pieter van der Zaag, whose thesis I had read with great interest (van der Zaag, 1992). I was curious to find out what had happened after the transfer. At the time of my research, the Mexican model of IMT had already achieved the status of a success, and visitors from all over the republic and even from abroad (like myself) started to arrive in El Grullo to satisfy their interest in the actual workings of WUAs.

However, I soon found out that in this district nobody referred to success in the same way as the official policy accounts did. Without doubt, the practice of irrigation management had changed significantly, and in some aspects such as maintenance and fee collection clearly for the better but, in everyday practice, the changes to organisational practices were much more complex than usually acknowledged in policy documents. In the El Grullo Irrigation District, people differed about the extent to which these changes were beneficial to them. This often depended on their own position in the transfer process and vis-à-vis the local groups involved in the WUA. The WUA's board was composed of prominent (ex-)politicians and members of the regional elite who all shared an interest in sugarcane production. An important role was played by the manager of the WUA, who was at the same time the secetary of the association of private sugarcane producers. He had very close ties to the landed elite and the sugarcane refinery of the irrigation district; and he favoured these in terms of irrigation management services. A financial agreement with the sugar refinery secured the advance of the irrigation fees of sugarcane producers to the WUA. The political and economic relations that the WUA board sustained through the WUA with the rural and political elite, the agro-industry, and the government bureaucracy clearly extended beyond a functional interest in irrigation management and a concern for its infrastructure. 
Although the above clearly co-determined the outcomes of the IMT policy, I found few similar observations in the policy literature. The prevailing categories of success and failure mystified rather than explained what was happening in actual irrigation management under the WUA. It led to a very incomplete picture of the reality of transfer in the field. For example, I observed that dominant approaches to irrigation management lacked a perspective on the politics of irrigation management, and therefore, conciously or not, deleted it from their accounts. As far as I could see, there was a clear discrepancy between what was described in the literature and what was happening in the field. To me it clearly did not correspond to the narrative of success that had become connected to the Mexican model. There was no public counterperspective to the official perspective that heralded the success of the IMT policy, although there were several elements in society, in academia and in the irrigation districts that objected to, and resisted, the policy under the proposed conditions. But they remained unorganised, dispersed and therefore developed no effective countervailing power. At that moment I was not able to fully explain this. It was only much later, towards the end of writing this book, that several of these threads, spun out over many years, came together and I was able to formulate the beginning of an explanation. This constitutes the last substantive chapter, Chapter 10, situated before the conclusions.

During the research itself, I became more and more fascinated by the topic of IMT, as it combined several of the themes in which I had developed an interest during my study and which I wanted to explore further: knowledge, organisation, technology, power and policy. After graduation, I had several, only partially related jobs, but my interest in doing research remained alive and grew in the back of my head. In order to be able to continue my work on this theme of $\mathrm{IMT}$, I decided to write a $\mathrm{PhD}$ research proposal for the Dutch research foundation WOTRO (Netherlands Foundation for the Advancement of Tropical Research). The research proposal that follows below was approved, and on this basis I started with the fieldwork in September of 1997. When my contract started, I immediately went to Mexico in order to maximise the two-year period of fieldwork, as people kept reminding me that this would be the only period in my life that I would be able to do extensive field research. Recently, when I re-read my original proposal, it struck me that it already contained the ingredients for a large number of the different arguments that I will make in the chapters of this book. The proposal also reads as a product of the diverse sources of influence indicated above. Hence, despite several changes, the research proposal is still an adequate point of departure for understanding what this book is about.

\subsection{The Research Proposal}

Neo-liberal Irrigation Policy Transformations in Western Mexico: An Organisational Perspective on Management Transfer

\section{Theme of the research}

Neo-liberal policies are restructuring state organisation and national economies in many parts of the world. Irrigation is a field in which they have a large impact. An important policy in this respect, which many Third World countries are presently considering, is 
Irrigation Management Transfer (IMT). This policy entails the transfer of management of irrigation systems from government agencies to local water users' groups and other private sector institutions $\mathbf{1}^{1}$. In this proposal it is argued that a wide array of forms of organising have to be taken into account in order to get to grips with the processes and outcomes of IMT. The actual social practices that constitute organisational forms, such as informal networks or formal institutions, are inadequately understood by formal representations of organisations. In order to increase my insights into the effects and processes involved, I propose to study different sets of organising practices pertaining to the management of an irrigation district.

\section{Policy background and the process of IMT in Mexico}

Mexico was one of the first countries in the Third World to implement the policy of IMT on a large scale. Under the influence of structural adjustment requirements, the government of president Salinas de Gortari committed itself in 1989 to a series of liberalisation and decentralisation programmes, affecting agricultural policies concerning subsidies, pricing, trade and public sector intervention (Poder Ejecutivo Federal, 1989). This policy reorientation was based on the neo-liberal belief that the removal of 'distorted market signals' due to government intervention and the increase of private sector investment in agriculture would lead to a restoration of economic growth and to increased agricultural production (Gorriz et al., 1995).

The following motives are commonly mentioned for the adoption of the IMT policy in Mexico. Years of inadequate maintenance had deteriorated the state of the irrigation and drainage infrastructure, causing low responsiveness to farmer water demands and low water conveyance efficiencies. In addition, the contribution of water user fees to the financing of irrigation management had seriously decreased over the decades (Gorriz et al., 1995). These problems became an unacceptable burden to the government budget. Hence, it concluded that the only way to ensure good operation of the districts was to make the direct beneficiaries responsible for the management. The national transfer programme has been supported by World Bank loans (Palacios Vélez, 1995).

From 1989 onwards, the government institution Comisión Nacional del Agua (CNA: National Water Commission) transferred the majority of its larger irrigation districts to newly formed water users' associations (WUAs) ${ }^{2}$. The CNA divides irrigation districts into modulos (irrigation modules) of 5-20 thousand hectares according to hydraulic boundaries. A WUA is established in every module.

\section{Formal organisational models and actual practices}

The two groups of water users in a module, ejidatarios and pequeños propietarios (private landowners) ${ }^{3}$, elect their own delegates to form a general assembly. The assembly functions as the supreme governing body of the WUA. It chooses an executive council and a vigilance committee, for a period of three years. This 'structure of participation' ensures user involvement in important matters such as the determination of water fees (Gorriz et al., 1995).

After the transfer, the CNA continues to manage the headworks of irrigation systems. Water is delivered in blocks to the modules in exchange for payment. The operation and 
maintenance (O\&M) of the modules is the responsibility of the WUAs. The executive council hires a manager who is responsible for carrying out and supervising the work. He contracts the rest of the staff necessary for O\&M and administration. The water guards (called canaleros) distribute the water to the fields according to an irrigation plan. Water distribution is carried out on demand. Only when water users comply with a number of by-laws of the WUA, such as current payment of fees and maintenance of on-farm canals, are they authorised to get water.

The second stage of the transfer programme foresees the creation of Societies of Limited Responsibility (SRLs) at the district level. These user organisations are to be responsible for the administration and operation of the main irrigation and drainage network and the maintenance equipment and machinery, thus achieving greater 'economies of scale' than individual modules (Gorriz et al., 1995). Since 1994, WUAs have been represented at the national level by the National Association of Irrigation Users (ANUR).

At the level of everyday organisational practices, the formal models presented above are clearly problematic in respect to the following points:

First, notwithstanding the formal rules and sanctions, practices such as unauthorised use of water and fee default remain common among water users. In practice, only in rare cases do offenders receive the official penalty, namely the refusal of water. These conflictive problems are most directly negotiated by the canalero, who only rarely decides to resort to official rules. Canaleros are inadequately portrayed as mere implementors of managerial rules and the irrigation plan. In practice, they have considerable discretion in conflict resolution and water distribution (van der Zaag, 1992). Empirical findings in Jalisco, Mexico, indicate that canaleros have retained their discretion and reproduced many of their existing practices under a newly established WUA.

Second, in contrast to the policy rhetoric concerning the 'structure of participation', Levine and Garces-Restrepo (1995) note the low level of direct participation of water users in the Mexican WUAs. They observe that, in many cases, large and powerful farmers have occupied the principal functions in WUAs. Menchaca and Torregrosa (1995) confirm that shifts and struggles among power and interest groups are central to IMT.

Third, although policy literature suggests that the government (CNA) transforms its role to a distant supporting agency, in practice it continues to intervene in the daily management of the district (Levine and Garces Restrepo, 1995), regarding the management of headworks, irrigation planning, the supervision of water use. In addition, CNA officials do not radically withdraw from influence, but tend to devise a variety of strategies to protect the sorts of interest they have in relation to irrigation, for instance by resisting the transfer, or allying themselves with particular user groups (van der Zaag, 1992).

\section{Releoance and research question}

There is a growing international interest in the impact and performance of the Mexican policy model. This model is internationally renowned and widely admired for the rapid 
pace with which irrigation systems have been transferred. The Mexican case is viewed as a successful example of IMT (Vermillion and Johnson, 1995), and the World Bank is promoting it as a model for Asia and other continents (Levine and Garces-Restrepo, 1995). This study, then, aims to have relevance to both national and international debates on IMT. For this purpose, it is important to critically assess the nature and background of the impacts of IMT and to establish whether the Mexican model is as widely applicable as currently suggested.

Instead of taking for granted neo-liberal policy discourse or formal organisational models, the questions I have to confront are what IMT means for local organisational practices as regards the allocation of scarce irrigation resources, which new forms of organisation are developed in response, and how actors impute meanings to these forms of organisation. The key research question that follows from this is therefore:

How have the organisational practices of different rural actors pertaining to the allocation of irrigation resources evolved over time and how are they rearranged in response to the transfer of irrigation districts to water users' associations?

\section{State of the art}

Since the second half of the nineteen eighties, a rich body of irrigation management literature has been developed on IMT policy. The vast majority of such writing adopts a neo-liberal standpoint, by portraying state intervention as the main obstacle to the numerous historical attempts to improve the management performance of large-scale irrigation systems (for instance Repetto, 1986; Svendsen, 1993; Vermillion and Johnson, 1995). These authors attribute a central role to the market for developing a more rational and efficient allocation of irrigation resources. The reader is often left with the impression that $\mathrm{MMT}$ is an irreversible, unproblematic and smooth transition from bureaucratic state control towards complete user determination. In virtually all discussions about the impact of IMT, the literature reports 'improved irrigation management performance' (Svendsen, 1993; Merrey, 1995; Garces-Restrepo and Vermillion, 1995). This is assessed using such performance criteria as efficiency, equity, accountability and adaptability. Explanations for these improvements are typically sought in the following institutional, financial and legal reforms associated with IMT:

1. Institutional reform: The analysis of institutional arrangements and reforms in the irrigation literature is strongly influenced by the new institutional economics of Ostrom (see Ostrom et al., 1993). She defines institutional arrangements as the specific rules that individuals use to relate to each other. Incentives are the result of these rules, which reward and constrain the benefits and costs of activities such as the operation and maintenance of an irrigation system. In Ostrom's analysis, this incentive structure determines the actions of social actors, because the individual is regarded as a rational decision maker, trying to generate net benefits in every resource allocation situation. As such, unsustainable irrigation infrastructure is caused by 'perverse incentives', motivating individuals to generate net costs rather than net benefits by neglecting maintenance (Ostrom et al., 1993). Individual, rational decision making and maximisation behaviour are considered sufficient to explain both organisational practices and larger social and political processes. 
The management literature examines IMT in terms of the improvement of rules and corresponding incentives. These rules and incentives are considered to provide the basic direction and energy for organisations to meet their stated performance objectives (Vermillion, 1991). Public service organisations are characterised by their bureaucratic rules, hierarchical structure, rent-seeking and upward accountability (Merrey, 1995). Bureaucrats have few incentives to manage irrigation infrastructure according to users' needs and are generally incapable of performing O\&M tasks, whereas nongovernmental institutions have a proper structure of incentives to manage according to performance criteria (Vermillion, 1991). Democratic electoral principles in the representative structure of WUAs are assumed to ensure accountability of management towards users.

2. Financial reform: IMT in Mexico is accompanied with substantial increases in the fees that water users pay for O\&M and administrative services. These are aimed at improving cost recovery and making WUAs financially self-sufficient (Small and Carruthers, 1991). Because the WUA management is dependent on the water users' fees, it is forced to be accountable to users' needs, since only satisfied users will pay (Vermillion and Johnson, 1995). The literature also discusses the introduction of positive financial incentives such as performance bonuses and higher wages, which are expected to lead to improved individual performance of personnel (Johnson et al., 1995).

3. Legal reform: The development of new water laws and water rights are found to be essential in enacting the new duties and obligations of institutions (Vermillion and Johnson, 1995). For instance, in the Mexican case, the 'clear policies', the new National Water Law and the Concession Titles, which WUAs receive, specify how irrigation districts must be financed and locally managed and are considered as the basis of their success (Gorriz et al., 1995; Vermillion and Johnson, 1995).

There are four major shortcomings of the above analysis:

First, it is assumed that the implementation of the IMT policy follows a linear process, which leads via neatly planned stages to 'most likely aggregate outcomes' (Ostrom et al., 1993). These approaches utilise a top-down and centralised policy model with the market instead of the state as the supreme rational regulator (Long and van der Ploeg, 1995). Such models are problematic, because transfer interventions enter into the existing lifeworlds and affect the interests of social groups such as water users, managers and bureaucrats, and are therefore contested and transformed in sometimes quite unexpected ways (Long and van der Ploeg, 1989). Governmental policies are interpreted and reconstructed by policy implementors and other actors in local arenas. The specific political, institutional and economic context significantly affects policy implementation and its outcomes (Grindle, 1977, 1980; de Vries, 1992). I want to argue that it is more useful to analyse IMT as a socially constructed process. It is political in nature, because it involves struggle, conflict and negotiation among interest groups trying to control others and the crucial resources involved (Law, 1994).

Second, the management literature explains social practices and processes by means of individual cost-benefit assessment (methodological individualism). This ignores the fact that IMT is a political process. Furthermore, its abstract notions of accountability and performance allude to simple tacit common interest or universal notions that things should 
work efficiently, people should interact democratically, and clients should control their service providers. I would like to argue that these notions tend to de-contextualise and depoliticise actual social practices and processes (Arce, 1994).

Third, the sort of institutional analysis that Ostrom and her followers apply inadequately represents irrigation organisations as purposive functional systems geared to the fulfilment of a clear set of performance objectives (Reed, 1992). The implicit model of human behaviour is essentially a behavioural deterministic one, suggesting that individual and collective organisational practices strictly emanate from a rational response to simple sets of institutional and legal rules and incentives. However, as I have argued, this cannot account for the concrete social intricacies and conflicts between different social actors in everyday organisational life. The analytical weakness lies in disregarding the considerable 'room for manoeuvre' or 'discretion' that different social actors have in dealing with these situations (Lipsky, 1980; Clay and Schaffer, 1984). Consequently, it fails to appreciate and analyse existing and emerging forms of organisations.

Fourth, this literature conceptualises the stakeholders involved in the transfer process as coherent and homogeneous groups of social actors with singular functional roles. Little attention is generally paid to social differentiation, particularly when it is based on noneconomic or non-legal factors. However, for example in Mexico there is a wide variety in groups of water users regarding socio-economic, cultural and technological aspects: e.g. ejidatarios/private landholders, maize/sugar-cane/vegetable producers, subsistence/export farmers, etc. (Levine and Garces-Restrepo, 1995; Menchaca and Torregrosa, 1995). Furthermore, water users, managers and bureaucrats have diverse (and multiple) economic, political and institutional sources of power that influence their social actions and the unfolding of the transfer process.

\section{Analytical framework}

The innovativeness of my approach lies in the fact that I aim to go beyond the discussed shortcomings of current analyses by adopting an alternative analytical framework. I propose to use an actor-oriented approach, which analyses IMT as a socially constructed process involving diverse groups of social actors. An actor-oriented approach implies taking, as the point of departure, actors' perceptions, practices and strategies pertaining the IMT process, and analysing how these are connected with their livelihood strategies (Long, 1989). I will incorporate a number of concepts from actor-network theory in my analytical framework in order to deal with the socio-technical nature of irrigation management.

\section{Organising practices}

In order not to assume that organisation is a given system or a stable social order, I analyse it as a recursive network that is the precarious outcome of actors' interactions, practices and strategies. The argument here is that there is no such thing as a single social order underlying patterns of organisation (Law, 1994). My approach focuses on the reproduction and transformation of these networks and on emergent organisational forms. Such a focus reveals how crucial practices and networks crosscut formal organisational boundaries, state and market regimes (Long, 1989), and conventional boundaries between the social, political, technological, etc. These analytical 
preoccupations are pursued by studying organising practices related to the scarce resources to be allocated in the operation, maintenance and administration of irrigation systems. Organising practices can thus be defined as: the sets of socio-technical practices that organise the access to and control over resources such as water, maintenance machinery, administrative means and other political and economic resources involved in irrigation management.

\section{Control}

The proposed analysis is operationalised by studying the organising practices regarding two dimensions of control. This corresponds to current analytical tendencies to study organisations from the perspective of practices of control (Reed, 1992; Mollinga, 1992). These two dimensions are separated for analytical purposes, but are intimately related in practice:

1. Socio-technical control: In the first place,-my interest is to research how different organisational actors attempt to establish everyday (managerial) control over the use of irrigation resources. The notion of socio-technical refers to the fact that irrigation management is not only practised by human actors but that humans also mobilise sets of non-humans such as technological artifacts, physical materials, paper inscriptions, etc. (Mollinga, 1992). For instance, a manager of operation, who wants to get water from location A to B is not finished when he has instructed his subordinates to do so; he also needs to ensure that the necessary water distribution devices are in place and function according to his will. Irrigation management is thus practised through networks of humans and non-humans, and its organising aspect is also performed, embodied and represented in materials (Law, 1994). I aim to analyse how different sets of actors mobilise, manage and control these socio-technical networks and how this changes in the process of IMT.

In the second place, I want to investigate the social and institutional impacts of calculative practices and representations (Miller and Hopwood, 1994), i.e. the programmes, techniques, apparatuses, documents and procedures through which institutions seek to embody their governmental ambitions. Miller and Rose (1992) show how contemporary calculative practices or technologies of government enable neoliberal efforts to autonomise state institutions from direct control and responsibility over the actions of individuals, organisations and societal domains, whilst retaining some form of action or control at a distance. Law and Akrich (1994) illustrate this with the example of how the introduction of accountancy in a privatised organisation leads to the reshaping of organisational spaces and activities, in order to express these activities in terms of calculable cash equivalents. The centres that accumulate these new data have the possibility to visualise and govern organisational spaces. The authors also suggest that such new practices lead to the engineering of the 'good customer', a docile and disciplined user who is willing to pay a certain fee in exchange for a specified service. At the same time the image of a 'good seller' is constructed, by creating a picture of accountable costs for specific activities (Law and Akrich, 1994).

This study intends to investigate whether IMT engenders the introduction or the transformation of calculative practices. I am interested in the impacts on organisational spaces and activities in irrigation, the level of control at a distance and the construction of 
new images concerning users and management. In relation to IMT, the importance of accountancy and regular audits of WUAs by neutral agencies has been signalled by some authors (Svendsen and Vermillion, 1995; Vermillion and Johnson, 1995). Furthermore, a range of performance appraisal methods are currently being used in irrigation management (Palacios-Vélez, 1995). Also relevant is the policy ideal to implement volumetric measuring by means of control points in the irrigation systems (Gorriz et al., 1995).

2. Economic and politico-institutional control: I intend to study how IMT leads to new opportunities and constraints for diverse interest groups in the local arena, which can result in renewed struggles over crucial resources. Central are the practices, projects, strategies and alliances which are (re)constituted with the aim of establishing economic and politico-institutional control over these resources. Long and van der Ploeg (1995) view actors' projects as the diverse representations and the material and social capabilities to mobilise resources utilised for achieving certain goals or ordering the future. These projects reflect specific sets of interests, commitments and prospects. Rather than assuming a hegemonic social structure, they choose to explore how actors' projects are being interlocked, through negotiation, enrolment, mobilisation or distantiation.

De Vries' concept of institutional projects is useful to identify the differential manners in which IMT can be implemented. Institutional projects are grounded in a particular, practical understanding of how relations between the institutions and their clients ought to be governed. They are the outcome of a learning process by which state managers develop a way of negotiating the demands of the central government, the political environment and the various organised client groups. In addition, policy implementors may face similar policy directives and intervention ideologies, but they interpret their tasks in different ways. They employ differential operational styles in response to the conflicting demands of the administrative and field domains in which they operate and to the different socio-political commitments and interests they have (de Vries, 1992).

\section{Agency}

An actor-oriented approach is bound to attribute agency to social actors, i.e. the capacity to process social experience and to devise ways of coping with life (Long, 1989). In line with post-structuralist debates on the de-centring of the subject, I do not designate agency as a purely individual or human characteristic, but conceive of it as embodied in socio-technical practices and networks, through which it can become effective (Foucault, 1977; Callon and Law, 1995)

\subsection{The Course of the Research}

\section{Changing the research location}

Originally, I wrote this research proposal with the irrigation district Ciénega de Chapala (024) in Michoacán as the intended research location. This was a pragmatic choice as it lay close to the Colegio de Michoacán, a research centre in Zamora, the base from which I had explored potential research locations during an earlier visit. When I started my 
fieldwork in Zamora, I became less convinced that the Ciénega was an ideal location for research. The rains had been very bad that year, and the irrigation would be severely limited and mainly for fodder crops for the local cattle husbandry industry. I decided that I would have to compare a number of irrigation districts to see which best fitted with my plans. I selected five districts in the West of Mexico within reasonable travelling distance of Zamora, Michoacán and Guadalajara, Jalisco. My choice was determined by the factor of access. It was not an option to just drop by any irrigation system and explain my research objectives to a WUA official. Although the WUAs are officially autonomous from the CNA, the CNA District Head remains an influential authority in the districts, to whom I would sooner or later become accountable. Presenting myself just like that to a District Head would trigger the bureaucratic need to consult the higher echelons and required me to go through the CNA headquarters in Mexico City. After that, it would still be very uncertain whether I would be given permission to carry out my work. Apart from saving time, it was important for me to remain independent from the CNA headquarters, as I needed to be able to diverge from their interpretation of affairs in the districts. I knew this could be understood as an attempt to discredit the institution, although this was not my intention.

What I needed was a personal introduction to the District Heads and subsequently to the WUAs. I used a network of contacts that I had built up during my earlier stays in the irrigation districts. Among them were several irrigation officials who brought me into contact with current District Heads. By means of these personal relations, I started visiting and making an inventarisation of these districts in order to make up my mind about a suitable research location. In addition, it gave me an impression of the kind of achievements and the range of problems that the WUAs were facing several years after transfer. A former District Head was helpful in pointing my attention towards the Northern Coast of Nayarit (024).

The old engineer introduced me to the District Head based in Tepic, with whom I developed a cordial relationship, and he sent me through to Santiago Ixcuintla - the tour that you make through the mountains before descending towards the coast in Chapter 4 . There I was received with open arms by the manager of the Left Bank WUA, and I immediately felt welcome. On one of the first days, I was invited to a banquet that he organised in honour of the District Head. I describe it in Chapter 6, and this pleasant type of encounter subsequently became central to my later research and my understanding of the region's politics (see also Chapter 8). I loved the whole environment. The wonderful seafood, the beer, and the music all enjoyed in the open, hot and humid air contributed to a cheerful atmosphere among these people that I came to like. It affected me in a way that, as I later found out, affected many other visitors to the region and that I today consider as essential to the culture of the region. This was not only very different from my own Calvinist upbringing in a relatively cold country (in whatever way you like to read that), but also from the more conservative Jalisco with which I had become acquainted during my MSc research.

It took me some time to decide on the Left Bank as my research location, because I felt that I had to take a balanced decision based on solid scientific grounds. I constructed a long list of criteria with which I gave the different regions a score for their suitability as research location. Amongst these criteria were: the size of the module, the number of years they were transferred, a mixture of different types of landholding, water users and 
crops, the degree of water scarcity, the nature of the water source, the irrigation infrastructure and field irrigation technology, the maintenance machinery capacity and the self-sufficiency problems, the degree of farmer organisation, state and agro-industrial intervention in the irrigation district, etc. Adding up the scores resulted in a draw between the Left Bank and the Ciénega de Chapala. The advice of a friend, Luz Nereida, was decisive. She told me to go for the region that I felt most passionate about, because I would have to work and live there for an extended period. After this, there was not a single doubt left. The Left Bank of the River Santiago became my research area and home.

\section{Fieldrwork and methodology}

This book is based on the ethnography of an organisation and the study of policy in the field of irrigation. Characteristic of ethnography is the study of daily life as it develops, while attempting to avoid intervention in its course. The basic methodological idea behind the research was therefore to map the sets of organising practices of different groups of social actors involved in the making of irrigation policy and organisation. This demanded the in-depth study of actual practices through the methodological device of 'following the actors' (Latour, 1987; Long, 1989).

In the first stage of my fieldwork in Nayarit, I concentrated initially on the organisational practices within the irrigation district. When I had established contacts within the Left Bank WUA, it was relatively easy to identify the key actors within and around the organisation. What helped here was my familiarity with WUAs in other places, which are similarly composed and named: la Asociacion (the association). According to the methodological principle of 'studying up' (Nader, 1972), I started working my way through the organisation from below. This meant developing a relation with the lower level personnel of the WUA in the field and the office.

I started off exploring water distribution practices by means of participant observation (Burgess, 1984) of the WUA's field personnel in their daily practices and routines. By accompanying several canaleros on my motor bike, I followed them through their operational sections, whilst they were operating the infrastructure, interacting with ejidatarios and private producers, and attempting to convince diverse groups of water users to pay their irrigation fees. In the process, I became friends with the canaleros. After identifying two canaleros with contrasting loyalties and personal histories, I constructed case studies of these field workers that focus on how the concrete social, material and spatial arrangements that make up their workspace affect their daily practice. I call these situated case studies. In addition, I used life histories and occupational career histories to understand the different strategies they employed for dealing with their daily work environment and for resolving certain problematic situations (Long, 1979). A chief advantage of these case studies was that they provided the opportunity to highlight and analyse the different organising practices that canaleros engaged in to distribute crucial resources and to manage everyday social problems (Long, 1989). At the same time, I also studied a variety of water users to reveal the different ways in which they strategically obtained access to water or maintenance services. 
Regarding the maintenance of the irrigation system, it was difficult to arrange to follow the machine workers who operate the maintenance machinery of the association in their daily routines. However, the advantage of spending time with the canaleros in the field was that we frequently encountered the machinery and talked with the machine workers. In addition, I went to the field on several occasions with the driver who provided diesel and oil to the machines and the trucks that were working scattered around and outside the Left Bank. This gave me a good idea about the motivations behind machinery movements. With the head of maintenance, I had a plus, because of the merit of being a compatriot of Leo Beenhakker, his all-time favourite coach of the football club, America.

I developed a basic understanding of the administration of a WUA by being in the WUA's office for long periods, waiting for the manager - which often became waiting for Godot. The great thing about a Mexican office from a researcher's point of view is that, once you have established a legitimate presence, nobody asks you to leave and you automatically become part of the office life or the furniture, whatever is your ambition. The drama then develops in front of your eyes. Through observation of the daily office routines, it became clear to me how fee collection and expenditure worked within the association and who were crucial actors in this respect. On occassions, I was able to help the secretaries with the kind of Microsoft problems that frustrate office work all around the globe. Being in the office also entailed the possibility of participating in the little parties and festivities that were organised among the personnel of the association.

The experiences described above gradually drew my attention to several managerial decisions and practices that brought the management of the WUA into view. I developed a friendship with the manager who enjoyed taking me with him on his trips around the region and demonstrating to me the importance of his work and the incentives that make it worthwile. In this manner, I was able to establish that his managerial practices and decisions were often related to wider politico-institional issues that extended beyond the immediate district level. The manager was part of a political group that maintained a network of political and institutional relations by controlling the association and its personnel, resources and facilities. This was the beginning of what became an extended case study of this political group to investigate the different strategies and practices that they developped to create space for their political and institutional projects (Long, 1989). The value of this approach is not necessarily to prove the typicality of a case, but rather to infer some theoretical principles pertaining to the IMT policy process and the organisational transformation and practices that this involves (Mitchell, 1983).

Interesting insights were obtained through social network analysis that explored how the political group in question mobilised networks of friends, real or ritual kin (co-parent ties), patrons and other local power holders, farmer leaders and their organisations, state officials and politicians in order to enrol them in their projects. However, it is important to stress that my use of the notion of network was different from that utilised by Boissevain (1974) and Mitchell (1983). In addition to purely social relations, my focus also encompassed non-humans such as technological artifacts, canals and maintenance machines, material resources like water, buildings, legal and planning documents and all manner of other things that these social actors use to establish, extend, and consolidate their network. 
There was something that I clearly did not anticipate in my research proposal, but to which the method of participant observation drew attention. When I accompanied the manager in his pick-up and we were driving at full speed between all kinds of offices and the field, I became increasingly intrigued about the following matter. This immensely dynamic personality of a manager was not only involved in the management of water flows or the coordination of machine movements. A significant part of his time went in organising and attending private parties and public meetings. The location of these meetings to which people were invited was often not the association's office, but the local seafood restaurant or the cantina.

What made the atmosphere of these meetings and the ongoing discussion or negotiation so much more pleasant was the practice of enjoying beer, local dishes and music simultaneously, or the prospect of doing so afterwards. This was a side of irrigation management that I had never thought and read about, although it only confirmed the nowadays widely accepted view that water always flows towards the use with the highest added value. The organisation of these events appeared to be enormously important to the way in which the manager and his patrons established wider relations, essential negotiations took place and strategies were developped. These events revealed how the cultural richness of organisational and political life in the region becomes intimately entangled with irrigation management. I came to understand these events as cultural performances that turned out to have an electoral and political purpose.

As a participant-observer at several such events that took place in the run-up to local elections, I saw how the WUA's staff, facilities and resources were drawn into the organisation of a campaign for a local political position. In order to reconstruct and analyse these events, I observed and described them by means of situational analysis (van Velsen, 1967) and event analysis (Handelman, 1990). In order to contextualise and understand my findings, I organised a series of semi-structured interviews with academics, politicians, government officials and journalists. I also collected data to acquire an historical understanding of contemporary socio-economic and political changes in the region by consulting official documents, government records and local and national newspapers.

About a year into my field research, things were going well, and then another unexpected development added a new dimension to my investigative endeavour. This initiated the second stage of my research. A former study companion, Flip Wester, came to work in the state of Guanajuato for the local International Water Management Institute (IWMI) office. In explorative discussions we considered the possibility of doing research on the genesis of the IMT policy. I had already been intrigued by this topic for several years, but was not sure how to research it. Coincidentally, a few weeks later I received a call from the Irrigation and Water Engineering Group of the Wageningen University inviting researchers and policy makers to write papers for a conference entitled The long road to commitment. A socio-political perspective on irrigation reform. To both of us this seemed a perfect opportunity to develop our ideas for research more concretely, and we decided to take up the invitation.

Because this second stage of the research concerned the life cycle of the IMT policy, which extends in time and space beyond what can be observed, ethnography of the policy process was only possible to a limited extent. We incorporated ethnographical 
impressions from our earlier fieldwork, policy conferences that we had attended and interviews that we had about the subject. However, the bulk of our research consisted of interviews with the key players in the conceptualisation and the execution of IMT, plus those people who were involved from different positions in state and society. Our list included former government officials, politicians, functionaries of international agencies, academics, and farmer leaders. Getting access to these people and interviewing them was a different ballgame than my usual method of following actors in the field, the office, or the cantina. They were people, usually males, living in the capital with busy jobs. However, getting an appointment was sometimes easier than I thought, in some cases through personal contacts, the institutional links of the IWMI office, and in other cases by just looking up an address and calling on a person. During the interviews I noticed that I had to adapt my language that had largely been shaped by the peasant environment to which I had grown accustomed. My strong language and behaviour occasionally led to frowns, which reminded me that I was in the capital, dealing with a different class of people. I should still offer my apologies for that.

We scheduled several trips to Mexico City for a round of interviews. We started out with basic propositions concerning the IMT process that we tested and improved through a round of semi-structured interviews with a carefully prepared questionnare. From the answers of our respondents came new propositions and questions that we used for the next round of interviews. Through experience, we learned to release a fixed order of questions to enable the respondents to set out their perspective on the IMT process, and then we posed leading questions to guide the interview. At a later stage, Luz Nereida joined us and helped to contextualise and frame the paper that we were writing for the Hyderabad Conference. The general policy background of IMT was examined with the help of policy and legal documents, internal reports and professional literature that we collected on the subject. Discourse analysis was useful for unravelling the concepts and arguments used in the policy literature to address certain conflictive issues (Parkin, 1990).

One of the most exciting moments of my research occurred in Hyderabad. Unexpectedly, the day before the presentation of papers, Dr. González Villareal came walking into the conference room. He was the ex-Director of the CNA and the main initiator of the IMT policy. He had come to the conference in his capacity as irrigation advisor to the Agricultural and Natural Resources Department of the World Bank in Washington. Our paper described his carreer and the achievements of his group (see Chapter 2). We had not yet succeeded in interviewing him. His presence provided a critical test for our findings, because he was probably the most qualified person to comment on our paper. He graciously agreed to referee it the next day. Powerpoint and Flip's perfect timing of bullets helped me through the presentation of the paper. Dr. González Villareal, in his comments afterwards, said that it reminded him of many of his own experiences. He also made very useful critical remarks, which we have tried to incorporate in later versions of the paper. A most interesting remark that he made was that he did not really like our use of the term 'hydrocrat', which draws together the words hydraulic and bureaucrat or technocrat. Obviously, the latter two words sound derogatory. He preferred the notion of hydro-politician.

This thesis deals with many controversial issues and raises high political stakes. However, it is not my intention to criticise or affect individual people and their careers. 
Therefore, I have changed the names of most protagonists. Dr. González Villareal is one of the persons whose actual name I use, because his appointment as Director of a government institution was political and he publicly assumed this reponsibility.

Concluding, the study of policy and the ethnography of an organisation were basically intertwined throughout my research journey, although the emphasis shifted. This divided my fieldwork into two stages. The first stage concerned a detailed organisation study of the Left Bank WUA on the Northern Coast of Nayarit. The second stage of my research covered the entire life cycle of the IMT policy, from its earliest roots until its international celebration as a policy model.

\section{Analytical developments}

During my research, the subsequent analysis of the empirical material, and the writing of this thesis, my analytical approach changed in two ways that require explanation.

Firstly, I prefer to use the concept of socio-material instead of socio-technical analysis, because $I$ think it is more appropriate for the broad variety of irrigation and policy practices that I analyse. The difference is not fundamental, as the former approach builds on the insights of the latter. Irrigation performance studies conceptualise irrigation technologies as neutral tools that fulfil practical and productive ends alone. The sociotechnical approach has a strong focus on the role of irrigation technology in water management and the wider political economy. The improvement is that it demonstrates that irrigation technology enables some powerful groups to get privileged access to water, whilst excluding others, as is the case in the classic example of the head-end versus the tail-end farmers (Mollinga, 1998). Hence, irrigation technology also mediates relations of power.

A socio-material aproach aims to show that, apart from irrigation technology, there are many other material artefacts and resources that also shape the politics and policy of irrigation management, such as for instance maintenance machines, irrigation fees, policy documents. The irrigation system that I studied has not experienced a major change in irrigation technology, but did experience a change in the form of management. Nevertheless, irrigation techology is one of several material elements that structure actual managerial practices and outcomes. For example, in Chapters 5 and 7 I will show that maintenance machinery is used as a tool in the hands of political players who operate from the WUA. Another example of the broader sets of materials involved in the politics of irrigation management are cultural materials such as food and drink. Chapters 6 and 8 illustrate the important role that the consumption of beer and local dishes plays in the political life of the group that controls the WUA and shows how this affects irrigation management. Hence, technologies and other material artefacts are also opportunities for the performance of taste and self-identity (Bourdieu, 1984), as articles of consumption and use.

A socio-material approach attempts to bring into view the totality of associations between people, technologies and resource flows that are engaged in irrigation management. As Latour has noted, in daily life we are never faced with technologies or social relations on their own, but always with combinations of humans and non-humans (Latour, 1992). In Chapters 5, 6 and 7, I indicate that irrigation management involves the 
control over various mobile and sometimes elusive composite entities, such as canaleroson-motor-bikes operating the network of canals, pump-operators-with-sprinklerinstallations using water from canals, and machine-operators that maintain the infrastructure. Further, I analyse the concrete socio-material arrangements that are mobilised in actual water distribution practices. I will call these operational arrangements. Operational arrangements are the host of physical devices, monetary resources, legal documents and human actors that a farmer would have to enrol to obtain access to water from the main system level for his crop (van der Zaag et al., 2001).

Like Michael (2000), I intend to explore how mundane technologies and other materials reinforce and undermine the typical arrangements and practices that comprise everyday life. Mundane, in this case, refers to the lack of novelty and technologies that are an unremarkable part of everyday life. For a WUA, such technologies are for example motor cycles, pick-ups, and Michael shows that mundane technology enables and constraints various modes of social, cultural and political comportment. These performances emerge from the relations between technologies, bodies, cultures and materials. When I say that technologies enable multiple performances (see Chapter 7), both meanings of the word performance are implied: an achievement and a staged presentation. Irrigation management studies use its first meaning when they design criteria to measure irrigation management performance. Anthropology mainly refers to its second meaning, when it studies social events as cultural performances. By bringing these two meanings together, I suggest that both aspects are valid lenses through which to study the use of mundane technologies in everyday life. Box 1 presents an example of the different uses of the concept of performance.

Secondly, both in the study of policy and the ethnography of an organisation my attention initially focused on the political and institutional, but later shifted to include also the cultural aspects of policy and irrigation management. The first focus I had anticipated with the politico-institutional axis of control in my analytical framework. However, this shift of focus towards the cultural richness of organisational and political life in irrigation management as well as in policy making, I did not really foresee. Nevertheless, I have incorporated these points in the perspective that I developed on Mexican politics:

In Mexico, the academic debates about politics have been dominated for a long time by state-centred perspectives. This perspective on the Mexican political system has emphasised the authoritarian, corporatist, and clientelist nature of the regime in explaining its prolonged stability (Aitken, 1999). The post-revolutionary Mexican state is seen as an all-powerful and pervasive authoritarian organisation that has effectively dominated civil society by incorporating peripheral areas and social sectors and coopting or coercing the opposition through vertical power chains and clientelist mechanisms (Pansters, 2000). In this perspective, power is understood as something that is amassed and brokered at the centre (Rubin, 1997), embodied by the figure of the president, and transmitted downward through corporatist mechanisms in the peasant, labour and popular sectors. The regime created political legitimacy and lubricated the patronage machine by sending a vertical flow of material benefits (e.g. subsidies and social programmes) from the centre through state hierarchies to its constituencies (Demmers, 1998). 
On a tour around his state, the governor of Nayarit recently received a petition from residents of an urban compound, the lower part of which was flooded because of a leaking canal. He passed it on to the CNA with instructions to the neighbouring WUA to solve the problem with its machinery. Today, two CNA officials arrive at the WUA office and convince its manager that he needs to accompany them to look at the problem. Because the manager has other plans and seems hardly interested, they tell him that the governor himself wants a direct answer. The officials' idea is that all three should go together in the CNA vehicle, but the manager insists on going in his own pick-up, which is a much newer and classier model with airconditioning. I join him and notice that he is annoyed because the CNA engineers pressed him to come. He starts the motor and steps on the gas and we drive away at full speed. He grumbles about government officials having a pleasant job, because they have nothing else to do. He points out the difference in work pressure between them and himself. Through the rear window I watch the CNA engineers in their much older pick-up disappearing from sight, because their vehicle is slow to build up their much more moderate speed.

On the road to the compound, the following sequence of events occurs twice. The WUA manager has to stop and parks on the side of the road to attend an employee and a user wanting to speak to him. The CNA pick-up passes us, but when the manager has resolved his business, he quickly speeds up, overtakes them, and disappears into the distance. Near the compound he has to wait at a crossroad for the two engineers, because he has no idea where to go. During the drive, we discuss the federally financed rehabilitation programme. The manager explains that it is delayed because of tramites (procedures) that have to be followed in the CNA, because authorisation has to come from the national headquarters in Mexico City. These delays make him so angry, he states. 'Everything with them goes so slowly and is neoer dealt with directly'. The way in which he exhibits this difference by outracing the government vehicle twice is clearly no coincidence. When the government officials arrive and take their time to get out, the manager starts complaining that he has only ten minutes to get to his next appointment. One of them quips that, at the speed he drove over here, he will need only five minutes for the fifteen-minute drive. The man remarks that I look terrified because of his driving.

In the above scene, the two pick-ups play a part in different performances. Firstly, when the performance of the pick-ups is measured in terms of speed and acceleration, the manager's pick-up is clearly superior to the government vehicle. However, to focus only on that aspect of performance would be to miss the point. The pick-ups also participate in a cultural performance. Through his use of the accelerator pedal, the manager makes visible his view of the difference between a dynamic, hardworking and hands-on type of manager and the slow, inefficient and bureaucratic government officials. The CNA officials do not participate in his contest and ridicule his behaviour and what it leads to. In the end, they cover the same distance and he has to wait for them. In addition, the condition of the pick-ups reveals the favourable financial situation of the WUA, by means of which the manager emphasises the prestige of his position. At times, he makes the government officials feel this difference. The whole scene also has a political aspect, because the governor pushes the WUA to mobilise its maintenance machinery for a political performance: a public work that benefits the governor's profile and that of his party in a pre-election year. In conclusion, technological artefacts are enrolled in multiple performances.

The state-centred view of political power attributes an instrumental role to the cacique (regional strongman) in the reproduction of the political system, elite domination, and the incorporation of the regional periphery by the political centre (Wolf, 1966; Bartra 1975; de la Peña, 1986). Caciques are understood to act as power brokers who operate between unequal societal levels and negotiate conflicting claims and regional interests by manipulating a network of patron-client relations. As resource brokers, they maintain their power by winning resources from above for the communities they represent (Gledhill, 1994: 109 quoted in Demmers, 1998). In this view, the corporatist system 
effectively controls this locally based form of clientelism and the decentralising potential of relatively autonomous caciques and their followers (Kaufman Purcell, 1981: 211 quoted in Demmers, 1998). In these state-centred approaches to politics, both power and resources thus find their origin in the state and, more precisely, the political centre from which they are hierarchically controlled and vertically disseminated and brokered by corporatist institutions and political mediators.

My line of analysis sympathises with contemporary scholarly work that questions the state-centred perspective on Mexican politics and aims to overcome its problems by 'decentring the regime' (Rubin, 1997; Aitken, 1999; Demmers, 1998; Pansters, 2000). These authors argue against an idea of the state as a discrete entity (Aitken, 1999) and the sole locus of power, with a strong and coherent centre driven by well-defined political programmes and omnipresent structures that effectively maintain societal domination over time (Rubin, 1997; de Vries, 2002; Pansters 2000). Hence, the tendency to overstate the presence of the corporatist state in provincial Mexico is questioned. In contrast to the conventional view, the establishment and entrance of corporatist organisations into regions has been a slow, uneven and contested process with a variety of outcomes in different parts of Mexico (Rubin, 1997; Aitken, 1999). In some states, regional power groups and bosses have been successful in retaining power for long periods, whereas in other states centralist tendencies dominated. At the local level, the influence of corporatist organisations and the nature of regional political processes vary considerably.

A common starting point has been to broaden the concept of politics, which was restricted to state and party politics, formal political institutions and electoral processes, by opening up space for locations and flows of power outside both the centre and official politics. Rubin makes a case for placing culture, the everyday practices of civil society groupings, and the region as a political location, within the discussions about power and the state (Rubin, 1997). As a result, the attention shifts to local and regional practices of rule in the context of national projects of state formation and intervention, and the specific cultural and political dynamics and effects that this has in different regions of Mexico (Aitken, 1999), for example in terms of local identities, political and popular cultures.

From the perspective of a study of the policy of IMT, I think two aspects are generally lacking in such studies of state formation and regional political cultures, which potentially provide new axes along which one can centre and de-centre the Mexican regime: firstly, the role of the federal bureaucracy as a powerful player in the formulation and execution of policy and the rise of high-level technocrats as a new political group in the government (Greenberg, 1970; Grindle, 1977; Centeno, 1994; Torres Espinosa, 1999). In Chapters 2, 3 and 10, I demonstrate that the emergence, execution and success of the IMT policy cannot be understood without considering the historically important, but contested, economic and political role of the hydraulic bureaucracy in agriculture, the rise of a transnational class of technocrats within it and the particular culture that such a bureaucracy represents. Secondly, a socio-material dimension to political organisation is absent from this literature. The hydraulic bureaucracy has manifested itself by creating a spatially distributed irrigation infrastructure that has transformed the political landscape of Mexico's rural regions. Besides constituting an (infra)structure of control for the state bureaucracy, these irrigation districts have become locations of power by themselves, 
partly based on the de-centralised capacity to control and distribute water and other scarce resources (see Chapters 4 and 8 ).

\subsection{Limitations of the Study}

The approach of this book is limited in three ways. Firstly, it does not aim to provide an analysis of the political economy of either policy reform or irrigation management. This is without doubt an important task, but one that this book has not set for itself, because it aims to point to other dynamics that have received too little attention within such a framework. Secondly, the book reveals the unarticulated orientation of the author towards the powers that be and the ways in which they become what they are. The drawback is that this study does not sufficiently call attention to the exclusion of the much less powerful agents from neo-liberal policy processes and irrigation management, in spite of its participatory rhetoric, and largely ignores the rural poverty, migration and marginalisation that this has reinforced. Thirdly, this study is largely based on an international literature on policy and irrigation management and directed towards an international audience by means of the English language. A shortcoming is that it inadequately represents the existing Mexican literature on some of these topics.

\subsection{Outline of the Chapters}

After this introductory chapter, the book contains nine substantive chapters that provide material for the conclusion. Each individual chapter presents empirical material that challenges an assumption regarding the IMT policy or irrigation management that has become accepted wisdom in the field. The chapters are organised according to the part they play in either the study of policy or the ethnography of an irrigation organisation. The ethnographical fieldwork in Nayarit is presented in five chapters that constitute the central part of this book. The three chapters that study the life cycle of the IMT policy sandwich these. Chapters 2 and 3 are placed at the start as they trace back the roots of the IMT policy and discuss how it developed and became effective throughout different parts of Mexico. Chapter 10 reviews the wider impact of Mexican IMT policy, as it became known as a successful case and a model for the rest of the world. Although the latter chapter continues the policy theme of those two earlier chapters, it is placed at the end of the thesis, as it builds on insights from all of the chapters and provides a contrast to the case study that precedes it. Chapters 4 to 9 present the organisational ethnography of a WUA and the impact of IMT in Nayarit. This part of the book is sub-divided according to the common understanding that irrigation management involves three types of activities: operation, maintenance and administration; and three sorts of material resources: water, maintenance resources (machinery and works), and finances.

Chapter 2 recounts the history of Mexican irrigation reforms that culminated in IMT. Contrary to what is generally believed, the political commitment to this policy was not triggered solely by the financial crisis of the state that led to a downward spiral in the districts; it also emerged from a much longer process of bureaucratic struggle revolving around the autonomy of the hydraulic bureaucracy and its control over the irrigation districts. 
Chapter 3 shows that the articulation, engineering or making of the IMT policy was a contested process. Hence, the actual policy package with which senior officials had to effectuate the transfer was experimented with, resisted and adapted significantly. After some time, this led to a standardisation of the package that contributed to an unforeseen acceleration in the pace of transfer in Mexico. I also argue that, contrary to what is generally expected, IMT in Mexico did not lead to a withdrawal of the state from irrigation, but served to reorder and strengthen bureaucratic control over irrigation management from a distance.

Chapter 4 takes the reader to the Northern Coast of Nayarit and situates the irrigation system on the Left Bank of the River Santiago in a wider regional landscape. In this manner, I emphasise that the analytical approaches that isolate an irrigation system as separate from its environment are flawed, because it overlaps with several political and administrative domains that affect irrigation management. This introductory chapter also questions the unproblematic use of the concept of 'water users' as a coherent and homogeneous group of social actors with similar interests. The chapter then recounts the contemporary history of the transfer of the Left Bank irrigation system and introduces the social actors and material artefacts that play a role in the organisational ethnography of the water users' association (WUA).

Chapter 5 falsifies the neo-institutional assumption that water distribution in particular, and organisational practices in general, are governed by a system of agreed rules and incentives. It presents the first of two contrasting case studies of canaleros in water distibution. These cases investigate the role of the canalero in relation to the operational arrangements with which he deals in his daily work and his social position vis-à-vis the WUA management. This chapter shows how a canalero's work is shaped, not by a set of rules, but by his frequent interactions with sprinkler irrigation and small-scale tobacco producers and the fact that he has rather distant relations with his superiors.

Chapter 6 challenges a popular view on the relation between patron-client relations and organisational practices in a Latin American context. It discusses the case of a canalero who is a client to the political group that is in control of the WUA and performs an important role in a network of large-scale rice producers that irrigate using the surface irrigation method. This case addresses the need to revise simple sociological models of patron-client relations in which the patron monopolises the power and resources on which his clients depend. I do this by focusing on the role that the client in this case plays in the distribution of various material and cultural resource flows that are essential in the reproduction of the political group.

Chapter 7 examines maintenance as an organisational practice that is a particularly useful entry point to analyse the transfer and functioning of irrigation systems, contrary to most analysis that automatically assumes that water is the most contested resource and its distribution the central activity of irrigation management. The approach taken illustrates that the managerial group, through their connection with maintenance machinery and the works it enables, engages in multiple performances. Machine use contributes not only to operational performance, in line with formal performance objectives, but also to other social, material and political practices and performances that transcend and change what are conceived to be the boundaries and objectives of an irrigation system. 
Chapter 8 argues that resource allocation is profoundly and inherently political, in contrast to contemporary managerial approaches that model it as an act of service provision and therefore essentially different from politics. A situational analysis of an election rally is the starting point to illustrate the political nature of resource allocation, the WUA as a political platform, and the rally as a cultural performance. It is a central chapter that shows how the political group in control of the WUA draws for electoral purposes on the material resources that are discussed in the other chapters of the organisational ethnography.

Chapter 9 focuses on the financial management of the WUA in order to challenge the policy view that the WUAs have generally achieved financial autonomy as an outcome of IMT and that they are accountable, both financially and electorally, to the larger community of water users.

Chapter 10 puts 'the success of the Mexican IMT model' - which has rarely been questioned or really qualified - between quotation marks. It analyses the cultural process of policy making that has generated the Mexican IMT policy model and follows the practices, means and events through which it has achieved increasing transnational circulation and popularity. The argument is that the success of a policy model is only a success within the cultural and ideological understandings and practices of the policy network in which it is generated and disseminated.

Chapter 11 presents the conclusions of this book and tries to explain the contrasting findings of the two directions in which this book has set out: the study of the IMT policy in Mexico and the organisational ethnography of actual practices, processes and outcomes in Nayarit. The gap between the internationally celebrated success of the policy and the empirical practice in the field needs to be made intelligible.

\section{Notes}

1 Many different terms are used in relation to IMT, such as turnover, self-governance and privatisation. The most important distinction is that IMT refers to cases in which only the management of an irrigation system is transferred, while privatisation refers to cases in which the juridical ownership of the infrastructure and related resources is also handed over.

2 Of the 5.2 million hectares of Mexico's irrigated land, 3.2 million hectares are organised in eighty irrigation districts, varying in size from a few thousand to systems of more than 200,000 hectares in the north of the country. The rest is organised in privately or collectively run small-scale systems called irrigation units. Most of the irrigation systems are gravity-based, with water being derived from storage reservoirs, by means of diversion dams and conveyance canals. At the end of 1994, the CNA had transferred thirty-six districts completely and eighteen partially (Gorriz et al., 1995).

3 The land reform which followed the Mexican Revolution of 1910 resulted in the establishment of two forms of land tenure: the ejido, which are corporately organised agrarian communities, and the pequeña propiedad (private ownership). Ejido land is government property but is granted to an ejidatario for use. Currently, as a consequence of articulo 27 of the new agrarian law and the national policy programme, PROCEDE, which have been implemented during the last few years, every ejidatario has to receive ownership documents of his plot and is presently legally entitled to sell or rent out his land. In spite of altered responsibilities, the ejido remains an important administrative unit both for the government and farmers, not least because of the ejidos' representation in the WUAs. 


\section{2 \\ The Politics of Creating Commitment: Irrigation reforms and the reconstitution of the hydraulic bureaucracy in Mexico'}

\subsection{Introduction}

In the past ten years, water management in Mexico has been radically reformed under the influence of neo-liberal government policies. The creation of the Comision Nacional del Agua (CNA: National Water Commission) ${ }^{2}$ in 1989, the transfer of government irrigation districts to water users' associations (WUAs) (1989-present) and the promulgation of a new water law (1992) exemplify this. Internationally, Mexico's Irrigation Management Transfer (IMT) programme has been heralded as a success and has drawn widespread attention for its rapid implementation. Consequently, it has been propagated as a model for other countries seeking to improve the performance of their public irrigation systems and cut burgeoning public expenditures (Groenfeldt, 1998).

Surprisingly for a reform of this magnitude, no attempt has been made to explain how it came about. Policy documents single out the strong commitment of the political leadership and policy managers to the IMT programme and the creation of appropriate legal and institutional frameworks as explanations for the origin and success of IMT (Gorriz et al., 1995; Groenfeldt, 1998). However, how and in which arenas this commitment was created and which actors were fundamental to this process remains unexplained. The literature presents the occurrence of IMT in Mexico as a logical and unavoidable outcome of the economic crisis of the 1980s. The argument goes that this crisis led to a large decrease in government funding for irrigation and a reduction in the payment of water fees by water users, resulting in a poor performance of the publicly managed irrigation districts and a widespread deterioration of the irrigation infrastructure. The irrigation reforms were thus an inevitable response of the Mexican government to this state of affairs (Gorriz et al., 1995; Johnson, 1997a, 1997b; Kloezen et al., 1997; Palacios Vélez, 1997, 1998). I posit that this line of argument does not suffice when it comes to understanding the emergence of the IMT policy and the strong commitment it enjoyed from senior politicians and bureaucrats.

To understand why IMT became a reality in the 1990s it is necessary to broaden the analysis to include the historical, political and bureaucratic ${ }^{*}$ processes that engendered and sustained Mexico's water reforms. Such an analysis, which takes policy actors as the unit of analysis and the articulation ${ }^{5}$ of reforms as the focus of attention, clarifies why and when water reforms are effectuated and how alliances are negotiated through which reforms gather momentum. Focusing on their political and bureaucratic embeddedness makes it possible to understand the trajectories and variable content of water reforms, the conflictive dynamic of their articulation, and their ramifications. In this regard it is important to acknowledge that policy making in Mexico '(..) does not result from pressures exerted by mass publics, nor does it derive from party platforms or ideology, 
nor from legislative consultation and compromise. Rather, it is an end product of elite bureaucratic and political interaction (...)' (Grindle, 1977:7). As a consequence, I focus on the political and bureaucratic actors, arenas and conditions that play a role in engendering policy ideas and bureaucratic transformations. ${ }^{6}$

The water reforms in Mexico were part of a larger set of neo-liberal reforms enacted during the presidency of Salinas de Gortari (1989-1994) with the support of international funding agencies. Decentralisation policies, such as the transfer of irrigation districts, are assumed to weaken the position of the bureaucracy by devolving authority and control over resources to organisations external to the government, reducing government subsidies and downsizing bureaucratic staff. This has led many people to believe that the hydraulic bureaucracy ${ }^{7}$ in Mexico had no part in defining or supporting the water reforms and that either the Mexican president or international funding agencies must have imposed it. This perception of reform processes also partly explains why policy documents place such emphasis on the need for a strong commitment to reform on the part of policy managers.

In contrast to this reading of the water reforms, this chapter argues that the composition of, and the commitment to, the water reforms emerged from a complex and protracted process of interaction and enrolment between policy actors such as senior hydrocrats, the Mexican presidential candidate, and World Bank officials. Segments of the hydraulic bureaucracy played a crucial role in the generation of policy ideas and the articulation of the water reform package in the $1980 \mathrm{~s}$, as part of an ongoing struggle within the Mexican bureaucracy. I argue that IMT became feasible because it was embedded in a broader reform package that resulted in greater autonomy for the hydraulic bureaucracy through the creation of a single water authority and the reordering of control over bureaucratic domains and resource flows. Thus, these neo-liberal water reforms were only possible as they combined decentralisation with the concentration of bureaucratic powers and generated important benefits for segments of the hydraulic bureaucracy.

The aim of this chapter is to stimulate debate on the role of hydraulic bureaucracies in water reforms. The management of irrigation by bureaucracies became a target of criticism in the late 1970s and 1980s' rural development literature (Bottrall, 1981a, 1981b; Chambers, 1988; Moore, 1981; Repetto, 1986; Wade, 1978, 1982; Wade and Seckler, 1990). This literature stressed the need to study the hydraulic bureaucracy, but only focused on the discrepancies between policy objectives and implementation, highlighting the problematic role of low-level field staff. By sustaining the divide between policy formulation and implementation, this literature viewed the bureaucracy solely as an instrument for attaining policy objectives, thus disregarding the role of senior hydrocrats in policy-making activities both before and after policy legislation (Clay and Schaffer, 1984; Long and van der Ploeg, 1989; Yanow, 1988). To overcome this, I view bureaucracies as 'the accumulated product of a social history of past policies [that] become congealed in institutional form and develop a network of interests around them, both inside and outside the bureaucracy' (Beetham, 1987:51). These networks of interests and concerns are rooted in the history and culture of particular bureaucracies, their relationship to larger socio-political constellations, as well as in actors' education and professional experiences. By focusing on the historical and cultural embeddedness of these overriding concerns, I do not attribute them to isolated individuals and therefore 
avoid placing too much emphasis on the intentional behaviour and strategic action of individuals. Hence, no criticism of individuals and their motives, values and beliefs is implied. Although this analysis of the water reforms in Mexico is by no means a comprehensive account of 'what really happened' and is at times speculative,' it demonstrates the benefits of bringing the bureaucracy back in when analysing water reforms.

The following section explores how the Mexican hydraulic bureaucracy developed a set of overriding concerns between 1926 and 1976 relating to control over irrigation infrastructure and bureaucratic and financial autonomy. These overriding concerns help us understand, in Section 3, why the merger between the hydraulic and agricultural bureaucracies in 1976 was so traumatic and led to an energetic struggle for renewed autonomy. Against this backdrop, the consolidation of the water reform package is analysed in Section 4, while Section 5 reviews how this consolidation resulted in IMT and the reconstitution of the hydraulic bureaucracy through the formation of the CNA. Lastly, Section 6 discusses the conclusions and implications of my analysis.

\subsection{The Construction Era (1926-1976) and the Formation of the Hydraulic Bureaucracy}

To understand policy articulation processes in Mexico, it is necessary to place the struggles between policy actors in the broader frame of historical, political and bureaucratic transformations. The answer to the question as to what is distinctive about the link between the Mexican political system, its bureaucracies, and the policy process can be found in several key developments in the country's political history. The political authorities that have ruled Mexico since the 1920s have managed to establish a relatively stable political regime compared to other parts of Latin America. The Mexican revolution (1910-1917) was appropriated by the triumphant political elites in the Partido Revolucionario Institucional (PRI: Institutional Revolutionary Party). Since its foundation in 1929, the PRI has ruled the country uninterruptedly, and, until a decade ago, without much politically organised challenge. According to some authors, the PRI owes its success to its early establishment of political and economic mechanisms for resolving conflicts within the elite and for ensuring mass support and political control. Through clientelism and corporative representation and control, the party successfully incorporated workers, farmers and the middle class (Camp, 1999; Grindle, 1996).

In agriculture, the expansion of irrigation ${ }^{10}$ and the centralisation of decision making was used by the Mexican regime to keep in check sharp socio-economic differences and to increase political control (Vargas Velázquez, 1996). This centralisation ${ }^{11}$ entailed the federal government strengthening its role in water management and consolidated the state's control over water through the formation and expansion of a hydraulic bureaucracy that enjoyed a large degree of bureaucratic and financial autonomy. ${ }^{12}$ This section reviews this process from 1926 to 1976 to understand how the network of interests and overriding concerns of the hydraulic bureaucracy were formed; it points out those aspects of bureaucratic transitions, culture and politics important for elucidating the creation of the CNA and the articulation of the IMT policy. I view these concerns not 
as historical or cultural constants, but as accumulated products of a history of legal, bureaucratic and policy transformations, embedded in a larger process of centralisation.

In his insightful work, El Agua de la Nacion, Aboites (1998) shows that the process of centralisation by which the federal government of Mexico increased its control over water had already started at the end of the $19^{\text {th }}$ century during the Porfirian regime. This trend was consolidated in Article 27 of the constitution drawn up after the Mexican Revolution in 1917, in which water in Mexico was defined as belonging to the nation and falling under federal jurisdiction. Article 27 also established that the only legal way to gain access to the nation's water is through a concession granted by the federal government. Based on Article 27, the centralisation of water management began in earnest in the 1920s, when President Calles launched a programme for the construction of large-scale irrigation systems (termed irrigation districts in Mexico). This programme found its legal expression in the Irrigation Law issued in 1926, which also created the Comisión Nacional de Irrigación (CNI; National Irrigation Commission), the first government agency solely devoted to the design and construction of irrigation districts and their subsequent management. Although exact data on the area irrigated before the creation of the CNI are not available, Orive Alba (1970) estimates it to have been some 800,000 ha. In twenty years (1926-1946) the CNI doubled this figure through the construction of 816,200 ha of large-scale irrigation systems and 21,343 ha of small-scale systems, mainly in Northern Mexico (SRH, 1975). Dam storage capacity in Mexico, which amounted to 88 million cubic meters (MCM) in 1900, increased to $22,717 \mathrm{MCM}$ by 1946 (SRH, 1976).

\section{Control over irrigation districts}

The construction, settlement and management of medium and large-scale irrigation districts entailed control over large sums of money as well as political control over the selection of beneficiaries of government programmes and their access to irrigated agriculture (Martínez, 1988). As a result, control over the irrigation districts and the resources allocated to this function were subjects of much bureaucratic competition between 'functional rivals'. Greenberg (1970) argues that the functional rivals of the hydraulic bureaucracy consisted of those agencies whose activities were similar enough that their personnel felt them to be in competition with each other. The Ministry of Agriculture in particular fits this bill.

Between the 1920s and 1940s, the content of irrigation policy was subject to both interbureaucratic struggles and the ups and downs in the relationship between the state and the peasantry. This revolved around the long-standing tension between policies targeting private capital as a means of increasing agricultural production and those directed at peasants to retain political support in rural areas (Fox, 1992; Gates, 1988; Stanford, 1993). Under President Calles in the 1920s, the construction of irrigation districts served to replace large landholdings (latifundia) with medium-sized family farms. The CNI was instrumental in the creation of this new class of farmers through the settlement and land distribution efforts it oversaw in the irrigation districts. In the mid1930s, President Cárdenas dealt with this challenge in quite a different manner by proceeding to make true the revolutionary promise of giving the 'land to the tiller', especially in regions where large landowners were amongst his political opponents. 
During his term, nearly half of the irrigated area was incorporated into ejidos ${ }^{13}$ (Wionczek, 1982). As the CNI was too closely linked with Calles' policies, Cárdenas transferred the administration and colonisation of the irrigation districts to his trustees at the Bank of Agricultural Credit in 1934. The CNI was vehemently opposed to this move and in 1943 won the inter-bureaucratic struggle and regained control over the administration and colonisation of most of the irrigation districts (Orive Alba 1970).

During this period, responsibilities for water development were spread over several federal ministries and agencies: irrigation with CNI, flood control with the Ministry of Communications and Public Works, potable water with the Ministry of Health, and hydroelectricity with the Federal Electricity Commission. During the presidential election campaign of 1946, the then director of the CNI convinced Alemán, the presidential candidate, of the need to correct this dispersion of administrative efforts. After Alemán became president this came to pass, and in December 1946 the Secretaria de Recursos Hidráulicos (SRH: Ministry of Water Resources) was created. This was a pioneering move in many respects and was the first time water was elevated to the level of a ministry in the Western Hemisphere. The SRH integrated the use of water resources and concentrated the government's efforts in this field in a single organisation. However, when the ministry was still being formed, the Secretaria de Agricultura y Ganaderia (SAG: Ministry of Agriculture and Livestock) persuaded Alemán that it should have authority over the irrigation districts, thus continuing its struggle with the hydraulic bureaucracy (Orive Alba 1970). Once again this met with severe resistance from the hydraulic bureaucracy, and Agriculture's control over the irrigation districts was to last only a short period, with the SRH regaining control over them in 1951.

The above shows how legal and policy transformations concerning irrigation management are subject to bureaucratic struggles between functional rivals, such as the $\mathrm{SRH}$ and the SAG. These transformations revolve around two crucial political phenomena in Mexico: presidentialism and the presidential term of six years (the sexenio). Presidentialism refers to the dominant role played by the president in reordering bureaucratic domains and in the materialisation of political and economic reforms during his sexenio. The sexenio amounts to a calendar of political time, as described by Grindle (1977). A relative rupture with the preceding administration typically characterises the beginning of each sexenio, through changes in the leadership at all levels of the federal administration. At the end of the sexenio, bureaucratic groups align themselves with and offer their support to close allies of the presidential candidate, as these will probably be appointed to top posts in the upcoming administration (Greenberg, 1970). These prospective senior government officials influence the presidential candidate's views on institutional and policy reforms as well as on the division of bureaucratic functions and allocation of resources. Policy changes and bureaucratic transitions are thus most frequently shaped and defined at the end of a sexenio, to be initiated at the beginning of a new sexenio. When viewed in a longer time frame, it becomes apparent that the radical ruptures in control over the irrigation districts are structured by the political calendar of the sexenio and in that regard turn out to be an element of continuity.

In the following decades until the creation of the Secretaria de Agricultura y Recursos Hidráulicos (SARH: Ministry of Agriculture and Water Resources) in 1976, the SRH consolidated its control over the irrigation districts and managed to keep the Ministry of 
Agriculture out. This culminated in 1972 with the promulgation of the Ley Federal de Aguas (Federal Water Law). Article 46 of this law establishes that the SRH is completely responsible for the irrigation districts, from construction to management, effectively forbidding user management of the districts (Diario Oficial, 1972). However, the various water laws promulgated between 1926 and 1947 contained provisions for the creation of water users' associations or water boards to manage irrigation districts. The 1929 water law already mentions water users' associations and confers legal status to them (SAyF, 1929). ${ }^{14}$ Subsequent water laws also allowed for the operation of irrigation districts by user associations or water boards, only to become illegal under the water law of 1972 . For example, the irrigation law of 1947 mentions that:

'Until the (...) the users are organised and sufficiently trained as to take charge [of the operation of the irrigation districts and irrigation units], the Ministry of Agriculture and Livestock will be in charge of the maintenance of the structures, water distribution and the overall operation of irrigation districts. For this reason, it will make efforts to organise water boards and water user associations, to whom in the end the operation of the irrigation districts will be handed over. When it is judged opportune, the districts or units will be turned over to their respective users, so they can operate them directly, albeit under the vigilance and supervision of the Ministry of Agriculture and Livestock.' (Diario Oficial, 1946:16; my translation)

In line with the law's provisions, water boards were charged with the operation of several districts in the north, such as Rio Yaqui, Río Mayo, Río Colorado and Delicias. But water monopolisation by commercial farmers combined with the lack of strong government support was in most cases detrimental to the continued existence of water boards. The control of most of these districts was returned to the SRH from the SAG in 1951, effectively ending the experiments with water boards ${ }^{15}$ (Palacios Vélez, 1993; Vargas Velázquez, 1996).

\section{Financial autonomy}

The monopoly of the CNI and the SRH in the construction of irrigation systems secured it a large and steady income flow between the 1930s and the 1970s. These resources represented an important element of continuity for the hydraulic bureaucracy and largely account for the financially wealthy and autonomous bureaucracy that the SRH became during this period. The SRH's budget was one of the largest among the federal agencies with 61 to 100 per cent of pubic investments in the agriculture sector going to the construction of irrigation works between 1926 and 1976. Further, it managed its own funds and had relative budgetary freedom from other bureaucratic entities, although subject to presidential and party priorities (Durán, 1988; Greenberg, 1970; Grindle, 1977; Wionczek, 1982).

It was only in the early 1960s that foreign loans started to become important for SRH (Durán, 1988; Greenberg, 1970; World Bank, 1983b). Because of its international reputation as an efficient and technically competent ministry, the SRH was very successful in acquiring international loans for irrigation construction purposes, thereby 
generating urgently needed foreign currency for the government. From 1966 to 1975, foreign loans constituted more than fifteen per cent of the SRH's irrigation investments on average (Durán, 1988; World Bank, 1983b). Mexico, and more particularly its hydraulic bureaucracy, became favoured clients of the World Bank. As a major recipient of external funding, the SRH was granted privileges not given to other ministries, such as a large degree of autonomy in making technical decisions and a significant budget to hire a cadre of well-trained professional engineers (Greenberg, 1970).

Another source of income for the hydraulic bureaucracy was the water charges it levied on irrigators. However, this source of income was much less stable and controllable. Apart from the fact that the water charges collected in the districts were never sufficient to fully cover Operation and Maintenance (O\&M) costs, the fees were not paid directly to the SRH but to the Ministry of Finance (van der Zaag, 1992). The initial policy intention under Calles was that those who benefited from state-built irrigation works would reimburse the state for its investment as well as fully cover the O\&M costs of the irrigation systems (Wionczek, 1982). This objective was reiterated in the 1947 irrigation law. Nonetheless, fee payment generally covered only a fraction of irrigation investments and O\&M costs (Aboites, 1998). Between 1950 and 1964, cost recovery averaged sixty per cent (Orive Alba, 1970). From 1965 to 1976 this average slipped slightly to around fifty-three per cent, but between 1977 and 1982 it dropped drastically to around twenty per cent (Johnson, 1997a).

Although it is unclear how fees were actually established by the different agencies responsible for the irrigation districts throughout the years, political criteria were often more relevant than technical and financial ones (Ascher, 1999; Wionczek, 1982). The argument often used to justify low water charges was that the poorer farmers in the districts would not be able to pay if the fees were raised (Wionczek, 1982). However, this does not explain why the fees were not adjusted in accordance with the increased value of irrigated land. Policies favouring low fee levels and the government's priority to invest in large construction works rather than in optimal use of the available infrastructure led to a sub-optimal use and deterioration of the irrigation infrastructure. ${ }^{16}$ However, this deterioration presented itself selectively, especially harming small farmers. Mediumsized and large producers were financially able to solve maintenance problems for themselves. Although supported in the name of social equity, low water service fees were mainly beneficial to larger farmers.

The above shows how financial autonomy became an important concern of the hydraulic bureaucracy. This concept refers to the degree to which a bureaucracy can generate and control its income flows, set its own budgets and decide on expenditure and investment independently from other bureaucratic entities. The more affluent a bureaucracy is, and the more budgetary freedom it has, the larger its degree of financial autonomy.

\section{Bureaucratic autonomy}

At the centre of the Mexican political system stand the president and the party. Officially, they decide on the programmes that the bureaucracies should undertake, in line with the political projects that they intend to carry out in the coming sexenio. The party has the power to appoint and remove officials at all levels of the bureaucracy (Greenberg, 1970). 
Hence, officials must maintain good relations with the party, and party activity is an important prerequisite for high-level appointments in the bureaucracy (Grindle, 1977).

The co-ordination of water management at the ministry level during the SRH era implied that senior hydrocrats stood in direct contact with the president. The minister was the central figure in the SRH, appointed by the president and directly responsible to him for all the actions of the ministry. The president allowed his minister - often a friend or political confidant - to appoint his own team (equipo) of trusted collaborators and left the internal operations and the management of funds to the discretion of the minister. The minister thus enjoyed a considerable degree of operative and budgetary autonomy, within the broad policy lines negotiated with the president. Historically, well-qualified men, all trained as civil engineers and with experience in the ministry led the SRH. The minister's technical qualifications were considered important to impress donor agencies during loan negotiations and to convince them that their money would be well spent. At times, the SRH minister played an important role in national politics and at least once in the presidential succession (Castañeda, 1999; Greenberg, 1970; Orive Alba, 1970).

During its thirty years of uninterrupted reign, the SRH was not constrained by any superior bureaucratic entity, such as for instance the Ministry of Agriculture. An important concern of senior hydrocrats thus became their bureaucratic autonomy, i.e. the degree of operative freedom and internal control that a bureaucracy has and the extent to which it can prevent external influence on decision making. In part this was possible because of the close relations with several Mexican presidents and the PRI and the important role that the hydraulic bureaucracy played in their political projects.

To illustrate how these overriding concerns are embedded in the history and culture of the hydraulic bureaucracy, it is necessary to review the composition of its staff and the consequences this had for the internal relationships, bureaucratic culture and network of interests that developed. The expansion of the hydraulic bureaucracy and the professional and bureaucratic formation of its cadre occurred in a complex of education and research institutions, professional associations, private construction companies and international organisations with which the hydraulic bureaucracy maintained close relations.

A distinct attribute of the hydraulic bureaucracy was the relatively homogeneous composition of its staff, with similar academic and bureaucratic careers, which contributed to the closed and hierarchical culture of the SRH and the strong sense of identity of hydraulic bureaucrats. The professional staff of the CNI and SRH consisted of civil and irrigation engineers with similar educational backgrounds and bureaucratic careers. The majority of these engineers were trained in two major Mexican engineering schools: the Faculty of Engineering of the National Autonomous University of Mexico (civil engineers) and the Chapingo National School of Agriculture (irrigation engineers). Apart from professional skills, students developed strong friendship bonds and clientele networks in these schools that benefited them in their bureaucratic careers. In addition, the relation between the bureaucracy and these education and research institutions was actively maintained, with SRH officials returning to their universities as lecturers and vice versa. 
The similar training and bureaucratic trajectories of most of the engineers had an important impact on the bureaucratic culture of the SRH. The SRH was a ministry with a small staff of well-paid engineers that worked in a structured and organised manner. There was little room for disobedience and both orders from superiors and the periodic transfers of officials ordered by headquarters were followed and accepted. In comparison with the Ministry of Agriculture, the SRH was known for its closed, conservative and authoritarian culture and the strong discipline of its staff. During the first decades of the hydraulic bureaucracy, its engineering staff developed a keen sense of its hydraulic mission and possessed a strong esprit de corps. Officials of the hydraulic bureaucracy identified with the grand tradition of Mexican hydraulic engineering and its major accomplishments and defined themselves as a distinct group with its own bureaucratic history and culture. This permitted a sense of pride towards the profession and the institution, strengthened by closed networks (to the outside world) of friendship and mutual support.

These networks of the hydraulic bureaucracy extended to construction companies. In the early 1940s, the SRH decided to tender contracts for the construction of dams and large irrigation works. This resulted in the formation of several Mexican construction companies, which played a major role in the development of the $\mathrm{SRH}$, since they served as contractors and consultants to the ministry. In addition, former members of the hydraulic bureaucracy frequently staffed them, and senior hydrocrats were advisors for these companies or had financial interests in them. The hydrocrat thus fulfilled different roles, namely that of bureaucrat, politician and businessman. Understandably, the close links with contractors resulted in pressures to give priority to construction projects and partly explains the strong construction bias of the hydraulic bureaucracy (Greenberg, 1970).

The relations with international organisations form another important field of institutional interactions. Because of the good reputation of the Mexican hydraulic bureaucracy, senior SRH engineers undertook consultancies for international organisations, such as the FAO, the Inter-American Development Bank and the World Bank. These contacts facilitated the negotiation of international loans in which the SRH became reasonably successful (Greenberg, 1970) and played an important role in obtaining the World Bank's support for the prestigious National Water Plan at the beginning of the 1970s, as detailed in the next section.

To recapitulate, three main points emerge from this section. First, from the 1920 s to the 1970s, irrigation development and management were characterised by increasing federal government intervention. Second, this centralisation of water management, coupled with the government priority for the development of large-scale irrigation, led to the formation, expansion and specialisation of a hydraulic bureaucracy. Over time, this bureaucracy developed specific overriding concerns, namely control over irrigation districts and bureaucratic and financial autonomy, and cemented its relative autonomy through the relations it maintained with the president, the party and a broader set of state institutions and funding agencies. Third, it is clear that user management of irrigation districts is not new, although the government did not actively support the operation of irrigation districts by users. This partly explains why most of them did not endure. 
2.3 Loss of Autonomy and the Emergence of Policy Ideas in the SARH Era (19761988)

\section{The SARH fusion}

In 1976, President López-Portillo merged the smaller but financially affluent SRH with the larger but financially poorer SAG to create the Secretaria de Agricultura y Recursos Hidráulicos (SARH: Ministry of Agriculture and Hydraulic Resources). The creation of the SARH was linked to several political, administrative and economic considerations. Apparently, senior SRH officials had backed a rival presidential candidate in 1975. This persuaded López-Portillo to 'punish' the SRH and remove certain bureaucratic groups from the political stage. In addition, as a Minister of Finance during the Echevarría administration (1970-1976) he had experienced severe problems with the SRH's lack of budgetary discipline. Although economically the tide was against him in 1976, LópezPortillo decided to expand the state's role in the economy. ${ }^{17}$ This was made possible by the discovery of new oil deposits and substantial increases in oil prices (Grindle, 1996). López-Portillo announced a far-reaching administrative reform to rationalise the wide array of bureaucracies created in previous decades (Martinez, 1988). This included the creation of the Secretaria de Programacion y Presupuesto (SPP: Ministry of Programming and Budget), a ministry that unified financial planning functions previously distributed among various ministries. ${ }^{18}$ The creation of the SARH was part of this administrative reform and served to unify all activities related to agriculture in one ministry (Arce, 1993).

With the creation of the SARH, the SRH was dissolved and effectively downgraded to the level of an under ministry. The SARH was divided into three under ministries, each headed by a deputy minister: Agriculture and Operation, Planning, and Hydraulic Infrastructure, to which most of the old SRH officials were assigned. As a result, senior hydrocrats were no longer in direct contact with the president. The deputy minister now had to submit his policy initiatives to the SARH minister, significantly curtailing his discretionary powers. I will illustrate below that senior hydrocrats lost control over crucial bureaucratic domains and resource flows to other bureaucratic groups that increasingly started to dominate the SARH. The hydraulic bureaucracy thus lost its dominant position and bureaucratic autonomy and was subjected to the control of the agricultural bureaucracy.

The bureaucratic merger entailed a serious demotion for the hydrocrats and provoked 'institutional turmoil' (Mestre, 1997). The SRH top echelons opposed the fusion, as they clearly understood that it would entail a significant loss of autonomy. For many hydrocrats, the fusion was traumatic, and they experienced the demise of the SRH as the end of the grand era of hydraulic engineering in Mexico. To make matters worse, they were fused with an old-time functional rival. ${ }^{19}$ In 1970, unaware of the fusion to come, Greenberg wrote that The sharing of power with the Agriculture Ministry is the result of a long history of struggle which saw first one, and then the other agency, in a position of dominance' (1970:87). The merger started a new phase in this historical struggle and engendered an energetic and politically expressed demand for renewed autonomy on the part of the hydrocrats. 
Although the irrigation districts were left intact, they became the responsibility of the Under Ministry of Agriculture and Operation, implying that the hydraulic bureaucracy lost control over the irrigation districts as well as the income flows associated with those districts (Palacios Vélez, 1994). In addition, after an initial phase in which the hydrocrats continued to dominate in the state delegations and the irrigation districts, many of them were replaced by agronomists (Arce, 1993). The subordinate position of the hydrocrats led to intensive conflicts between groups of ex-SRH and SAG officials. Not only were the academic and bureaucratic careers of the hydrocrats and the agronomists dissimilar; the conservative and authoritarian culture of the $\mathrm{SRH}$, the bureaucratic discipline, the professional identity they shared and the strong pride they felt towards the grand tradition of hydraulic engineering also made them feel very distinct from the SAG agronomists. These antagonistic cultures contributed to severe tensions between these two groups over the internal operation and control of the SARH. Ex-SRH officials at the time jokingly referred to the merger of SRH and SAG as the confusion instead of the fusion.

The displeasure of the hydrocrats over the loss of control was directed not only at the agronomists, but also at the growing influence of 'politicians' and 'administrators' in the ministry, i.e. non-engineers without experience and interest in hydraulic matters. The first SARH minister (1976-1982) was a politician without a professional degree, and the second minister (1982-1988) was a lawyer, something which radically broke the SRH tradition of being led by well-qualified men, trained as civil engineers and with a career in the SRH itself (Greenberg, 1970). In the SARH, ex-SRH officials were thus confronted with politically appointed administrators in positions that used to be occupied by engineers. The changed set of decision criteria, and especially the ignorance or neglect of specific technical criteria, was a recurrent source of frustration for them.

The hydrocrats in the SARH were also severely constrained in their financial autonomy. In the SRH, the major source of income had been the funds for the construction of irrigation systems. In the SARH, decisions about the construction funds were taken out of the hands of the hydrocrats and their deputy minister. Agronomists interfered with the decisions about construction funds and succeeded in diverting much of this funding to other purposes. The construction companies, the traditional beneficiaries of the contracts tendered by the SRH, were especially affected by this shift in decision-making power.

At the end of López-Portillo's sexenio, influential groups of civil engineers started to lobby for renewed bureaucratic autonomy and explicitly expressed their demand for an autonomous water authority during the election campaign of presidential candidate, De la Madrid, in 1982. During this campaign, a working group was formed to define water policies for the upcoming sexenio, and several campaign meetings were held on water, co-ordinated by Dr. González Villareal in close collaboration with De la Madrid's campaign manager, Carlos Salinas, who later also became president (IEPES, 1982).

Several politically influential ex-SRH ministers and senior hydrocrats participated in the working group and identified policy ideas strikingly similar to the one adopted six years later with the creation of the CNA. The working group agreed on the need to create a 'new water culture' among users and to increase their active participation. They also 
suggested the need to manage water at the level of the river basins. Another recommendation was the proposal to organise a 'financial system for water' that would give the hydraulic bureaucracy large discretionary powers over funds destined for the water sector. Lastly, the working group repeatedly stated that the authority to manage water should be located in a 'single water agency' (González Villareal, 1982a).

This attempt to re-establish autonomy did not succeed. After De la Madrid became president in 1982, the Under Ministry of Hydraulic Resources was maintained as a separate but dependent part of SARH. It is likely that a more autonomous authority was not feasible at this time because of the economic crisis that held the country in its grip. Thus, the ex-SRH engineers had to accept their subordinate position in the SARH for another six years, during which time their financial and bureaucratic autonomy was further curtailed. The working group of ex-SRH officials achieved only partial success through the appointment of their co-ordinator as the new Deputy Minister for Hydraulic Resources.

The financial situation of the SARH severely worsened between 1982 and 1988, largely as a result of the unprecedented economic crisis that hit Mexico in 1982. To deal with the crisis, De la Madrid, the first economist after a string of lawyers as president, adopted a neo-liberal approach that strongly departed from the populist and interventionist economic policies followed by previous presidents. This resulted in a restructuring of the SARH, the reduction of barriers to commerce, the abolition of subsidies for agricultural inputs and a liberalisation of agricultural prices (Vargas Velázquez, 1996). According to some observers, De la Madrid gave much less priority to agriculture than previous administrations not only because of the economic problems but also because it had lost its strategic importance for the country. This is understandable, as agriculture's share of the Gross Domestic Product (GDP) dropped to six per cent at the beginning of the 1980s, down from eleven per cent in the 1960s (Palacios Vélez, 1994).

\section{The emergence of a planning team, new experiences and policy ideas}

Partly in response to the difficult SARH era, new ideas concerning irrigation policy and the restoration of autonomy for the hydraulic bureaucracy were developed by senior hydrocrats. To understand their origins it is necessary to go back a little. The Plan Nacional Hidráulico (PNH: National Water Plan), a water master planning organisation created in 1973 to provide a frame of reference for future lending programmes in the field of water resources, played an important role in this. This new bureaucratic body led to the formation of a team of water resource planners that departed from the traditional construction bias of the hydraulic bureaucracy by developing a broader vision on water resource planning and management. The influence of multilateral funding and foreign expertise was significant in this respect, as we can see in Appendix 1. The planners working in the PNH developed policy ideas and accumulated particular experiences favouring participation by water users and the handing over of government tasks in water management. These can be seen as precursors to the creation of the CNA and the IMT policy. Other groups within the bureaucracy, more related to construction or O\&M departments, were much less receptive to these ideas. 
The first plan was received well by both president Echevarría and the World Bank in 1975, and two of its major recommendations were immediately implemented (Herrera Toledo, 1996). Firstly, the PNH was converted into a permanent planning agency falling under the SARH in 1976, thereby institutionalising the planning process. Dr. González Villareal continued to co-ordinate the PNH and basically kept on the same team. He reoriented the objectives of the $\mathrm{PNH}$ to support the implementation of policies and programmes contained in the first plan and to continue studying present and future water needs. During this time, the commission gained sufficient technical authority to play an important role in policy formulation and decision making at the highest levels of government (Herrera Toledo, 1996).

Secondly, the recognition that traditional large-scale irrigation development would not work in the humid tropical lowlands of the Gulf Coast resulted in the Programa de Desarrollo Rural Integrado del Trópico Humedo (PRODERITH: Programme for the Integrated Rural Development of the Humid Tropics). Interestingly, PRODERTTH fell under the PNH Commission, which was directly charged with executing works. In 1976 several pilot projects were started, centring on drainage, small-scale supplemental irrigation and intensive agricultural development. PRODERITH aimed to stimulate the social and productive development of traditionally marginalised villages in these regions (Herrera Toledo, 1996). The World Bank played a role in preparing the programme and also partially financed it. By 1985 when the pilot projects had been successfully implemented, a second phase was entered, in which the efforts were concentrated on transferring the developmental process and decision making to organisations of beneficiaries (Herrera Toledo, 1996).

Some of these regions had a conflictive history of authoritarian government intervention in terms of land development and forced resettlement schemes. The explosive social situation led to popular protests and military interventions. PRODERITH entered with an alternative approach, based on 'social participation', to the paternalist manner in which the government had intervened and tried to develop these regions in the past. The approach entailed negotiations with the communities in which people could participate in developing a local development plan on the basis of their problems and priorities. These plans served to involve and organise the communities and to determine the programme support activities in the region. The programme successfully established relations with the communities and carried out the development plans.

Different SARH officials acknowledged that the experience with this model of community participation in decision making was important in the development of policy ideas that also applied to the irrigation districts. Some observers state that it was a pilot or try out for what later became the transfer of irrigation districts. The group of planners accumulated valuable experiences with the organisation of producers, their participation in decision making and the handing over of responsibilities that were traditionally exercised by the government. In senior SARH officials' circles, concrete policy ideas started to develop in favour of more substantive user participation and the handing over of government tasks in the irrigation districts. 


\section{Shifting policy agendas}

The hydraulic bureaucracy especially felt the financial consequences of the economic crisis of 1982. During De la Madrid's sexenio, only 44.5 billion pesos were invested in the irrigation sector, compared to 89.8 billion pesos during the previous sexenio (in constant 1979 pesos) (Palacios Vélez, 1994). To make matters worse, the World Bank temporarily stopped lending to Mexico, as a response to the moratorium on payments of foreign debts that the government had declared. ${ }^{20}$ For the irrigation sector this was a strong departure from the past twenty years during which the Bank lent more than $\$ 800$ million (World Bank, 1983b). In the World Bank, the construction bias of the hydraulic bureaucracy also started to be a matter of debate around this time. Buras (1983) mentions that the World Bank wanted to see the orientation of the hydraulic bureaucracy change and was no longer willing to support the construction projects that many hydrocrats and construction companies had in mind. Although construction activity in these years did not stop, it was significantly reduced.

In line with international debates on irrigation management (Bottrall, 1981b), the 1983 World Bank review of the Mexican irrigation sector concluded that Mexico needed to shift attention away from the construction of new irrigation systems to improving the management and efficiency in existing systems. The report outlines a programme of repair and upgrading of existing systems and an increased role for users in decision making (World Bank, 1983a). The report goes on to recommend the bulk sale of water by the government to users' associations in the districts, who would then sell and distribute the water to its members, citing the successful use of this system in the Río Yaqui irrigation district. Although 'turnover' or ' $\mathrm{TMT}$ ' is not mentioned as such in the report, it is striking to see how its recommendations strongly coincide with the core of the IMT programme in the 1990s. The 1983 report signified an important shift in the Bank's agenda for the irrigation sector, and its recommendations influenced both the emergence of the IMT policy idea and its content.

Although user management of irrigation districts has been a recurrent theme throughout the history of irrigation development in Mexico, transfer as such was not on the policy agenda in the early 1980s, although discussions on user participation in irrigation increased during the 1970s and early 1980s. A key recommendation of the $1975 \mathrm{PNH}$ was to reduce the subsidies to the irrigation districts and to increase user participation in the financing of irrigation development, operation, maintenance and rehabilitation (SRH, 1975). During the period of the oil boom (1977 to 1982), the government's subsidies to the irrigation districts sharply increased to forty-six billion pesos, compared to twenty-two billion pesos between 1971 and 1976 (in constant 1979 pesos) (Palacios Vélez, 1994). However, the 1982 economic crisis led to a reconsideration of the amount of subsidies going to the irrigation districts. During De la Madrid's election campaign in 1982, several meetings on water issues were held, at which it was suggested to improve the 'participation' of users in the financing of the irrigation districts.

The Mexicans with access to (...) drainage and irrigation services are in a privileged situation. But those who benefit from these services also have a greater responsibility towards the nation; a responsibility which should imply an increased participation (...) in the financing of the 
administration of water and the works to utilise it.' (González Villareal, 1982b:21; my translation)

This recommendation was mirrored in the conclusions of an important World Bank study on the irrigation sector in Mexico, which singled out an 'across-the-board increase in water charges' as the most important policy decision that needed to be taken by the Mexican government concerning the irrigation sector (World Bank, 1983a). This proposal materialised in an amendment of the Ley Federal de Derechos (Federal Rights Law) in 1983. It legislated for the payment in 1984 of water charges sufficient to cover the costs of operation, maintenance and improvement of irrigation districts. In 1985, such payments would have to be sufficient to create a fund for improvements and expansion of the districts, and in 1986 to recover government investments in irrigation (World Bank, 1983b).

Actual cost recovery seriously lagged behind these ambitious objectives. Even though water charges were raised in many districts, inflation was much higher due to the severe economic crisis, rendering the rises largely superfluous. In addition, the government severely reduced the subsidies to the irrigation districts. The dramatic failure to persuade farmers to pay much higher water charges made it clear to senior hydrocrats that more drastic measures were needed. An increased role for water users in the management of irrigation districts became more important as an option to improve cost recovery in 1983 and 1984.

'It is fundamental to look for new ways in the operation of the districts
that would permit a more comprehensive participation of users in their
administration and financing, with the aim of rationalising possible
subsidies and preventing excessive bureaucratic intervention.'
(González Villareal, 1982a:123; my translation)

\section{Loss of control over the irrigation districts and further developments}

As one of the many reorganisations of the SARH during De la Madrid's sexenio, the irrigation districts were combined with the rainfed districts in 1985 to form rural development districts (Palacios Vélez, 1994). Ostensibly, the reason behind this policy was to reduce costs and improve the use of resources. However, it also entailed the further reduction of the hydraulic bureaucracy's control over the irrigation districts. The new rural development districts, which fell under the Under Ministry of Agriculture and Operation, became to an increasing extent the domain of agronomists. Moreover, due to the severe lack of funds, the irrigation districts' infrastructure was deteriorating quickly. This situation was completely unacceptable to senior hydrocrats, and the need to 'rescue' the irrigation districts was to play an important role in the definition of the IMT policy (Vargas Velázquez, 1996).

In 1985, a working group was formed between the SARH and the Ministry of Finance to review the tax law and to further define a fiscal policy for the use of water, with the aim of achieving financial self-sufficiency in the water sector. Besides industry and the commercial service sector, it was decided to include irrigated agriculture in the law, implying that farmers would have to pay an annual tax for the right to use water on top 
of water charges. The proposal was sent to Congress at the end of 1985, but, due to the serious problems agriculture faced as a result of the economic crisis, Congress established a zero tariff for the agricultural water tax (Palacios Vélez, 1996). This was a severe blow to the SARH, as it had been agreed in negotiations with the Ministry of Finance that the irrigation districts would no longer be subsidised and that the proposed water tax would be used to finance the irrigation sector.

According to several senior irrigation engineers, the then Deputy Minister of Hydraulic Resources, Dr. González Villareal, seriously started to consider the possibility of transferring the irrigation districts to water users in 1985. The ramifications of transfer and how to initiate it were discussed at a breakfast meeting in 1985 between the Minister of Agriculture, Dr. González Villareal and other senior SARH officials. They saw no way to reverse the already serious deterioration of the districts and to resolve the financial problems without drastic changes in the way the districts were administrated. They also understood that to obtain desperately needed external funds they had to accommodate the World Bank's new agenda. It was clear at this point that such elements had to be incorporated in the policy agenda for the next sexenio if it were to accomplish something for the hydraulic bureaucracy, i.e. the renewal of autonomy. To formally initiate the transfer of irrigation districts was not politically feasible in the middle of the sexenio, and the 1985 earthquake in Mexico City, which disrupted the country and destroyed the central SARH offices, seriously slowed down concrete initiatives.

In 1986, the World Bank resumed talks with the SARH and started to suggest possible new irrigation loans for the upcoming sexenio. The negotiations were led by Dr. Gonzalez-Villareal, who proved to be a skilful negotiator and came up with a number of home-grown policy initiatives, ${ }^{21}$ among which the loan proposal for transferring a limited number of irrigation districts. At the same time, a number of experiments with user management of irrigation districts in the Northwest and the formation of a river basin council and agency in the Lerma-Chapala Basin were initiated by the Deputy Ministry of Hydraulic Resources. From 1985 to 1987, transfer remained a policy idea with its modalities and characteristics still largely undefined, although its financial and institutional basis was seriously worked on.

The further loss of financial and bureaucratic autonomy and a weakening of the control over the irrigation districts by the hydraulic bureaucracy during the De la Madrid sexenio was unacceptable to most hydrocrats. For them, the major issue in water management was the dispersion of responsibilities and resources over different bureaucratic agencies. Although the SARH was legally responsible for the nation's waters, urban and industrial water use, water for hydropower, and water quality fell under other ministries (IEPES, 1987). It was argued that the lack of inter-ministerial co-ordination made it very difficult to manage water adequately. To senior hydrocrats it was clear that radically different policy scenarios had to be explored to extract the hydraulic bureaucracy from its worst crisis. Ideally, this would entail the re-constitution of an autonomous water authority that would concentrate the responsibilities and financial resource flows related to water. The emergence of IMT as a policy idea was closely intertwined with the aim of the hydraulic bureaucracy to re-establish financial and bureaucratic autonomy and control over the irrigation districts. To achieve this aim, different groups of ex-SRH engineers 
started exerting political pressure towards the end of the De la Madrid sexenio, setting the stage for the creation of an autonomous water authority.

\subsection{Towards a Reform Package}

\section{The policy actors}

In January 1989, Salinas created the CNA less than six weeks after he became president, and in June 1989 the National Development Plan, which endorsed IMT $^{22}$ and a wider water reform package, was released. These rapid developments indicate that in 1987 and 1988 disparate policy ideas, such as the transfer of irrigation districts, the creation of an autonomous water authority and water pricing, were articulated further and combined in a single reform package. This occurred during the run-up to the presidential elections in 1988 when an influential segment of water resource planners within the hydraulic bureaucracy negotiated the water reform package with the presidential candidate. Although international lending agencies were not directly involved in these negotiations, their position on necessary water reforms and the prospect of new loans played a crucial role in defining the reform package. This section outlines the different positions and agendas of these three policy actors and shows how they agreed on a reform package that included both a concentration ${ }^{23}$ and a decentralisation ${ }^{24}$ of bureaucratic domains and resource flows related to water. In particular, the role of the group of water resource planners in the articulation, packaging and consolidation of the reform package is highlighted.

The team of water resource planners formed by the PNH and led by Dr. González Villareal took the lead in proposing IMT to Salinas and convincing him of the need for an autonomous water authority during his election campaign. ${ }^{25}$ In this they were supported by different groups of civil engineers working for the Under Ministry of Hydraulic Resources in SARH, for construction companies or stationed at the Faculty of Engineering of the UNAM. The construction companies especially played an important role in supporting the demands of these engineers in line with their interests. When Salinas became a presidential candidate and started galvanising support from the bureaucracy for his campaign, this coalition of engineers offered him its support in return for the creation of an autonomous water agency (van der Zaag, 1992).

The three key policy actors involved in the articulation of the reform package were very familiar with each other's dispositions and agendas due to frequent interactions in the past. These can be summarised as follows:

1. Salinas espoused a neo-liberal agenda that aimed to modernise state-society relations and reduce government expenditures through decentralisation, shared responsibility between the public and private sector, and social reconciliation.

2. Dr. González Villareal and his team of water resource planners represented the hydraulic bureaucracy in its strong will to re-establish bureaucratic and financial autonomy, whilst supporting policy ideas concerning user participation and a financial system for water. 
3. The World Bank supported policies to reduce government intervention and expenditure in irrigation, amongst other things through decentralisation, water pricing reforms and increased user participation in decision making. As a favoured client of the Bank, Mexico had become eligible again for new loans after a period of austerity, implying that reform initiatives would be looked upon favourably (see Appendix 1 on the World Bank Lending History).

During the Salinas sexenio (1989-1994), De la Madrid's neo-liberal agenda was continued with increased intensity. During his election campaign in 1988, Salinas launched the plan to modernise rural Mexico by means of a set of economic, political and social reforms. He emphasised the need to break with the paternalist practices of the government in the rural areas with a strategy that would allow for more participation on the part of the social and the private sector. Key concepts in Salinas' discourse were shared responsibility (coresponsabilidad) and social consensus building or consultation (concertacion social). These ideas originated from his academic research on popular support for the political regime in rural communities and experiences with organising farmers (Cornelius et al., 1994; Gordillo de Anda, 1988).

In Salinas' vision, shared responsibility would be reached through social reconciliation efforts, both in the rural and urban areas. He proposed a mode of governance termed 'social liberalism', which sought to avoid the excesses of both unfettered free market capitalism and heavy-handed state intervention, thereby leading to the reduction of absolute poverty and an increase in social well-being (Cornelius et al., 1994). Salinas' ambitious agenda aimed to modernise the relations between state, society, and the market and strongly favoured decentralisation and participation of the social and private sector in water management. During his sexenio, Salinas followed a policy of liberalising trade, deregulating the economy, privatising parastatals, reforming the financial sector and fractionalising the corporate structure of the PRI (Grindle, 1996).

The group that played a key role in mapping out the course of the hydraulic bureaucracy and the irrigation districts during the 1980s and 1990s was the team of water resource planners under the direction of Dr. González Villareal, as already indicated in Section 2.3. They were the intellectual authors of many of the policy ideas presented to Salinas during his election campaign. Through his different contacts and positions in the bureaucracy, Dr. González Villareal came to represent the broadly shared claim of the hydraulic bureaucracy for bureaucratic and financial autonomy. ${ }^{26}$

As a SARH deputy ministry during De la Madrid's administration, Dr. González Villareal led the hydraulic bureaucracy in a time of severe crisis. In this period he frequently interacted with Salinas, who had an important say in setting SARH's budgets as Minister of Budget and Planning. Their discussion and interaction on water reforms in view of the state's difficulty to continue financing the irrigation districts and other forms of water use date from this period. Their public discourse suggests that they shared certain opinions and discursive topics, for example on 'social participation', although their formation is very different. Both also showed interest in the shared responsibility of the social and private sector in the financing of water management (González Villareal, 1982a; Poder Ejecutivo Federal, 1989). Finally, the IMT policy idea fitted with Salinas' plans to 
'modernise the countryside', in which strategies of 'social reconciliation', deregulation and decentralisation played an important role (Poder Ejecutivo Federal, 1989).

In addition, Dr. González Villareal and his team of water resource planners knew the world of international funding agencies well. They had developed good relations with officials of the World Bank during the PNH and were well informed about international trends in loan policies and irrigation management reform. The World Bank stopped making loans available for irrigation projects after 1982 and indicated the need for a shift in irrigation policies. As the Under Minister of SARH, González Villareal stayed in touch with the World Bank and initiated discussions on possible loan packages.

Thus, in 1988, Dr. González Villareal found himself centrally positioned to propose water reforms. He represented different groups of hydrocrats in the SARH and maintained good relations with academia and the influential construction sector. His respected vision and expertise on water resources and irrigation and his political participation in the $\mathrm{PRI}^{27}$ were important for his capacity to convince a wide array of political, bureaucratic and societal actors of the transformations needed in the water sector. In him Salinas saw a person with a vision of how to reform the water sector, the skills and authority to deal with potential resistance in the bureaucracy or among water users, and the necessary relations with influential interest groups and the World Bank. He thus became a central actor for Salinas in bringing about a reduction in public spending, giving a strong push to his policy agenda of modernising the relations in the countryside through decentralisation, reorganising the bureaucracy and acquiring international funding to support the proposed transformations.

\section{The election campaign}

In December 1987 and January 1988, five national meetings on water were held as part of Salinas' election campaign. That Salinas made this effort indicates that he saw the political and electoral importance of problems in the water sector. During these meetings co-ordinated by Villalobos Guerrero, an influential civil engineer, the contours of the water reform package for the next sexenio became clear. At the first meeting in Acapulco, Salinas asked Rovirosa Wade, who had been the SRH minister at the beginning of the 1970s, what he thought of the SAG/SRH fusion. Rovirosa Wade responded:

'I was slightly concerned [as] the conception of the water resource could get lost. Giving all the power to an independent entity, I think, would be a solution that the whole country is demanding for the management of water as a vital resource. In fact, I propose not that the SRH comes back, but that at least there would be an independent authority located in the Presidency of the Republic and that it is given all the power necessary for water management.' (IEPES, 1987:10; my translation)

It is remarkable that he rejects the possibility of recreating a ministry, something that certainly not everybody agreed upon at that point. During the same meeting, Salinas asked Dr. González Villareal his opinion on the risks of transferring irrigation districts to the users. His answer is illuminating: 
'The transfer of irrigation districts to users already was an established policy of this administration [of De la Madrid], which has encountered some difficulties. (...) Those of the Northwest are prepared to adopt their own administration. As a matter of fact, in the Río Yaqui irrigation district users already manage the maintenance, administration, and collection of fees and the delivery of water at lower levels. (...) In a programme that will be financed in the near future with international credit, called 'modernisation of irrigation districts', a subsequent phase after the original construction of the districts is proposed, consisting of the bulk delivery of water to the users and an administration directed by them (...). However, in the districts in the centre of the country (...) we believe that the process has to be more gradual. First, some rehabilitation and public investment will be needed, before a first phase of user organisation, if the process is to be effective.' (IEPES, 1987:7; my translation)

This indicates that the discussions with international lending agencies initiated in 1986 to negotiate loans for modernising and transferring a number of irrigation districts had reached such an advanced stage that Dr. González Villareal felt confident enough to announce publicly to Salinas that international loans for IMT would be forthcoming.

Another element of the reform package proposed during these meetings was the 'financial system for water', which had already been presented in the PNH (SRH, 1975). It was argued that a key aim of reforming the administration of water was to:

\begin{abstract}
'Allocate sufficient economic resources to show the will of our society to solve the problems of water, with larger federal, state and municipal contributions, and with a larger participation on the part of the users. The financial system for water, consisting of the investments, the water rights, the payment of differentiated tariffs for services, would be more sound if the fees and taxes collected are re-invested in the sector.' (PRI, 1988:41; my translation)
\end{abstract}

The financial system for water clearly reflects the concern of the hydraulic bureaucracy for financial autonomy. During the SARH period, the income flows relating to water were not controlled by the hydraulic bureaucracy, but were dispersed over different ministries. A concentration of the control over these income flows would significantly strengthen the financial autonomy of the authority.

At a meeting two months later, it became clear that the various policy ideas had been discussed in more detail with Salinas, as he publicly accepted the need for institutional reform in the water sector and the transfer of the irrigation districts. He stated that he took Wade's remarks on an independent water authority seriously, but emphasised that he did not want to 'take a step back on this track' (IEPES, 1987:14), thereby countering the demand for a new ministry. He did call for careful reflection on how the coordination of different water uses could be strengthened and agreed with the need to create 'one single water authority'. He attributed many capacities to this new authority, including the authority to determine its own programmes and budgets, something that 
the existing Under Ministry did not have. Lastly, he acknowledged that the creation of this new authority was a precondition for his proposed policies of decentralisation and social reconciliation and reaffirmed that the irrigation districts would be transferred (PRI, 1988). The reform package as a whole, containing both IMT and the creation of a new water authority, came together at the end of the campaign meetings on water in a PRI document published in June 1988 outlining the party's election platform.

The integrated management of water quantity and quality, by an
authority constituted as a water authority, creates the need to realise
legal adjustments that leave no doubt about the national property of
water, on the one hand, and that make the administrative reorientation
possible on the other. (...) It is a priority to rehabilitate and modernise
the irrigation and rainfed zones with the participation of the users and
the state government, so that when they are in a condition to operate
efficiently, they can be transferred gradually to the users.' (IEPES,
1988:33; my translation)

The same document considers four options for the legal structure of the new water authority.

1. Consolidation of the current administrative structure.

2. Integration of the water authority into the SARH by strengthening the Under Ministry of Hydraulic Resources or creating a deconcentrated authority ${ }^{28}$ in the ministry with full responsibility for all water related activities.

3. Creation of a new ministry, which would entail high political and financial costs and would go against the policy of austerity and a slimmer government, according to the document.

4. Creation of a public, decentralised authority (IEPES, 1988).

Although the creation of a new ministry was unlikely, the group of water resource planners formulated its charter, regulations and organisational structure in full detail in the latter half of 1988. In November 1988, Salinas resolutely ruled out this possibility, as the PRI did not have a majority in parliament to approve the creation of a new ministry. Instead, it was decided that the new water agency would become a deconcentrated authority that would fall under the SARH. The hydraulic bureaucracy was thus forced to accept the 'second best' option and had to go back to the drawing board to define the legal and financial structure for the new water authority. ${ }^{29}$

The above shows how different policy ideas became an integral part of the water reform package and how, as a consequence, it became more articulated during the election campaign of Salinas. This transition occurred in a small circle of policy actors, consisting of the president, senior hydrocrats and World Bank officials, as part of the policy agenda setting for the upcoming sexenio. Combining these different policy ideas in a reform package increased their feasibility, as it had become clear during De la Madrid's administration that merely recreating a water ministry as an individual reform was politically and financially unfeasible. To make the creation of an autonomous authority feasible, it had to be accompanied by a set of apparently paradoxical reforms: a concentration of bureaucratic domains and resource flows, a decentralisation of the 
irrigation districts and an active water pricing policy. If successful, this composite strategy would reduce government expenditure in water management, secure higher and more stable income flows from water use in different sectors, and attract international loans. In addition, it would enjoy the political support of the president and international lending agencies. When Salinas stated during his campaign that the new water authority was a precondition for his proposed policies of decentralisation and social reconciliation (PRI, 1988), he acknowledged the link between concentration and decentralisation measures. The composite strategy of concentration, decentralisation and water pricing made the reform package a financially, politically and bureaucratically viable option.

The reform package offered another advantage. Many observers state that Dr. González Villareal faced groups of middle and senior hydrocrats opposed to the transfer of the irrigation districts. The advantage that he could project to them was that the IMT policy opened up the possibility of reconstituting an autonomous water authority and that it would return a certain level of control over the districts, which at that time fell under the agricultural bureaucracy.

The World Bank did not directly influence the creation of the CNA or the selection of its director, but its financial and ideological support for the proposed reforms was crucial in making the creation of an autonomous water authority feasible. The role of the World Bank in promoting IMT was more direct, as it was clear that new irrigation loans would become available if IMT was implemented. However, it would be too simplistic to posit that the World Bank unilaterally imposed IMT and water reforms on the Mexican government and its hydraulic bureaucracy. This is not to deny the element of financial and ideological coercion, as every international loan is accompanied by some 'armtwisting', as one CNA official expressed it. The policy ideas leading to IMT were a product of historical experiences and concerns of a particular group of water resource planners, admittedly developed in close interaction with World Bank officials. If IMT was a condition attached to loans 'it did not cost the World Bank much trouble to convince the Mexicans', according to a well-informed interviewee. In light of the calibre of the hydrocrats as discussed above, it is difficult to see how they could have accepted a completely 'foreign' imposition of a policy that would affect them in such a drastic manner. The World Bank is limited in its influence when its policy agenda is not supported by, and does not create benefits for, the hydraulic bureaucracy.

From a definition of presidentialism, which attributes a dominant role to the president in policy and bureaucratic transformation, it could be argued that Salinas imposed the reforms on the hydraulic bureaucracy. However, it has been shown here that the hydraulic bureaucracy proposed concrete policy ideas to the presidential candidate and actually enrolled him in their effort to re-establish autonomy. As a presidential candidate, Salinas needed the political support of the hydrocrats as well as their support for achieving his ambitious reforms in the rural sector. Reciprocally, the authorisation of Salinas was crucial for the senior hydrocrats to achieve their objectives. His full support was especially needed to overcome potential resistance within the bureaucracy. Also, it is clear that Salinas did not concede all of the proposals made by the hydraulic bureaucracy, as exemplified by his refusal to create a new ministry. 
Without denying the political, financial and ideological coercion that is needed for a reform programme of this magnitude, it is clear that for all three policy actors there was a limit to the realisation of their agendas. I have highlighted the active role that segments of the bureaucracy played in the definition of the reform package. This is something that is often underrated by approaches that analyse policy formulation and implementation by focusing on the required commitment of politicians and international funding agencies to a single, isolated and black-boxed policy. This analysis shows that there was not one policy, well defined and isolated, to which the policy actors could choose to commit themselves or which was imposed by one of these actors. The individual elements of the reform package meant different things to the policy actors involved. At the end of the 1980s, the interaction between the different policy actors and their agendas had already gone through a trajectory that started with the PNH. During Salinas' election campaign, a process of interplay and mutual enrolment occurred in which the exact shape of the individual reforms was defined and hardened and the reform package as a whole became more irreversible. The commitment of the political leadership and influential segments of the bureaucracy to an individual policy such as IMT was the outcome of this protracted process of interplay.

\subsection{The Creation of the CNA and Irrigation Management Transfer}

\section{Bureaucratic autonomy}

In January 1989, Salinas created the Comisión Nacional del Agua as a deconcentrated agency of the SARH and designated Dr. González Villareal as its director. This appointment was long kept uncertain by Salinas, as the co-ordinator of his campaign meetings on water, Villalobos Guerrero, was also considered an eligible candidate. ${ }^{30}$ The CNA was the first 'modern institution' created by Salinas. However, its institutional setup remained unclear for several months after its creation, as all the effort in 1988 had gone into developing a charter and regulations for a ministry instead of a deconcentrated authority. A SARH official remembers that it basically took the whole of 1989 to establish the normal functioning of the CNA. This caused delays in implementing the ambitious reform package agreed in the campaign. The argument that was used for the creation of the CNA was as follows.

The "sectorisation" of the Federal Government's role in relation to water caused serious problems in co-ordinating water policies that were defined and implemented as a result of sectoral objectives, with very little intervention of SARH in its managerial role, thus aggravating the already critical problems of scarcity, conflicting uses and pollution in several of the major river basins in the country. Due to these existing institutional problems, (...) the Federal Government created the Comision Nacional del Agua as an autonomous agency (...) as the sole federal authority dealing with water problems and conflicts.' (CNA, 1990:5)

The sectoralisation mentioned above refers to the dispersed government responsibilities and resource flows regarding water in the SARH period. During the Salinas sexenio, 
these dispersed bureaucratic domains and resource flows were gradually concentrated in the CNA. The CNA integrated the quantitative aspect of water management, regarding for instance drinking water, industrial use, and irrigated agriculture in both irrigation districts and the smaller irrigation units, but it also became responsible for the qualitative aspects, such as water pollution. The concentration of these different domains strengthened the CNA in its bureaucratic autonomy.

As a deconcentrated agency, the CNA fell under the SARH but could function with relative autonomy. The choice of a deconcentrated authority was partly motivated by the intention to confine the financial autonomy of the new agency. In matters such as negotiations with funding agencies over international loans, the CNA would depend on the SARH. ${ }^{31}$ However, in spite of the chosen legal form, in practice the CNA gained a large degree of financial and bureaucratic autonomy.

When González Villareal was appointed as director of the CNA, he brought with him the team with which he had worked in the PNH and later in the Under Ministry of SARH. An important part of his group were water resource planners from the $\mathrm{PNH}$, others were civil engineers with a more traditional construction background. González Villareal also included experts from different disciplinary backgrounds and experiences, such as lawyers and social scientists. He appointed the members of his team to middle and high level posts, creating a group of subordinates that he could trust and with whom he had unambiguous hierarchical working relations. He knew what he could expect from them because of his intimate knowledge of their disciplinary background and bureaucratic trajectories. Several people have indicated that this was of crucial importance for the difficult bureaucratic reforms that the CNA was facing. During this period, the CNA was an institution in which civil engineers (re)gained a certain dominance, at the expense of other bureaucratic groups, particularly agronomists.

It is generally observed that Dr. Gonzalez Villareal had a direct relation with the president. The co-ordination of the IMT policy, which was a central activity of the CNA during its early years, was effected between the director and the president, with very little interference from the SARH minister. ${ }^{32}$ The federal status of the commission was strengthened with the creation of its technical council or governing body in 1991, which consisted of all the ministers from all the ministries involved with water policy. Institutional and sector co-ordination was set at the federal level within the technical council (Herrera Toledo, 1996:41).

\section{Control ooer the irrigation districts}

To regain control over the irrigation districts and to increase the levels of water charges paid by farmers, the CNA followed a seemingly paradoxical strategy of decentralising the management of the irrigation districts to the users. Although the involvement of user organisations in irrigation management sharply increased as a result of IMT, at the same time the hydraulic bureaucracy's control over the irrigation districts was reasserted through IMT. To unravel this paradox, this section indicates how the transfer of the irrigation districts strengthened both the financial and bureaucratic autonomy of the CNA. $^{33}$ 
The main objective of the Mexican IMT programme was to reduce public expenditure on irrigation through creating financially self-sufficient Water Users' Associations (WUAs) that would recover the full O\&M costs of the irrigation systems (CNA, 1994a; Espinosa de León and Trava Manzanilla, 1992; Gorriz et al., 1996; Johnson, 1997a, 1997b; Trava Manzanilla, 1994). Although the programme had the full backing of the Mexican president and its objectives were clear, it got off to a slow start in 1989, for several reasons discussed in more depth in Chapter 3. A particularly vexing problem was presented by the inadequacy of the legal framework, as the water law of 1972 prohibited the transfer of the irrigation districts.

The resolution of the legal problems in 1989 removed one of the hurdles to really start with IMT in the field. Equally important, the CNA regained control over the irrigation districts from SARH during the second half of 1989 and started establishing itself as the only water authority in the country (Palacios Vélez, 1996).

The IMT programme in Mexico consisted of the transfer of the management of secondary canal units to WUAs, and in several districts also the transfer of the management of the main canal system to a federation of WUAs. During the first phase of the transfer programme, the CNA divided the irrigation districts into irrigation units, termed modulos (modules), varying from 1,500 to 50,000 ha in size, on the basis of hydraulic boundaries (generally a secondary canal command area) and established a WUA in every module. The WUAs were formed as legally recognised non-profit civil associations to whom the CNA granted renewable concessions for the use of water and the irrigation infrastructure, for periods ranging from five to fifty years. The concessioned infrastructure generally included all the canals and drains falling within the boundaries of the modules as well as the roads and irrigation structures.

The WUAs were charged with the operation and maintenance of their module, which they had to fully finance by collecting irrigation service fees from their members. The instructions for the operation, administration and maintenance of the module, drawn up by the CNA in conjunction with the WUA are an important element of the Concession Title (Titulo de Concesion). These instructions set out, amongst other things, how irrigation service fees should be determined and how the WUA should maintain their module.

The state, represented by the CNA, retains ownership of the nation's waters as well as the irrigation infrastructure. The CNA remains ultimately responsible for the management of the irrigation districts, while the responsibility for operation, administration and maintenance is transferred to the WUAs (CNA, 1994). IMT did not imply a complete transfer of bureaucratic authority and control over the irrigation districts, because the CNA retains control over the head works and the main canal system and important oversight functions. Rather, the hydraulic bureaucracy regained and reordered its control over the irrigation districts, which contributed to its bureaucratic autonomy. 


\section{Financial autonomy}

Another important benefit of the water reforms was that they strengthened the CNA's financial autonomy. A crucial component of the creation of the CNA was the establishment of a 'financial system for water'. Under this system, CNA gained direct control over a range of financial resource flows as it became responsible for the collection and administration of the resources originating from the payment of rights for the use of the nation's waters. According to the law, all revenues generated by these rights are specifically allocated to the CNA' (CNA, 1994b:50; my translation). Through this legal provision, the CNA succeeded in concentrating the income flows related to water use in different sectors without interference by other ministries, thereby strengthening its financial autonomy. These water rights represented a significant and growing source of income for the CNA: water rights for the exploitation of the nation's waters (industry and service sector), bulk water delivery to the urban sector (drinking water levies), and water charges paid by the WUAs.

Analysing the income flows from the collection of water rights during the first six years of the CNA reveals a rapid increase: from 498.6 million pesos in 1989 to 2,341.3 million pesos in 1994 (see Table 1). The shares of these different income flows are significant, about sixty-three per cent originates from water rights taxes, eighteen per cent from bulk water delivery to cities and a mere five per cent from water charges paid by irrigators. This indicates the major importance of the water rights and urban water for the CNA's financial autonomy. Although the share of irrigation charges in total CNA income between 1988 and 1994 was relatively small, this needs to be seen in the context of the radically reduced government subsidies to the irrigation districts after their transfer and their increased self-sufficiency. In 1988 the level of cost recovery in the irrigation districts was eighteen per cent. In 1994, the water charges paid by water users in transferred districts fully covered O\&M costs, while at the national level cost recovery significantly increased to eighty per cent. In addition, the WUAs were paying the CNA for the operation of the head works and main system in the transferred systems (CNA, 1994b).

Table 1 Development of the CNA's income from water rights and fees (millions of constant 1994 pesos)

\begin{tabular}{lrrrrrr}
\hline & 1989 & 1990 & 1991 & 1992 & 1993 & 1994 \\
\hline $\begin{array}{l}\text { Bulk water } \\
\text { delivery to }\end{array}$ & 263.0 & 219.2 & 291.0 & 338.2 & 437.9 & 413.7 \\
$\begin{array}{l}\text { cities } \\
\begin{array}{l}\text { Water rights } \\
\text { taxes }\end{array}\end{array}$ & 188.0 & 682.1 & 964.0 & $1,376.1$ & $1,639.6$ & $1,460.7$ \\
$\begin{array}{l}\text { Irrigation } \\
\text { service fees }\end{array}$ & 45.0 & 85.5 & 129.3 & 144.8 & 127.1 & 112.6 \\
$\begin{array}{l}\text { Other income } \\
\text { sources }\end{array}$ & 2.6 & 13.6 & 25.8 & 118.1 & 307.0 & 354.3 \\
\hline Total & 498.6 & $1,000.4$ & $1,410.1$ & $1,977.2$ & $2,511.6$ & $2,341.3$ \\
\hline
\end{tabular}

Source: CNA, 1994b. 
Table 2 Financial self-sufficiency levels of the CNA (millions of constant 1994 pesos)

\begin{tabular}{lrrrrrr}
\hline & 1989 & 1990 & 1991 & 1992 & 1993 & 1994 \\
\hline External credit (1) & 152.4 & 262.1 & 996.9 & $1,527.7$ & 881.1 & 726.0 \\
Fiscal budget (2) & $\mathbf{8 1 8 . 2}$ & $1,531.0$ & $1,797.2$ & $1,781.4$ & $1,871.8$ & $2,184.0$ \\
Total Budget & 970.6 & $1,793.1$ & $2,794.1$ & $3,309.1$ & $2,732.9$ & $2,910.0$ \\
$\begin{array}{l}(3=1+2) \\
\text { Income (4) }\end{array}$ & 498.6 & $1,000.4$ & $1,410.1$ & $1,977.2$ & $2,511.6$ & $2,341.3$ \\
\hline Financial Self- & $51 \%$ & $56 \%$ & $50 \%$ & $60 \%$ & $92 \%$ & $80 \%$ \\
\hline sufficiency (=4/3) & & & & & & \\
\hline
\end{tabular}

Source: CNA, 1994b.

As all funds collected by CNA remain within the bureaucracy, its degree of financial selfsufficiency sharply increased, from fifty-one per cent in 1989 to ninety-two per cent in 1993 (see Table 2). Although the hydraulic bureaucracy increased its financial autonomy significantly through the establishment of the financial system for water, it could not directly negotiate international loans with funding agencies and was dependent on the SARH in this respect. However, new international loans for the irrigation and drinking water sector were initiated after a sexenio of financial drought, further strengthening the financial position of the CNA.

It can be concluded that, with the creation of the CNA as a deconcentrated authority, the hydraulic bureaucracy achieved its objective of re-establishing a relatively large degree of bureaucratic autonomy. The concentration of resource flows relating to the exploitation of the nation's waters and the international loans secured a growing income source, thereby accomplishing to a large extent the aim of financial autonomy. Through a carefully thought out composite strategy, consisting of concentration, decentralisation and water pricing, the CNA thus succeeded during the Salinas sexenio in establishing a large degree of autonomy.

\subsection{Conclusions}

In a sense, user management of irrigation districts has come full circle in Mexico if a longer historical view is taken. By the early 1990s, user management of irrigation districts was once again enshrined in policy and law, as it had been in the 1930s and 1940s. However, there was nothing logical or unavoidable about this happening. This chapter shows that to understand the articulation of reform policies it is necessary to centre on the interactions between policy actors and the short and long-term circumstances that shape the ways in which they try to advance particular policy ideas. As stated in the introduction, the aim of this chapter is to stimulate debate on the role of hydraulic bureaucracies in water reforms, thereby complementing the manner in which IMT and bureaucratic reform in Mexico have been discussed in the literature to date. I have shown how the creation of the CNA and the launching of IMT were strongly linked with the engagement of the Mexican hydraulic bureaucracy in policy articulation. It is clear that to understand water reforms, or the lack thereof, it is necessary to bring the hydraulic bureaucracy back into the analysis. 
Many observers assume that IMT was imposed on the hydraulic bureaucracy by the Mexican president and the World Bank, as they perceive an inherent contradiction in senior hydrocrats supporting a policy that apparently weakens their bureaucracy. This chapter highlights the inadequacies of this line of argument by widening the frame of analysis to include political and bureaucratic processes, indicating that the reforms were part of an ongoing struggle within the Mexican bureaucracy. It shows how the reform package did not entail a complete devolution or reduction of bureaucratic powers, but that it served to reorder bureaucratic control over essential domains and resources. The reform package enabled senior hydrocrats to express and materialise some of their pressing concerns, such as regaining bureaucratic and financial autonomy. Contrary to popular belief, the water reforms in Mexico generated important benefits for segments of the hydraulic bureaucracy. This indicates why they were committed to a broad reform programme of this nature.

The commitment to the water reform package was a temporal, situational and content specific outcome of a complex interplay between the presidential candidate, the World Bank and a group of senior hydrocrats. By focusing on these policy actors and their agendas, this chapter elucidates how the reform package emerged as an outcome of mutual persuasion, compromise and coercion between these policy actors. It gained momentum when the concentration of bureaucratic domains and resources in a single water authority, the decentralisation of the irrigation districts and active water pricing policies became part of the reform package. This packaging strategy made the reform viable financially, politically and institutionally, as it would attract international funding, reduce government subsidies, secure a steady income flow for the hydraulic bureaucracy, receive authorisation from the president and find sufficient support among the upper reaches of the hydraulic bureaucracy.

We have argued that it is necessary to rethink the relationship between water policy making and senior levels of the hydraulic bureaucracy. That commitment and political will are outcomes of policy articulation rather than prerequisites for reform has several implications for researching water reforms. Firstly, it suggests that it is necessary to conceive of contemporary water reforms as effects of specific political and bureaucratic policy practices and experiences. Secondly, it entails analysing how officials of international funding agencies, researchers, consultants, politicians and hydrocrats engage in their institutional reproduction by articulating reforms that reorder the control over contested bureaucratic domains, redirect essential resource flows, and redefine themselves and their clientele.

\section{Notes}

This chapter is based on a published paper written together with Flip Wester and Luz Nereida Pérez Prado (Rap et al., 2004).

2 Throughout the text, Mexican acronyms and abbreviations are used and Spanish words are generally italicised. For Spanish words frequently used in the text, this convention is dropped.

This becomes apparent if one takes into account that many of the conditions that are said to have led to IMT were often in place throughout the history of irrigation development in Mexico, without this leading to transfer. For example, Mexico suffered various serious economic crises between 1930 and 1980, with drastic consequences for irrigation, without this resulting in IMT. In addition, nearly all the works on IMT in Mexico single out the declining levels of water fee payments during the 1980s as the most important reason for transfer. Nevertheless, the concern for cost recovery is not new in Mexican 
irrigation policy circles and dates back to the Irrigation Law of 1926, which decreed that irrigation districts were to be financially self-sufficient. At several points in time, the Mexican government considered the level of water fee payment too low and made attempts to increase them, however in most cases without a lasting effect. Likewise, the poor maintenance of irrigation districts has been a recurrent theme in Mexico and the need for extensive rehabilitation was already identified in the 1960s. Lastly, ideas of increased user involvement in irrigation management were present in irrigation policy circles since at least the 1930s, and several districts were actually managed by users' associations from this time onwards. Although the legal conditions for such involvement were in place for several decades, this never resulted in a substantial number of irrigation districts being managed by its users.

The use of the term bureaucratic to qualify actors or processes is not intended to be derogatory, but simply refers to the actors and interactions within and between government agencies that influence the articulation of policies and reforms.

Defined here as the process by which policy actors support, modify, displace and translate different interests concerning a policy idea with as outcome that a policy or reform package becomes irreversible, or not. Seen in this way, commitment to policies is the outcome of struggles and negotiations between different policy actors. A 'successful' policy follows an unstable trajectory from a policy idea to a policy likelihood, and finally to a policy reality, i.e. it becomes more articulated, through which its content and composition is redefined and transformed. Focusing on policy articulation eliminates the artificial divide between policy formulation and implementation.

- This poses the methodological challenge of 'studying up', where participant observation and other research methods 'may not be readily portable to elite contexts' (Gusterson, 1997:116). In our research, 'studying up' meant interviewing senior members of the hydraulic bureaucracy and other key figures in the Salinas government, as well as staff of international organisations. I also interviewed Mexican scholars knowledgeable on irrigation development and policies and extensively read official documents and newspaper articles.

7 Defined here as the various government agencies that were responsible for the allocation, distribution and use of the nation's waters and the construction and administration of hydraulic infrastructure.

This term is a contraction of hydraulic bureaucrats and is used here to refer to engineers working in water bureaucracies. I thank Alex Bolding for suggesting this term. Others have pointed out that it may be better to designate senior hydrocrats as hydro-politicians, as this more accurately reflects their activities.

9 Due to the limitations of my study, such as the lack of public information on the processes underlying reforms in Mexico and the methodological difficulties in accessing this type of information, I can only present a schematic overview of the events, actors, arenas and processes that were fundamental in defining and constituting the water reforms.

10 Irrigation has been practised in Mexico since pre-Hispanic times, and by 1919 some 800,000 ha were irrigated (CNA, 1994b). At present, some 6.1 million ha are irrigable, of which 3.3 million ha are contained in 81 irrigation districts, constructed and, until recently, managed by the state, while 2.8 million ha are either in private or farmer-managed irrigation systems. Irrigated land contributes about 50 per cent of the total value of agricultural production and accounts for nearly 70 per cent of agricultural exports. Although agriculture only accounts for around 6.5 per cent of Mexico's GDP, it employs 22 per cent of the economically active population (INEGI, 1998).

11 See Aboites (1998) for a legally precise and Mexico specific definition of centralisation/ federalisation and an excellent historical overview of this process from 1888 to 1946.

${ }_{12}$ The term autonomy is not used to suggest absolute independence or isolation, but is used in a relative sense to express the position of the hydraulic bureaucracy in comparison with other bureaucracies.

13 Land reform communities created after the Mexican Revolution of 1910. Before the revision of Article 27 of the Constitution in 1992, ejido land belonged to the state, with a combination of community (ejido) and private (ejidatorio) usufruct. Ejido members are called ejidatarios.

${ }_{14}$ Instances of user management of irrigation districts in the 1930s based on this law were mentioned in interviews. However, I have been unable to document this and it remains unclear why and how many user associations were formed and what their attributes were.

is Water boards continued to function in several irrigation districts until the transfer programme started in the 1990s, such as in the Ciudad Juarez and the Tula districts. The most frequently mentioned 
and only documented case is that of Río Yaqui (IMTA n.d.), which was managed by water boards since 1947.

16 In 1960 the SRH estimated that more than 200,000 ha of the irrigation districts, or ten per cent of the irrigable area at that time, could not be used due to deteriorated or incomplete infrastructure. That same year, a proposal to increase water charges led to nothing. It was opposed by a group of 10,000 large producers with a strong commercial and productive weight at the national level (Wionczek, 1982). ${ }_{17}$ The number of federal government employees grew from 0.3 to 1.3 million between 1969 and 1976, the public sector deficit rose from 2.8 per cent of GDP in 1972 to 4.6 per cent in 1976, and inflation and foreign debt were also on the rise. This forced the government to devalue the peso in 1976 and to sign a stabilisation agreement with the IMF, in which it pledged to reduce government spending (Grindle, 1996).

${ }_{18}$ In the following two sexenios, this ministry functioned as a stepping-stone for its two subsequent ministers, Miguel de la Madrid and Carlos Salinas, to become president (Castañeda, 1999).

19 A telling joke that recalls the fusion of these long-time rivals recounts that it was like merging America and Chioas, the two major football clubs of Mexico with a long tradition of mutual rivalry.

m This was only the case for new loans. Loans that had already become effective before 1982, for example those to the irrigation sector of in total $\$ 335$ million, continued throughout the 1980s (World Bank, 1983b).

${ }_{n}$ Insiders stress that during the negotiations the concrete policy proposals came from the Mexican side.

22 The Plan mentions that 'the formation of organisations (...), which will become responsible for the operation and maintenance of the hydraulic infrastructure, is considered expedient. It is expected that the irrigation districts will be financially autonomous and administratively independent' (Poder Ejecutivo Federal, 1989:77; my translation). This phrase was used repeatedly in subsequent CNA policy documents to justify IMT.

${ }_{23}$ Concentration is used to refer to the integration of existing bureaucratic domains and resource flows regarding the exploitation of the nation's waters, formerly dispersed over different government agencies, into a 'single water authority'.

${ }_{24}$ Decentralisation is used here as the delegation of authority and financial resources conceming water management from the federal government to user or other lower level organisations, generally with the aim to reduce government expenditure through the creation of self-sufficient water management organisations. The choice of this definition is pragmatic. The disadvantage of the term is that it suggests a delegation of political power to lower levels in a territorial hierarchy, implying a political redefinition of the territory (Smith, 1985). It is questionable if this is so in the case of IMT. Although this debate is not entered into here, the reader is warned that this is not implied by the use of the term.

${ }_{3}$ In October 1987, De la Madrid designated Salinas as the presidential candidate for the PRI. The Mexican tradition of presidentialism and the dominance of the PRI for more than sixty years created a system of political transitions according to which the old president 'uncovered' the presidential candidate. This has been an important element of stability for the political system (Camp, 1999; Castañeda, 1999; Grindle, 1977).

26 Dr. González Villareal had good relationships with leaders of the guild of hydrocrats (ex-ministers and deputy ministers) and with important political actors. Through his position as president of the College of Civil Engineers he also maintained good relationships with civil engineers in the government, the academic world and in construction companies. He started his bureaucratic career during Echevarria's sexenio (1970-76), after completing an academic training in civil engineering at the UNAM and obtaining a PhD at the University of California at Berkeley, specialising in water resource planning. He worked as General Co-ordinator of the PNH from 1972 to 1982, first under the SRH and later under the SARH. The co-ordinator of the PNH was widely respected for his vision and expertise concerning the planning and management of water resources. In addition, he knew irrigation from a practical perspective. His father was a producer in the irrigation district of Rio Yaqui in the northern state of Sonora, a system that was user-managed for several decades. His respected position was acknowledged when he co-ordinated campaign meetings on water for De la Madrid in 1982. During these meetings he developed a set of ideas that were basically in embryo what was proposed at the end of the 1980s to Salinas.

${ }_{21}$ Dr. González Villareal was PRI candidate for governor of his home state of Sonora more than once. 
In Mexico, a deconcentrated authority is a semi-autonomous federal agency with the power to set its own policies, levy taxes and fines, issue permits and carry out acts of authority. This contrasts with decentralised public agencies, which are also semi-autonomous, but depend on their mother ministry for overall policy guidelines and direction.

29 A senior SARH official mentioned this course of events at the time.

30 Villalobos Guerrero became the CNA Director during the next sexenio of president Zedillo (19942000).

31 Based on interviews with senior SARH officials.

${ }_{32}$ Based on interviews with ex-CNA and senior SARH officials.

33 This presentation is necessarily schematic and does not pay attention to the actors involved in transfer, how the CNA overcame resistance from the users and parts of the hydraulic bureaucracy, nor how the IMT policy was further articulated in the field. 



\section{3 \\ Engineering a Policy Package:
From the slow to the fast track}

\subsection{Introduction}

Chapter 2 showed how interactions between various policy actors led to the production and articulation of water reforms in Mexico. Policy articulation is the process by which policy actors support, modify, displace and coalesce around a policy idea with as outcome that a policy or reform package becomes less or more standardised. Government bureaucracies often play a crucial role in this because of the way policies are institutionalised and made routine. A 'successful' policy follows a trajectory through which it becomes more articulated and dominant, through the enrolment of the necessary actors. 'Trials of strength' may transform the characteristics and meaning of the policy, but they also result in the hardening of the reform package and the increasing momentum with which it expands outwards and becomes more 'real'.

Chapter 2 also argued that there is nothing 'natural', 'logical' or 'unavoidable' about irrigation reforms, but that they are produced by particular institutional constellations and have particular effects. Its focus was the gestation period leading to the birth of irrigation management transfer (IMT) as a reality in Mexico. Chapter 3 continues this theme, looking at the birth and early development of the project. I construct this argument by investigating the development of the irrigation transfer policy, not as a centrally controlled and uncontested process but as one that results from interactions between policy actors such as hydrocrats, ${ }^{2}$, water user leaders, politicians and international lending agencies, transforming what was initially a weak policy idea into an internationally declared success halfway through the 1990s. I am particularly interested in how a standardised IMT package was developed, consisting of specific technologies of governance and how this contributed to the acceleration of the transfer process after 1991. I use the term 'technologies of governance' for the programmes, techniques, legal documents, and procedures through which agencies seek to embody their governmental or managerial ambitions ${ }^{3}$. For example, technologies of governance that played a role in the effectuation of IMT were a step-by-step procedure for transfer, in addition to legal and organisational models that helped to materialise water user management.

\subsection{Standardising the Transfer Package: Assembling Technologies of Governance through Initiatives and Resistance on the Ground (1989-1991)}

The previous chapter details the historical, political and bureaucratic transformations in Mexico relating to water that resulted in the consolidation of a water reform package in the run-up to the presidential elections of July 1988. The composition of these reforms and the commitment to them emerged from a protracted process of interaction and 
enrolment between policy actors such as senior hydrocrats, the Mexican presidential candidate and international lending agencies.

\section{Assembling the transfer package through initiatives on the ground}

Although IMT had the full backing of the president and senior hydrocrats, it got off to a slow start in 1989. As a policy initiative, the broad outlines were clear. The intention was to gradually transfer a selected number of irrigation districts to financially self-sufficient user organisations, combined with the rehabilitation of irrigation infrastructure where necessary, but how the hydrocracy was going to effectuate the transfer was completely unclear. Several issues had first to be resolved. Firstly, IMT had to be designed from the ground up. Secondly, the transfer of irrigation districts to WUAs was illegal under the 1972 water law. Thirdly, the irrigation districts were still part of the rural development districts, over which the Comisión Nacional del Agua (CNA: National Water Commission) had no control. Fourthly, the large majority of the irrigation districts were not financially self-sufficient, with the government subsidising eighty-five per cent of O\&M costs on average. Achieving financially autonomous districts seemed difficult, as efforts to convince farmers to pay modestly higher water fees had consistently failed in the past (Wionczek, 1982). In addition, many of the irrigation districts were severely run down in the perception of the farmers, making it unlikely that they would willingly accept the infrastructure. Lastly, the fact that the CNA had just been created meant that most of 1989 was dedicated to establishing CNA as an autonomous organisation.

As outlined in Chapter 1, the concept of IMT was not new in Mexico when it was formally introduced in 1989. Many actors on the ground had already considerable experience in this regard. The Plan Nacional Hidrálico (PNH: National Water Plan) led to the formation of a team of water resource planners who had departed from the traditional construction bias of the hydraulic bureaucracy by developing a broader vision on water resource planning and management. The planners working in the PNH developed policy ideas and accumulated particular experiences favouring participation by water users and handing over of government tasks in water management. Dr. González Villareal was leading actor whose respected position was acknowledged when he coordinated campaign meetings on water for presidential candidate, De la Madrid, in 1982. During these meetings he developed a set of ideas that were basically in embryo what was proposed at the end of the 1980s to Salinas. Expertise was thus available, but the choice of people who would make IMT a reality was crucial. At the end of 1988, Dr. Ramos, who had worked ${ }^{4}$ under Dr. González Villareal in the SARH as Director of Water Development and was present at early discussions on transfer, was appointed as Head of Irrigation Districts to initiate IMT. Dr. Ramos was a respected irrigation engineer with not only a solid track record in the $\mathrm{SRH}$ and $\mathrm{SARH}^{5}$ but also international experience. Around the same time, the World Bank hired new staff with extensive experience in water management in the private sector to be stationed in Mexico to work on the IMT programme. Officials of the Bank were enthusiastic about the prospects for such a programme in Mexico and in 1988 sent staff missions to pledge its support and initiate loan discussions.

When Dr. Ramos and his team started working on transfer in 1989, they had little to go on except for several initiatives with transfer on the ground, initiated in the 1980s in 
selected irrigation districts, including El Grullo (see Map 1, Jalisco Sur: 094), Río Mayo (038), Río Yaqui (041) and Delicias (005) (Palacios Vélez, 1992; van der Zaag, 1992). In particular, the way irrigation management was organised in Río Yaqui, where water distribution and maintenance from the secondary canal level and down had always been managed by users, appeared to be a useful model for the IMT programme. These transfer initiatives on the ground had developed their own momentum and initially appeared to escape the control of the CNA at the federal level.

Through a careful process of co-optation and appropriation by senior hydrocrats in 1989, these initiatives were brought under the control of the CNA and used to assemble the technologies of governance that came to constitute the IMT policy package. Attempts to initiate transfer in other irrigation districts in 1990 and early 1991 encountered resistance from farmers, unions, regional bureaucratic staff and the administrative section of the hydrocracy. This resistance further shaped the development of a set of technologies, such as a step-by-step procedure to organise, promote and enact transfer, as well as particular legal and organisational models. In addition, a new water law was drafted to 'legalise' transfer, and substantial international funding was secured for the IMT programme. The pre-1989 history of how the technologies of governance that came to constitute the IMT package were assembled is detailed in Appendix 3.

A particularly vexing obstacle facing IMT was that the legal framework was inadequate, as the water law of 1972 prohibited the transfer of the irrigation districts. To resolve this issue, a group of CNA lawyers and senior hydrocrats devised an ingenious legal construction, based on the transfer initiatives on the ground, which consisted of dividing the districts into irrigation units. Under Article 77 of the 1972 water law, irrigation units are defined as farmer-managed irrigation systems with users' associations fully responsible for O\&M and collecting water fees. Article 78 of the law states that two or more irrigation units could be joined to form an irrigation district (Diario Oficial, 1972). Based on these clauses, the lawyers argued that an irrigation district could be considered to exist of various irrigation units, which were called modulos (modules) to prevent confusion (Palacios Vélez, 1994a). An additional spin given to this legal construction by the CNA lawyers was to constitute the WUAs as civil associations. This was necessary to ensure that the WUAs would fall under the control of CNA, as 'normal' WUAs for irrigation units as provided for by the 1972 water law would fall under the responsibility of the SARH (Espinosa de León, 1994).

The above shows how contested the WUAs were in 1989 and indicates that transferring the irrigation districts was not simply a question of creating WUAs and handing over operation and maintenance tasks to them. A very specific technology of governance was assembled in the form of WUAs constituted as civil associations, which made it possible to circumvent the legal restrictions on transfer on the one hand, while ensuring that the CNA would retain control over the irrigation districts and the WUAs on the other. This technology of governance was subsequently used in other districts, and was legally sanctioned in 1992 when a new water law was enacted. The technology ensured bureaucratic control over the irrigation districts for the CNA in its attempt to gain bureaucratic autonomy. 
60 The Success of a Policy Model

Map 1 Irrigation Districts in Mexico




During 1987 and 1988, SARH officials helped farmer leaders in the El Grullo District to form a WUA (see Appendix 3). Towards the end of 1989, the board of the El Grullo WUA learnt that local and state CNA engineers were sending negative messages to headquarters about their capability to manage their module. The board saw the need to call on the govemor of Jalisco, who was in favour of transfer, to exert political pressure. The governor accompanied the board on a trip to Mexico City in late 1989, where they obtained an audience with Dr. González Villareal. Their intention was to show that they were well organised. The governor made it clear to Dr. González Villareal that he wanted to be the first state to have an irrigation system transferred. According to the impression of the board members, Dr. González Villareal was not pleased with the speed at which things were developing in El Grullo. Apparently he was not convinced that the WUA could already operate and maintain the system, and he thought it would be important to have an engineer as manager of the WUA. The proposal was made that the board's secretary, who was a civil engineer by training, would be the manager. This was important to convince Dr. González Villareal, and in the end he agreed to the transfer. A $\mathrm{CNA}$ official remembers:

The president [Salinas] oboiously had the Director of the CNA under pressure, asking him what was happening with the transfer, but no progress was forthcoming. That's when they pulled the El Grullo Association from up their sleeve and said to the president that El Grullo was transferred. El Grullo was transferred with a procedure that was corrupted from the beginning. It did not really follow a democratic procedure, as we did in other districts. But it was forced by the circumstances.

After the meeting in Mexico City, the board held several talks with CNA district officials to prepare for the official transfer. In 1989 and 1990, senior CNA engineers visited El Grullo several times to draw up the new regulations and charter of the association as well as the Concession Title (Titulo de Concesion). During these visits the CNA officials expressed their concern that the elections for board positions might create or revive conflicts between ejidatarios (members of ejidos ${ }^{6}$ ) and private landowners. After lengthy discussions, this issue was resolved by deciding to alternate the posts of president and treasurer of the WUA every three years between representatives of the ejidatarios and representatives of the private farmers. Thus, in the first three years an ejidatario could be president and a private farmer secretary, and the next three years it would be the other way around. This technology of governance combined traditionally separate spheres of influence on the WUA's board. This was crucial for reaching agreements between groups of farmers that had historically been opposed to each other and served to establish alliances between the leaders of these groups. The alternancia (alternation) was established in the charter of the El Grullo Association, which served as the basis for the charters drawn up in other associations later on. At the beginning of 1990, the operation was turned over and the Concession Title was presented to the WUA in May 1990. A CNA official remarked:

The first district to be completely transferred was El Grullo, Jalisco, in 1990. The users eoen wanted to start operating the district a year before, but we said: 'You have to learn a bit, let's do the operation in a parallel form with personnel of the CNA during this year.' So the process of transfer was started in 1989 and in 1990 it was completely transferred: the concession was handed over. 
In El Grullo, the transfer process developed a momentum that was difficult for the CNA to control, because of political pressures from the governor and the Mexican president himself. However, the CNA ingeniously appropriated this transfer already initiated on the ground and then used it to promote IMT. The transfer initiative in El Grullo served to develop several crucial technologies of governance, such as using the loopholes in the 1972 water law to form WUAs, constituting WUAs as civil associations, alternating the presidency of the WUA, joint operation of the irrigation district in the first year after transfer, and the Concession Titles which outlined in detail the tasks and responsibilities of the WUA and the CNA, that were to form the core of the IMT programme in later years. These technologies of governance also ensured that the CNA would not lose control over the irrigation districts or the transfer process.

Based on the experiences of transfer initiatives on the ground in El Grullo and in Rio Mayo in 1989, Dr. Ramos and his team started to assemble a transfer package consisting of specific technologies of governance that would make transfer possible. At the same time, a serious start was made with drawing up a new water law. This was necessary not only to legalise IMT but more generally to confer powers on the CNA as the single water authority in the country. To formulate the new water law, a select group of lawyers and senior engineers was formed in the CNA in 1989. One of the key CNA lawyers at the time remembers:

At the start of 1989 we had a very general idea about how to ensure user participation. Howeoer, we started from zero as far as the legal issues were concerned. Everything had to be designed and worked out from a legal point of view. The legal design was drawn up in 1989 by this team and me. We wrote the concession titles and the statutes for the associations. During this process it was very important to listen to the users. We held many meetings in several irrigation districts, mainly in Sonora, in which I carefully listened to the complaints put forward by the users. I did not go to El Grullo, but we also had engineers working there. The idea of alternating the presidency of the associations came up at this time, based on experiences in the field. This is included in the statutes. The content of the concession titles, the statutes and the rest did not change much after 1989, although it was refined a bit. I would work until late at night in 1989 on these legal issues to make transfer possible.

The resolution of the legal problems in 1989, based on initiatives on the ground in EI Grullo and hard work at the national level, lay the groundwork for the design of the transfer package. Another important development in 1989 was that the CNA regained control over the irrigation districts from the SARH in September 1989 by extracting them from the rural development districts and started establishing itself as the sole water authority in the country. Based on these achievements, the National Programme for the Decentralisation of the Irrigation Districts was drawn up towards the end of 1989, outlining twenty-one districts to be transferred between 1990 and 1994. These districts were carefully selected based on an assessment by the CNA of the willingness of the users to accept IMT (CNA, 1991a; World Bank, 1991). Most of them were large, commercially-oriented districts located in the north of Mexico with few infrastructural problems. 


\section{The slow track and the standardised transfer package}

The transfer of irrigation districts to users was officially initiated by the CNA towards the end of 1989, with two modules (out of a total of fifteen) in the Río Culiacán irrigation district having the honour to be the first to be formally transferred, in January 1990 (CNA/SARH, 1992:6). All sixteen modules in Río Mayo were transferred in 1990, as well as one module in Jalisco Sur (El Grullo) in May 1990. By the end of 1990, a total of 130,366 ha had been transferred in Mexico, all located in these three irrigation districts. Thus, the progress with transfer in 1989 and 1990 was rather slow, in keeping with the original slow track transfer programme designed by Dr. Ramos and his team around three key activities: substantially raise irrigation service fees, rehabilitate and modernise the twenty-one irrigation districts listed for transfer, and finalise the transfer of eight districts by the end of 1992, three by the end of 1993 and the remaining ten by mid 1994 (CNA, 1991b).

Although the number of hectares formally transferred in 1990 was quite low, this does not mean nothing happened on the ground. In nineteen irrigation districts, the CNA undertook steps to initiate transfer, while in all irrigation districts attempts were made to substantially increase irrigation fees, as a prerequisite for transfer (CNA, 1991b:7). People directly involved with transfer in 1990 and 1991 indicated that it was a period of many confrontations and frictions, as Dr. Ramos and his team largely encountered users who were opposed to IMT. This again emphasises the element of overcoming resistance.

'The transfer of the districts was not an easy task; it was necessary to overcome many obstacles of which several stand out, namely the acceptance on the part of the users of the change to an operational set-up [for the irrigation districts] to which they were not accustomed and that demanded a higher degree of responsibility; the acceptance of the infrastructure in the poor state of maintenance it was in; and the increases in the water fees to achieve financial self-sufficiency.' (Espinosa de León, 1998: 6; my translation)

Attempts by the CNA to convince users to accept the poorly maintained irrigation infrastructure, while at the same time agreeing to pay significantly higher water fees and taking on greater responsibilities in the management of the irrigation districts, were met with staunch resistance in 1990 and early 1991. In addition, many of the CNA field staff, heads of irrigation districts and the administrative section of the CNA strongly resisted IMT, as it was clear that they would lose either their jobs or control over financial resource flows. These difficulties with transfer were likened to pulling a cart up a hill. In the beginning the going is very slow and heavy, and you need to mobilise a lot of power to get the cart rolling. You know things will be easy once you get the cart to the top of the hill, but until then it will be very hard work. To mobilise this power on the ground, the transfer package was further refined, while a crucial shove was given to the IMT cart by international lending agencies.

In 1991, the CNA was successful in obtaining international funding to support its full irrigation and drainage programme, including the IMT programme (see Appendix 2). The loan, for a total of US $\$ 400$ million, was to finance part of the CNA's irrigation and 
drainage investment programme for the fiscal years 1991 through 1994, totalling US\$1.2 billion. It was the first time that the World Bank financed a government's full irrigation, drainage and flood control programme for a specified number of years - termed a timeslice operation in Bank jargon - anywhere in the world. For the Bank this was an important innovation, as it provided much more scope for policy dialogue and flexibility during loan execution. Instead of funding the construction of a specific irrigation system, the time-slice loan made it possible to reassess investment priorities and redirect resource flows. Not surprisingly, the loan enshrined the slow track transfer model, targeting the twenty-one irrigation districts earmarked for rehabilitation and transfer (with US\$100 million from the loan), while deferred maintenance would be carried out in the remaining fifty-six districts (with US\$49 million from the loan). Interestingly, US\$200 million of the loan were earmarked for the construction of three new irrigation districts and the completion of works in twenty-three other districts, while only US\$5 million were earmarked for institutional development (read IMT). The objective of transfer, in the Bank's perspective, was to reduce government subsidies to the irrigation districts to zero and to seek the long-term sustainability of the irrigation systems.

Under Dr. Ramos, the transfer package and its constitutive elements were adapted and redesigned in response to a set of experiments, consensus building, experiences and clashes in the field. These experiences were fed back to the national level, where they were discussed and evaluated by a transfer policy committee presided over by Dr. González Villareal, and during loan negotiations with the World Bank. This led to new ideas that were consequently brought back to the field. Such feedback mechanisms, which were centrally directed by the $\mathrm{CNA}$, led to a convergence of dispersed experiences and ideas on how to implement the transfer. The central tenets of the transfer package emerged out of this process of centring (CNA, 1991c). The package consisted of a set of carefully selected and designed technologies of governance: the step-by-step procedure for organising and promoting transfer, the organisational and legal models, and legal, technical and administrative documents and requirements, as well as substantial funds for rehabilitating the irrigation districts and promoting transfer. The following briefly describes the transfer procedure, while how the transfer package played out in the field is explored in greater detail in the next section.

In July 1991, the CNA published an important document entitled Instructions for the Transfer of the Irrigation Districts to Water Users (CNA, 1991c). This document contains detailed instructions for CNA staff and water users on how to organise and transfer the irrigation districts, and indicates that the transfer programme should consist of two phases. In the first phase, WUAs constituted as civil associations are organised per module. The CNA concedes a water volume and transfers the operation, maintenance and administration of part of the infrastructure and machinery to these WUAs. After an unspecified period of time, during the second phase it is decided how the main irrigation system is to be managed, either by a federation of WUAs called a SRL (Sociedad de Responsabilidad Limitada), a private company or by the CNA. At all times, the CNA retains control over the dams and headworks of the irrigation system and supervises the WUAs and SRLs according to institutional, administrative and technical criteria to which they have agreed in the Concession Title. The most important criteria are that the WUAs and SRLs have to be administratively independent and financially self-sufficient, by means of the fees paid by WUA members. The first phase of the transfer programme 
consisted of the following steps (CNA, 1991c): Diagnosis; Promotion; To constitute a WUA; Acceptance of commitments; Concession title; Physical transfer of the module; Parallel operation. These steps are spelt out more fully in Appendix 4.

The publication of these transfer guidelines brought closure to the package on which Dr. Ramos and his team had worked so hard in the previous two years. In effect, the point of no return had been reached. The IMT policy no longer only consisted of statements of intent, but had become a programme with objectives, benchmarks, deadlines to be met and procedures to be followed. In effect, policy discourse was materialised in specific technologies of governance. By publishing the instructions, the CNA top management not only reaffirmed its commitment to the policy but also made it that much less reversible.

\section{The slow track runs aground}

Although Dr. Ramos and his team managed to design the slow track transfer programme and obtain funding for it - significant achievements in and of themselves they were less successful in convincing the users to accept transfer. After the easy successes in three irrigation districts where transfer initiatives had already developed their own momentum, the slow track ground to a halt in 1991 in the other eighteen irrigation districts listed for transfer. For example, in the Alto Río Lerma irrigation district, located in the central part of Mexico and covering some 112,700 ha, it was planned to transfer 29,579 ha in 1991, 27,124 ha in 1992, 42,246 ha in 1993 and 13,832 ha in 1994 (CNA, 1991b). A diagnosis carried out by the Instituto Mexicano de Technologia del Agua (IMTA: Mexican Institute of Water Technology) in early 1991 to initiate transfer revealed that both ejidatarios and private farmers were vehemently opposed to transfer. Wealthy, commercial farmers were of the opinion that the transfer of secondary canals would not solve anything; that only with the transfer of the main irrigation system and the dam would make things better. A group of wealthy farmers even offered to buy the dam from the government. Middle-income farmers were not that opposed to transfer, but only if the irrigation infrastructure was rehabilitated and transferred to them in good condition. They were divided on the issue of the dam, with some siding with the large farmers and others stating that the government should continue to control the dam, as it would lead to too many conflicts between farmers if the dam was in private hands. The ejidatarios, mostly poor to very poor farmers, did not want transfer at all, as they feared it would only lead to more conflicts between farmers and further rises in irrigation service fees. The strong resistance to transfer in Alto Río Lerma resulted in zero hectares being formally transferred in 1991 and contributed to the dismissal of Dr. Ramos.

Towards mid 1991 it became apparent that the slow track transfer programme was not making much headway, as only 82,716 ha of the 479,360 ha planned for 1991 had been transferred. Around the same time, Dr. Ramos was relieved of his post as Head of the Irrigation Districts and demoted to IMTA. Several people have suggested that the reason for his dismissal was that he was against transfer. The description above of the very active role he played in designing the transfer package belies this conclusion. A more accurate assessment would be that the administrative section of the CNA was opposed to IMT, as they would lose control over the procurement of equipment, and hence substantial sums of money, if WUAs were formed in the irrigation districts. Also, more 
generally in the hydrocracy there was resistance to IMT, and it is likely that a conjunctural coalition of discontent formed to oust Dr. Ramos. Lastly, Dr. Ramos' approach to transfer, with its emphasis on rehabilitation first and then the gradual transfer of a limited number of districts, became a liability. He had opted for the slow track and was a real técnico ${ }^{7}$ who was reluctant to make political deals and wanted to carry out the transfer based on a well-defined plan. People close to him mentioned that he had a linear and bureaucratic approach to implementing the transfer package, and that the political dimensions of transfer surpassed him. To more fully understand the replacement of Dr. Ramos by Dr. Urzúa, it is necessary to consider the shifting political tide in Mexico in mid 1991, and the transition of IMT from the slow to the fast track.

\subsection{Over the Hill: Accelerated Transfer and Success (1992-1994)}

\section{A shifting political tide}

In August 1991, when Dr. Urzúa was appointed as the new Head of the Irrigation Districts, the Partido Reoolucionario Institucional (PRI: Institutional Revolutionary Party) regained an outright majority in Congress in mid-term elections. This political victory for President Salinas, who started out as one of the weakest presidents of Mexico (Grindle, 1996), is generally considered the major turning point of his presidency. After August 1991, Salinas used his renewed electoral legitimacy to carrying out a radical neo-liberal reform programme (Centeno, 1994, Cornelius et al., 1994, Grindle, 1996, Teichman, 1997). The widely disputed nature of his election in 1988 had motivated Salinas to take a balanced approach in his plans to modernise the state and the economy under the banner of social liberalism, which he had carried during his election campaign. This was necessary to regain political support among rural groups and urban popular movements, which the PRI corporate structure was losing. The strategy of concertacion social (consensus building) focused on establishing problem-solving partnerships between the state and independent peasant and urban popular movements. With consensus building agreements, Economic Solidarity Pacts and the National Solidarity Programme (PRONASOL), Salinas had access to powerful political and financial instruments for building consensus between his administration and those groups who had supported the opposition during the last elections (Demmers, 1999). His intention to rebuild links with the peasant sector was seen to be embodied in his appointment of several widely respected academics and representatives of non-PRI peasant organisations to crucial posts in his administration. Dr. Gordillo, whose ideas on autonomous peasant organisation were very influential in Salinas' electoral campaign, was appointed as Undersecretary of Concertation in the SARH, a post specifically created to attend to peasant organisations and form solidarity pacts (Gordillo de Anda, 1988).

The appointment of Luis Téllez, a young technocrat and Salinas confidant, as SARH Undersecretary of Planning and Carlos Hank González, an important PRI dinosaur, as SARH Minister in the beginning of 1990 cast doubt on Salinas' social liberalism project for the rural sector. Although from different political groups, both enjoyed full support from the private sector. These bureaucratic rearrangements curtailed the influence of Gordillo within the SARH and ended the effective use of consensus building agreements with which the Under Ministry of Concertacion had aimed to establish alliances with and 
mobilise the demands of peasant groups during the first two years of Salinas' administration (De la Fuente and MacKinlay, 1994). It also opened the way for preparing more comprehensive neo-liberal reforms in legal matters concerning the ownership of land and the management of water. However, such constitutional and legislative reforms were not viable without a majority in the Mexican Congress, which the PRI did not have before the August 1991 elections.

PRONASOL, a massive social welfare programme to alleviate rural poverty carried out directly by the Office of the Presidency, had a much more sustained political impact. The programme emphasised self-help, community participation and limited bureaucracy, and financed a wide array of local community projects, varying from schools, electrification, drinking water, and health care, to rural infrastructure. PRONASOL was particularly used to strengthen the presidency, reinforce presidentialism, and restore the personal credibility of Salinas by the close personal identification of the programme with the president (rather than with the party). The programme was also instrumental in rebuilding electoral support for the PRI (Cornelius et al., 1994). It did so by especially favouring areas that had supported the opposition, undermining the alliance of social movements and diffusing much of the grass-roots opposition to the government (Centeno, 1994). At the same time it had a depoliticising and demobilising effect, by focusing on local community projects and 'technical issues' rather than mobilising independent political demands and alliances (Cook et al., 1994; Demmers, 1999).

The electoral victory of 1991 significantly strengthened Salinas' position as a statesman, restored the traditional authority of the presidency, and prepared the way for the neoliberal authoritarian style of government that characterised the latter half of his administration (de la Garza Toledo, 1994). The fact that Salinas started to put through a more pronounced neo-liberal policy programme in the rural sector was reinforced by the increased influence of the technocratic elite in the SARH with more direct links with the business community, who advanced policy ideas in respect of modernising the rural economy, restructuring state intervention and trade liberalisation. Consensus building and corresponsabilidad (shared responsibility) between the government and the social sector was pushed into the background of government discourse, and the participation of the private sector in public projects was more broadly welcomed. The CNA also, in itself favouring a more moderate and bureaucratic approach and gaining in autonomy from the SARH, was confronted with this stronger neo-liberal policy surge. For example, the bill for a New Water Law, originally prepared in secret by a team of lawyers contracted by the CNA, was significantly altered under the influence of more radical neo-liberal ideas of the economist Téllez to drastically liberalise water markets, as appeared in discussions at the World Bank in 1992. The appointment of Dr. Urzúa as Head of the Irrigation Districts fits in with this set of broader developments within the government and the agricultural bureaucracy.

In 1992, Salinas succeeded in putting a revision of article 27 of the Mexican Constitution through the PRI-dominated Congress without a lot of opposition or public dissent, although it was widely debated in the press and academic circles (Grindle, 1996, Nuijten, 1998). This changed the legal basis of land ownership and the ejido system. Later that year, the National Water Law, which forms the legal basis of the transfer programme and the concession of water rights, enabled the CNA to create river basin councils, and 
partly opened up water markets, was accepted with even fewer public problems for the president. Although part of the opposition walked out on the voting of the bill, a public and academic debate on these reforms did not ensue. It was argued that these legal adjustments would improve the productivity and competitiveness of Mexican agriculture, which was considered necessary because the Salinas administration had entered into negotiations on a free trade agreement (NAFTA) with Canada and the United States.

By 1993, the presidency was stronger than ever (Grindle, 1996). Through a series of legal initiatives and government programmes, supported by encouraging economic recovery and a significant reduction in inflation, Salinas centralised and enhanced presidential power. He shifted the centre of political decision making from the political areas of the government (PRI, Ministry of Interior) to the financial planning areas (Ministries of Finance and of Planning and Budget), something which coincides with the rise within many sections of the government bureaucracy of technocrats educated abroad (Centeno, 1994). Towards the end of his administration, Salinas was increasingly praised as one of Mexico's most successful presidents and rumours mentioned him as a candidate for the post of director of the World Trade Organization (Centeno, 1994). His policies found ample resonance in international organisations, such as the World Bank, WTO, IMF, $\mathrm{IADB}$ and the FAO, and he received international recognition for his demonstrated commitment and capabilities to realise drastic economic, legal and government reforms. A senior SARH official wrote the following on the relation between the general wave of optimism within the government and the acceleration of the transfer during those years:

From 1992 and the approoal of the new article 27 onwards, an extremely optimistic vision preoailed in the entire government on the possibilities of deepening the reforms without any political cost. They took for granted a consensus, which in the case of the rural sector had to be renewed constantly. In this context in which in many areas the reforms were being implemented based on a delicate process of consensus, they changed to a relatively frantic phase of fast track.

The shifting political tide during the Salinas administration thus greatly enhanced the acceleration of the transfer programme. In particular, the optimism among technocratic elites in the agricultural and the hydraulic bureaucracy about the possibility of reforming the state and the economy played a role. It was considered possible that Mexico would join the ranks of first world countries. The encouraging results and enthusiastic responses from the international community inspired this optimism. Informed government officials and members of Congress expressed the view that Salinas wanted to demonstrate to the world his abilities as president of Mexico and reforming statesman and was starting to show signs of megalomania.' A congress member claimed that the transfer of much more than the number of districts and irrigated area originally planned would have been very much in keeping with Salinas' psychology. ${ }^{10}$ A government official speculated that Salinas increased the political pressure on the director of the CNA to speed up the rate of transfer and to transfer as much as possible before the end of his administration. He added to this that Salinas was not the kind of president that permitted disobedience on the part of his ministers and directors - a common trait within the Mexican regime of presidentialism which grants maximum authority to the 
president. When Salinas ordered something to be done in three weeks, it had to happen'.11

\section{Enter Urzuia; the 'big mover'}

In the summer of 1991, Dr. Urzúa was called by acquaintances in the government asking if he was interested in the position of Head of the Directorate of Irrigation Districts (DID). Given his career in the SRH and SARH and his experience in managing irrigation districts, this is not really surprising ${ }^{12}$. Urzúa's profile reveals a distinguished irrigation expert with valuable experience in the operation and management of large irrigation districts in the north of the country. Throughout his career he demonstrated his adaptability to different local and national conditions, as well as to politics. Having worked in different bureaucratic, educational and commercial contexts he knew how to participate in teams, to follow up orders from superiors and to issue orders to subordinates. During his professional career, he built up a network of contacts within the agricultural and the hydraulic bureaucracy, irrigation districts, educational institutions, the private sector and within the government in different parts of the country. This made him very suitable to reorganise the preparatory work of his predecessor in order to successfully execute the objective of transferring a large variety of irrigation districts in a relatively short time. Insiders praised Urzúa for his skill in dealing with the political aspects of fulfilling a bureaucratic mission and his capacity to strike deals with government officials, ejido leaders and associations of private farmers, politicians, and private sector interest groups. He was typified as inquisitive and sensitive to the political realities of negotiating between different powerful interest groups and stakeholders affected by the transfer, and getting them to accept the indicated policy line. Under Urzúa, the role of private capital in the realisation of the transfer increased. His own experience in the private sector explains his firm belief in the capacity of private enterprises to work more efficiently than government bureaucracy as administrators of resources. Correctly formed WUAs, created to provide services, could also obtain this advantage of private enterprise in the management of water and related resources. In such a conducive environment, a user could develop an entrepreneurial spirit:

The responsibility acquired by the user with the transfer encourages him to better take care of the infrastructure of which he is in charge, to make more efficient use of the available resources, to raise productivity, and to develop an entrepreneurial spirit, to seek to increase the value of his produce, just like an agricultural irrigation company'. (Espinosa de Leon and Trava, 1992: 7; my translation)

\section{Accelerating into the fast track}

When Dr. Urzúa joined the CNA, it was clear that rapid progress had to be made with IMT. He was made responsible for producing concrete results for the CNA's political superiors and financing agencies, to prove that the CNA was taking its transfer mission seriously and that it was capable of carrying it out. The conditions he encountered were undoubtedly more favourable than those his predecessor had faced. A large amount of work had already been done by many parts of the CNA dedicated to transfer, and he found the general framework for transferring the irrigation districts in place, designed by 
Dr. Ramos and his team. As a result of the period full of clashes and conflicts, meetings and negotiations that his predecessor experienced when he was bringing the idea of transfer to the field, and the consultation and feedback which took place within the CNA on the basis of these experiences, a workable model of transfer was produced. Urzúa also found an organisational structure at his disposal that was organised to promote transfer, to get water users organised and committed, and to prepare them for actual transfer.

Urzúa thus started off with a team of engineers experienced in working with and developing the procedures, models and technologies for transfer. This paved the way for a more routine-like implementation of the policy package in different parts of the country and significantly facilitated the acceleration of the transfer. Urzía is generally credited as the 'big mover' and the person who gave the proverbial cart, already rolling and approaching the top of the hill, the final push. After this, the transfer process accelerated into the fast track, seemingly travelling downhill effortlessly by the natural pull of gravity. I have tried to nuance this idea by showing the conditions under which he entered the CNA. Urzúa and his team took up a standardised policy package, maintained and consolidated it by applying it in an ever-increasing number of irrigation districts, firstly mainly in Sinaloa and Sonora, Alto Río Lerma, and the North, where the main large-scale districts are located, and then also in other corners of the country, where more medium and small-scale and often the poorer, more run down and socially and politically problematic systems are located.

At the end of 1991, a great effort was made to make up for the first part of the year in which actual transfer was negligible and the process had seemed to stall. The efforts of Dr. Urzúa and his team concentrated on the Northwest and particularly the Culiacan District (010) in Sinaloa and the Rio Yaqui District (041) in Sonora. In the former district, successful efforts to convince and negotiate with important regional leaders led to a massive transfer of two-thirds of the District - almost 200,000 ha. This very much surprised official expectations, because the transfer of this district had been planned for a later date and at a much slower pace. In the Río Yaqui District, the earlier transfer initiatives started to pay off, with more than half the district, approximately 144,000 ha, transferred in the last months of 1991. In the Central Northern region, more than half of the Delicias District (005) was transferred. Although in other districts less progress was made, the two huge districts in the Northwest alone sufficed to nearly comply with the planned transfer of 479,360 ha in 1991. Thus, in the last months of 1991, Dr. Urzua succeeded in quickly catching up with the original planning agreed with the World Bank in loan documents, giving a much needed boost to the transfer programme and proving his worth.

At the beginning of 1992, it was already becoming clear that the original idea of transferring twenty-one districts over a period of four years was outdated. The transfer in those districts was proving to take less time than originally envisaged. This resulted from the increasing political pressure and the increased interest on the part of producer groups to take over the modules, because they became aware that there was something at stake. Mention was made that it would perhaps be possible to exceed the original planning and transfer more districts. This was met with assent at the national political level. It was expected that the chain of events brought about in the districts first transferred could be accelerated by more intensive promotion of the transfer and that the 
transfer of the rest of the eighty irrigation districts would require much less work. In 1992, transfer activities around the country multiplied, and the fast track was seriously pursued. Urzúa's team succeeded in transferring nearly a million ha, some 300,000 ha more than originally planned under the slow track. More than half of this area was located in the Northwest. In addition, the DID broadened its focus on the Northwest and included the Central Northern region and the Mid-Western region of the LermaBalsas watershed. The process of transfer was also disseminated to a much larger number of districts. Some of these had not even been considered in the original planning. In the Northwest, the Districts of Rio Sinaloa (063) and Río Fuerte (075) spectacularly surpassed expectations with, respectively, around 100,000 and 200,000 ha. In the North, Bajo Río San Juan (026), a district where Urzúa had worked, was transferred and Delicias was completed. Particularly striking is the complete devolution of the Alto Rio Lerma District (011) at the end of 1992, after Urzúa had reached agreements with influential political and entrepreneurial groups (see Chapter 11). In addition, transfer was initiated in several other districts in the centre of Mexico.

In 1993, the transfer policy was consolidated, although the area transferred decreased somewhat to approximately 725,000 ha. Nonetheless, this was 300,000 ha more than planned under the slow track programme, and also 100,000 ha more than planned under the fast track programme. The activities of the DID were now even more clearly dispersed among different regions. Relatively, the Central Northern Region became more important, particularly the Bajo Río Bravo District (025) of around 250,000 ha, which was completely transferred. Again, the number of districts where the DID achieved transfer increased significantly in the Central Northern and the Lerma-Balsas region. In general, these are smaller districts than the large ones of more than 50,000 ha which were transferred during the first years. In 1994, the transfer slowed down significantly, because the end of Salinas' term was approaching - a period in Mexican politics in which the bureaucracy concentrates on the presidential succession. Around 230,000 ha were transferred, mainly in the Northwest. Figure 1 is a diagrammatic representation of the area transferred in the period 1989-1994.

The standardisation and closure of the transfer policy package initiated under Dr. Ramos was completed with the arrival of Urzúa and the increased political pressure to get the process going. As a result of the subsequent phase of institutionalisation and routinisation through which the CNA implements, promotes and generalises the policy package, it became standardized and black-boxed. Thus there was a strong tendency towards a policy package mixed out of a given set of available options and inputs. Such an objectification of the IMT policy, the process through which it acquired a seemingly tangible existence and legitimacy (Shore and Wright, 1997), again contributed to a more rapid dissemination. 
Figure 1 Area transferred in the period 1989-1994

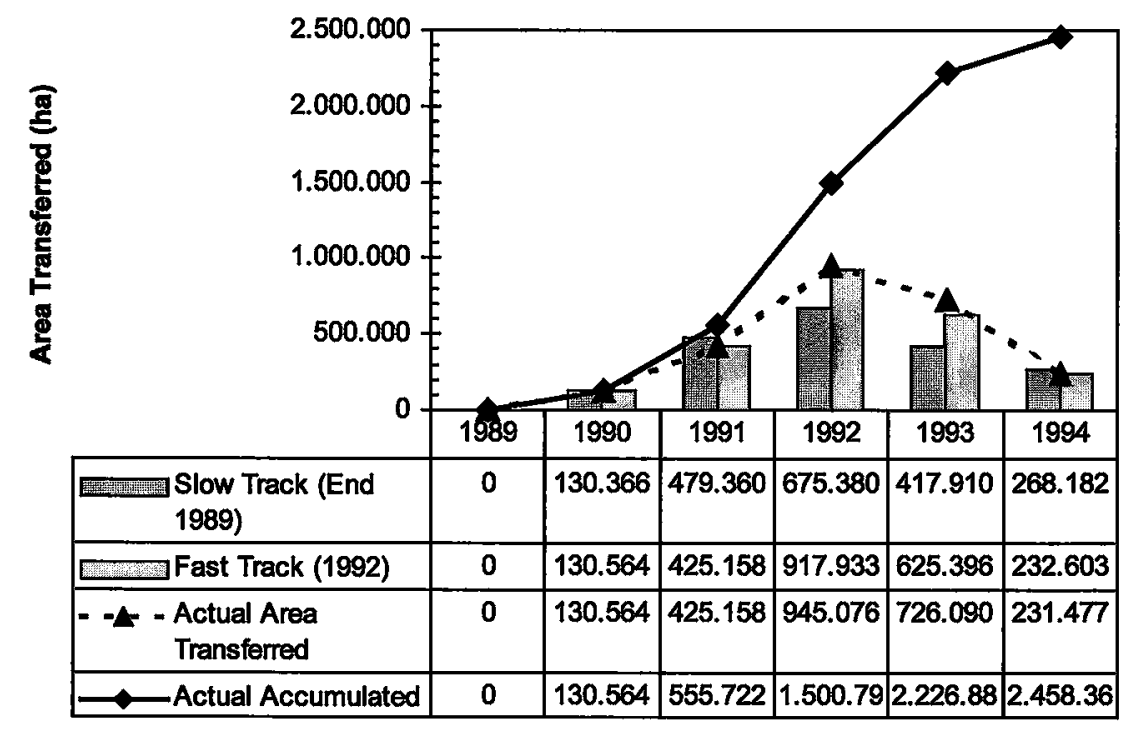

The policy package, with its ever more routine application, was still adaptable to different local circumstances and demands, in terms of a set of variables, such as the number of delegates of an ejido, the size of a module or the exact sequence in which the steps of the transfer procedure are taken. This allowed it to be flexibly adjusted in response to particular local conditions and demands of local producer groups and organisations. However, the general framework remained intact. The closure of the policy model and its accelerated dissemination means that the space, time, effort and resources available for broad consensus building and careful assessment of the implicated costs and benefits of the policy were reduced. This corresponded with a more general political trend in the Salinas administration, as discussed above. During the first years of his administration (1989-1991), the political climate was in favour of consensus building, and a large number of meetings were organised in the irrigation districts first in line for transfer, such as Culiacan, Delicias and Alto Río Lerma and other districts in the Northwest of the country. For example, in Alto Río Lerma more than 400 meetings were organised with thousands of farmers from the district (Gorriz and Groenfeldt, 1995), among other reasons because of significant resistance and difficulties in convincing influential groups of farmers. When Urzúa arrived, he found the users more 'tame' and more adapted to the idea that the government would apply this policy. After the elections of August 1991, broad consensus building processes lost their direct political importance to the government, and a more authoritarian president and government pursued a neo-liberal agenda. The CNA increasingly prescribed the general parameters within which the policy had to be accepted, and according to which water users had to organise 
themselves for transfer. After 1991, the targeting and enrolment of potential leaders and producer groups which were granted access to the negotiations leading to transfer became more selective and directed by the DID.

At the beginning of 1992, the expectation also began to take hold among CNA officials that the Mexican model could be exported to other countries. At World Bank meetings, the attention of government representatives from other countries was drawn to the Mexican case, and it was suggested that the CNA should play an advisory role and undertake consultancies in other countries in order to explain the Mexican experience, the procedure followed and the organisational models underlying IMT. At the end of 1992, the Mexican transfer model was presented to the world at an international conference of the International Commission on Irrigation and Drainage (ICID), where it was declared a success and drew the attention of irrigation experts from all over the world as the first example of transfer in the history of irrigation development (Espinosa de León and Trava, 1992). In 1993, the CNA received unusual praise from the director of Agriculture and Hydraulic Resources of the World Bank. In a national paper, the SARH proudly announced this, emphasising that the Bank normally does not send this type of congratulations. The public recognition goes as follows:

The progress realised in Mexico in the past three years in relation to the participation of water users in the administration of their irrigation systems is extraordinary and indeed without comparison in the world. (...) In no other country have similar successes be achieved compared to those in Mexico regarding the transfer of the administration of large-scale irrigation projects'. (El Financiero, 13 July 1993; my translation)

A CNA official characterises the general mood within the CNA around that time as follows:

In 1993 and 1994 they began transfers without being certain yet that they were going to function, without having resolved the social problem totally. In 93 and 94 the Salinas sexenio was coming to an end...I feel that they grew fond of $i t:$ One went well, two, then you are certain you can launch five, ten, twenty. You become enthusiastic. You stant to take up things without being totally certain how the last one functioned, the other one has to function.

\subsection{The policy package in action}

Although the IMT policy package became more standardised under Urzúa, DID strategies to convince water users of the need to take over the irrigation district in practice varied per district. The local willingness or resistance of groups, the relationships between different power bases and leaderships, the conditions of the infrastructure and the difficulties with getting the substantial fee increases accepted, forced the DID to follow different approaches. However, in most cases there is a clear element of political and financial force applied by the CNA, following the presidential instruction. It was argued that the transfer had to be enforced, because otherwise the irrigation districts would stop functioning. The government would not renew subsidies. Opposing groups of farmers from irrigation districts were faced with a situation in which they had to agree 
to the transfer. However, this led to very complicated situations, both socially and politically, which were often related to other existing social, ethnic or political problems. In some extreme cases, violent protests resulted, such as in the Tula District $(003)^{13}$ where the CNA offices were set on fire. The broad opposition met among many farmers was also dealt with by other more subtle means that limited public conflict and open opposition. In fact, the CNA used an array of techniques and strategies, partly already engrained in the policy package, to overcome the problems of opposition and advance with the transfer. For example, several techniques of governance enabled the DID to associate with those leaderships and interest groups that were in favour of, or could be persuaded to accept, the transfer. Negotiations took place with selected local leaders. Calculated distribution of resources, and sometimes of positions, further facilitated the surmounting and neutralisation of essential points of opposition. In addition, the concerted effort of the CNA to promote transfer further improved its acceptance among a public of producers not directly involved in the process.

The manner in which Urzúa and his team put the policy package into use shows significant similarities with what the literature on change management identifies as key activities for successful policy implementation (Sutton, 1999). The diagnostics stage provided for under the transfer guidelines served among other things to 'identify change agents' and 'recognise barriers to change' in irrigation districts where the CNA initiated efforts to transfer. The subsequent phases of intensive promotion of the transfer were instrumental in building support for reform, reforming organisational structures, and mobilising resources. This model, which prescribes how policy can be promoted and disseminated, significantly contributed to the accelerated dissemination and consolidation of the transfer. Below, I will review how the diagnostics, promotion and further steps taken by the CNA, actually work out in practice.

Although Urzúa and his team largely took up the master plan as developed by his predecessor, they kept adapting it in actual use and in response to the circumstances and demands encountered on the ground. The diagnostics were applied more strategically as a 'sounding out of opinion' to evaluate the willingness of different groups of farmers and their leaders to participate in the transfer. The approach taken was to interview important and influential people in an irrigation district and to ask their opinion about the transfer: included were leaders of ejidatarios, private landholders, political leaders, such as municipal presidents, special interest groups, e.g. rich and powerful farmers, and representatives of producer organisations.

Initially, in many districts the mood was against the transfer, among other things because of the bad state of the infrastructure and the substantial increase of irrigation service fees that preceded the transfer (IMTA, 1992). Well-informed government officials estimate that, when the CNA started their efforts, around sixty per cent of farmers in the irrigation districts opposed the transfer, thirty per cent were not aware of the changes, and only around ten per cent supported IMT. Many farmers had a very negative opinion about the physical state and functioning of the infrastructure. In many districts, farmers argued that the infrastructure had to be improved to an acceptable level before they would agree to take over the district. However, CNA engineers opined that the situation was not so bad at all and that farmers had a very local, and thus limited, view of infrastructural and operational problems. Scenarios were discussed in which the 
government committed itself to invest in the rehabilitation and deferred maintenance of semi-run down infrastructure.

By means of the diagnostics, CNA officials detected other 'barriers to change'. As part of a set of basic components of the IMT programme, a senior CNA official mentions the following two explicit aims:

- Elimination of the nefarious O\&M workers' union, which during the past twenty years had been a serious obstacle, rather than a facilitator, of the water distribution process through the canal network.

- Elimination of corrupt campesino (peasant) leaders who, through their political influence, systematically hindered any attempt being made at district level to raise the water fees and improve $O \& M$ conditions ${ }^{14}$.

These 'corrupt unionised people' were especially found among the canaleros (people in charge of distributing water at the field level) and at the SARH, who would lose their jobs, influence and income sources because of the transfer. The diagnostics also served to assess the position of the District Head and his higher level district personnel, who could potentially block or slow down the transfer because it would lead to a serious reduction of the district and its influence. ${ }^{15}$

Teams of engineers and lawyers were sent from CNA headquarters in the Federal District to the CNA state and district delegations and to the different irrigation districts to promote and negotiate the transfer and to get it organised. The District Head received instructions to divide the district into different 'homogeneous modules' (command areas) and to prepare a fee increase to be paid by the water users in order to achieve selfsufficiency.

Because the organisation of farmers at the field level was blocked by the district field personnel, the idea of forming temporary companies of promoters to bypass the blockade of the canaleros' was taken up from loan negotiation meetings at the World Bank. The concept of teams of field organisers had been used by the World Bank and USAID in earlier loan projects in the Philippines and in Sri Lanka during the 1970s and 1980s (Uphoff, 1992). They are formed by engineers, economists or sociologists from outside the irrigation district with organisational capacity and are trained to deliver the promotional message. The companies of promoters were instructed by the DID about the general strategy of transfer and the steps that had to be taken to form a WUA. Subsequently, they went around the assemblies of ejidos and associations of private landholders to inform them about what the government was proposing. They explained the objectives of transfer, the rights and obligations involved and the need for a substantial fee increase. Groups of producers were informed that to realise the transfer they would have to organise themselves in a certain way. These companies of promoters soon detected the need to designate delegates. They encountered the practical problem of having to deal with large numbers of 'water users' organised according to different types of landownership: ejidos and private landholding. In response, they generated the idea of creating from all the assemblies of ejidos and the associations of private landholders in a designated area a fictitious assembly called the assembly of delegates. This corresponded with an existing practice of state and bureaucratic intervention and civil representation in rural organisations. After the acceptation of this idea at the highest level, the promoters were given the responsibility to organise the assembly of delegates 
with a fixed number of delegates from the assemblies of ejidos and the associations of private landholders.

The assembly of delegates was then given the responsibility of constituting the WUA. For the CNA, the inclusion and enrolment of an assembly of delegates to mediate with all water users facilitated the political problem of implementing the transfer in a context where a majority of water users opposed it.

Models designed by the CNA define the legal and organisational form of the WUA. They dictate that the assembly of delegates is the body with supreme authority in the civil association. The assembly elects a board with a president, secretary and a treasurer from among themselves. Furthermore, they assign a Control Committee, presided over by a president and with CNA participation. The board contracts personnel on a temporary basis for the operation, maintenance and administration of the module. Unlike the government-based workers, these people do not get fixed salaries, are generally not organised in a union and can easily be fired. In this way, the influence of the unions is eliminated.

\section{A process of inclusion and exclusion}

The information produced by the diagnostics basically served as a useful starting point for granting selective access to the negotiations leading to transfer. It was the basis on which the CNA could target and convince potentially willing leaders and enrol them to lead and direct the organisation of the water users according to a number of prescribed steps and models. The diagnostics also looked at the possibility of reaching agreements between different influential local leaders and groups (CNA, 1991c) in order to form an alliance of forces that would support the transfer. At the same time, the diagnostic information could be used to identify and target those groups and leaders resistant to the idea of transfer, because they expected to lose as a result of it. The next step would then be to neutralise, by-pass, or exclude the resisting or blocking elements from the process in order to proceed with the following steps. The teams of CNA engineers and communication specialists from the IMTA who were sent out to the districts to undertake the diagnostics received careful instructions. Urzúa's concern was to be informed about whom to talk to and whom not to, in order for the DID to negotiate the transfer.

The DID thus entered a selective process of including certain leaderships and interest groups in the negotiations and preparations for the transfer and excluding others. It targeted the politically influential, economically powerful and organised groups in the district. This group of farmers was generally more favourable to the transfer than the large majority of farmers. They had their power bases in local PRI-affiliated organisations for peasants and for private producers, the Confederación Nacional de Campesinos (CNC: National Peasant Confederation and the Confederación Nacional de Propietarios Rurales (CNPR: National Confederation of Rural Proprietors), or in other existing producer organisations. As such, they maintained close relations with the district, with local political forces within the PRI, and elite interest groups, such as agricultural entrepreneurs. They often operated with the political support of local deputies (MPs), senators, or governors. Their experience with the leadership of producer organisations, 
their political support for the PRI and government policy, influenced their favourable position towards the transfer. In addition, from their position they were well informed about the significant financial and political importance that the WUAs would have. Further, they were aware of the significant control over water, maintenance services and other crucial resources that managing a WUA would imply. These types of leaders were in many cases enrolled to mediate for 'the water users' and negotiated the transfer with the DID.

The agreements that were negotiated with these groups in the end often materialised in positions for their members on the board of the newly established WUAs. Leaders who participated in the process from the beginning were also likely to take up a post on the board of the WUA or place one of their supporters on it. Because these leaders were identified and targeted from early on, they received first hand information about how to organise a WUA. In socially and politically more complicated and divided districts, the CNA negotiated the transfer between different political and interest groups by assigning posts to them, or established alliances between the different leaders or groups. Under the alternation concept pioneered in El Grullo, in most cases the majority group was given the presidency for the first period and the minority group the treasury. In this way, an alternation between spheres of influence was secured on the committee. In practice, this was found to be essential to solve the problem of reaching agreements with and associating different groups of ejidatarios and private landholders, or influential leaders and opposing interest groups, who originally envisioned different forms of organisation. It served to establish alliances of leaders and to unite different groups in one organisation of users.

The selective access granted by the DID significantly simplified the process of securing the increase in irrigation service fees and acceptance of the transfer. It also contributed to the acceleration of forming WUAs. A senior CNA official says the following about this:

One of the important things was to choose the leaders; one had to look who was the leader, go to him and convince him. For example, the president of the Association of Farmers of Culiacan. At the beginning we had four or five meetings which were very tense. We said to him: 'look, the problem is that the gooernment does not have money anymore to go on subsidising the irrigation districts. If you do not take charge of the infrastructure, you will end up without water. In the end, many of these leaders, agricultural entrepreneurs also, in the Northwest of the country began to see that these changes were necessary, and we began to have a good acceptance in some districts like Río Mayo, Delicias, the central part of Río Lerma. The district chiefs did very intensive work.

Initially, the position of the economically powerful groups of large agricultural entrepreneurs was generally more neutral. These producers, who own agro-industrial companies and administer large areas in irrigation districts for export agriculture, often maintained close relations with the district and already enjoyed relatively privileged access to water and maintenance services. They were not directly interested in the transfer because they would have to pay higher fees. However, they became convinced of the need to support the transfer, in part because they saw evidence in the first districts transferred that they could acquire direct control over crucial resources, such as water, and that the WUAs were becoming politically and financially powerful organisations. An 
example is the Alto Rio Lerma District where a group of influential agro-industrial entrepreneurs linked to the then Minister of Agriculture, Usabiaga, at first opposed the transfer. Early in 1992, they reached an agreement with the DID, after which they supported the creation of the WUAs in which several of them received the post of president. More generally, the participation of private enterprises in the transfer increased when Urzúa was head of the DID and in line with a general shift in government priority during the latter part of the Salinas administration. Private capital entered as a possible concessionary of maintenance and administration services of the modules or the SRL.

As an effect of the selective approach pursued during the diagnosis and promotion, DID mainly engaged with popular leaders, local politicians and entrepreneurs who represented organisations allied to the PRI regime. In most modules the board was therefore occupied by PRI supporters. Only a limited number of modules were controlled by popular leaders with links with the opposition. In particular, the left wing party, Partido de Reoolucion Democratica (PRD), the main opponent of the PRI in the 1988 and 1991 election, had a substantial rural following. However, they did not really gain influence in the districts through the modules in the way that the PRI did. El Carrizo is an exception (076). In El Carrizo, Sinaloa, in order to prevent conflicts in the district the DID had to negotiate with leaders linked to the PRD, and the district was divided into two modules with PRD supporters and two with government allied leaders.

The employment of the standard model of a Water Users' Association as the organisational unit to which a module is transferred served a bureaucratic need of establishing a certain level of control at a distance. CNA officials emphasise that the advantage of the selected and prescribed form of a WUA is that modules could not be transferred to existing forms of organisations. Four different levels of farmer organisations existed in the irrigation districts before the transfer:

1. Ejidos and organisations of private producers which are part of respectively the CNC and the CNPP, the PRI affiliated organisations with local delegations at the municipal level

2. Associations of ejidos and private producers

3. Associations of Collective Interest (ARIC), e.g. ARIC of tobacco producers in Nayarit (see Chapter 8)

4. Large national federations of producers organised on the basis of a product, e.g. National Federation of Vegetable Producers.

However, these existing organisational forms, which were traditionally used by the Mexican State for political and bureaucratic intermediation and exercising patronage, were not taken by the CNA as a point of departure for the transfer. Neither the corporative organisation CNC nor the ARICs are included in the organisational set-up for the transfer. The CNA made very selective use of the existing organisational base in the districts. At the lowest level, the ejidos and the private landholders were represented by delegates to the assembly. At a higher level, the influential leaderships and political groups, who had their power and economic base in producer organisations, were consulted and included in the negotiation process, if this was deemed necessary for advancing the transfer. However, this did not lead to a formal representation of those organisations in the process of transfer, the WUAs and irrigation management. A leader 
from a popular organisation active in one of the districts reflects on the origins and effects of the WUA model. He suspects that it stems from a recommendation of the World Bank, because he thinks that otherwise it would have been much more likely for the Mexican government to involve the $\mathrm{CNC}$ or other existing organisations more directly. He elaborates:

These are conceptions of organisation which are going to influence everything. The management of the district will be with those who are organised in some way. By making the associations obligatory, you can be in a cooperative society or in an ejido, but as such you cannot enter the management of water, when you are not in the association. So, you are obliged to become part of a system which is super controlled by the CNA.

When asked for the underlying motivation behind the application of this WUA model, a influential CNA official argues that water is a public good whose administration should not be mixed with existing organisations based on type of land tenure, crop, or credit provision. This would only lead to favouritism in the distribution of water and a general division between the water users, he argues. Within a WUA, both ejidatarios and private landholders become 'water users' of the system. The decision to alternate the board positions between leaders from the two land tenure sectors contributed to this sense of community. CNA officials assert that a positive impact of the WUA and the alternation is that the users become a homogeneous group. They tell anecdotes in which farmers have stopped addressing each other as 'ejidatarios' and 'private landowners' and prefer to call each other 'water users' nowadays. According to these accounts, the formation of user organisations was accompanied by a homogenisation which caused these social groups to mitigate their mutual divisions, conflicts and hatred.

A number of other potentially opposing interest groups, identified through the diagnostics, that threatened to oppose the transfer were effectively externalised as a result of the organisational models that were designed and applied: the ejido and CNC leaders, the O\&M workers' union of the SARH, and the district chiefs and confidence personnel. In the new organisational set-up, these potentially restraining influences were externalised from influence in the WUAs and in irrigation management. According to a senior CNA engineer, the 'corrupt campesino leaders' used to enjoy considerable influence on irrigation management and traditionally opposed substantial fee increases in the districts to defend their electorate. However, their influence was curtailed by the transfer. He points out that decisions on the increase of irrigation service fees are taken by the Hydraulic Committee. The campesinos or ejidatarios are democratically represented in this body as 'water users' by the presidents of the WUAs. As a consequence of this changed mode of representation, the ejido and $\mathrm{CNC}$ leaders that used to influence such matters no longer have direct influence. The increases in irrigation service fees are therefore not in danger in his opinion. Another impact of the chosen form of WUA organisation is that only 'water users' can act as delegates and therefore also as members and board members. To determine who qualifies as a water user, a technology of governance called the padron de usuarios is used. This is a list of registered users compiled by the CNA and included in the Concession Title. Only the farmers with a normal water right, i.e. those who own a specified parcel of land within the module and the physical boundaries of the districts are included. Those with a temporary or precarious right are excluded from access to the WUA. Any rural leader not 
organised according to this model of organisation, and not registered as a water user, can expect to be excluded from the new WUAs and thus from controlling irrigation management and the resources involved.

The SARH unions lost influence because the WUA personnel were employed under temporary contracts and could no longer be organised in government unions. Under the Salinas government, the influential government unions were severely weakened, and Salinas made a point of not accepting opposition to his policies. Officials confirm that the reduction of base personnel was a consequence of the transfer, and the pension regulations were negotiated on a personal basis with the SARH union leader, who was a Congress member at the time. The number of CNA district personnel was reduced in phases. Most of the base workers in the CNA (around 5,000 people) were retired and received a pension, others were shifted to other CNA departments, and a limited group was contracted by the WUA on temporary contracts.

Something which is less emphasised in the literature on IMT is the phased strategy of rotating and removing District Chiefs and State Delegation Heads. This was crucial in neutralising potential opposition or retaining the influence of CNA higher level personnel in the districts and state delegations. A senior CNA engineer recounts how a generally applied rule within the CNA was that a District Chief plus his close associates were removed from their posts and shifted to other districts in the country, in most cases to be fired at a later stage. The intention of this rule was to prevent the District Chief resisting and restraining the transfer, or mobilising a protest against the personnel cuts and the reduction of their influence in the district and the insecurity of their incoming resource flows. The functionary admits that this was a sort of a 'kamikaze exercise', because the District Chiefs, who played an important part in organising the transfer, in the end also lost their jobs ${ }^{17}$.

\section{Promotion of the transfer: show cases and public campaigns}

The acceleration of the process of transfer occurred because of a concerted effort on the part of the CNA in cooperation with IMTA to promote and disseminate the idea of transfer. Documents, videos and other audio-visual materials were produced by experts in mass communication from especially instituted departments in the CNA and IMTA (see Chapter 10). Information on the transfer process, largely conceived from within the DID, was communicated to the irrigation districts and contributed to the public awareness of the intended mode of transfer and the opportunities and benefits for protagonists. These campaigns of government information transmitted a precise scenario of how the CNA believed the transfer process should take place in order to prevent misunderstandings and presumptions about its form and implications. Further, these communicative means allowed a rapid distribution of information to state level and district CNA representatives closely involved in extending this information and starting up the process of transfer, and who thus had to be aware of the implications of the process.

Besides the centrally-coordinated circulation of information, documents, videos and the use of mass media, a vast movement of people around the country was also organised by the CNA. Social scientists from IMTA were mobilised to diagnose the situation in irrigation districts. Teams of engineers and lawyers were sent from the CNA 
headquarters to the CNA state and district delegations and to the different irrigation districts to promote the transfer and get it organised and started. They assisted locally organised companies of promoters and, at a later stage, trained water users to take over the management of a module. In addition, groups of board members and managers of WUAs were taken on trips to early pilot projects of WUAs to convince them of the possibilities, the opportunities and the benefits to be gained from taking over irrigation infrastructure, maintenance machinery, and administrative resources. Irrigation districts such as El Grullo were visited by many delegated groups of water users from all over the country as exemplars or showcases of successful WUA management. These delegations were then used to promote the message of positive results in their own districts. After 1991, the number of available showcases increased, as more districts were transferred. The careful selection by the CNA of the more commercially oriented and relatively modern and well-maintained irrigation districts added to the positive image of transfer. International interest also increased, as IMT in Mexico became a model in itself.

A review of the national and regional newspapers at the time shows that the press only paid attention to official government information on IMT. In contrast to the broad public and academic debate on the revision of famous article 27 of the constitution concerning landownership that was amply aired in the press, the water management reforms received little attention. The papers mainly reported on the official ceremonies of transfer throughout the country, which were generally attended by important political leaders, party representatives, top-level bureaucrats and large crowds of people. During these ceremonies, the Concession Title was handed over to WUAs. These public events of high political importance were often presided over by the president himself, the Minister of Agriculture, or the Director of the CNA. They made speeches on the agricultural and irrigation policy of the Salinas administration, emphasising the need to eradicate government paternalism and to stimulate the shared responsibility of the water users and the private sector (CNA, 1992). The achievements and successes of the Salinas government were enumerated. Local government functionaries and WUAs presidents thanked the president and his functionaries for their beneficial policies. These ceremonies and the way they were reported via the media were thus crucial for government information campaigns and public awareness of CNA policies and achievements and progress concerning IMT. Besides reporting on these ceremonies and reproducing CNA data on the progress and benefits of the transfer, few papers actually discussed the process and its impacts on the rural sector in more depth ${ }^{18}$. In addition, virtually no attention is given to the widespread dissent in the irrigation districts concerning the transfer. As a result, the opposition in different irrigation districts remained isolated, deprived of information from other districts, and took place mostly behind the scenes.

\section{Calculated distribution of resources}

Another strategy used by the DID to manage opposition in the irrigation districts was through 'the calculated distribution of public resources' (Grindle, 1996). This approach made producers focus on the allocation process instead of opposing the transfer itself. By opening or closing access to resources and by promising to invest more or less in a district, the DID selectively enticed and sanctioned organised user groups according to their willingness to go along with CNA directions. User groups who were retarding the 
advance of the transfer risked missing out on the resources and projects that the DID distributed among the irrigation districts. A huge reservoir of financial resources available to the CNA was associated with the time-slice loan agreed in 1991 for construction, modernisation, rehabilitation, deferred maintenance, and O\&M equipment for irrigation districts. However, these investments were programmed in twenty-one districts that were part of the original plan. The majority of the expenses were targeted at eleven districts in the north of the country, particularly those in the Northwest.

The aim of rehabilitating and modernising twenty-one districts shifted to transferring the majority of the districts, and the transfer accelerated, as discussed above. The districts that were subsequently considered for transfer generally had a less modern and more run down infrastructure. The promise of rehabilitating the districts and undertaking deferred maintenance in exchange for transfer was implicitly maintained. This improved the acceptance of the transfer, although in reality it was impossible to earmark financial resources for this purpose, because the government was already committed to its financial contribution required by the time-slice loan. The rehabilitation in those districts that were not part of the original loan agreement was carried out by patching on a very selective basis. The barely available resources for this purpose were allocated as a result of negotiations between the DID and local producer groups, something that helped to improve the acceptance and the advance of transfer in those districts. The lack of actual rehabilitation in those districts was partly compensated by giving the modules new maintenance machinery. Also, the allocation of these machines was used to stimulate the producers to accept the transfer. Another partial solution on the part of the CNA was to promote decentralised funding schemes for rehabilitation and modernisation projects. Under the programme, Alianza para el Campo, such projects were co-financed by combining federal, state and municipal efforts and resources together with those of the modules.

\subsection{Conclusion}

I have looked at the standardisation, acceleration and effects of the irrigation transfer policy in Mexico in order to study the process of policy articulation. My focus was primarily on how a standardised policy package was developed, consisting of a set of specific technologies of governance. During an initial phase, these technologies were selected and redesigned in response to a set of dispersed trials of strength: experiments, consultations, and clashes in the field, and negotiations and discussions at the national level. Feedback mechanisms co-ordinated by the hydraulic bureaucracy led to a convergence of dispersed experiences and ideas on how to implement the transfer. In addition to the increase in political pressure and the finalisation of a loan agreement to fund the transfer, the IMT package reached closure with the arrival of a new hydrocrat who was made responsible for the progress of the transfer. The standardised policy package allowed the CNA to promote, organise and expand transfer on a large scale. The institutionalisation and routinisation of the package in action enhanced an acceleration of transfer.

In the districts, the ground was prepared using a step-by-step approach, starting with diagnostics, followed by a targeted promotion of the transfer. The basic idea behind the 
first step was to map out elements neutral or favourable to the transfer, and to locate the barriers to change. Subsequently, the policy package worked to include and direct the well-disposed leaderships and exclude resisting or uncontrollable elements. The DID entered a process of preparation and selective negotiation with politically influential and economically powerful and organised groups in the district. Interest groups identified as opposed to the transfer were effectively externalised as a result of the use of the WUA model and related technologies of governance. Promotion campaigns and a calculated distribution of resources further improved the acceptance of the transfer and resulted in its acceleration.

Chapter 2 and 3 showed how through IMT the hydraulic bureaucracy regained autonomy and reordered its control over the irrigation districts. The institutionalisation and routinisation of a standardised set of governing technologies contributed for the CNA to a certain control at a distance over the WUAs. This is significant in the context of a prolonged bureaucratic struggle over the irrigation districts, as discussed in Chapter 2. However, this sort of bureaucratic control at a distance is not entirely new. Enge and Whiteford (1989) also observe that rural organisations, such as ejidos and farmermanaged irrigation units, have structural and procedural limitations that are imposed by SARH regulations. In spite of limited control of the SARH over the decentralised irrigation units that these authors study, they all have comparable by-laws, personnel, election procedures and operation modes. Hence, the users must from an association or junta de agua (water board) to assure compliance with the conditions set forth by the SARH (Enge and Whiteford, 1989: 127-129).

Concluding, I argue here that in spite of its ideological promise, neo-liberal policy does not lead to less government but to more subtle and less visible technologies of bureaucratic reproduction, intervention and control. In practice, neo-liberal reforms often result in more subtle methods of intervention and control based on ideas of freedom, enterprise, management and the market; all of which function to make the regulatory power of the state more diffuse and less visible (Shore and Wright, 1997). In a similar fashion, Miller and Rose (1992) show how contemporary calculation practices, such as used in accountancy, enable state agencies to withdraw from direct control and responsibility over the actions of individuals, organisations and societal domains, while retaining control at a distance.

Likewise, Mosse (1999) shows that the transfer of social technologies associated with contemporary ideologies of 'community management' in Indian tank irrigation, e.g. criteria for group membership, meetings and account keeping, serves to meet administrative needs of irrigation bureaucracies by providing a means to consult with local people to harness local leadership, mechanism to channel development inputs, and meet bureaucratic requirements of orderliness, uniformity, quantifiability and control'. He goes on to argue that the uniformity and standardisation of social organisation in local irrigation systems and the politics of institutional change are essential to a recasting of the irrigation organisation in bureaucratic terms. The unit of administration becomes the homogenised farmers' association. These observations correspond with what was discussed in this chapter. 
Nevertheless, the technologies of governance that were discussed in this chapter do not produce a unilateral expansion of bureaucratic state control. The organisational ethnography that follows in Chapters 4 to 9 shows that the newly formed WUAs can become convergence points for a form of control over people, resources, and infrastructure, which is not necessarily located within the state, but also does not singularly represent market forces or civil society.

\section{Notes}

1 A previous version of this chapter was written as a paper together with Flip Wester of the Irrigation and Water Engineering Group, Wageningen University.

2 This term is a contraction of hydraulic bureaucrats and is used here to refer to professionals, generally civil and irrigation engineers, working in hydraulic bureaucracies (termed hydrocracies in the remainder of the text for consistency).

${ }^{3}$ I have adapted this term from Miller and Rose's 'technologies of government' (Miller and Rose, 1992). Their concept suggests the expansion of state bureaucratic power, whereas I think that the technologies I refer to also enable the acquisition of power outside of the government. The term governance is not used in a normative sense, as in 'good governance'.

Dr. Ramos had left SARH in 1986, frustrated and traumatised by the loss of influence of irrigation and civil engineers in decision making.

${ }_{5}$ Dr. Ramos graduated from the National School of Agriculture in Chapingo in 1956 as an irrigation engineer and, like many of his generation, immediately went to work for the government. For thirteen years he climbed the ranks in the SRH and gained much experience in the management of irrigation districts. In 1969 he went to Columbia to work on irrigation projects there. In the early 1970s he returned to Chapingo to obtain his masters degree at the Colegio de Postgraduados and in 1976 received his $\mathrm{PhD}$ from the University of Arizona, both of which degrees dealt with improving the operation of irrigation districts. In addition, he personally knew many of the chief engineers working in the irrigation districts. When he was invited in 1988 to become Head of Irrigation Districts, he was working in the Dominican Republic on an irrigation transfer programme financed by USAID.

- Land reform communities created after the Mexican Revolution of 1910. Ejido land belongs to the state, with a combination of community (ejido) and private (ejidatorio) usuffuct, and since the amendment of Article 27 of the Constitution in 1992 ejidatarios can sell their land. The other category of landowners in Mexico are called pequeños propietarios: private farmers with a limit on land ownership of 100 ha.

7 Centeno (1994: 104-106) defines políticos as the 'dinosaurs' of the regime, responsible for managing the corporate structure of the party and ensuring that elections are won through militancy. The burocratas politicos make their careers inside the national office of the party and traditionally were the most powerful wing of the governing elite concerned with maintaining political stability. The técnicos are the specialists in the bureaucracy, committed to their area of expertise and generally reluctant to play the 'dirty games' of politics. The tecnocratas, finally, combine the educational credentials of the técnicos with the political acumen of the politicos and were able to transfer their control over technical areas to overall command of the state. Characteristically, they are committed to the imposition of a single, exclusive policy paradigm, based on neo-liberal models of economics, through political negotiation.

- Written response to questionnaire, September 1999.

- Interview, Mexico City, August 3, 1999.

10 Interview, Mexico City, August 3, 1999.

$11 \quad$ Interview, Mexico City, August 3, 1999.

12 Dr. Urzua was educated as an agronomist with a speciality in irrigation in the 1950s at the then military college of Chapingo. There he met many, later colleague, engineers among whom the senior students Ramos and Vargas, who both also played a crucial role in the transfer. During the 1950s and 1960 s he worked as a district engineer in large irrigation systems in the Northeast (Bajo Bravo, Bajo San Juan) and Northwest (Río Fuerte) of the country and specialised in the operation of irrigation systems over 100,000 hectares. After changing to the irrigation and drainage engineering section within the $\mathrm{SRH}$, he discovered the need for more in-depth study of soil-water-plant relations. He retired from the 
SRH to do a Master's degree at the Colegio de Postgraduados in 1972, at that time led by Dr. Ramos' brother. Subsequently, he got the opportunity to do a $\mathrm{PhD}$ at the Colorado State University and decided to further investigate the optimisation of an on-farm water allocation system. When the SRH was merged into the SARH in 1976, Urzúa was working as a professor at the Colegio. In 1977 he was asked to become state manager of the SARH in the Northwest (Baja California) where he stayed for the next decade. He then returned to the federal district of Mexico where he broadened his horizons by working for the state government for two years. At the start of Salinas' administration, he became a businessman by creating a company specialising in PVC pipes for irrigation systems.

${ }_{13}$ At the end of 1999, the Tula District was one of the few remaining districts still not transferred.

${ }^{14}$ Written response to questions on the origins of IMT by a ex-CNA official.

15 These higher level bureaucrats have a different type of appointment than the lower level personnel. These 'confidence personnel' are more directly dependent on their superiors for continued employment. This means they cannot unionise and can be more easily dismissed (Grindle, 1977).

16 Interview Mexico City, August 1999.

17 Interview with an ex-CNA official.

18 For an exception see El Financiero of July 13, 1993. 


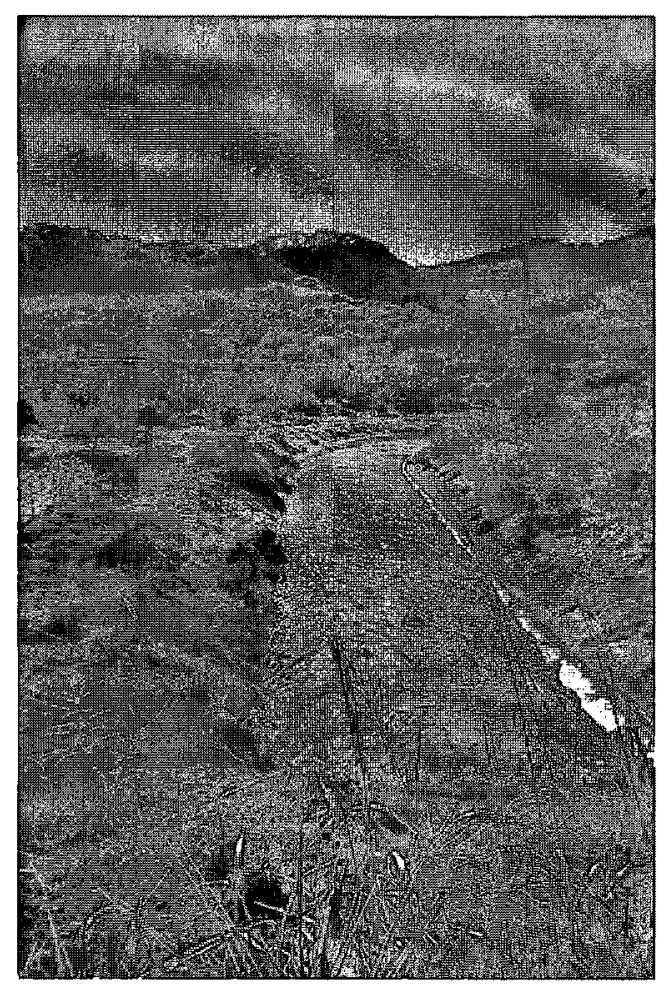

Photo 2 The first metres of the main canal

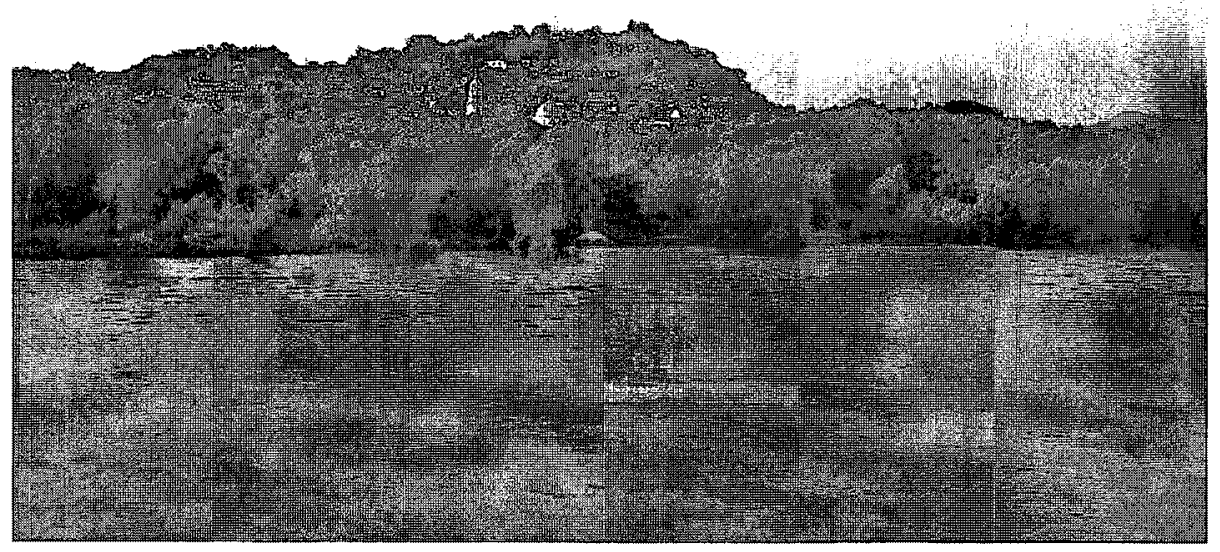

Photo 3 Santiago Ixcuintla from the Right Bank of the River Santiago 


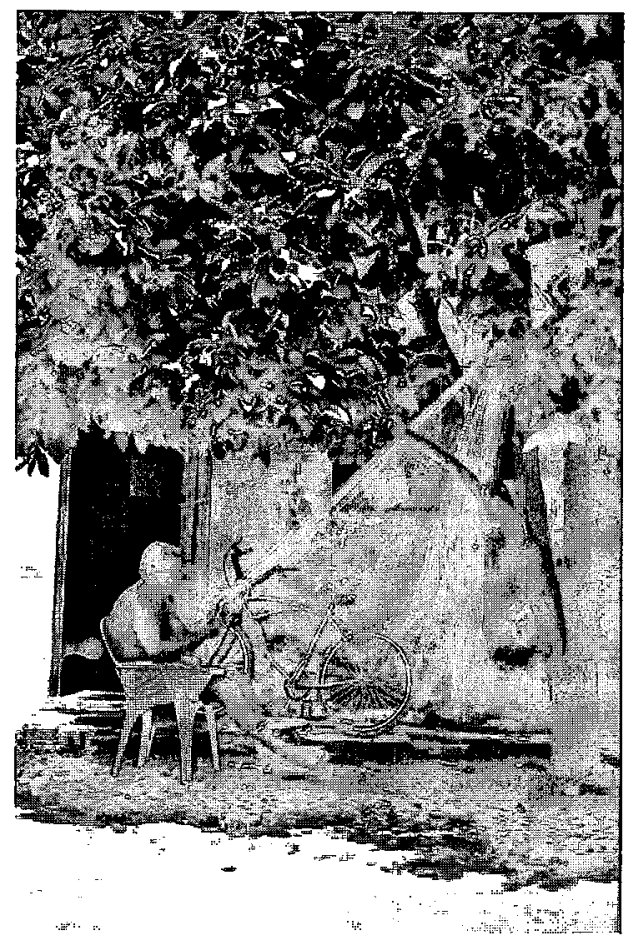

Photo 4 A fisherman repairing his net 


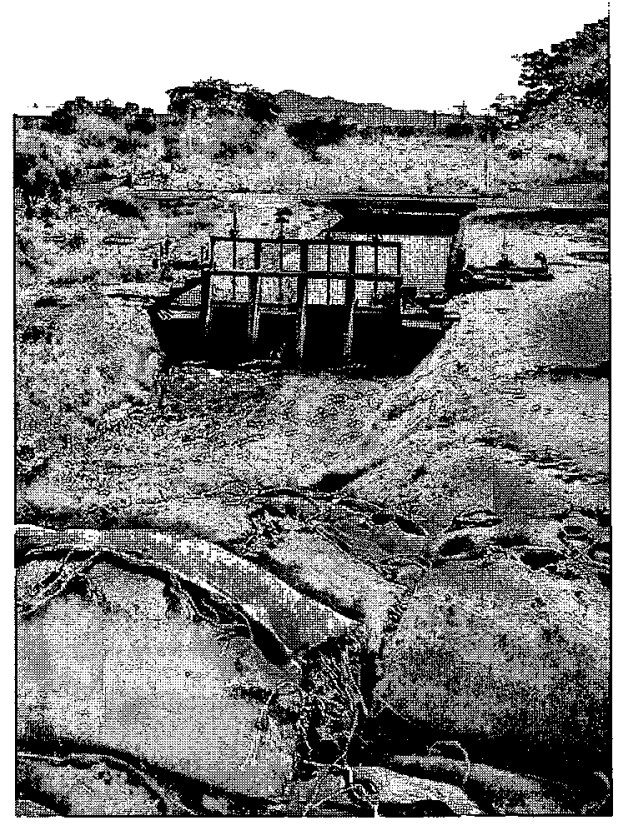

Photo 5 A cross-regulator from on top of a tobacco truck 


\section{4 \\ An Introduction to the Region:
The Left Bank of the Santiago River}

It is hot, we are going through sugarcane fields, there is a putrid smell of fermented cane juice, we pass by sugar refineries, whose names become famous every six years, because at the beginning of each period it is discovered that they are badly administered, after that they are forgotten and remain badly administered for another six years.

From a travel story of Jorge Ibargüengoitia, who is driving through the countryside of Vera Cruz, Mexico. My translation.

DRAMATIS PERSONAE:

Pérez

Nuñez

Guttiérez

Hijar Juárez

Becerra

Caminante

Emilio González

Flores Muñoz

Gascón Mercado first president of the Santiago Patronato and the Left Bank WUA, local deputy (MP) and large producer and leader of a political group

second president of the WIIA and ejido president manager of the WUA

local doctor and other leader of the political group

head of operation of the irrigation district, later district head

local leader and president of the San Blas Patronato

gooemor (1981-1987), union leader

gooernor (1945-1951), minister of agriculture (1952-1958)

governor (1963-1969) with influential political family

PROPS:

Left Bank

Santiago River

Aguamilpa

Amado Nervo

Irrigation infrastructure

WUA office

Sprinkler installations

Crops

Tobacco barns

Rice-processing plant

Bridge

Right Bank

Boundaries

Maintenance machines

run-of-the-river irrigation system

the river feeding the irrigation module

hydroelectric dam on the Santiago Rioer

headworks of the Left Bank module, concrete diversion weir

network of connected canals and drains of distinct levels

in Villa Hidalgo

systems used for sprinkler irrigation

beans, tobacco, cereals, rice, vegetables, etc.

clusters of barns for flue-curing tobacco

near Sauta

palm-log bridge replaced by a concrete bridge, connects the Left with the Right Bank

irrigation system in extension on the other river bank

intersecting limits of irrigation module, electoral districts and the Santiago and San Blas municipalities

machinery to carry out maintenance of irrigation works 


\subsection{Introduction}

This chapter will commence with a description of the regional landscape that has shaped the life and work of the inhabitants of the Northern Coast of Nayarit. As an informed outsider who has learned to read the landscape, I will lead you through the Santiago Valley. By means of observations about the scenery, inspired by Jorge Ibargüengoitia, I shall point out what have become meaningful landmarks to me and what it is I see through them. We proceed with a tour around the irrigation system on the Left Bank of the River Santiago, which is the topic of my study. I focus on the way in which public infrastructural works tell us something about the historical and political landscape of the region and, conversely, about how the placing of these works in the wider coastal landscape has influenced regional politics. The section ends with a description of the climatic contrast between the wet and the dry season that affects the rhythms of agricultural, economic, and cultural life of the region. Thereafter, Section 4.3 shows how the irrigation system is situated within this landscape. I discuss the most essential ecological, physical, and technological aspects of irrigation and drainage. In the chapters to come I will show how those material elements constrain, as well as enable, the management of the irrigation system. A concise analysis of the distribution of land and crops in the system follows, in order to indicate the socio-economic differentiation among producer groups and to explain why I am cautious with using the concept 'users'. In Section 4.4, this extensive descriptive introduction impels me to discuss a matter that is not immediately visible in the landscape, although it could perhaps be inferred. I will show that the irrigation system is not an isolated entity, but overlaps with several political and organisational domains that affect irrigation management. The end of this section recounts the contemporary history of the transfer of the Left Bank irrigation system. It illustrates how this policy intervention became politically and institutionally embedded and tied up with the vicissitudes of a local political group. It also introduces the actors who play a role in the organisational ethnography of the Water Users' Association (WUA) that follows in the coming chapters.' The last section draws conclusions about the region of study.

\section{2 The Regional Landscape}

\section{Entering the region}

The study is situated in the northwest of the state of Nayarit, facing the Pacific Ocean. On leaving the central capital of Tepic and headed for the coast, taking the western branch of the Pan-American. Highway in a northwesterly direction, you have to cross a capricious mountain range, after which you slowly descend to sea level. Between the twists and turns of the road you catch a glimpse of the Southern Pacific Railroad that traverses canyons via bridges that hang over unfathomable depths. Over the last kilometres to the coast, the mountain range changes into foothills that gently slope into the Santiago Valley. As you are coming down the highway, an unexpected, panoramic view opens itself up to you. The great Santiago River meanders in broad curves through the tropical lowlands to find a final escape in the Pacific Ocean. Whilst you admire the lush green vegetation interspersed with occasional palm trees, you feel a moist heat that slowly penetrates the vehicle and begins to affect you. This first experience of 
overwhelming natural exuberance is meaningful. These are the forces that have shaped the tropical coastal landscape, and they permeate all human effort to transform and manage its resources. Irrigation is, as we shall see, a living testimony.

Map 2 The regions of Nayarit

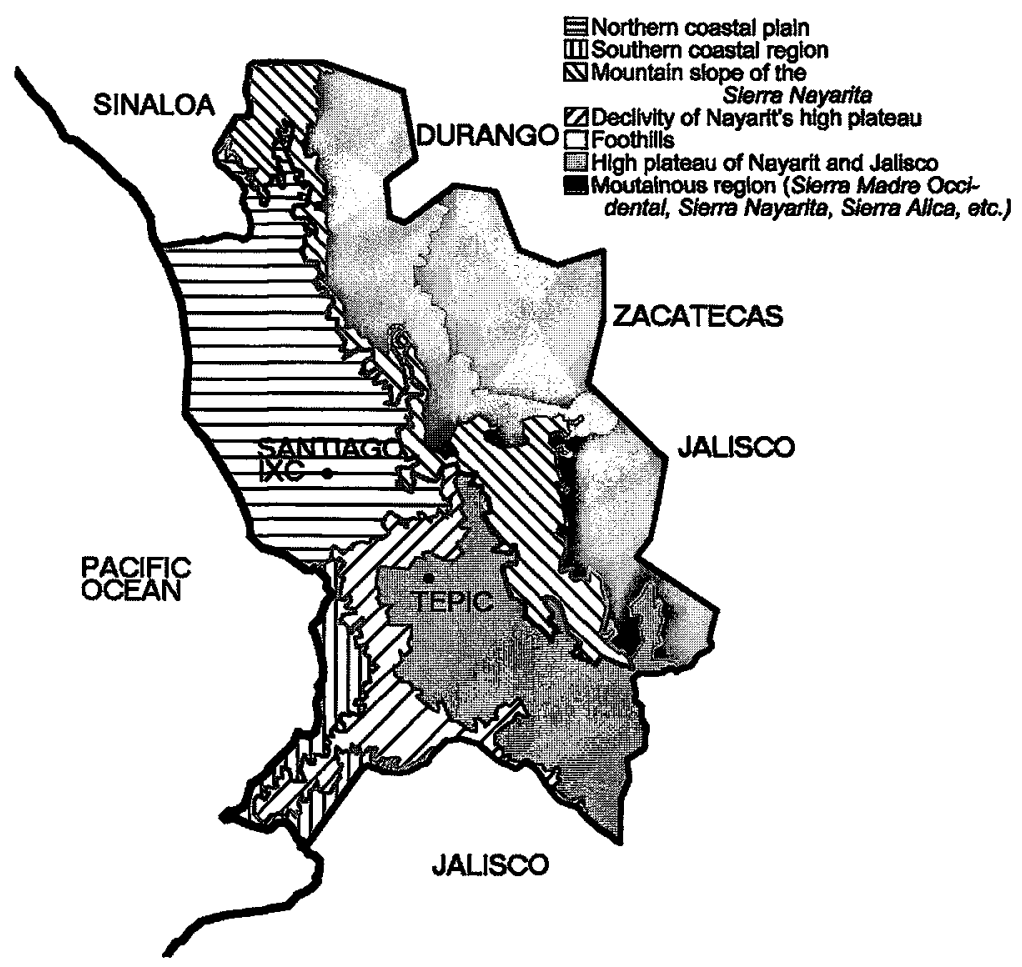

The Northern Coast of Nayarit is a coastal plain roughly forty kilometres wide and eighty kilometres long (see Map above). It extends from a line of low mountains south of the Santiago River into the northern state of Sinaloa and is locked in between the ocean and the western mountain range called Sierra Madre Occidental that comes down along the coast all the way from the United States. The geographical isolation from the rest of the state has shaped the history of the region. It provides a partial explanation for why culturally the mestizo ${ }^{2}$ population from the northern coast feel they stand apart, and why at times they experience more cultural proximity to the southern plains of Sinaloa than to the central plateau and the southern coast of Nayarit, which bear more of the conservative influence from Jalisco, or to the mountain area which is dominated by Indian groups ${ }^{3}$.

The tropical climatic conditions further distinguish the coastal region from neighbouring regions. Throughout the year, green vegetation dominates the coastal panorama, unlike other more arid parts of Western Mexico. The coast has a sub-humid tropical savannah climate with a rainy season in the summer (climate type AWws according to Koppen). The average annual temperature is $23.4^{\circ} \mathrm{C}$. The hottest months, with temperatures up to $40^{\circ} \mathrm{C}$, are between May and October. The average annual rainfall is high, more than 
$1,600 \mathrm{~mm}$, but it largely falls in the period from June to October. This rainy season (las lluvias) is thus characterised also by the hot and humid climate, a rapid growth of natural vegetation, flooding and occasional tornados. The intense sensation of moist heat gives life to the telling story that people from the coast do not fear the devil, because they welcome the heat that makes hell such an unpleasant place for other mortals. After the rains, the temperatures become lower for a few months but then rise again towards the rainy season. However, the heat is then generally not felt so much, because of the lower humidity.

After entering the municipality of Santiago and crossing a large irrigation canal, but before reaching the Santiago River, you arrive at a crossroads. The road that branches off in a westerly direction leads to the southern bank of the river. This area is called 'the Left Bank' and harbours the irrigation module that is the topic of this study. The road takes us right through the irrigation system from the head to the tail-end. We shall return to this road. If we continue on the international highway, we cross the broad Santiago River over the sole concrete bridge for miles around. On the riverbanks you catch a first glimpse of fields growing tobacco of the Burley variety, irrigated with a pump and sprinklers from the river. The soil close to the river is extremely fertile, because the river floods during the rainy season and annually renews the soil with river sediments. Such soil is rated among the best in the country for the production of Burley tobacco.

If we proceeded, the highway would take us to the most northern towns of Nayarit and then to Sinaloa. We pass a turning to the left, that goes through the irrigation module on the Right Bank of the river, and that would take us to Santiago Ixcuintla. But, let me return to the river that gave this town its name and that has been so very important for this region.

We encounter the Great River of Santiago (Rio Grande de Santiago) in the downstream section of the Lerma-Chapala-Santiago river basin (see Map 3). It is the longest river in Mexico and has one of the highest annual discharges, serving as the major collector of this important river basin. Under the name Lerma, it rises in the central highlands near Toluca and crosses El Bajio, which comprises several states, before entering Lake Chapala near the city of Guadalajara. The Santiago River is a very modest river when it departs from there and before it crosses the Sierra Madre Occidental, where it hugely increases in size. When the river abandons the western mountain range, it enters and runs through the coastal plains that are part of the river's delta. The river flows into the Pacific Ocean north of the harbour town of San Blas. During the rainy season from June to September, along its course through the mountains it grows into a large and mighty river. For centuries the river violently debouched into the plains to engorge everything within its reach and inundate large parts of the coast. This recurring annual pattern has intensely shaped the agro-ecology of the riverine landscape around Santiago, its human settlements, and the life of its population.

But men controlled the fancies of this river through infrastructure. During the 1970s, protective barriers were constructed on both sides of the river to restrict its impact and keep it to its course. In 1994, the prestigious hydroelectric dam of Aguamilpa was finished in the Sierra Alica. The Mexican president, Salinas, inaugurated one of the largest works completed during his sexenio (six year term of office). 
Map 3 The course of the Great River of Santiago in Nayarit

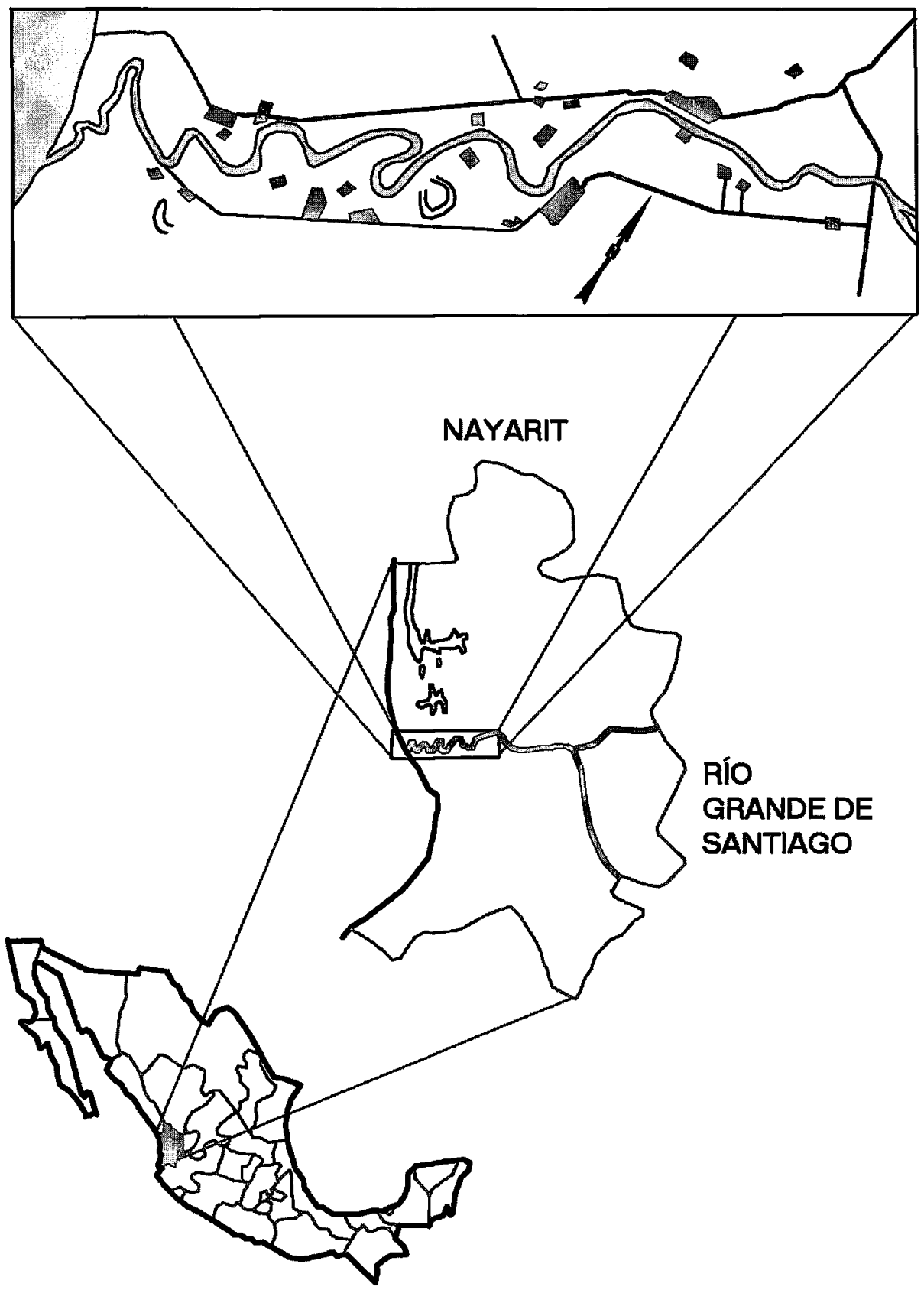

He was accompanied by the new governor of Nayarit, who had greatly benefited during his campaign as candidate for the Partido Reoolucionario Institucional (PRI: Institutional Revolutionary Party) from the widely publicised prospect of the completion of this huge 
dam that would produce electricity for several states. Both politicians proudly celebrated the fact that it was the third highest dam in Mexico with a curtain of 187 metres and the fourth dam in terms of installed capacity. The dam of San Rafael, situated lower down, regulates the outflow of Aguamilpa, maintains a stable outflow for the two irrigation modules that depend on it, and prevents major flooding in the coastal region.

Before flowing into the Pacific Ocean, the river meets a sub-tropical wetland ecosystem that it has helped to shape. It consists of marshes, lagoons and estuaries that are characterised by a tidal regime, brackish water and mangrove vegetation. The wetlands extend to the north along the coastline, where other rivers also feed it. They are home to a great variety of interesting wildlife and migratory birds. It is a region where many inhabitants live off a mixture of aquaculture (e.g. shrimp and oyster production), inshore fishing, agriculture, and, more recently, tourism. During the 1990s, international companies started large aquaculture projects here, threatening the fragile agro-ecological system. The irrigation and drainage canals on the left and right banks of the river interfere with this network of estuaries and natural drains. Some are presently used as collector drains, and this makes it impossible to establish whether drains are man-made or natural.

The continuously changing meanderings of this river over centuries, and the annually recurring floods, deposited thick layers of sediment on the riverbanks. This produced highly fertile sandy clay soils. These soils were suitable for an inundation agriculture that required neither artificial fertilisation nor irrigation. The older settlers remember the work required to open up the land to cultivation and remove the profuse jungle-like vegetation. But it was worth it. For example, tobacco was a crop that thrived in these soils saturated with river sediment. A seedling planted after the inundations resulted in a heavy dark tobacco plant easily towering above an adult man ${ }^{6}$. The growing of beans without irrigation or fertilisation was another productive and profitable affair. Although the floods have gradually been controlled, and the inundation agriculture has evolved into an irrigated agriculture, this past still affects current irrigation practices. Many subsistence farmers continue to grow beans without sufficient additional irrigation and chemical fertilisers. Because the soil does not benefit any longer from the residual moisture and fertilisation from the inundations, salinisation has become a problem, particularly in the tail-end of the irrigation system. As a result, bean yields have dropped significantly.

\section{The construction and organisational use of public infrastructure on the coast}

On this journey through the irrigation system, my focus rests on public works, the different networks of communication, hydraulic and productive infrastructure in the landscape. These products of decades of state intervention and market penetration have transformed the physical as well as the political landscape. The tour leads us through different agro-ecological zones and different forms of land tenure.

When we return to the international highway, a few kilometres before we branch off to the irrigation system, at a place called El Jicote, the highway, the railway, the river and the main irrigation canal come really close together, after which they each go their own way. The highway and railway continue north towards the United States, whereas both the river and the irrigation canal that has been diverted from it make a round curve 
towards the southwest and the ocean. We take the road that branches off and leads us through the Left Bank irrigation system and roughly runs parallel to the river on its way to the ocean.

Towards the river lies a sea of small tobacco fields. Close to the river you see the Burley variety, whilst further away Virginia dominates. In this fringe zone along the river, the tobacco cultivation is undertaken by small-scale ejidatarios (members of ejidos'). They mainly work for the major tobacco companies in the area: MODERNA and TADESA, which are subsidiaries of the two largest international tobacco consortia in the world.

During these productive months, the fields are crowded with tabaqueros (tobacco producers) doing and coordinating the work, gangs of labourers picking and packing the mature tobacco, and bomberos (pump operators) installing their sprinkler systems. In whatever direction you look, there are sprinkler pipes spraying water into the air to wet the soil and the plants beneath. When you approach a field that is being irrigated, you will see that the bombero has installed a pump close to a canal or a drain with its intake pipe in the water source. They carry and connect aluminium pipes with sprinklers into a long line, which they will move every few hours so that the whole field is covered. The pump delivers pressure to the long pipeline laid out in the field. This produces fountains at a regular distance and of a similar shape. When you look towards the burning sun through the mist of water drops that hang in the air, you see many small fragments of rainbows. This most visible flow of water symbolises the feverish activity produced by the labour intensive tobacco crop, as well as the intense flows of human, fossil, and mechanical energy that feed its production.

Near the village of Valle Lerma rises a large cluster of dozens of barns for flue-curing tobacco. Several such sites lie scattered throughout this tobacco region. The surrounding area is overgrown with weeds and the barns are left unused, falling into disrepair. During the 1970s and 1980s these sites were owned by the government parastatal, Tabamex. They used to be thriving places bustling with activity, where hundreds of workers received the Virginia tobacco, packed and unpacked the barns and cured the tobacco. Although they were mostly temporary workers, they had certain privileges and were organised under the government union, Confederación de Trabajadores de México (CTM: Confederation of Mexican Workers). For three decades this union in Nayarit was led by Don Emilio González, before he became governor from 1981 to 1987. The government-controlled clusters of barns were a political base for the CTM and its leader during electoral times that, not coincidentally, never overlapped with the tobacco season. The Tabamex workers, plus their pick-ups, printing and communication facilities and other state resources were commissioned and employed to support the official PRI candidate in his campaign (Pacheco, 1990).

Just before El Tizate, we pass the place where the main irrigation canal bifurcates into two secondary canals that cover the whole irrigation system. Near this point lies the area office of the Comision Nacional del Agua (CNA: National Water Commission) on an old government compound that looks nun down. A decade ago, there were still many technicians, extensionists, soil and climate specialists, laboratory personnel, and secretaries working here for different federal and state agricultural agencies in support of 
the countryside, but in these neo-liberal times of a retreating state such effort has been reduced to a minimum.

When the road diverges further from the river, we pass through the land of private producers. These fields look more deserted than the small and crowded ejido tobacco plots that we saw closer to the river. We look over large tracks of private property. Extensive green pastures with cattle and rice fields divided up by borders dominate the scene. These fields require large and constant water volumes, applied by means of surface irrigation rather than sprinkler irrigation. The smaller private producers irrigate, the larger ones employ an irrigator. They open the intake structure of the nearby canal and let the water flow into field ditches, after which it runs onto large tracks of pasture land or enters the compartmentalised rice field and infiltrates. A significant part of the land lies fallow, because of the low profitability of agriculture and a lack of investment funds on the part of producers.

The fragmented and varying pattern of land distribution that we see in the irrigation landscape is the visible outcome of a remarkable regional history of agrarian reform. At the beginning of the $20^{\text {th }}$ century, land in Nayarit was extremely concentrated in large landholdings (haciendas) that were owned in large part by an oligarchy of only a few, mostly foreign, trading firms and run by politically well-connected persons and families (Contreras Valdez, 2001). In the haciendas on the northern coast, cotton, tobacco, and cattle husbandry were important agricultural activities. But a lot of land also remained unexploited. These rural parts of the coast were scarcely populated. The existent population worked mostly as labourers or small-scale producers under the hacienda. Two decades after the Mexican Revolution, this agrarian structure was radically changed during a sweeping wave of land reform. Article 27 of the Mexican Constitution defined two important forms of land tenure: small private property (pequeña propiedad) and ejidos. Between 1935 and 1940, the majority of private land in Nayarit was expropriated and granted to newly formed ejidos. Some of the land became pequeña propiedad. The inflow of immigrants from nearby states accelerated the distribution of land and led to a rapid increase in the coastal population and the establishment of many new rural communities $^{8}$. As a result of this large-scale distribution of most of the land, Nayarit received the name of El Estado Ejido (The Ejido State) in Mexico.

In the decades that followed, this transformed into the following pattern of land distribution on the left bank: A small group of large pequeños propietarios (private land owners) owns large parcels of land, a large majority of ejidatarios only a few hectares, and some medium producers more than the average ejidatario, sometimes both ejido and private land. This pattern of land distribution is further complicated by the largescale leasing and selling of land. The latter was illegal but widely practised before the reform of article 27 of the constitution in 1992. At the end of the 1990s, the government programme to map ejido boundaries and provide the ejidatarios with land certificates (PROCEDE), which made these land transfers legally possible, was largely concluded. Despite what some people expected, this did not immediately result in the large-scale sale of ejido land and the disappearance of the ejido as an important rural institution.

We pass by another deserted cluster of barns, where the wild vegetation has taken over. In El Papalote we arrive at a central crossroads, where we can go in three directions and 
to where we shall return. For the moment, we turn left and go to the village of Sauta. Halfway there, we find an old rice-processing plant that is closed down and left to proliferating vegetation. This factory was originally run by its owners from Sinaloa, but it was bought in 1988 by a producers' association with support from the state government and loans from the bank. The first years of the association were very good. Around 4,000 hectares were planted with rice on the Left Bank, and the harvest was processed here. The large profits made it possible to repay the loans. In 1994, rice prices decreased due to cheap imports from abroad. The devastating effect that this had on the association revealed that it was being mismanaged. A loan to accommodate the substantial financial advances to producers could not be repaid, because many producers did not pay their debts. This meant bankruptcy for the factory. Today, the rice producers have to sell their produce to middlemen and purchasers from outside at much lower prices. Additional problems with proliferating weeds only further weakened the production of rice and caused a reduction in the hectarage cultivated in the region. Local politicians involved in the association attempted recently to counter this development by establishing a new rice producers' organisation and restoring the processing plant with assistance from the state government, but they failed. Rice producers mistrusted the new organisation and were unwilling to invest large sums of money in the repayment of the debt, because of the expectation that the factory would be politically managed again.

When we continue on passed the village of Sauta, we are already in another municipality, that of San Blas. This is an area characterised today by a landscape of smoothly undulating hills covered with fruit trees that produce various tropical fruits, such as mangos, bananas, and several local fruits. We arrive at what is currently an agricultural experimental station but was formerly the ranch of Gilberto Flores Muñoz, who was state governor from 1945 to 1951, and then Minister of Agriculture from 1952 until the 1958 elections. At this point he nearly became the presidential candidate for the PRI, but lost. This ended his role at national level, but his political dominance as the grand cacique of Nayarit lasted until the 1970s. Flores Muñoz ruled the state with absolute authority, repressing every possible form of dissent among the population. As governor, Flores Muñoz transformed Nayarit into the 'granary of the republic', boosting the cultivated agricultural area and the production of grains. It is most likely that this achievement contributed to his post as Minister of Agriculture and supported the construction of an irrigation system here in his home region, where he owned a ranch and large amounts of land. The construction of the canals started at the end of the 1940s. In his time, this political figure significantly transformed the region agriculturally, infrastructurally and politically, something that older engineers and ejidatarios can read from the landscape.

When we return to the crossroads and proceed, we arrive in the tobacco village, La Presa, situated on the bank of the Santiago River. The La Presa ejido cultivates more than 1,000 hectares of tobacco, the largest area in the whole country. This high quality ejido land is extremely fragmented, with a multitude of tobacco producers farming sometimes just one or two hectares (see Chapter 5). On the other bank of the river lies the municipal capital, Santiago Ixcuintla'. Santiago is the political, administrative and commercial centre of the municipality and has a population of around 20,000 inhabitants. People from around the valley visit Santiago for its government offices, businesses and shops, transport and health services, and entertainment. They come to the town for 'work, money and vice' (Fisher, 1953). As you approach the town, you can 
see it from a great distance, as it is built on a solitary hill that rises steeply out of the plain. This characteristic hill has houses built all over it and a church on its slope. For centuries the spot has served as a refuge to man when the river rose and flooded the town. For the Spanish conquistadors who arrived here in the $16^{\text {th }}$ century, this kind of hill was often a symbolic spot for a Catholic church in order to visually impose their reign and religion upon the resident Indian population. I am not sure whether this was the case here, but it triggers a lively imagination. The rainy season presents the following scenario: a darkening sky over Santiago unleashing continuous heavy rains and the solitary hill with its white edifice towering as a refuge above the inundated plain. For ages, the rainy season must have driven even the not-so-spiritually-inclined closer to God.

Nowadays, the view from the top of this hill over the landscape and infrastructure of the river reveals the current political and electoral condition of the region. We see the construction of two large infrastructural works, a concrete bridge over the River Santiago and an expansion of the Right Bank irrigation system. Nayarit is approaching the election year 1999, a time in which the federal state proves not to have retreated entirely. Before every governorship elections, a temporary recovery in investment from the federal government reinforces the electoral position of the official PRI candidate (Pacheco, 1990). These major infrastructural projects are part of a longstanding political practice to bind voters to the PRI through public works that materialise and symbolise the government's promise to develop the region. Further, several local and regional politicians circle around these works, like bees around a honey pot, making claims in the papers about the decisive role they have played in their final effectuation.

For many decades, a fragile and narrow palm-log bridge has connected the Left and the Right Bank of the municipality. In the rainy season, the river grows wild and devours the bridge, taking its remains to the ocean. Although a small ferry temporarily overcomes this problem for pedestrians and cyclists, motorised traffic has to make a thirty-kilometre detour via the international highway to get to the other side of the river. Only after the rainy season, when the water level has dropped, can the wooden bridge be rebuilt. This situation is an old source of discontent to many inhabitants of the municipality. For several decades, the construction of a permanent bridge has been discussed but has always been postponed, keeping the Left Bank separated from its municipal capital. In view of the PRI's precarious electoral situation, the plan recently re-surfaced and the federal government now finally intends to make it concrete.

Another extraordinary infrastructural project to which the landscape is subjected is the extension of the Right Bank irrigation system in an era when construction of irrigation infrastructure in Mexico has radically diminished in comparison to the preceding decades. The idea is to extend the canal system and expand the command area of the irrigation module on the Right Bank to a similar size as the Left Bank (officially designed to irrigate around 20,000 hectares). Hence, what we see from this hilltop are two severaldecades-old government plans that made no progress for so long but will now finally be harnessed because of the build up of political momentum. Both projects are perfectly timed and largely finished just before the elections, enabling president Zedillo to officially inaugurate them, something that enlarges their symbolic and electoral importance for the PRI. It seems no coincidence that these works are targeted at the 
municipality of Santiago where the left-wing opposition has always been strong and has proven to be capable of winning elections at the expense of the ruling party. This municipality will prove to be a strategic turning point for winning the governorship elections - all the more so when, at a later stage, it happens that both the official and the opposition candidate for governor come from Santiago Ixcuintla ${ }^{10}$.

After returning to the crossroads, we now turn right and drive towards Villa Hidalgo, formerly called El Nuevo (the new). It is the largest village on the Left Bank with around 12,000 inhabitants and has a commercial and administrative centre of regional importance, considerable residential areas, and four ejidos. The ejido called Villa Hidalgo is the largest irrigating ejido on the Left Bank. Together, these four ejidos possess more than 4,000 hectares, most of which is irrigable. On the ejido land spread out around the village, the peasants mainly produce beans, sorghum, tobacco, bananas, and tomatoes. The office of the Left Bank Water Users' Association is located in Villa Hidalgo.

We continue along the road and pass the municipal boundary, entering the municipality of San Blas. Here starts a newer section of the irrigation system, constructed during a rehabilitation of the irrigation infrastructure during the first half of the 1970s. We pass by Aután, a village and ejido that is famous for the political family of Gascón Mercado that comes from here. Their identification with the regional peasant movement against the monopoly of foreign tobacco companies laid the foundation for the nationalisation of the tobacco industry and the formation of the parastatal, Tabamex, at the beginning of the 1970s. Julian was governor for the PRI from 1963 to 1969, whilst his younger and more radical brother, Alejandro, was mayor of Tepic from 1972 to 1975 and won the governorship elections for the popular socialist party, PPS, in 1975. However, his victory was not conceded by the PRI. Whilst the Gascón brothers were in government they did a lot for Aután and the wider region in terms of public works, such as for example protection around the river to prevent flooding.

We arrive in Guadelupe Victoria, where we continue towards the tail-end of the irrigation system. Here, the soils start experiencing problems with salinisation, and this makes the production of tobacco unfeasible. As a result, there is more bean and tomato production in this area. The groups of women seen working in the field at harvest time are usually picking tomatoes. You can turn left and drive through the lagoons and estuaries towards San Blas. On the way, you pass along a recently constructed system of ponds for industrialised shrimp production for export. These are owned by international companies that received active support from shareholders at the highest political levels in the country.

The municipal capital of San Blas is an historic harbour town on the Pacific coast. Most of its inhabitants make a living from tourism, agriculture and/or fishing. The little harbour was a strategic point for the Spanish empire, as part of the Pacific route along which Franciscan friars explored the Californias (Baja California and California, USA). During the $19^{\text {th }}$ century, San Blas was one of the principal commercial and strategic harbours on the Pacific coast of Mexico, but it lost its importance when the American economy started to expand. Near San Blas, where the tail-water of the irrigation system flows via drains and estuaries or the river into the ocean, we end this tour. 


\section{The wet and the dry season}

The social life of a region manifests itself not only in space, but also through time. On the Northern Coast of Nayarit, a seasonal change in climate also influences the seasonal rhythms of economic life. In order to understand this, it is crucial to know that, in spite of a recession, agriculture remains the backbone of the coastal economy. Hence, the strong climatic contrast between the dry season (las secas) and the wet season (las lluvias) affects not only the calendar of irrigated agriculture, but also the tempo of economic circulation and the rhythm of cultural life. The seasons have brought into being a cycle of life and work that is central to the culture of the region. During the dry season, agricultural and other economic activities accelerate, whereas the rainy season generally shows a much slower pace of life. I will illustrate this by running through the production cycle of tobacco. Tobacco is the motor of economic life and the axis of work and political organisation in the region. The crop is planted between October and January and harvested between February and May. From June to October, the land is left to rest and recover in most cases.

Soon after the rainy season, the tobacco companies start to sow tobacco seed and raise the seedlings in nurseries. From October onwards, these are delivered to the producers who then plant them. The coastal economy then starts to roll, because the tobacco companies begin to advance production investments to the tobacco producers according to a calendar of works to finance their production activities. Agro-industrial companies, banks, and local middlemen also release their advances and loans for other promising crops around this time. This has a reinvigorating effect on the entire business and service industry in regional towns like Santiago and Villa Hidalgo.

Tobacco is a labour intensive crop that provides work for many inhabitants of Nayarit. For flue-cured tobacco, gangs of workers are temporarily employed in the harvesting and collecting of tobacco leaves, the filling and emptying of tobacco barns and the packing of the cured tobacco. Among them are women and men from the area, but also temporary immigrants. Since time immemorial, indigenous groups of Huichols and Coras have been employed in sun-curing tobacco. During the harvest season, they migrate with entire families from the mountains to the lowlands, where they live and work under adverse conditions at the tobacco plantations. They harvest mature tobacco leaves and thread them on long strings. The strings of harvested tobacco are hung on wooden racks and then covered, so that the leaves can dry in the hot wind. Although these indigenous tribes are very experienced at this work, they are paid very low wages. In addition, the tobacco producers employ pump operators to irrigate their tobacco with sprinklers (see Chapter 5) and truck drivers who transport the cured tobacco to the processing and storage plants in Tepic. Shopkeepers also profit from the growers' need for inputs. In short, this busy time of hard work and increased investments boosts the regional flows of sweat and money.

When the last leaves have been harvested and cured, tobacco production no longer provides work for the many producers, labourers, company employees, and other people economically dependent upon it. In May, the tobacco companies start to pay the tobacco producers for their produce and the entire cycle of work at one time. This payment leads to a collective release of energies. Many celebrate the end of the tobacco cycle in cantinas 
around the region, spending a lot of the tobacco profits on beer, food, and music. In addition, pay-time coincides with many regional festivities, such as rodeos, bailes (dances), and village fiestas, for example the annual festivities of Santiago Ixcuintla. At such festivities, visitors are struck by the unusually large quantities of beer flowing ${ }^{11}$.

The arrival of the rainy season announces a general slow-down of all human activity, somehow in contrast to the explosive natural force of the falling rains, the rising river and the rapidly growing vegetation. Agriculture in particular is affected because the wet season creates many problems with flooded fields, severe wind storms, plant diseases, fungi and weeds, that cause crop losses and lower productivity. Because of thriving weeds and winds even a crop like rice, which withstands and even benefits from the abundant rainfall, produces significantly less during the rainy season. Nevertheless, until a few years ago many small tobacco farmers rented out their land for a small amount of money to larger rice cultivators after harvesting the tobacco. However, because of the infestation with wild rice varieties that this caused, the decrease in the domestic rice price due to foreign imports (see Chapter 6), and the preference of the tobacco companies for a fallow period, this is no longer an alternative source of funds for these small producers. During the rainy season, a significantly smaller area is thus planted and irrigated than in the dry season.

Life and work assume a slower pace when the rain starts to fall and the river rises. The heavy rainfall, the extremely moist heat, the mosquitoes make it comprehensible that this is traditionally a period of rest, during which the intensity of most activities slows down significantly. Agriculture thus generates little income and spending at this time. The income from the last harvest has been largely spent, and therefore there is not enough to eat and drink in the poorer households. Additional activities like fishing become more important. Other small-scale farmers and land labourers migrate to the United States in order to bridge this period and earn extra money to be able to initiate the new agricultural cycle. Some of them go to southern tobacco-producing states like Virginia and the Carolinas, where they work as land labourers in the tobacco fields. Many others work in the rural or urban sector of California. Most of them return home when the next tobacco season is about to begin. What is striking about the pattern of migration that tobacco generates is thus that it consists of two flows of labour, one transregional between the mountains and the plains of Nayarit and the other trans-national between the Northern Coast and different parts of the USA.

At this time of year you find few people in the fields; most of them are close to their homes in the villages. The cantinas are much emptier than at pay-time. You see people in front of their houses, sitting on a chair, or dozing in a hammock. In the shade of a tree, a man is quietly knotting a fishing net, repairing a cart or seeking refreshment in a cool drink. Women sit outside their houses, sewing, whilst they discuss village affairs and the adventures of their family in El Norte (the US). The cultural tempo of life, the industriousness and circulation rate of all kinds of resources, seem to slip into a lower gear around this time of year on the Northern Coast of Nayarit. 


\subsection{Irrigated Agriculture}

\section{Irrigation infrastructure and technology, water availability and field conditions}

The Left Bank of the River Santiago is a run-of-the-river system (see Map 4). The construction of the Left Bank irrigation system was started at the end of the 1940s by the Ministry of Hydraulic Resources (SRH) ${ }^{12}$. Before that time, irrigation existed on a smaller scale on the haciendas. The new irrigation system that started operating in the early 1950s consisted of direct intakes from the river that let water into a system of earthen canals. These intakes needed frequent reconstruction. When the river was low in the dry season, it was also difficult to sufficiently feed the intakes and a lot of water was lost on the way to the field, so only part of the roughly 12,000 hectares was actually irrigated. At the beginning of the 1970s, the SRH rehabilitated, lined, and expanded the system to roughly 20,000 hectares of irrigable land. A concrete diversion weir (presa derivadora), called the Amado Nervo dam, constructed thirty-five kilometres upstream of Santiago, improved the situation. This enabled the construction of a main canal at a higher topographical level and thus the extension of the irrigation system. The headworks consist of an adjustable inlet structure that regulates the flow into the main canal.

Since the completion of the upstream Aguamilpa and San Rafael dams, the weir normally receives a constant discharge throughout the year that is more than sufficient for irrigation purposes. So, water availability is not a problem anymore for the Left Bank. Most of the river's water still continues on its way to the Pacific Ocean. Only an additional fraction is consumed by a pump station further downstream that provides water to the smaller Right Bank of the River Santiago irrigation system. The Right Bank of the Santiago River irrigates approximately 4,000 hectares annually ${ }^{13}$. This will increase significantly after the extension of the Right Bank system, but still not endanger the Left Bank. It is only at some future date, when the San Pedro module near Tuxpan and even modules in Sinaloa are connected as planned and benefit from the river's water, that this comfortable situation may change.

The canal principal (main canal) on the Left Bank has a maximum capacity of $25 \mathrm{~m}^{3} / \mathrm{s}$ and a total length of forty-nine kilometres. It bifurcates from the river on its western bank, but initially follows it in a northerly direction. Before the river turns west, the canal makes an even sharper turn in a southwesterly direction, opens up space and determines the dimensions for the irrigation system. In this curve of the main canal near the village of El Tizate, the principal lateral has its intake at exactly 17 kilometres and 369.64 metres from the inception of the head canal. This lateral is often called 'the 17' but, even more frequently, this lateral and the main canal are referred to as 'the main canals'. According to the hierarchy of the canals, this is incorrect, but in practical operation they do have a similar function. The total flow of the main canal is often exactly divided in two and these canals get half each. Subsequently, the 17 largely follows the course of the river until the tail-end reaches the village of Guadelupe Victoria. The main canal bends in a more southerly direction towards the village of Reforma Agraria. The two main canals enclose a V-shaped command area with their tail-ends at only a few kilometres distance from the Pacific Ocean. The irrigated area is girded on one side by the Santiago River and on the other by foothills extending from the Sierra Alica. Along the river, a narrow strip of land is registered as 'national territory' that does not officially belong to the irrigation district. 


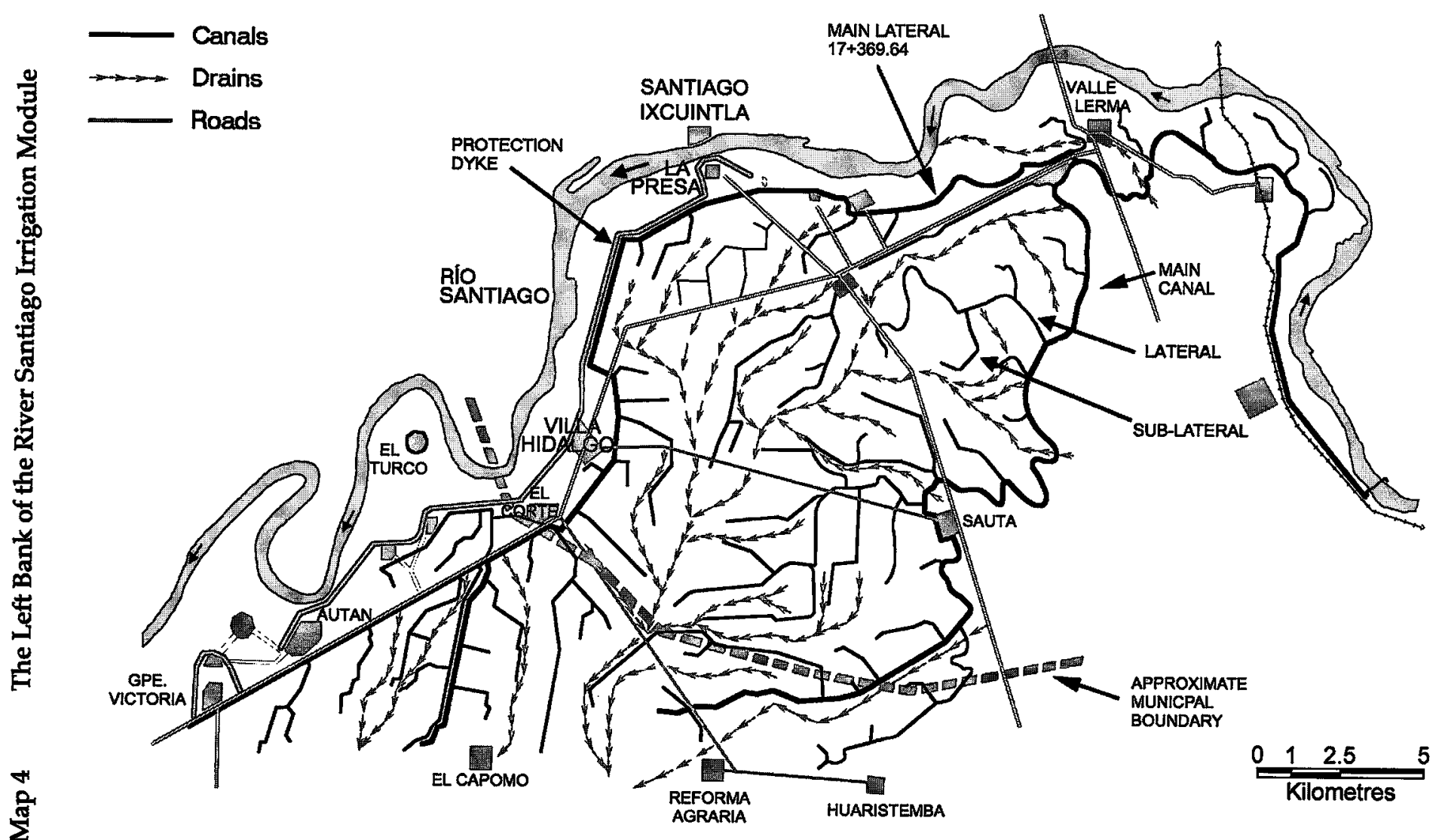


According to government documentation, the command area of the irrigation system is around 20,000 hectares, of which the main canal irrigates slightly more than half and the 17 slightly less. However, the area actually irrigated per year by the Left Bank system has been limited to 12,500 hectares on average during the last decade. The main canal delivers water to 257 kilometres of laterales (secondary canals). Via sub-laterales (tertiary canals), ramales (field canals), and in some cases even sub-ramales, the water arrives at the fields. The majority of these canals are lined. In the fields, water is conveyed in regaderas (furrows). Gated cross-regulators maintain the up-stream water level in the canals up to the sub-laterals and in some cases the field canals, in order to achieve sufficient 'head' for the intake structures and field inlets. Intake structures are manually operated undershot devices with a delizante (vertical plate) and an adjustable hand wheel. The gate opening under the plate can be adjusted by means of a screw thread that allows a large range of settings and flows. These structures are called the 'guillotinetype', by virtue of their sliding plate ${ }^{14}$.

Further, the Left Bank has 193 kilometres of drains. Many of the minor 'sub-drains' start at the end of a sub-lateral or field canal instead of at the field level. They come together in larger drains, which in turn discharge into collector drains. Several major collector drains carry a local name instead of a number, suggesting that they were already part of the familiar landscape before the introduction of bureaucratically numbered canals ${ }^{15}$. Nevertheless, it is often difficult to distinguish between man-made or natural drains, because they have different and often mixed origins and are in many cases rapidly overgrown with lush vegetation. Some parts are clearly dug by machines, whereas other parts existed before the construction of canals, as part of an historically eroded complex of streams that drained the flood plains and was connected with the estuaries near the coast.

Definitively the most striking feature of irrigation on the Northern Coast of Nayarit is the visible omnipresence of riego por asperción (overhead or sprinkler irrigation). Currently, it has become the most dominant field irrigation technology on the Northern Coast, applied to the economically important crops, such as tobacco, beans, chillies, tomatoes, and sorghum. On the Left Bank, around sixty per cent of the non-perennial crop area in the main irrigation season is irrigated with sprinklers, whilst only about forty per cent uses surface irrigation. Basin irrigation is applied to rice, both in the irrigation season and in the rainy season. Further, border and furrow irrigation are used in the cultivation of sorghum, maize, and vegetables. Although groundwater irrigation and trickle irrigation exist, they are not widely applied within the system, mainly because of the abundant water availability, the high rainfall, and high groundwater levels. This picture contrasts with the majority of Mexican medium and large-scale irrigation districts, which are usually dominated by surface irrigation, often with additional groundwater irrigation and occasional trickle irrigation.

The existent complex of irrigation infrastructure and field technologies situated in the landscape enables as well as constrains the everyday practice of irrigation. I will first sum up the enabling and then the constraining factors. The following two features allow a certain flexibility of use: 
First of all, an important feature of this type of irrigation system is that, like many others in Mexico, it does not have the systematic hierarchical order and rigidity that irrigation systems in, for example, the British design tradition possess. For instance, irrigated plots within the system receive water from all types of canals, including the main and lateral canals. The design logic and practice materialised in this infrastructure would be misunderstood by trying to establish either a well-defined hierarchy of canals or a clearcut and standardised definition of a tertiary block. In part, the network of canals is a response to particular topographical and landscape details of this coastal region. Van der Zaag points to the flexibility of this type of infrastructure which leaves farmers free in their crop choice and allows many variations in crops, plots, and water demand (van der Zaag, 1992). The large operational freedom it gives to canaleros (people in charge of distributing water at the field level) and farmers makes it difficult for the irrigation management to control the distribution of water centrally. At the same time, it demands more of a canalero's knowledge and competences (see the following two chapters).

Secondly, with a sprinkler installation it is possible to pump water from water sources that lie below field level. As a result, the gravity-based canal system is not the only way for a farmer to get access to water, and therefore the physical boundaries of the irrigation system are not so clear-cut. For example, the network of drains is an often underemphasised element in the complexity and flexibility of irrigation systems. Drains gain extra importance because they can also be used as a source of irrigation water. The tailwater from a canal that runs into a drain can be (re-)used outside the boundaries of the irrigation module. With a pump and a sprinkler system, people can also use the river, natural ponds and streams as water sources. In other places, the former main canal is still used both for drainage and the supply of water. This complex of water sources and the fluidity of physical boundaries greatly increase the complications for the irrigation management in their effort to control access to water and exclude free riders.

The following three constraining factors are associated with the dominance of sprinkler irrigation over the last decades. Because of this dominance, institutions and farmers were never really pushed to invest in the field canals, field drains, and land levelling that are required for surface irrigation. Today, this limits the possibilities for a farmer to freely choose crops or an irrigation method.

Firstly, a poorly developed system of field drainage causes huge problems with floods and water logging during and after the rainy season. The existing system is insufficient to carry off excess water from cultivated fields or maintain groundwater levels and therefore potentially causes crop losses. As a result, during the rainy season only a limited area is cultivated.

Secondly, most of the irrigated land was never levelled. The tropical coastal plains in which the irrigation canals and drains are nested generally have irregular contours, although without great differences in altitude. Government programmes for this purpose had very limited impact. Only a select group of private landholders had the means to invest in land levelling and field drainage. Both aforementioned complications of irrigation and drainage are generally greater towards the tail-end of the system, closer to the estuary system. 
Thirdly, although surface irrigation of crops like tobacco is technologically feasible and cost saving, as often demonstrated on a small scale, the existent social and material conditions of irrigating farmers will not easily allow sprinkler irrigation to be replaced. The disadvantage of sprinkler irrigation is that it is very expensive for small-scale tobacco producers, who have to hire the equipment. Meanwhile water is relatively cheap and abundant.

\section{Differentiation in crops and land}

The policy literature usually conceptualises water users as rather coherent and homogeneous groups of social actors with similar interests. Little attention is generally paid to differentiation among water users. However, on the Left Bank there is a wide variety of water users with different socio-economic, organisational, and political characteristics, who often have conflicting interests, for example, ejidatarios and private landholders; farmers of tobacco, rice, beans or sorghum; small, medium and large-scale cultivators; subsistence, commercial or export producers, etc. This variety will be explored below.

The main irrigation cycle, referred to as 'autumn-winter' or '1997-1998', corresponds with the dry season from October to June. The rainy season runs from June to September and has a less important irrigation cycle (spring-summer 1998). During the 1997-1998 irrigation season, a total of 12,873 hectares were cultivated, of which 8,698 hectares were irrigated in the Left Bank irrigation system. This area of 12,873 hectares consisted of 3,669 hectares of beans, 2,348 hectares of tobacco, 1,665 hectares of sorghum, 1,367 of maize, 966 hectares of rice, 723 hectares of vegetables (such as tomatoes, chillies, etc.) and 560 hectares of other crops (e.g. jicama, a local root crop). In addition, the two most important perennial crops are fruit trees with 926 hectares and pasture with 649 hectares. Figure 2 is a pie chart depiction of the percentage crop distribution in the 1997/98 irrigation season. In the 1998 rainy season, 1,980 hectares were cultivated, of which only rice at 1,778 hectares is of importance.

The Northern Coast of Nayarit is especially known in Mexico for the production of beans and tobacco. In particular, the black beans that are produced here are beloved in the centre of the country. Beans require few inputs, little labour and irrigation and are therefore widely cultivated, often by ejidatarios who produce a few hectares in addition to another crop, in many cases tobacco. Only a small portion of the beans sown (483 hectares) is reported as irrigated, because the crop requires few irrigation turns. It is difficult to verify whether farmers do not really irrigate. This explains the difference between the cultivated and irrigated area. In spite of the removal of the former government marketing board (CONASUPO), the trade in beans is extremely regulated by the state government under the pretext of plant health measures.

Because of its geographical isolation, the exit roads from the coast can be easily monitored to prevent individual farmers leaving the state with their produce and selling it to whomever they want. This is to the benefit of traders associated with state politicians who pay relatively low prices and are allowed to export to the states where there is high demand and proportional prices. 


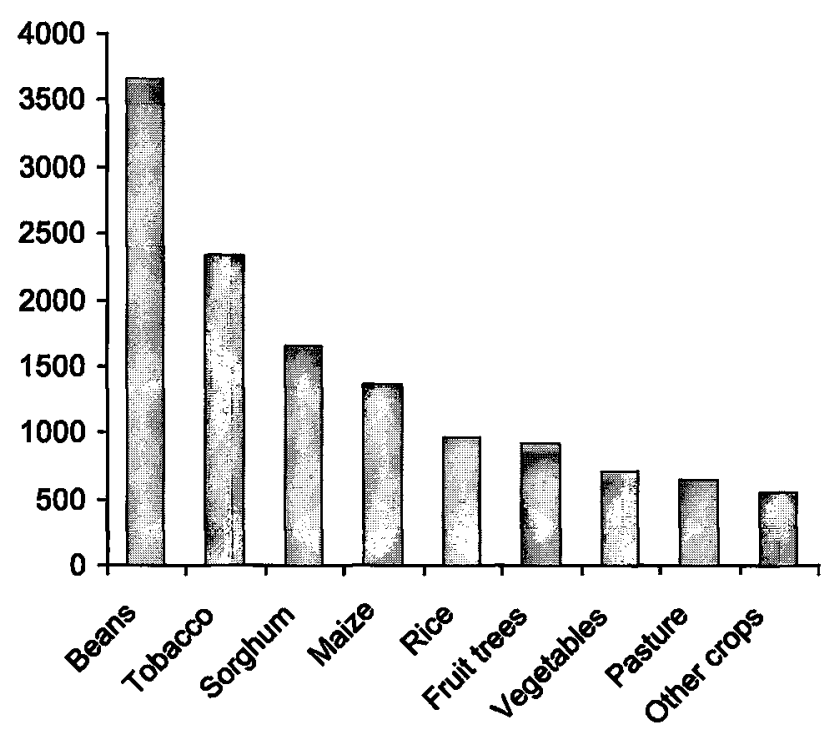

Figure 2 Crop distribution in the 1997/98 irrigation season

Source: Left Bank WUA, annual report (WUA, 1998)

In Mexico, around eighty per cent of the light tobacco used for cigarettes, Burley and Virginia, is produced in Nayarit. Tobacco is a highly labour intensive crop, requiring a specific irrigation, input, and technological regime. On the Left Bank, the vast majority of tobacco farmers are ejidatarios and small or medium-sized producers. Since the privatisation of the parastatal, Tabamex, multinational tobacco companies operate under contract agriculture. This is commercially unfavourable to the majority of tobacco producers, who have few options but to stay in production because of the basic livelihood that they secure by producing tobacco, the debts they have incurred, and the lack of other more profitable crops or local forms of employment. The new institutional set-up for tobacco exploitation is, however, profitable for the companies and the state government. The federal government also benefits through taxation. Both beans and tobacco are thus subsistence crops for most producers and simultaneously of political and economic importance to the state government.

A large proportion of the cereals, maize and sorghum, are also produced under a form of contract farming. Commercial seed companies pre-finance production investments to mostly medium-sized producers and provide them with hybrid seeds and a technological package. Rice and pasture are water-demanding crops that are mostly produced by medium and large-scale producers, among whom there are many private landholders. The production and export of fruits depends a lot on whether there are processing and packing plants available that comply with US customs standards. Individual producers of vegetables depend on highly variable markets, and therefore storing and trading houses from major cities or other agro-industrial firms from outside are usually involved. 
Hence, there is enormous variety in the type of crops produced by 'the water users' of the Left Bank irrigation system. The same kind of differentiation among water users occurs on the basis of landownership. As at 1998, the distribution of land among the officially registered water users of the irrigation module is as follows. Of roughly 20,000 irrigable hectares, three quarters is owned by ejidatarios and only a quarter by private landholders. Around 3,500 ejidatarios own on average 4 hectares, whilst about 200 private landowners have on average 22 hectares each ${ }^{16}$.

This brings me to three reasons why I use the policy abstraction 'water user' with great caution. In the first place, this enormous differentiation among the water users from the Left Bank cautions me not to use this term undifferentiatedly. Throughout the thesis I therefore alternate between different terms, such as ejidatario, tobacco producer, rice farmer, or irrigator depending on the context. In the second place, in the field it is often not so clear at all who should be considered as the water user. Many landowners, who are officially registered as water users, rent out their land to other producers ${ }^{17}$. In addition, the people that actually irrigate the land are frequently not the owners of the crop. Instead, irrigators and pump operators are hired as skilled labourers to do this work. Hence, the person actually using water in the field is often neither the person who has to pay the irrigation fee nor the registered water user. Thirdly, farmers seldom identify themselves as water users outside the domain of the WUA ${ }^{18}$. Hence, it is premature to assume that the policy abstraction water user has become widely accepted and internalised by the target population, let alone that it regulates individual behaviour and the practice of water distribution and fee payment.

Throughout the rest of this thesis I do not pay attention to class formation among irrigating farmers on the Left Bank and their different lifeworlds, livelihoods and identities. This is not because it is not important, but because it is not the principal topic of this study. The topic is the management practice of the irrigation system by a WUA.

\subsection{The Irrigation System in a Wider Perspective}

\section{The WUA and its overlapping domains}

The Left Bank irrigation module is a hydraulic irrigation unit with a command area of approximately 20,000 hectares. The WUA that was established here comprises twentyfour ejidos. The WUA's highest organ is the assembly of delegates, which is formed through indirect elections. The assembly consists of twenty-five delegates: one delegate for each ejido and one to represent the private landholders, chosen by the constituencies in their respective assemblies. The assembly elects a board of directors and a control committee for a period of three years. The former consists of a president, a secretary, and a treasurer and is responsible for the daily management. The latter exercises control over them.

In spite of what conventional organisational models often presume, the WUA is not an isolated organisational entity with clearly delimited boundaries and responsibilities (Reed, 1992), but overlaps with several other administrative and political domains. This has crucial political consequences that influence the management of irrigated agriculture. 
Often, several organisations are intermingled, and a partial or total coincidence of leaders and membership exists. During meetings, issues are treated and decisions taken that involve other organisations. The complexity increases when more organisations are interlinked. This means that the organisations depend more on personalised relations and the face-to-face negotiations of their leaders (González, 1998). Below I will discuss two other types of boundaries with which the irrigation module intersects, namely municipal and electoral boundaries.

Firstly, the irrigation system lies in three different municipalities that carry the name of their capital: Tepic, Santiago Ixcuintla and San Blas (see Map 5). Only a small fragment in the top belongs to Tepic, a more significant part in the tail-end to San Blas, and the largest and most important upper and central part of the module to Santiago Ixcuintla. Other organisations often follow these municipal lines. For example, like all other PRIaffiliated organisations, the Confederación Nacional de Campesinos (CNC: National Peasant Confederation), has a representation in every municipality, the municipal peasant committee (CMC). The ejidos are organised under the CMC. For the Left Bank irrigation module this means that a majority of fourteen ejidos fall under the CMC in Santiago, a minority of nine ejidos fall under San Blas, and only one falls under Tepic. This is also reflected in the proportional division of the WUA's Assembly of Delegates, consisting of one delegate from every ejido, complemented by one for the private producers. Hence, the imbalance in favour of the Santiago delegates strongly affects the management of the Left Bank module.

Secondly, to make it more complicated, there are also electoral districts to take into account. Nayarit has twenty municipalities and eighteen local electoral districts. Every district elects a local deputy (MP) to represent it in the state congress. The large municipality of Santiago consists of three electoral districts, of which district XII in the southeast of the municipality covers the upper and central part of the Left Bank module. District IX of San Blas covers the tail-end of the irrigation module mentioned earlier. The resultant division of the irrigation module into two political constituencies with different delegates deeply affects the management of the irrigation system, as we shall see in Chapters 7 and 8.

González describes how leaders use producer organisations as platforms to expand and maintain a network of institutional relations, control over different organisations, and access to new projects and resources. These rural leaders try to maintain their own position or to impose one of their own people. Some of the leaders, who start out as ejido commissioners, cultivate and extend their political and institutional networks of relations and compete for posts in other organisations. For others, the producer organisation forms the basis for founding new organisations often with the same leadership (González, 1998).

The related phenomenon of intermediation is also a dominant theme in Mexican rural studies. Because rural leaders have posts in various local organisations and develop personal networks, they become obligatory intermediaries for access to strategic resources of both private and public institutions. They develop a network of institutional relations between government and local institutions and acquire privileged access to 
government projects and resources. This dependence of producer groups on this relation with the leader nourishes clientelism.

Map 5 Municipalities in Nayarit

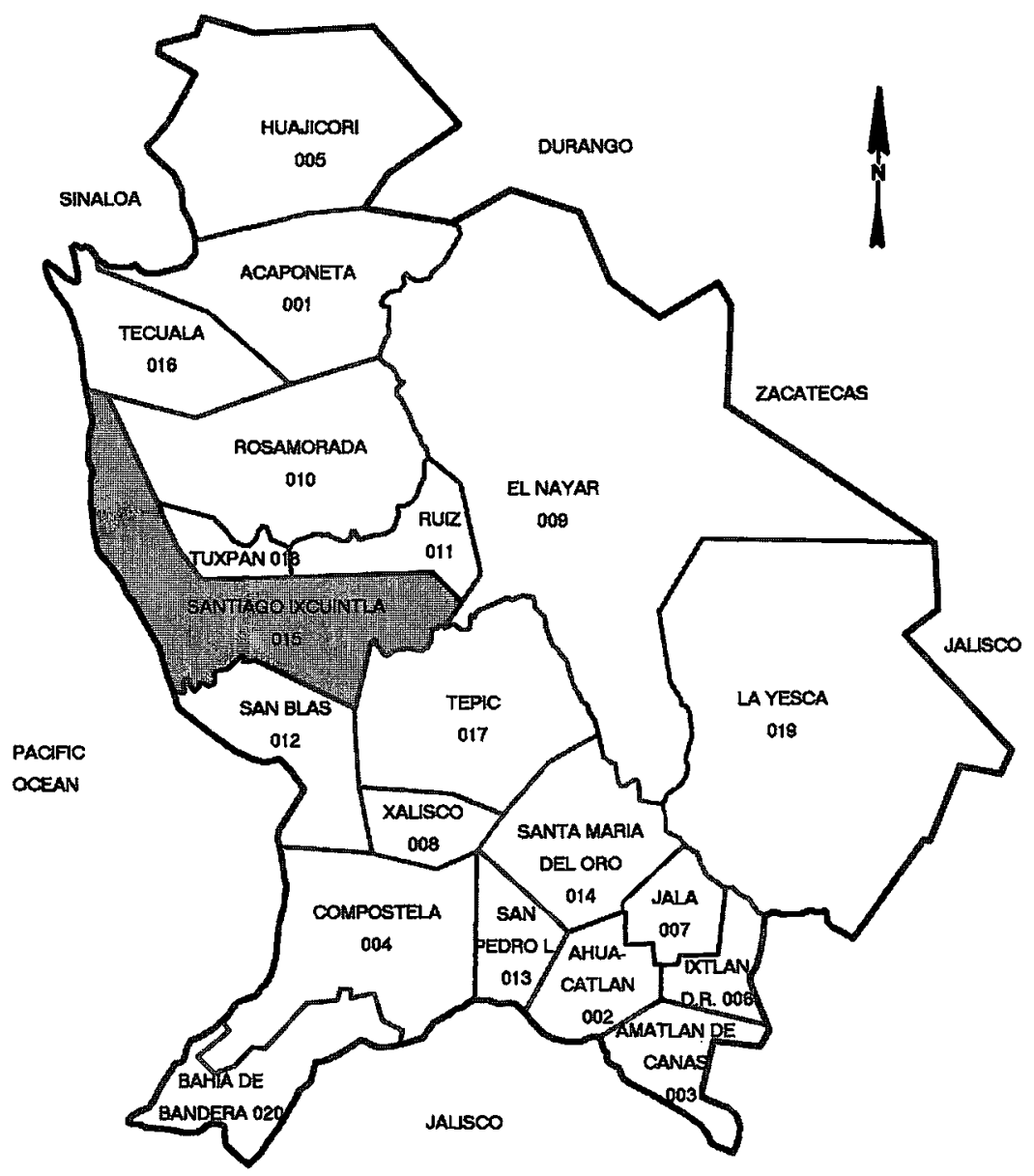




\section{The contemporary history of transfer}

Nayarit has one irrigation district, called The State of Nayarit (043) ${ }^{19}$. To it pertain four major irrigation units: the Left and the Right Bank of the River Santiago, the Right Bank of the River San Pedro and Valle de Banderas and several smaller irrigation units. All of these lie scattered throughout Nayarit. Before the transfer, the highest organ of the district was the Directive Committee, which was presided over by the governor of Nayarit, and consisted further of several government officials and representatives of the ejido sector and the private producers from every irrigation unit. Officially, the Directive Committee decided the annual irrigation and cropping plans and the level of irrigation fees, but in practice decisions were prepared by the Ministry of Agriculture and Water Resources' (SARH) District Head in coordination with regional political and economic elites and then approved by the committee and superior SARH levels (Kloezen, 2002; van der Zaag, 1992).

At the beginning of the 1990s, the CNA started to implement the federal policy of transfer in the irrigation district. Federal CNA officials from the Directorate of Irrigation Districts (DID) arrived in Santiago to initiate talks about it. The user representatives that participated in these discussions were initially very hesitant about the transfer. As in many other irrigation districts, a major objection was the poor condition of the irrigation infrastructure that they would manage. Further, they feared the responsibility of taking over the irrigation system. In the years that followed, the DID in coordination with the district overcame this initial resistance. On the Left Bank, the following elements played a central role in achieving this and simultaneously determined the course of the local transfer process that will be reported below: federal government pressures and incentives, the CNA district officials who selected two local leaders according to their political constituencies, and disputed control over maintenance machines. These elements reflect the more general strategy of the DID as recounted in Chapter 3, but also provide a local background against which to understand the following chapters.

One of the aforementioned local leaders, Antonio Caminante, appeared on the scene as far back as the beginning of the 1970s, when he became involved as an ejido president in the promotion of the 'canalisation' of the San Blas area. Before that, the canals only covered the Santiago area and did not reach the San Blas municipality. The SRH extended the existing infrastructure into San Blas during a major rehabilitation programme. Around 1974, the canal Guadelupe Victoria was put into use, and the land of many ejidatarios was serviced with irrigation (see Map 4). After that, Caminante was asked to become regional representative for the peasants from the Left Bank in the SARH District. His personal relation at the time was with the District Head of Operation, Becerra, who much later became the CNA District Head.

The maintenance of the infrastructure became a recurring concern for Caminante, as the SARH functioned poorly in this respect. Little of the federal maintenance budget was actually allocated in the field. In addition, the SARH had only three old maintenance machines at its disposal: a dragline, a loader, and a truck. Brigades of slashers carried out the rest of the work. Their joint impact was insufficient. As a result, most of the canals and drains at the tail-end of the system became rapidly overgrown and silted up, as the 
vegetation grew very fast and the river still carried a lot of sediment. The state of the canals and outlet structures worsened.

When the talks about the transfer started, Caminante seized the opportunity to request a machine from the DID Head, arguing that they had insufficient maintenance capacity. He was successful, and in 1990 the district received a new Caterpillar tractor. This coincided with the formation of the patronatos de apoyo (assistant managing boards) ${ }^{20}$, an initial step towards the transfer. The District Head decided that San Blas and Santiago were to have separate irrigation modules with organisations called patronatos that would have their own staff for water distribution and fee collection in their module. The irrigation fees were increased with the objective that the CNA and patronatos would both finance about half of the managerial expenses. Control over the maintenance machines remained with the district.

The CNA district selected two local leaders to represent the water users in Santiago and San Blas. Caminante became president of the patronato of San Blas, and the District Representative for the private producers, a young lawyer, Gonzálo Pérez, from a politically connected family of Villa Hidalgo, became president for the upper Santiago part of the system. The following selection criteria seem to have counted: both represented a section of the producers in their constituency and had a network of political and bureaucratic contacts in the govemment. Both also had pre-existing and personal relations with CNA district officials. Their experience as leaders and representatives in the CNA was also important, as other user representatives initially feared the responsibility of these managerial positions.

From 1990 to 1993, the patronatos functioned separately, but not to the satisfaction of the CNA and the patronatos. Caminante claims that in San Blas they completely depended on Villa Hidalgo for receiving water and getting the machines. This meant that the machines hardly ever reached the San Blas tail-end region and thus led to a neglect of maintenance. Meanwhile, the pressure from the DID in Mexico to complete the legal process of transfer increased. It was decided that, in order to reduce costs, conflicts, and complications, it was more convenient to fuse the two modules into one for the official transfer. In 1992, Valle de Banderas became the first module to be transferred.

In the Assembly of Delegates of the newly merged WUA, the nine ejido delegates from San Blas were a minority against the delegates from Santiago. Caminante was excluded from elections, because he did not qualify for a position. He was not included in the users' register (padron de usuarios), as he did not own land in the irrigation district. Consequently, it was easy for Pérez to win the elections for the presidency and select his own board of directors. In September 1993, the Left Bank was officially transferred, and around this time the WUA received a new motor grader and a hydraulic excavator from the CNA. Pérez subsequently did not keep to the informal agreement made with Caminante that the president from Santiago would be replaced after two years by one from San Blas.

In retrospect, the negotiation of maintenance machines was central to the transfer and counted as legitimation for both patronato presidents' role in the process. Just like Caminante, Pérez claimed to have negotiated for two machines with the head of the DID 
and considered this as a personal trophy that illustrated his leadership qualities ${ }^{21}$. The machines thus played an important role as catalyst or incentive in farmer leaders' acceptance of the transfer ${ }^{2}$. Chapter 7 will show the political importance for local leaders to control machines - an importance that will further clarify their interest in these resources.

Further, the last element in the CNA strategy to overcome the initial resistance to transfer was that CNA officials promised the WUA to rehabilitate the irrigation infrastructure after the transfer. Perhaps unsurprisingly, this rehabilitation never took place, a problem with which the WUA is still confronted today ${ }^{23}$. But what this promise did do was increase the momentum of the transfer.

In sum, the historical account of the transfer offered above confirms the idea, also raised in Chapter 3, that the transfer was effected under a combination of federal government pressure, the role of district engineers to identify and include well-disposed rural leaders (and exclude others) as the user representatives in the process, the selective allocation of government resources (e.g. machines) to these leaders and the WUAs as incentives to continue with the transfer, and the unfulfilled promise of rehabilitation. What will become clear in the following chapters is that the disputes between the San Blas and Santiago areas regarding the dominance of the latter's leadership, and control over crucial resources such as the machines, continued to play a role in the management of the WUA.

\section{A local political group in formation: Presenting the cast of actors}

Pérez is a local lawyer from Villa Hidalgo with political relations at the state level. During his youth through his politically active mother, Pérez had frequently interacted with important political figures in the state. Nayarit's political patriarch, Don Emilio, and Felix Torres, current mayor of Tepic, adopted him as a protégé. Through a typical mixture of political, family, and business relations that overflowed into his activities in the student union at the university, Pérez received a kind of implicit political training from these patrons. His younger brother started out as a bodyguard and later became one of Don Emilio's private secretaries. On this basis he developed activities in ACASPEN, a transport union for taxi and truck drivers that controlled access to working permits. Both Don Emilio and Felix Torres own land and villas in the region and are involved in commercial activities and trade of all sorts. Pérez oversees part of their properties and commercial activities.

Don Emilio became governor of Nayarit from 1981 to 1987, after decades of prominent political positions in the government union, CTM, and the dominant political PRI at the regional and federal level. Pérez rapidly built up significant wealth in the transport and trade of unmentionable goods from the eastern mountains of Nayarit via the Pacific Ocean to further destinations. From 1988 to 1993, Don Emilio was president of the Senate and maintained close relations with President Salinas. From this position he retained influence over politics in Nayarit and supported his allies and protégés. There is no evidence that he directly influenced Pérez' election as president of the patronato and later the WUA, but it is clear that it did Pérez no harm and benefited him in keeping abreast of the latest developments in the CNA and the transfer policy at the federal level. 
Whilst he established himself as president of the irrigation system, Pérez significantly expanded his area under production, partly owned and otherwise hired around the irrigation system. He invested his earnings in the large-scale cultivation of rice, a lucrative and booming crop around that time. He developed good relations with the CNA District Head by producing and investing in rice with him. This friendship facilitated Pérez' control over the WUA and its maintenance machinery.

In the patronato, he invited his old school friend, Nuñez, to return to their native village, Villa Hidalgo, to work with him as secretary. Until that time Nuñez, who lacked a professional degree, had a casual career working in different trades. He owned a plot of a few hectares in the ejido of Solorceño, which he did not cultivate but rented out and later even sold. This means that he needed to live off the political positions that he acquired. Pérez supported him financially and politically in acquiring the position of president of the ejido based in Villa Hidalgo. As president of the WUA, Pérez appointed another schoolmate and close associate, Guttiérez. He was called from a job up north as agronomist in Fertimex, a parastatal providing the rural areas with fertilisers, which was about to be privatised in those days. Pérez nurtured the leadership qualities of his protégés through the WUA. Further, several of the board members together with Pérez were involved in the management of the local rice-processing factory discussed earlier. As to the rest, this group largely filled the vacancies in the staff with people related through friendship, family, compadrazgo (ritual co-parenthood) or patronazgo (patronage). This facilitated the internal control of the WUA.

Hence, Perrez formed with others a local political sub-group ${ }^{24}$ whose self-proclaimed constituency is the Left Bank of the municipality of Santiago with Villa Hidalgo as its centre. This group in formation ${ }^{25}$ established a web of relations with, and positions in, local organisations in the area, such as the preparatory college $e^{26}$, several ejidos around Villa Hidalgo, the church, the union division of ACASPEN, the nearby rice-processing plant and the local PRI office. Through these multiple organisations, the group developed a loose clientele network and a support base on the Left Bank and extended its relations in the state government. Further, the group developed a network of political, commercial and friendship relations with several large farmers and ejido commissioners within the irrigation district. These favoured farmers mainly produce rice, sorghum, or pasture for cattle husbandry, like Pérez himself. Good relations with the ejido presidents and popular leaders in the ejidos of the Left Bank are important for the group. These leaders have significant influence over the rural population in elections and generally elect close associates as their representatives on government bodies and in organisations such as the WUA. This is one way in which the group also keeps control over who sits on the Assembly of Delegates of the WUA.

In 1993, the governorship elections caused serious political consternation in the region. After the privatisation of the tobacco parastatal Tabamex in 1991, the agronomistbusinessman-politician Lopéz Tirado opportunely organised a popular movement of rural producers on the Northern Coast that mobilised popular discontent about agricultural decline. Among other things, they protested against the poor compensation payments to producers and workers, who were officially shareholders of Tabamex. This movement became the base from which he attempted to reach the governorship for the centre-left party, Partido de la Reoolución Democrática (PRD: Democratic Revolution 
Party). Throughout the state, intense political unrest surrounded these elections. In the end, despite public protest, the authorities only acknowledged the PRD to have won district XII on the Left Bank of the Santiago River. The local PRI in district XII remained in shock and deeply divided after losing the district to a follower of Lopéz Tirado. Pérez and his group demonstrated their political pragmatism by locally supporting the opposition, because the PRI candidate was from an antagonistic group in Villa Hidalgo. In the following three years, Pérez' group reorganised the local PRI and united the remaining groups under their leadership. They appointed new PRI section heads in the district, among whom several of the canaleros of the WUA in order to control the district politically.

As a point of interest in the relation between irrigation and politics, it is important to note how Pérez' political group defines its political constituency. The Left Bank effectively encompasses the irrigation system as it was before its expansion into the San Blas municipality during the early 1970s. This spatial definition thus excludes the expansion zone at the tail-end of the irrigation module and a small fraction that belongs to the municipality of Tepic. It is also interesting that the Left Bank as a territorial space probably received its name after the construction of the irrigation system in the 1940s. The introduction of irrigation thus determined both the name and the boundaries of a geographical space that also became a political constituency to some.

In 1996, another leader of this political group, a doctor Hijar Juárez from a locally respected family, who is also identified with Felix Torres, was launched as PRI candidate for mayor in Santiago. He suffered a clear defeat that generated enormous discontent in the group. They realised that they had limited possibilities of winning municipal elections. In response, they publicly promoted the idea of the Left Bank as an independent municipality and thus an electoral constituency with Villa Hidalgo as capital. There is no doubt that they would have an excellent candidate for mayor. Although the group was not successful at that time, the idea remained alive amongst them and kept recurring as a political claim during subsequent elections.

The use of this spatial and political denomination is thus specifically used by this group to distinguish themselves from the Right Bank, the municipal capital of Santiago, and San Blas, and particularly from the competing political groups belonging to those places. It is also a way of positioning themselves vis-à-vis the state government and acquiring popular support among the population as the legitimate leadership of the Left Bank. The group consistently cultivates a separate identity for people from the Left Bank. They claim that its population, producers, and other interest groups are misunderstood and not represented by politicians from the other side of the river. Politicians who have their popular base on the right side of the river are not at all preoccupied with establishing their difference in relation to people from the other side of the river. In fact, people hardly ever identify themselves as originating from the Right Bank. Hence, this politics of identity and belonging reflects a political ambition and a strategy with clear inclusionary as well as exclusionary effects. In the coming chapters I shall show how this also affected irrigation management.

Because of internal struggles, ruptures and division in the $\mathrm{PRD}$, the left-wing opposition arrived weakened at the 1996 local elections. With the assistance of his political patron, 
Felix Torres, Pérez became the only serious candidate as regional deputy for district XII on the Left Bank and won. Pérez declared in the local press: 'We won, because we united all the forces, we smoothed conflicts and we worked on the basis of our principles and platforms ${ }^{27}$. Within the PRI, Pérez gained considerable prestige by 'rescuing the district' from the opposition. On termination of Pérez' three-year term as WUA president in 1996, the San Blas delegates proposed one of their number as the new president. This man also gained support in the Santiago municipality and threatened to win the elections. Yet, at a pleasant breakfast meeting before the elections, Pérez bought the votes of several delegates for his protégé and secured the victory for Nuñez.

\subsection{Conclusion}

In this chapter, we have passed several infrastructural works that materialised successive phases of federal government intervention and agro-industrial capital penetration and affected the organisation of irrigated agriculture. Without going into too much historical depth, this tour reveals that local and regional politics played a major role throughout the construction, organised use, and demise of these public works and that this again benefited or backfired on the actual politics in the area. This provides the background against which to study a new wave of restructuration policies that flooded the countryside from the end of the 1980s. The Left Bank irrigation system appears to be an interesting area to analyse the impact of this range of new policies. Such a study enables us to view exactly how these policies transformed this agricultural region from one that was marked by a particularly high level of government intervention, through policies that favoured rural development and agricultural modemisation since the early $1970 \mathrm{~s}$, to one with a lower degree of such interference. The gradual retreat of the federal state has opened up a number of organisational spaces in which newly organised groups and private interests get to manage infrastructure and resources of a public nature. Whether this new management regime has the liberating effect predicted by neo-liberal theory is the broader question that motivates this study and the choice of this region.

\section{Notes}

1 From now I will name the organisation the 'association', as local people refer to it, or the 'WUA' as policy makers and experts call it.

A person of mixed racial ancestry (especially mixed European and Native American ancestry). Some sixty per cent of the Mexican population is mestizo, with thirty per cent being Indian and some nine per cent of European descent.

${ }^{3}$ For a geographical description of other regions of Nayarit see Appendix 5. The coast as a transition region has a most interesting cultural mix of norteño (Northern Mexico), ranchero, Indian and even African influences connected with the diverse cultural and geographical origins of its population.

This basin is not merely a natural phenomenon, but is simultaneously constructed through a range of bureaucratic and research institutions, among which the CNA basin level organisation that incorporates all of the states in the basin.

${ }_{3}$ Aguamilpa was planned as one of the final pieces of a large interconnected system of dams to irrigate to the arid Northwest (SHINO). See Chapter 2. Although the World Bank refused to finance this plan, it did partially finance one of its masterpieces.

6 See also Gascón-Mercado (1988).

' Land reform communities created after the Mexican Revolution of 1910. Ejido land belongs to the state, with a combination of community (ejido) and private (ejidatario) usufruct, and since the amendment of Article 27 of the Constitution in 1992 ejidatarios can sell their land. The other category of 
landowners in Mexico is called pequeños propietarios: private farmers with a limit on land ownership of 100 ha.

s This occurred through the emergence of a young, radical, local political group that favoured land reform and was willing to attack the interests of the large landowners. This led to the decline of the political and institutional control that these powerful families had in Nayarit. The group had support from the Mexican president Cardenas (1934-1940), who became known as the president who gave the land to the ejidatarios (Contreras Valdez, 2001).

The name of Santiago Ixcuintla combines its Spanish and indigenous origins: Ixcuintla can be translated from Náhuatl as 'place of dogs', after a special type of hairless dog that the Huichol Indians keep in the mountainous region where they live. The name is usually shortened to Santiago.

${ }_{10}$ Lucas Vallarta for the PRI and Antonio Echeverría for the alliance of opposition parties PAN (Partido de Acción Nacional), PRD (Partido de Revolución Democrática), PT (Partido de Trabajo), etc.

"A representative of a large beer company, called MODERNA, once told me that besides some parts of Sinaloa, this area has in fact the highest consumption per capita of the whole Republic.

${ }_{12}$ SRH documents and other literature mention different dates, from 1946 to 1949, as starting dates.

13 New extensions, which are promised to irrigate about 20,000 hectares, will consume much more of the river's waters.

${ }_{14}$ Some of the data above were derived from the following sources: (CNA, 1992; Juarez Guitron, 1991; Nava Salcedo, 1997; SARH, 1985; SRH, 1948; SRH, 1971; SRH, n.d.).

${ }_{15}$ Relación de Drenes, Distrito de Riego no. 043 (Report), CNA, Subdirección General de Infrastructura Hidroagricola, Gerencia de Distritos de Riego, 1993.

16 Based on data from the Segundo Informe de Actividades, Asociacion de Usuarios de la Unidad de Riego de la Margen Izquierda del Río Santiago, A.C., Modulo 2, 1997-1998.

17 The padron de usuarios is the list of registered users compiled by the CNA and included in the Concession Title.

${ }_{18}$ On different occasions, farmers define themselves in various ways, but almost never as usuarios, which is the term that the policy literature and WUAs generally use for them. The following anecdote illustrates this point. I was talking to a small tobacco producer on his plot that lay near to a canal. I could see that it had been recently irrigated by some pump operator with a sprinkler installation. I asked him what a usuario needed to do in order to irrigate. To me this was a most obvious question. He returned my question by asking 'iusuario de que?' (user of what?). Without knowing it, he had drawn my attention to the fact that he was much more than just a user of water and that this concept therefore did not necessarily determine his behaviour. The interaction of many small-scale farmers with the WUA and its policy discourse is fairly limited; so is their knowledge of how the WUA exactly functions and what is the distinction with the CNA district.

19 Since 1985, it has been part of the Rural Development District of the SARH (see also Chapter 3).

20 Mexican legal entity: board, trust, council.

n Pérez' information on this, however, appears inconsistent.

2 CNA officials claim that the new machines that were bought and transferred to the boards of newly established associations were never a means of convincing local farmer leaders to accept the transfer (interview ex-CNA official, 09-02-2002). However, the dates of these transfers and the impressions of many local leaders in irrigation systems around Jalisco, Michoacán, Guerrero, Colima and Nayarit suggest the opposite (see also Kloezen, 2000: 83; World Bank, 2001: 7).

${ }^{23}$ Ex-officials of the DID explicitly deny that this promise was ever made to convince the users to accept the transfer. However, in different districts of Mexico, WUA leaders keep re-invoking this promise that was made to them. It remains a point of controversy between them and the CNA.

${ }_{24}$ Using Hernández Rodríquez' definition, I consider the local political group from Villa Hidalgo on which I focus to consist of Pérez, Nuñez, Guttiérez, and several field workers who are all based in the association, together with the young brother of Pérez and Hijar Juárez, a local doctor, who are based in other local institutions. This local sub-group is again part of a larger political group that played a major role in Nayarit politics (Hernández Rodríquez, 1997),

${ }_{25}$ I am presenting a rather mechanical picture of the development and coherence of a political group, for the sake of the argument. The hierarchy and coherence of such a group are fluctuating variables, depending on various factors. Its members can be involved in different groups and have contradictory interests to the leadership. Also, the leadership can change in relation to the positions that they occupy in political or other organisations. 
118 The Success of a Policy Model

${ }_{20}$ Preparatoria is a sort of tertiary college after secondary education, preparing students for the university. These local colleges are part of the university based in the capital, Tepic.

27 Realidades de Nayarit (local newspaper), 9 July 1996. 'Villa Hidalgo: PRI recupera sin problema el XII Distrito Federal'. 


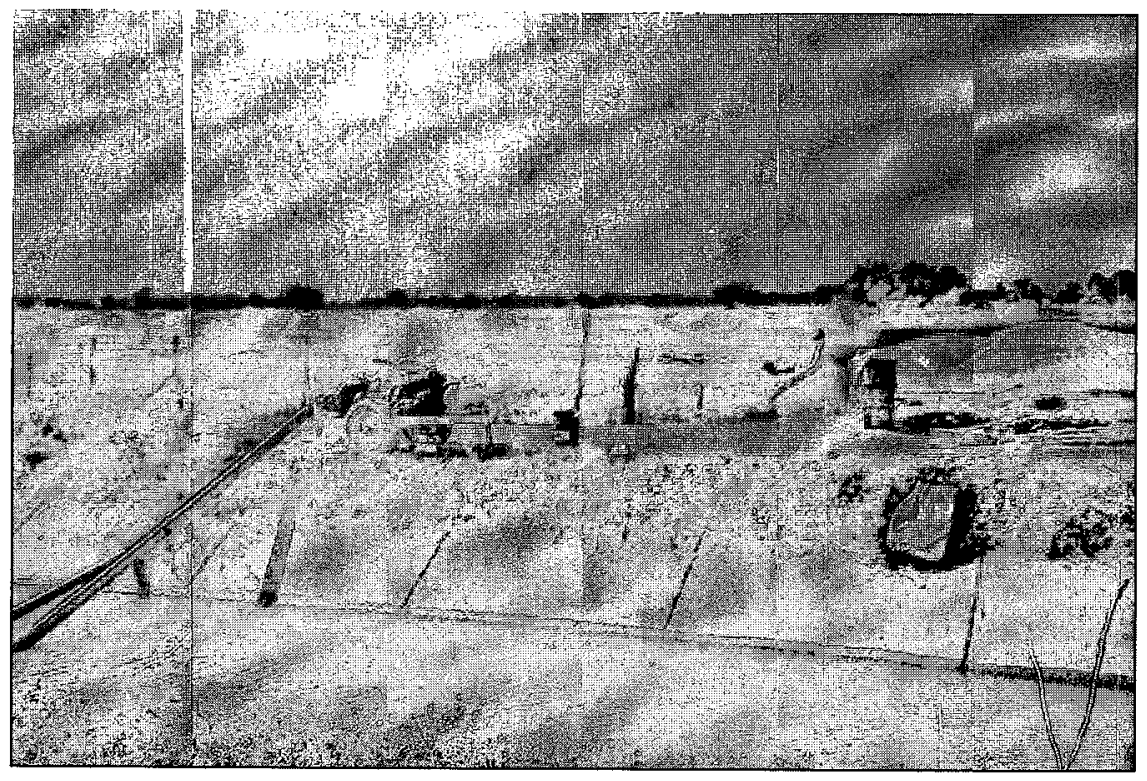

\section{Photo 6 A sprinkler pump}

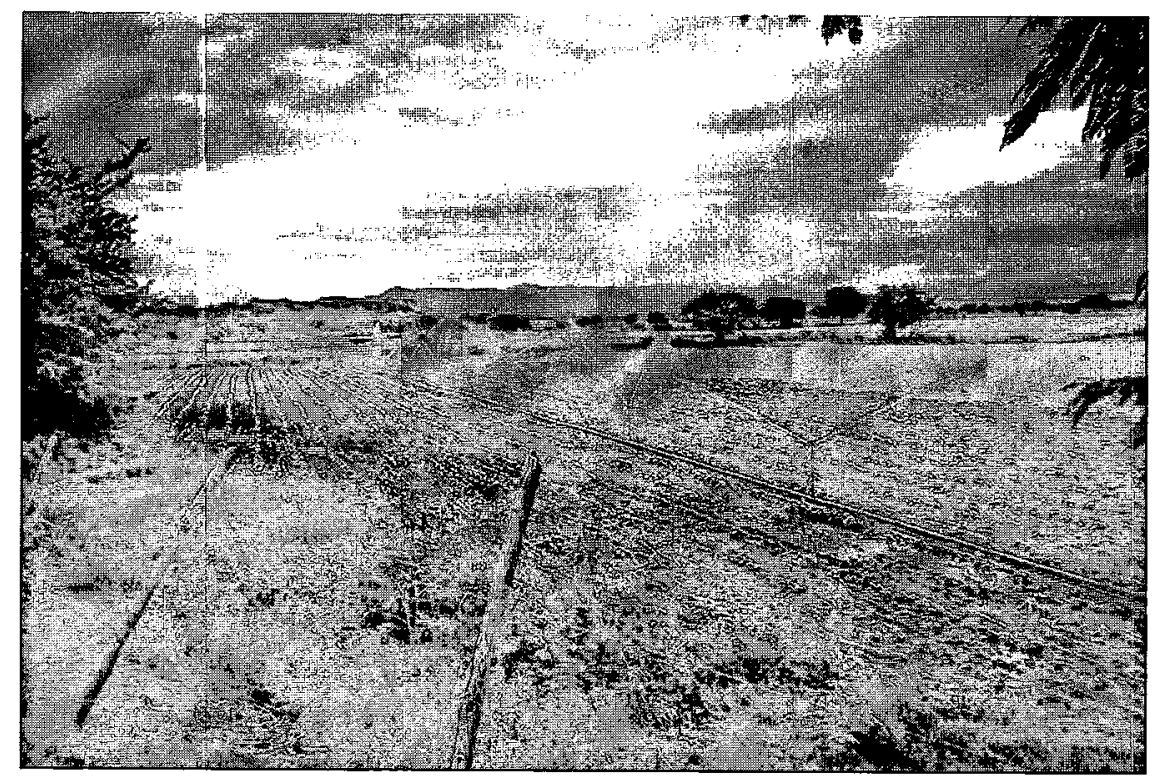

Photo 7 A pipeline with sprinklers 


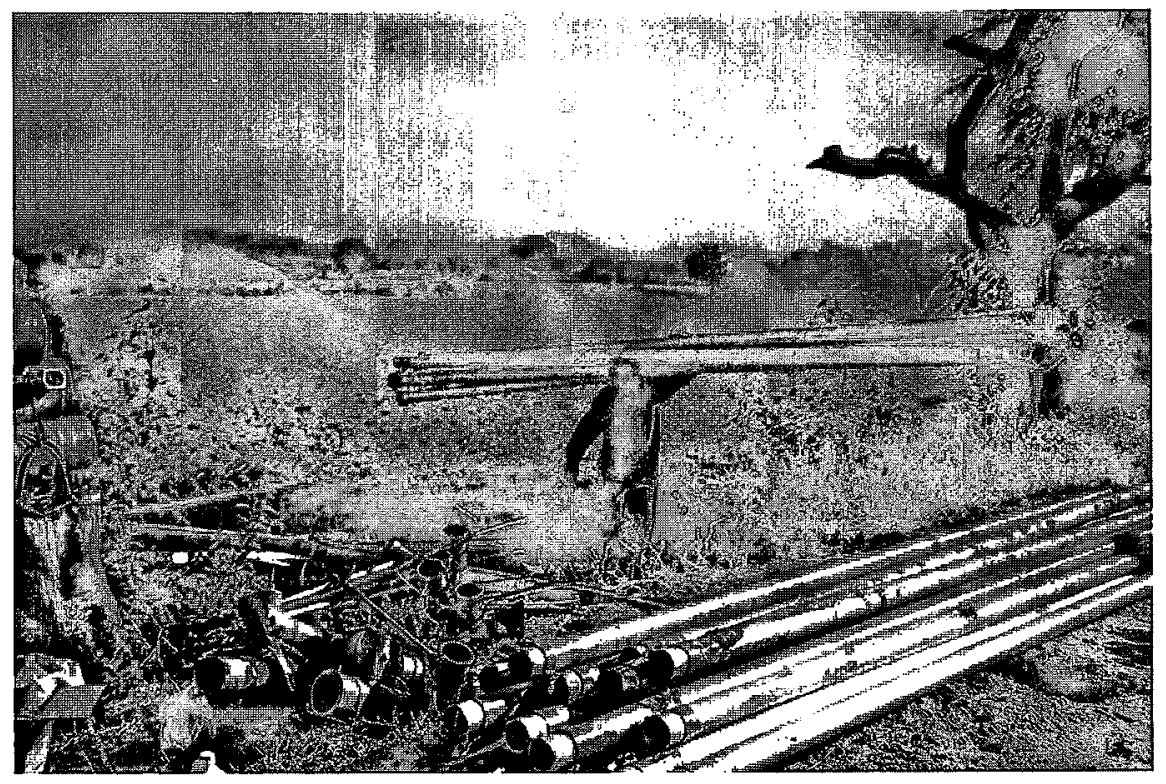

Photo 8 A bombero carrying pipes

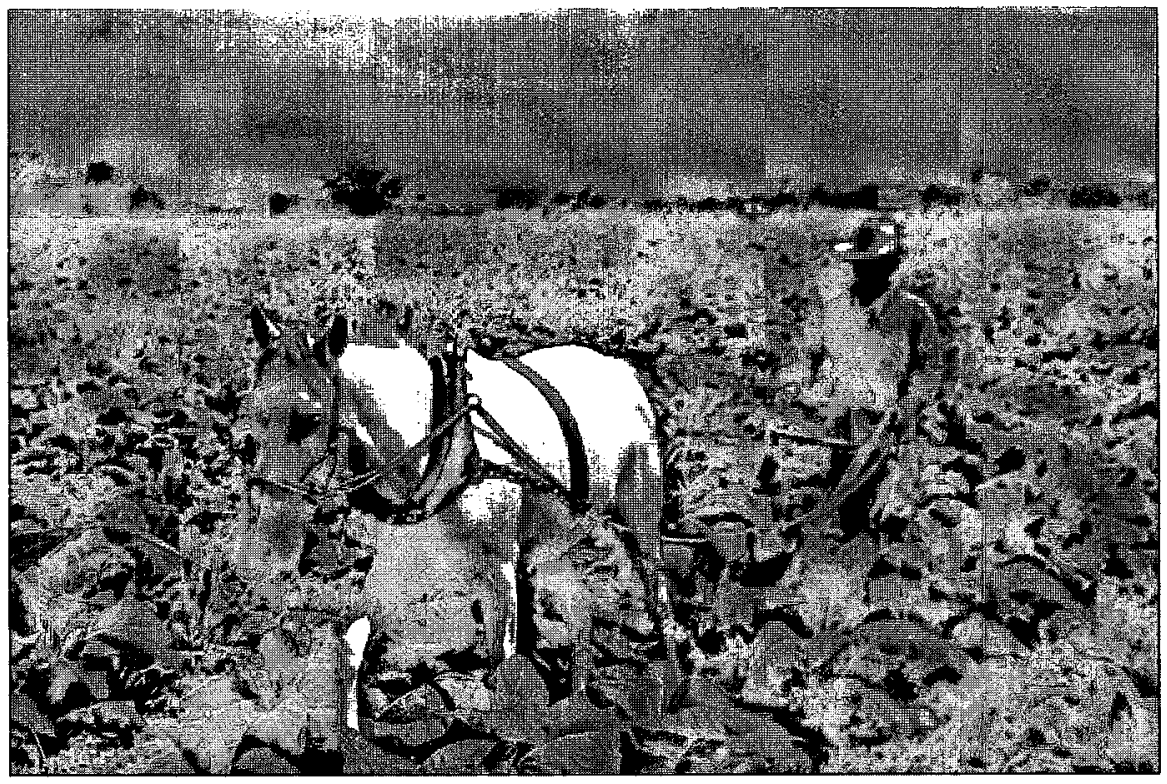

Photo 9 A tabaquero and his horse working the land 


\section{5 \\ Following the Current: A situated case study of a canalero}

Mejor que sigues el corriente (It is better to follow the current)

A former canalero's statement on the pressures that canaleros deal with and the problems they have to resolve in their daily work ${ }^{1}$

\section{DRAMATIS PERSONAE:}

Laguna

Tabaqueros

Guttiérez

Bomberos

Pérez

\section{Diego Guttiérez}

Icazar

Ejidatarios

Dominguez

Quiroz

Dario

Nuñez

Becerra canalero, engineer from Villa Hidalgo

tobacco producers

manager of the WUA, Laguna's superior

operators of sprinkler installations

former president of the WUA, local deputy and large producer and leader of $a$ political group

canalero, downstream colleague of Laguna

canalero, engineer, friend of Laguna

members of ejidos

superoising canalero and upstream colleague

canalero, engineer, and compadre

canalero, tail end colleague

president of the WIIA

CNA district head and former head of operation

PROPS:

Rules

Irrigation infrastructure

Canal structures

Sprinkler installations

Crop

Ejido fields

Irrigation water

Irrigation fees

List with signatures

Planning and reporting sheets Information flows

Motor bike

Radio

network of connected canals and drains of distinct leoels cross-regulators, sluices, intake structures

systems used for sprinkler irrigation: pipes, sprinklers, pump, intake pipe tobacco

plots of ejidatarios within an ejido

flows of $\mathrm{H}_{2} \mathrm{O}$ used for irrigation

fees paid by farmers to the WUA for irrigation, maintenance, and administrative services

a list of registered tobacco producers that needs to be signed by their group leaders so that tobacco companies adoance their irrigation fees to the WUA

standard forms that canaleros use to plan and report water use

flows of information co-ordinated by the canalero

means of transport

means of communication 


\subsection{Introduction}

\section{Operational rules of water distribution}

Recent literature on irrigation management has been heavily influenced by ideas from institutional economics. Ostrom (Ostrom, 1990; Ostrom et al., 1993) analyses irrigation associations as a set of rules in use, generated by a community cooperative ethic and expressing a consensual equilibrium outcome of self-interested actors (Mosse, 1997). These rules produce behavioural incentives that reward and constrain the benefits and costs of irrigation officials and water users in the operation and maintenance of an irrigation system. So, rules and incentives are considered to provide the basic direction and energy for organisations to meet their stated performance objectives (Vermillion, 1991). This type of neo-institutional analysis suggests that individual and collective organisational practices strictly emanate from a rational response to coherent sets of institutional rules and incentives. The analytical weakness of this assumption lies in disregarding the considerable room for manoeuvre and agency that different social actors have in dealing with these situations (Clay and Schaffer, 1984; Lipsky, 1980; Long, 2001). Consequently, such analysis fails to appreciate and analyse a diversity of existing and emerging forms of organisational practice.

Current managerial models of Water Users' Associations (WUAs) based on this set of neo-institutional ideas presume that a set of agreed rules ensures co-operative behaviour among a circumscribed community of rational actors. These actors assume different organisational positions and roles. The WUA employs managers and field personnel to provide services to the water users, who are the client constituency. An established set of operational rules distributes authorities, competencies and responsibilities among these actors. ${ }^{2}$. On the Left Bank of the River Santiago, where we examine these ideas empirically, two operational rules are crucial for orderly water distribution and timely irrigation fee payment. The first rule stipulates that a water user must request an irrigation turn a fixed number of days in advance; the second rule requires water users to pay their irrigation fee before receiving the first irrigation turn.

The train of thought initiated by these rules leads to an ideal organisational picture of orderly water distribution and timely fee payment. It runs like this: a WUA manager centrally compiles the water users' irrigation requests and on this basis programmes the required water supply for a period of a week in agreement with the annual irrigation programme. On a daily basis his field workers, called canaleros in Mexico, put this planning into practice. They secure adequate and timely water provision by coordinating the supply of water entering the canal network with the demand of the water users in the field. Water users are eligible to receive water in exchange for a timely fee payment and irrigation request. Sanctions apply that prevent water users from free-riding behaviour. As farmers receive their water turns on time, they are in the position to stimulate optimal plant growth. As a result, satisfied farmers with good productivity are increasingly willing to pay their irrigation fees on time. This enables the WUA to fully finance the operation and maintenance of the irrigation system so that it becomes selfsufficient.

In contrast to this rule-based approach, I will argue that water distribution and use practices are not governed by a system of agreed rules and therefore falsify this idealised 
and harmonious picture of organisational practices. In addition, they are not practices that are centrally controlled by a manager from an office, who is able to coordinate the planning and execution of irrigation through a set of rules and procedures. Furthermore, an analysis of operational rules erroneously suggests that they are applied evenly in a homogeneous irrigation setting and that water distribution practices are thus in principle the same everywhere. The above arguments point to a more de-centred understanding of the distribution and use of water in a heterogeneous irrigation setting.

Van der Zaag (van der Zaag, 1992) contributes an important improvement upon the rule-based approach and steers us towards a more de-centred understanding. $\mathrm{He}$ demonstrates that in practice it is not a set of allocation rules but, rather, the canaleros that mediate the service relation between the irrigation institution and the irrigating constituency. From their intermediary position, they obtain a certain autonomy in decision making and derive a professional competence from their experience with the irrigation system and the day-to-day water distribution in the field (van der Zaag, 1992).

I will try to complement van der Zaag's analysis by enriching it with new insights through the detailed study of the canalero's practice in water distribution and fee administration. In the first place, this chapter shows that rules are regularly subverted, whilst the canalero has insufficient authority and sanctions to control fee default and the uncoordinated access to water. This means that the canalero's professional competence and authority are not uncontested. In the second place, we have to understand different patterns of water distribution and fee administration, as well as the mediating role that the canaleros play in this, resulting from the concrete social, material and spatial relations which constitute the workspace in which the canaleros operate. This requires a situated case study, as the title of this chapter indicates.

To this purpose, we need to analyse an irrigation system as a spatial arrangement of social and material elements. In different operational sections of the irrigation system, diverging combinations of such elements make up the workspace of the canalero. Because such heterogeneous workspaces vary from each other, the patterns of water distribution and fee administration become rather different and therefore create a distinct role for the canalero.

I will present two contrasting case studies of canaleros, one in this chapter and one in the next. These cases most clearly differ in two aspects: firstly, the operational arrangements mobilised in the irrigation of a farmer's crop; secondly, the social position of the canalero relative to the political group controlling water distribution. This chapter considers sprinkler irrigation in small-scale tobacco production, whereas the next focuses on surface irrigation in large-scale rice production. The intermediary role of the canalero varies according to which operational arrangements dominate his sections. But it is not just the spatial and material differences emphasised in this chapter that matter here: the canaleros' social position vis-à-vis the political group that controls the management of the WUA is also important. This chapter presents the case of canalero Laguna, who has a much more distant relation to his superiors than canalero Diego, who figures as the protagonist of the next chapter. He is identified as part of the group that is in control of the WUA, and he performs an important role in a network of favoured rice producers. The position of this canalero is thus very different from Laguna's. 


\section{A canalero's competence in water distribution}

In his study of the Autlán-El Grullo irrigation district in Jalisco, van der Zaag (van der Zaag, 1992) emphasises the crucial role of the canaleros in the operation of this government managed irrigation system. As already stated, the canaleros are the field personnel that carry out water distribution and the registration of water fees on a daily basis. Through a particular interpretation of his tasks and a professional competence, the canalero produces a linkage between an irrigation institution and the water users. According to van der Zaag, the canalero faces the 'canalero's dilemma': a situation in which he has to make constant choices between demands of his superiors in the district and farmers in the field, which are often mutually incompatible. He shows how a canalero solves this dilemma by acting and consciously shaping his working arrangements. Although the canaleros can be victims of their situation, they also have the possibility to counteract to the pressures from both sides. In this manner, they create their own autonomous field of action, which they have preserved over more than a decade in spite of several administrative reorganisations, van der Zaag contends (van der Zaag, 1992).

The canaleros distribute water from the main canal, via the lateral and sub-lateral canals, to the intake of individual farm plots. They operate the cross-regulators, sluices, and gates and are responsible for the weekly programming of water volumes that their sections require. At field level they are also responsible for scheduling and supervising irrigation turns for the farmers who irrigate their crops. Van der Zaag offers a lively description of how the canaleros move around their area on motor bikes, ride along the canals, cross the fields and speed on the dirt roads. Although they are field workers, they do not simply execute guidelines received from above, but adapt them to the varying needs, constraints and demands experienced at field level.

In describing the daily routines of the canaleros, van der Zaag emphasises their proficient and situation-specific knowledge of the physical infrastructure, canals, water flows, fields, crops, farmers and irrigators in the section where they are working. The canalero derives his professional competence and a degree of authority in decision making from his experience and knowledge of programming, adjusting gates and estimating water flows. This relative freedom can be applied with different professional and personal benefits as a result. A canalero's normal field encounters illustrate the shared experience and mutual respect between the canalero and the farmers. The canaleros sometimes grant users favours in water distribution, in exchange for small bribes, presents, or access to resources such as credit.

In spite of the fact that this type of field worker represents the frontline of many irrigation organisations around the world, the irrigation literature has traditionally given little attention to these actors and rather tends to focus on the role of irrigation engineers, bureaucrats and managers in their hydraulic institutions (Chambers, 1988; Uphoff et al., 1991; Wade, 1988) ${ }^{3}$. The conventional irrigation engineering literature is especially geared to reducing 'the human element', which causes incompetent management of irrigation systems and hampers the achievement of efficient and equitable irrigation, by introducing fixed distribution works (Horst, 1990) or automated 
water control (Plusquellec et al., 1994). Such engineering perspectives very much embody the idea of an ideal technical order and formal policy objectives.

As a reaction to such approaches, van der Zaag shows the strength of human competence in the actual practice of water distribution at field level ${ }^{4}$. The canal infrastructure of the Autlán-El Grullo system with its adjustable gates and intakes appears a complex system to manage. This infrastructural flexibility is not a weakness, because it allows the canalero to competently use it and respond to diversity in crops, plots and water demand. The particular form of the technical infrastructure influences the water distribution but does not completely determine it, because the canalero has 'internalised' the physical properties of the system. We learn that if canaleros receive adequate financial, social and material rewards and sufficient responsibility, they are able to contribute substantially to 'the performance' of an irrigation system by 'making it work'.

\section{In a heterogeneous working space}

In irrigation studies, there is increasing recognition that irrigation systems are sociotechnical systems (Huppert, 1989; Mollinga, 1998; Uphoff, 1986; van der Zaag, 1992; Vincent, 1997). In an irrigation system, access to water is mediated by a spatial network of social and material actors, elements and relations. To organise the distribution of water you not only require human actors such as managers, field workers and farmers to follow operational rules, but you also need to mobilise non-human elements such as a spatially distributed network of canals, drains and fields, irrigation technologies, as well as other material resource flows such as planning sheets, documents, money, information, etc. In the actual practice of irrigation, we are never faced with just either material objects or social relations; rather, the non-human and human are assembled into a heterogeneous actor-network (Latour, 1987; Law, 1994). An irrigation system is thus operated and accessed by a heterogeneous association made up of human and nonhuman elements (Kortelainen, 1999). In sum, an irrigation system is a socio-material arrangement. The heterogeneous elements that make up this arrangement are usually not homogeneously distributed over space.

Conventional sociological approaches are then flawed when applied to the complex working arrangement of canaleros, because they assume a centrally located official in a homogeneous and spatially bounded workplace, who administers ordered flows of resources, files or cases. Studies of lower level bureaucrats, front line workers, or field workers of large bureaucratic agencies have traditionally focused on the 'modern', institutionalised and spatially circumscribed workplaces that are typical of urban bureaucracies, factories, or laboratories (Law and Akrich, 1994; Lipsky, 1980; Sternberg and Horvath, 1999). Such workspaces are characterised by a high degree of social, material and spatial standardisation and therefore require a relatively standard set of competencies from the worker. The homogenised and ordered nature of the work environment and of the incoming and outgoing flows of clients, files and resources is too easily taken for granted. All conditions are engineered so that a front line worker is placed at the centre and functions as an 'obligatory passage point' in his workspace (Latour, 1987). 
Analytically, the situation of a canalero is much more complex. The central activities of a canalero are water distribution, fee administration and information brokerage. In these activities, the canalero mediates between the organisational levels of the WUA management and water users. This mediation occurs through the canalero's control over a spatially delimited part of the technological infrastructure and over different sets of resource flows: water, irrigation fees, documents, information, etc. When we compare the canalero with the lower level official described above, we notice the following differences: Firstly, canaleros are actors that operate in heterogeneous workspaces in which they require and learn specific competencies but not others, something that cannot be circumscribed by a standard set of operational rules. Secondly, canaleros are engaged in a de-centred practice of 'ordering' flows, which means that they do not occupy a sole centre from which they exercise control. The canaleros' success in positioning themselves as an obligatory passage point in these networks and flows consequently differs. Thirdly, canaleros on their motor bikes are mobile actors, who are constantly moving about in order to mediate between different spatially distributed arrangements of social actors, physical structures and resource flows.

A socio-material arrangement embodies a certain distribution of competencies and performances between humans and non-humans (Latour, 1992). A canalero's competence to control water flows is thus embedded in the specific set of social, material and spatial relations that are mobilised in water use practices (Hutchins, 1995); but so is his inability to make these relations work in another manner (Roep, 2000). This requires a meticulous study of the social, material and spatial arrangements within which canaleros operate. In this chapter and the next, I therefore concentrate on two different operational arrangements that are financially and politically important to the WUA and examine how they affect the competences of the canalero in question. I define 'operational arrangements' as the host of physical devices, monetary resources, legal documents and human actors that a farmer would have to enrol to obtain access to water from the main system level for his crop (van der Zaag, et al., 2001).

In the next section I focus on the theory and practice of the tasks the canalero fulfils on the Left Bank. Then I describe the formation of the Left Bank canaleros. Section 5.3 presents the case study of canalero Laguna. His life history is followed by a short description of the two sections of the irrigation system for which he is responsible. This description ends by signalling the most labour-demanding characteristic of these sections, namely the operational arrangement involved in sprinkler irrigation and smallscale tobacco production. When we follow Laguna along one of the busiest canals in his sections, we encounter the problems of control with which he deals in his work and observe how he responds to them. These experiences are compared with those of an excolleague and his successor. Further, they lead to Laguna's opinions about his superiors and their policies. Finally, Section 5.4 draws the conclusions of this chapter.

\subsection{The Left Bank Canaleros}

Both the Left Bank and Autlán-El Grullo are in the fortunate situation of having no absolute water scarcity. If everybody stuck to the rules, they would all receive sufficient water on time. Water availability here is thus not the kind of problem that it is in most other irrigated parts of Mexico. Hence, the volumetric water price and the irrigation fees 
are relatively low. In addition, the Left Bank irrigation infrastructure is equally flexible as described above for Autlán-El Grullo (see also Chapter 4). This would appear an ideal point of departure for a Water Users' Association to establish an orderly water distribution and financial self-sufficiency in line with the established operational rules.

Instead, we encounter a slightly chaotic and sub-optimal situation in which water distribution is far from efficient, plots are flooded, 'free riders' take water without paying fees or requesting an irrigation turn, and farmers do not receive their irrigation turns on time. In addition, a group of well-connected large producers enjoys privileged access to water. These 'problems of control' in the distribution of water introduce a relative scarcity of water. As a result the equality, convenience, reliability (predictability) and timeliness of water distribution to individual farmers is problematic (Chambers, 1988), particularly towards the tail-end of the system. In addition, the collection of irrigation fees is not a straightforward task. However, the situation could be more dramatic if it were not for the competent role that the canaleros play in partly resolving these problems.

\section{Operational sections and task distribution: theory and practice}

A map of the Left Bank irrigation system shows that it is divided into thirteen sections for purposes of system operation (see Map 6). A section consists of a part of the main canal and various minor canals, and its boundaries generally are larger collector drains. On the map, it is basically a geographically bounded spatial arrangement of irrigation canals, drains, and fields. As was emphasised in the introduction, the individual sections are heterogeneous spaces. Besides the similarities, the sections contain diverging collections of farmers, crops, plots and field irrigation technologies (see for example Table 3), i.e. the specific social and material aspects of irrigation and agriculture in each section. The differences between these workspaces generate distinct patterns of water demand and distribution and therefore change the work of a canalero and the competencies that he requires. To illustrate this, I will mention just a few obvious contrasts between the sections that have implications for water distribution: head-end vs. tail-end location (high vs lower water availability and reliability), smaller ejido ${ }^{6}$ plots vs. larger private landholdings (small vs. large volumes), tobacco vs. rice production (small volumes but unpredictable in timing vs. standard water allocation per time unit), and the operational arrangements involved in sprinkler and surface irrigation.

An organisational chart of the association indicates that the general manager is responsible for the operation and administration of the irrigation system. The actual water distribution and the registration of water fees in the field are undertaken by a team of seven canaleros. Although the manager is formally responsible, in practice he is hardly involved and leaves the daily distribution to his subordinate, the supervising canalero. This experienced canalero supervises the work of the other six canaleros, who are each responsible for two sections. Further, he operates the most upstream section of the irrigation system. From there he can also monitor the incoming discharge into the main canal and co-ordinate adjustments with the Comision Nacional del Agua (CNA: National Water Commission) at the dam. He stays in contact with the CNA district on a regular basis for the daily water requests, weekly programming, and monthly reporting. 


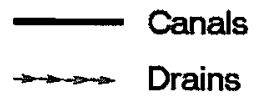

- Section boundaries

1 Section number

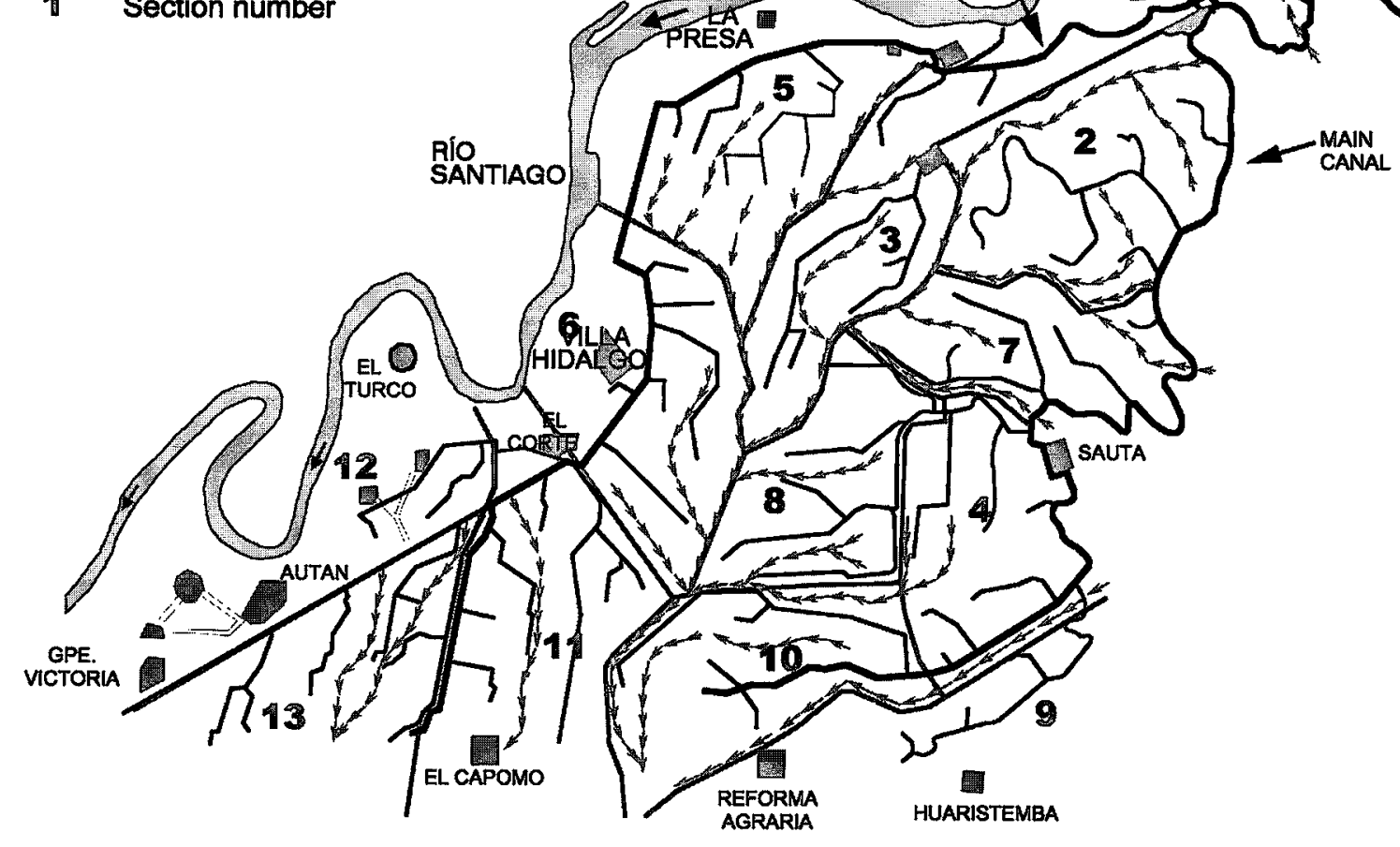

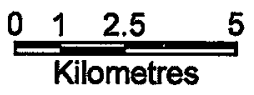


Even the annual irrigation planning, which has a limited influence over daily water distribution, is not carried out by the general manager, but by the local CNA supervisor. The manager appears to have limited experience and interest in the field of water distribution. The supervision of the supervising canalero is also limited, which means that the canaleros have a degree of autonomy in distributing water in their sections. Occasionally, the manager, Guttiérez, organises a meeting with all canaleros to discuss operational issues and the progress in fee collection matters.

The canalero's central activities are water distribution, fee administration and information brokerage. An examination of the relevant official rules of conduct concerning these activities starts in the by-laws of the Left Bank WUA. The Concession Title $^{7}$ establishes the legal terms for the concession of the infrastructure by the government to the WUA. It is a formal document produced by the Directorate of Irrigation Districts (DID) from the federal office of the CNA and signed at the time of official transfer. This document includes the operational instructions for the association. According to these instructions, water distribution is carried out on the basis of 'weekly demand'. The instructions state that a water user has to request an irrigation turn before the end of the week from his canalero in order to be able to irrigate during the next week. The canalero collects all these irrigation requests and passes them on. On this basis, the manager is able to programme the water need for the thirteen sections for the period of a week.

The canalero releases the programmed discharge from the main canal or main lateral into the sub-laterals and lower level field canals. He does this by backing up the water in the main lateral to an adequate level by means of adjusting the radial gates and the intake structures. Subsequently, he monitors whether sufficient water is flowing through for the number of irrigation turns programmed along a particular canal. When the canalero has opened a field intake or authorised a farmer to take a turn, his responsibility ends. The farmer is expected to take over from here at the agreed time and to irrigate his field for an agreed number of hours or days. The canalero carries a field notebook in which he registers the dates of the delivered irrigation turns. This booklet allows him to check the number of irrigation turns that a producer has had, to programme and to make up a report of all the irrigation turns and water volumes allocated. These reports are gathered on a monthly basis and submitted as a report by the supervising canalero to the CNA.

In actual field practice, the canaleros themselves instead refer to a period of three days' notice ${ }^{8}$. However, it often happens that water users do not request an irrigation turn from their canalero. The canaleros are confronted with the practical difficulties of refusing irrigation turns to those water users who bypass them. This makes the actual water demand an unpredictable factor, as it is only partly expressed via centred administrative planning procedures. It also in part responds to a de-centred field dynamic that is difficult for the canalero to control. During the week, the canalero therefore occasionally has to adapt his weekly planning and demand less or more water for his sections. When this is the case for several sections, the WUA sends a request to the CNA to alter the total discharge from the dam. 
Before starting to irrigate, water users have to pay a user fee per hectare of land to be irrigated. Formally, they require an irrigation request form from the canalero stating the crop and the number of hectares that the user wants to irrigate on a plot. With this form, the user has to go to the WUA office and pay the respective irrigation fee, which is a fixed rate per crop for every irrigated hectare. In return he receives an irrigation permit. These receipts again have to be shown to the canalero in order to irrigate for the first time. According to the Concession Title, the WUA is not allowed to allocate water to a user who has not paid his fee. The WUA depends on the canalero to correctly register the irrigated area and to motivate water users to pay their fees.

In spite of these rules, fee default remains a major problem for the WUA. The WUA does not have effective sanctions to discipline free riders who take irrigation turns before or without paying their fees, or to exclude them from access to water. The most effective means to counter fee default are two financial agreements with a major federal subsidy provider and multinational tobacco enterprises involved in irrigated production. These agreements are explained in more detail in Chapter 9. For this chapter it is important to know the following. The tobacco companies advance the irrigation fees of their tobacco producers to the WUA and deduct these expenses before the final disbursement of these farmers' profits. This secures a significant part of the WUA's annual fee collection.

Besides their formally prescribed tasks, the Left Bank canaleros perform other activities and roles in line with their intermediary position. For a majority of users, the canalero is the only representative with whom they entertain some kind of relation and encounter with some frequency whilst in the field. Many ejidatarios (members of ejidos) only go to the office of the association in Villa Hidalgo when they have to pay their fees. They have no relation with the association's board or management, or their ejido delegate. The canalero is an important source of information for them regarding, for instance, irrigation fees or crop subsidies. When the canalero is driving through the fields, he is easily approachable with regard to questions and complaints that users want to direct at the association. In addition, the canalero sometimes acts as a sort of agricultural extensionist or technical advisor for some producers.

For the board and the group that controls the management of the WUA, the canaleros also fulfil activities that by-laws do not define. The canaleros are their 'eyes and hands in the field' (van der Zaag, 1992), a means through which they are able to 'act at a distance' (Latour, 1987; van der Zaag, 1992). Their usability and mobility in the field and accessibility from the office are greatly enhanced by the canaleros' radios and motor bikes. They are put into action for a variety of purposes, which occasionally have little to do with their job. For example, the canaleros have to assist with organising public meetings for the association or political meetings for the group that controls the WUA. They help to arrange the chairs and distribute food or drinks.

\section{The formation of a group of canaleros}

When the CNA officially handed over the Left Bank module to the association in 1993, the majority of the fifteen canaleros retired on a pension in the years that followed. Only two of them continued to work for the association. Both Dominguez and Dario were in their forties, had lower technical qualifications, and approximately fifteen years' experience as canaleros. Dominguez became the supervising canalero because he had 
more experience and his patron was the then Head of the Operation Department and later the District Head of the CNA, Becerra. Both of them developed relations of mutual respect with their superior, Guttiérez. Besides Guttiérez' cousin, Diego, who had only a lower technical degree, the association employed a group of young agronomy graduates in their thirties as canaleros. They graduated from the agricultural college of Tepic, had a few years' working experience and participated with success in a course organised by the CNA. All canaleros originate from the area.

After the transfer, work pressure increased considerably for the canaleros. During the era of government management (Ministry of Hydraulic Resources [SRH], Ministry of Agriculture and Water Resources' [SARH], CNA), each canalero operated the infrastructure in one of the thirteen sections in the irrigation system. Today, six canaleros are each responsible for two neighbouring sections. In addition, the administration of fee payment has become a much more demanding task under the WUA. In line with the increased workload, the canaleros' working conditions improved after the transfer, but this turned out not to be a structural change. Initially, their wage increased significantly and, unlike before, their motor bikes were paid for and maintained by the association, and they received radios through which they could communicate with the main station. However, in the years that followed, their wage was not adjusted for inflation and therefore decreased in real terms, and their working conditions gradually deteriorated. Under the WUA, they lost their secure appointment, automatic membership of the influential government unions, reliable payment of salaries, occasional bonuses, rights to a pension, and further training. After two years their medical insurance was also annulled. As a consequence, the canaleros became much more dependent on the management of the association than they had been before under government management and lost some of the autonomy that they had had in their work and remuneration. Several canaleros were fired or replaced under conditions that remained unspecified. A number of them were accused of taking bribes from farmers, whereas other people suggest that a lack of loyalty to their superiors played a role. This served as a threat to the other canaleros.

The formation history of the canaleros determines their loyalty to the political group, led by Pérez, in control of the management of the WUA. Diego, the cousin of the manager Guttiérez, is most clearly absorbed in the dynamics of the aforementioned group, as will be illustrated in the next chapter. The four agronomy graduates are less closely related to Pérez' political group. They developed a mutual friendship bond on the basis of their shared educational background and working relations, and a secretly critical stance towards the management of the association. During my fieldwork, several conflicts emerged between the canaleros and the management. Laguna, who serves as the case example in this chapter, is the most outspoken of the canaleros concerning their deteriorating working conditions. The two more experienced canaleros have a different position. Dominguez plays an important role for Guttiérez as a field representative and supervisor of the canaleros. He co-ordinates the actions of canaleros both in the field and when they are needed to arrange a meeting, for example an assembly of delegates or a more public meeting. Dario, the other older canalero, maintains more distant relations with the other canaleros and with Guttiérez, and plans to resign within a few years.

The group of canaleros is fragmented along the lines of their different loyalties and commitments, trajectories. The fact that they are divided during negotiations on their 
working conditions frustrates most of them. In private, these mutual differences become very clear. Although they often sit or drink together on public occasions, the group of engineers socialises separately from Guttiérez, Diego, Dominguez and other personnel. During such private encounters, for instance at birthday parties or in a cantina, they tend to criticise and make jokes about each other. Frequently, these jokes concern their manhood, drinking behaviour or their dealings with women, but they also contain criticism of their social, economic and professional commitments.

The majority of the canaleros have spent most of their careers with the association working in two fixed sections, yet on several occasions the management have attempted to switch them between different sections, though never with much success. As a consequence, they have experience of working other sections of the Left Bank system usually only for a short period, because of the reversal of the managerial decision. For example, during the '97-98 season Diego started in sections 4 and 8, but in February, halfway through the season, he was changed back to sections 6 and 11. Three other canaleros, amongst whom was Laguna, were also changed back to their former sections. Pérez and Nuñez (president and secretary, respectively, of the Left Bank WUA) make those decisions. Diego states that they aim to prevent the canaleros developing too great a friendship with users and committing fraud, i.e. accepting bribes. Nevertheless, he finds it peculiar to do this halfway through the irrigation season when water distribution is still very intensive. He explains that, when a canalero starts to work in a new section, he can never get to know the users, canals, and water levels rapidly. To learn this you need at least six months, Diego argues. A colleague of his calls Pérez capricious for moving the canaleros about and suggests that there are also other interests at work apart from preventing the canaleros from accepting bribes. He refers to the production interests of Pérez and a group of favoured large-scale rice and sorghum producers (see Chapter 6). The way in which the canaleros are dispersed over the system thus takes into account the spatial distribution of these producers' land in the irrigation system and the relationship they have with particular canaleros. At the beginning of the '98-99 season, several canaleros changed sections.

During the rainy season, the canaleros' work pressure in terms of water distribution and fee administration significantly decreases. The management argues that, because of the lack of irrigation and fee payment, there are not sufficient revenues coming in to keep the full body of staff employed. To cut down on salaries, three canaleros, a mechanic and some secretarial help are temporarily relieved of their duties. This is possible because of the nature of their temporary contracts. Although generally the canaleros with other sources of income are the ones sent home, there is always an immanent threat that they will have no income during those months. This creates dependency and discourages them from being very critical of their superiors.

\subsection{Case Study Laguna}

\section{Life history and professional experience}

Laguna is a relatively young canalero of 32 years of age from the village of Villa Hidalgo. He recently married Dinora, aged 23 , who is also working for the association, as a secretary. They are living just a few blocks from the office. A few months after I get to 
know them, Dinora shows signs of pregnancy. Both are well-educated and have studied in the state capital of Tepic. Dinora completed a degree in business studies at the university. Privately she admits that this secretarial job is below her level and that she aspires to a more responsible job, more in line with her degree. However, given her circumstances it is difficult to find such a job in the rural village of Villa Hidalgo. Married relatively old in Mexican terms and already expecting his first child, Laguna is determined to make his marriage work. He takes his work very seriously and actively considers the prospects that he has within the association as a canalero with an agronomist's degree. Although he likes a beer, he refrains from drinking and going to the local cantinas. This is perhaps why he is still relatively lean compared with some other canaleros.

Unlike most families in Villa Hidalgo, Laguna's family is not engaged in agriculture and owns no land. His parents and some of his sisters work as schoolteachers in different parts of the state. Laguna instead decided to study agronomy. After his studies, he worked together with Quiroz for Pacífico, one of the four tobacco companies active in the region. During that period, they promised to become each other's compadres (coparents) when one of them became a father. After two years, Pacífico laid off a large group of its field inspectors. Both Laguna and Quiroz became jobless. After the privatisation of Tabamex at the beginning of the 1990s, heralding the onset of a wider economic decline in the region, the demand for agronomists reduced significantly. Many of them started working as taxi drivers, or engaged in petty trade; others depended on their family plot for income, or migrated to the United States. None of these were options for Laguna, and it was difficult for him to find a job.

He worked for some time in Tepic, until he participated in the aforementioned course organised by the CNA in November of 1993. The idea behind such courses was the training and selection of new canaleros, who would work for the three newly established Water Users' Associations in the region: the Left and Right Bank of the Santiago River and the Right Bank of the Tuxpan River. According to Laguna, the participants were promised that the manager of the new associations would be picked from the group of trainees. A group of around fifty people participated, which indicates the amount of interest in these jobs. Although the minimum qualification for the job was a diploma from an agricultural college, many agronomic engineers with a university degree participated. The training part of the course was very general, according to Laguna. The CNA District Head and former Chief of Operation, Becerra, presented topics on the calculation of water volumes and irrigation depths required for particular crop areas. Laguna found it really simple, because it had all been part of his study as an agronomist. The course concluded with an exam. Both Laguna and Quiroz scored well. Together with Diego and another ex-colleague, they were selected to work for the association on the Left Bank of the Santiago River. Unlike Diego, Laguna did not have prior relations with persons from the board of the association ${ }^{10}$. As promised, the two nearby associations appointed managers from the group of course participants. However, the Left Bank appointed Guttiérez, a close associate and compadre of that association's president, although he had not participated in the course.

In 1993, Laguna started working as a canalero. The first period he experienced as very difficult. Originally, Laguna was supposed to be trained by one of the CNA's ex- 
canaleros, Juan, from the village of La Presa. However, when he arrived it appeared that all the old canaleros had already moved to the CNA offices in El Tizate for reasons that were not clear to him. As mentioned above, only two CNA canaleros with more than a decade of experience continued to work for the association, Dario and Dominguez, who became the supervising canalero. However, they did not have a clear role in Laguna's training either. Laguna recalls that he went to the field for the first time with another canalero who was fairly inexperienced himself. He remembers that that same day he was sent by this man along a lateral canal with the instruction to go and watch, without any further guidance. As he was driving along the canal on his motor bike, farmers came up to him asking him for water. He did not know anything and had no idea of what to do. The only thing was to start giving water out to these farmers and adjusting the control structures. It was very stressful and created many tensions for him and his young colleagues, some of whom could not handle the pressure.

During his first weeks he made many mistakes, because he had nobody to show him what to do or how to solve a particular problem. On several occasions, this resulted in angry farmers demanding water, or accusations from his colleague canaleros that he was using too much water. 'Theory is not like practice', he states, indicating that the techniques and concepts that he learned during his formal education and the CNA course were hardly useful for doing the work of a canalero. He learned slowly by actually distributing the water, by trying out different things and also by observing and interacting with his colleagues and irrigating farmers.

Laguna's education as an engineer over-qualifies him, because he does not really require this degree for the job. What it does do is determine his critical outlook on his work and working conditions, as will become clear in the course of the chapter, and his aspirations to move on and find a job as a teacher or engineer. Further, together with his engineercolleagues he manifests a distinction towards their less educated colleagues and experiences an injustice in the better salary conditions of their superior, who has a similar education.

\section{Sections as a work space}

Laguna is working for the third year in the relatively upstream sections 3 and 5 of the irrigation system (see Map 4). These are contrasting sections in terms not only of the type of land ownership, farmers ${ }^{11}$, cropping patterns and field irrigation technologies, but also of plot size and the number of farmers to whom he has to distribute water (see Table 3). I shall mainly focus on section 5 (see Map 7), which is one of the largest and most demanding workspaces for a canalero, as it is dominated by small-scale tobacco production and sprinkler irrigation. I will concentrate on the problems, demands, and complexities that the specific operational arrangements involved in irrigation create in terms of the canalero's central activities.

Both sections are located next to each other and depend on the main lateral 'the 17 ' that branches off from the main canal, on the spot where section 3 begins. Because of the relatively head-end location of these sections, they are generally never short of water. The two sections cover an area of about 3,400 hectares for potential irrigation. Around 1,900 hectares are actually irrigated, roughly divided over 500 fields cultivated by several 
hundred farmers. Laguna controls a sixteen-kilometre stretch of main canal and approximately thirty kilometres of lined lateral, sub-lateral and lower level canals. In addition, his sections are confined by a set of major drains and intersected by many minor drains.

Laguna's sections are located on the riverbank just opposite Santiago Ixcuintla, the municipal capital. The sections comprise several smaller villages, each with a few hundred or a thousand inhabitants. The fact that the ejido lies at the centre of the public life in these villages indicates their rural character. Because Laguna is from Villa Hidalgo, he did not really know the farmers when he started to work here. Getting to know the many people involved in irrigation has taken Laguna several years. After three years, he knows hundreds of producers, bomberos (pump operators), irrigators and other villagers who are involved in the production of tobacco. Because of his young age and despite his degree as agronomist, Laguna does not have an authoritarian attitude towards the ejidatarios with whom he engages. He is friendly and respectful towards most of the irrigating farmers and bomberos that he encounters in the field and tries to prevent or mediate conflicts with them. Occasionally, he advises farmers about how to deal with the association's management, because he is very critical of their approach towards the users. Yet, Laguna does not seem to have a large intimate network of personal contacts, and his relations with the multitude of people in the field remain a bit detached.

Section 5 consists of more than 1,000 hectares of land actually irrigated. Most of the land belongs to the ejido of La Presa, which is the largest tobacco producing ejido in the region, with over 1,000 hectares of tobacco. The tobacco cultivation is undertaken by hundreds of small-scale producers. The extremely fragmented pattern of land distribution and ownership is even further complicated by the large-scale leasing of land for the production of tobacco. On average, the irrigated tobacco plots are three hectares. This contrasts sharply with, for example, section 3 that typically contains much larger irrigated holdings of approximately eight hectares. In other sections the ejido plots also tend to be larger (on average four hectares). For the canalero, the daily water distribution and fee administration in a big section with a large number of plots and producers involves a huge workload.

Section 5 is a politically important space for the association's management, because of the political and institutional importance of tobacco and the fact that some leaders and some of their clientele, allies and friends are based here, particularly among the ejido commissioners and delegates of the association's assembly. For the association, the financial importance of section 5 exceeds that of many other sections, because its fee collection potential is much higher (see Table 3 and Chapter 9).

In order to bank these revenues, Laguna needs to connect the WUA's administration with that of the tobacco companies. This involves the complicated task of linking an official, but outdated, CNA list of water users and plots with a list of registered tobacco producers that often do not coincide. The companies transfer the irrigation fee for individual tobacco producers, who are organised in groups, only when they receive a group leader's signature to confirm that they are receiving water. To get this signature and find out which plots a tobacco producer is using and to which water user this corresponds, the canalero needs to visit all group leaders in his section. This is a very 
labour intensive task and requires an intimate knowledge of the multitude of plots, ejidatarios and tobacco producers in section 5 . The association receives a periodic payment in respect of lists completed by the canalero. The management thus pressures the canaleros in tobacco sections to make haste with this activity. The canaleros in their turn complain about the various demanding tasks that they have to fulfil. In addition, these administrative procedures leave very little room for presents or bribes from tobacco farmers to the canaleros in exchange for water.

Table $3 \quad$ Sections 3 and 5 in Autumn-Winter 1999

\begin{tabular}{|c|c|c|c|c|}
\hline & & Section 3 & & Section 5 \\
\hline Landholding pattern & & 1,440 & & 1,821 \\
\hline (hectare) & & 38 & & 4 \\
\hline Private land (\%) & & 62 & & 96 \\
\hline Ejidos (\%) & & & & \\
\hline Number of producers & & 224 & & 541 \\
\hline Private land holders (\%) & & 5 & & 1 \\
\hline Ejidatarios (\%) & & 95 & & 99 \\
\hline Cropping pattern (ha) & & & & \\
\hline 1. & Pasture & 277 & Tobacco & 900 \\
\hline 2. & Rice & 132 & Beans & 75 \\
\hline 3. & Sorghum & 99 & Sorghum & 37 \\
\hline 4. & Tobacco & 55 & Jicama & 33 \\
\hline 5. & Beans & 28 & Tomatoes & 26 \\
\hline 6. & Other crops & 30 & Perennials & 23 \\
\hline Irrigated area (ha) & & 621 & & 1,094 \\
\hline Number of irrigated plots & & 75 & & 421 \\
\hline $\begin{array}{l}\text { Average irrigated plot size } \\
\text { (ha) }\end{array}$ & & 8.3 & & 3.1 \\
\hline $\begin{array}{l}\text { Irrigation technology } \\
\text { (Percentage of area): }\end{array}$ & & & & \\
\hline Sprinkler irrigation & & 16 & & 95 \\
\hline Surface irrigation & & 84 & & 5 \\
\hline Irrigation fee agreements & & & & \\
\hline potential* $(\%)$ & & 51 & & 93 \\
\hline
\end{tabular}

Source: Overview irrigated crops, Association, 1998-1999 (WUA, 1999);

Irrigation plan 1989-1999 (CNA, 1999)

* This is the percentage of hectares of a section that potentially falls under the agreements with PROCAMPO, the tobacco or sorghum companies. In the case of PROCAMPO, this includes the area under the eligible food crops, although it is not clear how much of this is actually registered for PROCAMPO. Thus, it gives a good but rough indication of how much of the fees can be collected through these financial agreements.

\section{The operational arrangement of sprinkler irrigation for tobacco}

The prevailing irrigation method in section 5 is sprinkler irrigation. Like in other parts of the Northern Coast, it is considered the traditional form of irrigation. Initially, tobacco companies introduced the first pumps and mobile sprinkler systems to the region in order to irrigate the lighter tobacco varieties they had started to produce. After the nationalisation of the tobacco market at the beginning of the 1970s, the parastatal, Tabamex, started to intervene in almost every phase of the tobacco production cycle 
(Jáuregui et al., 1980). Amongst other things, it arranged the irrigation of tobacco plots for thousands of tobacco producers in the region according to a complex scheme. This further increased the use and the number of sprinkler systems. Special staff, sprinkler installations, and other means and resources were allocated for this purpose. Most tobacco producers thus never experienced the need to buy a system for themselves, in spite of their sometimes-significant profits. In addition, they gained little experience with the actual irrigation themselves. Tabamex staff and the additional private owners who rented out their installations determined the timing of irrigation turns.

Within this institutionalised distribution of assets, competences and labour, individual tobacco producers had no need to request an irrigation turn and therefore failed to develop a routine. This situation remained largely the same after the dismantling of Tabamex in 1991. The tobacco companies who became active in the area decided to decentralise the costly and labour intensive task of irrigation to their tobacco producers. They started giving out loans to the producers to buy a sprinkler system. However, most small-scale tobacco producers were not sufficiently profitable to qualify for such loans. Therefore, these farmers hired sprinkler systems from more well-to-do farmers, and the companies started pre-financing this for five irrigation turns per cycle. The high cost of this is paid for by these farmers at the end of the season. In addition, the companies started advancing the irrigation fees of their tobacco producers to the WUA. As a result, these producers developed no need to interact with either the WUA or the canalero to get permission for irrigation and learn about their operational rules.

This institutional history clarifies the particular distribution of assets, competences and costs that determines the current irrigation practice. Most tobacco producers thus have to look for a fellow farmer willing to rent out a sprinkler installation to them every time they want to irrigate. Often they try to find somebody close to their plot, or from their own village. These scarce installations have thus become the critical link around which irrigating farmers organise their access to water.

The owners of a sprinkler installation normally employ a bombero and, sometimes, additional regadores (irrigators) as labourers. The sprinkler systems used in this area can be characterised as periodic-move systems or, more precisely, hand-moved lateral systems (Cornish, 1998; Keller and Bliesner, 1990). The (non-human) components of these systems consist of a diesel pump with a capacity of forty litres per second, a temporarily fixed main line and hand-moved laterals, which transport the water under a certain pressure to the connected sprinklers. The bombero is responsible for installing, operating and maintaining the pump. Together with the other irrigators, he connects the pipes to form a main line and a lateral. After a few hours, when a track of land has been irrigated, they move the lateral a few metres to irrigate the next bit.

The owner of the pump, and also the bombero and his irrigators, are paid per hectare. This encourages them to irrigate rapidly and not to lose time in order to cover a greater area in a week. Particularly at the height of the irrigation season from November to March, a bombero earns a salary that is significantly higher than that of an ordinary land labourer. Many plots need to be irrigated, and the pumps, sprinkler systems and their operators are in high demand and are moving from one field to another. The owner of the pump can basically rent it out to anyone he wants. In order to bring the necessary 
components together to get his land irrigated, a tabaquero (tobacco producer) is thus very dependent on the timing, quality and financing of work by others. Many small-scale tobacco producers thus play a limited role in the actual irrigation of their crops. They only have a rough idea when the bombero and the sprinkler system will arrive to irrigate their field, and all they can do is wait for that moment. It has never been an established practice among these tobacco producers to request an irrigation turn from the canalero, and it is also difficult in practice for them to request it three days in advance, because the timing of their irrigation turn is dependent on the availability of a sprinkler system.

In practice, when the bombero arrives with the whole installation at a field, he immediately starts installing the pump and throws in the 'pichancha' (intake pipe), if there is sufficient level in the canal or drain from which he intends to draw the water. The latter is usually not a problem in this section, especially at the head-end of canals. The bombero does not await the consent of the canalero or the tabaquero, neither of whom in most cases is present at that moment. A bombero basically does not need the canalero to give him access to water, because he can easily physically bypass him with a pump and an intake pipe. For them, this is simply the shortest and most time saving link to water. The canalero is in this case therefore not the most essential intermediary; what is more, his capacity to monitor pumps along a canal is limited. Irrigating farmers whose fields are located towards the tail-end or near a drain, where the delivery of water is more irregular or insecure, are more likely to inform the canalero. When there is no water available, it sometimes happens that angry farmers or bomberos blame the canalero for not allocating sufficient water.

The following focuses on Laguna's work of distributing water under this kind of operational arrangement, bringing to the fore the particular problems of control, contradictions, and complexities that he has to resolve in his daily practice.

\section{In the field: Driving along 'the $10^{\prime}$}

In spite of the overall abundance of water, the canaleros unanimously agree that the head-end of section 5 is one of the most difficult and demanding sections. They measure the difficulty and the workload of this section by the number of sheets Laguna requires for the programming and reporting of irrigation. When I ask him about section 5 , he demonstratively waves in the air six or seven reporting sheets that he has painstakingly filled out. He stresses that some of his colleagues can suffice with only one or two pages per section. His weekly programmes and monthly reports require a lot of work, because of the large area, the large numbers of irrigating tobacco producers and their plots that have to be registered. This gives an indication of the amount and intensity of his work, and his long working days. It requires enormous flexibility on the part of a canalero to ensure that the available water supply in the main canals satisfies real demand in the field.

When I join Laguna in his work in February 1998, still at the height of the main irrigation season, he departs from his house on his motor bike in the early morning. He works until the late afternoon, with an interruption at lunchtime. Most of the day he can be found in the field, but in the afternoon he sometimes needs to check an administrative matter with one of the secretaries or is called to the office via the radio by Guttiérez. 
Having followed Laguna for several days, I find it difficult to derive a fixed daily routine, because his activity is determined by many factors: the route that he takes along the canals, the priorities he has on that day, and the things that unexpectedly come up in the field or the office. Laguna has considerable autonomy in determining his own working schedule and how he solves problems in the field. In these months of feverish activity in the field and at the office, his days are usually organised around the distribution of water and the administrative operations associated with fee collection, mostly from the tobacco producers in his sections.

At this time of year when many farmers are irrigating, Laguna needs to make frequent adjustments to gates and intakes in the main canals, laterals, sub-laterals, and lower level canals. This often determines his route through the sections. He has to return two to three times a day to check the level in the canals. Especially when an additional amount of water for the tail-end sections has been let into the main canal, he has to ensure that the radial gates in the main lateral are adjusted so that this extra volume arrives in the downstream sections. As an upstream canalero, he can be easily accused by his downstream colleagues of using the water that they requested for his own sections when he is in need for water. From the main lateral, Laguna normally drives downstream along the sub-laterals and minor canals, where he checks the running irrigation turns and the water levels in the canals, whilst adjusting some gates. Meanwhile, he observes and talks to farmers, pump operators and irrigators, and other people that he encounters or seeks out in the field. Laguna alternates easily between opening gates and searching for particular tobacco producers who need to sign an agreement for him.

The sub-lateral $10+539.77$ of the lateral 17 , called 'the $10^{\prime}$ by the canaleros, is about five kilometres long and has three sub-laterals (see Maps 4 and 7). It is equipped with nine cross-regulators and thirteen direct field intakes. This canal presents several of the control problems that Laguna is experiencing in distributing water in this section, but in an even more intense way. The reason for this is that the canal is entirely dominated by small-scale tobacco production and sprinkler irrigation of many small plots. A rough calculation shows us that this canal, its laterals, and the drains connected to it irrigate more than 100 small plots, owned by a similar number of ejidatarios. On several occasions, Laguna emphasises the complexities and unexpected situations he encounters on this canal.

Early one February morning, Laguna and I drive towards the inception of the 10 on the main lateral, near a crossroads just outside the village of La Presa. Arriving there, we meet the local CNA supervisor. We stand close to a cross-regulator in the main lateral, which backs up the water level to a height that ensures that sufficient discharge flows into the 10. The CNA supervisor comments to Laguna about the water in the main lateral being backed up to a very high level. The water is even flowing over the spillway of the cross-regulator, which is meant only for an excessive flow, such as occurs, for example, during a rainstorm. The supervisor is worried that, as a result, the downstream canaleros will not receive their requested volumes on time. Laguna responds that the situation is more complicated than the supervisor thinks. His aim is to maintain the water level exactly at the height of the spillway. He has to do this in order to cover the whole of the 10 . 


\section{Map 7 Section 5}

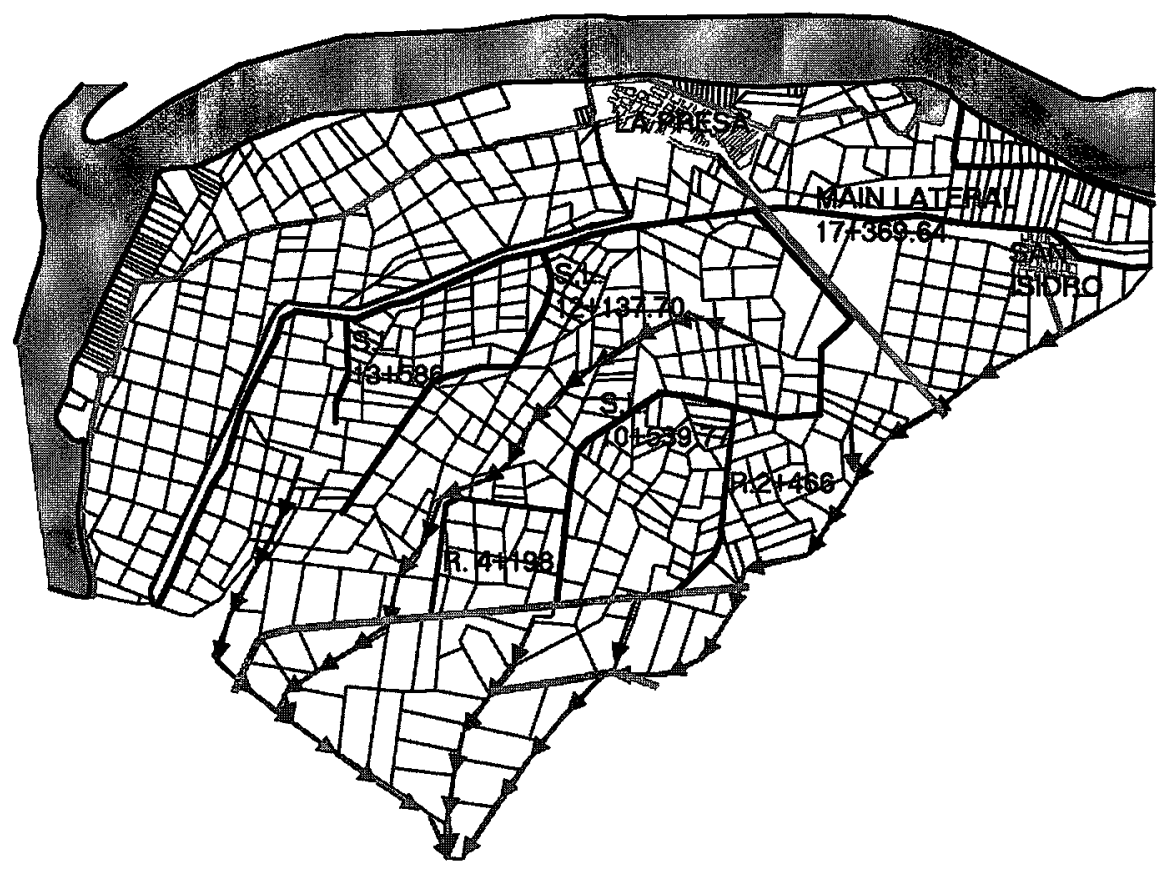

According to Laguna, the canal is badly constructed. It runs 'in reverse'. The intake of the canal is much too high and the canal does not have a gradient. Moreover, the end reach of the canal even goes up slightly. If he lowered the water level in the main lateral by just twenty centimetres, this would mean that the water flow would not reach the end of the 10. He would come into serious conflict with the tail-enders of the canal and those who use the tail water from the drain connected to it. His solution anticipates the water demand of these tail-enders, although some of them irrigate land that lies far away from a canal and several have not requested an irrigation turn. Damming up the water level at this point of the main lateral is a tricky business for Laguna, not least because it also affects the downstream water distribution of other colleagues, because they may receive their water later than requested. Laguna claims to have learned to deal with this infrastructural defect in this way through his experience of experimenting with water levels, adjusting the cross-regulator, and distributing water among these tobacco producers. The canaleros face similar problems with other sub-laterals.

When we arrive at the $2+466$ (a sub-lateral of the 10), Laguna points to two pumps placed on the road next to the 10 . According to Laguna, he found these pumps working this morning without being apprised of the fact that these tobacco producers were planning to irrigate. In addition, two other pumps were placed on the drain connected to the 10 into which water is released. As we drive along the 2 we encounter another two pumps that are irrigating. Although several of these pumps were not specifically programmed by Laguna, he estimates that the present flow in the 10 will be sufficient for the six pumps that he has observed. In his programme of last week and in determining 
the actual inflow for the 10 this morning, he deliberately took into account the fact that some pumps would unexpectedly appear on the canal and consume an extra flow. He programmed and allocated water for a few additional pumps. However, sometimes this precautionary measure is not enough. Then he requests an additional amount of water for his section. The supervising canalero coordinates these mid-weekly requests with the dam.

The total number of pumps on a canal thus determines the actual water demand. But Laguna never has an exact idea of how many pumps will be placed along the canal during a weekday. Admittedly, the pumps only consume a limited and predictable water flow $(40 \mathrm{l} / \mathrm{s})$. However, it is not the individual water demand but the unpredictability of the number of working pumps that creates problems for him. It can happen that from one moment to the next suddenly around ten pumps are placed on the canal, whereas only three or four farmers have forewarned him. The over-consumption causes the water level to drop rapidly, as a result of which the more downstream tobacco producers cannot irrigate. Meeting the rapidly increased demand immediately with the available supply of water becomes problematic. As a consequence, Laguna is confronted with angry downstream farmers who want to irrigate at once, because they have hired a sprinkler system and risk the bombero going somewhere else first, when they cannot irrigate right away. In spite of the fact that most tobacco producers along this canal come from the ejido of La Presa, there exists limited mutual social control on having the permission of the canalero to irrigate. This is caused partly because the actual irrigation is carried out by bomberos, who can easily dodge agreements, operational rules and the canaleros' authority. Getting the canaleros' permission is simply not their concern. The following day it can just as easily happen that Laguna finds only a few bomberos irrigating at the canal, with the result that the allocated water flow runs idly towards the ocean.

Recently, Laguna was attending a meeting when he was warned via his radio that the placing of four pumps on the 2 was creating conflicts over the available water. He had to speed to the place and found that the pumps were indeed working without his consent. Because the canal did not contain sufficient water, the bomberos and tobacco producers started to quarrel. In the end they blamed him because there was not enough water, although none of them had requested a water turn. He had to go down to settle the conflict and let more water into the 10 and the 2 in order to allow them to irrigate. Although he might not have programmed this extra quantity, he prefers to prevent conflicts with the tobacco producers and bomberos awaiting or taking a turn. Laguna is blamed regularly for not supplying sufficient water, in spite of the fact that few farmers actually inform him of their requirements.

According to Laguna, the unpredictability of the water demand requires him to regularly monitor the number of pumps along the whole length of the canal. To review the situation in the event of problems, he needs to check the whole sub-lateral and not just the field intakes, because the bomberos can basically start irrigating wherever and whenever they want to. At the height of the tobacco season, he passes along the 10 at least twice a day and sometimes even more often in order to check on the water level and make revisions when necessary. These decisions are largely tacit, based on Laguna's implicit knowledge and experience with this canal and its dynamic water demand. It is 
also not in his interest to make such decisions explicit, as they can be very conflictive. $\mathrm{He}$ is well aware of the impact they might have downstream, i.e. the lack of water for his downstream colleagues, but that is not his direct concern. He is not directly confronted with the angry farmers who have planned an irrigation turn but do not receive it on time. The only thing to bother about is his downstream colleagues who are accusing him of taking too much water. His response to that is generally evasive.

Laguna does not penalise this constant infringement upon the rules that he is supposed to monitor. As we drive along the 2, Laguna takes active notice of which fields are being irrigated without his permission, but does not get off his motor bike to intervene. If we stop to talk to tobacco producers or bomberos, it is usually about other business, such as the payment of the fee for this tobacco plot, or the name of a plot owner that Laguna is looking for. For instance, when Laguna sees two pumps working at the other side of the main lateral, we go to the field and see three men walking around with tubes. They are irrigating a field of jicama (a Mexican turnip crop). Laguna tells me that this is already the plot's second irrigation but that the irrigation fee has not been paid yet, in spite of the fact that he has already informed the owner of the plot once. The man lives in Tepic, the state capital, and is not usually around. Laguna asks one of the bomberos in charge whether the owner has already paid the fee. The bombero confirms this, but he fails to come up with a receipt. Laguna tells him to bring the receipt the next time he is irrigating. He does not make mention of the fact that neither the owner nor the bombero informed him about this irrigation turn, let alone apply a sanction. It appears he can do little to sanction these people.

I ask Laguna what he does with farmers who do not inform him on time before starting to irrigate. According to Laguna, he tells them that the next time they should inform him. However, being in the field with him, I witness nothing of the sort. Moreover, in the days I spent with Laguna I have never seen him reprimanding a farmer about an irrigation turn that was not requested or not on time, in spite of the fact that he frequently complains about the difficulties that this presents to him. His busy daily schedule keeps him from reprimanding tobacco producers and bomberos for breaking this operational rule. In addition, applying a sanction is not really an effective option for Laguna. He claims to have told people over and over again to inform him if they want to irrigate, but that it has had little result. The same farmers continue to irrigate without his permission. Reprimanding has only produced conflicts with farmers and bomberos, which he prefers to avoid. Laguna seems to have reconciled himself with the situation that he is often bypassed and does not have effective control over the actual water distribution.

But why does Laguna not use sanctions such as imposing a fine or sending for the hydraulic police, which is a special police department in Tepic for these matters? $\mathrm{He}$ responds that if he took such a measure the manager would immediately rescind it. Last year the hydraulic police finally visited the system. This visit was one of the few times that they came to the Left Bank. They removed an intake pipe (quitar la pichancha) of a farmer who had not yet paid his irrigation fee. Removing an intake pipe from a canal is something that the management often talks about and that the canaleros threaten, but in practice it hardly ever happens. In this case, the only thing the manager did the next day when the police had left was to give this man his pipe back without any reprimand. This example backs up Laguna's argument that the canaleros do not feel supported by the 
management. On several occasions, his superior has undone his decisions or simply bypassed him. Such actions demotivate him from enforcing this particular operational rule.

Near a cross-regulator in the 2, I notice that the water is backed up close to the rim of the canal. I ask him why. Laguna responds that he did not cause this. Some farmers must have let the gate down during the night because they wanted more water. Laguna has not given them permission to do this. He rectifies the situation by bringing the gate up. Although he acknowledges that people have transgressed the operational rule that they should receive his permission, he does not take any further action. He seems used to people contesting his authority by moving structures without his permission. On other occasions, it seems that somebody moved a gate without an obvious motive, perhaps some boys who crossed the structure to get to the other side of the canal. When Laguna finds that people have moved a gate, he responds by returning it. In the case of repetition or when he suspects a notorious farmer, he may use a lock or make a remark to bystanders or particular farmers. However, it is often difficult to prove who moved the gate, and Laguna argues that it is not in his interest to create conflicts by accusing people, falsely or otherwise. Earlier on the day near the main lateral, we passed a crossregulator. He puts a lock on the only gate that is functioning. When I ask him why he does this, he claims that the user of the upstream intake in the past dropped the gate several times, so that he would get more water. He knows this person by now and therefore takes precautions. During the field trips, I observe that Laguna has several locks (about five to six in his sections) attached to gates of check and intake structures, especially at locations where he knows from experience that gates are often moved with the risk of no water arriving or flooding being caused at the tail-end of a canal. In some cases, he suspects a particular farmer who has a personal record of such malpractice, or he is informed about a group of women doing their laundry in the canal who have moved the gate because they need more water.

Two experiences to compare: A former and a new canalero on the scene

In the shadow of an old guamuchil tree, close to the 10, Laguna discusses some of his work-related problems with an ex-canalero. Juan worked for the SARH and the CNA for twenty years and retired soon after the transfer of the irrigation system. When I ask him what has changed in the work of the canalero, he responds that very little has changed. It is true that the canaleros are more technologically advanced nowadays, being equipped with radios and motor bikes by the association. Laguna adds that the canaleros presently manage two sections and therefore a larger irrigated area. Juan, however, continues. He explains that the other day he witnessed the flooding of a plot, which was caused by farmers who had moved a gate without the canalero's permission. This also frequently happened in his day. Another thing that remains the same is that they also told producers again and again to request water on time, but this did not change a thing.

Laguna seems to agree with the elder, experienced man. He argues that when he tells users to wait for their turn, somewhat later he receives an order from the office to give them water. 'They take away my authority', Laguna states. When he tells farmers that they have to wait before they can irrigate, they go to the association and ask if they can get water directly. Nuñez and Guttiérez give in to such requests because they have commitments with these farmers, or because they are engaged in a political campaign 
and in need for support. Therefore, as canaleros they do not feel that the manager supports them. He claims not to be able to do anything, because the next time these farmers laugh in his face.

'Mejor que sigues el corriente' (It is better to follow the current), the ex-canalero concludes. For a canalero it is better to give in to certain pressures that he faces, rather than resist them. Some producers develop special relations with the office, the former canalero confides in me. The canalero cannot prevent that, he opines. This did not change in the past and will not change in the future. Following the current means that the canalero cannot always regulate the flow and control access to it. However, it does not imply mere passivity.

The following experience will illustrate how a canalero acquires competence in dealing with particular social, material and spatial complexities through 'on-the-job-learning'. As a result of a managerial decision, Laguna switched sections with his colleague, Icazar, during the 1998-1999 season. These switches often occurred, although usually not for a long period. It was different this time. Before, Icazar had mainly worked in sections 4 and 8, which are located close to his native village, San Isidro. Those sections are characterised more by the surface irrigation of food crops, such as rice, sorghum, and maize. This is the first year Icazar has worked in tobacco section 5 .

During his first month, I meet Icazar in the field. From his sweaty face and the desperate look in his eyes, I can tell that he is having a hard time. When I ask him about it he complains that, unlike Laguna, he does not know this section. A major problem is that there are so many different producers, whom he does not yet know. The difference, he argues, is that Laguna has already had several years of experience and consequently could drive around in a more relaxed fashion. He thinks that the people are 'más cabrón', which translates best as 'more difficult' here, whereas people in other sections are more easygoing. He goes on to explain that when he passes the 10 in the morning he only sees one pump, but when he returns at midday there are suddenly five more sprinkler installations pumping from the canal. 'The people just place their pump and start to irrigate. As a result, the water does not reach the end of the canal so the farmers there start rebuking you'. Initially, he became angry and told them that they should inform him when they want to irrigate. In the section where he previously worked, he was not used to such a majority of producers not informing him of their intention to irrigate. After some time in section 5 , he realised that it was no use, because there was slim chance that the tobacco producers would start informing him. According to Icazar, most producers do not understand the need to inform him and just take water, because they are unaware of the consequences further downstream, where there can be a lack of water.

Another example shows that Icazar is also acquiring a competence in making use of the important task that he fulfils in administrating the financial agreement with the tobacco companies. After a few months in section 5 , he realises that the significant revenue flow that he generates through his administrative efforts dries up too quickly when they pass through the hands of the management. He fears that in the coming months their salary payment will suffer because of that. Hence, Icazar resists pressures from his superiors to speed up this work and deliberately delays collecting the signatures that the WUA needs for the effectuation of the payments. He attempts to spread the revenues over the season so that there is sufficient money for the salaries. 


\section{Managerial control and labour relations}

The direct involvement of Laguna's superior, Guttierez, with his work as a canalero is limited, and Laguna interprets this as a lack of commitment and support. In contrast to this, Guttiérez' expectations are high and his occasional instructions very forceful, according to Laguna. He expects a quick response when he instructs him to immediately give water to a particular farmer, or pushes him to finish seeking out a list of tobacco producers that he wants to submit to a tobacco company for their fee payment. Laguna is dissatisfied with the fact that, in exchange, his superior does not support the canaleros when they are pushing for higher wages or when they have a conflict with farmers. It is a general complaint among canaleros that Guttiérez easily gives in to the producers that come to him with complaints or requests and authorises them to take water or overrules the canaleros' decisions. This, they feel, undermines the canaleros' authority vis-à-vis these farmers.

In addition, the manager's political group has certain commitments with a group of favoured large producers who have effectively been given privileged access to irrigation water for the rice, maize, sorghum and pasture that they produce. The canaleros are expected to take this into account. Some of these large producers can contact Guttiérez and the canaleros directly, because they have access to the same radio frequency. This makes it possible for them to quickly request an irrigation turn, demand more water from the canaleros, eavesdrop on their conversations and communicate with the manager. In effecting water distribution, Laguna is well aware of the commitments that the board and the management of the association have with particular, powerful producers in his zone. Although he does not always respond to their wishes for a quick irrigation turn or more water, Laguna complains about the fact that the management undermines his authority, because they often support the claims of farmers, because they have commitments or are engaged in a political campaign. As canalero he has to deal with such contradictions. The problem remains the same with these producers. Guttiérez' position is ambiguous in this matter. When they complain about it, he tells the canaleros not to give any of the favoured producers more water, but at the same time he does nothing to prevent them from demanding it.

Laguna starts to spout out his criticism of the board and management of the association, and how the canaleros' difficult position results from their activities. He warns me not to get the wrong impression from the stories and behaviour of the manager, who creates the impression that he is dynamic and hard working. He criticises the fact that the current group of the ex-president and local diputado Pérez, the president Nuñez, and the manager Guttiérez form a closed group that decides on everything that happens in the association. Neither the association delegates nor the CNA are able to control this group. He berates the 'corruption' that the group practices, the resources that they extract from the association, the privileged access to water they give to a select group of favoured producers and the machines that they use for trabajos particulares (private jobs) outside of the irrigation district.

Laguna is especially critical of his own superior, Guttiérez, who lacks the expertise for his job, he says. He simply obeys his patron, Pérez. Laguna argues that Guttiérez does not do his job well and that what he does is not very difficult. He illustrates this with some 
examples. Once, for instance, Laguna took over Guttiérez' job for a short time and came to that conclusion. In addition, Guttiérez does not really know what the work of the canalero entails. On one occasion, when Laguna was on a short vacation, Guttiérez permitted a farmer to open an inlet structure with a very steep slope, in spite of the lock that he had connected to it. On this site it often happened that women opened up the inlet in order to wash, without knowing what they caused at the tail-end, so he kept it locked. Guttiérez gave permission to remove the lock by force and ordered the opening of the inlet with twenty turns of the hand wheel, on the assumption that it would deliver a flow of forty litres per second. In reality, it turned out to be ten-fold that amount and this led to large-scale flooding at the bottom of the canal. According to Laguna, Guttiérez not only failed to see the consequences of his actions, but also undermined the authority of the canalero, by giving permission to remove a lock.

A major underlying source of frustration for Laguna is the canaleros' poor working conditions, for example their low salary, just a third of what their superior earns. In spite of this, their superiors are still very demanding. In addition, the payment of their salaries is erratic, their contracts are temporary and they have no medical insurance. It happened on several occasions that, when the association was out of money, Pérez pre-financed all the salaries of the personnel. The management presented this as an act of benevolence and commitment on the part of Pérez, strengthening the sense of personal obligation and dependency. Laguna has pleaded for a salary increase or insurance, but to no avail. He deplores the division amongst the canaleros and the fact that they do not have a union. Because the WUA management directly controls the working conditions of the canaleros, they are able to practice a sort of 'divide and rule' over them.

Although in private Laguna is very cynical about the association's management and his own working conditions, he usually does not express his criticism of his superior in public. He only trusts a limited group of confidants in these matters, such as his engineer colleagues. Only occasionally has he open confrontations with Guttiérez. These conflicts emerge especially in times of high work pressure and when the salaries are not paid. Several times they resulted in Guttiérez threatening to fire him. Laguna is really concerned about the risk of losing his job, because with a young pregnant wife and a new house he needs a steady salary. 'They can make your life and work very difficult, so that you have to resign yourself, he explains. In the past, several of his colleagues did not get their contracts renewed, because they were accused of taking bribes. Laguna suspects that they were actually too critical for the management. At the same time, Laguna knows that Guttiérez will not carry out his threats, certainly not during the irrigation season. $\mathrm{He}$ needs Laguna, because he does his job well.

\subsection{Conclusion}

The observed water use practices demonstrate that self-interest amongst farmers leads them to break operational rules, and this generates not a consensual equilibrium outcome but a conflict of interest. Head-end farmers who do not request an irrigation turn are not confronted with the consequences of their behaviour in the way that tailend farmers are. The canalero's role here is to mediate and curtail the effects of these patterns of behaviour. 
A canalero does not acquire a competence in dealing with such control problems through a formal education, courses, or operational rules. The role of more experienced canaleros is also limited. Rather, Laguna acquired a detailed knowledge of the idiosyncrasies of his section and the complexities involved in water distribution mainly through learning in the course of his work. Over time, this experience taught him skills, such as how to maintain a water level in a canal, anticipate and respond to the unpredictable patterns of water demand, and negotiate between the demands of different groups of irrigators and his superiors concerning water distribution.

Much of the embodied cognition and competence that canaleros use on the job is acquired implicitly without the intention to learn or awareness of having learned (Spaeth, 1999). Therefore, to understand it we should address the tacit, implicit or subconscious dimension of such cognition (Baumard, 1999; Sparrow, 1998; Sternberg and Horvath, 1999). "The tacit knowing which shows itself in the intelligent action of a practitioner' is called 'knowing in action', by Schön (Schön, 1983). It concerns the skills, tacit feel (Sparrow, 1998), or know how of a practitioner. I refer to a kind of cognition that is implicit in the competent performance of a practitioner and that is not necessarily readily accessible as conscious rules. Laguna demonstrates in his water distribution practices a tacit knowing or feel, which he acquired largely by 'learning by doing' and on-the-job-training.

These competent practices of a canalero are not a commodity that can be transferred from place to place and cannot be expressed in terms of official rules of conduct. Rules are so variously interpreted and so loosely enforced that one cannot define a uniform standard of competent practice. If one is to understand people's behaviour at work, one needs to recognise their expertise, regardless of the degree of formality in its development. One needs to recognise its multiplicity, rather than seek the single set of rules that best characterise it (Sparrow, 1998).

Hence, it is not a set of allocation rules that determines water distribution, but rather a service relation that has persisted despite several bureaucratic reorganisations, in which the canalero mediates between officials and farmers (Mosse, 1997). This corresponds with van der Zaag's observation that a professional group of canaleros assumes an intermediary position and derives a competence from their experience with the irrigation system and day-to-day water distribution (van der Zaag, 1992). The case study presented in this chapter contributes in two ways to these insights.

Firstly, the canalero's authority and competence over water distribution are contested on a regular basis ${ }^{12}$. In section 5 of the irrigation system, Laguna's authority and competence are frequently subverted by tobacco producers and bomberos. They bypass the canalero by irrigating without getting his permission or paying fees. But his superior also circumvents him occasionally, by giving producers permission to take water or break a lock. Operational rules do not provide straightforward solutions to the many problems of control, and lack of it, that canaleros experience. In actual water distribution, canaleros have to anticipate, adapt and respond to the immediate material and social demands they are posed. Their success in positioning themselves as obligatory passage points (Latour, 1987) or effective mediators differs. Laguna's experiences on the 10 in this respect are slightly more extreme than in other parts of his sections. However, the 
conclusion that operational rules do not necessarily determine actual distribution practices applies to the system as a whole and beyond.

Secondly, the canalero's competence is contested and embedded in concrete social, material and spatial relations (Hutchins, 1995). Laguna's experience became evident in his dealing with the specific combinations of sprinkler irrigation and small-scale tobacco production. This point came across even more clearly through Laguna's colleague who succeeded him in section 5 . First he experienced, and then had to learn how to deal with, its complexities. Even so, this does not imply that this type of cognition or the learning process is purely personal and that it cannot at all be exchanged or transferred. Of course, there is significant overlap in the canaleros' experiences with crops, irrigation technologies, farmers on the Left Bank; and most canaleros have worked for some time in other sections. Yet, they have developed a greater degree of competence and experience in the sections of the irrigation system where they have worked for the longest period.

'Following the current' as a statement perfectly reflects the canalero's predicament. From his position, it is sometimes difficult to regulate water demand, exclude farmers from access to water, and impose sanctions when necessary. Therefore, he is unable to resist particular pressures and has to 'follow the current'. However, this does not mean that the canalero is completely at the mercy of what irrigators decide to do. He responds actively, and his actions have important effects. Laguna's competence lies precisely in dealing with such 'problems of control' and in curtailing their negative consequences. $\mathrm{He}$ has learned to anticipate the unpredictable water demand and respond to the social and technical difficulties of distributing water and controlling its use. For instance, he monitors the water levels in the canals, adjusts structures and water flows accordingly, divides water on the spot, settles conflicts, negotiates with farmers, sometimes tells them to await their turns, or he requests more water from the dam. In addition, he anticipates particular problems by programming more irrigation turns than strictly required, in order to have sufficient water in case of unannounced irrigators. By putting locks on inlet structures, he prevents farmers from taking water or causing floods. He also avoids conflicts over water and takes care that the water requested by tail-enders really reaches the tail-end. The canalero's participation in water distribution is much more a de-centred and adaptive performance (Richards, 1985) than a centrally regulated one.

My conclusion is not that operational rules have no relation whatsoever to the distribution and use of water. Operational rules are not just bureaucratically imposed and completely meaningless to the daily practice of the canalero, even when they are not supported by effective incentives or sanctions. Admittedly, the three-day rule seems to originate from old bureaucratic management prescriptions, which did not take into account local irrigation practices and seem to apply more to surface irrigation. However, Laguna especially employs it discursively when he explains why water distribution is such a complex undertaking and why he is not to blame for the negative impacts of mismanagement. The three-day rule seems to embody an idea of the ideal and orderly practice of water distribution that canaleros have. Referring to the rule serves the symbolic purpose of demonstrating that they, as canaleros, are not responsible when, for instance, they cannot deliver an irrigation turn on time. It legitimises their role and performance as canaleros, whilst extending the blame or unleashing their frustrations towards the users, or in other cases the management. It is striking that the canaleros 
especially are starting to use the term los usuarios (the users) instead of producers, ejidatarios, or tabaqueros, in association with this rule. It hints to a concept of a 'good user' and a normative idea of conduct (Law and Akrich, 1994).

Operational rules define a proper and rational conduct and ascribe a certain identity or label to real life actors (Wood, 1985). They prescribe a normative idea of conduct for organisational actors with fixed identities and rationalities. The rules posit an image of 'the good water user', a rational and disciplined user who is willing to pay a certain fee on time in exchange for a specified service, namely timely and adequate water allocations (Law and Akrich, 1994). At the same time, the image of a 'competent manager' is constructed. WUA managers are assumed to be the centre of decision making, competent and authoritative individuals (Meinzen-Dick et al., 1995) and agents with a circumscribed area of authority or competence. They ought to be capable of programming and controlling water distribution from a distance by means of rationalised and centred procedures of water distribution planning. Proper sanctions enable them to discipline the conduct of rent-seeking subordinates and free riding water users in operating infrastructure and regulating access to resources such as water. Operational rules are often used more as a standard, norm or ideal of orderly and rational irrigation management. Neo-institutional models of organisation that presume that sets of agreed rules and incentives determine irrigation management are often better at projecting a normative image of what should be done than at describing what is actually done in practice.

\section{Notes}

$1 \quad$ Field notes, February 1998.

2 According to Ostrom (Ostrom, 1990), such operational rules are nested in collective choice rules and constitutional rules which govern the process of rule making and the eligibility or legitimacy of the governing authority. They prescribe when, where and how to withdraw water, how to monitor the actions of users, what information must be exchanged or withheld, and what rewards and sanctions will be assigned to actions and outcomes (Ostrom, 1990: 52).

3 It is only recently that studies on field workers in irrigation have filled this gap: e.g. the bailiff in Zimbabwe (Manzungu, 1999) and canal operators in Peru (Vos, 2002).

4 I thank Alex Bolding for some of these observations made above.

5 Bolding and van der Zaag (2001) use a similar concept which they call 'water networks'. I prefer not to use that term here, because I want to keep the possibility open that resources other than water can come to dominate such a network.

- Land reform communities created after the Mexican Revolution of 1910. Before the revision of Article 27 of the Constitution in 1992, ejido land belonged to the state, with a combination of community (ejido) and private (ejidatorio) usufruct. Ejido members are called ejidatarios.

Annex 5 of the 'Titulo de Concesion' (CNA, 1993).

Old District documents from the 1970s already mention this term of three days.

9 If, for some reason, a crop has been established before fee payment, it is legally impossible to refuse water to this crop.

${ }_{10}$ At a later date, the current president of the association asked him if he would be his compadre at the baptism of his daughter, as both were working closely together with him.

"I Iill use the term 'water user' only when it is explicitly mentioned by documents or interviewees.

12 Although van der Zaag gives several examples of this, it is not made part of his conceptual deliberations in a satisfactory manner. 


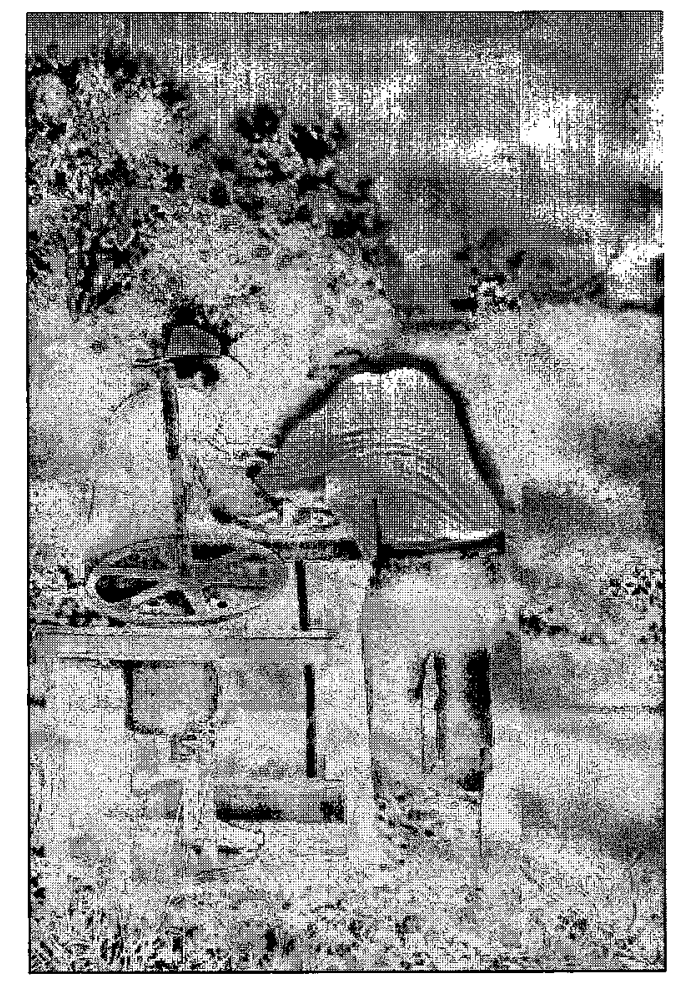

Photo 10 The canalero and an irrigator closing an inlet

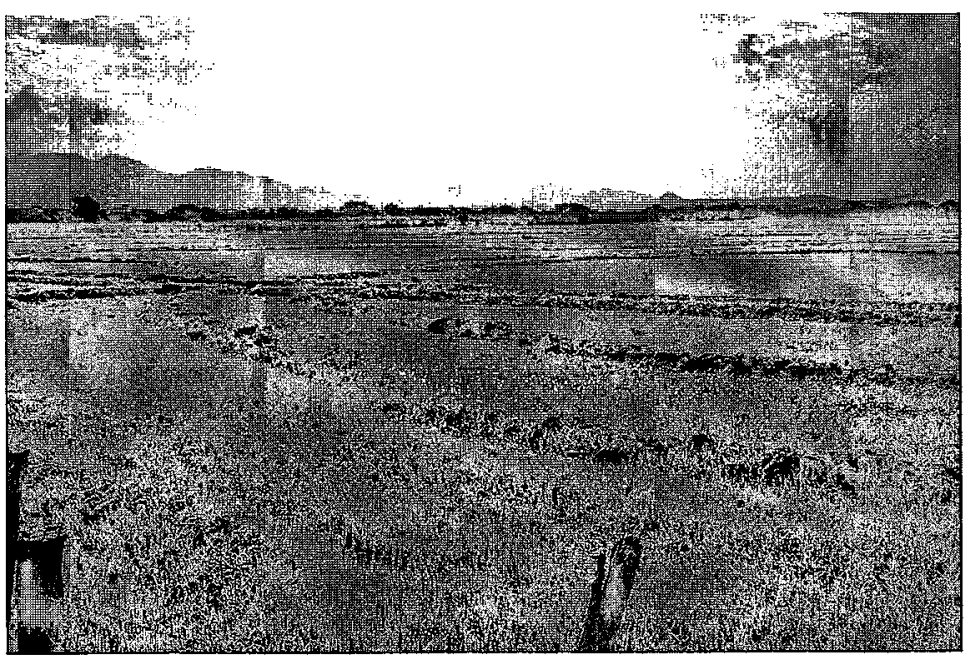

Photo 11 A rice field with bunds 

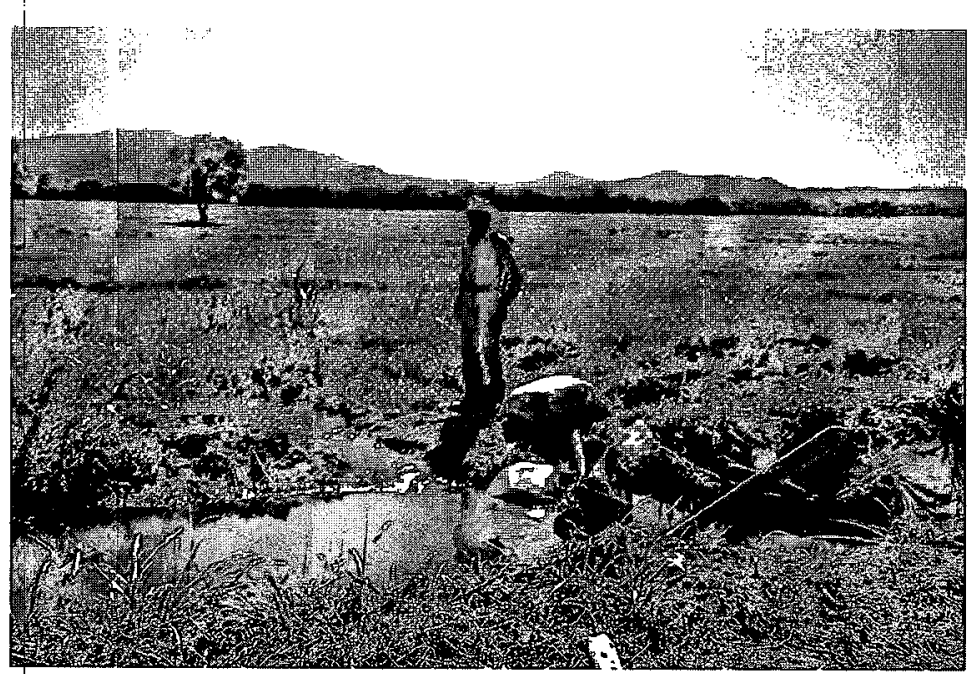

Photo 12 An irrigator working on an irrigation furrow 


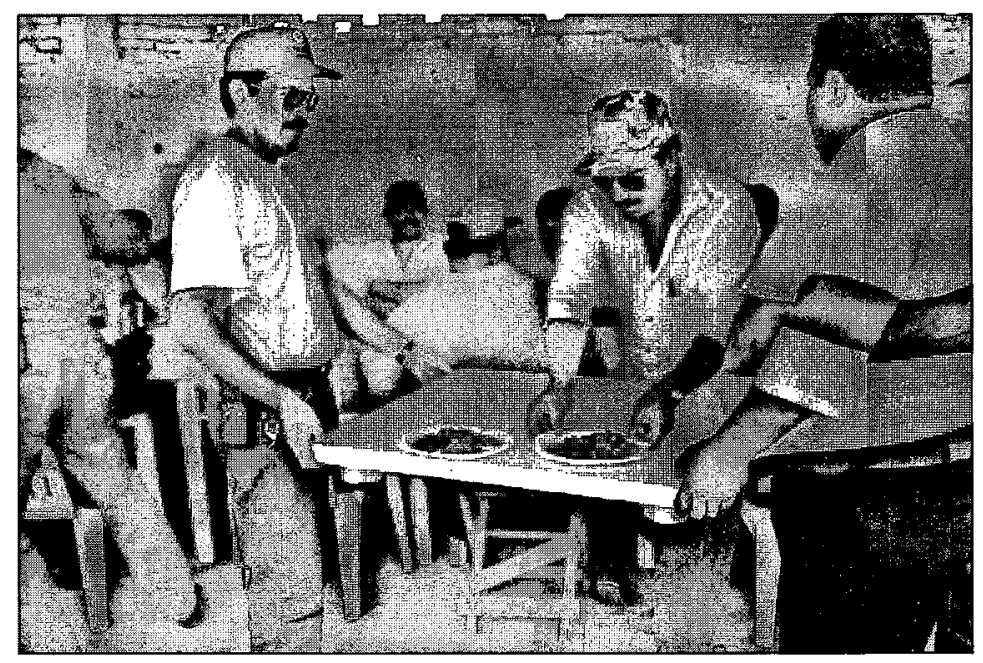

Photo 13 Canaleros distributing food 


\section{6 \\ The Client in a Political Group: The case and place of a canalero}

For a Mexican, life offers the possibility to 'chingar' or to be 'chingado'. That is to humiliate, punish and offend. Or the converse. This concept of social life as struggle fatally engenders the division of society into strong and weak. The strong - los chingones, without scruples, hard and inexorable - surround themselves with keen and interested faithful followers. Subservience towards the powerful - especially among the class of the 'politicos', that is of the professionals of public affairs - is one of the deplorable consequences of this situation. Another, no les\$ degrading, is the adhesion to persons and not to principles. Frequently, our politicians mix public with personal affairs.

Octavio Paz, my translation (Paz, 1994).

\section{DRAMATIS PERSONAE:}

Diego Guttiérez

Guttiérez

Pérez

Nuñez

Laguna

Icazar

Ejidatarios

Pequeños propietarios

Dominguez

Quiroz

Dario

Becerra

Network of favoured producers

PROPS:

Irrigation infrastructure

Canal structures

Crop

Weeds

Rice fields

Bunds

Constant water flows

Drink

Food

Albures

Music

Irrigation fees

Information flows

Motor bike

Radio

Maintenance machines canalero and client

manager of the WLA, Diego's cousin, superior and compadre

Diego's patron, former president of the WUA, local deputy and large producer and leader of a political group

president of the WUA

canalero, engineer and Diego's upstream colleague

canalero, engineer

members of ejidos

private producers

superoising canalero and upstream colleague

canalero, engineer

canalero, tail end colleague

CNA district head and former head of operation

Frederico Haro, Norberto, Aguirre, Bernardo Ulloa

network of connected canals and drains of distinct leoels

cross-regulatros, sluices, intake structures

rice, sorghum, maize

wild rice

rice plots with bunds and irrigation furrows

borders that divide up the rice fields in blocks

Pactfico beer

seafood, meat, tortillas

jokes with a double meaning and a sexual undertone

machinery to carry out maintenance of irrigation works 


\subsection{Introduction}

In the preceding chapter, I have analysed the group of canaleros (people in charge of the distribution of water at field level) of the Left Bank irrigation system, like Van der Zaag (1992), as an occupational community with a shared body of practices, a culture, and an understanding of irrigation management that is rooted in past practice. Under the Water Users' Association (WUA), this group has become fragmented and divided in contrast to the close group that van der Zaag depicted under public management. The transfer of the irrigation system and the formation of a political group within its boundaries have reinforced this fragmentation. There are several reasons for this:

Firstly, the WUA employed canaleros with distinct professional and educational backgrounds and qualifications. Secondly, the transfer of the irrigation system to the WUA has eradicated a generation of experienced canaleros. This rupture with the past has altered their process of initiation, socialisation, learning and group formation. Under the former bureaucratic management, new canaleros were supervised, trained and initiated by the older canaleros, who passed on a body of knowledge, practices, understandings on how to cope with particular complexities and conflicts in their work situation, as well as rules and norms of group behaviour and loyalty. Sharing this base was important in engendering a group culture. This was reflected in their respect for a retired canalero who initiated more than half of the group and acted as a sort of father figure to them. Such a process can be instrumental in the formation of hierarchical group relations embedded in a certain mutual respect and loyalty and in producing a practical distribution of tasks and cognition (Hutchins, 1995). This process of group formation was interrupted when the association took over the operation of the infrastructure. After transfer, canaleros were hired and fired more erratically. Thirdly, political and patronclient relations intermingle with employment relations among the WUA staff and in the canaleros' group. The political group that has established itself in the WUA privileges its clients, and these clients are expected to be loyal to the group in return. The canaleros who are not clearly identified with the political group are to a lesser extent subject to similar clientelist expectations. Under the new management regime, labour relations and working conditions have significantly deteriorated for the canaleros. As they are no longer protected by unions and fixed contracts, they are subject to increased job insecurity and financial dependency on the management. This has created the possibility for the management to 'divide and rule' over the group of canaleros, playing on their differences and dependencies and securing their divided loyalty.

These de facto changes that irrigation management transfer (IMT) has generated demonstrate the importance of something that is often taken for granted in policy approaches that consider irrigation management reform as merely a technical matter: resource allocation cannot be culturally disconnected from political and patron-client relations. In the case of the canaleros, it becomes clear that their work is not just evaluated on professional or technical criteria, but also in terms of cultural expectations associated with the clientelist relations in which they are engaged. To further elaborate this point, I will present the case study of the canalero, Diego, who is a client of the political group that controls the WUA on the Left Bank of the River Santiago. Because Diego is part of this group, he has a privileged position and does his work differently than the rest of his colleagues. This case will address the need to revise conventional 
sociological models that take patron-client relations to be straightforward, unilateral and vertical, in which the patron monopolises the power and resources on which his clients depend. These top-down models fail to explore the actual operation of clientelism at the everyday level. By focusing on the role that the client in this case plays in the distribution of various material and cultural resource flows, which are essential in the reproduction of the political group, I will refine the analysis of patron-client relations.

\section{Political groups and clientelism}

Political groups are made up of patron-client relations. In existing analyses, clientelism presupposes strong economic and power inequalities in which a patron monopolises the resources that are vital for his clients. According to such a perspective, political groups are manifestations of personal links motivated exclusively by material interest, and held together by fear of their leader, who obliges the members to act in conformity with his objectives (Hernández Rodríquez, 1997). This reduces the clients of a political group to mere subjects of the patron's power and dependent upon his control over resources. Such a unilateral image of patron-client relations within a political group is problematic. This case will show that a leader does not monopolise all the power and resources of his group and that group members and clients play a culturally competent role in organising access to the resources that are important to the group and its leader.

As Larissa iLomnitz points out, the prolonged nature of patron-client relations is associated with cultural variables and moral principles such as confianza (trust) ${ }^{1}$, compadrazgd (ritual kinship), loyalty, and friendship (Adler Lomnitz, 1994; Lomnitz, 1977). In splte of the dimension of subordination in the (patron-client) relationship, it is perceived, both publicly and privately, as evolving from friendship or kinship bonds (Enge and Whiteford, 1989: 171). The durability of these networks is derived from the identification with shared cultural and normative values, ideas and aspirations that develop bedause of a daily working relationship. In Mexico, political groups often share specific cultural values. Confianza is the cultural base of existence of an equipo (team or group), not only in personal loyalty but also in work performance. A relationship of personal trust is important, but not in a manner that is blind to the competences and experience of a co-operator (Greenberg, 1970; Grindle, 1977; Hernández Rodríquez, 1997). Another related cultural element underlying the functioning of political groups is cuatismo. Lomnitz defines it as the Mexican form of male friendship. She emphasises the role of alcohol in such friendships (Adler Lomnitz, 1994). Family and compadrazgo relations are also elements that strengthen the bonds of political groups.

The power of a patron is often based on his influence, which enables him to place close associates in different jobs to which he can delegate functions (Adler Lomnitz, 1994). In the politics of appointments, at times administrative spaces are shared with other groups, but a politician delegates the most important functions to those he sees as talented and competent people. This creates the need for both capacity and confianza, or better: reliability (Hernández Rodríquez, 1997). This is associated with the interrelation between political groups and the bureaucracy in Mexico and the way in which the political calendar dictates the replacement of politicians and high officials after every sexenio (the ssix-year presidential term) (Camp, 1993; Grindle, 1977). During the sexenio, a patron needs not only to improve his own position, but also to prepare the way for his 
close associates as potential successors and place them in strategic political or bureaucratic positions. In addition, the group needs to free the resources and build the support necessary to fulfil its shared aspirations to ascend. A political group thus assumes a distribution of organisational positions and tasks, and professional as well as cultural competences that are employed in the distribution of resource flows and the reproduction and advancement of the group.

In order to analyse the political group that controls the management of the Left Bank WUA, I make flexible use of existing definitions of social networks (Auyero, 2000; Hernández Rodríquez, 1997; Long, 2001). A political group is a social network with an inner and an outer circle of relations. The inner circle of a political group is composed of the closest followers of a leader, with whom he shares political and administrative experience, professional trajectory, and aspirations of power and career building. They are people who work directly and intensely with each other and develop strong ties of long-lasting friendship, parentage, or fictive kinship, and a mutual sense of loyalty. This inner circle helps the leader with the distribution of goods, problem solving and information gathering (Auyero, 2000). The outer circle is composed of a more extended, loosely-knit network of weak ties with friends or acquaintances of the leaders of the group (Long, 2001). This outer circle of a political group is maintained or extended through its capacity to deliver special favours, goods, services, or information. Hence, these are affinities and commitments of a different duration (Hernández Rodríquez, 1997). It is important not to view a political group as a static whole. Throughout its development, new leaders emerge, whereas older ones lose ground, just as the network gains and loses members, and changes in composition and in the range of organisational domains and positions that it encompasses.

\section{Diego}

The inner circle of the political group that controls the Left Bank association consists of the patron, Pérez, the up and coming leader, Nuñez, their subordinate, Guttiérez, and several of their clients among the personnel. This hierarchically arranged group is again part of a large political network dominating politics in the state of Nayarit. The outer circle of the group is extensive, but in part consists of a network of several favoured large producers who are favoured clients and enjoy privileged support and access to the association's resources.

Diego belongs to Pérez' equipo. In 1993, Diego participated in the CNA course and examination organised to select personnel for the newly established associations. On completion of the course he was employed by the association, after Pérez had become president and his cousin and compadre (co-parent), Guttiérez, its manager. Because the patron Pérez, first president of the association and current president of the control committee, provided him with a secure job and other privileges, Diego can be considered as his client. Specifically, Diego's colleagues see him as part of Pérez' group. He never expresses it himself as such, but his behaviour and statements make it obvious.

Diego has known Pérez from as early as his preparatoria (high school) days in Villa Hidalgo. Over the years, the Guttiérez and Pérez' families maintained close relations, not only at social events, but also by sharing political preferences, relations and posts in 
local producer and political organisations, usually related to the Partido Reroolucionario Institucional (PRI). Diego harbours an ambivalent mixture of feelings for his patron: admiration, friendship, deference, disapproval, loyalty and fear. He usually respectfully calls him el ilicenciado (referring to Pérez' university education as a lawyer) and only occasionally juses his first name, Gonzálo. Being part of Pérez' group creates particular expectations, obligations and responsibilities regarding his work as a canalero. At times he is critical of his superiors because of that, but usually he complies.

That Diego is a client of Pérez has influenced the choice of the sections in which he works. Since 1993, he has worked most of the time in sections 6 and 11, which are located in the middle stretch of the Left Bank system and receive water from the main lateral 19 (see Map 6). This area mainly covers the ejido land of the four ejidos based in Villa Hidalge and several smaller ejidos in its environs. Diego knows the area in which he works like the back of his hand, because he was born and grew up here. Among the farmers from Villa Hidalgo, both ejidatarios and private landholders, he has many friends, neighbours, and acquaintances. For him it is a good place to work. It is close to Villa, where he lives, and he knows all the canals and the producers there. Diego points out that the experience that a canalero has in certain sections is very much related to the canal lay out, the people, the crops, the water availability, etc. in those particular spatial settings. As I have argued in Chapter 5, a canalero's competence cannot automatically be transferred to other sections because of the idiosyncratic social, material and spatial arrangements in which it is embedded.

\subsection{Diego as a Cultural Agent}

\section{A pleasant acquaintance}

Diego always made a big impression on me. The image of his corporeal magnitude planted on a| motor bike remains forever imprinted on my retina. On the Northern Coast of Nayarit there are many people who are as big as Diego, but he was my first real acquaintance with someone so extremely heavy. He manifests an amusing awareness of his bodily presence. On one occasion, I give him a photo of himself portrayed in full glory. With a smile he points at the photo and proudly refers to his personalidad (personality).

On one of the first days that I spend at the association's office, I get to meet many new people, amongst them Diego Guttiérez. I am not the most important visitor today. The CNA District Head and some of his subordinates from Tepic are also in the office. He has come to check a financial agreement concerning rehabilitation measures with the association's manager, Guttiérez, Diego's cousin and superior. After Guttiérez has made some promises concerning the allocation of financial resources to a maintenance programme supported by the federal government via the CNA, the District Head is satisfied. Then, the association president, Nuñez, and Guttiérez invite the visitors to eat with them. We go by car to a seafood restaurant just outside Villa Hidalgo. With the CNA personnel and some association personnel we sit around a table for an extremely lively lunch in the open-air restaurant. A thatched roof protects us from the sun, and a light breeze pleasantly tempers the humid heat. 
I am seated next to Diego and I immediately like him because he cracks a lot of jokes and keeps putting cold Pacifico beers in front of me. This is the brand of beer that, as the name suggests, people drink along the Pacific Coast of Mexico. He takes them from a bucket of ice that the waitress has placed next to him. He ensures that the bottles arrive shortly before I manage to finish the current one. Diego looks after the visitors and the other important people at the table in this way. A large variety of seafood appears on the table, fresh from the Pacific Ocean or the local estuaries and nearby lakes. Diego explains to me how to peal the shrimps, and eat the ceoiche (raw seafood with lemon, salt and chilli), and the smoked fish with a tortilla, Huichol sauce and a squeeze of lemon. All this seafood is so typical of this coastal region. Apart from looking after others, he takes care of himself and enjoys the beer and the food in considerable quantities and with an admirable tempo. The other canaleros also feast upon the good food and the beer, but in more moderate quantities that match with their slimmer physiques. They remain silent and in the background.

The conversation is cheerful not least because of Diego's clown-like behaviour, one hand resting on his belly. Several jokes around the table refer to Diego's physical condition. The men start to exchange albures, jokes with a double meaning and a sexual undertone, which produce a hilarious atmosphere in the group. I exaggerate my amazement about the frequent humorous allusions of the men to sex among males. I tell them that this is something I experienced for the first time here on the Northern Coast of Nayarit. In the much more conservative states of Jalisco and Michoacán, I was never informed about the existence of anything of the sort. The men die of laughter when I claim that such a thing can only be witnessed here and that we do not have anything of the sort in my country.

The humour of these men is full of corporeal abundance and pleasure, sexual depravation and alcoholic enjoyment. Diego plays a key role in this, and not only by his voluminous presence and the way he casually hangs in his chair: his jokes also become ever more daring, by offending the political enemies of this group. Spirits rise and more bottles appear on the table. With his rough language and decreasing respect for absent moral and political authorities, he shows that he does not care much anymore about standards of correct behaviour, something that only adds to the fun of his audience. He is like a jester who creates atmosphere in the group.

Because of the good mood, it is decided to hire a group of musicians to play some ranchero songs for us. Diego negotiates with the musicians over the price we are to pay them per song. Guttiérez asks the visitors in our company, the District Head and myself, to choose a song we would like to hear. The blaring jukebox is silenced and the musicians start to play. The requested songs put us visitors in the spotlight. The District Head appears to enjoy the respect that he is paid as an important person in this manner. After these two songs, Guttiérez requests a song. On his cue, the musicians start to play. With a deep, dark and resounding voice Guttiérez himself sings the song that glorifies the beauty of Nayarit. He demonstrates his vocal skills with the dramatic long notes that he draws at the end of a strophe. We all drink more. When darkness has already fallen, the District Head suddenly decides that he is returning to Tepic. He thanks his hosts, Nuñez and Guttiérez. The CNA staff rise, say their goodbyes to the WUA personnel and get into their pick-ups with a satisfied look on their faces. I say farewell to Diego and watch him make his weaving way to his motor bike, then ride straight home. 


\section{A family and life history}

The Guttiérez family comes from the village of Pueblo Nuevo, which was later renamed Villa Hidalgo. Their father worked there as a hacienda administrator. From the 1930s onwards, the Mexican government started to distribute the land of five or six large latifundios (vast rural properties) that owned most of the land in Nayarit, and the old haciendas collapsed. However, like most other hacienda employees, their father did not register as an ejidatario and apply for land. After living for a period in a nearby village, the family came back to Villa Hidalgo in 1950 and, a few years later, the father bought three eight-hectare plots for each of his sons in the ejido of Solorceño. This is one of the four ejidos in the village. During the fifties, all this land was incorporated into the irrigation district. Like most other ejidatarios, the three young men engaged in tobacco cultivation. They produced tobacco for a Mexican, and later a multinational, tobacco company that worked in the area. They did well during this period in which the tobacco industry brought a lot of prosperity to the region. After the nationalisation of tobacco in the 1970s, one of the brothers worked as field supervisor for the parastatal Tabamex and another for a local sugarcane refinery.

When Diego was a boy, his mother died at a young age. His father, who was one of the aforementioned three brothers, soon re-married and started a new family. On the Northern Coast it is not at all uncommon for a man to marry more than once and/or have several children, acknowledged or not, with different women. Although his father remained in Villa Hidalgo, Diego had to go and live with the rest of the Guttiérez family who more of less adopted him. As a consequence, he still bears a strong grudge towards his father and does not get along well with him. He dislikes his half-brother. Instead, Diego interacts a lot more with his uncles and cousins, especially with his cousin Guttiérez, who is the same age. As a boy, Diego worked in a local Tabamex plantero (nursery) close to Villa to earn some money. This was in an era when tobacco cultivation was pervasive around Villa and most ejidatarios made their living from tobacco. Nowadays tobacco has lost its importance in the area and more and more people are planting sorghum ${ }^{3}$. Diego enjoyed a lower agricultural education at one of the regional agricultural colleges. He calls himself 'technical advisor' on that account. After graduation, Diego worked for two years for a local Tabamex laboratory. There he saw a significant decrease in the cultivation of tobacco around Villa, due to deteriorating prices and a widespread attack of a fungus disease called 'Moho azul' (Blue moth).

Diego married before he was twenty years old. Soon afterwards, his first and only child, a daughter, was born. After the dissolution of Tabamex and the economic depression of the 1980s, Diego worked for some time as a butcher's assistant in the local market of Villa Hidalgo, because no work in his field was available. Diego was in his thirties when he started working as a canalero for the association in his native village, Villa Hidalgo. According to Diego, it is not easy to provide a living for his wife and daughter with his current wage. Here his experience as a butcher's assistant comes in handy. At the weekend, he runs a small taco stand together with his wife near his house to complement his wage as a canalero. Although Diego is not an ejidatario - his father still holds on to his own plot of land in the ejido - he normally cultivates small plots of rice of two to three hectares, which he usually borrows from a favoured producer. However, he does not earn a lot of money from it. Although in principle this activity might give him 
some additional income, in practice he is not very successful and barely earns a profit, because of the low quality of land and seeds that he is given, or because of lengthy flooding of his plot.

Occasionally, Diego has marital problems - not incomprehensible - regarding his drinking behaviour. However, he never talks about it. In spite of my asking him to introduce me to his family, he never complies with this request, as if he is somehow ashamed to invite me to his modest house. It remains a mystery to me exactly why. Once, when we are drinking, he says that he wants to enjoy his life now. Totally unexpectedly, he confides in me that he does not want to live to be fifty years of age. Surprised, I ask him why, but he shrugs his shoulders.

\section{A family birthday}

On Guttiérez's father birthday, I get to meet Diego's uncles. Only Diego's father is absent. As on most other occasions, Diego does not bring his wife or daughter. A brother of Guttiérez's mother and his son are visiting especially for the occasion from San Pedro Lagunillas, the village in southeastern Nayarit from which Guttiérez's mother originates. This village lies towards the state of Jalisco. I am in the company of Diego, Guttiérez and their visiting cousin drinking beer. We stand around a brass tub in which the meat of an entire pig is being prepared in its own fat, as is the custom at such parties. Whilst Diego is fishing the chicharrones (fried pieces of pork skin) out of the boiling fat, we are discussing their cousin's region of descent, which lies in the southeastern part of Nayarit and borders the state of Jalisco. To go there from the coast, you have to cross a large mountain range and foothills that are connected to the Sierra Madre. It is a region where traditionally a lot of sugarcane is produced for the sugarcane refineries in Iztlán del Rio and Tepic. The climate is much more temperate than the sub-tropical coastal regions. Many people from Nayarit have pointed out to me that the Northern Coast of Nayarit is not only geographically separated but also culturally distinct from other parts of Nayarit. For instance, culturally the southeastern region of Nayarit that we are talking about is closer to the ranchero and mestizo rural groups of Jalisco. The northern coast of the state is culturally thought to be closer to los norteños from the northern states of Sinaloa and Sonora, in custom, people, food and beverages.

Guttiérez states that in his cousin's village the people live much closer to their rural roots than here on the coast. They still ride horses, something that is rarely seen around here. Guttiérez and Diego recount their visit to the village when they were boys. They recall the time that Diego climbed on a horse and was thrown off again just as quickly. Since that day, he has never mounted a horse again, he solemnly swears. The story is even funnier when I imagine Diego's corpulent body flying through the air. Then it strikes me that both Diego and Guttiérez are relatively heavy compared to their rather lean and fitlooking cousin. We continue talking about the difference between the two regions. The visiting cousin tells us that a problem that they have in their ejido is that there is no irrigation, unlike here where they have a lot of water. Diego who is already quite under the influence, merrily calls out 'Yo regalo el agua a todos' (I give away the water for free to everyone). The men roar with laughter. 
When the better quality meat is ready, we have to sit down with a plate and join the table where the older folks are seated. I sit in front of a row of three older men, including the visiting one. Whilst we are enjoying the good meat, I am again struck by the divergence in physical appearance. Guttierrez's father and his brother from the coast are both heavy and cheerful men, with voluminous bellies, fleshy chins, sweaty faces and a sombrero that only just fits and is placed slightly upwards as a protection against the heat. This is in sharp contrast to the visitor, who is a more grim looking slim man, with the wrinkled leather skin which one sees in older rancheros, who have spent a life time working under the blazing sun. The sombrero adds to this image by being firmly placed on his head, torn just above his eyes. It has a small cord connected to it, which horsemen hang in front of their face in order not to lose their sombrero. Then, it suddenly occurs to me that this family scene, this happy collection of spirited bodies, reveals their diverging life histories in culturally and climatologically very distinct parts of Nayarit. The bodily dissimilarities now seem to represent an historical accumulation of contrasting ways of life. The social life of tobacco and sugarcane is reflected in a cultural preference for either Pacifico bee or tequila. I have to admit that at this point I myself am slightly intoxicated and consequently may have lost some of my scientific distance. However, I find it a nice metaphor for something that has struck me so many times since I came to the Northern Coast of Nayarit and followed engineers, producers and politicians. I have been amazed about the extremely popular pastime of people that characterises so much of the social life and manifests a great passion for drinking beer and a developed taste for local meat and seafood dishes. The bodies of the Guttiérez brothers appear to be the materialisation, or perhaps the symbol, of those particular cultural likings. In other words, the body is the living evidence of a specific trajectory of cultural preferences. The Guttiérez family shows how such preferences become embodied.

When the old brothers Guttiérez touch upon the subject of their absent brother, Diego becomes sentimental. Holding back the tears, he regrets that his father is such a closed person and that he does not like these family reunions. However, he reconciles himself with the fact that 'my father is my father'. Then, he quietly disappears from the party. His uncles, who smilingly observe his emotions, explain his behaviour by telling me that Diego is zeloso (jealous), because his father remarried when his mother died. It is clearly not an emotion that an adult man is expected to display in public.

\section{Organising public eoents}

Some of Diego's qualities described above are mobilised by his patrons in organising similar kinds of parties, meetings, and public gatherings. These cultural events are essential to politics on the Northern Coast, as we will see in Chapter 8 and 9. The character of such festive encounters is reflected in the abundant provision and consumption of specific local dishes and beer. Catering to the specific likings of the attendees requires particular cultural competences of the group. When Pérez or Nuñez intend to organise a meeting, they enlist Guttiérez. Guttiérez then distributes the work and often mobilises the lower personnel of the association.

Diego is frequently called in and made responsible for organising the food. In his previous career as a butcher's assistant, he gained extensive knowledge about different qualities of meat and their preparation for diverse popular foods, such as tacos or birria, a 
regional goat meat dish, particularly served during special celebrations and public gatherings. Hence, Guttiérez leaves Diego to choose the type and amount of meat, the responsibility for buying the food and organising its preparation. On one occasion, Guttiérez is asked to organise a presentation for a fertiliser company that wants to introduce organic fertilisers for interested rice, sorghum and maize producers. He instructs Diego: 'Diego, I want you to look for a pig of around hundred kilos at Aguirre's place'. Aguirre is a favoured large producer, who provides the pig because he has an interest in the company. Guttierrez says that he expects around fifty people. After arranging the pig, Diego also organises the slaughtering and the preparation of the meat and is present during the event, as are the other canaleros. They help with setting up the chairs and preparing the food. When they bring around the plates of food to the attendees, particularly after a long and serious presentation, the mood of the meeting changes. It is naturally accompanied with some beers, which further animates the atmosphere. This celebration of the introduction of an agricultural innovation is not unlike how a political candidate would be promoted on the Northern Coast.

On another occasion, Guttiérez asks Diego to arrange a carne asada (a dish of roasted meat prepared at a barbecue). We go to the local market and order the veal, and at another stall we buy a large number of tortillas. Then we go in search of a barbecue. I ask Diego what the occasion is. He complains that Guttiérez often does not even tell him what exactly the meeting is for.

\section{Diego in the group of canaleros}

Diego's position is different from other canaleros because he is part of the group of their patron, Pérez, and superiors, Nuñez and Guttiérez. As a client, a stronger bond of loyalty and moral obligation binds him. His relation with the rest of the canaleros is therefore rather distant, especially with the group of three engineers, Laguna, Icazar and Quiroz. They basically share the idea that Diego belongs to 'them', implying Pérez' group.

In Laguna's opinion, Diego is privileged: 'He drinks a lot, drives around on his motor bike and neglects his work and this is tolerated by the management. Laguna explains that Diego is often invited by producers to drink with them in a cantina or elsewhere. That is why Diego can afford to be drinking so often, whereas his salary is just as meagre as his. He claims that if you agree to such invitations you have a compromiso (commitment or understanding) with these producers to be at their service, for instance when they ask for water. Accepting beer and food from farmers thus premeditates special favours in water distribution. This is the case to a different extent for all canaleros, who occasionally accept such gifts, but Diego is particularly known for it. He accepts invitations quite openly, and his superiors do not reprimand him for it.

Laguna understands that Diego also drinks a lot because of the pressure of his work as a canalero. Particularly during the busiest period of the irrigation cycle, everybody comes asking for water and you are constantly bothered via the radio, in the field, at the office, and even at home. Sometimes the canaleros switch off their radio so as not to be bothered when they are drinking. Later, they act as if their reception was bad, because they were working in the field far away from the office. Amongst the canaleros they have a joke that refers to such occasions. When somebody asks where a canalero is, they say 
that he is echando agua, which means putting water in a canal, but they simultaneously make a gesture that clarifies that they are rather referring to its second meaning: throwing back beers. Nevertheless, Laguna disapproves of Diego's excessive drinking, although he does not express this view in public. The canaleros are often together as a group at meetings or in the office and have to collaborate in the field and thus they have to be on manageable terms.

As a group, the engineer-canaleros do not socialise much with Diego outside their work, for instance at the festivities that they visit. During the annual fiesta of his ejido, Icazar organises a small dinner party at his house and invites all association staff. Laguna, Quiroz and myself have come to enjoy the birria and beer, as people are accustomed to invite their friends and relations for food before the rodeo. We are in the backyard, which is fenced off from other nearby gardens. Behind the fence I see Diego, who is one of the invited guests at a party of a farmer and a neighbour of Icazar. When I approach to greet him, he asks me what I am doing there. He tacitly disapproves of the company I am in. He says that he has already eaten and drunk. On my return to his colleagues, they confirm my unconscious observation that Diego is quite drunk already. They suppose that he must have been drinking the whole day. In a little while, he will not be able to return home again and tomorrow he will not remember where he has left his motor bike - like last year, they speculate with a grin. Icazar expects that Diego will be complaining that he was not invited, although in reality Icazar invited everybody from the office. Later, during the rodeo, I encounter Diego who gets very sentimental about the fact that he was not invited to Icazar' place. When I specifically ask him about it, he admits that he was invited but indicates that he did not feel invited, because Icazar emphasised that it would be very simple and only a meal.

The mutual attitude of the canaleros mostly shines through in the observations and jokes they make about each other. The jokes about Diego invariably involve his weight and drinking behaviour. For example, on one occasion I join Quiroz in the field. The motor bike I have borrowed from the association breaks down, because of a loosened welded plate that was intended to mend the frame. Quiroz jokingly tells me not to worry about it being my fault, because it was a motor bike used by Diego. Diego overhears the conversation and is forced to smile, but he tells Quiroz not to talk like that. Later, Quiroz tells me that all the broken carcasses of motor bikes in the association yard were once Diego's. Apart from his weight, Diego does not take care of his motor bike, Quiroz states disapprovingly. He drives around drunk on it and falls down or smashes it.

Diego heartily dislikes the jokes that are made about his drinking behaviour, but there is little he can do about it. He hates it when I tell him that people have informed me about his recent alcoholic escapades. He even suspects his own cousin of spreading such stories. When he is sober he is not proud of them; when he has been drinking he does not care. He counters the stories about him with other stories. He launches bitter attacks on his engineer-colleagues, especially by reproaching them or making fun of their lack of masculinity, accusing them of not wanting to sleep with prostitutes and that they are thus joto or mayate (homosexual). 


\section{Intermediate analysis}

In what I have described so far, I have illustrated the importance of a cultural competence rather than a merely technical competence in irrigation management. This goes beyond, and sometimes conflicts with, Diego's official position as a canalero. As the client of a political group, Diego displays this cultural competence in the organisation, performance and enjoyment of festive events. For these pleasurable occasions, the preparation and consumption of food and beer is central to building and maintaining organisational and political relations on the Northern Coast. Diego demonstrates a set of locally valued artistic skills and cultural preferences, such as telling jokes, a popular taste for food and beer, and ordering music. These contribute to an atmosphere of male conviviality, complicity and trust that affirm relations of social and political commitment, such as for example with the CNA District Head. Hence, Diego's clientship has required him to develop this cultural competence. Even his body manifests this role as a cultural agent, if not the trajectory of cultural preferences that he has followed. Indeed, Diego's body is subject to, as well as the subject of, the drinking, eating and hilarious humour that he displays.

Besides distributing water, Diego plays a role in the distribution of another wet, alcoholic, resource flow. The connection between these two activities is recapitulated in the canaleros' joke about echando agua, which refers to managing both the flows of irrigation water and of beer. The connection becomes further evident from the fact that Diego seems particularly inclined to accept beer as a gift in exchange for immediate access to water.

\subsection{Privileged Support to Large Producers}

A favoured clientele of around seven major producers of rice, sorghum and maize belong to the outer circle of Pérez' political group. They are connected because most of them work from Villa Hidalgo and maintain friendship, commercial and political relations with this group, which is itself heavily involved in rice and sorghum production and the organisation and representation of its producers vis-à-vis the state government and agro-industrial enterprises. By different means, the group receives financial as well as political support from these influential producers. Although this outer circle of large producers is not necessarily a close network and might at times have contradictory interests, for Pérez' political group they are interesting partners, as they are generally well organised and represent their interests both at the state and national level. They have a network of connections with the government, agro-industrial companies, and rice and sorghum producers, and they fulfil different functions in local producers' organisations and ejidos. Some of them are moneylenders. In addition, they are large employers in the region, who use their influence in the government to pressure for low minimum salaries for agricultural labourers.

Since the local rice-processing factory went broke, factories from outside the region have penetrated the regional market. They pre-finance medium-sized producers who lack the capital, inputs and machines to produce. The most important processing factory lies in Ixtlan del Rio in the southeast of Nayarit. It distributes inputs and coordinates the 
production and harvesting via a local representative, Frederico González, who is at the same time a large rice producer from Villa Hidalgo. This factory is able to set low prices and deduct high input expenses at the end of the season. This makes rice production a commercially unattractive enterprise for such producers, and causes many of them to drop out of it.

Hence, rice production is nowadays only profitable for productores fuertes (powerful producers), Diego argues. These aforementioned seven producers account for most of the area under production, among whom are Pérez (ex-president of the association), Frederico Haro (local representative of the processing factory), Norberto (treasurer of the association), Aguirre, and Bernardo Ulloa (ex-CNA employee). They are both ejidatarios and private producers and own and rent land in both categories. Although the fields they rent are distributed over the whole irrigation system, they are mainly concentrated around the four ejidos of Villa Hidalgo. Another production zone lies closer to San Isidro and El Tizate. Besides producing rice during the irrigation and rainy season, they also produce sorghum and maize during the main irrigation cycle.

The WUA plays an important role in the mutual exchange of benefits between the political group and its outer circle of large producers. Some of the benefits and services that these producers receive from the association are the following: Several of them have reached financial agreements with the management that allow them to postpone or reduce their fee payment until after the harvest. This creates non-transparent revenue flows that the political group in the WUA can use for personal, political and electoral purposes, as Chapter 8 will show. In addition, the irrigation fee for rice is kept artificially low compared to other irrigated crops that consume much less water, like beans or tobacco. These producers also get privileged access to the association's maintenance machines (see also Chapter 7). Further, the management supports field experiments on rice conducted by the agricultural research institution, INIFAP, in Santiago. Furthermore, these producers have a major interest in receiving privileged access to irrigation water. Several of them were given direct access to the canaleros via their radio system, to enhance this. Finally, the association and the canaleros are a useful source of information about where plots are available to rent. More than any other canalero, Diego plays a central role in their access to ample irrigation water and crucial information and in the production of rice in general. He maintains a friendly relationship with several of these producers.

\section{Access to irrigation water}

During the main irrigation cycle, as a result of farmers taking water without requesting an irrigation turn, it happens that Diego cannot deliver the water that he promised to other downstream farmers on time. When he discusses the difficulty of solving this problem, he takes the case of a large producer, who has hired fifty people as labourers and pays them a daily salary. Diego emphasises how grave the problems are when this man does not receive water on time. This remark of Diego's reflects a concern with larger producers, such as Pérez, and accounts for his inclination to immediately respond to the requests of such producers, although this might again affect other producers further downstream. 
In the rainy season, only rice is planted and irrigated on a large scale. Although rice cultivation is a lot less productive during the rainy season, for several agronomic and climatic reasons it is the only crop that is not so vulnerable to the heavy rainfall, windstorms, and water logging which normally occur at this time of the year. The production of rice experienced its peak in the area at the beginning of the 1990s. The Left Bank became the most important rice producing area in Nayarit, and possibly in surrounding states, thanks to its ample water and favourable productive and institutional conditions. Particularly during the last five years, the area under rice in the rainy season has significantly decreased from more than 4,000 to just 1,000 hectares. Reasons vary from the spreading of wild rice varieties that are detrimental to commercial hybrid rice production, the decreasing price of rice as an impact of the NAFTA agreement, problems in local rice producers' organisations and the bankruptcy of the local processing factory in El Tizate.

Because the area actually irrigated on the Left Bank decreases significantly during this season, the workload and revenues also reduce. As a result, the thirteen sections were split up between four rather than seven canaleros during the last two rainy seasons. Diego's position, however, is not under threat like that of other canaleros. This indicates his privileged position as a client of the political group. Additional reasons for keeping Diego on his job are that his two sections are especially important in terms of rice production and that he fulfils a central role in the water distribution to rice producers. During the 1998 rainy season, apart from his own sections 6 and 11, Diego operated 12 and 13 also, which are located towards the tail-end. Despite this, Diego's work is much less demanding at this time in comparison with the main irrigation cycle. There are various reasons for this. The first is that he controls a much smaller and more compact area of a few hundred hectares of rice and less than a hundred hectares of maize and sorghum. The second reason is that he manages relatively stable discharges. The irrigation and cultivation of rice involves large but constant volumes of water that are applied by means of surface irrigation. The constant flows used to maintain a certain level in the basins make the water distribution a relatively orderly and predictable affair for the canalero. The canals consequently also have relatively constant levels, and this requires limited supervision. The third reason is that Diego has to co-ordinate the water distribution to a limited number of rice producers with medium-sized or large connected parcels of land $d^{5}$. This takes place in most cases through their field irrigators or regadores who are in the field a lot of the time and thus can easily be reached by him. He coordinates the water demands, arranges the distribution of the available flows with them, and in many cases he grants them the right to close or open an intake, which saves him work. Finally, the larger degree of homogeneity of operational arrangements involved in rice cultivation and surface irrigation reduces the number of control problems for the canalero.

In the field, Diego indicates a problem that he experiences with these rice producers. $\mathrm{He}$ shows me that in reality in rice plots much more water is used than the official and required water allocation. Engineers explained to him that rice only requires a stable flow of four to five litres per second per hectare after an initial phase in which the crop becomes established. He points to a nearby rice field that is receiving more than double that. Still this is not to the satisfaction of the farmer. He elaborates that rice producers want as much water as they can get for combating weeds, so that they can minimise the 
expenses of labour, mechanical or chemical means. 'The bad habit of the user', according to Diego, 'is to always want more water'. Later, he tells me about the case of Aguirre, a large rice producer who has a rice plot of ten hectares in his section. This plot would roughly require a constant flow of fifty litres per second. Instead Aguirre, who maintains close relations with Nuñez and Guttiérez, easily demands a flow as large as 200 litres per second. Diego says that he could explain the officially required water layers to Aguirre, but that he would not want to understand.

During the 1998 rainy season, I also witness some cases of serious over-irrigation. I join Diego when he is about to stop the irrigation to several rice fields in consultation with the producers and the field irrigators. Standing in a rice field along the 24 in section 12, Diego shows me the grain and the physique of the rice plant. It has matured, and it is consequently time to cut off the water. We stand close to a field inlet, through which a lot of water is flowing into the field. I ask him how much water is entering the field. He estimates around 150 litres per second for the ten-hectare plot. He adds that this is actually too much, three times as much as the fifty litres really required. He claims to give so much because otherwise the producer would come and demand more water. The producer wants a lot of water in this period so the grain will gain weight just before stopping the irrigation. This makes a difference to the final yield and profit. Near a much larger field of around fifty hectares of rice we see the water flowing through two intakes into field canals. Diego estimates that around 350 litres is actually entering the rice field, whereas 250 litres would be sufficient in his opinion. Diego claims that he gives more water than required only to those who ask him for it. He says that he does it to get rid of them or because he does not want to get into trouble with producers who push him to give more water.

Diego confirms that over-irrigation by rice producers during the main irrigation cycle can cause problems in sections further downstream. He claims to deal with this problem by now and then measuring the water flow in the presence of the producer. Diego demonstrates the provisional method that the canaleros use for this: They measure the water velocity over a distance of a few meters with a little straw and estimate the crosssection of the field ditch. In this manner he shows the producer that he is receiving too much water. Unfortunately, farmers are not content in most cases and demand more water or open the intake themselves after some time. Laguna recounts that Diego recently measured the inflow at Pérez' intakes and found that he received more than double the prescribed four litres. When Pérez saw this, he responded theatrically, 'quita me el agua' (take the water away from me). Nevertheless, it is Laguna's experience that the next time Pérez will do the same again and demand more water. The problem remains the same: 'All productores fuertes (powerful producers) always want more water'.

\section{Information on suitable land to rent}

Because of the widespread infestation of land on the Left Bank with wild rice, there is an increasing shortage of land that has not been used before for rice production. All major producers are diligently looking for the remaining uninfested land to rent for rice production. 
The infestation of rice fields with wild rice occurs through polluted seed material, crossfertilisation and the wild rice seeds that remain in the soil after harvesting. It has taken many former rice lands out of production. For example, in the La Presa ejido until recently a lot of tobacco fields were rented out by ejidatarios during the rainy season to produce rice. The large rice producers who rent a lot of land generally have little interest in taking effective counter measures. They leave the land after a few years when the infestation rate is too high and transfer to other plots. They are now confronted with the backlash of this strategy.

In the field, Diego displays a detailed and practical knowledge of the rice crop and the problematic features of its production. He shows me that the degree of infestation with weeds like arroz negro, arroz rojo and arrozon is not yet as serious as in other parts of the system. Then, he demonstrates how to distinguish these wild rice varieties and recounts how their similarity to commercial rice is a problem in combating them. Although the infestation generally occurs through the soil and contaminated seed material, few producers use certified seed and take the necessary measures to prevent further infestation. Pointing to the mature crop, he argues that he will be shutting off the water, because the grain is already full-grown and the plot needs to dry up in order to be in a condition to harvest. The irrigator of this plot has just arrived and they discuss shutting off the water now. They agree, and the irrigator helps Diego to close down the intake, because Diego does not succeed in turning the rusty wheel of the structure on his own.

It is preferable to plant rice on land that has not been used before for rice production because there is a smaller chance of infestation with wild rice. Consequently, the harvested rice is purer and of a higher quality and qualifies for a higher price. I ask him if there is any virgin land left. Although there is not a lot, he knows of some locations and where they are situated. He tells me that large rice producers such as Bernardo and Frederico ask him where they can find such land to rent. He claims that he helps them to find and rent it. He also finds a plot for himself.

\section{The canalero and large producers}

In a conversation about water distribution, Diego claims that there is a lot of favouritism in the association. The powerful producers are generally given a lot of water and do not have to wait their turn when they request it. The three-days' notice rule does not apply to them, and they often get rapid access. In addition, he is critical of the fact that several of these rich producers have large debts in irrigation fees with the association and keep postponing their payment. Diego is well aware of their close contacts with Pérez, Nuñez and his own cousin. He is reminded of it by their access to the association's radio system. Diego on occasions indicates that he feels ambivalent about the privileged access he is granting to these producers. "We should give a producer of two hectares the same service as a productor fuerte', he opines. However, this is not the case. The small farmers are instructed by the canalero to request an irrigation turn in advance and they are reprimanded when they just take water, whereas this does not count for people like Pérez, Diego states. He also frequently points to the difference between these large producers and the many ejidatarios who barely have sufficient resources to keep cultivating their land. For example, on a field trip we encounter an old, tired man with a sunburned face coming back from his field with his horse and a plough. Diego points out 
that this is what the situation is like here. This old man works himself into a sweat the whole day long, making furrows one by one, whereas people like Frederico and Aguirre have a machine that makes four to five furrows at a time.

At the same time, Diego has a lot of admiration and respect for these producers. This is especially clear when he refers to them as los productores chingones, which is a stronger version of productores fuertes. Chingon expresses in a typical Mexican way their size, success and superiority as agricultural producers ${ }^{6}$. For example, Diego tells me about Bernardo Ulloa, who started producing rice when he was still working as a local CNA representative for the association. We see some of his extensive rice fields, and Diego says that he has a lot capital para mover (capital to mobilise), indicating with a gesture of his right hand an imaginary pile of money. I ask him what he mobilises, to which Diego responds: fumigants, herbicides, people, etc. This makes his agriculture more profitable than that of smaller farmers, he explains. About another productor chingon he remarks that the man is a capitalist and has a lot of land and produces several hundreds of hectares. 'El mueoa mucha gente' (he mobilises a lot of people) and a bit later 'el mueoa camionetas y muchas maquinas' (he mobilises trucks and a lot of machines). Diego regards this as a great responsibility that should not be taken lightly. His admiration appears when he sums up the nature and number of activities in which these producers are involved. He empathises with people like Pérez and Frederico when he is explaining to me that it is very difficult to do so many things at the same time and that it results in a lot of pressure. 'Some people have problems managing only two hectares. Imagine managing seoeral hundreds of hectares. You constantly have things on your mind, what to do when a pump or a truck breaks down?'

It strikes me how easily Diego mentions such heterogeneous matters as herbicides, people and machines in expressing how powerful and capable these producers are. Also, his emphasis on the movement and mobilisation of people, machines and other resources in representing the dynamic qualities of these producers and the complexity of their work is noteworthy. He measures the potency of these agricultural producers by the amount of land and assets they own and the number of people working for him. Diego starts to list the other types of businesses in which they engage and sketches their personal history, the origin of their fortune, the organisations in which they are influential and the nature of their political relations in the state government. It all contributes to his admiration.

Diego is part of a wider network of mutual exchange of favours, goods and services between the association and these large rice producers. He provides them with access to water and information about uninfested land. More than the other canaleros, Diego is influenced by this relationship with the favoured clientele. Although it is clearly an unequal exchange of benefits, it is not a one-sided relation. Diego has an interest in these exchanges. In return, he receives support from some of the rice producers to cultivate rice in terms of land, seed and other resources and services. Usually he produces around two hectares in his own section. This is practical for him, because he can irrigate the crop whilst he is in the field for his work. He has easy access to ample water. Because Diego possesses neither land nor capital, and taking into account all the other required inputs and the low price of rice, I ask him if it is really profitable for him to produce rice. He assures me that it is. He can gain something, because people lend him the land. If he had to hire land, it would be a different case. In most cases, he arranges to 
use a small plot belonging to Pérez, Frederico Haro, or some other favoured large producer. In addition, they pass on some seed to him, cultivate his plot with large machinery ${ }^{7}$, or clear it of wild rice with a group of their labourers when they are in the neighbourhood. Frederico finances the fertilisers for him, settles his earlier debts, and gives him an extra amount of money to finance the rest, in his role as a representative of the processing factory from Iztlan in the region. These are just small expenses compared to their bulk operations. Despite all the support that Diego succeeds in mobilising, he is not particularly successful with his rice harvests. During the 1998 rainy season his crop failed because his field could not be drained on time and he ended up with a negative result.

Nevertheless, during the next irrigation cycle to my surprise he has found another plot on which to produce rice. He explains this renewed attempt by stating 'let's see whether it is business in the irrigation season'. This strikes me as an expression of the large entrepreneurs with whom he socialises and who produce rice commercially, rather than the small landless producer that he is. I ask Diego why he does not try an easier and less risky crop, for example beans. He answers that beans requires cultivation at different times in their life cycle. This would cost him money for every job (around \$US 50 each time), whereas in rice fewer jobs are required and they are easier to have done by large producers. Again he sounds like an entrepreneur when he talks about arranging such jobs for free. Standing near his plot, Diego proudly shows me the recently sown plot and confides in me that he is producing here together with his cousin Guttiérez. They are sharing the expenses. The plot belongs to his compadre who lent it to him. Guttiérez arranged the certified seed. The levelled basins with bunds around them were constructed using equipment and personnel belonging to the association.

Diego's field encounters with producers such as Frederico or Aguirre, or at the office, reveal an element of friendship. They are always very amicable towards him and take care never to demand their water. They rather make him part of their problems and anxieties and let him feel responsible in that way. Diego very much values the personal interest that is taken in him - the greetings when he passes by on his motor bike, or a little chat at the roadside. Further, friendship relations with the canaleros are reified by inviting them for celebrations, rodeos and drinks. People like Frederico and Norberto attend small parties for association staff to which they are invited. They mingle with the group of canaleros and drink with them. Just as they casually gossip, joke and exchange anecdotes, they also discuss their irrigation plans with them. This is important in maintaining a sphere of male complicity and friendship (cuatismo) with the canaleros. More than the others, Diego is sensitive to such attention.

\subsection{Privileged Access Pérez}

Pérez is the largest rice producer in the region. At the beginning of the 1990s, he cultivated nearly a thousand hectares, which subsequently diminished to a few hundred hectares. Recently, he is increasing his production of sorghum and produces some maize and beans on the side. Through his continuing influence in the association, he has placed Diego in sections 6 and 11 for the irrigation season, where he owns and rents large tracks of land. Pérez is different from the other entrepreneurs, because he generally maintains more distance from the canaleros, is less friendly, and assumes a more 
superior position. In addition, Pérez is very demanding regarding his access to irrigation water. He does not appreciate canaleros who tell him to wait for his irrigation turns when he intends to irrigate. He expects immediate and full access to irrigation water and an instantaneous response to his instructions. Unlike Dario who has long experience as a canalero and might tell Pérez to wait, Diego responds immediately to his requests. Another canalero, Quiroz, therefore calls Diego not very responsible in his work. 'He does not care at all. If "they" ask him for water, he immediately gives it to them. He uses the water that other canaleros have requested'. Diego's extra sections for the rainy season, 12 and 13, are located above those of Dario ${ }^{8}$. As a result, the latter occasionally does not receive the planned discharge in his sections.

Within Pérez' political group there exists a certain implicit delegation of responsibilities. Within it, Diego acts as a sort of field representative for Pérez. He sees to it that Pérez' productive interests are met. $\mathrm{He}$ is well informed about these activities within the irrigation system and knows the exact locations of the plots on which Pérez is producing. During the $97 / 98$ season, Pérez owns around 600 hectares and rents another 300 hectares.

According to Diego, when Pérez asks him for water there is no way he can refuse it or let him wait, even if he has not requested an irrigation turn on time. This could mean that other farmers remain without water. 'Hay confianza' is the explanation he offers, indicating that he has relations of trust and friendship with Pérez within which the mutual exchange of favours and services is expected. I ask Diego what Pérez could do if he refused him water or gave him less. He answers that Pérez could not directly force him to give water. As a canalero, he would act according to the rules. Yet, Pérez would call Guttiérez on his radio to complain. Guttiérez would then call up Diego and instruct him to give the water immediately. He explains that Pérez is very powerful, against which he as a canalero can do very little:

Economically, relationally and politically he is very strong. At the moment he is deputy of this region and he has connected himself with Emilio Gonzalez, who is a powerful ex-governor of Nayarit. Apart from that he has many sprinkler installations and machines...

It happens that Pérez' personnel starts irrigating with a pump without even asking his permission. Although he is critical about this, Diego feels that he can do very little about it. Pérez contacts him on the radio to tell him when and where he wants water. Diego has to comply with such a demand.

Pérez owns large properties at the tail-end of two sub-lateral canals in Diego's sections. These lands are situated far from the easily reachable main canals. In the middle of the main irrigation season in 1998, I drive with Diego down one of these sub-laterals in section 11. Diego is in a hurry to check whether sufficient water is reaching the end of the canal. 'This is worrying me at the moment', he explains nervously. As we are driving, Diego tells me that we are approaching a large plot of around 140 hectares belonging to el licenciado. The previous afternoon, Pérez had informed him via his radio that he wanted water the next day, so this moming he got up at five o'clock to open the intake of the sub-lateral. This is why he is so concerned now to see how much the water has 
advanced and whether it is already reaching Pérez' plot at the tail-end. Diego remarks that Pérez' land lies officially outside the irrigation district. The association is thus not obliged to give him servicio there... (yet it does).

Halfway down the canal, Diego suddenly decides to go back to open a cross-regulator further. Apparently he has reckoned that not enough water is reaching this point and that it is advancing too slowly. Whilst he goes back, I proceed along the canal to Pérez' property. Reaching the tail, a vast terrain lies open to me. At some distance, I see some workers who are irrigating young sorghum with sprinklers'. At the end of the lined canal, a reasonably new intake structure lets the water from the canal into what looks like an earthen drain. However, the workers are using this 'drainage water' to irrigate the sorghum. Further up, a machine operator working for the association is cleaning the drain on a machine. Near the outlet I encounter a bombero (pump operator) who is working on a nearby chilli field. He is coming to see if he can get water. All the water is going to Pérez' field now, and he thinks it should be distributed. The man tells me that the structure and the drains were constructed only three years ago. Pérez started producing rice and sorghum two years ago. Before, that the land belonged to a nearby ejido. At that time, it was mostly left uncultivated because it did not have access to irrigation water from the canal and it was not levelled. Pérez, who was then the president of the association, bought the land and opened it up for cultivation and irrigation $^{10}$. The man returns to his field.

When Diego arrives, he establishes that the water is arriving at the tail. With his arm he removes the sweat from his forehead. He seems to be relieved, and the stress disappears from his face. For a moment I forget about machismo and ask him if he was afraid. He denies this, but accounts for his behaviour by stating that Pérez would otherwise be bothering him over the radio all the time ${ }^{11}$. I ask him whether Pérez would not leave the communication with the canaleros to his acting manager in view of his job as diputado. This is not the case, 'that's the way he is', he responds. Diego depicts Pérez in a critical undertone as always wanting to know what is happening and interfering personally in his affairs.

We walk onto Pérez' fields. Diego greets the bomberos who are busy irrigating. The machine operator is happy to see us and we have a chat. We discuss the fact that the drains are not constructed correctly, as they do not have a gradient and the water has no way out. Because in practice they are used as canals, they convey a lot of water and silt. As a consequence, they fill up with sediment rapidly and have to be cleaned now. The men talk over the recent agricultural and political operations of el licenciado and laugh about his ability to get what he wants. Then the operator asks Diego about the recent election meeting of the association's president, Nuñez, at the regional peasant committee (CMC) in Santiago. Diego recounts the events and the good food that they served and enjoyed. He warns that next Sunday the elections for the CMC will take place in Santiago and that there will be plenty of birria. The operator then says he will try to attend, because it has been a long time since he had a good plate of birria.

When we visit other sorghum fields belonging to Pérez later that day, Diego points to the huge amount of water entering the fields. He claims that Pérez always wants to see his canals lleno, lleno (full, full). An amount of water that is sufficient for twenty hectares is entering a plot of ten hectares. Pérez wants the field irrigator to finish irrigating this 
plot as rapidly as possible within four to five hours, to pay him only the daily salary of fifty pesos. But this is a bad irrigation method according to Diego, because a lot of water is lost this way to the groundwater and the crop does not sufficiently absorb it. From a bent position he lifts himself up, straightens his back, pushes his chest forward to impersonate the sorghum. Pérez prefers to irrigate as much land as possible with a restricted amount of labour and time. It saves him labour expenses, among others, and it is possible because he gets ample access to irrigation water.

A few days later I am out and about with Diego again and we check another of Pérez' sorghum fields, where a significant water flow is entering. Yesterday, Diego was informed that Pérez' workers would start irrigating here early in the morning with sprinklers. Unfortunately nobody is present, no pump is installed and the water streams idly to the drain. Diego calls Guttiérez on the radio and asks him to call Pérez' office and ask what their plan is. In the event of their not irrigating, he will close the intake. Diego explains that he could easily also close the intake at once, but that probably Pérez would call him in one hour to let him know that he wants water. It strikes me that Diego acts here like a field manager for Pérez, taking into account his interests to the fullest extent. At such moments his work as a canalero is not separated from his clientship of Pérez' equipo. In fact his performance under these circumstances embodies this relationship. He works for his patron Pérez, rather than for the association, or the water users. On other occasions also this is apparent, for instance when he coordinates irrigation turns with Pérez' workers or in accordance with what he thinks is Pérez' interest.

During Pérez' three-year period as deputy for the PRI in the state parliament, the canaleros at some point were all assigned to function as local party representatives with the aim of removing unfavourable elements from the local PRI departments. However, Diego's loyalty also has limits. When Pérez, Nuñez and Guttiérez again try to assign him to a job as local representative of the PRI, he refuses. This results in a row. He is clearly frustrated by this and states that he never liked politics. 'What they want is to mix work with politics and that is not good', he clarifies his moral objections. He does not want a political post. As a seccional he would have to organise things, keep lists of PRI members and mover la gente (mobilise the people). He would earn very little but would expect to get another position from there with which he would earn more. However, he dislikes politicians, because when they get a position they forget about their supporters.

\subsection{Conclusion}

This chapter has illustrated that the position, tasks and competences of a canalero depend on how patron-client relations are articulated through a WUA and intertwined with resource allocation.

Diego is a loyal client of a political group. He has a privileged position in the group of canaleros in terms of job security, the allocation of benefits and the liberties that he enjoys. The other side of the equation is that he assumes a central position in the distribution of at least three sets of resource flows: the flow of cultural materials such as food and alcoholic items; the flow of water; and the flow of information. Following the first flow presents Diego as an agent with particular cultural competences in the organisation of public events. The second and third flows indicate that Diego is 
strategically positioned as a canalero to work in particular sections of the irrigation system that are of special interest to the group. He provides the group's patron and an outer circle and clientele of favoured producers with privileged access to water and information. The distribution of positions and workspaces in the association thus anticipates the allocation of resources. Clients like Diego thus have a delegated role in organising the access to multiple resource flows that underlie the reproduction and the advancement of the group. The positioning and competences of clients in terms of resource distribution thus should also be understood in terms of their contribution to the development of a political group as a whole. This is not only motivated by material interest, but also manifests cultural variables and moral principles of trust, friendship, obligation, complicity, and a sense of belonging.

Therefore, patron-client relationships are not the unilateral relations that they are often portrayed to be, in which the patron monopolises all power and resources and has complete central control over an organisational or territorial space, its people and resources. A political group assumes the distribution of positions, tasks, and professional as well as cultural competences. It is a dispersed and heterogeneous network, in terms of the power, competence, and resource flows that it circulates and distributes and that maintain group relations.

Being a client and a canalero at the same time is hardly a comfortable position. Diego is deeply divided between conflicting sets of professional and cultural expectations and demands concerning his conduct as a canalero and as a client. Competence is important for both the client and the canalero, but may be defined differently according to these distinct frames of reference. From the professional viewpoint of other canaleros, the expectations of his patrons conflict with professional standards of behaviour and occasionally lead to incompetent conduct. However, the canaleros who criticise him for his behaviour have a different position, because they are not in the same way clients of the political group. Therefore they are confronted to a lesser extent with the expectations and obligations, but also the benefits, that this implies. It is a question of degree rather than an absolute matter, because all canaleros in some way have to deal with the clientelist expectations of their supervisors and are subject to their demands. For several colleagues, this is their reason for socially excluding Diego from their circle and making him the focus of their suppressed anger, envy, contempt, and humour. It is not my intention to conclude that Diego is an apathetic victim corrupted by the pressures of his patrons. He identifies with the professional standards and service ethic of the canaleros and tries to act upon them, and it frustrates him when this is not possible, given the forces that he faces and to which he belongs. This frustration about his contradictory situation seems to find a release through his tragic flight into alcohol, coarse language and rough humour, and the tendency to break things - his own sometimes rather selfdestructive way to 'chingar'.

Diego displays a deeply ambivalent attitude and mixture of sentiments towards both his patrons and his colleagues. He does not approve of the favouritism in the association and the way in which it provides privileged access to water and other services, especially when he finds out that several of the favoured producers are behind with their fee payment. However, at the same time he admires how these productores chingones get things done and is instrumental in making this happen. The ambiguity can also be noted in how he sympathises with different classes of producers. On the one hand, he feels 
sorry for the poor peasant who works himself into a sweat with his plough, whom he considers as a user of the WUA's services with equal rights, although he knows that that is not the reality. On the other hand, Diego really empathises with the large producers. This is shown, for example, by the way in which he visualises the nature of their problems if they have to wait for water whilst having fifty people ready to work. He even talks their language and shares their ideology about what it is to be chingon as a producer. In addition, he presents his own situation as a marginal rice producer in terms of an entrepreneur assessing his business opportunities and skilfully arranging profitable deals. This shows the importance for him of a sense of belonging, particularly because he is excluded from the social circle of some of his colleagues.

The concept of productores chingones that Diego uses shows all-powerful actors that control a variety of people, machines, resource flows, land, and have connections with influential politicians. I find two things interesting about this. Firstly, he sees the heterogeneous networks that these producers manage as a source and manifestation of their power. Hence, he locates their powerfulness not only in their social and political relations, but also in the material artefacts, relations and resources involved. Secondly, in some way it echoes the quote of Octavio $\mathrm{Paz}$ at the beginning of this chapter. The distinction between the strong and the weak, besides reflecting Mexican social life, also presents an ideology that justifies and obscures individual and group behaviour. This presents Diego as completely powerless and his patrons as all-powerful, which is a simplification of the client-patron relations and the distribution of resource flows described in this chapter.

Limón (1989) rightly maintains against Paz that the sexually charged language and humour - full of word games, obscene allusions and double meanings - that uses chingar in its different forms to express social differences is not just about humiliation and violation, as its aggressive literal meaning suggests, but paradoxically contributes to the interactional production of friendship, trust and respect. Although one does not speak of friendship, community or belonging, one practices it in the symbolic action of meat, body, language, and, I might add, liquor (Limón, 1989: 480). In my opinion, Diego's case shows that, by engaging in this type of discursive practice, a client is capable of expressing a deep ambiguity towards those for and with whom he works, revealing both the violent and the friendship aspects of the patron-client relation in which he is involved.

Recalling the former chapter, which argued that everyday irrigation practices are not governed by straightforward sets of rules, this chapter illustrates an additional point that David Mosse has made (Mosse, 1997). Some people, like for example Pérez and the group of large rice producers, possess the capital or authority to deviate from rules without sanctions or public notice, or to regularise action which does not conform to the rules (Bourdieu, 1977). Rules are publicly evoked as much to justify individual behaviour as to order collective behaviour. Individuals vary in their capacity to strategically manipulate the rules according to individual needs, to put him/herself in the right or claim water. Rules are often used to establish relations of dominance and control. They are publicly accepted or official norms and encode the interests of some people better than others. They can be part of the ideologies through which institutions obscure and protect certain sectional interests and values rather than others (Reed, 1992). Or they 
reveal managerial talk that conceals political action behind the apparent neutral invocation of good practices (Strathern, 2000).

\section{Notes}

1 Confianza refers to reciprocal networks of familiarity, closeness, trust, confidence and friendship in which exchange of all kinds of favours is common (Lomnitz, 1977).

${ }_{2}$ Land reform communities created after the Mexican Revolution of 1910. Ejido land belongs to the state, with a combination of community (ejido) and private (ejidatario) usufruct, and since the amendment of Article 27 of the Constitution in 1992 ejidatarios can sell their land. The other category of landowners in Mexico is called pequeños propietarios: private farmers with a limit on land ownership of 100 ha.

${ }_{3}$ In fact, more ejidatarios are planting beans around Villa. However, this seems to be a less demanding crop for Diego, amongst other things because it needs very few irrigation turns.

These words are not meant to be friendly. Joto means homosexual and is virtually always a negative qualification, although not necessarily to be taken literally. Mayate, which is also a large noisy insect with tentacles, is a frequently used term for the male on the receiving end. It is employed in both a disdainful and a humorous sense, and often symbolises relations of power inequality, or ridicules male intimacy.

3 Rice plots are usually over ten hectares, because of the low profitability and high capital investment.

According to Octavio Paz, this typical Mexican word epitomises the male aggressiveness, invulnerability, violent nature and other attributes of (arbitrary) power. It is possible to be un chingon in business, politics, in crime and with women. The verb chingar indicates the triumph of the closed, the macho, the strong, over the open ( $\mathrm{Paz}, 1994)$.

The majority of farmers in the region do not have the large machines that are needed for a particular cultivation of the land and need to rent a machine from a larger producer.

This means that his sections are located upstream along the main lateral of Dario's sections.

9 Young sorghum receives around three irrigation turns by means of sprinklers. For the last three turns, the irrigation method changes to surface irrigation.

10 The land could be bought at a low price for this reason and through his good contacts with the ejido committee. It was levelled and made ready for irrigation with machinery belonging to the association. Estimates of its size vary from 140 to 200 hectares.

"Chingando, politely translated. 


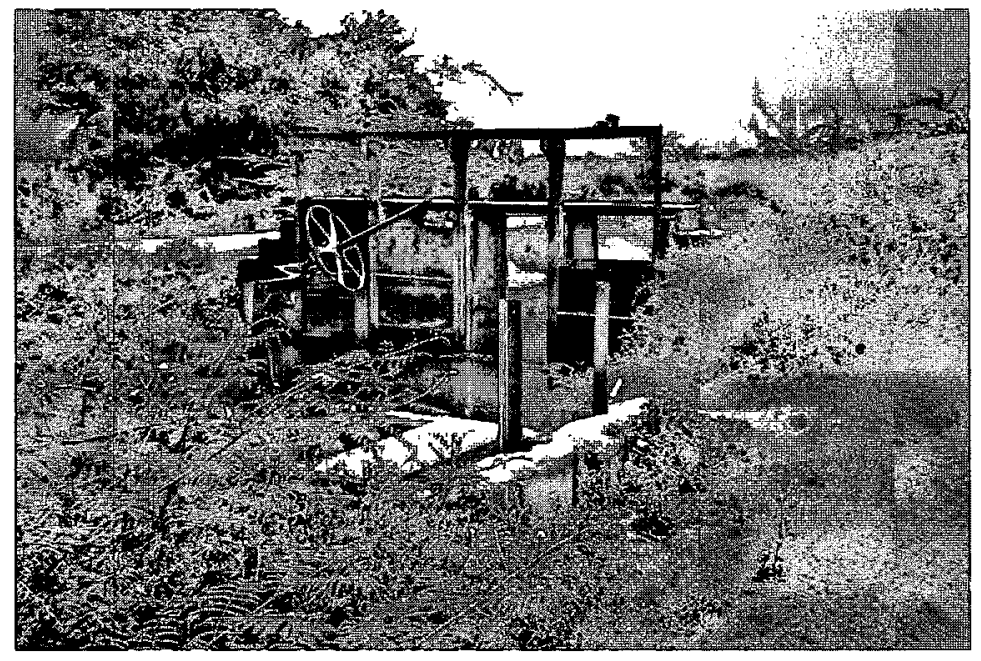

\section{Photo 14 A neglected cross-regulator}

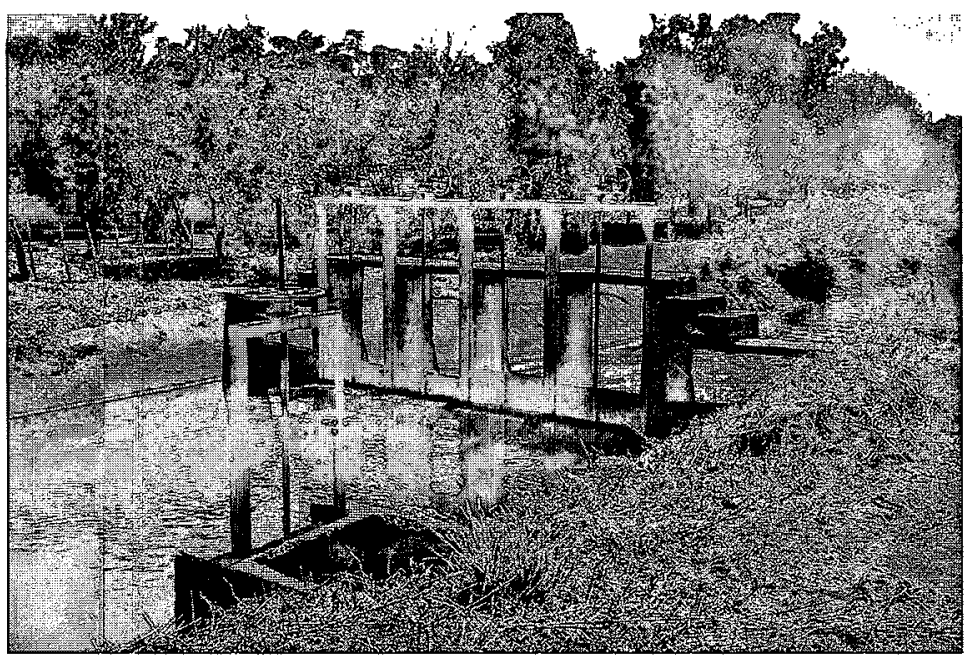

Photo 15 A new cross-regulator 


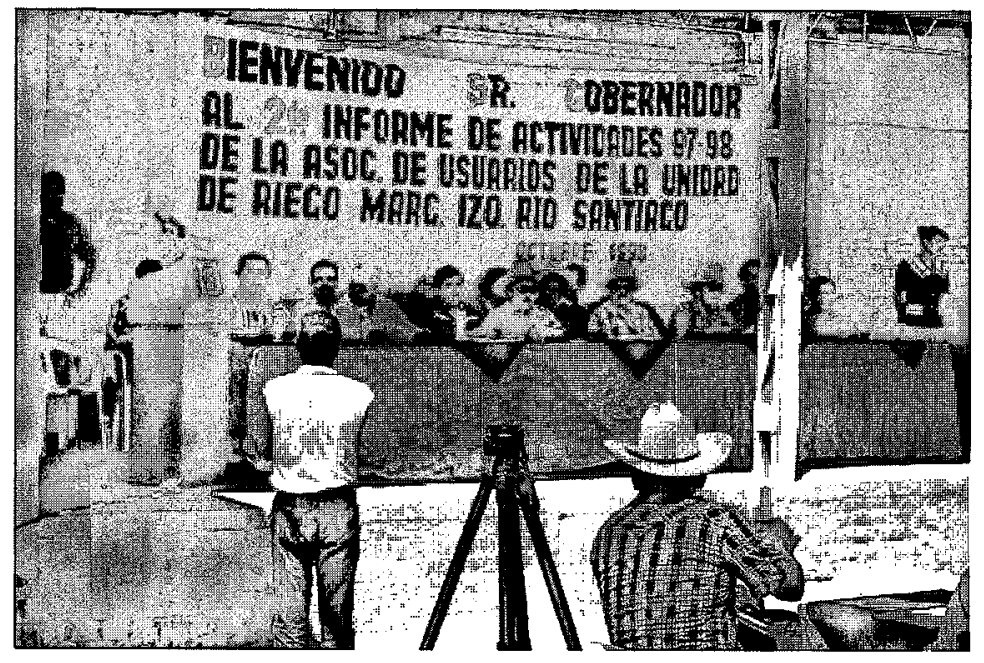

Photo 16 The podium at the annual assemblee of the WUA

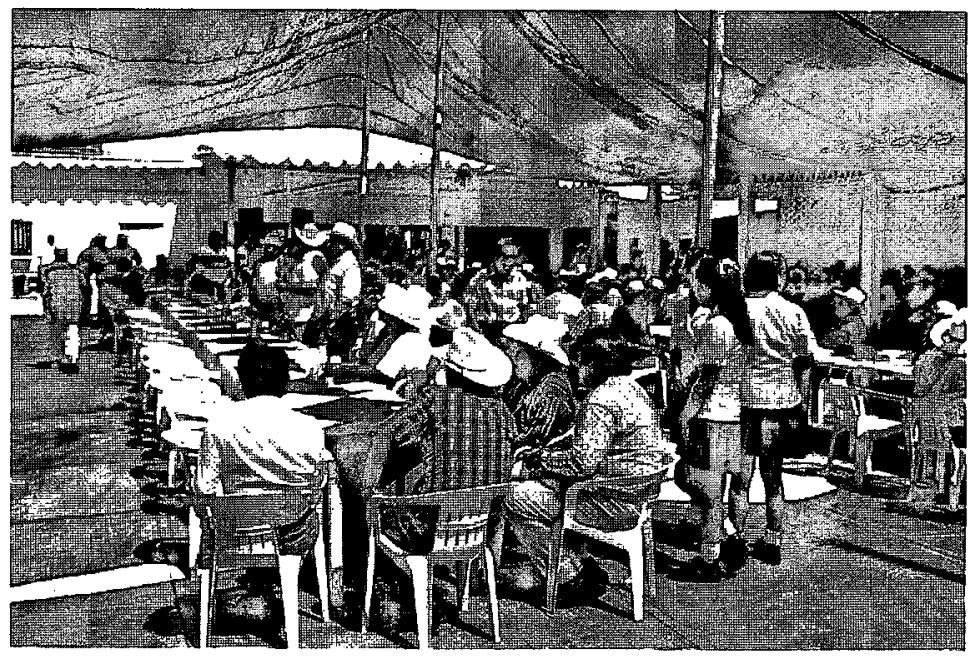

Photo 17 The water user delegates facing the podium 


\section{7 \\ The Multiple Performances of Maintenance Machinery}

\author{
DRAMATIS PERSONAE: \\ Machine operators \\ Guttiérez \\ Nuñez \\ Jiménez \\ Leopoldo \\ Delegates
}

Network of favoured producers

Pérez

Becerra

Minister of Agriculture

Governor

PROPS:

Maintenance machines

Maintenance programme Maintenance reports

Concession Title

Organisational chart

Infrastructure

Canal structures

Spare parts
Vegetation
Boundaries
Public works
Drink
Food
Banda music
Pick-ups
Radios, telephones

nine workers operating the machinery

manager of the WUA, Diego's cousin, superior and compadre

president of the WLIA

head of maintenance

distributes diesel and oil among the machines and the trucks

twenty-five representatives of ejidatarios and private producers in the general assembly of the WULA

large producers who get privileged access to maintenance seroices: Frederico Haro, Norberto, Aguirre, Bernardo Ulloa

Diego's patron, former president of the WUA, local deputy and large producer and leader of a political group

CNA district head

of Nayarit

of Nayarit

machinery to carry out maintenance of irrigation works: dragline, motor grader, backhoe loader, hydraulic excaoator, tractor, loader, light machine and three trucks

annual plan of maintenance activities

monthly and annual reports of maintenance activities

establishes the legal terms for the concession of the infrastructure by the gooernment to the WIIA

representation of organisational hierarchy and task division

network of connected canals, drains and roads of distinct leoels

cross-regulators and intake structures consisting of individual parts, such as plates, bolts, cables

machine parts

weeds, shrubs, trees, water plants, etc.

limits of irrigation module, electoral districts and municipalities

enabled by machinery: e.g. roads, bridges, village squares, sports fields, drainage and sewage systems

beer

birria: a local goat meat dish

music played by a brass orchestra

means of transport

means of communication 


\subsection{Introduction}

Recent studies of irrigation management performance are flawed in their understanding of actual irrigation management practices. In their analyses, these studies have as their point of departure a coherent but incorrect set of assumptions. The first is that irrigation schemes are functional systems with clear-cut boundaries and outputs. The second is that modern irrigation institutions such as Water Users' Associations (WUAs) strictly mobilise the inputs that they manage - people, machines and other resources according to a pre-defined set of service provision objectives. In other chapters (5 and 8 ) I discuss the associated idea that WUAs have an inherently better structure of rules and incentives than state bureaucracies to accomplish this. These studies define what I call operational performance as the degree to which the objectives are realised. They limit their analysis to those managerial practices that correspond with technological prescriptions, system boundaries and annual programmes, and that can be evaluated using quantifiable performance criteria ${ }^{1}$. In addition, performance studies explain the measured outputs and postulate improvements accordingly. This chapter illustrates how these two aforementioned analytical assumptions are problematic by examining the practice of maintenance in the Left Bank irrigation system.

The problem with performance analysis is that it de-politicises irrigation management by omiting certain social, material and political practices and performances that constitute irrigation management and influence its wider impact. In the next chapter I will argue that culture and politics are pictured as external to everyday managerial practices and performances of irrigation organisations. This type of analysis inadequately represents irrigation organisations as purposive functional systems geared to the fulfilment of a clear set of performance objectives (Reed, 1992). It models managerial practices and performances as instrumental action. In this manner, a predetermined desired outcome follows from the execution of programmes and rational responses to rules and incentives. Service provision objectives for irrigation institutions are generally externally framed in broad technical, financial and a-political terms: efficiency, equity, accountability and adaptability (Ostrom, 1992). Through a set of performance criteria we are able to measure the extent to which actual water distribution is efficient, adequate or convenient in relation to a set of stated objectives. However, we are clearly not able to measure the extent to which it enhances a manager's prestige, patronage, or power through control of a water supply (Chambers, 1988: 123). But the infeasibility of measuring these phenomena does not preclude their importance to actual irrigation management.

This chapter argues for the analysis of irrigation maintenance as a socio-material practice. Such an approach facilitates the elucidation of how managerial groups through their connection with maintenance machinery engage in multiple performances. Machine use contributes not only to operational performance, but also to other social, material and political practices and performances that transcend and change what are conceived to be the boundaries and objectives of an irrigation system. For this purpose, the chapter presents an account of the mobilisation of machine-operators, which are the composite entities of maintenance machines and operators executing maintenance work. It is useful to consider the machines with their operators (machine-operators) as co(a)gents (Michael, 2000) or composite entities, consisting of human and material parts 
interacting. The hyphen between machine and operator is meant to remind the reader of the constant interaction between both parts. By documenting the actual use of machineoperators beyond operational performances, this chapter shows that these entities enable and constrain various other modes of social, material and political comportment. From the analysis it emerges that maintenance machines are an appreciated source of revenue and political support for politicians and WUA managers, who seek to improve their position and that of their more extended social network.

Maintenance is a particularly useful entry point to analyse the functioning of irrigation systems. Maintenance resources can be just as scarce or even scarcer than water. The maintenance machinery that WUAs have been controlling since the transfer is a scarce and highly strategic asset for which there is high demand and a variety of uses in and around irrigation systems. This is more widely recognised in the study of small-scale and farmer-managed irrigation systems, where the mobilisation of human labour and resources for maintenance is considered crucial, than in the case of larger irrigation systems, which tend to focus on the contested use of irrigation water or financial selfsufficiency and rent-seeking ${ }^{2}$. Recently, however, there has been more recognition of this point (Sijbrandij and van der Zaag, 1993; Wester et al., 2000; Huppert et al., 2001; Kloezen, 2002).

\subsection{Maintenance on the Left Bank}

\section{Operational performance}

In many irrigation organisations, the services provided or the validity of decisions made are difficult to assess because performance objectives are not stipulated, criteria are not specified and the standards of quality have not been internally agreed upon (Brewer et al, 1997; Kloezen 2002). For example, in Mexico the Concession Title ${ }^{3}$ written by the Comision Nacional del Agua (CNA: National Water Commission) on the transfer of irrigation management to a WUA contains a standard operation and maintenance (O\&M) manual for all WUAs and thus no specific management targets. Federal government institutions and international agencies that fund most research posit performance objectives and indicators from externally derived, internationally agreed and standardised approaches and review how different irrigation organisations score comparatively ${ }^{4}$. Such approaches frame everyday managerial practices and performances in terms of operational objectives, i.e. services delivered (work achieved) in accordance with the quantity, time or location of a programmed set of activities and revenues collected in accordance with the annual budget. This overlooks the existence of practices and performances that are not programmed or budgeted, or that cannot be evaluated in terms of performance indicators.

Operational performance in maintenance is an outcome of the heterogeneous and distributed network of mobile machine-operators that the association uses to carry out maintenance. In this chapter I want to look at the mobilisation of machine-operators, defined above as composite entities of maintenance machines and operators that execute maintenance work, in support of the political group in control of the WUA. The scope of action and capacity of a machine in terms of the quantity and quality of work done ${ }^{5}$ in spatially distributed places emerges from both the social and material characteristics of 
this mobile entity and the wider support network in which it is embedded. Both the material condition and properties of the machines: fuel consumption, maintenance and reparation requirements, availability of spare parts, and the social aspects of their use: the operators, their skills, employment relations, working hours, and remuneration, determine the capacity and mobility of these machine-operators. This is crucial to the variety of performances that these machine-operators enable and for which the political group in charge chooses to allocate them.

The need to focus on the maintenance of irrigation infrastructure emerges from four observations about the current situation in Mexican irrigation districts. Firstly, the deteriorated state of the infrastructure and the deferred maintenance during the 1980s were important reasons that led to irrigation management transfer (see Chapter 2). Secondly, the majority of irrigation systems were not rehabilitated before or after the transfer. Instead, the CNA transferred the old maintenance machinery and distributed new maintenance machinery and government funds for rehabilitation to the WUAs (see Chapters 3 and 4). The new machinery was of a lighter type than the older heavy machinery, and therefore more suitable for the required job of cleaning lower-level canals and drains. Thirdly, around sixty per cent of the current budget of WUAs is dedicated to maintenance, thirty per cent to operation and only ten per cent to administration. Maintenance is thus the largest expenditure of WUAs (see Chapter 9). Fourthly, maintenance resources can be scarcer than water. This is especially true in cases such as the Left Bank or Autlán-El Grullo, where water is abundant, but it applies more generally also.

On the Northern Coast of Nayarit, the high rainfall and tropical temperatures cause rapid vegetation growth. Water plants, weeds, grass, shrubs, and trees grow much faster than in other irrigated areas of the country. This demands an enormous maintenance capacity, in terms of personnel, machines and resources, which the WUA finds difficult to meet. Sometimes it is necessary to clean a canal twice instead of once a year because of the accumulated vegetation, silt and water plants. During and after the rainy period (las lluvias), the extensive network of primary, secondary and tertiary canals and drains has to be cleaned by the WUA's machinery. Manual weeding, cleaning and herbicide application is also used, but to a lesser extent. Individual water users do not always meet their obligation to clean their stretch of field canals before the irrigation season starts, but this is not the topic of this chapter. During the period of October to March, the WUA uses the machinery to clean the earthen drains to have them open for the rainy season. during which they have to process large volumes of water. The lined canals are cleaned the whole year through. Especially near the beginning of the irrigation season, the WUA deploys the machines on the canals to make them ready for the irrigation season.

\section{The presentation of the annual maintenance report}

In October 1998, the association organises its annual informe (reporting) in the open assembly space of the Villa Hidalgo ejido ${ }^{6}$. During this large public event, the board presents its yearly management report. The political significance of the event is underlined by the participation in it of the Governor of Nayarit and the state Minister of Agriculture, and the attendance of several regional politicians, ejido commissioners and functionaries of rural organisations. The governor, the minister, the board and several 
other prominent figures together form the presidium. They are seated in front of an open space on a high podium behind a wooden counter, which is generally used in Mexican political events for the authorities. A large banner behind them states the occasion: The second informe of the current administration of the association. The twenty-five delegates are seated behind a row of tables below the podium, protected from the sun by a light material hanging above them. An open space exposed to the hot sun behind the delegates separates them from the crowd of attendees at the back, among whom there are many lower functionaries, ejidatarios, water users and other people. The cultural specificity of the event is made evident by a local music group of wind and rhythm instruments that is playing the popular banda music (brass orchestra) and the preparation of birria (a local goat meat dish) that will be distributed with beers and soft drinks by the canaleros (people in charge of the distribution of water in the field) to the few hundred attendees at the end of the meeting. The banda plays on the arrival and departure of the governor and subsequently after every individual speaker to reinforce their words. The crowd, as it quietly awaits the speeches, becomes animated by the lively music and the prospect of good food and drink, and applauds enthusiastically in response to the speakers.

On a platform in the front, a professional announcer equipped with a microphone and a sound system introduces the speakers. As the first speaker, the president of the association, Nuñez, welcomes the governor, other important guests, the delegates, water users and the audience. The delegates and the prominent guests at the meeting have received the annual management report and can read with Nuñez whilst he presents the achievements of this year in operation, maintenance and administration, respectively. In the report a special section deals with maintenance. It contains a list with fifteen categories of maintenance activities (see Table 4) ${ }^{8}$. Having arrived at this section, Nuñez reads aloud per category the total amount of work achieved (in kilometres, hectares, volume or number) and the total expenses incurred. He sums up the entire numbers mentioned in the report. The numbers after the comma only seem to add to the achievement. Nuñez makes some clarifications about the maintenance activities and the repair of several machines. In addition, he mentions that the association entered a federal programme for the rehabilitation and modernisation of irrigation systems, as part of which gates and weirs were rehabilitated. The association and the federal government co-financed the programme and both contributed 100,000 Mexican pesos (US\$25,000). In a similar manner, Nuñez presents the data on operation and administration, after which he arrives at the total expenses and the sources of revenue. Nuñez admits a budgetary loss for this year caused by adverse circumstances and a failure to collect sufficient fees, but then continues to enumerate the accomplishments and the beneficial projects, state and national level organisations in which the association is involved to improve the irrigation infrastructure and the productive conditions for the water users and producers of this area. When the CNA District Head Becerra, the Minister of Agriculture and the Governor have also spoken, the delegates are asked if they approve the annual report, after which they collectively raise their hands and express their approval by calling d'acuerdo or aprobado (o.k.). 
184 The Success of a Policy Model

Table 4 Annual maintenance programme and report compared ${ }^{9}$

\begin{tabular}{|c|c|c|c|}
\hline $1997 / 1998$ & Programmed & Executed & Percentage (\%) \\
\hline Total maintenance budget & $\$ 1,357,682$ & $\$ 844,357$ & 62 \\
\hline \multirow{2}{*}{$\begin{array}{l}\text { 1. Cleaning and weeding by } \\
\text { hand }\end{array}$} & $70.7 \mathrm{~km}$ & $72.7 \mathrm{~km}$ & 103 \\
\hline & $\$ 27,080$ & $\$ 39,836$ & 147 \\
\hline \multirow{2}{*}{$\begin{array}{l}\text { 2. Cleaning with light } \\
\text { machine Alamo }\end{array}$} & $197 \mathrm{~km}$ & $41.5 \mathrm{~km}$ & 21 \\
\hline & $\$ 54,217$ & $\$ 14,387$ & 27 \\
\hline \multirow{2}{*}{$\begin{array}{l}\text { 3. Manual weeding and } \\
\text { herbicide application }\end{array}$} & $21.6 \mathrm{~km}$ & $1.4 \mathrm{~km}$ & 7 \\
\hline & $\$ 15,973$ & $\$ 13,3467$ & 84 \\
\hline \multirow{2}{*}{$\begin{array}{l}\text { 4. Water plant extraction } \\
\text { back hoe loader }\end{array}$} & $187.7 \mathrm{~km}$ & $119 \mathrm{~km}$ & 63 \\
\hline & $\$ 107.865$ & $\$ 33,489$ & 31 \\
\hline \multirow{2}{*}{$\begin{array}{l}\text { 5. Canal cleaning back hoe } \\
\text { loader }\end{array}$} & $11.7 \mathrm{~km}$ & $7.7 \mathrm{~km}$ & 66 \\
\hline & $\$ 45,341$ & $\$ 32,564$ & 72 \\
\hline \multirow{2}{*}{$\begin{array}{l}\text { 6. Roads and canal banks } \\
\text { with loader/ trucks }\end{array}$} & $1,080 \mathrm{~km}$ & $62.2 \mathrm{~km}$ & 0.058 \\
\hline & $\$ 67,548$ & $\$ 156,965$ & 232 \\
\hline \multirow[t]{2}{*}{ 7. Repair canal lining } & $0.067 \mathrm{~km}$ & $0.087 \mathrm{~km}$ & 130 \\
\hline & $\$ 12,661$ & $\$ 11,980$ & 95 \\
\hline \multirow{2}{*}{$\begin{array}{l}\text { 8. Plant extraction with } \\
\text { Caterpillar tractor }\end{array}$} & $46.7 \mathrm{~km}$ & $6.2 \mathrm{~km}$ & 13 \\
\hline & $\$ 76,385$ & $\$ 2,915$ & 4 \\
\hline \multirow{2}{*}{$\begin{array}{l}\text { 9. Cleaning drains with } \\
\text { dragline }\end{array}$} & $56.8 \mathrm{~km}$ & $44.2 \mathrm{~km}$ & 78 \\
\hline & $\$ 334,009$ & $\$ 54,768$ & 16 \\
\hline \multirow{2}{*}{$\begin{array}{l}\text { 10. Road construction with } \\
\text { motor grader }\end{array}$} & $280.6 \mathrm{~km}$ & $77.1 \mathrm{~km}$ & 27 \\
\hline & $\$ 210,486$ & $\$ 56,079$ & 27 \\
\hline \multirow[t]{2}{*}{ 11. Repair structures by hand } & $21 \mathrm{~km}$ & $21 \mathrm{~km}$ & 100 \\
\hline & $\$ 29,043$ & $\$ 11,027$ & 38 \\
\hline \multirow{2}{*}{$\begin{array}{l}\text { 12. Painting and oiling } \\
\text { structures }\end{array}$} & $100 \mathrm{~km}$ & $260 \mathrm{~km}$ & 260 \\
\hline & $\$ 10,000$ & $\$ 22,118$ & 221 \\
\hline \multirow{2}{*}{$\begin{array}{l}\text { 13. Studies and projects } \\
\text { topographical brigade }\end{array}$} & $90.000 \mathrm{~km}$ & $57.334 \mathrm{~km}$ & 64 \\
\hline & $\$ 108,000$ & $\$ 105,827$ & 98 \\
\hline \multirow[t]{2}{*}{ 14. Machine repair } & $6 \mathrm{~km}$ & $13.4 \mathrm{~km}$ & 223 \\
\hline & $\$ 100,546$ & $\$ 227,417$ & 226 \\
\hline \multirow[t]{2}{*}{ 15. Supervision of works } & $1 \mathrm{~km}$ & $0.8 \mathrm{~km}$ & 83 \\
\hline & $\$ 75,000$ & $\$ 61,549$ & 82 \\
\hline
\end{tabular}


Whilst the food and drink are being distributed and the banda is playing popular songs, a feeling of satisfaction comes over the crowd. When the governor has finished his meal and personally answered a number of requests from people that approach him, he stands up to indicate that the formal part of the meeting is over. His pall bearers follow him to the line of pick-ups that will take them back to Tepic. The popular celebration continues until the beer is finished. Then people leave.

\section{Intermediate analysis}

Neither the maintenance programme nor the report mention a set of stated performance objectives or criteria or 'an internally agreed service level' on the basis of which it would be possible to establish the operational performance of the association. In addition, it is effectively impossible to make a simple comparison between the planned and executed maintenance, either in terms of the location of works, or of the actual and programmed expenses per maintenance activity. The actual expenses: 844,357 pesos (about US\$211,089) and programmed maintenance expenses: 1,357,682 pesos (about US\$339,420) over 1997/1998 differ so much that it is difficult to evaluate the quantity of realised maintenance work in relation to the original plans $s^{10}$. The percentages of executed work in relation to planned, both in kilometres, cost and cost per unit vary so widely that it is impossible to make any general statements about the maintenance performance. A comparison with previous years is also difficult, because the type of information presented is different in every annual report. No information from before the transfer is publicly available.

The absence of a publicly available, consensual and standardised system of performance assessment makes it impossible to compare and validate assumptions about the improvement of maintenance performance, or for delegates or CNA officials to monitor maintenance performance in a univocal manner. The only useful conclusion that can be drawn from these data is the indication they give of the budgetary importance of different maintenance activities and the machines with which they are undertaken. In $1997 / 1998$ it is striking that the annual costs of machine repair turn out to be very high. It is by far the largest item of expenditure and constitutes more than a quarter of total maintenance expenditure (see Table 4 , item 14) ${ }^{11}$. The second largest expense is the construction and maintenance of roads and the strengthening of canal banks with a loader, trucks and the motor grader, which add up to a fifth of the total budget (items 6 and 10), and the third is the execution of topographical studies and projects (one eighth). The motor grader, the loader, the hydraulic excavator and the trucks are the most intensively used machines, expensive both in terms of work and repairs. Further on in this chapter we will see that these sources of expenses are also important sources of income for the group in charge of the association.

Maintenance programmes, budgets and reports are not straightforward regulatory devices that are capable of controlling the direction and movements of people, technological devices and resource flows in an organisation, and thus the operational performance of maintenance.

In this meeting, the association president does not render account of the operational performance. By means of the presentation of an annual report, he rather performs a 
kind of answerability and transparency to the delegates and the water users. However, the meeting and the annual report are, in these circumstances, hardly a source of public accountability. In practice, the board hardly involves the delegates in discussions concerning basic managerial decisions. Instead they inform them afterwards, if they inform them at all. The presentation of the annual report is largely ceremonial and obscures the reality of machine-operators in the field.

The following chapter analyses this type of meetings as cultural performance, i.e. the enactment of a cultural repertoire in view of a political campaign. Without going into much detail, I shall point out the most important elements. Firstly, for the political group organising the meeting it is important who is present at it. They have been rather successful, as the most crucial political authorities in the state attend. A significant part of the group's electoral constituency that has come to the meeting is able to see this. This emphasises how well connected Nuñez is. Secondly, the physical organisation of people and space reveals who the central actors are in this cultural performance. By giving a speech as president of the WUA, Nuñez further develops his political profile. Thirdly, the skilful mobilisation of a set of cultural commodities - food drink and music - enhances the good atmosphere of the meeting and draws attention to the message that needs to be got across. The meeting primarily serves to diffuse an image of good management and political leadership to the public of users, delegates, functionaries, local leaders, politicians, higher political and bureaucratic authorities.

\section{Impressions in the field}

The manager, Guttiérez, and the CNA supervisor, Blanco, make a field trip to show me some of the maintenance machinery at work. In Guttiérez's air-conditioned and wellmaintained pick-up, the three of us drive along the canals and drains in search of the hydraulic excavator that Guttiérez put to work in this area yesterday. Although we do not know exactly how far the operator has advanced with his work and where we can find him, we can spot the machine from a long distance away because it towers above the crops and trees.

The low mobility and high visibility of the machines makes it relatively easy for the manager to supervise their movements when he drives through the area in his car. To reach the machine via some small sandy roads we have to cross several puddles of water created by the sprinklers operating in neighbouring tobacco fields. When we arrive near the machine, Guttiérez parks the pick-up and we get out. We watch the hydraulic excavator removing the lush vegetation from the canal bank of a sub-lateral. The operator is moving the hydraulic arm sideways to bring the young trees and shrubs down, after which he uses the arm to uproot the vegetation, lift it and put it aside. Blanco remarks that for the machine it is not good to use the arm laterally to attack the trees, because it could destroy the cables and hydraulic wiring attached to the arm. This machine is not really meant for removing such high vegetation, but under these circumstances it would be preferable to attack it with the excavating device. Guttiérez agrees and Blanco makes the same observation to the operator who follows his instructions.

When we drive on, we see parts of the system where the sub-lateral canals are even more overgrown, particularly towards the tail-end of the system, when we get closer to 
San Blas. Small trees indicate that it is more than a year since they have been cleaned. We also look at the state of the intake structures, gates, and the weirs, of which many are broken and only partly functioning. Parts are missing, such as plates, bolts, cables. Gates are held up with barbed wire or with a stick or sandbags underneath, because devices are missing, or more water is needed. Guttiérez explains that, on the transfer of the system, a lot of the canals and drains were in a poorly maintained state and that many of the gates and intakes were in media vida (half alive, needing repair). Some canals and drains had not been cleaned for many years. Later, on the main canal near El Tizate just before the off-take of lateral 17, we review two major radial weir gates. We get out and observe that the cables of one of the gates are broken, that it cannot be lifted anymore. Fortunately, the other gate is functioning, which is sufficient according to Guttiérez. He claims that, at the transfer, sixty per cent of all the structures were broken, whilst at the moment it is around forty per cent, because of the association's repair activities. It is Guttiérez' opinion that this all has to do with 'the culture of the user'. People steal parts of the gates to sell as scrap iron; they move the intake structures without permission, sometimes even without a clear purpose. Nowadays this is becoming less frequent, because there is already more consciousness among the users about such issues.

Having discussed the topic with a variety of insiders and outsiders, I get the general impression that the condition of the infrastructure has partially improved in comparison with the 1980s when the maintenance carried out by the Ministry of Agriculture and Hydraulic Resources, SARH, was very limited (see Chapter 4). The canals and drains are cleaner and the roads are more accessible, people contend. In general, from the perspective of water distribution, the delay in water turns caused by silted canals is limited to hours or occasionally days, but not much longer than that. This is short in comparison to other schemes. The condition of the drains also appears to have improved, although it is far from ideal. Siltation and vegetation growth is rapid, and a lack of maintenance can cause severe drainage problems, particularly in the rainy season. The structures and the canal lining have been in a mediocre but functional condition since the transfer. Although a rehabilitation of the infrastructure was not carried out before or after the transfer, the association has carried out some minor repair activities. Driving through the Left Bank, one notes a striking contrast in the maintenance condition of the infrastructure between the top end and centrally located parts of the system and the tail-end sections, particularly towards San Blas (sections 9,10,11,12, and 13; see Map 6). The latter parts clearly have benefited less from the maintenance efforts of the association than the ejidos located around Villa Hidalgo. This difference also existed to some extent during the government era of irrigation (see Chapter 4). In the ejidos belonging to the municipality of San Blas, the canals are generally more silted, and this leads to delays in irrigation. The drains and roads are clearly more overgrown with weeds, shrubs and trees. In addition, the obvious lack of field drains affects crops negatively in the rainy period. Some insiders argue that the lack of maintenance efforts is related to the lower irrigation fee payment of farmers in this area. This is partly true. However, as will be explained later in this chapter, it is mostly related to the political constituency and presence of the political group that took charge of the association.

Of all four WUAs in Nayarit, the Left Bank manages the largest number of machines, because it has the largest irrigated area to maintain. The other WUAs feel disadvantaged in this respect. Nevertheless, Guttiérez argues that the association does not have 
sufficient machines in good condition for the maintenance needs of the system. Machinery repair is a large drain on the budget of the association. A number of the machines were old and in a bad shape when they were transferred and they continue to present problems. The old Link-Belt backhoe loader broke down near a canal in El Corte some time ago and the state of the machine makes it too costly to repair or move it. The dragline from the early 1970s does not work at full capacity anymore. It breaks down and has to be repaired regularly ${ }^{12}$. Another problem faced by the association is that it is difficult to acquire spare parts for the new machines they received from the CNA around the time of the transfer. The decision to buy certain makes of machines was made by the CNA in Mexico City and could not be influenced by the association. Guttiérez suggests that CNA officials had personal interests in buying these particular machines, as they were bought from foreign companies without an ample network of suppliers around the country. For example, the motor grader, Huber, was handed over by the CNA completely new in 1991, when the patronatos de apoyo (assistant managing boards) ${ }^{13}$ were functioning (see Chapter 4). It broke down after being used intensely and inexpertly. It remained idle for months, because there was no money to repair it. Recently, it was brought to a workshop in Tepic where it awaited repair. The particular spare part needed was impossible to find in Mexico and eventually had to be imported from Canada.

Because of the frequent breakdown and disrepair of machines, and to keep up with the maintenance requirements, the association participates in an exchange of machines with four other associations in Nayarit. This exchange of machines, which happens without mutual payment, is co-ordinated by the CNA, according to the availability of machines and maintenance needs of these four irrigation modules and one rainfed module in Nayarit. Another example is the Hyundai excavator, which was handed over to the association around the time of the transfer in 1993. There was a large demand for this machine, it was used intensively and new spare parts were needed to keep it working, but they were not always easy to find rapidly.

To do something about the general disrepair of the operational infrastructure, the association entered a CNA programme for the rehabilitation and modernisation of irrigation systems. It is part of a larger federal government programme Alianza para el Campo (Alliance for the Countryside) ${ }^{14}$, which enables the co-financing of rural development investments. A certain number of gates and weirs were repaired or renewed. The association financed this by asking the water users for an additional irrigation fee of fifteen pesos per hectare (US\$2) ${ }^{15}$. It contributed 100,000 Mexican pesos (US\$25,000), an amount which the federal government, through the CNA, doubled. The works were carried out by a private engineering company from the northern state of Sinaloa. This company, which tendered the lowest bid in an open contest for the contract, had undertaken similar works in earlier years for the association and the CNA. The company turned out to have the lowest bid and was selected after an open competition and collective bidding by various companies. Minor repair activities to the infrastructure were undertaken by field personnel of the association. 


\subsection{The Organisation of Maintenance}

\section{An organisational chart}

On a November morning I visit the association 's office. Blanco accompanies me. He is responsible for supervising and supporting the activities of the association on the Left Bank. On our way, the supervisor is good-natured. He is curious about what the manager will tell me when I ask him how management functions, and he instructs me about what to ask him. Although they are compadres (co-parents), the two men have clearly diverging institutional positions and interests. After Guttiérez welcomes us, Blanco asks him for an organisational chart of the association. Guttiérez looks in the Concession Title, a document that stipulates the terms and conditions under which the CNA has transferred the module to the association. He finds the official chart of a WUA according to CNA head quarters, studies it, but draws the conclusion that it is not correct. Then he starts drawing his own. After a few minutes he shows the chart depicted in Figure 3.

What strikes me immediately is the absence from his chart of a General Assembly, the highest authority according to the official chart. I ask Guttiérez about the frequency of these meetings of delegates. He responds that it was intended to organise monthly meetings, but that many of the twenty-five delegates do not show up, because they have their own work. Therefore, they only organise a meeting when they encounter a problem that they want to discuss with the delegates. Although Guttiérez does not say who 'they' are, it is clear that he is referring mainly to the group of Pérez, Nuñez, and himself that effectively has managed the association since its formation.

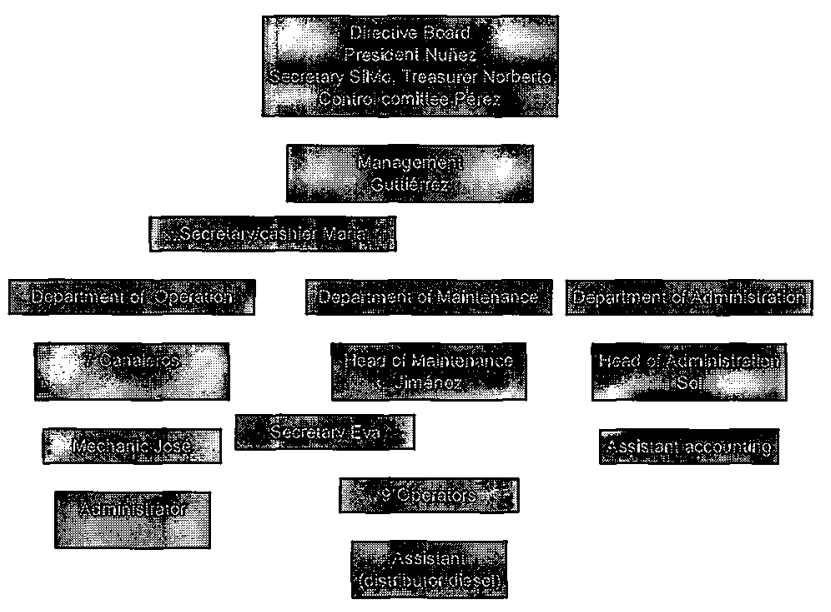

Figure 3 Guttiérez' organisational chart

Guttiérez goes through a pile of documents behind his desk and draws out a copy of the annual maintenance programme for 1997/1998. The page that he opens for me details 
the maintenance budget expenses planned for this year. The expenses (Mexican pesos) are divided over the following six major maintenance areas:

- Distribution net (canals):

384,211

- Drainage net:

410,395

- Road net:

210,486

- Structures (division structures, etc.):

69,043

- Studies and projects:

108,000

- Supervision and repair of machines:

TOTAL

In total, these expenses are about sixty-five per cent of the association's total planned budget for the coming year. Maintenance is by far the largest proportion of expenditure, because, for operation and administration respectively, only around twenty-five per cent and ten per cent are allocated ${ }^{16}$. The maintenance plan details for each canal, drain or road the quantity of a programmed activity in volume, area, length and costs. These activities vary from levelling roads, dredging drains, extraction of silt and water plants, to consolidation of canal banks.

Guttierez gives an overview of the infrastructure that the association operates and maintains: 231.95 kilometres of canals (with 271 weirs, 106 lateral intakes and 440 field intakes), 193.6 kilometres of drains, and 301.13 kilometres of roads ${ }^{17}$. For the maintenance of this irrigation infrastructure, the association has seven operating machines and three trucks at its disposal. This is a significant increase in machine capacity in comparison with the SARH days before the transfer (before 1991), when the district only had a dragline, a backhoe loader and a motor grader for both the Left and the Right Bank of the River Santiago. A lot of maintenance work was contracted out to private firms, because the machines were under repair or there was a huge backlog in maintenance. SARH engineers often had links to these private firms through which they also benefited personally. Reviewing the maintenance personnel, Guttiérez points out that the fact that all of the nine maintenance operators constantly work on one of these machines or trucks prevents machines or workers being left idle, as frequently happened before. The use of manual labour for weeding, extraction of plants and removal of shrubs and trees, and the application of chemicals has been significantly reduced under the association in comparison with the situation under the SARH, which employed fixed teams of manual labourers. When manual labour is needed for this purpose, temporarily contracted teams of workers generally do it.

In sum, after the transfer of the Left Bank module, maintenance is carried out with more machinery and with fewer staff working full-time on the machines. This has resulted in increased maintenance capacity. According to the annual maintenance report, the available maintenance machines (with year of acquisition) are used for the following purposes:

- A dragline Link-Belt to clean drains (1972)

- A motor grader Huber used for preparing roads (1991) 
- A backhoe loader Link-Belt and a hydraulic excavator Hyundai Robex (around 1993) used for excavating, cleaning and dredging of canals, and the extraction of water plants

- A Caterpillar tractor (1990) and a Clark Michigan loader (1978) for excavating, soil transport, preparation of roads, the extraction of plants and removal of shrubs and trees, and consolidation of canal banks.

- A light machine Fiat Alamo to extract water plants from drains and canals and to clear their banks from vegetation.

- Three trucks of different makes for soil transport for roads and canal banks.

Above, Guttiérez presented a set of documents that separately represent the association's organisation of staff, machinery and financial resources in space and time: the maintenance programme that centrally plans the spatial and timely distribution of maintenance work; the organisational chart, which spells out the vertical distribution of decision-making authority and work; the maintenance budget that programmes the allocation of financial resources and the technical specifications which prescribe the correct use of the machinery. From these accounts, I get the impression that maintenance under the association is the mechanical implementation of a central process of planning, decision making and regulation to which a significant part of its resources, personnel and machinery is allocated.

\section{The political group and the machine-operators}

The manager is a central figure because he co-ordinates the association's personnel, machinery and resources allocated to maintenance in the field. He is also situated at a nodal point of the political group that controls the WUA. Together with the president and influenced by the president of the control committee and a wider circle of favoured producers, they decide what is done with demands and claims on the machinery. Although Guttiérez and Nuñez have many other tasks demanding their attention, they are often directly involved in the decisions about where to move the maintenance machinery. This illustrates its strategic importance. They decide according to group interests whether to follow the regular maintenance programme or to dispense particular favours and services by means of the machinery.

According to Guttiérez' organisational chart, the head of maintenance, Jiménez, controls the association's daily maintenance routine (see Figure 3). He is responsible for supervising the maintenance personnel and monitoring the progress of the maintenance machinery in the field. In addition, he is also expected to prepare the annual maintenance programmes and monthly reports. However, the paper hierarchy provided by Guttiérez does not correspond with the actual working relationships.

Jiménez is a middle-aged, pot-bellied man, who used to work as a topographer under the SARH and the CNA. He is from the state capital of Tepic where the CNA head offices are located. When the association was formed in 1993, he was one of the few CNA employees employed by the association. Jiménez is regularly to be found in his office, which lies in the courtyard at the back of the association's building. With a fan directed towards him and maps enthusiastically scattered around the office, he is working on some calculation sheets. He is preparing the levelling of a plot or the 
construction of a drain. At the beginning of the rice cycle, Jimenez is also intensely involved in the measurements needed for the layout of bunds in rice fields. The concentrated expression on his sweaty face tells me that he enjoys this work. In his position as topographer, Jiménez is one of the few persons in the area who has at his disposal a complete set of instruments and tools to take topographic measurements for agricultural purposes. There are other engineers who claim that they have the necessary skills and emphasise that taking measurements is nothing difficult, but they do not have access to such instruments. This leads to jealous comments about Jiménez' beneficial position. Jiménez does his topographic work for the association, but also sometimes accepts assignments on a personal basis. For such private assignments, he charges lower than the official tariffs of private companies. They are a lucrative business, both for the association and himself, given the large interest and the limited topographic capacity in the area. Pérez, Guttiérez, Norberto and a group of favoured rice producers particularly benefit from Jiménez' services. Because Jiménez is not really part of Pérez' group, he appears thankful to Guttiérez for allowing him to work, to accept private assignments and make some extra income. Consequently, he displays loyalty to him.

In addition, Jiménez does not have a pick-up or a radio of his own. He only goes to the field from time to time to supervise the machine-operators. Leopoldo, the person who distributes diesel and oil among the machines and the trucks, uses the only pick-up allocated to maintenance. Leopoldo is a compadre of Pérez. Jiménez depends on Leopoldo when he needs to go to the field. Leopoldo does not really like his superior, Jiménez, because he is always ordering him around on matters about which he is not really competent. For example, he tells him to do things more quickly, to repair a machine, when this is not really possible. Leopoldo is of the opinion that he only thinks of himself as important and that this is very tiring. So Leopoldo tries to avoid him and, when possible, does not always comply with his instructions. According to this alternative organisational hierarchy, it is much more important to comply with the instructions from Guttiérez, Pérez, or Nuñez.

Because the head of maintenance does not have at his disposal a pick-up, radio contact or close relations with his operators, he is unable to monitor the movements and work of the machine-operators. Therefore, he is unable to check the report sheets they hand over to him and which form the basis of the maintenance reports to the CNA. These sheets mention their location, daily progress, and fuel consumption, data that he uses for his monthly reporting to the CNA. It follows that for relative outsiders to the daily maintenance routine, such as CNA district officials, the delegates, let alone farmers, it is very difficult to survey the use and movements of the machines in order to monitor their operational performance and make the management accountable.

Hence, in practice Jiménez is both socially and materially severely constrained in these tasks, as he is not authorised to make decisions regarding the machinery or personnel and oversee the maintenance work effectively by means of a pick-up. These tasks thus largely rest with others. For example, Blanco assists with the maintenance programming and budgeting (because of a supposed lack of expertise on the part of Guttiérez and Jiménez), and the secretary usually does the monthly reporting. Jiménez is only partly responsible for plans and reports on the quantity and quality of work 
Instructing the operators and steering the maintenance works in the field falls to Guttiérez and his employees and confidants, Leopoldo and Aldama. Guttiérez keeps in close contact with them by radio. Besides his maintenance work, Aldama is also an active delegate from the El Corte ejido. At the beginning of the 1990s, he was the treasurer of the rice refinery near La Sauta, until it was closed down because of financial problems in 1994. From this period, he knows both Emilio, the large rice producer who preceded him as treasurer, and Pérez, who was a member of the board ${ }^{18}$. Aldama maintains friendly relations with Pérez and his group. This is why he was asked to be a vocal (stand in) for President Nuñez, whom he would replace in the event of something happening. Presently, he supervises the work of the association's three trucks. Usually he accompanies one of the truck drivers and thus can often be found in the field. Guttiérez maintains a relation of friendship and trust with Aldama, and leaves him a lot of discretion in his work.

Together with Guttiérez I attend a few alcoholic encounters with Aldama, a heavy drinker, somebody who competes with Diego in terms of his bodily dimensions. One particular afternoon we see the trucks parked close to a cantina. We enter the place where Aldama, the three truck drivers and the operator of the loader are drinking. Guttiérez pays for some of their beers and we drink, exchange jokes and laugh with them in an amicable atmosphere. When we have left and are driving back to Villa, Guttiérez imparts an instructive insight: 'You have to learn that it is oery important to coexist with the workers'. He explains that they very much appreciate it if you spend some time and drink with them. This is very important for your relations with them and their motivation to work, he states. The maintenance of relations of friendship with the operators through these kinds of encounters appears important to Guttiérez, because it generates a sense of belonging to a group and enhances worker loyalty.

Behind Jiménez' office lies the half-covered workshop of the mechanic, Juan. As I make small talk with Juan, we look at the machine park in the courtyard where vehicles await use or repair. Some machines have been parked here for a long time, because no money is available for their repair, or because of the difficulties of acquiring the spare parts. Juan suggest that it also has to do with the fact that some operators do not have the skills or experience that it takes to correctly operate and maintain a machine. He gives the example of the Clark Michigan tractor used for maintaining roads and canal banks. Although it was still in a reasonable state when it was transferred, it presently breaks down constantly. The former operator was very irresponsible and did not maintain the machine. He did not know, until it was too late, that the four wheels have to be greased every now and then. The new operator is more responsible and skilled in this respect. There are good operators if you look for them, but they are not always hired because other criteria come into play.

Most of the nine operators are related in some way or belong to Pérez' group. This means that expertise is not always the most important criterion for recruitment. What is also important here is that these people owe their secure job and income to Pérez, Nuñez and Guttiérez, and are thus expected to be loyal to them. Some of these confidants have better working conditions and incentives than others in the association. In addition, they are allowed to extract private benefit from their work or are allowed extra leeway in their work without being reprimanded. This creates an obligation. 
Others, who do not answer to the clientelist expectations of the group, endanger their position and are likely to be in less beneficial and crucial positions. Like the canaleros, the maintenance workers are not unionised and can be easily fired. Although salaries were raised significantly after the transfer, this was in part nullified by the annual rate of inflation, as salaries were not index-linked. The maintenance workers have become more dependent on their superiors for their job security than in the government days.

\subsection{The Socio-Material Practice of Maintenance}

\section{Actual patterns of maintenance}

The assembly of delegates and the management agreed early in Nuñez term as president that they preferred a spatial zoning policy for the use of the maintenance machinery. This meant that a machine would finish the maintenance of canals or drains in a particular zone or section according to a fixed route, before moving to another zone. It was also agreed that in addition to quantities and costs, the annual maintenance report would mention the locations of maintenance works. These measures were expected to rationalise the execution of the maintenance programme by minimising the cost of displacement of machines and preventing misuse of the machinery. With the zoning policy and the maintenance programme, it would be easy to review the progress on a map of the irrigation system, as the planning and corresponding advances along the line elements (canals, and so on) can be made visible. The delegates were aware of, but could not prevent, this zoning principle being dropped just a few months into Nunez' presidential period, because Nuñez' group mobilised the machines according to personal and group interests. In practice, a much wider field of forces, priorities and pressures was at work than the paper planning of maintenance and such a zoning policy reflected.

As a result, the daily practice of maintenance shows enormously complex and irregular patterns of machine movements from one spot in the system to the next (Sijbrandij, 1989; van der Zaag, 1992). The maintenance work appears to be delivered at random, the traces distributed like those of a spider's legs (see Map 8). These patterns are hardly intelligible from the programmed maintenance activities on canals, drains and roads, or from the zoning policy that demands certain continuity and fixed machine routes. The maintenance programme is in reality only in part decisive in determining the mobilisation, work, routes and movements of the machines. The programme does not prescribe a fixed time schedule or spatial sequence in which the planned work is arranged, so it leaves open when and where a machine is allocated.

The machine-operators or truck drivers are constantly moving along a web of canals, drains, fields and roads. The machine-operators travel a lot across and sometimes outside the system. When they are finished in one spot, they get instructions to move to the next. At night, the heavy machinery is usually left in the field where the day's work finishes. Operators are brought to their machines by pick-up in the morning and work all day long on a canal or a drain, usually with no other companion than the noise of their machine. The diesel distributor, Leopoldo, who brings, checks and refills their diesel and oil is their most frequent visitor. He also brings them instructions from 
Guttiérez or the president about where to go after they have finished in their present location. This is because he is in touch with the office through his radio.

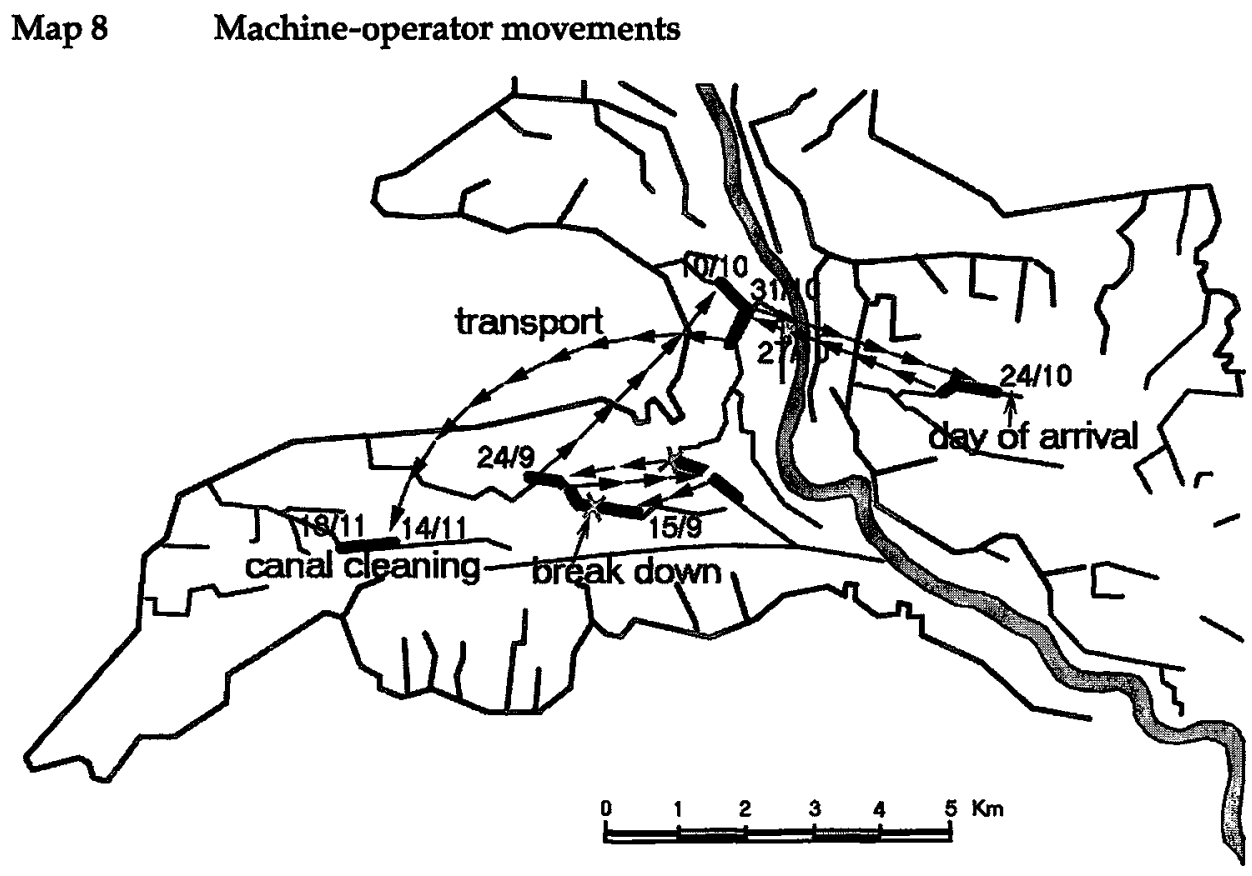

Source: (van der Zaag, 1992: 119)

The operational performance of maintenance is hampered because the moderate physical condition and the frequent breakdown of machines produce irregular and discontinuous patterns of movements and work. This is caused by their very intensive use. Although the repair of machines is carried out much more quickly than under the government, it may still take considerable time, because of the lack of spare parts or financial resources, and it is often necessary for a machine to discontinue its route and work in order to be returned to the association's yard or a workshop somewhere else. When the repair is completed, there may be other priorities preventing it from returning to the spot where it was working. Another bottleneck which hampers the advance of regular maintenance is the displacement of machinery when emergencies arise, such as the sudden flooding of the river, canals or drains that may threaten fields or villages. In some cases, the association is asked by local politicians to send their machinery for the resolution or prevention of such emergencies.

The political group in charge of the association thus controls the actual decisions about the day-to-day use and movement of the machine-operators. Nuñez and Guttierez in particular are centre stage in determining the use of the machinery and their operators, strongly influenced by Pérez, the treasurer Norberto and a network of favoured large producers who regularly lay claim to the use of machines. Guttiérez benefits from the close ties that he has with the group of confidants that works in maintenance, who are 
instrumental in the movement of machine-personnel in line with the group's pragmatic needs. The machine-operators take part in a cascade of social, material and political performances of this political group. As such, the mobile machine-operators are like the flexible legs of a spider that move around a dispersed network of canals and weave a web of relations. This web of relations extends beyond, and shifts the physical boundaries of, the irrigation system, as we will see below.

\section{The Hyundai operator and the canalero outside the irrigation system}

I have described the following scene before in Section 6.4, where I emphasise how Diego provides his patron, Pérez, with privileged access to irrigation water. Here I will focus on the particular use of machinery. In the middle of the main irrigation season in 1998, I drive with Diego down one of the sub-laterals in his section. Diego is in a hurry to check whether sufficient water is reaching the end of the canal. Pérez owns two large properties at the tail-end of two sub-lateral canals in Diego's sections. Diego remarks that these properties are officially not part of the irrigation district and that they lie immediately outside it. The association is not obliged to give him servicio here...(but it does). Not many people are likely to notice this, because these lands are situated far from the easily reachable main canals and the paved roads.

At the end of the lined canal we find a reasonably new outlet structure that lets through the water flow that Diego has just ensured. The canal outlet lets the water stream into what looks like an earthen drain. In the field, a few bomberos (pump operators) have installed a pump near this drain and are using this flow of drainage water to irrigate young sorghum with a sprinkler installation. The structure and the drains were constructed only three years ago. The association's machine-operators worked day and night on the immense job of removing the vegetation, levelling the land, constructing field drains, and making it ready for irrigation. Two years ago, Pérez had started producing rice and sorghum.

Further down the field, an association operator is cleaning the drain with the hydraulic excavator, Hyundai. He is glad of some distraction in this remote spot and so we have a chat. The man is one of the association's most experienced and capable operators. As machine-operator, he worked in several Central American countries on the PanAmerican Highway running from Mexico to South America. Although his salary is much lower now that he works for the association, he is happy with the steady income. He and the Hyundai are almost constantly engaged throughout the year, and they move around a lot in the area.

We discuss the fact that the drains on which he is working are not constructed correctly, as they do not have a gradient and the water has no way out. In practice, they are used as canals. Because they convey a lot of silt-laden water, they rapidly fill up with sediment and have to be cleaned regularly. The operator wants to make them a lot deeper but thinks that there will not be enough time, because the excavator is needed somewhere else. To do a good job on the three drains, the operator estimates he needs about sixty hours or one week of work, but he doubts that he will be given the time to finish it, because there is an almost constant demand on his machine. He says that he will have to wait and see what Nuñez wants. 
The men continue to talk about Pérez' recent agricultural and political operations and laugh about his way of achieving things. As his clients, they respect and enjoy the productive and political skill of their patron, in which they participate.

\section{Machine-operators beyond boundaries}

The example above reveals how Pérez, as leader of the political group in charge of the association ${ }^{19}$, uses its operational arrangements to expand his network of irrigated agricultural production. Machine-operators, canaleros on motor bikes, outlet structures outside the irrigation system, and drains that turn out to be canals, are the composite entities that take part in this. These operational arrangements thus enable Pérez to engage in more than operational performances and extend beyond the boundaries of the irrigation district.

By means of the machine-operators, the political group maintains a web of social and political relations that constitutes a source of revenue and political support. Below we will explore several examples. Firstly, a wider group of favoured large producers, who are part of the outer circle of the group, benefits from privileged access to the machinery, personnel and resource flows involved in maintenance (see also Chapter 6). Because these producers own large areas of land in need of levelling and preparation for irrigated rice, sorghum and maize production, or where the canals and drains need to be cleaned, they occasionally make requests to use the machine-operators. These activities might fall within the maintenance programme, but they also might not. These producers make claims on the use of the machinery and are granted favours by the association's management. The machine-operators are thus used not as collective but group assets in order to reproduce bonds or create alliances, in spite of the fact that the expenses are charged to the wider constituency of users. These favoured producers may come to the office, make a phone call to Guttiérez or Nuñez, or call them on their radio, in order to impart their request. They are generally asked to wait some days until the machine in question is finished its work in hand and becomes free. When their request is approved, the machine is moved to the private plot of the producer, or the canal, drain or roads that are connected to it and require work. Norberto and Emilio, with whom the group shares many different organisational, economic and political interests and friendship bonds, often make such claims and are consequently frequent users of the machinery.

Secondly, the association's machine-operators are also mobilised for purposes other than operational and productive ones. Norberto, for instance, in his function as treasurer of the association and ejido commissioner of Sauta also deployed the Caterpillar, the Hyundai and the Clark Michigan loader for several weeks in 1998 in the construction of an asphalt road to Sauta. It is unclear what the association earned from these investments. However, Norberto personally benefited a lot from the situation. His motive was not just financial but also political, as he faced elections in his ejido and expected to generate political support and to improve his public image as a leader by organising an important public work for his people that greatly improved access to the village.

Within the rural political economy and the sub-tropical coastal landscape of Nayarit, the type of heavy machinery the association has at its disposal is a scarce and highly strategic asset for which there is an almost constant demand for a variety of uses ${ }^{20}$. The public 
works enabled by machine-operators are an appreciated source of political support and legitimation for politicians, government officials, ejido and rural leaders, who seek to improve their public image of competent and effective leadership. Under the PRI (Partido Reoolucionario Institucional: Institutional Revolutionary Party), building these types of public infrastructure projects was a common practice for acquiring political support. Public roads, bridges, village squares, sports fields, drainage and sewage systems are good examples (see also Chapter 8). Maintenance machinery is therefore at times a much-demanded political tool that is subject to different claims. The mobilisation of the machines often occurs in exchange for support between politically allied groups and is part of a cultural exchange of favours (favores) and services (servicios politicos) to establish and maintain friendships and political alliances. There is of course a reciprocity in such types of exchange. Depending on the time and circumstances, some form of capital is expected in return: e.g. cash payment, favours, and political support.

Thirdly, another highly strategic use is the leasing out of the machine-operators in order to generate an extra source of revenue and support for political campaigning, as we will see in the next chapter. This has both financial and political aspects that are often intertwined. The association's rates for leasing out these machines per hour (around 125 US\$ for the hydraulic excavator, Hyundai) are below the commercial rates, particularly in view of the lack of heavy machinery in the area.

For example, the association's board gives ample support to Don Victor Gámez, a large cattle holder, with a few hundred hectares of pasture. The very existence of the holding depends on almost constant and ample access to water for his pasture, and access to the association's machinery for field improvement activities, such as levelling, making field canals and drains and soil transport. The motor grader, the trucks, the loader and their operators are used for these purposes. Although Don Victor pays a good fee per hour of machine use to Guttiérez in return, these services come relatively cheap to him, because the fee charged is below the commercial rate. However, the rationality behind such exchanges or transactions is never only commercial. The leasing of the machineoperators is often enmeshed with friendship relations, political transactions and alliance building. Don Victor, who has been a personal friend of the Pérez and Guttiérez families for many years, is an influential man with close political and business relations with the most important political families and entrepreneurial groups in Nayarit. He is one of the members of the Alica group, the largest entrepreneurial group in Nayarit, which supports one of its affluent members, Antonio Echeverría, and a political successor of Don Emilio González, the influential ex-governor, in his campaign to become the new governor in 1999. His support for Nuñez' campaign at the coast and in the capital may be useful to gather support among local leaders, politicians, government officials and businessmen.

Particularly when the association's financial situation is deteriorating towards the end of the irrigation season or in the rainy period, when fee collection drops, this revenue flow is crucial for the association and the group in charge when it is running a campaign. It has been especially important because Nuñez does not have additional sources of revenue from other walks of life, apart from his affluent patron Pérez. However, what it costs to let a machine work, and the payback, is not publicly known. The way in which the acquired cash is allocated is not very transparent for outsiders, observers or delegates, as this machine use is not programmed, reported or administrated per job and 
no receipts are given to the beneficiaries. In addition, as the next chapter shows, the machine-operators are even put to work outside of the irrigation system. This is difficult to monitor. For these reasons, this is a crucial source of revenue for Nuñez' group and enables them to organise and finance campaigns to support his political career and ambitions.

Another case in a similar category of machinery leasing is when an ejido requests the use of the machinery for improvement activities in or around the ejido. This might happen via the ejido's delegate or an ejido commissioner applying for the machinery. The chance of such a request succeeding depends very much on the relationship of this delegate or the ejido committee with Nuñez' group and it is considered a personal favour that they dispense. For example, the El Corte ejido commissioned the Hyundai and its operator to make a drain in order to drain a pond of water close to a village compound. The pond, which grew during the rainy period, threatened to inundate the compound. The ejido board, the association and the municipality reached an agreement to co-finance this safety measure. The association would put in their machine, the ejido paid five to ten per cent of the expenses, and the municipality paid for the diesel and the operator. Again this was not merely a commercial deal, but also embedded in Nuñez' political friendship relations with this ejido committee. The delegate for this ejido is Aldama, who is close to both the ejido's president and to Nuñez. Nuñez might expect the ejido to support him in pursuing his political ideals.

Early in 1998, Nuñez follows a similar path to that of his political patron, the regional deputy for the Left Bank, Pérez, and uses the association as a springboard to advance his political career. He wins the elections for presidency of the Municipal Peasant Committee (CMC) of Santiago Ixcuintla in February 1998. Subsequently, in 1999 Pérez, Nuñez and Guttiérez campaign for a range of political and administrative positions at the municipal and state level. Pérez' group acquires political and financial support from the aforementioned favoured producer groups, ejido committees, and influential politicians and leaders by dispensing a set of favours and services through the association. The machine-operators and maintenance works play an important role here in acquiring the necessary political and financial capital for their political campaign.

The downside of the aforementioned political use of the machinery by the group means that the maintenance efforts are not equally distributed over the irrigation system. In part this explains the striking difference in maintenance conditions between the core political constituency of the group and the areas that fall outside it, to the benefit of the former and the detriment of the latter. The fact that the boundaries of the irrigation system intersect with municipal and electoral district boundaries causes this complicated situation (see Chapter 4). This defines the constituency of the political group based in the WUA and consequently also the networks of political support that they favour and sustain. Their political constituency covers the central and largest part of the irrigation system that belongs to the municipality of Santiago Ixcuintla. Because Pérez represents this electoral district in his function as deputy of the state parliament, this territory has been the historical support base of his group. It mainly consists of ejido committees, producer groups, entrepreneurs, and clientele in and around the village of Villa Hidalgo. Nuñez initially also acquired a good deal of his support for the municipal CMC election from this area, particularly through the association. 
However, this political constituency excludes the coastal fringe zone at the tail-end of the irrigation system, which belongs to the San Blas municipality. This means that the ejido committees, delegates, influential agrarian leaders and producer groups from that area are not part of the political constituency of Pérez' group ${ }^{21}$. Ejido presidents, delegates, and politicians complain that they cannot exercise effective leverage over the association to get regular maintenance and special works with the maintenance machines, as a result of which less maintenance work is carried out here than upstream.

A former politician from the Autan ejido of the municipality of San Blas complains about the fact that, since the transfer of the irrigation districts, they do not have the possibility of intervening anymore when they want to question the allocation of water or machines. 'When the SARH still administrated, we were always in the position to phone the Secretary of Agriculture and ask about what was happening. We had the right to protest. Now if you call Tepic (i.e. the CNA), they tell you that the system is ours'. The message they get is that, as water users, they have elected the board and they should change it when it no longer satisfies. The effect is that local politicians cannot exercise influence over the use of the machinery. It appears that, in terms of maintenance service provision, the physical boundaries of the irrigation system have contracted and exclude the San Blas area.

\subsection{Conclusion}

The presentation of maintenance reports and organisational charts provides managerial idealisations of the allocation of personnel, machines and resources. This practice reproduces the managerial myth of regulatory devices that are capable of rationalising and determining the directions and movements of people, technological devices and resource flows in an organisation. Underlying this is the idea that people, technologies and resources engaged in irrigation management are strictly mobilised according to an operational set of rules and service provision objectives. This reduces the role of, for example, maintenance machines to technological inputs that have a fixed operational purpose. The assumption is that their operational performance automatically follows from the O\&M manual and the maintenance programme: a hydraulic excavator is used for cleaning $x$ number of canal stretches, a truck for transporting $y$ quantity of material. This type of account projects an image of ideal orders and the separated worlds of people, machines and resources involved in actual maintenance practices. This hardly provides a source of public accountability. However, the conclusion is not that these representations are completely meaningless, but that they are part of the wide array of ordering practices and performances that shape everyday management.

This chapter presented a socio-material analysis of maintenance that yields a number of analytical insights to challenge approaches that analyse irrigation schemes as systems with fixed boundaries. Following the erratic patterns of machine movements in the irrigation system shows that they go beyond the physical boundaries of the irrigation system and even shift these outwards. In other, less favoured parts of the system that do not fall within the constituency of the group in charge, the result is a contraction of the boundaries. This partially excludes groups of users from services for which they pay fees. 
This analysis allows an understanding of how a political group, through its connection with machine-operators, engages in multiple performances. It shows that the use of maintenance machinery contributes not only to the operational performance of maintenance in the irrigation system, but also to other social, material and political practices and performances that transcend and change what are conceived to be the boundaries and objectives of the irrigation system. These performances, which contribute to the formation and reproduction of the political group and its outer circle of favoured producers and political clientele, have a detrimental effect on the operational performance of the irrigation system. In the case that I have studied, the political group that controls the Left Bank WUA mobilises the machinery with a view to reproducing itself and enhancing its interest, rather than achieving a defined level of service provision that is agreed upon by the user representatives.

The concern for maintenance is nothing new. During the 1980s, the lack of federal funds for SARH irrigation districts was largely translated into a severe lack of maintenance, leading to deferred maintenance and an increasing need for rehabilitation (Palacios Vélez, 1994). This led to many problems in water distribution, in terms of delayed water turns and large areas of irrigation districts that could not be irrigated. The SARH maintenance departments experienced five major constraints:

1. Strong control on the part of the federal office and long administrative lines (Kloezen, 2002)

2. Severely restricted financial budget and financial dependency on the federal office

3. Frequent breakdown of machines and tight bureaucratic rules for the purchase of spare parts

4. O\&M responsibilities residing in different departments

5. Lack of accountability to the water users (van der Zaag, 1992).

An additional set of observations from actual field research gives rise to a more comprehensive form of analysis of maintenance performance. The SARH maintenance department was led autocratically by its head, who enjoyed high discretionary power and controlled the use of the maintenance machines almost entirely (Sijbrandij, 1989; van der Zaag, 1992; Kloezen, 2002). For Autlán-El Grullo, Sijbrandij (1989) and van der Zaag observe that the machinery was used as a personal asset to help out friends (van der Zaag, 1992: 123) or a favoured company (116). Further, the hiring out of machines outside the system for private persons and institutions generated extra income. This type of practice occurred to such an extent that a maintenance operator exclaimed about the movement of machines: 'this is pure politics' (115). Van der Zaag concluded that heavy machinery is a scarce and contested resource; in the case of the El Grullo system, it is even much scarcer than water. My conclusion is that maintenance machines, personnel and resources are mobilised for more than just operational performances, for example for political purposes. This does not alter after transfer.

The policy of transfer has undeniably produced significant changes in the organisation of maintenance, but they are not unambiguous improvements. The partial improvement of maintenance under the WUA can in large part be explained by the following changes after the transfer. Firstly, the WUA benefited from a large degree of autonomy from the federal government and the CNA, and the localised control over maintenance. Secondly, the financial resources for maintenance have increased considerably since the 1980s 
when the system was under government management. Direct control over a maintenance budget and the incoming irrigation fees enable the WUA to allocate resources more flexibly and swiftly. Thirdly, the financial leeway and the cancelling of tight bureaucratic rules for the purchase of spare parts contributed to the quicker repair of machines, thus preventing loss of time and working capacity. Fourthly, the WUA has a larger and more adequate machine capacity, because of three new and lighter machines received around the time of the transfer. Fifthly, a reorganisation of the personnel and longer working days for the maintenance workers have contributed to increased maintenance capacity. Fewer maintenance personnel are employed, but they are nearly all working on a fixed machine and for more hours per day.

Nevertheless, I find little evidence that the changes in maintenance are the result of financial or electoral accountability to the water users or the control of the association's assembly of delegates. In addition, the frequent and prolonged breakdown of machines is to a lesser extent still a problem due to other reasons, such as their intensive and sometimes inexpert use, financial problems, or the difficulty of acquiring spare parts. Although the changes in maintenance have contributed to an increased maintenance effort under the WUA, this has not equally benefited all irrigating farmers and different parts of the system. Specific producer groups and parts of the system have received preferential attention, because of a relationship with the political group in charge. This has put other farmers and parts of the system at a disadvantage. Further, the question is whether the partially improved maintenance can be sustained in the longer run, given the frequent disrepair of the machinery and the continuing deterioration of the infrastructure. It cannot undo the fact that a major rehabilitation has never taken place since the 1970s, something that will become a problem in the not so distant future.

Finally, when I back away a little and consider the argument made in Chapter 3 that the maintenance machines played an important role as catalyst in the acceptance of the transfer and that the new machines were understood as personal trophies by local leaders in the negotiation with the CNA, it becomes more understandable why the machines are used as personal and group assets employed for political purposes. By means of the machine-operators, the political group maintains a web of social and political relations that constitutes a source of revenue and political support. In the next chapter we shall see how this group uses this as a basis for the purpose of organising a political campaign. The above analysis, showing that irrigation systems do not have fixed boundaries and clear-cut outputs and that machines enable multiple performances, demonstrates that contemporary irrigation performance studies are flawed in this respect.

\section{Notes}

In the irrigation management literature, performance criteria are used as managerial and bureaucratic yardsticks to assess irrigation performance and the outcomes of policy interventions that seek to improve management. These performance criteria are taken to be stated management targets (Guda and Lincoln 1987), internally agreed service levels (Van Hofwegen, 1996; Bos, 1997), internally set standards and indicators (Small and Svendsen, 1992). Such techniques can help managers to monitor the quality of operational performance (Murray-Rust and Snellen, 1993) in relation to a defined and agreed level of service provision (Huppert et al., 2001). Further, because organisational practices are made available to outside enquiry, the measures are thought to encourage managers to 
become transparent about means and ends, more managerial in response to market forces and more accountable to water users (Vos, 2002; Kloezen, 2002).

2 This in spite of the illustrious example of Karl Wittfogel (Wittfogel, 1957).

3 Annex 5 of the 'Titulo de Concesión': Instructioo de operacion, conseroación y administración decentralizada del modulo 2, 'Asociacion de Usuarios de la Unidad de Riego Margen Izquierda Rio Santiago, A.C.', del Distrito de Riego Num. 043 Estado de Nayarit, (CNA, 1993)

${ }_{4}$ See IWMI's benchmarking project at http://www.cgiar.org/iwmi/.

5 Measured in length or area of maintained canals, drains or roads or volume of extracted material.

- Land reform communities created after the Mexican Revolution of 1910. Before the revision of Article 27 of the Constitution in 1992, ejido land belonged to the state, with a combination of community (ejido) and private (ejidatorio) usufruct. Ejido members are called ejidatarios.

I will focus on the presentation of maintenance results of this year by the association's president.

Further, another list of executed maintenance works is included, neatly ordered according to the location of works on canals, drains, or roads. This long list is not presented by the president during this event.

- Constructed on the basis of the association's annual maintenance report 1997-1998.

${ }_{10}$ Structural over-budgeting results in low irrigation fees, and this has made it possible not to increase irrigation fees too much.

"Second annual report of activities, 'Asociación de Usuarios de la Unidad de Riego de la Margen Izquierda del Rio Santiago, A.C. Modulo 2'.

${ }_{12}$ The Clark Michigan loader and the Caterpillar tractor are also repaired on a regular basis after a period of intensive use. Also a black Dodge truck is under repair at the moment after having been used intensively for transporting sand.

${ }_{13}$ Mexican legal entity: board, trust, council.

${ }_{14}$ The Peso por Peso programme, initiated by President Zedillo.

15 Assuming to irrigate and collect fees for more than 12,000 hectares.

${ }_{16}$ The average programmed maintenance budget is sixty to seventy per cent of the total budget and thus is the most important source of expenses and money.

${ }_{17}$ The numbers after the comma are not skipped and seem to add to the achievement.

18 'Vocal' (speaker): member of the board with voice and vote but without a post.

19 Firstly as president of the association and later as president of the control committee.

20. Some geographical, climatic and infrastructural factors contributing to this demand are the high rainfall and vegetation growth, the undulating terrain and the historical absence of substantial levelling and plot level drainage programmes in the irrigated areas.

${ }_{21}$ The ejido presidents and delegates from San Blas were evidently not part of this campaign, because of their earlier conflicts and differences and because they are allied to another CMC in San Blas. 


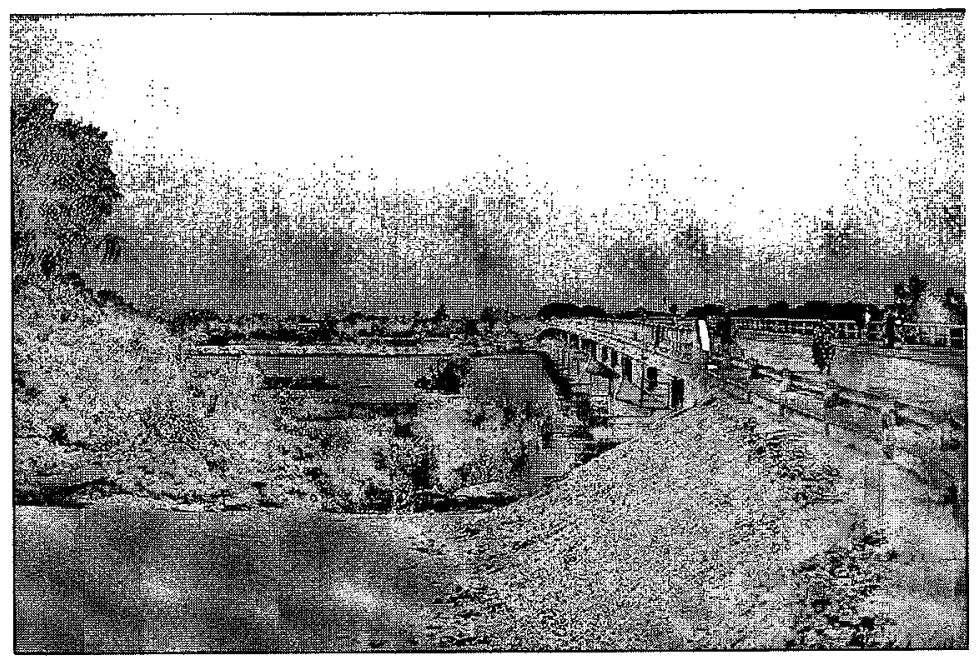

Photo 18 The new bridge over the River Santiago

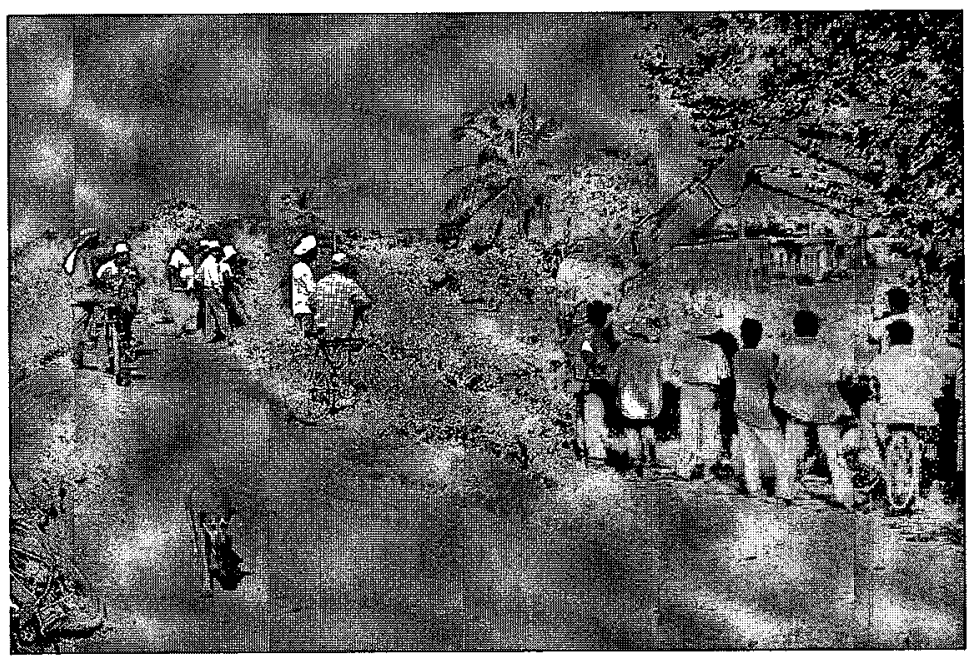

Photo 19 A public work carried out with maintenance machinery 


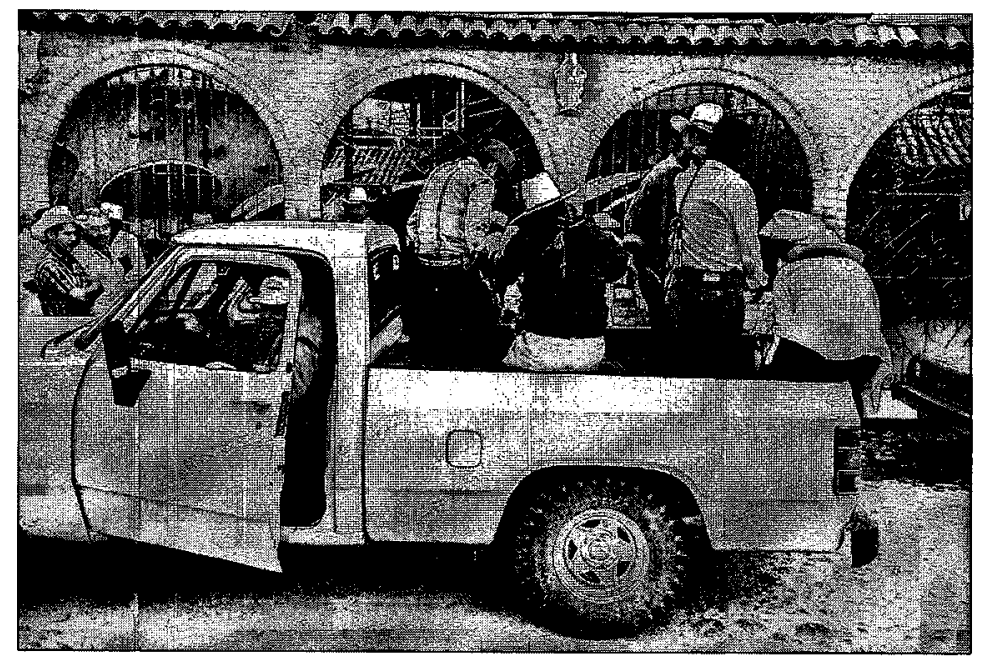

Photo 20 Ejido commissioners arriving at the rally 


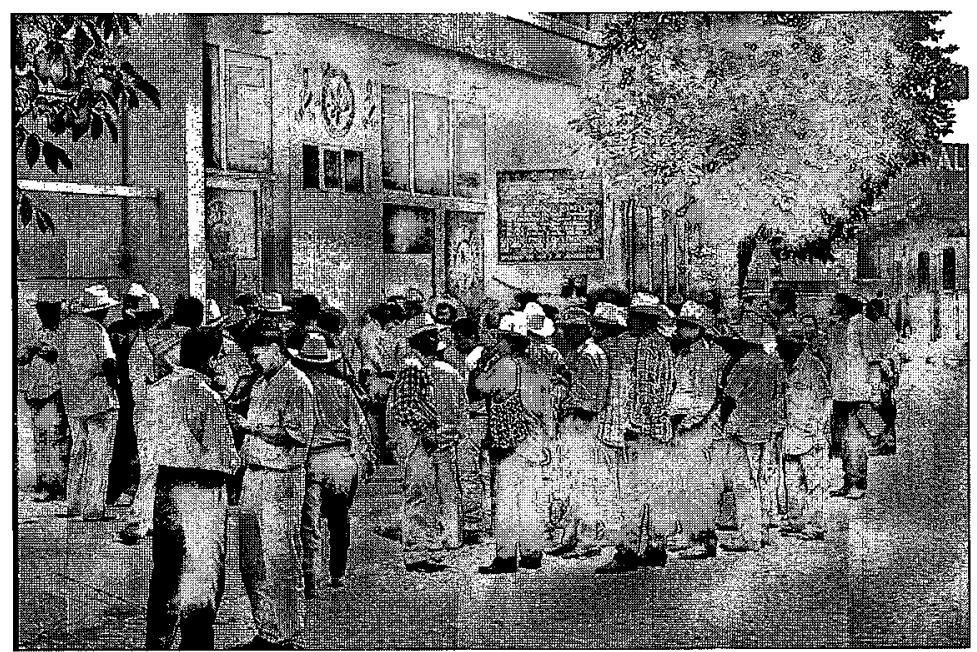

Photo 21 Waiting for the election results

in front of the CMC building 


\section{The Cultural Performance of an Election Rally: Using the WUA as a political platform}

\author{
DRAMATIS PERSONAE: \\ Nuñez \\ Uribe \\ Bruno Nava \\ Guttiérez \\ WUA staff \\ Pérez \\ Felix Torres \\ Rigoberto Ochoa \\ Don Emilio González \\ Leal, Gerardo Soto, El Güerro \\ Ejido commissioners
}

Mayor second president of the WUA, ejido president, candidate president CMC

Nuñez' right hand in the ejido, a board member of Sanidad Vegetal and coordinator campaign meetings

ejido commissioner and second person on Nuñez' list of candidates

manager of the WUA

canaleros, maintenance staff

former president of the WUA, local deputy and large producer and leader of a political group

mayor of Tepic, patron of Nuñez' group

governor (1993-1999), CTM leader

govemor (1981-1987), CTM leader

current and former presidents of the tobacco producers' organisation ARIC

president, secretary, and treasurer of an ejido committee and the president of the control committee

municipal president of Santiago Lxcuintla

PROPS:

Santiago River

Left Bank

Right Bank

Bridge

Cantinas and restaurants

Irrigation infrastructure

WUA office

CMC building

Crops

Maintenance machines

Pick-ups, motor bikes

Radios, telephones

Drink

Food

Green flag, green shirt

Local newspapers

Revenue flows

river feeding the irrigation module and separating the Right and the Left Bank river bank and run-of-the-river irrigation system

river bank and irrigation system in extension

palm-log bridge replaced by a concrete bridge, connects the Left with the Right Bank

recreational venues on the embankment of Santiago, apt for political encounters

network of connected canals and drains of distinct leoels

in Villa Hidalgo

municipal peasant committee in Santiago

beans and tobacco

machinery to carry out maintenance and public works

means of transport

means of communication

soft drinks, beers

frijoles charros (fried beans) with tortillas, birria (goat's meat dish) identification symbols for the green list

el Diario de Aztlan, Meridiano de la Costa, Realidades de Nayarit generated to finance the campaign 


\subsection{Introduction: Organisational Models of Resource Management and Politics}

Resource management theories have underpinned the Mexican policy model of irrigation management transfer (IMT) to local user organisations and raised high expectations for improved management performance. Central to most such theories is that they view resource allocation as an act of service provision to a defined group of users. In this view, service provision consists of largely technical and financial operations to control means and deliver resources, performed by a functional management entity that is especially created for this purpose. Service provision, i.e. activities concerned with the acquisition and distribution of power and authority, is generally understood as something that is essentially different from politics.

In irrigation management literature, 'politics' usually has negative connotations (Mollinga, 2001). Interference by politicians is thought of as a major obstacle to 'efficient' or 'rational' water management. External political intervention in water management is reported to generate irregularities, rents, spoils, and privileges for the benefit of select groups or to affect staff transfers and promotions in irrigation agencies (Ostrom, 1992; Repetto, 1986; Uphoff et al., 1991). Hence, politics is defined as a problematic phenomenon to be excluded from service provision. In prescriptive models for service provision, politics is defined as external to resource management, and hence effectively excluded from the analysis (Huppert et al., 2001). It is this assumption or prescription that this chapter will critically evaluate.

My argument is that resource allocation is profoundly and inherently political. There are different forms of politics possible, some more beneficial than others to the interests of its diverse user groups, but it is impossible to exclude politics from the allocation of resources altogether. The relationship between the two is reciprocal and recursive, implying that both are a precarious outcome of their mutual interaction or reordering (Law, 1994). This means on the one hand that resource allocation - I am of course particularly referring to irrigation management - is a politically contested terrain, as is acknowledged by recent analytical approaches (Mehta, 2000; Mollinga, 1998, 2001; Mosse, 1997). But, the converse is also true. Politics permeates resource allocation, and vice versa. To illustrate this, this chapter shows how irrigation management organisations and their resource allocation practices can be appropriated in support of the advancement of political candidates to elected government offices and the electoral campaigns of political parties, whilst disabling and excluding others from such opportunities. This urges us to re-consider IMT as a political process that not only reshapes and reorders the organisational control over irrigation management practices but can also have a critical impact on the emergence, consolidation and success of political actors and their parties.

Below I will present three congruent analytical approaches to water management that maintain such a separation between politics and service provision. The first example uses irrigation management approaches based on the normative premise that irrigation management entities (should) function as autonomous and special purpose organisations. In line with neo-institutional economics, the transfer of irrigation management is examined by these approaches in terms of the improvement of rules and corresponding incentives for service provision (Ostrom, 1990; Ostrom et al., 1993). The 
structure of rules and incentives is considered to provide the basic direction and energy for organisations to meet their stated performance objectives (Ostrom, 1990; Vermillion, 1991). Public service organisations are characterised by their bureaucratic rules, hierarchical structure, rent-seeking and upward accountability (Merrey, 1995), whereas Water Users' Associations (WUAs) in contrast have a better structure of incentives to manage according to externally agreed purposes and performance standards (Vermillion and Johnson, 1995). In addition, the latter are downwardly accountable to the water users, because their budgets depend on farmers' irrigation fees (Small and Carruthers, 1991). The release from government constraints liberates WUA managers' 'will to manage' (Oorthuizen and Kloezen, 1995; Vermillion, 1991), it redirects their professional energies, and increases their efforts towards operation and maintenance (O\&M) (Moore, 1989). Management theories assume that a manager's predisposition is to react to such greater managerial autonomy in innovative, creative and business-oriented ways in response to technical and market exigencies (Hales, 1999). In addition, the electoral and financial accountability of the WUA management to water users is considered the key to more transparent and accessible decision making and more appropriate and flexible management solutions to locally specific problems (Vermillion, 1991). This set of structural and organisational factors that apply to autonomous and special purpose organisations is expected to result in more efficient and cost-effective service provision and thus in improved management performance and financial cost-recovery (Merrey, 1995; Small and Carruthers, 1991).

A related approach describes irrigation systems as a set of nested systems, each of which has its own particular set of objectives (Bos et al., 1994; Small and Svendsen, 1992). Five hierarchically ordered systems are recognised: irrigation system, irrigated agricultural system, agricultural economic system, rural economic system, and politico-economic system. The linkage between the systems is that the outputs of one system become part of inputs of the next system, establishing a means-end framework. Such relations are by implication asymmetrical. The nested system places irrigation management in the service of superior levels of objectives. In this analytic scheme, politics and irrigation management are thus completely discrete and asymmetrical activities that interact solely on the basis of a means-end framework.

A third analytical approach discerns an external and an internal dimension of governance (Rogers, 2002; Rogers and Hall, 2003), which is a sophistication of what was earlier plainly called a technical and a political dimension of governance Johnson and Minis, 1996). Although Rogers (2002: 10) acknowledges that there is a political element to water governance, he states that:

the politics of water governance are typically the sociological factors (structures, institutions, etc.) that lie outside the immediate operations of water provision (...). The governance of water is nested within these factors. Politics is factors outside the water sector, reflecting the more general sociology of the country involved, that is to say, of the water provider's setting.'

The politics of water governance (exterior governance) thus provides an external setting for the water provision enterprise (interior or water governance). Water governance can draw strength from external governance structures. Conversely, if the service provider 
succeeds, it can also validate and strengthen the politics that made it possible. Further, political interference and conflict can paralyse services, or prevent the emergence of new forms of service provision. External governance can thus work either for the good or the ill of the service provider or resource manager (Rogers and Hall, 2003). A favourable, or at least neutral, external environment is found to be critical for the existence and success of a water service provider (Rogers, 2002; Rogers and Hall, 2003). According to this approach, the relation between the political setting and water governance varies between positive, negative or neutral, but they remain external to each other. Therefore, it is hardly surprising that there is a strong focus on decentralisation as a way of providing an enabling environment for effective service provision Johnson and Minis, 1996; Rogers, 2002). Rogers uses the Mexican model of water reforms as an example of providing such an enabling environment for effective provision. In line with most policy literature, his version is surprisingly a-political and focuses mainly on the CNA's (Comision Nacional del Agua: National Water Commission) ability to implement the reforms and provide a supervisory and regulatory framework that assists WUAs to fulfil their (technical) requirements to become self-sufficient, well performing and productive modules (Espinosa de León and Trava Manzanilla, 1992; Gorriz et al., 1995; Johnson, 1997a; Palacios Vélez, 1997; Garcés Restrepo, 2001; Rogers, 2002').

At the core of these three approaches to water management lie two crucial analytical limitations. In the first place, there exists the belief in a systematic distinction between an internal, autonomous, or single-purpose enterprise of service provision and an external political environment. Though politics and resource allocation may be related, they remain intrinsically separated and asymmetrical activities. Hence, politics is inaccurately perceived as an exogenous variable to resource distribution. In the second place, the conceptualisation of the irrigation management transfer policy as a way of providing an enabling environment for effective service provision obscures its political and institutional effects. These limitations are problematic because they reduce resource allocation to an a-political enterprise of service provision, empty of history and culture. By obscuring the fact that resource allocation is profoundly political, these theories depoliticise both the policy process of IMT and the everyday resource practices of user organisations that emerge from this.

In the wake of what is widely agreed to be a certain decline or retreat of the state apparatus, we find the upsurge of a range of forms of power and authority that have not been well described or analysed to date (Ferguson, 1998). New organisational actors, termed user organisations, emerge to occupy the institutionalised policy domains that these neo-liberal reforms have vacated. The criticised type of analysis under-emphasises the possibility that devolution may trigger politically motivated resource allocation and institution building, driven not by the expected entrepreneurial responses to local technical or market exigencies, but rather by ambitious exigencies looking to control policy areas vacated by state downsizing (Hales, 1999; Snyder, 1999). Further, this type of analysis obscures the fact that control over infrastructure, people, and resource flows provides political opportunities. The political and producer elite groups that frequently come to dominate these user organisations are in a favourable position to appropriate these resources by generating and sustaining political support among electoral constituencies and lubricating campaign politics (Fallaw, 2002). Under such 
circumstances, these political incumbents are able to convert a WUA into a platform that enables political ascendancy.

\section{De-centring Mexican politics}

In Mexico, Water Users' Associations (WUAs) are an interesting case in which to study the everyday entanglement of resource allocation, producer organisation, and politics. For several decades, the corporatist peasant organisations are no longer the privileged interlocutors for resource allocation and the political representation of rural producers vis-à-vis government institutions, the agro-industrial enterprises and other forces. At present there exist multiple organisations that represent demands and forms of participation that do not operate along corporatist lines (Vargas Velázquez et al., 2000). Like other types of producer organisations, WUAs constitute new spaces to represent producers and acquire control over an organisational and physical network that generates important social, material, cultural, and political resources. The WUAs become public institutions that are uniquely placed to articulate positions of power and political affiliation, provide opportunities to challenge authority, and canvass political support in culturally and historically specific ways (Mosse, 1999). Put differently, resource management by a WUA depends on how power and authority are articulated through these public institutions and how diffuse networks of political patronage and personal obligation are intertwined with resource allocation (Mosse, 1997) ${ }^{2}$.

My approach builds on an emergent literature that analyses the complex relations between the organisation of resource allocation and politics (e.g. Mosse, 1997; Fallaw, 2002). In my view, politics cannot be reduced to utilitarian means-end relations based on material self-interest, according to which public organisations are used instrumentally by rent-seeking officials and politicians to optimise access to resources for political purposes (Repetto, 1986; Mollinga, 2001). I favour a broader understanding of Mexican politics that acknowledges that the political is constantly expressed and articulated in terms of cultural forms and performances (Cohen quoted in Thompson, 1997). As a result, my view of politics includes both cultural performance and ritual in institutional settings (Beezley et al., 1994; Munro, 1999), and the social and material practices of resource distribution that reinforce these (e.g. Adler Lomnitz, 1994; Auyero, 2000; Fallaw, 2002). It is through these specific cultural practices and performances that political authority is produced, maintained, or expanded.

Munro (1999) identifies certain forms of organisational behaviour as cultural performance. He shows how managers construct their cultural performances to make themselves visible to one another, both as members of a group and as individual managers who are identifiably 'in control' (Strathern, 2000). An emphasis on cultural performances focuses on the accomplished ways people make cultural material visible and available. Display is critical here. If culture is elusive and in the background, or constitutes an 'imagined reality' (Parkin et al., 1996), cultural performance is the show that expresses and envisions the cultural. When managers (or politicians) try to show others what they are doing or have done, their actions take on a 'performed-for-anaudience' aspect. For example, Gupta (1995) shows how even bribe giving is a cultural practice that requires a great degree of performative competence. 
Like a ritual, performance tries to persuade participants of the way the world is. Rather than being an empty or opaque show of form, it is meant to have transformative and engaging effects on the participants in a performance. Munro's understanding of cultural performance is not limited to exhibitions taking place during state ceremonies and public rituals (Beezley et al., 1994). Therefore, it can be introduced in connection with everyday resource use practices and events in which political actors engage. This stimulated me to think about politics as a de-centred endeavour, involving particular social and material practices of resource distribution in a multiplicity of spatially distributed sites and locations and (in)formal performative settings. In this manner, seemingly unrelated and dispersed practices in which the WUA was involved, such as the organisation of drinking parties in cantinas, water allocation practices at canals, and the movement of maintenance machinery in the field, became politically intelligible as contributing to the formation of a political alliance and culminating in a major election event.

This chapter presents a situational analysis (Gluckman, 1958; Van Velsen, 1967) of an election rally that evidences the political use of a WUA. The value of this method is not to prove the typicality of the case, but rather to infer some theoretical insights pertaining to the relation between politics and resource allocation. First and foremost, the case substantiates the claim that resource allocation is intrinsically political. Further, the ethnographic account demonstrates how a local political group appropriates the WUA, and draws on its staff, facilities, and resources for political ends that extend beyond immediate concerns for the irrigation system and its user constituency. By using the WUA as a platform, this group asserts authority and expands its support base for the advancement of political candidates to elective offices in the municipal government. Analysing the election rally as a cultural performance illustrates how resources are mobilised politically, not in an instrumental manner, but according to culturally and materially specific and established ways of conducting politics. In the particular case that I study, this adversely affects the resource base of the WUA.

Before presenting and analysing how the election rally unfolds as a social drama, I will have to set the scene and indicate how the choreography of the event has come about and how actors and resources have become enrolled in its performance. The chapter thus continues with an overview of the contemporary political and institutional processes of rural transformation that give rise to the election rally. Then, I will situate it on the electoral calendar of Nayarit and outline its spatial and chronological delimitation. This will lead me to sketch out the political and organisational landscape in which the election rally takes place. Then, the political campaign that precedes the election rally is described. Section 8.2 contains a situational analysis of the rally itself. In Section 8.3 , the event is used as starting point for an analysis of the political nature of resource allocation, the WUA as a political platform and the rally as a cultural performance. In the final section, 8.4, the conclusions of this chapter are drawn.

\section{The region, producer organisations and electoral politics}

The WUA on which I focus is located on the Left Bank of the River Santiago, on the Pacific Coast of Nayarit, Western Mexico. The management and politics of the WUA on the Left Bank of Santiago municipality is embedded in a wider field of political parties and producer organisations operating in the municipality of Santiago, on the Northern 
Coast, and in the entire state of Nayarit. Since the beginning of the 1990s, under the influence of a series of neo-liberal policies and political reforms launched by the national government of President Salinas (1989-1994) and subsequently President Zedillo (1994$2000)$, this wider political and institutional field has undergone drastic changes. Hence, the transfer of irrigation management to WUAs is only one of a series of convoluted changes, occurring at various political and administrative levels.

Several partially connected political and institutional processes of rural transformation were unfolding in the region during the 1990s and led to the emergence of 'new' organisational actors with overlapping constituencies in an increasingly competitive political arena. The three most important processes are presented in this section. Firstly, deregulation policies in agriculture affected what had long been the principal motor of economic development and the prime source of income, organisation and political control in Nayarit: tobacco production (see Chapter 4). This induced the dismantling of the government parastatal for tobacco production, Tabamex, the re-entry of multinational tobacco enterprises in the productive process, the decline of corporatist representations of the Confederación de Trabajadores de México (CTM: Confederation of Mexican Workers) and the national peasant confederation, Confederacion Nacional de Campesinos (CNC: National Peasant Confederation) ${ }^{3}$, and the establishment of the tobacco producers' organisation, Asociación Rural de Interés Colectioo (ARIC: Rural Association of Collective Interest $)^{4}$. Secondly, bureaucratic retrenchment of the Ministry of Agriculture vacated policy areas that were also taken over by new producers' associations, such as the WUAs in the irrigation districts, and Sanidad Vegetal, a municipal section of the producers' organisation that protects plant hygiene, prevents the spread of plant diseases, and authorises the transportation of agricultural products. Thirdly, the weakening of political and corporatist structures of the ruling party, Partido Reoolucionario Institucional (PRI: Institutional Revolutionary Party), and a more competitive electoral landscape in recent years led to a more open political arena. As a result, several political parties disputed electoral positions, and the imposition of political candidates became more complicated for the PRI.

These processes of state disengagement and political reform in the rural sphere coalesced towards the end of the decade with the onset of a series of political campaigns and elections in Nayarit. Their political ramifications could be observed during the elections to the Comité Municipal de Campesinos (CMC: Municipal Peasant Committee) in Santiago at the beginning of 1998. Two of the aforementioned producer associations facilitated the rise of political groups that disputed control over the CMC. In this chapter, I will present a situational analysis of an election rally in these heavily contested elections. I will especially focus on the political group that used the Left Bank WUA as a political platform to challenge the political control of ARIC over the CMC. These two producer associations were appropriated by different political groups that had their networks and patrons in the PRI. In this sense, they were only partly 'new' political actors. Just as Tabamex and other bureaucratic agencies had played a central role in the political life of Nayarit during the 1970s and 1980s, these producer associations gained in political importance, particularly in rural areas where agriculture still constituted a major source of income and investment, such as in Santiago. These organisations did this amongst other things by launching candidates for electoral positions and/or giving 
political, organisational, and financial support to the campaigns of allied politicians and of the political party, PRI.

The Nayarit electoral calendar provides some insights into the political point in time at which the rally takes place. Every state in Mexico elects a governor for a period of six years (sexenio). Nayarit is administratively divided into twenty municipalities and politically into eighteen electoral districts. Local elections for mayors and deputies take place every other three years. The CMC elections in February 1998 occurred in the runup to local and state elections in Nayarit. In July 1999, the voters elected a new governor, but also voted for the renovation of the local congress and the municipal presidencies in the state ${ }^{5}$. Subsequently, internal elections in both ARIC and the Left Bank WUA took place during the second half of 1999. During pre-election years in Mexico, bureaucratic and political groups align themselves with candidates that have a chance of being appointed or elected to key posts in the upcoming administration. ${ }^{6}$. Political contenders gather electoral, organisational and financial support among politically influential or financially affluent organisations, leaders and groups within their constituency, or among other interest groups. Both the ARIC and the WUA group were engaged in the same type of political activity, although not always openly. In this manner, they positioned themselves as candidates for mayor, deputy or other political or administrative functions with a view to increasing their political influence. In addition, their political activity was also directed at maintaining their influence in the producer organisations from which they operated.

At the beginning of the 1990s, ARIC was established as a state-level organisation for tobacco producers to formally represent their interests in the annual tobacco price negotiations with the four major multinational tobacco companies working in Nayarit. The organisation also provided a set of basic services to the tobacco producers, such as social, medical and life insurances, which are financed by the companies. Besides providing these services, ARIC proved to be generally incapable of negotiating substantially higher tobacco prices. These remained far below official world market prices". Decisions of this kind lay with the companies and higher governmental levels. As a result, ARIC lost credibility among tobacco producers and many called for its removal. The livelihoods of many of the smaller ejidatarios ${ }^{8}$ depend in large part on the small profit margins from a few hectares of tobacco and beans, the insurances provided by the tobacco cultivation, and income or remittances from seasonal migration to the US by members of the family. The producers considered ARIC to be an organisation that represented the interests of the tobacco companies, the governor and the PRI government. The headquarters of ARIC are located in Tepic, close to the offices of the tobacco companies and the state government. Its president and managers were criticised in the local press for never visiting the region and for not attending to the problems and questions of tobacco producers.

Despite its unpopularity among the majority of producers, ARIC was a financially affluent and politically influential rural organisation. ARIC received a stable source of income from the tobacco companies. They subtracted a fixed amount for ARIC from every kilo of tobacco that was supplied by a producer, resulting in substantial budgets. At the national level, the Nayarit ARIC that represented a large majority of the nation's tobacco producers was affiliated to the $\mathrm{CNC}$ and became one of its more influential rural 
associations (De la Fuente and MacKinlay, 1994). Since its creation, ARIC was controlled by the group of its first president, popularly called El Güerro (The White). Although he was a popular leader on his own account, he owed his political career and this position to Don Emilio, the patriarch of PRI politics in Nayarit. At the state level, the financing by ARIC of the political campaigns of several PRI governorship candidates enhanced their political fortunes. The El Güerro group, and the successors that El Güerro appointed, exerted patronage and built a selective support base among agrarian leaders and ejidos in the tobacco producing municipalities on the Northern Coast of Nayarit. The CMCs proved to be central in this respect, particularly the committee representing the municipality of Santiago, where most tobacco is produced. Both El Gïerro and the current president, Gerardo Soto, started out as CMC president in Santiago before leading ARIC. A close connection existed between ARIC and the CMC, manifested by the financial and administrative support the latter received. At the beginning of 1998, this pattern was continued when ARIC put forward Leal as their new candidate for the presidency of the CMC. Leal was the brother of the former municipal president of Santiago from the major tobacco producing ejido of Amapa nearby Santiago. Yet, despite support from ARIC and the municipal administration, the political tide was shifting.

Leal's competitor, Nuñez, for the presidency of the CMC belonged to another political group whose political constituency was the Left Bank part of the electoral district XII in the Santiago municipality with Villa Hidalgo as its centre. Here they controlled a variety of local organisations, most importantly the Left Bank irrigation module of which Nuñez was president. Nuñez was the owner of a plot of a few hectares in the ejido of Solorceño, which he did not cultivate but rented out and later sold. Consequently, the association was his only source of income, although officially he did not receive a wage as president.

Nuñez followed a similar path to that of Pérez (see Chapter 4) and used the association as a platform to launch his political campaign and promote himself as a candidate for the political position of president of the CMC. During the course of 1997 and 1998, the group attempted to expand their support base in ejidos and among producer groups on the northern bank of the river with a view to establishing themselves politically in the municipal capital of Santiago, and indirectly in the state capital of Tepic. Nuñez and Pérez positioned themselves in the local media and on public occasions as spokespersons representing the interests of the rural and the ejido sector and specific producer groups, such as bean and tobacco producers, in the municipality. As part of a larger scheme, the political group supported the candidacy of their patron, Felix Torres, the mayor of Tepic, who registered as one of the six PRI candidates for governor of Nayarit. They expected to benefit from his influence in the party and with the departing governor to negotiate public positions in the party, sectoral organisations or the state bureaucracy for some of his confidants.

In support of its political ambitions to attain elective office, the group draws on a heterogeneous set of resources to which the association provides access and mobilises these resources. This range of financial, human, and material resources serves to organise a political campaign in the form of a series of private encounters to mobilise a popular support base. Only with the help of these means is Nunez able to build a broad but precarious alliance of support among ejido commissioners that challenges ARIC's authority as the dominant producer organisation in the region. In addition, these 
resources enable Nuñez and his group of followers and employees to organise and execute three political meetings to secure popular support. At these meetings the distribution of food and beer among potential voters acquires supreme cultural and political importance.

According to the conventional corporatist practice, the list of PRI candidates for local political positions was negotiated behind the scenes as a 'power quota' among competing political groups and, in the end, unilaterally decided by the governor or the party. A nomination by the PRI for mayor, deputy or president of the CMC usually guaranteed one's election, because of the PRI's virtual monopoly on elected public offices (cf. Enge and Whiteford, 1989: 126). In Santiago, as in many other Mexican towns, the PRI recruited a significant number of nominations for such posts among representatives of the local sections of the PRI affiliated organisations, CNC, CTM, and Confederación Nacional de Organizaciones Populares (CNOP: National Confederation of Popular Organisations). The groups that controlled these sections bargained and competed behind the scene for positions. They manoeuvred within their corporatist structures and the party, built alliances, and looked for the support of political patrons. In return, corporatist organisations were expected to deliver the votes and organisational support of their rank and file for the PRI, even if this required coercion or fraud ${ }^{10}$ (Samstad, 2002). In the past, the groups controlling the CMC in Santiago had been reasonably successful in using the CMC to bargain for the positions of mayor and deputies. In the last three decades, the CMC delivered a mayor for four three-year electoral periods.

The CMC president chairs the monthly assembly meetings in which ejido commissioners discuss administrative and political matters affecting agriculture and the ejidos. Further, the CMC officially represents the ejidos in their relations with the political and bureaucratic bodies of the municipal, state, and federal government. A CMC president's participation in committees for the rural and agricultural sector enables him to win influence over government agricultural policy and the allocation of funds and subsidies at different governmental levels. In this position, he is also able to make friends with, and put pressure on, responsible government officials concerning access to government resources and other policy matters. For example, in former government days, the CMC president was a member of the SRH District Committee and influenced the annual establishment of irrigation fees.

The political influence of the CMC slowly decreased after the 1980s because of the reduction of financial flows from the federal state due to budgetary restrictions, and a reduced say in production issues as a result of state disengagement. Nevertheless, in Santiago this tendency was tempered, as the favourable relations that the CMC maintained with ARIC and the PRI mayor provided some financial support and permitted it to continue functioning as a privileged space of negotiation with political and government institutions. As a result, the CMC president still acquired access to political and bureaucratic offices, committees and officials in the municipal capital of Santiago, the state capital Tepic, and even in Mexico City. To move between these different spheres of influence and have access to different governmental levels helps to establish an extensive networks of contacts, mutual favours and resource exchange something that is essential for a political career in Mexico. In his capacity as municipal 
ejido representative, a CMC president is able to claim government support for the rural sector and negotiate funds and subsidies. The degree of control he acquires over these flows can serve as a source of patronage vis-à-vis ejido commissioners and rural leaders. The CMC thus remained a strategic staging post for gaining access to positions in the municipality and political ascendancy generally. For the last couple of years, this opportunity had been controlled by the ARIC-based group. As the CMC elections occurred in the run-up to an important election year, they were decisive for the future of both competing political groups.

At the same time, these organisation-based priista groups had to take into account a changing political spectrum. By the mid-1980s, the electoral arena had been liberalised and the political space for opposition had expanded to the extent that the PRI found itself increasingly challenged at the ballot box (Klesner, 1997). During his presidential term, Zedillo (1994-2000) promoted a series of electoral and party reforms that further reinforced a trend towards more competitive and transparent elections. Nayarit's governor, Rigoberto Ochoa, who was scheduled to leave office after the elections of 1999, apparently responded to these national reforms and increasing demands for internal democratisation, popular consultation and a reduced role for the corporatist sectors in the nomination process of the PRI. He gave a public signal to this effect in view of the upcoming elections by refraining from publicly favouring or intervening on behalf of one of the two candidates for the $\mathrm{CMC}$ in Santiago and their antagonistic groups within the $\mathrm{PRI}^{11}$. The elections among the ejido delegates were really decisive in this respect, unlike most preceding ones. In addition, the electoral spectrum had become much more competitive and pluralist during the 1990s. An electoral victory for the PRI in Nayarit and many Mexican regions was less secure than ever, particularly in the municipality of Santiago. PRI candidates for mayor or deputy not only competed more openly amongst each other for the candidacy, but also had to compete with other political parties in order to win the popular vote. In addition, opposition forces attempted to establish a foothold in the campaigns for the $\mathrm{CMC}, \mathrm{ARIC}$ and the WUAs.

After winning the elections, Nuñez subsequently used the CMC as a springboard in the municipal capital from which to launch Pérez as PRI candidate for mayor of Santiago. As CMC president, Nuñez had access to the municipal, state, and federal organisation of the PRI and influence in the designation of political posts. As the representative of the peasant sector in the municipality, he expressed his preference on behalf of the peasant sector for Pérez and mobilised support for him among ejido commissioners, government officials and politicians. With highly competitive state and local elections coming up, the national PRI was eager to provide such government programmes and resources to gain back its declining popular support. Nuñez attempted to benefit from this, by publicly highlighting the PRI's role in acquiring government support for his constituency ${ }^{12}$. Subsequently, Nuñez' group mutually supported each other in campaigning for a range of elective and (non-elective) administrative positions in the municipal and the state government or in a producers' organisation during the elections of 1999. Summarising, this political group appropriated rural organisations, among which the WUA and the $\mathrm{CMC}$, to extend its influence and construct an ascending path to the municipal presidency and other political offices. 
The setting of the rally

On a February morning in 1998, an election rally took place in the municipal capital of Santiago Ixcuintla. Nuñez, the president of the WUA in Villa Hidalgo, organised this pre-election meeting accompanied with a breakfast for his supporters. The rally is to round off Nuñez' campaign for the presidency of the CMC. Nuñez heads a list (planilla) of candidate board members that he compiled of ejido leaders ${ }^{13}$ from around the municipality. The list was registered as the green list and is popularly referred to in the local press as Unidad Campesina (peasant unity). The CMC integrates the fifty-four ejidos in the municipality of Santiago. Every three years, these ejidos are authorised to send four ejido commissioners for the election of a new CMC board ${ }^{14}$. After the rally, Nuñez, together with his candidate board members and a crowd of voting ejido delegates and supporters, collectively walk up to the election poll at the local CMC building. They manage to present a small majority of 101 ejido commissioners, sufficient to win the elections. It is my intention here to focus on the organisational and performative elements of the election rally and the campaign through which Nuñez wins the election. and assumes the leadership of the $\mathrm{CMC}$.

In Santiago, an embankment protects the town from flooding by the river. It lies close to the town's centre and the local CMC building and is thus a convenient spot for Nuñez to gather his political supporters from both banks of the municipality. The rally will take place in an outdoor venue at the side of the embankment. The event was announced to start at an early hour, but it is still quiet at the embankment when I arrive. I take the time to enjoy the fresh morning air and look around. In about an hour, whilst the heat increases, commercial activity will start to bustle along the cobblestone road at the embankment. Women sell fish and shrimps, and traders display their colourful plastic Tupperware and other household items. The muddy vans of tobacco producers coming from the corners of the municipality are stationed along the embankment. Their owners will be fetching the week's groceries or buying insecticides at the market and the shops in the centre of town. Later on in the day, some of them may pause at one of the restaurants or cantinas located along the embankment. Groups of musicians with instruments stroll along the pavement on their way to play in those venues that are usually reserved for male recreation. When these mariachis (regional music groups) or combos do not find customers for their songs, there is always a jukebox blasting. Until the evening falls, their loud banda music (brass orchestra) reverberates through the hot and humid air. Next to an artificially lit hotel of questionable reputation, offering rooms for forbidden pleasures, there is a spot where the town's drunkards gather around a last bottle of cheap mescal, to eventually sleep it off on the pavement.

Although the embankment appears to be a somewhat marginal zone on the periphery of Santiago, it is located within a stone's throw of the central plaza (square). As in any other Mexican town, the plaza in Santiago is the administrative and political centre of town, where the municipal palace and several other important political and government offices are situated. This apparently paradoxical vicinity, and some of my initial experiences at the embankment that follow here, will illustrate that in Mexican politics, and particularly on the Northern Coast of Nayarit, the centre and the periphery, government offices and cantinas, or the political and the festive, are innately intertwined. 
On one of my first working visits to Santiago, I was taken by some government engineers to one of the cantinas on the embankment. They are slightly darkened venues that respectable women do not frequent. After we seated ourselves around a table, a waitress brought us our first round of beers. Whilst we were drinking, the men then informed me, to my great surprise, that our waitress was in reality a transsexual. In fact, all the waitresses were. The engineers pointed out enthusiastically that these converted waiters walked so much better than real women. These (wo)men made themselves very attractive with their big breasts, shaven legs, and feminine walk. So, their intent in bringing me here had been to warn me, in order that I would not get confused when I was drunk, the men explained. Nothing funnier than that. Their roaring laughter told me not take them too seriously, as their genuine fascination with 'these girls' was alternated with albures. In Mexico, albures, playful jingles, developed as language games that persist among the popular classes ${ }^{15}$. The engineers exchanged a succession of such jokes and mental word games that revolved around the most skilful ways of trying out and provoking the other. Despite the alcohol in my blood and the loud distracting music from the jukebox, they required me to remain alert. Apparently simple questions, like 'do you like chilli?, contained implicit allusions to my implied homosexuality or other deviant sexual preferences. At the time I felt tremendously incapable of responding skilfully. This sort of humorous exchange appeared to be an all important pastime among drinking men in the cantinas of rural Santiago, engaging people of different status and class backgrounds. In a pleasant atmosphere, this practice draws people together and generates bonds of trust and friendship between them (see also Chapter 6). In my time in Santiago I learned that I only really gained respect and became part of a group of males, when I was capable of laughing about, responding to, but preferably, cracking albures myself.

The engineers prudently pointed out from the crowd of townsmen and farmers some locally well-known people in the cantina. Several ejido leaders and local politicians were seated at the tables around us. We also saw local business people and I was told that union representatives, municipal and other government officials like themselves also frequented the bars here. Like most ordinary people, they were also drinking, laughing, and discussing affairs with friends, associates, or allies. The engineers exchanged some of the gossip and rumours circulating about these local celebrities and their most recent endeavours. This revealed a typical Mexican and male fascination with power and sexuality, languages which are intimately intertwined and mutually reinforcing.

Through gossip, laughter, fascination and speculation, our conversation arrived at the recent conspicuous activity of Nuñez, who was spotted several times around here in the company of ejido commissioners, inviting them to extensive drinking sessions. One engineer secretly revealed the fact that Nuñez was engaged in a campaign to become president of the CMC and aspired to succeed Pérez as deputy for District XII. The men continued to speculate about Pérez' plans to participate in the elections for mayor of Santiago, but reckoned that his chances of becoming the PRI candidate and winning the elections were not so large, as he was hardly known at this side of the river. Of course, you never know in the PRI what the support from his patron, Felix Torres, could do for him. 
Through these initial experiences, it became clear to me that these apparently marginal recreational spaces such as cantinas and restaurants are central to forging social and political bonds in this rural sphere. They are convenient places for the organisation of festive encounters in which collective drinking and eating and popular music take on political importance. Three reasons come to mind. First of all, in these pleasurable encounters, it matters who is the person who invites others and provides them with drink, food and music. This act creates a basic inequality, which presupposes a certain reciprocity ${ }^{16}$. Being provided with such pleasures creates a feeling of obligation and the need to return this favour. Secondly, the collective enjoyment of food, music and beers and the mutual exchange of jokes and gossip contribute to an atmosphere of trust between people that are united in celebrating matters of mutual interest (see also Chapter 6). Political bonds depend on a certain level of trust between people that favours will be reciprocated in the future (Dealy, 1992). This is a useful basis to negotiate problems and agreements, exchange favours, conspire around shared ambitions and political plans, and celebrate commitments. Thirdly, a well-performed drinking session or a comida política (political meal) has an immense additional value for a political candidate to establish and celebrate commitments, gain support, and free resources and facilities for an electoral campaign. Aspiring politicians patronise such events to organise their support within the cultural hemisphere of the Northern Coast of Nayarit. These get-togethers clearly have a performative quality and require skilful orchestration and the profuse dispensing and enjoyment of food and drinks. What occurs is that these shared experiences make it visible to, and felt by, the invitees that they are part of something; it includes individuals in a larger collective. Therefore, these localised cultural practices and performances can contribute to building and consolidating a political alliance and support base, something that Nuñez was involved in at that moment.

\section{Nuñez' campaign}

Following Nuñez' group in their daily work for the association taught me some other things as well. Pérez, Nuñez and Guttiérez, its leading members, were not only responsible for the management the WUA, but were also involved in electoral struggles for political positions and in different commercial dealings. In fact, in their everyday practice they were politicians, popular leaders and managers at the same time, who switched between their roles in 'the government', 'civil society organisations', and 'the market'. Often it was difficult, not to say impossible, to establish where one role stopped and the other began. They were inextricably interwoven and mutually reinforcing. While I was tracing Nuñez' footsteps, it was evident that the presidency of the association gave him the opportunity to increase his local standing as a public figure and develop a profile as political leader. The office building of the association in Villa Hidalgo was useful for receiving guests and doing business in a confidential environment. Nuñez had a special desk for this purpose. Behind it, he worked on matters for the association, but also for his ejido and the local PRI, and he co-ordinated his campaign for the CMC. When he received ejido commissioners or other important people, Nuñez displayed with splendour the great responsibility that managing the largest irrigation system in Nayarit entailed. He would give orders to the secretaries, make an important call, decide on the application of large sums of money and hence demonstrate the important position that he had as president. From behind this desk he also had the authority to distribute favours to help out an ejido commissioner regarding a canal or the use of a machine. 
Another thing that struck me initially was the frequency with which Nunez and Guttierez would spend their working hours outside the office or away from the field. At least several times a week they invited producers, ejido leaders, government officials, or politicians to a local cantina or a favourite seafood restaurant of theirs. Whilst enjoying beers, local specialities and music, they would discuss local politics, develop complicities, exchange favours, and negotiate arrangements in a pleasant atmosphere, much as described above. Humour and gossip contributed to establishing relations of trust. Often there was a subservient group member present: canalero Diego (see Chapter 6) or Leopoldo, the association's driver and maintenance assistant. They performed an important role in animating and entertaining the visitors with jokes, stories, and anecdotes. Diego caused hilarity with his fatness, extravagant eating and drinking, and verbal abuse of the opponents of his patrons. Leopoldo performed a similar role with hilarious gay parodies. In addition, they opened beer bottles for the invited guests at a tempo that would make most of them drunk. They also knew when to order a music group to play the songs liked by important men. When the atmosphere was right, Guttiérez would impress his guests by singing a couple of his favourite ranchero songs with a deep masculine voice, celebrating the beauty of Nayarit, its mountainous landscape and lush vegetation, and the abundance of wonderful seafood and pretty women. Interestingly, the managers of the association took visible pleasure in organising these parties and proudly displayed their proficiency and generosity in this field and enjoyed the performative skill of their endeavours.

What could not go unnoticed was the amount of time, labour, and resources that Nuñez' group and his subordinates in the association invested in organising these festive occasions. For association insiders, it was evident that in organising these occasions as part of his campaign, Nuñez' group was drawing on the association's resource base. In this way, Nuñez and his group controlled a large complex of infrastructure, facilities, resources, and revenue flows that connected them with a constituency of beneficiaries: ejidos, producer groups and other water users on the Left Bank. Through this complex, they were in the position to dispense resources, deliver services and distribute favours to the voting ejido commissioners from the municipality, as also those from the Right Bank, in order to generate political support, and to third parties in exchange for financial and political support for Nuñez' political campaign. Hence, the association's resources were concentrated on launching and consolidating the political careers and realising the ambitions of its main political proponents. This political appropriation of facilities, staff and other resources was intensified during Nuñez and Pérez' campaigns for the CMC and the mayorship of Santiago.

In the year preceding the CMC elections, Nuñez' campaign was directed at building a broad alliance of ejido leaders, activists, and producer groups to support him in challenging the ARIC-based political group and in competing for the presidency of the CMC. He consolidated his original support base on the Left Bank, partly constituted through the association and its network, and extended it by incorporating ejido leaders, organisations and groups that operated in ejidos on the larger Right Bank of the river. Nuñez' presidency of the Solorceño ejido gave him access to the CMC meetings in Santiago. This opened up the possibility of developing personal relations with ejido commissioners not affiliated to the inner circle of the dominant ARIC group, or to becoming acquainted with those who had removed themselves and were critical of the ARIC's leadership in the hope of enlisting their support in publicly opposing and 
incriminating them; or renewing links with leaders who were politically close to his patron, Felix Torres. Nuñez and a few close associates were building an alliance by gathering and negotiating support among this select but diverse group of opinion leaders. These opinion leaders in large part consisted of a professional class of political leaders, entrepreneurs, and activists with political ambitions and the capacity to mobilise a group of followers for the upcoming CMC elections. The very same people frequently have a track record in their ejidos, local committees, producer or political organisations. Several of them will figure actively in the following description of the election rally. Their followers, generally with less experience, profile, resources and ambition, will be presented as flat characters, because they are not important to the development of the story. Some of the popular leaders that supported Nuñez belonged to opposition parties, such as the PRD, which is remarkable given the fact that the rally involved a PRIaffiliated organisation. Nuñez formed a fragile alliance that was only temporarily stable and effective until the elections, without the alliance having a shared political identity and common views on how to tackle the problems of the ejidatarios of the region.

Nuñez associated himself with several opinion leaders among the ejido commissioners and convinced them to become part of his alliance, amongst other things by promising them a position on his candidate list for the $\mathrm{CMC}$, or by negotiating a set of favours and resources for them. The private negotiation of these favours, resources, and positions offered by Nuñez often occurred during festive encounters patronised by him as described above, or sometimes as a result of public celebrations, such as a local rodeo or the annual festivities of an ejido. Nuñez and his close associates thus built a precarious alliance and consolidated it by organising and attending a corollary of drinking parties and 'political meals' throughout the municipality. A select audience of ejido leaders and activists were invited by them and treated to ample beer, food and music.

The association's president unified several of the diverse currents in his alliance by taking a strong anti-ARIC position. He launched a crusade against ARIC, denouncing the corruption, nepotism, and incompetence of its leaders. In this manner, he mobilised general discontent among tobacco farmers and other producer segments in the ejidos of the municipality. The political messages through which Nuñez united different groups centred on the deplorable state of agriculture in the region. Recurrent topics of Nuñez' conversation were the problems that ejidatarios experienced in terms of low prices for crops such as beans and tobacco, the poor marketing possibilities, and the lack of government programmes to solve these problems. Nuñez and his collaborators fiercely attacked ARIC and his opponent's group for being responsible and accused them of acting against the interests of the peasants. During the drinking parties, stories were told about ARIC officials passively sitting in their remote offices in Tepic, not coming out to the field, and ignoring the problems of producers. Rumours about their corruption or moral decadence were actively fed. Their incompetence and immorality was often expressed and joked about in sexual metaphors, which denied them masculinity.

Nuñez acquired publicity and popular support by sponsoring a campaign of recrimination against his competitors and ARIC by journalists in local papers. At the same time, these papers projected a favourable image of Nuñez' leadership. His coalition, called Unidad Campesina, was portrayed as the real representative of the peasant sector's interests, the one that would achieve better prices, marketing 
opportunities, and support programmes. This type of local paper is read by many politically informed ejidatarios and farmers, and is an important popular source of news and opinions. An informed friend of mine warned me not to take these papers as independent news sources, because they play up to their paymasters and their owners. Local politicians pay the reporters to publicise their version of the news as part of an election campaign. As a result, they often contain the most serious mutual accusations of corruption and incompetence that make or break public images ${ }^{17}$. To sum up, this publicity campaign was an expensive affair for Nuñez that was financed from revenue sources within the association.

It is important to emphasise that the election rally was not an isolated event. It concluded a series of private encounters during the preceding months at which Nuñez painstakingly constructed an alliance of support. Nuñez's campaign subsequently culminated in three political rallies in a row meant to mobilise the popular support that he had acquired and at which he would publicly assume leadership of the alliance. During this series of private, and later more public, meetings a regional culture of power was enacted (De Vries, 2002). Much of the acting out of this culture during the election rally had been prepared, mirrored and reiterated during these earlier events. As part of an even larger framework, the meeting enacts a personalist and populist regional culture of power that has greatly influenced politics in the small state of Nayarit over a longer time span of several decades. It also evidences a material culture involving the generous and ritual offering of food and drink to popular crowds of potential voters and material benefits to selected leaders to reinforce the political support that the rally is meant to generate. The election was actually meant to take place after the second public meeting, but the sitting CMC president cancelled it at the last moment, according to Nuñez because their opponents were afraid of losing. The third and last in this series of public rallies, which was followed by the elections, is described below.

\subsection{The Election Rally}

I turn towards the venue on the side of the embankment where Nuñez is preparing for today's elections. It consists of an enclosed space in the open air with a swimming pool and a long building with a bar and kitchen at the back. The plastic tables and chairs that are carefully positioned in the open space facing a speaker's platform await the arrival of more than a hundred ejido delegates. In about an hour, Nuñez' supporters will enjoy breakfast together and listen to Nuñez' speech here before going to the polls. Nuñez and Uribe are seated behind one of the tables. The latter is Nuñez' right hand in the Solorceño ejido, and a board member of the municipal section of Sanidad Vegetal. Uribe has been involved in co-ordinating his campaign for the presidency of the CMC during the last months. Nuñez, a short man, wears a green shirt, matching the colour of the list that he is heading. Nearby a green flag is being raised on a flagpole.

Both men are reading the local newspapers. I greet them and ask what the papers have to say. Nuñez silently passes me this morning's edition of the local paper El Diario. A front-page article announces that today elections will be held at the CMC between two antagonistic groups. Nuñez is supported by 'honest ejido leaders' with a 'democratic vocation', whilst his adversary, Leal, heads the red list and represents the most 
reactionary and discredited current, supported by the tobacco producers' organisation, ARIC. The last group is headed by its patron and ex-president the 'corrupt Magdaleno Hinojosa', alias El Güerro (The White), and its current president, Gerardo Soto, who evoke sad recollections among people from the countryside, according the paper. Nuñez seems to be pleased with these favourable reports.

Around eight o'clock, Leopoldo, the association's maintenance assistant, parks the pickup that he drives for the association. In the back he carries several huge pans containing a locally common breakfast dish of meat, tortillas and beans and brings them into the kitchen. I ask him what time he got up at to fetch breakfast. He tells me that he woke at 4.30 and started to collect ejido delegates and Nuñez supporters from the most remote ranchos (rural hamlets) in the municipality. His pick-up was loaded and he estimates that he transported 50 to 100 people. Many of these people have no means of transport and their ejidos are not serviced by public transport. They would not have come otherwise, he explains. The opportunity to do some shopping in Santiago, and then the prospect of having good food and doing some proper drinking on election day, persuaded several of them to come. After doing this, he returned to Villa Hidalgo to collect the breakfast. Whilst I am talking to Leopoldo, other association staff members (canaleros [persons in charge of distribution water at field level], machine operators and truck drivers) now start arriving. They have collected ejido commissioners from other ejidos around the municipality and transported them in the back of the association's pick-ups. Most are men wearing sombreros or baseball caps and ordinary clothes, indicating a modest peasant background. They get off the pick-up and sit down at the tables. Slowly the place starts to look crowded.

Several well-known ejido leaders and peasant activists from the region are arriving under their own steam. Nuñez has clearly succeeded in bringing together a wide coalition of political leaders and activists, producer groups and organisations that have supported him during his campaign. Some of the ejido commissioners that I see arriving have actively helped Nuñez with his campaign for the CMC and are now registered as part of his candidate board. When Nuñez wins the elections, they expect to get a position within the CMC. For example, there is Bruno Nava, the Pozo de Ibarra ejido commissioner who will be appointed as 'bean marketing' president, exploring new opportunities for selling beans at a higher price. He will be responsible for enlisting political support and government resources for this. Others have negotiated some personal favours with Nuñez that I happen to have heard about. For example, an activist from Santiago acquired a job for his son as assistant at the association.

Another of Nunez' supporters is Nacho Xavier, the current president of Sanidad Vegetal and a colleague of Uribe. A week ago at a campaign meeting he fiercely attacked the ARIC-based group and accused them of using ARIC's pick-ups to transport ejido delegates to elections and of using organisational funds to offer bribes in exchange for votes. He claimed that this kind of corruption had to stop and that Nuñez in contrast did not spend a single peso on his own political campaign. Virgen and Uribe intend to stand for re-election at the end of this year and require Nuñez' support against the candidate that the ARIC-based group is putting forward. At that same meeting, another ejido commissioner continued the recriminations against the competing ARIC group and stated that he did not want to have anything to do with people like El Güerro, Gerardo 
Soto, Leal and their followers. 'Nuñez confronted them and he was not afraid of them. If only Gerardo Soto, the current leader of ARIC, had more vision. But that is not the case, so a change is badly needed. That change is provided by Nuñez' planilla'. After this a young man stood up and emphasised the need for unity among the attendees. He said that it was in the interest of the government that peasants would not unite but, rather, remain divided.

From the crowd that is present, it is evident that Nuñez has been able to ally both groups that operate within the PRI and some opposition groups in his effort to capture the CMC. For example, we see Domingo Xavier, an ejido commissioner and ex-deputy for the PRD. At an earlier campaign event organised two weeks previously, he deployed his skills as orator in favour of Nuñez and his spirited speech drew an enthusiastic response from the audience. He claimed to have suggested Bruno Nava as secretary of the planilla and said that he had a lot of confidence in him, which he emphasised by firmly shaking his hand afterwards.

Several of the organisers of Nuñez' campaign walked nervously around counting the ejido commissioners present and allowed to vote. They were checking a list drawn up on the basis of the two earlier public events. The campaign event two weeks previously in the auditorium of the $\mathrm{CMC}$ had had quite a good tumout of delegates. To attract the commissioners, Nuñez and his collaborators promoted the meeting by spreading the word that they would serve beers and birria, a popular goat's meat dish often consumed in rural areas of Western Mexico at festive occasions and political events. At the beginning of the event, some of the few women in the crowd of sombreros and baseball caps were asked to serve the birria on plastic plates. Nuñez and Uribe were actively distributing the plates of food from the front stage to the back of the auditorium among the seated delegates who patiently awaited their food. Nuñez asked the women to serve small portions, because he was concerned about whether there would be enough to go round. When Uribe opened the meeting, he mentioned the lack of food and added that hopefully people felt satisfied. With their stomachs filled, the beer also slowly found its way to the thirsty throats in the audience. Uribe continued with the presentation of the two other members of Nuñez' planilla. The candidates were enthusiastically applauded and greeted with cheers.

Meanwhile, Nuñez and Uribe took their seats behind an elongated podium block as part of the presidium positioned on the stage in front of the auditorium. They were surrounded by large signs for the PRI and the CNC. In the presidium they were accompanied by a locally well-known agricultural engineer working for the federal government and another official representing government authority and agronomic expertise. Uribe welcomed them. He indicated a tall güero (white man) seated in the first row and introduced me as an engineer from Holland, here on a technology exchange. Uribe praised the fact that people like "engineer Eduardo came all this way to co-operate with us on the Left Bank, thanks to our president of the Left Bank'. I stood up and uncomfortably greeted the people in the auditorium who were applauding. Subsequently, the audience listened to a series of speeches started by Nuñez and followed by a number of supporting ejido leaders. The audience responded approvingly with shouts of encouragement, loud exclamations, clapping and jokes. Although the floor was opened for other comments from the audience, most commissioners chose not to speak in public. The interventions were made by the politically more experienced and 
eloquent participants. These were usually better educated and not without means, judging by their clothes and conduct.

At that meeting, Nuñez counted around 142 voting supporters, more than the 109 votes required, and concluded that this would be enough to win. Nevertheless he urged the ejido comissioners to convince their colleagues to come to the elections, because they still needed more support for a secure victory. After the event, the organisers of Nuñez' campaign were optimistic but indicated their insecurity, as the turnout and loyalties of delegates remained unpredictable until the very end. These rallies were not necessarily a reliable indicator of actual voting at the poll. Delegates could easily change sides during the weeks before the election, because of a similarly pleasant event, or promises and payoffs that the opposing group could offer in the meantime. At the event that was held after the postponed elections, only around eighty people turned up. The organisers were slightly concerned about the difficulties of again mobilising all of these voters next time. In response, Nuñez pleaded that people's interest and commitment should not diminish and all present should urge their friends and acquaintances to come and vote the following week. Today at the rally the organisers count around 107 votes, which normally would be sufficient to win the elections. However, they note the absence of several people who committed themselves to come to the breakfast and worry about their votes. Nuñez deliberates with his collaborators about what to do. Nuñez decides to send Leopoldo with his pick-up to collect a certain commissioner who has not arrived yet.

Outside on the pavement, I start a conversation with the principal of the local agricultural college in Villa Hidalgo. He has come to express his support for Nuñez, in spite of the fact that he cannot vote. Like everybody else who was involved in the campaign, he was mobilised this morning to bring some of Nuñez' supporters from ejidos around the municipality to Santiago. The principal only recently migrated to Nayarit from the northern state of Sonora. Although he is an outsider, he has developed a keen interest in political relations in the region, just like myself. This enlivens our conversations on the sideline. Recently, he has explained to me his interest in developing a bond with deputy Pérez' group. Pérez has influence on the education committee of the state congress, in the university in Tepic, and the preparatory college in Villa Hidalgo. So, the principal expects that in the future Pérez will be able to secure government funds for his school. To this purpose he offered his close associate, Guttiérez, the manager of the association, a job as part-time teacher in his school, and he gladly accepted because of the additional salary. The principal informs me that Nuñez' alliance is fighting against the predominance of a small group here 'on the Right Bank', which has always dominated politically and distributed posts in the $C M C$, the municipality and in the tobacco producers' organisation, ARIC. People from the Left Bank of the river have had little influence on politics within the municipality, he tells me. As a newcomer to the region, he thinks it is remarkable that a river brings about so much discord. However, because Nuñez is supported by most ejidos on the Left Bank and has now also acquired support in several ejidos on the Right Bank, he can be expected to win the elections.

Whilst we discuss regional politics, Pérez arrives in his white pick-up. He starts to greet people around us, particularly the ejido commissioners that he knows from the Left Bank. It is as if he came to remind them of a commitment. The principal whispers with 
awe that this man is a diputado (deputy) and that he belongs to Nuñez' group. He is also a producer; he clarifies, forgetting my familiarity with the topic. Pérez comes walking up to us and firmly shakes our hands. The principal confers with Pérez about the fact that he was to bring the secretary of the Villa Hidalgo ejido with him, but could not find him. He gives the impression that he is rendering account to somebody who is behind the organisation of the campaign. Pérez responds that he will go to Villa to search for him and bring him here. He departs and after that I do not see him anymore today. I conclude for myself that Pérez is playing a role in the background of Nuñez' campaign. Pérez officially represents the private producers of the Left Bank. Therefore Nuñez cannot afford to be identified too much with him, because they represent contradictory interest groups. Nuñez refrains from publicly referring to his relations with influential PRI politicians, such as Pérez, Felix Torres, or the governor. In the local papers he explicitly denies such relations and emphasises his prime loyalty to the peasant sector. This proximity could harm his coalition that contains opposition forces. Later, the principal asks me if I noticed Pérez' muddy boots. He thinks that this is clearly deliberate. Pérez wants to show that he is an ordinary producer just like all the ejidatarios, not an elitist private producer. Despite his background role, Pérez clearly wants to make his own impression on the ejido commissioners, with a view to future political ambitions.

When the principal and I decide to go inside, most tables are already occupied by ejido commissioners and their following. The first dishes of pork and frijoles charros (fried beans) with tortillas are being distributed on plastic plates among the waiting crowd. Besides association personnel and some of the organisers of the campaign, it strikes me that Nuñez himself is also fully engaged in bringing around the plates of food to his potential voters. He personally inquires of several people what they want to eat and drink. With careful ceremony, he collects their food from the kitchen and rapidly and humbly satisfies their wishes by personally bringing it to them. We proceed towards the kitchen and the principal remarks, 'you see, here are the chiefs', pointing at Guttiérez. In the kitchen, untypically, there are no women. Uribe, Nuñez' right hand, and Laguna, a canalero from the association, among others, are serving the food from the pans onto the plates and handing them to those who are running in and out of the kitchen. We get a plate and sit down to eat. I ask the principal why Nuñez busies himself so much with delivering food to everybody. He explains that Nuñez shows himself as people like to see him. By bringing around food and drink he shows that he is an ordinary person, open and personally approachable by everybody. I add my impression that Nuñez wants to show that he is their servidor (servant), a word that he has used before, and the principal nods enthusiastically to confirm my impression.

After most delegates have finished their breakfast and look satisfied, Nuñez walks up to the speakers' platform. He begins a fiery speech in which he addresses them as compañeros (comrades) and once as hermanos de clase (class brothers). Nuñez promises that when he attains the presidency he will not betray their trust and will truly represent their interests, particularly those of the bean and tobacco producers, unlike the present CMC and the ARIC who clearly have been neglecting the interests of the campesinos (peasants). Nuñez intends to fight for a fair price for beans and tobacco and all other crops. 'Vamos a luchar por todos...' (we are going to struggle for everybody). He promises progreso $y$ bienestar (progress and prosperity) for all campesinos. Then he states that it is 
necessary to speak strongly to the governor to make him aware of what they need. Nuñez also promises to work on bringing in new companies from outside that will generate employment, on government projects and infrastructure works, such as the new bridge and the expansion of the Right Bank irrigation module. This will make agriculture flourish again, as in days of La Costa de Oro (the Gold Coast), a popular reference to the rich backdrop of collectively remembered images of the golden years of tobacco cultivation and great rural prosperity on the Northern Coast of Nayarit during the 1960 s and the 1970 s.

Suddenly, Nunez dramatically exclaims that it is 'now or neoer...' and that 'it is time for change', creating the feeling that urgent action is needed and that a hope for change is justified. He claims that they will convince with actions and not with words. Since he is totally committed himself, he only asks his audience to be the same. He needs everybody's support. With his powerful voice, accentuating gestures and use of inciting and revolutionary language, he awakens the audience that gradually starts to manifest increasing excitement. They applaud and from time to time shout to express their approval. At the end of his speech Nuñez pleads for unidad (unity). On winning the elections, Nuñez will offer his opponent the job of secretary of the $\mathrm{CMC}$, in order to prevent unnecessary discord, something that they agreed with each other. Nevertheless, he does not doubt that victory will be theirs. 'We will win the election', he finishes confidently. To round off the speech somebody shouts arriba la planilla verde, supporting the green candidate list. In response, the audience cheers and applauds enthusiastically.

When Nuñez' speech has finished, the crowd automatically flows out onto the pavement into a procession, with the green flag taken down from its pole and held triumphantly in its forward line. Nuñez takes the lead with his planilla behind him and his crowd of supporters following. They walk towards the central plaza of Santiago, which they pass on their way towards the CMC building. It is only a short walk of a few minutes. The procession arrives far too early for the election and thus the supporters wait in the shade across the road opposite the entrance. The supporters of the red planilla arrive in smaller and disparate groups. It is only around eleven o'clock that the pack of voting ejido commissioners is allowed into the large auditorium where they can register to vote. The door of the building closes behind them. Nobody else is left in the building, except for the mayor, representatives from the PRI and the national CNC. Whilst awaiting the result, we have plenty of time to study the pale and flaking paint layers that are coming off the dilapidated CMC building. This is a sharp contrast to the freshly painted office of the association in Villa Hidalgo. The state of these offices seems to reflect the difference in financial situation. The green supporters stand out because of their occasional cheers in favour of their planilla and their apparent optimism about their prospects of winning; the reds remain quietly in the background. Guttiérez functions as Nuñez' nerve centre outside, co-ordinating the information flows amongst the supporters.

After more than an hour of waiting, suddenly a bursting wave of cheers rises from the CMC building, announcing the immanent result. The door opens and the news comes out. Nuñez has won the election. The green supporters are happy and wave their flag, although anxiety is felt about an unexpectedly narrow victory. The green crowd outside flows inside, whilst most of the reds are leaving: Guttiérez and the principal are elated and see Nuñez giving a speech thanking his supporters in the front of the auditorium on 
the stage. After him, first the mayor of Santiago and then a representative of the PRI make speeches, stressing the need for unidad and co-operation to the benefit and progress of the peasantry.

After the speeches, the triumphant supporters move to the Santiago fairground. These are premises on the periphery of town, designated to host its annual festivities. A series of long tables are placed in the open air to celebrate the victory with a large banquet for the ejido delegates and to thank them for supporting Nuñez and his green candidates. I arrive when the party is in full swing. The large crowd of people indicates that those who fancy a free meal of birria with beer somewhat freely interpret the notion of supporter. The remains of consumed goat bones and plastic plates on the ground and collections of finished bottles on the tables reflect the euphoria that is felt among Nuñez' supporters. The cheerful song of a spirited ejido commissioner over a speaker system reinforces this impression, much to the entertainment of his colleagues around the tables. The canaleros are distributing the beers and also consuming one or two themselves. To the side of this spectacle, a small group of collaborators around Nuñez is seriously evaluating the close victory and speculating about those votes that were unexpectedly not cast in favour of Nuñez. Guttiérez tells me that he is concerned that tomorrow will be a very busy day in terms of water distribution on the Left Bank. At the moment, there is only one canalero in the field, because most of them are here at the election event in Santiago. The celebrations continue for hours until all the crates of beer are finished and everybody returns home.

\subsection{Analysis}

\section{The association as a political platform}

Below I will analyse Nuñez' election rally as a cultural performance. Cultural performance turns around a concern with what appears on stage, and therefore it may dissimulate (Law, 1994). The performance of political events often draws the spotlight onto the political candidate and his/her popular support and therefore narrows the perspective down to what is displayed and made visible to the outside world. A good public performance focuses attention on the subject, making one forget the media that make it possible. However, to understand how that very same cultural performance is produced and organised, what and who contribute and benefit, who are excluded, and what its exact effects are on the organisations involved, it is necessary also to look backstage to see the mundane events, hidden agendas, power struggles and the resource practices of everyday organisational life (Long, 1989; Law, 1994; Reed, 1992; Munro, 1999). On the basis of the episode observed above, it becomes evident what enables Nuñez' public performance and his apparently spontaneous display of generous and charismatic leadership. I will concentrate here on two related issues that had most impact on the management of the association.

During the electoral campaigns, the political group in charge of the association controlled an array of resources that were concentrated on launching and consolidating the political careers and furthering the ambitions of its main proponents to capture positions in politically influential organisations. Using the association as a political 
platform, and drawing and building on its concrete social and material resources, greatly facilitated the election victories of Pérez as a deputy and of Nuñez at the $C M C$, and continued afterwards. The first issue is, therefore, that Nuñez' public performance obscures the hard work, time, skill and energy that were invested by his political group and a grouping of allied politicians and activists in building the alliance of support and organising the events. The second issue is that the group drew extensively on the association's facilities, revenues and other resources for their political ends.

So, in the first place the organisation of the election rally is not simply Nuñez' individual accomplishment as a politician, but the result of a performative competence and a distribution of labour and competences among a larger collective (Hutchins, 1995) ${ }^{18}$. His political group played a central role in organising the campaign event and in mobilising his voters. During the entire campaign, the group displayed their cultural credentials and a mutual task division in organising these events. The field staff of the association demonstrated a certain experience in preparing them and the modes of enjoyment, based on previous political events during which they provided the organisational footwork for Pérez and Nuñez. For the staff it became a routine matter to transport and arrange tables and chairs, and to fetch and distribute food and drink before and during the meetings and popular events organised and patronised by their patrons. Access to a radio system greatly facilitated communication among superiors and subordinates, and turned out to be particularly handy in the organisation of these events. Further, Guttiérez and Pérez were actively involved in the co-ordination of the campaign. Guttiérez supported Nuñez at the daily level from the association, in the meantime developing his personal political skills, for instance by helping Nuñez to write and improve his speeches. Although Pérez consciously kept himself in the background, he is Nuñez' patron. It was he who manoeuvred him into position and educated him in organising these very same political events. Another important figure in the organisation of the campaign is Nuñez' right hand man in his ejido, Uribe, who co-ordinated the public events and acted as a speaker. In addition, several local leaders, politicians, activists and organisations played a role in the events. Municipal and state level politicians and agencies influenced the election from a distance.

Secondly, over a longer period of time, the group drew extensively on the association's staff, facilities, and resources for their political ends. In previous chapters, such heterogeneous combinations of human actors, non-human technologies and resource flows involved in irrigation management were analysed as operational arrangements. This chapter argues that such operational arrangements are used for more than just service provision. Nuñez' campaign illustrates that controlling these operational arrangements significantly enlarged the group's scope for political action. This facilitated building and expanding an alliance of political support, but it also freed up resources and generated a stream of unreported revenues to organise and finance an expensive political campaign. However, the political appropriation of these operational arrangements not only had concrete political effects, but also (adversely) affected the operational use of these arrangements. This weakened their financial and infrastructural viability, and the physical condition of the machinery and transport facilities. In addition, it reinforced the gradually deteriorating financial situation of the association, the frequent break-down of machinery, and increasing controversy and decreasing support for the group among the association's personnel, the delegates, and the CNA. Although the latter were 
unintended effects, they were largely taken for granted by the management of the association whilst they were fully engaged in their campaign.

I will briefly review the political opportunities and resources generated through motorised mobility, maintenance machinery, water distribution, and the financial administration of the association and the impacts of their political use on the association's resource base and service provision.

\section{Motorised political mobility}

The association has at its disposal a mobile fleet of motor bikes and vehicles operated by its staff and lubricated with gasoline and financial flows. These became useful at different points in time as campaign tools and as enablers of the political action of the group in charge. These operational arrangements were used as a means of political mobility for the candidate and his campaign organisers and of political mobilisation of its supporters to expand its political support base in the municipality. This degree of political mobility and the opportunities for popular mobilisation in Santiago were formerly largely restricted to government or party officials and wealthy producers.

The election rally was made possible by the mobile fleet from the association and other public organisations, and by some supporters with private resources. This enabled the transportation of a large crowd of potential voters from the most remote ejidos around the municipality to the election event in Santiago ${ }^{19}$. When the organisers of the campaign feared that some secure votes would not turn up, Nuñez sent out a pick-up to fetch them. The association's facilities to transport voters to the ballot box proved to be essential in winning the $\mathrm{CMC}$ elections.

Before and after the elections, the president of the association, Nuñez, became mobile because of his full-time access to an association pick-up truck. As a result, he was always able to travel quickly to the municipal capital, Santiago. This enabled him to attend meetings and strengthen his political presence at the $\mathrm{CMC}$, the municipality and in the PRI, and to develop complicities and political support by organising small parties and the three political rallies on Santiago's embankment. Getting to Santiago from the Left Bank of the municipality was especially complicated during the rainy season when the campaign was at its height, because of the temporary absence of a bridge nearby to quickly cross the river. This political mobility also gave Nuñez and the organisers of his campaign the opportunity to freely move around in the municipality and drive to different villages, and even reach the most remote ejidos within an hour.

In this manner, Nuñez was able to organise a series of festive encounters with potential supporters and build an alliance of support for his candidacy in the upcoming elections. After winning the CMC elections, Nuñez enlarged his political action range and mobility when he became increasingly involved in his work in Santiago and in the campaign of his patrons, Pérez for mayor and Felix Torres for governor. As 1998 progressed, he also started to drive more frequently to Tepic for meetings at state level of the $\mathrm{CNC}$, the PRI, the Ministry of Agriculture, and other government institutions. Not only did he represent the CMC and the association on government committees, but he also met with the 
governor and other influential PRI politicians and government bureaucrats and engaged in political lobbying to advance his political career and that of his group.

Guttiérez and the association's other staff also benefited from the mobility facilitated by the use of cars and motor bikes in ways that were exploited politically. Guttiérez was able to move around the region in his pick-up, with the fuel and maintenance costs fully covered. As manager, Guttiérez moved around the villages, fields and institutions of the Left Bank and interacted intensively with different producer groups. In doing this, he represented the interests of his patron, Pérez, and superior, Nuñez, and became active in the organisation of their subsequent political campaigns. Transport facilities provided him the opportunity to visit village festivities, organise drinking parties in local cantinas, and offer favours in exchange for the ejido commissioners' support in the upcoming elections. In addition, the canaleros moved around in the field on their motor bikes and were remarkably well informed about the region and the political and agricultural issues at hand. As such they constituted an important source of political information for Pérez' group. In addition, they facilitated political footwork, through the preparation of events and the diffusion of information and documents from and to Santiago and among the supportive forces of the alliance around the municipality. Their access to a radio system also facilitated communication and quickened the exchange of information.

During 1998 and 1999, Nuñez intensified his number of flights to Mexico City to represent the association and the three other irrigation modules in Nayarit at the National Association of WUAs (ANUR) and the CMC at the CNC and PRI headquarters, something that conveniently coincided with the preparations of the 1999 elections in Nayarit. In the capital, he looked for opportunities to commercialise beans for his constituency of peasant producers from the Santiago municipality. At the national CNC and the PRI, he pleaded for government support programmes along these lines, as this was one of the promises he had made during his campaign for the CMC. In the light of the upcoming elections and the PRI's need for popular support, these institutions were more willing to receive him. Under these favourable conditions, he was able also to represent the interests of his group, keep abreast of national and state level political developments and to develop relations in the capital. As the CMC had access to very few financial resources and had no means of transport, he continued to move around in the association's pick-up, although gradually allocating less time to the daily management of the association. In addition, his increased travel expenses were financed to a large extent by the association.

\section{Maintenance machinery movement}

The association controlled a stock of heavy machinery, such as a dragline, a hydraulic excavator, and several trucks. In Chapter 7, I have argued that heavy machinery is as a commercially and politically interesting asset for which there is an almost constant demand. For example, the public works that are enabled by heavy machinery are an appreciated source of political support and legitimation for ejido and rural leaders, who seek to improve their public image of competent and effective leadership. Because the machines are mobile and difficult to survey, the group freely moved the machines around in line with its most immediate financial and political interests. 
Nuñez used the machinery mainly to advance his political campaign in two ways. Firstly, the mobile machines constituted an important resource to generate political support and expand the action range of Nuñez' political alliance to the Right Bank of the municipality, which had previously been left uncovered. Nuñez and Guttiérez sent around maintenance machines and trucks to do agreed favours or provide services to several ejido commissioners outside the Left Bank irrigation district who played an important role in acquiring support for his alliance ${ }^{20}$. Secondly, the group used the heavy maintenance machinery as a source of (illegitimate) revenue to finance its political campaigns. To run a political campaign, Nuñez required a substantial and steady source of revenue. This need was partially fulfilled by privately renting out the machinery to third parties who paid an hourly rental fee. In the period prior to the $\mathrm{CMC}$ elections, different machines were spotted doing private jobs. Employees critical of the association would point out to me that, for example, the trucks were engaged for weeks in transporting gravel and sand to the private holdings of a wealthy and favoured cattle farmer for the construction of farm roads. Other machines were used to prepare the roads, level parcels of land and construct field canals. The indebted beneficiary paid for the material plus the agreed hourly rate directly to the president or the manager. These revenues were invested in the campaign in one way or another ${ }^{21}$.

The unfortunate impact of the political use of the machinery was that the Left Bank infrastructure received insufficient maintenance, in particular the tail-end section of the system that did not belong to the electoral constituency of the group, because it is part of the San Blas municipality. Further, the condition of the machines deteriorated due to their intensive and inappropriate use and a failure to maintain them ${ }^{22}$. As a result, substantial repair costs were incurred, and expensive spare parts had to be ordered from outside the region, as a consequence of which the motor bikes, trucks and machines were often left unused for long periods.

\section{Water distribution}

Nuñez' political group, via the team of canaleros operating the irrigation infrastructure of the Left Bank module, gave privileged access to irrigation water to several large, favoured producers in exchange for special fee payment agreements and political support ${ }^{23}$. Because the Left Bank system generally does not suffer from water scarcity, the effects of this practice were not extremely serious for other producers and ejidos, except for the unpredictability of irrigation turns. These arrangements, which were kept secret from the assembly of delegates and the CNA, freed up unreported revenue flows for the management that were invested directly in the organisation of the political campaign. Water itself was unsuitable as a political resource for building a broad alliance of support, i.e. in exchange for political support and votes from ejido commissioners, because it was not a scarce good and its distribution network is spatially limited to the Left Bank irrigation module. This made it unsuitable for expanding Nuñez' support base to the Right Bank of the river.

\section{Administration and financial revenues}

This political use of the association's operational arrangements for mobility, maintenance, and water distribution drained its financial reserves, as it led to huge fuel, 
labour, repair, and other expenses. In addition, Nuñez directly diverted financial resources from the administration of the association to his campaign, something that also adversely affected the organisation's financial status. With those financial resources, he paid among other things for the series of parties he organised and the publicity campaign in local papers. When the campaign for the CMC took place, the association's revenues from irrigation fee payments for the main irrigation cycle quickly dried up, much earlier than in other years. As early as halfway through the main irrigation cycle in March 1998, just after the elections, the association experienced severe cash flow problems, which meant that the payment of salaries and bills was postponed. As a result, the association's personnel did not receive wages for periods of several weeks, something to which they had grown accustomed over the years. Efforts to actively prevent fee default were insufficient during the campaign period, and only intensified after the elections. The association requested a loan from BANRURAL, with its properties as collateral, which it could only finish repaying ten months into the next main irrigation cycle (1998/1999).

After becoming president of the CMC, Nuñez increased his political radius of action. His travel and other political expenses remained considerable, as the elections of 1999 were approaching and he and his patrons were again aspiring to elective positions. The CMC itself turned out to have few revenue sources, particularly after ARIC stopped its financial support, and the municipality also appeared not to be very forthcoming. This is understandable from a political viewpoint, as these entities were controlled by different groups within the PRI that competed for the same political positions, for example the municipal presidency. As a result, in the association the final balance of Nunez' last year in office (1999) was negative. All these factors led to growing discontent and more articulated criticism among the association's delegates and staff and with the CNA and the state government.

\section{The election rally as a cultural performance}

The election event unmistakably reflects a personalist and populist political culture that is more common in other regions of Mexico and bears clear traces of the clientelist and corporatist set of relations that have dominated Mexican politics over several decades. I especially focus here on specific cultural traits of politics that show its performative aspects and a degree of regional specificity. After summing up the following five elements, I will continue with how this contributes to legitimising political authority and leadership, whilst acquiring and managing political support for Nuñez' alliance. Firstly, policy issues have an ambiguous role in this form of rural politics. Secondly, a statist discourse continues to prevail. Thirdly, there is an interesting contrast embodied in the type of leadership that is displayed - a contrast that accentuates servitude and humility on the one hand and authority on the other. This is most clearly expressed in the leader who personally patronises his supporters and distributes food and drink among them to bind them to him and legitimise his leadership. A fourth element is the performative balance between a campaign of recriminations against opponents and an emphasis on the fact that the political alliance represents consensus and unity. Finally, an important element of the campaign is manifested in the culturally and materially specific forms in which the political leadership appeals to, engages, and mobilises supporters, such as 
through the display and enjoyment of the good side of life, the profuse dispensing and consumption of food and drink, and collective regional recollections of past prosperity.

In view of the central role that the WUA plays in the organisation of the event, and the way in which its operational arrangements and resources enable Nuñez and his alliance to acquire political support, it is surprising to see that the association does not figure at all in the policies that Nuñez proposes to carry out as president of the CMC. This tempers our expectations about potential benefits accruing to the association as a result of the participation of its management in regional politics. More generally, the event exposes an ambiguity concerning the role of policy in contemporary rural politics. This is not to say that policies are unimportant. The issues of low crop prices and the malfunctioning of ARIC are general concerns among many peasants and producers, and a basis around which Nunez' alliance was formed. But there is also a performative aspect to challenging these issues of general discontent. Virtually everybody agrees about them, but little can be done to change them from this level, given international market relations and political relations between the multinational tobacco enterprises and national and state government in which ARIC's position is strengthened and left unchallenged. The issues about which Nuñez makes representations to the federal and state government on behalf of his constituency, however, are insufficient as a basis to build a political alliance and gain popular support. This is bome out by the rest of the analysis, which emphasises the culturally and materially specific forms of political engagement and mobilisation engaged in by Nuñez.

Nuñez' call to attract more companies from outside the region to create employment is perhaps a new element in an otherwise rather conventional statist discourse that emphasises the need for state support for the peasantry. This is understandable, because it is the raison d'être of the corporatist organ he wishes to represent. Nuñez' demands for a return of populist redistributive policies, like federal price support for the bean producers, and his support for the construction of large infrastructural works in the municipality appear outdated in times of state disengagement, but are to be understood in the context of the approaching elections. During this period, the PRI did its best to regain electoral support along the established lines of targeted supports and subsidised goods to the popular classes, and infrastructural works of large symbolical importance to regional development. This creates some room for negotiation, interest representation and performative display for local PRI representatives, such as Pérez and Nuñez.

\section{Displays of leadership and authority}

During the campaign events, Nuñez gets to perform a central role, manifesting his authority as the political leader of the alliance that he has united. The campaign meetings serve as special occasions to commemorate the leader's good deeds and strong points. They display and legitimise his leadership position via different media: his visible acts like the physical distribution of food, his spoken discourse, the praise he receives from other supporters, the applause and response he gets, and the written press that reports his triumphs to the outside world.

Nuñez is presented by himself and others as an honest leader from a humble peasant background who represents a wider imagined constituency of peasants (campesinos) and 
the ejido sector in the municipality of Santiago. He displays his commitment to act as a servant to his companions and struggle for their interests, and he makes it clear that he expects their commitment in return. Nuñez claims to fight for progress and the wellbeing of all ejidatarios, and claims the opposite for his opponents. Yet, this humble approach to representing his electoral base coexists with the contrasting image of an authoritative or strong leader. The change that Nunez promises to bring about, the confidence he displays about winning the elections, his firm stance towards the governor and his opponents, his charismatic and expressive body language, not to mention his eloquent discourse, all contribute to the same impression. They show a strong and resolute leader with the commitment, authority and capacity to lead, to serve the interests of his constituency, and to enforce change. The rally also affords him an opportunity to reiterate the moral values on which his authority rests. Humility and authority are clearly two sides of the same coin; both appeal to people's ideals about leadership and, as a result, legitimise Nuñez' candidacy.

Eloquently, Nuñez situates himself as a vital link in the transition from the rural past to the future. His revolutionary language and the symbols that surround him revive popular recollections of a prosperous regional past and call to mind a revolutionary peasantry historically united in the struggle for land and liberty. To generate hope for a better future, Nuñez refers to the introduction of new government programmes, large infrastructural works, companies from outside. He and others create a sense of urgency and a need for radical change, which the alliance promises to bring. Nuñez' symbolic act as leader of the alliance continues when he walks at the front of the ritual procession towards the election poll, with his direct collaborators and supporters behind him, embodying the hierarchy of authority in his alliance in a way that echoes fragments of the Mexican Revolution. Finally, having been elected and inaugurated as president of the CMC, Nuñez rewards his supporters in style by means of a large festive banquet with alcohol, food, and live music.

Besides positioning himself in relation to his associates and voters, he also positions himself as a legitimate and responsible leader vis-à-vis the governorship, the PRI, the $\mathrm{CNC}$, and the municipality. This requires a fine balance between dismissing and antagonising his opponents, and pleading for unity and consensus as is the customary practice within the PRI. In the run-up to the election, Nuñez and his associates thus launched a campaign of denouncements to blacken the name of his rival, whilst towards the end of the campaign, they emphasised the need to reconcile differences and their willingness to even work together with their opponents. Further, a signal that Nuñez sends out is that his alliance is a legitimate force with a significant support base and that he is a leader within the PRI whom it cannot afford to lose. Defecting to the opposition is no longer as inconceivable as it was before (Klesner, 1997).

Several members of the alliance reinforce Nuñez' leadership by publicly granting him their support. They glorify Nuñez as a potent and courageous leader by claiming that he is not afraid to face and challenge his opponents or the governor, and that he will bring about radical change. Others associate him with appealing to sources of government authority, agronomic expertise and foreign advanced technology. Again others fiercely discredit the leadership of ARIC and the competing political group by telling of their corruptness and disclosing their misuse of resources for political purposes. The most 
striking example reveals a rather ironic aspect of the performance. The president of Sanidad Vegetal fiercely criticises their adversaries for using organisational resources in support of their campaign, ignoring for a moment the fact that he and Nuñez are doing exactly same thing. This is something of which insiders are conscious.

Finally, Nuñez makes a visible effort to personally bring food and drink to his potential voters, to emphasise the fact that it is his priority to patronise and cater for their individual needs. All of his energy is directed at personally pleasing individual delegates in a larger audience. The performance visualises the image of a political leader committed to serving the needs of his people. In addition, it also emphasises that it is Nuñez in person who provides them with these pleasures and to whom they should be thankful. Through this act, Nuñez reminds several individual ejido commissioners of their mutual complicities and commitments developed before, over a longer period, at earlier encounters, or through the promise of a favour or a job. For the wider audience of ejido commissioners, this personal act positions Nuñez as the legitimate political leader who qualifies for popular support and is worthy of receiving their vote.

As I have argued before, the provision, the collective consumption and enjoyment of food and alcohol implies a certain reciprocity and nurtures relations of trust and cuatismo. The form of wet politics that Nunez and his associates practice is directed at generating votes at the ballot box (Fallaw, 2003). Further, the event conveys and articulates a sense of common identity and purpose for the alliance, whilst masking existing social divisions and class distinctions. The ideology of unity is reinforced through the name of the alliance and by pointing out to the crowd that they are all campesinos (Enge and Whiteford, 1989: 180). Nevertheless, in spite of incurring feelings of obligation, trust and identity, the commissioners may still decide not to vote for Nuñez, and their voting behaviour remains to some extent uncontrollable and unpredictable, because of the (formerly unknown) secrecy of voting. But the rally is more than a simple transactional or coercive setting, it is also a performative setting that works implicitly, to concentrate, influence, and guide an audience of voters on their way to the polls. The performative setting, the choreography and sequence of events, and the enjoyment of the intrinsic qualities of the performance also generate an emotional state among the audience that enhances a favourable electoral result. Alcohol, food and music have a significant contribution to make in terms of producing these altered states of consciousness.

This election rally is an orchestrated performance in which disparate groups are gathered, united in a wider alliance, and orientated to vote for its leader. First of all, the widely advertised prospect of such enjoyment attracts a sizeable audience of potential voters from all comers of the municipality. Secondly, it actively works to relate the individual ejido commissioners to a larger collective, the alliance, which at the outset of the campaign was still very fragmented. In other words, the collective experience of the commissioners has an engaging effect on them, by making them part of an alliance. Thirdly, collective enjoyment plays a major role in inspiring and canalising positive emotions in favour of the leader. Evoking, canalising, and capitalising on collectively experienced emotions, such as enjoyment, comradeship and the euphoria of belonging to a winning alliance, has the effect of strengthening the coherence of the alliance. It is not by chance that the organisers carefully monitored the collective mood of the events, reflected by the audience's emotional responses, such as applause, laughter, and 
satisfaction. Both the number of well-disposed delegates and the pleasant atmosphere among them made the organisers more confident of victory. By joining the emotional and the political, the performance of this event relates the individual to the collective and simultaneously to its leader in a culturally specific manner.

\section{Post-analysis}

The importance that Nuñez and his associates attach to the public distribution of food and drink is not peculiar to the president of the WUA. It is something that, for example, the competing group of El Güerro is also known to engage in. In Nayarit, as in many other states of Mexico, political leaders have a popular tradition of patronising public festivities during which popular crowds are collectively pleased through the profuse flow of beer and local specialities, adorned with revolutionary discourses and live musical performance ${ }^{24}$. During such events, the politicians (in Nayarit) are personally approachable to discuss and resolve the needs of ordinary people. Organising these public modes of enjoyment, particularly during election time, is a central means to garner popular electoral support for the PRI government, as well as for select socialist parties with post-revolutionary governmental experience. Nuñez acquired such cultural skills via an implicit political training by his patrons, Pérez and Felix Torres, who in turn emulated the political style and leadership qualities of the patriarch of Nayarit politics, Don Emilio. Don Emilio, in turn, was influenced by the syndical populism of his patron, Fidel Velazquez, national leader of the CTM for several decades, and by the popular politics of Alejandro Gascon who was mayor of Tepic (1972-1975) and won the governorship of Nayarit for the Partido Popular Socialista (Popular Socialist Party) in 1975, although the latter victory was never acknowledged by the PRI. Both politicians again were influenced by the founder of both the CTM and the PPS, Lombardo Toledano.

De Vries observes a similar phenomenon in the nearby state of Jalisco. He observes that the art of managing people entails that they should become part of a whole, of a wider design. But in Mexico, and particularly in the state of Jalisco, this cohesion should occur in a culturally specific way, which is with food and drink, with musical groups and mariachis. This involves organising parties and recognising the ejidatarios' yearning for community. Such a particular culture of power is important in developing a style of management and involves a willingness to engage in personalised relations with ejidatarios and the ability to organise public modes of enjoyment (De Vries, 2002).

In addition, Ben Fallaw (2003) demonstrates the importance of 'wet politics' for consecutive socialist governments in the state of Yucatán around the time of the Mexican revolution. They benefited from the revenues generated by a state-run monopoly on alcohol, whilst illegal revenues greased and lubricated the provincial politics machine. Alcohol also became central to the political culture of Yucatan socialism and the government's ability to mobilise electoral support by using the power of alcohol to draw lower class males to rallies and polling stations. Political intermediaries distributed alcohol in exchange for the promise of votes. The ritual and generous offering of alcohol turned voting into a wet fiesta and the possibility of drinking (and being entertained with musical bands at civic festivals) came to be seen as a basic entitlement by male peasants and workers. The way in which these politicians organise their electoral support is not 
surprising, given the cultural and ceremonial significance of alcohol, food and music in popular celebrations around Latin America. In many regions of Mexico, politics also appropriated specific elements of campaigning from Catholic folk festivals (Beezley et al, 1994; Fallaw, 2003).

In sum, the public display of leadership authority and the building of an electoral support base necessary to win elections occurs through engaging with a culturally specific register that is the product of a national and regional political history. Among other things, this often requires politicians to patronise festive encounters and rallies, celebrate complicities and the joining of forces, and organise collective enjoyment and the public dispensing of food and drink. With variations, this can be found in many other regions of Mexico.

\subsection{Conclusions}

This chapter has argued that, in contrast to resource management theories that analyse resource allocation as an enterprise of service provision and suppose that politics is an exogenous variable, resource allocation is intrinsically political. The chapter has illustrated how a user organisation can become a political platform for a select group of users who appropriate its operational arrangements and concentrate its resources on launching and consolidating the political careers and ambitions of its main proponents through access to representative positions. Analysing the final election rally as a cultural performance has illustrated how resources are mobilised politically, according to culturally and materially appealing, meaningful and established ways of engaging in politics and representing power and authority.

The implication for institutional economics and resource management theories is that it cannot be assumed that the restructuring of rules and incentives that occurs with the transition from government to user management of public resources produces managerial responses that are in conformity with a unidimensional economic rationality and therefore bound to result in improved service provision. A broad variety of human rationalities exist, and therefore a much wider set of economic, political and cultural responses are possible outcomes of these policy transformations, as we have seen in the case of Irrigation Management Transfer. This theoretical implication is much more broadly applicable than to this particular case alone, as these ideas are very influential around the world in conceptualising resource allocation policies and practices.

Although the influence of politics over resource allocation can be very detrimental, as we have seen, it is not an option to simply exclude it from our field of vision. A useful and obvious route to argue this is to substantiate the claim that resource allocation is politically contested. However, I choose to posit the idea that the relation between politics and resource allocation is reciprocal. Just as politics permeates conflicts and decisions over resource allocation, the canalisation and concentration of resources also lubricates 'the politics machine'. If we follow this machine metaphor, it does not suffice to analyse the mechanical workings of the politics machine, but an urge should be created to explore the untrodden territories of 'machine politics'. Similarly, our focus on the politics of water conflicts remains unsatisfactory if we do not also penetrate the 
possibilities of 'wet politics', inquiring into how different interconnected sets of resource flows lubricate and grease politics. These flows can serve as fuel for political machinery, or as the lifeblood of a political body, to use another metaphor for resource politics. Finally, motorised political mobility should persuade us to do away with static versions of state politics and awaken our interest in the spatial mobility of political action.

I have looked at a particular case of resource politics, but I suppose that the approach I used can provide interesting insights into the co-evolvement of resource management and political regimes in other places. It has the potential to produce new, provoking ideas about the interaction of material and political culture. Allowing politics to re-enter the analysis of resource allocation has another great advantage, that is, it allows the normalisation of politics. This brings politics back into the discussion of everyday practices of resource distribution, not as an external determinant, but as something that is at the same time also being constituted by such contingent and heterogeneous practices. This involves moving away from a state-centred towards a more decentred focus on politics, which includes culture and everyday organisational and resource practices in the understanding of politics.

It has not been my intention to argue that every form of water user organisation is bound to be perverted by politics, although the kind of politics looked at in this case appeared as particularly erosive to any kind of egalitarian, democratic or sustainable resource management. I do not mean to say that this form of politicisation of resource management is necessarily a generalised phenomenon in water users' associations in Mexico, but it is also certainly not an exceptional development. The exact extent of its occurrence needs to be established through other research. Without doubt, there are equally significant examples available of a more symbiotic relation between politics, user organisation and resource management. My analysis merely implies that, in looking at new forms of policy, organisation, or technologies of resource management, it is crucial also to consider the political use and implications of such forms of reordering.

\section{Notes}

1 His case study is presented by the main proponent of the success of the Mexican model, the exCNA director Dr. González Villareal. See also Chapter 10.

${ }_{2}$ Regarding both references to Mosse, I have significantly revised his phrases to use them for my own purposes. The responsibility for the contents is mine.

${ }^{3}$ The CNC is one of the three major corporatist organisations incorporated in the dominant political party, PRI, and for a long time provided much of its political stability and control. At the state level, the CMC is superseded by the Liga de Comunidades Agrarias y Sindicatos Campesinos (League of Agrarian Communities and Peasant Unions).

${ }_{4}$ Complete name: Asociación Rural de Interés Colectivo de Productores de Tabaco Constituyente 'General Esteban Baca Calderón'.

$5 \quad$ Eighteen deputies (MPs) represent their district in the State Congress in Tepic.

- See, for example, Grindle, 1977; Greenberg, 1970.

7 ARIC was politically subjected to agreements between the federal and state government and the companies. Further, they depended economically on the companies, which were unwilling to pay higher prices.

8 Land reform communities created after the Mexican Revolution of 1910. Before the revision of Article 27 of the Constitution in 1992, ejido land belonged to the state, with a combination of community (ejido) and private (ejidatorio) usufruct. Ejido members are called ejidatarios. 
$9 \quad$ For Pérez' political group, 'the Left Bank' effectively means their self-proclaimed political constituency. This definition excludes the coastal fringe zone at the tail-end of the irrigation module, which belongs to the San Blas municipality, and a small fraction that belongs to the municipality of Tepic. The effect of this can be observed in the lack of maintenance of the irrigation infrastructure in the San Blas area and the fact that WUA delegates from San Blas feel that the Left Bank obviously excludes them (see Chapters 4,7 and 8). The use of this spatial and political denomination is thus specifically used by this group to distinguish themselves from 'the Right Bank', the municipal capital of Santiago, and San Blas, and particularly from the competing political groups belonging to those places. It is also a way of positioning themselves vis-à-vis the state government and acquiring popular support among the population as the legitimate leadership of the Left Bank. People and politicians who live on the Santiago side of the river are not at all preoccupied with establishing their difference in relation to people from the other side of the river. In fact, people hardly ever identify themselves as originating from the Right Bank. Concluding, this type of spatial or territorial politics of belonging thus represents a very selective political strategy with clear inclusionary as well as exclusionary effects.

${ }_{10}$ When the decision was made, the political struggle ended for the time being. The official version read that the candidate was chosen 'by consensus'. An implicit rule of the political game in the PRI was to accept failure, discipline followers and call for united support for the chosen contender. The implicit promise that there would be another chance was always left open.

i1 This of course does not preclude the possibility of his supporting one of the candidates outside of the public domain. Neither does it preclude the possibility that a negotiation between political groups at the state level may lie behind this election result. This was difficult to establish due to the closed nature of the state level PRI ranks. However, it can certainly not be the only explanation, because relations among different groups in the PRI were tense in view of the question of the governorship the following year.

${ }_{12}$ Nuñez (and many other regional politicians) claimed government resources and demanded support programmes that would secure higher bean prices and benefit the many small-scale bean producers in the area. Because the former government parastatals were abolished, newly formed producer cooperatives were provided with a loan to collectively market the bean harvest and achieve higher prices. The PRI sought to win political support for the new PRI governorship with this action, and local politicians, such as Nuñez, benefited from that by publicly emphasising their role in this scheme.

${ }_{13}$ The ejido assembly elects an executive committee, consisting of the following ejido commissioners: a president or comisariado ejidal, a secretary, and a treasurer. In addition, the assembly chooses a control committee.

${ }_{14}$ Each of the fifty-four ejidos is allowed to send its president, secretary, and treasurer of the ejido committee and the president of the control committee, which implies a total of 216 votes

${ }^{15}$ They serve as a vehicle for transmitting ideas of social and political protest or sexual misbehaviour (Beezley et al., 1994).

${ }_{16}$ Something that is expressed in the saying 'There is no such thing as a free lunch'. Nobel laureate Milton Friedman took this phrase to summarise the nature of all (economic) transactions as the title for a book (Friedman, 1975). 'What Friedman said was that for every benefit there is an offsetting cost, and while that cost may be temporarily imperceptible it exists indeed, and will eventually make itself known'. See www.greekshares.com/afford.asp.

17 Notwithstanding this, I find them useful to follow the actions and positions of local producer or political leaders and their groups, the kind of discourses they engage in, and the image of the political leadership, connections and public authority that they want to project.

18 See also Chapters 5 and 6.

19 This practice is very similar to the way in which government cars, personnel and resources used to be and still are mobilised for PRI events. The difference is that, in this case, the transport is mobilised and financed from non-government resources diverted from a WUA.

20 Public roads, village squares, sports fields, drainage and sewage systems are good examples of much-demanded public works. Heavy machinery is therefore at times a strategic political tool, which is subject to different political or electoral claims (see Chapter 7).

${ }_{21}$ This type of private job was not programmed and usually no receipts were given to the beneficiaries. The financial revenues generated by these operations were not reported in the books, and their allocation was completely non-transparent for observers or delegates. The association's accountant was a cousin of Pérez and not hired for the purpose of critical oversight. 
2 Most of the machinery was already rather obsolete and in need of repair; only a few items were new when the association started using them. The WUA employed machine operators, most of whom were not professionally trained but were close associates of Pérez.

${ }_{23}$ The rationale behind providing privileged access was never just financial, but was enmeshed with relations of friendship, commerce, and political support.

24 It also corresponds with the specific cultural likings of many rural people on the Northern Coast of Nayarit for generous leaders who publicly share their wealth and sponsor the (embodied) alcoholic and gastronomic pleasures of the common people. This has to be understood in the context of heterogeneous factors such as relatively low levels of education among the population, late urbanisation, the political dominance of one party over a long period, the tropical climate (as drinking men like to emphasise), the widespread tobacco cultivation causing a seasonal period of peak income, etc. The Northern Coast of Nayarit is an area with one of the highest beer consumption rates per capita in Mexico, comparable to Sinaloa. 


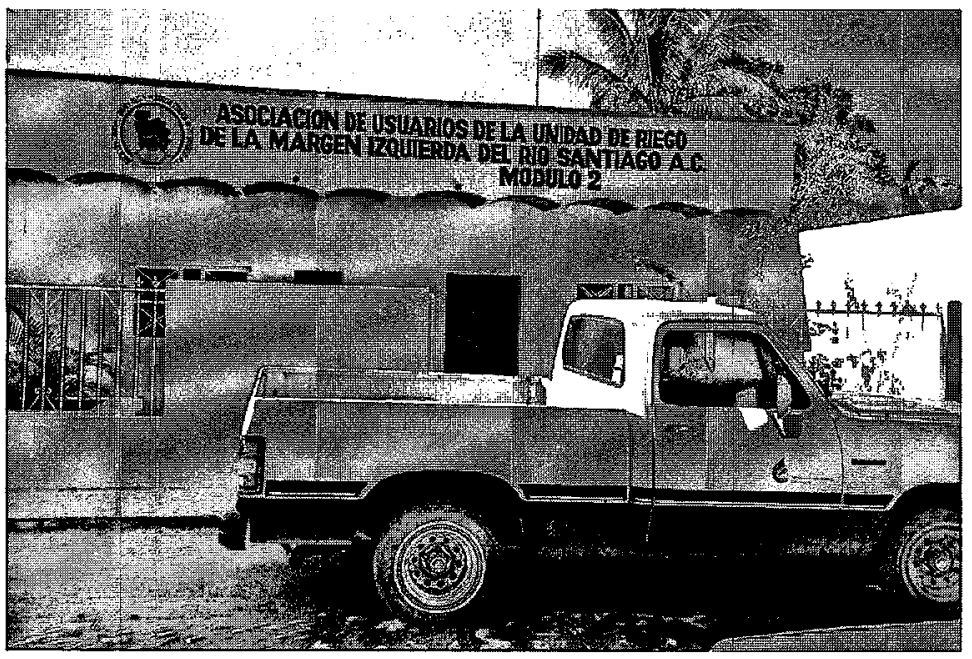

Photo 22 A CNA pick-up parked in front of the new WUA office

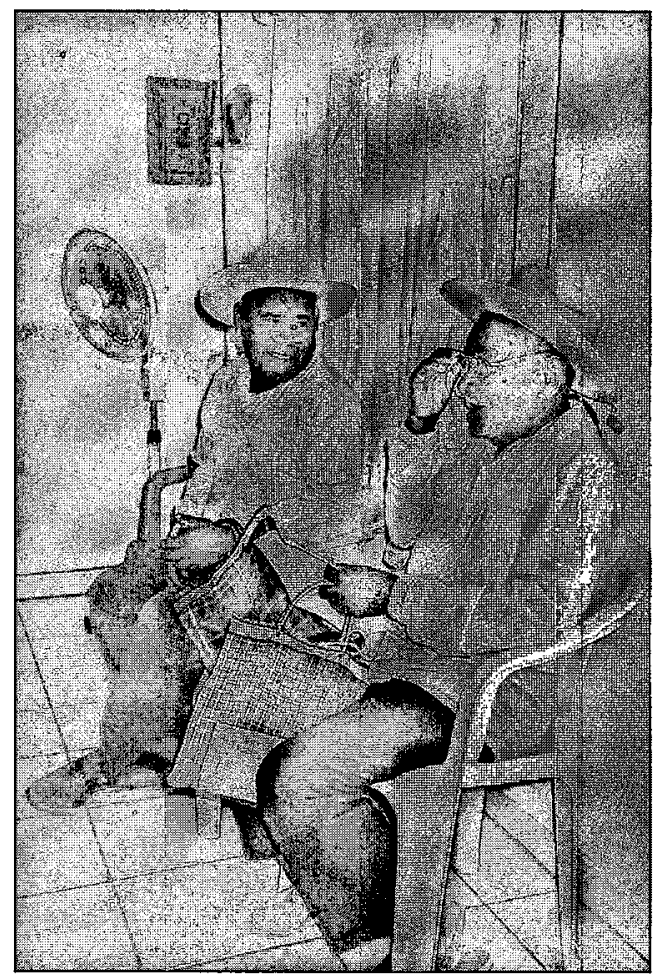

Photo 23 An ejidatario in the office about to pay his irrigation fee 


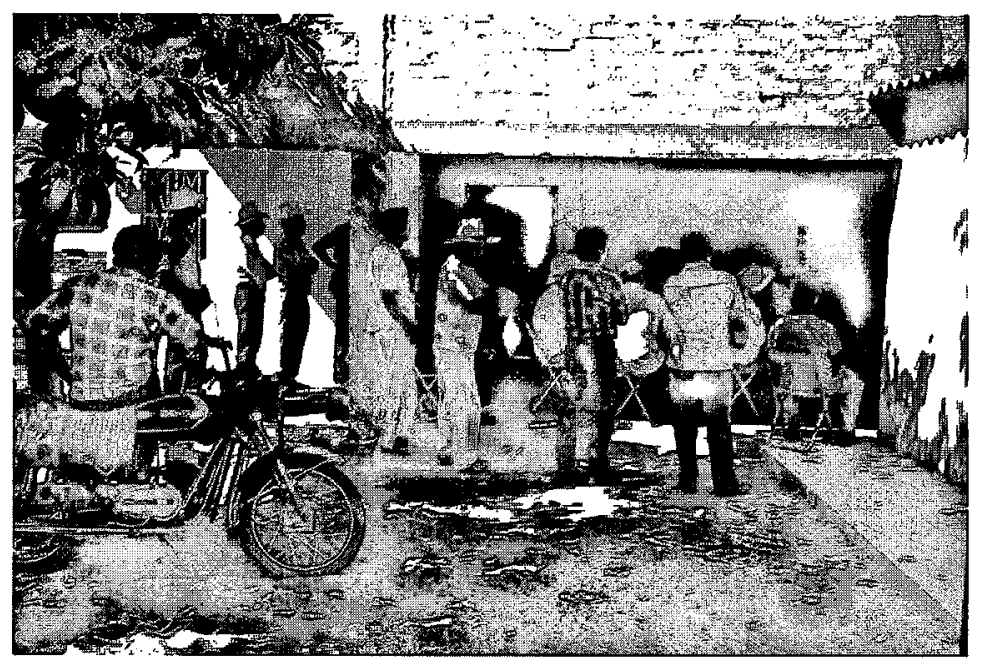

Photo 24 An assembly meeting from the back

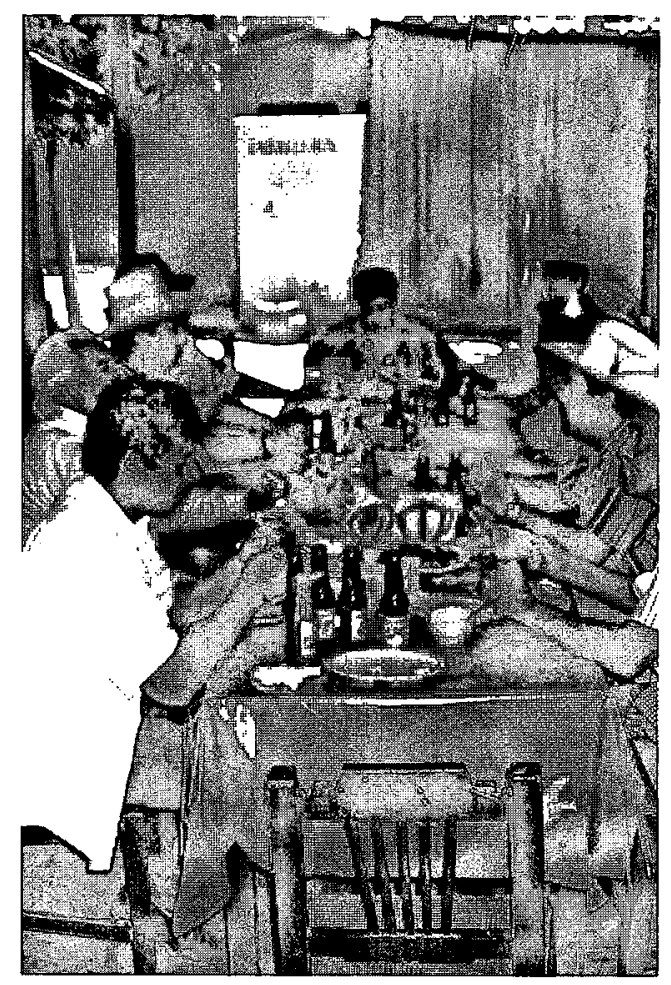

Photo 25 After the assembly 


\title{
Accountability in Times of Financial Crisis
}

\author{
DRAMATIS PERSONAE: \\ Nuñez \\ Guttiérez \\ Blanco \\ Ochoa \\ Becerra \\ Norberto \\ Silvio \\ Pérez \\ Delegates \\ Network of favoured producers \\ Laguna \\ Diego \\ Rigoberto Ochoa \\ president of the WUA \\ manager of the WUA, Laguna's superior \\ CNA unit head for the Left Bank \\ CNA State Director of Nayarit: the supreme representatioe of the CNA in \\ the state \\ CNA district head and former head of operation \\ treasurer WULA, ejido president Sauta \\ secretary WUA \\ former president of the WUA, local deputy and large producer and leader of a \\ political group \\ twenty-five representatives of ejidatarios and private producers in the general \\ assembly of the WUA \\ large producers with whom the WUA reaches financial agreements and who \\ get privileged access to services \\ canalero (see Chapter 5) \\ canalero, Guttierez' cousin (see Chapter 6) \\ governor (1993-1999), CTM leader
}

PROPS:

Irrigation fees

Water in blocks

PROCAMPO

Financial agreements

Financial contracts

Alianza para el Campo

Fuel voucher

Financial documentation

Concession Title

Maintenance machines

Spare parts

Crops

Amado Neroo

Irrigation infrastructure

WUA office

fees paid by individual farmers to the WUIA for irrigation, maintenance, and administratioe services

WUA pays the CNA per received volume of water according to an annually determined volumetric water price

Programa de Apoyos Directos al Campo: Direct food crop subsidies based on plot size

informal agreements with favoured producers to allow postponed fee payment in exchange for financial compensation

formal agreements with tobacco companies to adoance irrigation fees

Alliance for the Countryside: federal support programme for the rural sector

voucher for a certain quantity of gasoline

annual budgets/reports, monthly reports

establishes the legal terms for the concession of the infrastructure by the government to the WUA

machinery to carry out maintenance of irrigation works

machine parts

beans, tobacco, cereals, rice, etc.

headworks of the Left Bank module, concrete diversion weir

network of connected canals and drains of distinct leoels

in Villa Hidalgo 


\subsection{Introduction}

At the core of contemporary theories and policies on user organisations in natural resource management lies the idea of accountability. Two kinds of accountability relations are generally considered to be important for user organisations: on the one hand, the relation with a circumscribed community of resource users; on the other hand, the relation with a regulatory government authority. Although these normative ideas have become engrained in the formation, and effective in the dissemination, of government policies that organise irrigation, as demonstrated in the first part of this book, it is not always clear what relation they bear to actual organisational practices and behaviour. For that reason, this chapter investigates these two forms of accountability in the case of a Water Users' Association (WUA). I will start with the WUA's relation to the Comision Nacional del Agua (CNA: National Water Commission) as regulatory authority or final arbiter. At a later point in the chapter I will discuss the relation of the elected directive board and management of the WUA with the assembly of delegates, which represents the larger community of water users and is formally the WUA's highest decision-making authority. I explicate below my reason for focusing particularly on the financial management of the WUA.

Since the early 1980s, advocates of neo-liberal irrigation reforms have proposed to solve the problem of the poor performance of large-scale and publicly managed irrigation systems through the introduction of quasi-market incentives into their management (Kloezen, 2002; Repetto, 1986; Uphoff et al., 1991). In line with these ideas, a major motivation behind the Mexican Irrigation Management Transfer (IMT) programme was the reduction of public expenditure on irrigation management by creating financially self-sufficient WUAs that would recover the full operating costs of irrigation systems (Espinosa de León and Trava-Manzanilla, 1992; Gorriz et al., 1995; Johnson, 1997a; Trava-Manzanilla, 1994). Two central concepts in this respect are financial autonomy and accountability. The expectation is that the substantial increases in irrigation service fees that water users pay after the transfer will enable the WUAs to achieve financial autonomy from the government. Because henceforward the WUA management is dependent on the water users' fees, it is forced to be accountable to users' needs, since only satisfied users will pay (Vermillion and Johnson, 1995). The literature also discusses the introduction of positive financial incentives such as performance bonuses and higher wages, which are expected to lead to improved individual performance of personnel (Johnson, 1995).

Following the neo-liberal doctrine, resource management theories generally identify WUAs as the natural opposite of government institutions. It has become accepted wisdom that, on the one hand, public irrigation management is generally constrained by upward accountability, rent seeking, hierarchical structure, bureaucratic rules (Merrey, 1995), and a lack of incentives to manage according to users' needs (Vermillion and Johnson, 1995). On the other hand, WUAs are blessed with a set of virtues that are a remarkable inversion of all of these aforementioned vices. Hence, they are represented as semi-autonomous service provision entities that are accountable to their user-clients, because they are dependent on their clients' demand for water and other services and their willingness to pay irrigation service fees according to market rates. WUAs are seen as co-operative institutions owned by their users, directed by representative assemblies elected by users, and financed through the fees paid for irrigation services by users. The 
staff is therefore doubly responsible to the membership through both electoral and financial channels and obliged to work well to satisfy the users. In other words; the staff is hired and directly controlled by the users themselves, and that stimulates a better quality of service provision (Kloezen, 2002). Unsatisfactory or rent-seeking staff members can lose their jobs through the mediation of delegates. Individual water users who try to free ride by withholding fees without a valid reason may be deprived of water (Moore, 1989) ${ }^{1}$.

The theory postulates financial accountability in WUAs to work as follows: Firstly, the financial autonomy of WUAs and their dependency on the collection of user fees is expected to create a set of incentives that increases the amount of managerial effort that the WUA invests in improving the quantity and quality of operation and maintenance $(\mathrm{O} \& M)$. Secondly, the WUAs' structure of rules allows for more flexible and responsive management that delivers more appropriate services. This generates more satisfied users willing to pay their fees, and thus improves fee collection. Thirdly, financial autonomy leads to cost-effective management, reducing unnecessary costs and improving revenue collection. Fourthly, WUAs will also effect greater water use efficiency, because their financial autonomy completely depends on this scarce resource (Oorthuizen, 2003). Fifthly, the introduction of a set of financial accounting and auditing measures and requirements is believed to improve the transparency of the WUAs' financial management to the users and the CNA. The use of computers, well-trained professional staff and external auditors has facilitated auditing. The WUAs' 'Concession Title' further requires and enables internal and external auditing on the basis of the submission of annual budgets and regular approval of expenditure accounts and O\&M reports. These interventions generate improvements in transparency that help WUAs to become financially accountable (Kloezen, 2002) and therefore manageable 'from a distance' by both the users and the CNA.

In theory, electoral accountability functions in the following manner: Democratic electoral principles in the representative structure of WUAs make the management downwardly accountable to their users, unlike former government institutions. The users appoint delegates to represent their ejido ${ }^{3}$ or private producers' association in the WUAs' assembly. Their prerogative to elect and appoint allows them to replace managers or personnel when they do not perform satisfactorily.

In contradiction of the theory, this chapter will illustrate that a WUA can operate as a body that is largely unresponsive and non-transparent to its user delegates as well as to the regulatory authority, CNA. This shows that formal, direct and isolated accountability relations between a service provider, water users, and a government authority do not work automatically. In this particular case of a WUA, several political, institutional and financial practices and processes subvert and mediate these supposed control mechanisms and therefore nullify the effectiveness of formal accountability relations. It follows that preconceived ideas about accountability are not useful for understanding the combinations of forces working in and on WUAs and their impact on managerial performance.

The chapter continues as follows: Section 9.2 starts with the problematic practice of fee collection in the WUA and then introduces the actors, hierarchies and settings of the CNA and the WUA that are involved in the latter's financial crisis. Section 9.3 follows 
with detailed accounts of two consecutive assembly meetings organised as a reaction to the deteriorating financial situation of the association, interjected with short explanatory comments. Then, in Section 9.4 the lack of accountability that emerges from the picture presented of the meetings is analysed within wider political, institutional and financial relations. I assess how different state, market and community institutions and mechanisms influence the practice of accountability in WUAs. Finally, I draw conclusions and emphasise the need to transcend conventional public-private and state-society dichotomies to understand actual organising practices of user organisations that manage public resources.

\subsection{Financial Accountability: The CNA and the WUA}

\section{Fee collection and financial management}

When the government bureaucracy managed the irrigation district, fee collection was severely limited. The irrigation fees were kept at a low level and rarely adjusted for inflation or cost increases. Attempts to increase the fees, or improve the rates of collection, generally met fierce opposition from local political leaders (often Comité Municipal de Campesinos: Municipal Peasant Committee, CMC), who derived political support among their political clientele in the irrigation district, primarily the ejidatarios (see Chapter 8). In fact, the fees were usually the outcome of negotiated agreements between the district engineers and local ejido leaders (van der Zaag, 1992). On the Left Bank, the CMC president was a member of the District Committee and influenced the annual establishment of irrigation fees. At the end of the 1970s, the CMC president ritually pressured for the lowering of proposed fee increases to acquire political support among rural producers, something that benefited his election as municipal president. The District Head would give in to this pressure, as he started the ritual negotiations on purpose at a higher level in order to arrive at what he desired ${ }^{4}$. Nevertheless, the District's leeway for fee increases was thus limited because of political criteria (see also Chapter 3).

Irrigating farmers were meant to pay their irrigation service fees at the government offices in El Tizate, but many farmers did not pay them. Meanwhile, the district did not put much effort into collecting them, because these funds were directly channelled to Hacienda (Ministry of Finance) in Mexico. The district was left unaffected by the low fee collection, because its budget depended not on it, but on other political and bureaucratic factors. Canaleros (people in charge of distributing water in the field) and district engineers sometimes benefited from this situation, because they received bribes from farmers who wanted access to water without paying the irrigation fee.

After management transfer, the CNA district remains in control of the headworks and wholesales water 'in blocks' to the WUAs. The latter pay the CNA for the services it provides according to an annually determined volumetric water price that differs per module. Because the Left Bank module is a run-of-the-river system in which the diversion of water occurs by means of gravity, the CNA incurs low costs with the O\&M of the headworks. Therefore, the Left Bank WUA pays by far the lowest water price of 1.17 pesos per $1000 \mathrm{~m}^{3}$, whilst the other modules' water price is two to five times higher. 
Two other modules, the Right Bank of the River Santiago and Valle de Banderas, are situated above the level of the river and therefore require a pump station to drive water into the main canal. As a result, the CNA incurs high electricity expenses, which it has to recoup from these modules. Because the federal subsidies on electricity were removed recently, there is more pressure on the producers to pay their fees and the modules to pay their debts to the CNA in order to cover the electricity bills. Otherwise there will simply not be any water, because the electricity will be cut off. On the Left Bank, water has never been that scarce and expensive. As a result, the producers and the WUA management have no experience with rationing water use. In the event of the Left Bank not paying its water debts to the CNA, as recorded below, the CNA has the legal possibility of cutting off the water to the whole system. Such cuts have never been maintained over a prolonged period however, presumably because of the enormous impact, political upheaval and legal problems that it would cause ${ }^{6}$.

In recent years, the federal CNA in Mexico City increased its pressure to have districts completely finance their budgets, initially with the exception of salaries, from the payments made by WUAs for water. In response, the CNA district lowered its budget by cutting costs and increased the financial contributions of the WUAs, which was possible because of their improved fee collection. As a result, the district achieved a 100 per cent fee recovery rate in 1996-1997 for the first time, as the programmed CNA district expenses and the actual recovered revenues from the WUAs corresponded (see Appendix 7 , Table 6, column 6) ${ }^{7}$. Although this was an important achievement, in itself it did not guarantee the WUAs' self-sufficiency. It is interesting to note that the budget of the Left Bank WUA is twice as large as that of the CNA district, and it finances about a third of the latter's. This distribution of financial power and the CNA's partial dependency on the Left Bank is clear-cut and, as we will see, this influences other political and institutional aspects of their relations (see Appendix 7, Table 6).

The original policy objective for WUAs was to become self-sufficient by seasonally charging land and crop-based fees to individual farmers. This should generate enough revenues to cover not just an association's own expenses but also a share of the CNA district budget ${ }^{8}$. After the transfer, the irrigation fees per hectare of irrigated crop were raised significantly and a minimal fee was introduced for land within the module that was not irrigated. Particularly after the 1992-1993 cycle, when one association was officially formed for the entire Left Bank module, the fees increased considerably (see Appendix 7, Table 6, column 2). However, after this initial fee increase, the fees and fee collection did not increase in proportion to inflation and the expenditure of the association. Pérez, the then president of the association, prevented substantial fee increases, as he was afraid of losing political support in the ejidos that had elected him as deputy. Only this year (1997-1998) the fees were increased by thirty-three per cent, and an incidental thirty-five peso levy per hectare was imposed for a special rehabilitation project and maintenance of the main irrigation infrastructure. Nuñez, president of the Left Bank Water Users' Association, and the board had severe difficulties in having this increase accepted among the delegate assembly and ejido commissioners on the Left Bank'. Hence, in these financial matters, politics continues to play a role.

During its first full productive year, 1993-1994, the WUA's self-sufficiency - actual fee collection over actual expenditure - significantly improved, and exceeded 100 per cent 
(see Appendix 7, Table 5). However, thereafter the self-sufficiency decreased, leading to negative annual balances in 1996-1997 and 1997-1998. During the latter year, selfsufficiency recovered slightly from this negative trend, partly because of increased fee levels. The actual expense patterns of the association appear to be moving in the direction of the CNA guideline that WUAs should allocate sixty per cent of their budgets to maintenance, twenty-five per cent to operation and fifteen per cent to administration (Kloezen, 2002). The revenues paid to the CNA for managing the headworks, which are not part of this guideline, have decreased in relative terms over the years as a proportion of the overall budget. These financial data from official WUA and CNA reports should not, however, be taken as a transparent and absolute reflection of the financial status of the WUA. For example, the data reported on fee collection by the association do not always correspond with those of the CNA (see Appendix 7, Tables 1 and 2). In addition, several expenses and revenues are not reported in the books by the WUA management (see Chapters 7 and 8 ). Further, these essential self-sufficiency and fee recovery rates are not systematically reported in the WUA's annual reports. Both the data and the reports from which they stem hardly reflect the kind of financial crisis that took place during the main irrigation cycle of 1997-1998, with which this chapter deals.

Hence, in spite of the optimistic expectations of the financial autonomy advocates, fee default continues to be a serious problem for the WUA. Farmers are supposed to pay their fees before they receive their first irrigation turn, and this is expected to ensure high fee collection rates (Johnson, 1997a; Palacios Vélez, 1997; Vermillion, 1997). Nevertheless, this formal rule formulated by the CNA in the by-laws of the WUA is not and has never been a generalised custom. Reasons for this that are mentioned among farmers are a lack of money, the idea that water (as a public good) should be provided free like before, the bribes that need to be paid to the canaleros and a lack of trust in the financial management of the WUA. Hence, the WUA continues to be confronted with the practical difficulties of refusing irrigation turns to defaulting water users ${ }^{20}$. In addition, it does not have effective sanctions to discipline free riders that take their irrigation turns before paying their fees (see Chapter 5).

As the theory predicts, the WUA's direct interest in fee collection motivated the management to increase its effort in relation to fee collection, although not necessarily through the improvement of services (see Chapters 5, 6, and 7). Hence, the increased fee collection does not necessarily imply improved user satisfaction. In any case, the WUA management realised that remaining dependent on individual farmers to pay the increased irrigation fee would lead to a very erratic and insecure income flow, which would not be sufficient to finance the running costs of the association. However, they had other possibilities of increasing their revenues, thereby circumventing the (un)willingness of individual users to pay their fees and rendering user satisfaction inconsequential. Five types of financial shortcut mechanisms with government and market institutions and selected clients reduced their dependence on, and 'downward accountability' to, the larger mass of individual users. To start with, halfway through the 1990s, the association's management negotiated two important financial agreements with government and market institutions that secured more than half of their annual fee collection in the agricultural year 1997-1998. 
Firstly, following the example of other WUAs in other states, the management of the association reached financial agreements with the state level of the Federal Ministry of Agriculture (SAGAR) and the multinational tobacco companies to overcome this problem. A special office of SAGAR administered an extensive crop subsidy programme Programa de Apoyos Directos al Campo (PROCAMPO: Direct Agricultural Support Payments Programme), for basic food crops, such as beans, maize and sorghum, initiated by the Salinas administration (1989-1994). The WUA negotiated a deal whereby farmers registered as water users could only receive this annual subsidy on presentation of a receipt from the WUA that confirmed their fee had been paid. The disbursement of the subsidies took place at the WUA office in Villa Hidalgo. A long line of ejidatiarios had no option but to sign for the automatic deduction of the irrigation fee from their PROCAMPO subsidy. Otherwise, they could not receive the remainder of the money. Among them were many bean producers, who register as not irrigating (claiming to use residual moisture from the soil) but have to pay a minimal fee for maintenance and rehabilitation. Through this financial agreement with a public subsidy provider, the association effectively ensured fee payment from an important section of the water users, the PROCAMPO beneficiaries, amounting to slightly more than a quarter of all the collected fees in 1997-1998.

Secondly, another contract was signed with the four multinational tobacco companies that are active in the region. The association followed the example of WUAs in other regions, which negotiated similar agreements with regionally important agro-industrial enterprises $^{12}$. The tobacco companies agreed that they would advance the irrigation fees of their tobacco producers to the WUA and deduct these expenses before the final disbursement of these farmers' profits. For the WUA, this secures about a quarter of their annual fee collection. However, in order to effectuate this financial shortcut and bank the revenues, the association needs to connect its own administration with that of the tobacco companies. To prevent legal problems, the companies will only transfer the irrigation fee for individual tobacco producers, who are organised in groups, when they receive a group leader's signature to confirm that they are receiving water.

This linking occurs through a set of administrative procedures and operations that require detailed knowledge of the complicated field situation and the operational arrangements of people, land, water and technologies engaged in tobacco production and water distribution (see Chapter 5). The canalero plays an important part in this intensive task of intermediation between the two administrations and the field situation (see also van der Zaag, 1992). Hence, the canaleros, who work in the sections along the Santiago River where a lot of tobacco is grown, are crucial intermediaries for the management to access an important and relatively secure source of income. Collecting and handing in the signatures and administrative data takes them several months, during which time the association receives periodical payment as and when fees are collected. The management pressures the canaleros to complete this task; the latter in turn complain about the many demanding tasks they have to fulfil.

Although these financial shortcuts provide a large portion of the revenues and have significantly improved fee collection, they are, for unknown reasons, not reported in the annual reports of the association. The fact that the management does not publicly refer to these agreements renders fee collection largely non-transparent to the user delegates. 
The CNA district was instrumental in reaching the first agreement and is informed about the second agreement, but in ways other than through the WUA's financial reporting.

Thirdly, as reported in Chapter 7, the management has access to an additional and strategic source of revenue through the leasing of maintenance machinery. The way in which this revenue is allocated is not very transparent for outside observers or delegates, as it is not programmed, reported or administrated per job and no receipts are given out to the beneficiaries. For these reasons, this source of revenue is available to Nuñez' group to organise and finance other walks of life.

Fourthly, the board reached agreements (convenios) with a number of larger producers of sorghum, rice and pasture, allowing them not to pay their fees until harvest time. The claim was that they were not able to pay their fees at the beginning of the season due to temporarily unfavourable circumstances. This aforementioned select group of politically and commercially favoured producers (see also Chapter 6) supported, both financially and politically, the group in control of the association. At a later date, it was established that the latter group received from these producers financial contributions that remained outside the association's accounting. As these agreements were reported neither in the financial reports nor in the assembly, they remained non-transparent and difficult to control.

Fifthly, the association participated in the federal government programme for the rural sector Alianza para el Campo through which they received financial support for a number of essential rehabilitation works on the infrastructure executed during 1998. Because this programme works under the condition that fifty per cent of the expenses of the planned works have to be financed by the counterpart, the management financed this with a levy of thirty-five pesos per hectare on top of the irrigation fee.

Because revenue sources and expenses are not always accurately reported in the annual financial reports of the association, I henceforth refrain from using its data as absolute facts about its financial status and use them rather as indicators of quantities and trends. This also implies that I think that the financial situation of the association is not transparent to user delegates and the CNA.

\section{The actors and the setting: The Assembly of Delegates and the CNA}

According to the association's organisation chart, the general assembly of delegates is its supreme body of authority ${ }^{13}$. Every three years it elects the three members of the directive board and the two members of the control committee from among its own members. It also has the faculty of removing board members. The general assembly consists of representatives from the twenty-four ejidos that lie within its command area and one representative of the association of private landholders. Ideally, a regular assembly meeting should be organised every month, in which the board renders account of their daily management decisions. Extraordinary assemblies are only convened for special matters. At the start of 1998, the last 'assembly', as people call the meeting, had been organised several months previously. The monthly frequency is never met because of the low attendance of delegates according to the manager, Guttiérez. So the board only organises assemblies when very urgent matters come up, he tells me. Below, two 
consecutive assemblies organised in April of 1998 are discussed. The first is a regular one convened by the board, and the second is an extraordinary assembly organised at the request of the CNA district.

In the everyday management of the association, few delegates visit the office, as a consequence of which they are hardly involved or informed. An exception is Aldama, Nuñez' stand-in for the presidency, but he is employed as a maintenance worker (see Chapter 7). Of the directive board and control committee, the president Nuñez is around most, followed by Pérez, president of the control committee, and the treasurer, Norberto. In most cases the latter two do not stay for long because they are occupied with many other agricultural, organisational or political activities. The secretary, Silvio, only comes in occasionally. This indicated order in frequency of presence also reflects the extent to which each of them is involved in the association's management and informed about the decisions taken.

Most of the delegates that do turn up to assemblies are confidants of the political group that controls the association and originate from ejidos in the political constituency of this group: the Left Bank of the municipality of Santiago. They also voted the current board into office. Conspicuously absent are most delegates from the municipality of San Blas, who voted against the board and are critical of the management and its bias in service provision that excludes their ejidos from particular services and privileges. This can be understood from an historical perspective on the formation of the association and the difference between the municipal and political constituencies (see Chapters 4 and 8). Although most delegates are not very well informed through the assemblies, they are aware of, or suspect, how things are managed in the association. Some may not find it problematic. Several others have their doubts. They have varied motivations for not voicing such opinions in public or when an assembly is held. Several delegates maintain friendship relations with Nuñez and the board, sustained through small personal favours, occasional festive meals, and even compadrazgo (co-parenthood). This generates a sense of friendship, loyalty or complicity that forms a basis to connive with the board. Some owe their position to Pérez or Nuñez, or fear losing it through the influence that these politicians have on their ejido committee. Others fear the cacique (political boss) Pérez, el licenciado ${ }^{14}$, as he is called. Awe, respect and admiration are accorded to him because of his university education as a lawyer, his political profile and relations with the governor and other politicians, and rumoured violent nature. Most delegates do not have the same degree of education and network of political friends and feel insecure about opposing him and his close associates. The few delegates who have tried to comment upon the actual course of business have desisted, realising the fruitlessness of their action.

The Concession Title mentions the possibility of CNA officials attending the assemblies as external observers. The only CNA official who normally avails of this opportunity is the local CNA unit head, Blanco. He works under the CNA District Head in Tepic, but has his office on the Left Bank in El Tizate and supervises the association's activities as a kind of technical advisor. He mediates the administrative link and channels information between the CNA district and the association and needs to manage conflicting loyalties. At the association, Blanco assists in a number of administrative tasks that the CNA requires it to fulfil, but for which the manager lacks the interest and takes no time, such 
as for instance the programming and reporting of O\&M activities. In exchange for these services, Guttiérez now and then helps him out with fuel vouchers when he has exhausted his limited monthly fuel budget. This enables him to move from Santiago to Villa Hidalgo and around the entire Left Bank system. Sometimes Guttiérez invites him to a drinking party. They are building up a friendship relationship. However, under pressure from his superior, cracks have started to appear in this relationship. Blanco sometimes dislikes his superior, the District Head, after being authoritatively ordered around, but he is also dependent on him, particularly because of the threat of being transferred to another irrigation module in Nayarit, away from his residence in Santiago. These different loyalties are further complicated because both men are his compadres. ${ }^{15}$

The District Head, Becerra, maintains more distant and accommodating relations with the association. He is critical of several aspects of its management but does not make this publicly known and claims that he cannot intervene at this moment, as these are matters for the delegates. As we have seen, the district is financially dependent upon the WUAs and shares an interest in acquiring subsidies and programme support from the federal government. In addition, Nuñez and Guttiérez, who, whenever he visits the association, tend to invite him to a copious meal with all the seafood specialities, music and drink that makes the coast such a pleasant place, usually treat the District Head with respect.

However, the District Head's approach to the Left Bank Association has recently changed, motivating him to request an extraordinary assembly. At a meeting at the superior CNA level of the Alto Rio Llerma and Santiago Basin, where all District Heads in this region were gathered, CNA officials pointed out to him the poor financial performance and agricultural productivity in the Nayarit modules. Since then, he has clearly been concerned to improve the reports on the degree of self-sufficiency that are being sent to the CNA head quarters in Mexico City, because currently they suggest that the situation in the WUAs is slipping from his control. In addition, the financial crisis concerns him because he is more than ever financially dependent on the WUAs. The State Director of Nayarit, Dr. Ochoa, has worked in this function for about six years, but was never closely concerned with the association, leaving this completely to the District Head. He also must have received orders from higher bureaucratic levels motivating him to attend an assembly for the very first time. Both CNA officials have to be extremely careful about what they do. Because of their positions as deputy to state congress and CMC leader, their membership of the agricultural committee at the state level, and their relations with the governor and with the PRI (Partido Revolucionario Institucional: Institutional Revolutionary Party), Pérez and Nuñez can exert political pressure for their removal or transfer.

\section{The preceding episode: $A$ financial crisis}

In March 1998, about a month after the association's president Nuñez' electoral victory at the CMC in Santiago, the association's financial problems are mounting. In the preceding months, Nuñez' group had materialised its control over the association and its resources in at least two ways: firstly, through the political campaign that enabled Nuñez to occupy his new political office at the $\mathrm{CMC}$; and secondly by physically constructing a new office for the association. As demonstrated in the preceding two chapters, this campaign involved the intensive political use of resources such as the maintenance 
machinery, pick-ups and personnel. The building of the new office required the purchase of land and materials and the payment of contractors. Together, these two major projects have thus already completely drained the association's financial resource base early in the season. As a consequence, it is not capable of paying its debts to the CNA in relation to the consumed 'water in blocks'. In response, the CNA district exerts pressure on the association to fulfil its financial obligations, and the formerly relatively harmonious relations deteriorate. Subsequently, the association tries to solve its problems by requesting a loan from a local bank and increasing its pressure on the canaleros and the user delegates to improve the lagging fee collection.

Aware of the association's financial situation, I ask canalero Laguna (see Chapter 5) whether they have yet been paid their salaries. He lets me know that this is not the case, and half-jokingly asks me to lend him some money. Laguna continues that this situation is very de-motivating, because he has to work hard, the users are constantly asking him for water at short notice, whilst he is not being paid. 'And on top of that, they blame you', pointing to the manager's office. He explains that they reproach him for not collecting more fees, pushing users to pay their fees, whereas he is doing his best within the means at his disposal. When I ask him whether the situation will continue like this, he confirms that it will. He states that in former years the difficult period without salaries fell around June, July, August during the rainy season, after the main irrigation cycle when the tobacco, beans, cereals and vegetables had been harvested and before the new cycle would yield fee payment. But this year it is only March and they are already running out of money. Laguna whispers that this is the result of their political movements, the corruption and the money they put into their own pockets. They have spent all the money; it is bad administration, he concludes.

A week later I witness an encounter between Guttiérez and Blanco, that further reflects the CNA district's financial dependency on the association, the serious financial crisis of the latter, and the resulting deteriorating relations between these two institutions. As a result, small cracks appear in Blanco's co-operation and friendship with Guttiérez. Recently, their difference in income has become a matter of dispute. Guttiérez ridicules Blanco's financial and working conditions as a government worker. Being pressured by his superior, Blanco questions the extravagant life style of his compadre, the association's failure to pay its debts to the CNA, and implicitly its involvement with politics. When Blanco has finished the business he came to do, he notifies Guttiérez, who is working behind his desk, that he is going to his office in El Tizate and asks him if he does not have some fuel money for him. With a dramatic gesture, Guttiérez seizes his wallet from his pocket and looks in it. He reports that he is out of money, because he used it up yesterday on oysters, a popular seafood at the coast. Then he asks Blanco if he does not have any money left for fuel. Blanco confirms this and adds that he has not yet received his two-weekly salary. In response to Guttiérez he also grabs his wallet and says that he will show him how little he earns. He cannot find the paper but states that he earns 800 pesos per two weeks. 'Eight hundred pesos per week', Guttiérez corrects him, himself earning around two to three times as much. When he turns out to be wrong, he seems slightly surprised, but it does not change his attitude. He replies that his salary has not yet been paid either. He laughs, visibly enjoying his sense of control. Whilst he starts another conversation with somebody else, Blanco again asks (begs?) him : for twenty pesos, and adds 'hermano' (brother) to his request. At that moment canalero Diego 
enters and asks in Blanco's presence for petrol money. Guttiérez immediately calls the secretary and instructs her to give Diego thirty pesos. 'And for me...?', Blanco hazards. Guttiérez makes no effort to respond. Diego goes off, whilst a male and female ejidatario enter the office and claim Guttiérez' attention. Blanco remains standing in the corner for a while and then bestirs himself and walks out without saying goodbye to anybody. The scene expresses not only their personal difference in economic standing and a humiliating demonstration of difference in power and in control over resources, but also a growing institutional rift between the CNA and the association.

Later that day, two representatives from the bank, BANRURAL, ${ }^{16}$ visit the association's office. For several hours they compile an inventory of the association's assets and liabilities, which will serve as collateral for the loan it requested from the bank because of its financial situation. They are asking Guttiérez questions about the nature of the requested loan of 250,000 pesos. He explains that at that moment they have a debt to the CNA of 52,000 pesos, the cost of several months of water let into the system by the CNA at the diversion dam. As for the rest, he has to settle a debt of 80,000 pesos ${ }^{17}$ before he can pay the CNA. One of the bankers asks for an explanation of the irrigation fees and the amount of collective user debt of 180,000 pesos due to the association. Guttiérez explains that not all the fees will be paid, but that they have the advantage of the deals with PROCAMPO and the tobacco companies to secure the payment of that share of the fees. He indicates that he wants to explore the possibilities of a financial arrangement via BANRURAL, where the irrigation fees would automatically be deducted from the PROCAMPO subsidies and transferred to the association, without the intervention of the users, as already happens in some districts in the North.

The bankers inquire why Guttiérez intends to repay the loan over a ten-month period. $\mathrm{He}$ explains that during the coming months and in the intermediate irrigation cycle there will be relatively few hectares sown. Therefore they expect few revenues and these are needed for the running expenses and to pay earlier debts. The high revenue period runs from September to December, when the main irrigation cycle commences. The bankers leave with a complete file of the association's concessions, signed documents, bank statements, etc. They also ask for proof of other outstanding debts, but accept Guttiérez' word that those are not available.

Again a week later I am present when the CNA District Head of Maintenance from Tepic discusses with Guttiérez where to find a spare part for the broken down motor grader. After he leaves, I ask Guttiérez why this man was here. He responds that he came to collect the debt that the association has with the CNA district. Guttiérez agreed with him to pay 15,000 pesos this week and the rest next week. The CNA's increasing pressure for the repayment of the debt prevents the association from paying out any salaries, in spite of the approaching Easter holidays.

Guttiérez explains that it was the Head of Maintenance that came, because of internal reorganisations in the CNA. He continues that the government wants to remove all the posts that do not really deliver. For example, Salinas sold or abolished all parastatals, whilst he, Guttiérez, was working to his heart's content with the parastatal Fertimex. He relaxes by leaning backwards in his chair, folding his arms behind his neck, and looking at the ceiling. I had a pick-up, he recalls with a smile, and I only drove from here to 
there, and slept in the best hotels. But to this beautiful period came an end, he sighs regretfully.

That the manager's current existence is ever more stressful nowadays is clear from the following account of a delegate assembly. My concern is to highlight the manner in which the managerial group of the association presents and aims to resolve its financial crisis. I am interested in the way it is explained and where the responsibility for its occurrence is placed. Further, I will draw attention to the way in which the board is not accountable to the delegates in the authorisation of its essential financial decisions.

\subsection{Two Consecutive Delegate Assemblies}

\section{A regular assembly}

On 8 April 1998, I arrive at the association early in the moming, because the first assembly since my arrival is to be held and I would not want to miss a thing. Guttiérez' office is closed, whilst he is involved in an intensive confidential conversation with Nuñez about the coming assembly. So, I continue to the courtyard where the canaleros have arranged chairs for the assembly. They have already been waiting some time for Guttiérez who has summoned them to the office, so I talk with them for a while. They tell me that they have been redistributed over the module's thirteen sections, due to the dismissal of two of their colleagues. One of them was fired recently, because of accusations of anomalies in his work, which means that he received bribes from users to deliver water. The canalero did not deny to other canaleros that he had accepted bribes as more of them do, but he was also most outspoken in his criticism of the board, and this, they believed, triggered his dismissal. The other canalero was sent home only temporarily until the next irrigation cycle, just like the technician and some other staff, because of the seasonal low in revenues.

The set-up for the assembly is as follows: The board members are seated behind a long wooden counter, carried over from a store by the canaleros, who also put up rows of chairs for the delegates facing the counter. Just before ten o'clock, the appointed time for meeting, Guttiérez irritably comes rushing out of his office and sits behind the counter, whilst the five canaleros dash towards the first two rows of chairs. Guttiérez apologises for being late. From the back, the scene is reminiscent of a boys' school classroom. Diego, in the first row, neat parting in his hair, sits straight and nods now and then to confirm the words of his cousin, whilst some of the others demonstrate their reservations by their disinterested position on their chairs. Guttiérez commences by stating that they do not have the money to pay their next salaries. He appeals for the canaleros' assistance in ensuring payment of all unpaid amounts due in respect of irrigation. The secretary is printing out a list of debtors per section, with which they will have to work. There are many, according to Guttiérez; particularly the larger areas of thirty to forty hectares planted with rice will have to be paid for, he urges them. He reminds them that the association did its best to pay their last salary and in exchange he expects their cooperation. Especially now that there are only five canaleros, they need to increase their effort. He instructs them not to give any more water to debtors and to remove the intake pipe of a sprinkler pump if they are irrigating anyway (see Chapter 5). The canaleros 
mumble some affirmative remarks. Guttierez then distributes the lists with some specifications about them, after which he walks back to the office.

Most canaleros walk to their motorcycles and depart. I accompany Laguna, who confirms that a considerable number of water users have not paid their fees yet. However, he thinks it is not so easy to remove an intake pipe or cut the water when somebody is irrigating. Often users get very aggressive when a canalero tries to do that. That is why he warns those who do not pay that they should go to the office to do so. If they persist, then it is their responsibility. I ask him what happens if they continue nonetheless to use water. Laguna claims that he reports this to the office, so that the management has to resolve it. To really cut the water they should mobilise the authorities, for example the Hydraulic Police in Tepic. However, this has not occurred for a long time. It is his opinion that in the end the management itself is to blame for the fact that users do not pay their fees. Another canalero at a later point in time makes a similar comment. He thinks the management itself is guilty for allowing and trusting the users to irrigate at the beginning of the season, with the promise that they will pay later. The canaleros are not to blame when they subsequently do not pay. As a result, users laugh at them when they press them to.

The delegates very slowly come trickling in, although it is past ten o'clock. Blanco also arrives. Small groups stand in a shady part of the courtyard talking to each other. There is concern about whether sufficient delegates are present to hold the assembly. Nunez greets and speaks with some of them for a while. Then he takes his seat in the centre behind the counter. Guttiérez sits right next to him, with the secretary of the board to the far left. Only after Nuñez starts to talk does the treasurer, Norberto, take his place to his right. The delegates who keep arriving have also taken their seats. Blanco and I sit at the back, whilst the canaleros stand around and listen.

Nuñez observes that it has been a long time since the last assembly was organised, and explains this in terms of having been very busy. He mentions that Pérez is also aware of the meeting and that he will surely arrive soon, but he never does. Nuñez says that he is aware that the delegates have problems in their ejidos and that they have remarks to make. In this meeting their wishes will be met. He does not come back to this later. The secretary is given the opportunity to read out the list of twenty-four delegates to check the attendance. In total he counts thirteen delegates. Nuñez concludes that they have a legal quorum (half of the total +1 ) and that they can continue with the assembly. He reads the agenda for the meeting, to which he does not strictly adhere.

Guttiérez starts off by welcoming all delegates to the association's new building and reminds them of the fact that this will be the first assembly here. He is pleased that finally they now have their own building and do not have to pay rent any longer, like in the old place. Nuñez complements Guttiérez by addressing the delegates 'the whole construction cost a lot of money, but I think that you agree with the fact that we now have our own place'.

Meanwhile, Guttiérez distributes an overview of the association's expenses and a monthly irrigation progress report up to and including March. Subsequently, he gets the opportunity to comment upon the progress of irrigated and sowed surfaces in relation to 
the annual irrigation programme. He presents the programmed and actual irrigated areas for the total irrigation year (1997-1998): approximately respectively 19,000 hectares and 12,000 hectares (sixty-three per cent); and for the main irrigation cycle (autumnwinter): respectively 16,000 and 8,500 hectares (fifty-three per cent) ${ }^{18}$. Guttiérez reminds the delegates that they should not forget that they programmed so many hectares, much more than usually realised, in order to pay the same relatively low water price per volume to the CNA as last year $\left(1.17\right.$ pesos $\left./ \mathrm{m}^{3}\right)$.

Guttiérez explains that the fee collection lagged behind because of the unusual rains of the previous December and January, in connection with $E l$ Niño. The irrigation of beans, in particular, for which one or two irrigation turns usually suffices, is much less than other years ${ }^{19}$. Another thing is that the irrigated area under rice is decreasing every year, because of problems with weeds and decreasing prices (see Chapter 6). As a result, the much less than expected irrigation negatively affects the fee collection. Guttiérez expresses the hope that intermediate crops (sowed between the two cycles), the perennial crops and the crops of the spring-summer cycle (during the rainy season) will recover part of this backlog.

The treasurer is called upon to report on the financial situation. He takes the sheet with the monthly financial reports that Guttiérez has just distributed among the delegates and systematically enumerates all the items and the totals (see Appendix 7, Table 7). According to the programme, around 2,700,000 pesos need to be collected in the 19971998 cycle. To date $1,400,000$ pesos have been collected. This means a fee recovery rate of fifty-two per cent, but this is not mentioned on the paper. The missing fees have not been collected yet. He continues to summarise recent data on water consumption and required payment to the CNA.

- Total water consumption $\left(\mathrm{m}^{3}\right)$

131,000

- Required payment to the CNA (pesos) : $\quad 150,000$

- Actual payment (pesos)

- Debt to the CNA (pesos)

100,000

50,000

The treasurer limits himself to reading all the figures; this does not evoke any response from the delegates. Nuñez concludes for him that the association is behind with its payments to the CNA. He finds this worrisome, as they should not fall into the bad habit of red numbers. He calls on the help of the delegates to improve the fee collection, because he thinks that fee default is also their responsibility. A delegate confirms that it is indeed also their responsibility, but that they have not been able to do much so far. In former years, the list they received of fee defaulters in their ejido enabled them to do something. Nuñez is quick to respond that those lists are ready right now and that they will be distributed among the delegates after the meeting.

A delegate from the Villa Hidalgo ejido opines that canaleros have to be more vigilant in correctly registering the areas irrigated and indicating the producers who have not paid their fees. They should also ensure that these producers pay. Nuñez supports this attack on the canaleros and publicly addresses Guttiérez about this. The secretary stands up and expresses the view that those canaleros who do not do their job should be changed. 
The treasurer's presentation of the association's expenditures to date reveals that these have exceeded total revenues, but he prefers to emphasise that actual expenditure generally lags behind programmed expenditure. Nunez intervenes, saying that they have taken administrative measures to curtail expenditures. For example, the ejidos that request machinery for their works now have to pay for the cost of their operation including the salaries of the operator; and the staff of the association has been reduced. In reaction, the aforementioned delegate from Villa Hidalgo congratulates the board on the measures they have taken to reduce personnel and expenditure. Nuñez continues to explain that there were a number of unforeseen expenditures that were not incorporated in the original budget and for which they did not ask permission from the majority of delegates. He mentions the newly constructed building and the 50,000 pesos lent by the bank to purchase the ground.

Nuñez now informs the delegates that they have requested a loan of 250,000 pesos from BANRURAL and that the bank has already approved it. He argues that it is important for the assembly to approve this loan. 'The word is yours', he says, after which he continues to explain that, with the increased problems with weeds in rice and the low prices, it is likely that a smaller area will be irrigated and fewer fees collected. The loan is therefore very necessary to prevent financial problems and to continue the operation and maintenance activities. He concludes by observing 'I believe you agree with this loan'. In response, the secretary emphasises the need to continue with the development of the administration. One delegate warns the board about the risk of the association's current financial performance. He remains a sole voice, as his concern is not taken up by others.

Under the last item of the meeting, a canalero asks for support for the construction of a road near Villa Hidalgo. Nuñez does not grant him this, but refers him to the governor to request support and to the treasurer who has some recent experience with similar road construction. A little later the treasurer makes a sudden interjection, saying that the operators of the machinery should make better use of it. This would reduce repairs and expenses.

At the end of the meeting, Guttierez distributes printed lists of fee defaulters per ejido to the delegates and calls on them to discuss this list at the upcoming ejido assembly and help the association to improve its financial situation.

When the meeting is over, Nuñez waits a little while until the two to three slightly critical elements have left and then invites the remaining nine delegates and the board members, plus the CNA unit head, for a copious lunch in a nearby restaurant. Nuñez uses this pleasant occasion to re-confirm his relations with the better-disposed delegates. A pleasant conversation ensues that touches upon the price of sorghum and recent political developments in the state, leaving managerial issues to one side.

\section{Comments}

What is striking in this meeting is the way in which the managerial group explains the financial crisis. The major causes of the association's mounting expenditures are not discussed: the president's political campaign, the use of the machinery and the building of a new office. Instead, the manager and president understandably choose to focus on 
the disappointing fee collection and conveniently disregard their own role in this. Their explanation narrows the set of causes down to external problems, such as climatic phenomena and agro-ecological production difficulties, and to the insufficient efforts of the canaleros and the delegates to collect fees.

The management proposes to counter this financial crisis through a selective number of solutions:

- Permanent and temporary personnel reductions to cut costs

- Increased pressure on the canaleros to increase the fee-collection effort

- The mobilisation of the delegates to improve fee collection

- A loan to counter the most immediate lack of funds.

The fact that some delegates approve the dismissal of a rent-seeking canalero can be interpreted as sign of accountability of the staff to the delegates (Kloezen, 2002: 149151). However, when rent seeking is understood as a broader phenomenon not limited to lower level personnel and not necessarily merely economically motivated, it is also a good way for the management to cut costs, discharge critical elements, and control staff.

In his motivational talk to the canaleros, the manager basically attributes the financial crisis to their lack of effort to collect fees, and therefore the failure to pay their salary is presented as their own problem. The canaleros are expected not to object to such a presentation of affairs. On the optimistic assumption that satisfied users pay their fees, one may expect that this motivational talk will cause canaleros to increase their effort and to do their work better, which would then result in higher fee payment. To some extent the latter may occur, but such an interpretation does not acknowledge the problem that canaleros face in trying to exclude free riders, not least because of the informal agreements that the management has made with select groups of farmers.

Instead of the delegates making the managerial group accountable for their financial decisions, it is the other way around. The delegates are made accountable by the management for their lack of effort to collect fees in their ejidos. Just as with the canaleros, lists of fee defaulters are passed around to facilitate this activity.

The idea that the management is hardly accountable to the delegates is strengthened by the fact that no assemblies were held to consult the delegates in a period when the management took comprehensive financial decisions, such as the political campaign, the expensive, intensive and destructive use of the machinery, its use outside the module, the construction of a new office and the request for a loan. These decisions are not the subject of discussion; they are presented as unforeseen expenditures or 'approved' by the president in the name of the delegates. This distribution of power and a sense of complicity or loyalty are sealed with a convivial meal that rounds off the meeting.

The following episode of this financial drama recounts an extraordinary assembly in which the CNA tries to make the association accountable for its financial operations. Nevertheless, it fails to address the underlying political causes of the crisis and to motivate the delegates to speak up and take control over decisions in the association. 


\section{An extraordinary assembly}

\section{Preamble}

Three weeks later, an extraordinary assembly is organised, this time on the initiative of the CNA. It is rumoured that Ochoa, the State Director of the CNA, will come, but nobody is informed about which topic he wants to address on this exceptional visit. The CNA unit head is extremely nervous about this senior boss coming to his area. Guttiérez takes it in a more relaxed manner. Blanco asks him why Nuñez has not arrived yet and why the delegates were not asked to arrive earlier, so that at least they would be on time. He mentions that Ochoa is a very difficult person who will arrive on time and will want to start right away.

Suddenly, a convoy of several new and large CNA pick-ups comes to a standstill in front of the office of the association. Ochoa and Becerra arrive with an entourage of CNA officials in their slipstream. They enter the office and vigorously start shaking hands with the manager, the office staff and the delegates. Nuñez phones a little later and promises to be here in ten minutes. Guttiérez asks Ochoa for permission to wait for him, but, as after fifteen minutes Nuñez has not arrived, Guttiérez decides to start the meeting without him. He gestures to the delegates to sit down and takes a seat in front of the audience at the left end of the counter. He welcomes Ochoa, who is seated in the centre of the counter and calls on him to speak. On either side of Ochoa sit the secretary and the treasurer of the association. Becerra sits strikingly quietly in the right corner. In contrast to other occasions he hardly intervenes during the meeting. Instead, he prefers to listen submissively to the words of his superior, as if he has been severely reprimanded. I count around eleven delegates, and later two or three more, but this time the procedure of establishing a quorum is skipped, to move on to more urgent matters. The canaleros, who are standing at the back, after some time silently take responsibility for distributing soft drinks among the attendees.

\section{The State Director of the CNA speaks}

With a powerful voice and authority, Ochoa delivers an oration for almost half an hour. The one-sided flow of words is interrupted just once. He starts to tell the delegates that he wants to exchange thoughts with them about the association's administrative situation. The District Head, Becerra, had asked him to speak with the board about this. His reaction was that he would want to speak with everybody, including the delegates. It is his opinion that the association was not just the board, but also the delegates. This is important to him, he emphasises. The delegates represent the users from different ejidos and in their name they have to take decisions and express their opinions about how the association should function.

In Nayarit there is only one irrigation district consisting of four modules, Ochoa explains to the delegates. In Valle de Banderas, in spite of a water shortage, the WUA is performing well administratively. In other parts of the district there are also problems with water availability, but they find themselves in a better state than here. The Left Bank is by far the largest part of the district, but despite a surplus of water 'we are doing poorly'. The first point he wants to discuss is that the association is behind in its payment 
to the CNA for the used 'water in blocks', in the amount of 60,000 pesos ${ }^{20}$. He claims that Valle de Banderas always pays its debts on time. Ochoa rhetorically asks how it is possible that a module under these favourable conditions has such a low percentage of fee collection, namely just forty-five per cent. Ochoa draws a comparison with Sinaloa and Sonora, where he worked before, and where fee collections of around ninety-five per cent are reached.

According to the law, it is compulsory for the user to pay his fees. If this does not happen, the CNA has the power to cut off the water until the association pays. Ochoa argues that fee collection is everybody's responsibility: the board, the manager... Meaningfully he states that 'friendship is one thing, but commitments (compromisos) are another'. These should not be confused. He goes on to make it clear, however, that it is also the delegates' responsibility. They also have the right to be involved in decision making. They have elected Nuñez, but they can also correct him. If they think that the manager is not performing well, they have the capacity to remove him; or if they want the board to change certain things in the administration, they can give voice to this. But rights, Ochoa declares, also entail responsibilities. It is the duty of a delegate to ensure that the users in his ejido pay the fees. The responsibility should be very personal, as if the delegate would otherwise have to pay the fees himself.

The State Director continues with a penetrating voice and an expression of concern on his face to discuss another point of attention: the machines. He tells the delegates that according to his information several machines have not been used for a very long time and that as a result they are behind programme. He questions how it is possible that the machines are left unrepaired for such a long period. If it is due to lack of money, then they have not done enough on fee recovery. Ochoa acknowledges that the transferred machinery was old and in poor shape in large part, but this was because there was nothing else available. Therefore it is the responsibility of the board and the manager to manage the machinery well and appoint skilled staff. Friendship cannot be a reason for employing somebody, he suggests.

Ochoa warns the delegates that if the machines are not in use and not meeting their targets the CNA could decide to take them away and deploy them somewhere else. This should be prevented. In Mexico City they can also see from the reports that machines are left unused. He runs through a list of machines that have broken down or are left unused: the backhoe loader, the motor grader, a tractor, etc. Further, he mentions that he has received information that the dragline is presently working on the Right Bank, which is not the idea for the machines, when the Left Bank programme has not been finished yet. It is suggested that the delegates go to Valle de Banderas to see the maintenance situation there. Ochoa explains a few things about the module and how, despite difficult circumstances, they were able to improve ...

Then suddenly Nuñez comes bursting in. When he enters, he crudely interrupts Ochoa's oration and politely calls 'good afternoon' to the delegates. Several delegates return his greetings. Whilst Nuñez passes through the rows of chairs, the other board members anticipate his coming by changing seats, so that he can take a seat next to Ochoa at the centre of the counter. As a consequence, the District Head is forced further into the right corner, almost pressed up against the wall. 
When the dust from this long-expected arrival has settled, Ochoa regains the audience's attention. He summarises for Nuñez what he has been telling the delegates about his worries with regard to the administration of the association, about the low fee recovery and the diversion of the machinery. Another point that he wants to discuss is that the governor has indicated that he wants to make a tour (recorrido) of the four irrigation systems in Nayarit. His intention is not to speak to the delegates but to visit the countryside (el campo). Ochoa recalls a most embarrassing moment not too long before when the governor on a tour in San Pedro pointed an overgrown canal out to him and emphasised how unpleasant this was for him. He wants to prevent this from happening again. He informed the San Pedro WUA and they cleaned the canal and told him that now he could send the governor around.

Towards the end of his oration Ochoa makes a number of smaller observations - for example, that the association is several months behind in its maintenance, operation and administration reports to the CNA. He reminds the people that reporting is an obligation and that it is important to do this on time, because the CNA has to send them through to Mexico City. Further, he praises the opportunities presented in the government programme Alianza para el Campo, which is insufficiently used in his opinion.

To round off, Ochoa returns to his observations regarding the responsibilities of the delegates. He states that an assembly should be organised every month, so that the delegates are well informed to take decisions. It is his intention to visit these monthly meetings. At the end of his monologue he acknowledges that his observations have perhaps been hard, but that he wants them to be clear. It is possible that he is wrong and, if that is so, this should be said to him. Finally, he invites the delegates to express their views.

\section{Comments}

The CNA State Director comes to deliver a message to the board and the delegates. Although he claims to have the intention of exchanging thoughts with the delegates, his interventions are structured in the form of a monologue. His uni-directional flow of words is interrupted only once by Nuñez, who wants to show he is not impressed by Ochoa's demonstration of authority and joins him in the driving seat of the meeting.

Ochoa indicates several concerns. His principal message is a warning that the association needs to fulfil its financial obligations to the CNA, or otherwise the CNA has the power to sanction them for not complying. By contrasting the favourable conditions but poor results of the Left Bank with other modules that perform better according to him in terms of fee collection, he indicates that paying its debts to the CNA is really the most minimal requirement that the WUA needs to fulfil. A second point that Ochoa discusses is the poor condition and use of the machinery leading to a backlog in maintenance, which he also claims to be able to penalise by taking the machinery away from the association. A third problem is the delay in the association's reporting. Finally, Ochoa demands a monthly assembly meeting, which he intends to visit.

Although the message is clear, it is not entirely straightforward. In spite of the absence of deputy Pérez, who is engaged in his campaign for mayor and of whom the CNA officials 
have most to fear politically, Ochoa does not directly criticise the board or make it accountable for its decisions. Publicly opposing political candidates of the government party, the PRI, could lead to open confrontation, something that is politically very risky and thus unfeasible for the CNA officials. The board could appeal to political mechanisms in the state government beyond the control of the CNA. Although he appears to be aware of the underlying political causes of the financial problems, he only hints at them in his remarks about friendships and agreements. Rather, Ochoa cautiously attempts to mobilise the delegates by informing them about their rights and responsibilities and telling them to take seriously their personal duty to participate actively in the assemblies and to assist in fee collection.

Ochoa makes it clear to which institutions he feels accountable as CNA director: the federal CNA in Mexico City and the governor of Nayarit. His circumspect approach to the board of the WUA anticipates the contrasting expectations from these different political levels and government institutions. Yet, the immediate pressures that have motivated him to undertake this unusual mission are open to speculation.

\section{Nuñez and Guttiérez' response}

In a routine manner, Nuñez takes the initiative to respond. He apologises and provides an excuse for being late. His welcome to Ochoa is courteous, according to a common Mexican formula, letting him know that the new offices also belong to him ('también es tuya'). Nuñez also thanks him for his observations, which he qualifies as firm but useful.

In his response, Nuñez follows Ochoa's points of critique that he has written on a paper nameplate. In relation to fee collection he acknowledges that it has lagged behind. However, he reports that, because of the unexpected recent rains (unlike most other years), fewer producers have decided to irrigate their beans and therefore more of them pay only a minimal fee. Others registered at the time of PROCAMPO reimbursement for a minimal fee, yet later they did plant a crop and started to irrigate without paying the rest. The fact that many fees have not been paid is the fault of the canaleros, Nuñez opines. They should take care that the fees are paid or otherwise users should not get water. It has reached the point that five consecutive salary periods could not be paid, but that is the canaleros' fault.

About the machinery, Nuñez states that several came to a standstill because it was difficult to get spare parts. One machine that they received after the transfer is probably the only one of its kind in Mexico, and therefore it is very difficult to acquire parts for it. The motor grader broke down after being lent out as part of a CNA-organised exchange programme for machinery among the irrigation modules in Nayarit. They contacted companies as far away as Canada to obtain a certain part, which delayed the repair. About the dragline that is working on the Right Bank, he tells the delegates that it had broken down some time previously and there was no money to repair it. They needed the machine on the Right Bank, so the deal was the association would lend it out in exchange for the Right Bank water association repairing it. Nuñez continues that given the lack of repair funds they requested a loan of 250,000 pesos at BANRURAL. This loan was approved at the last assembly meeting. 
Immediately after Nuñez has finished, Guttiérez follows. The beginning of his argument is basically an extensive repetition of what his superior has said. Then he adds three new things. Firstly, he mentions that the association has reached agreements with several sorghum and rice producers, who could not pay their fee at this moment. They promise to pay their fees at harvest time. Secondly, the assembly was informed at its last meeting about the fee collection lagging behind. He uses Blanco's presence to increase the power of his words. Every delegate was given a list of fee defaulters, but unfortunately this has not led to their payment yet. Thirdly, the dragline is working on the Right Bank because the tobacco companies made an urgent request for help as more than 100 hectares of tobacco was drying out. He defends the decision to send the machine, although he admits that in principle they are not obliged to send machinery.

When Guttiérez is finished, Ochoa again invites the delegates to make comments, but Guttiérez resumes and states that it is a good thing that delegates make comments. He continues to talk for several minutes, for example about his expectation that in the coming (rainy season) cycle there will not be so much rice planted as preceding years, because of a problem with weeds (see Chapter 6). Then the treasurer invites the delegates to tell the meeting without hesitation what people are saying in the streets.

\section{Comments}

Much as in the last assembly, the president and the manager of the association devolve direct responsibility for the financial crisis upon the canaleros, and shift attention towards the role of the delegates and external causes for the lack of fee recovery. The last assembly is now presented as an occasion where the delegates were informed about these problems and then approved a number of decisions, such as the loan and solutions to counter low fee collection, which suggests a shared responsibility and accountability between the board and the delegates. Consciously or not, both the president and the manager follow a discursive strategy to talk as much as possible and display confidence in their decisions to the delegates. This has the result of their recovering the initiative in the meeting and leaves little space for the delegates who would like to take up the State Director's invitation to speak. Although Nuñez and Guttiérez largely succeed in deflecting the state representative's invitation to the delegates to participate, some of the audience finally do speak.

The delegates

In the front row, a canalero has been asking for permission to speak for some time now. He grasps the first opportunity and asks why the dragline is working on the Right Bank. Nunez explains that the deal was in exchange for its repair, an explanation that satisfies the delegate.

Another delegate expresses his opinion that, for every machine, there should be one skilled operator who knows how to maintain it. Nuñez responds that they could not find them in Villa Hidalgo, the neighbouring village of El Corte, or in any other village in the surrounding area. The delegate then confirms Guttiérez' assertion that the delegates were informed at the preceding assembly about the fee collection problems and that they received a list of fee defaulters. 
A third delegate remarks that the management should not tolerate sorghum: and rice producers not paying their fees. He is critical of the fee defaulting rice producers who already pay a relatively low fee, considering the quantities of water that they expect. Guttiérez immediately objects that the list of fee defaulters consists of tobacco producers, bean producers, rice producers, etc. Nuñez adds that many of them irrigate with pumps from the river and only pay a minimal fee.

The secretary of the board intervenes and says that last year there was a lot of resistance to the fee increase and that it was therefore a very difficult decision. His words are confirmed by nods from delegates who remember this. At the time he supported this decision and now they can see how necessary it was. In response, another delegate reminds the meeting that during the fee negotiations they were promised that, if the fee increase were realised, the association's financial problems would be over. But now it appeared that this was not the case. After a while Nuñez responds to this critique with an air of contrition: 'Indeed there have been decisions that we should not have taken', but then emphasises that they were always in favour of the association. In response, two delegates make remarks about the building of the office.

When the discussion returns again to the machines, Norberto suddenly stands up and states loud and clear that he does not agree with the machines working somewhere else, when their programme has not yet been completed. Further, he reminds everybody of the fact that at the last meeting he had pleaded for better treatment of the machinery. Nuñez is clearly annoyed and reacts, saying that Norberto is also a member of the board as treasurer and therefore should also take responsibility. He mentions that it is remarked that the machines can only be found in Sauta with Norberto. He is therefore also responsible for the decisions, Nuñez argues, whilst Norberto looks straight ahead and does not respond to these accusations. Nuñez continues that it is asked how it is possible that machines can only be found with Pérez and in Sauta. He asks the meeting 'Is Pérez still in the association then?' - a question that is left hanging in the air.

\section{The Director's final words}

Towards the end of the meeting Ochoa indicates that he wants to make a few concluding observations. He repeats most of his earlier observations. For example, he opines that the machines need to be used in a better way. The need to repair them as quickly as possible should be a constant concern for the manager. At this point, Ochoa offers the help of the CNA. He also expresses the view that the machines should only be lent out when the programme is completed. The CNA has been flexible in permitting the exchange of machines between modules, but this should not be to the detriment of programmed activities. Where they use the machinery is thereafter entirely their decision, in which he and even the governor cannot intervene.

Ochoa emphasises again how important it is for the association to pay its fee to the CNA and that for this they have to ensure that users pay their fees. If necessary, the CNA has the power to close down the intake and not let water run into the system. He states that it is a good thing that they have acquired a loan, but the question is who is going to pay the interest? Nuñez nods in response. To conclude, Ochoa asks if there are any other 
observations, and this engenders another series of remarks by Nuñez, Guttiérez and some delegates.

The secretary rises and states that he is willing to organise a monthly assembly if that is what Ochoa wants, and he asks Ochoa about his intentions to visit these. Ochoa again confirms his interest in being informed and attending them. But he also asks the delegates to invite their colleagues, as not all the delegates participate in the association.

Ochoa thanks the delegates, stands up and walks away from the long counter. Everybody then stands up. Ochoa starts shaking the delegates' hands and, after, those of the canaleros who have been listening at the back. Then he walks through the office, greeting some people, and walking on to his pick-up. Soon afterwards the CNA convoy of cars leaves for Tepic.

\section{After the meeting}

When the CNA officials have left the building, Nuñez still has a few announcements to make regarding the outcome of negotiations in Tepic that he attended this morning as $\mathrm{CMC}$ president. One is about the minimum price of sorghum. Another is about the CMC's attempt to collectively sell beans for smallholder ejidatarios from the municipality at better prices in Mexico City. This was one of Nuñez' electoral promises, in which he has been unsuccessful so far. He acknowledges that they have experienced many setbacks, but claims that they are not yet defeated. After this, the delegates leave or form small groups to discuss the meeting.

At the back of the courtyard, the CNA Unit Head, Blanco, is discussing things with Guttiérez and the favoured delegate Aldama, who is also a maintenance worker for the association. Blanco has been remarkably quiet during the meeting, because he does not want to emphasise his own role in initiating it. Guttiérez opines that the meeting was hard, but also good. The delegate looks meaningfully at Blanco and wonders aloud how it is possible that Ochoa was aware of these things. Blanco makes a joke to which Guttiérez has to laugh and this distracts attention. Guttiérez notes that their misfortune is that all the machines broke down one after the other. Somebody says something critical about the absence of several delegates, to which Blanco responds that it was fortunate that the delegates from San Blas were absent, suggesting that they would have been much more critical in the presence of Ochoa. When Guttiérez has walked away, Blanco summarises the meeting with 'it was a scolding'. The delegate again subtly questions his role in this, which Blanco denies by stating 'No, not me, I work here'. Then his eye falls on me. 'Look out for him, he works for the $D E A^{\prime 21}$, he jokes, again shifting the attention away from himself.

I walk towards canalero Laguna and tell him that, according to the board, it is all their fault. 'You see', he says indignantly, 'they blame us'. It is striking that during the meeting the canaleros keep in the background and are apparently expected not to speak, in spite of their being critiqued. Laguna swallows his critical note, so that a delegate who is close to Nuñez and joins our company cannot hear it. This delegate also speaks of a scolding. He is of the opinion that they should not have built the new office, although now at least they save the monthly rent that was paid for the old one. 
Together with Blanco I depart, after we have helped to put away the chairs. In his pickup he relaxes and he repeats that it was a scolding, for everybody. But it is good that they are finally concentrating their attention on the poor administration. Something has to change, he states. Blanco admits that a fee recovery rate of forty-five per cent is very $10 w^{2}$. The problem is that they reach agreements with friends and acquaintances. Blanco thinks that the canaleros are right when they say that it is not their fault. The only thing that would really help is cutting the water supply from the dam. 'Let's talk clearly, why beat about the bush?' Blanco asks. There is a lot of money here, but they use the association for their positions. You shall see that when Pérez is on campaign, they will use the machinery politically. 'That is the problem, everything is politics', he opines. 'What do you think Nuñez' campaign cost?'. 'But we are also guilty', Blanco declares. The CNA allows the association to programme far too many hectares in order to lower the amount paid to the CNA.

I ask him about his CNA superiors. He informs me that they are around long enough to know what is happening. 'They know everything, they just cannot say a thing. Ochoa and Becerra do not really intervene, because they do not want problems with deputy Pérez. That is why they enlisted the help of the delegates, he explains, they want them to exert more control over the board. The delegates were not informed about everything; for example, the fact that a machine was working on the Right Bank was new to them. After the meeting Ochoa had told Blanco to be more vigilant (estar pendiente). This is easy for Ochoa to say, he declares. Ochoa is in a position to say something like 'remove that machinery from there'. 'But if I say something like that they won't let me in anymore'. Yet, he has high hopes that things will change after this. At the next assembly they will want to project a different image in order to demonstrate that the association is working.

With regard to the Valle de Banderas module, I ask Blanco whether it really functions much better than their association. He tells me that they also faced many problems and that three consecutive presidents were removed from their positions. However, just like on the Right Bank of the Santiago River, that module depends on pumps to get water into the system. The users need to pay their fee to cover the high electricity expenses; otherwise there is simply no water. On the Left Bank, water is always available.

\section{Epilogue}

In theory, the association's management is accountable to the assembly, but in practice important decisions, such as the loan request, informal agreements on fee collection, and the use of machinery, are taken without consultation with the delegates or approved post-hoc. Admittedly, the important decision to increase fees was indeed discussed and approved by the assembly, partly because it immediately affected the delegates, as they had to defend it to the users. The CNA State Director's attempt to activate delegates to take charge of the former type of decisions does not suddenly change the general pattern and make the board accountable. His plan fails for the moment. Although some delegates bring forward a few points on which the board needs to render account, they do not really take them to task on these issues. The atmosphere prohibits it. In this respect, the fact that the most critical delegates from the municipality of San Blas are absent is favourable for the board. The most serious, yet covert, critiques of the financial management are rendered ineffectual by the president, who remorsefully accepts 
collective responsibility for some unspecified decisions and subsequently averts personal consequences by stating that they were made with the best of intentions.

Retrospectively, several interventions on the part of board members have to be seen in the light of political ambitions to be re-elected to the board, preferably as president, in the coming year. Firstly, the unexpected declaration of the treasurer that he opposes the machine use unpleasantly surprises his president, who gets back at him with a razorsharp and specific counter accusation by implicating him in the use of machinery for purposes other than maintenance. This effectively results in the treasurer's silence. Nuñez' response clearly illustrates that public comments about the management are not appreciated. Secondly, the secretary more cautiously departs from Nuñez' line and makes a gesture in the direction of the CNA by demonstrating his willingness to organise monthly meetings. Thirdly, with the newly constructed office and his display of it as a home to the delegates and the CNA, Nuñez demonstrates his achievements as president and qualifies for re-election to the board ${ }^{23}$.

In a longer time perspective, the pressure exerted by the CNA appears to produce results, but this can be deceptive. Firstly, financially, the fee recovery rate increases from fifty-two to sixty-six per cent in the remaining months of the productive year, and the association achieves an eighty-four per cent self-sufficiency rate. The WUA's annual financial report mentions a budget deficit, but does not fully reflect the financial crisis. Secondly, the frequency of meetings indeed increases in the year after this extraordinary assembly. However, the patterns of interaction hardly change. It is interesting to note that the State Director does not fulfil his promise to attend the assemblies. A few months later he is removed from his position. It remains open to speculation whether there is a link with his intervention in this meeting. However, his transfer is particularly understandable in the wider perspective of approaching state elections. Similar to national elections (see Chapter 2), this generates a political and bureaucratic struggle in the broad field of public, private and community institutions of Nayarit. The governor then anticipates his succession through a transfer of high bureaucratic officials ${ }^{24}$. Thirdly, weeks and months after the meeting, the association's machines continue to work outside the module, and its resources continue to be mobilised in support of the group's political aspirations. The board is not made responsible for such decisions. Relations with the CNA district further deteriorate. The effect of the CNA pressure was thus largely financial, involved political risk, but did not succeed in addressing the political root causes of the managerial problems in the association.

\subsection{Analysis}

This case of a water users' association shows that the financial autonomy of user organisations and the introduction of quasi-market incentives resulting from the transfer of irrigation management do not necessarily lead to their self-sufficiency and financial accountability. In addition, the WUA does not fulfil the theoretical expectations concerning the improvement of quantity and quality of services, let alone its longer-term financial, organisational or infrastructural viability. Hence, the organisational model that is used in theory and policy does not correspond with the actual organisational practice in a number of ways. 
As the theory predicts, there has indeed been a managerial effort to decrease unnecessary expenditure and increase revenue in order to achieve self-sufficiency. Nevertheless, in response to the financial crisis the effort at cost-effective management is selective and part of a wider set of political and institutional considerations. On the one hand, the management reduced expenditure by firing and giving flexible contracts to canaleros, and it increased the pressure on both canaleros and delegates to improve fee collection. Meanwhile, the management itself did not fulfil its minimal obligations to pay the canaleros' salaries and consult and inform the delegates. On the other hand, the enormous investment of time, money and resources in Nuñez' political campaign, and the informal agreements with favoured clients, increased costs and lowered fee recovery. This is not addressed as a problem. These are just some of the problems that hamper the association in achieving self-sufficiency.

One can also recognise a managerial effort to improve and make particular services more appropriate. However, this effort is also selective, for example towards particular client groups belonging to their political constituencies, some of which lie outside the irrigation system, and others who are not water users at all, such as the tobacco companies that negotiate an agreement and contract a machine. Other user groups are excluded because they lack the political or financial clout to demand services. For example, maintenance machines are hardly employed in the San Blas area (see Chapter 7). Rather than a uniform improvement of services, a concentration of services occurs, targeted at those who are either politically influential or financially capable enough to support the political group in control of the association (see Chapter 8).

Further, in spite of the transparency norms that underlie the organisational charters and audit procedures, the WUA management establishes several largely non-transparent administrative shortcut mechanisms. These financial agreements with a broad array of federal subsidy providers, agro-industrial companies, a bank, and privileged groups of politically influential and financially capable producers, contribute to financial autonomy, but also to a lack of financial accountability to water users and the CNA. They imply that the management is only to a limited extent directly dependent on fee-paying users and their satisfaction with the services delivered. Several of these shortcut mechanisms give greater autonomy to the management and help them to escape financial accountability mechanisms. In addition, the interlocking of the WUA in a network of new dependencies by reason of these agreements puts the meaning of 'financial autonomy' and its causal connection with improved performance into perspective.

The way in which this WUA operates in practice does not correspond with the organisational model that stems from policy, underlies its own organisational charter and postulates that user organisations are accountable to their user constituency (see also Chapter 3). What is more, in this case it is even the other way around. The board disclaims direct responsibility for the financial crisis and instead tries to make the canaleros and delegates accountable for their limited effort in fee collection. In important financial and O\&M decisions, the management is to a limited extent accountable to the assembly of delegates that represents the larger community of users. The assembly does not function as an autonomous body with transparent audit and performance data, regular meetings and the necessary political and institutional counterweight to challenge decisions or remove unresponsive staff or directives. At times, the management does its 
best to manifest the ideals of accountability and transparency to make its actual lack in practice appear less problematic (see also Chapter 7).

Most active delegates are tied in some way to the board. An historical account of the formation of the association (see Chapters 4 and 8 ) clarifies the different relations of the board with the more active and well-disposed delegates and with those who do not attend meetings, because they belong to a different political constituency and municipality. Even when delegates intend to, it is difficult for them to exert pressure on the board and to hold the management directly accountable for the performance of its duties.

The meetings recounted above further reveal that the political use of resources was ongoing for several years without interference from the CNA, which only came into action when the district's own source of revenue was under threat. The CNA's pressure appears effective in settling its outstanding debts, yet it does not directly address the political root causes of the association's financial crisis. Instead, they attempt to mobilise the delegates in these matters, but without success. The three CNA officials from module, district, and state level all seem to fear the accusation of intervening in the association. This is risky, as it can be understood as a political act, which might generate counter pressure from the politicians involved favouring their transfer. For the moment, the CNA appears politically impotent to intervene effectively, partly because of larger political and electoral considerations. This practice contrasts with the image of a neutral oversight agency that can correct a service provider when it transgresses pre-determined rules.

In summary, the formal financial and elective accountability relations that theory and policy assume are weak in practice. Actual accountability relations are not isolated oneto-one relations that determine the functional behaviour of a limited set of key actors within an irrigation context. For example, the independent financial power of fee-paying water users is subverted by several shortcut mechanisms. Further, the assembly of delegates is unable to act as its highest and autonomous decision-making body. In addition, the CNA can only exert limited regulatory control over the WUA and is incapable of directly addressing the political and rent-seeking problems at hand. Contemporary accountancy technologies do not suffice to achieve transparent auditing and govern the WUA's managerial conduct from a distance.

\subsection{Conclusion}

This chapter has shown that financial self-sufficiency and accountability are not an inevitable outcome of the retreat of state agencies and the financial autonomy given to lower level managerial bodies, such as WUAs. Oorthuizen (2003) comes to a very similar conclusion when he examines the relations between financial autonomy, accountability and management performance in the case of the National Irrigation Administration (NIA) in the Philippines. He finds that the NIA decreased the amount of managerial effort put into O\&M services. Further, it drastically cut expenditures, leading to a deterioration of services, particularly in politically disadvantaged tail-end areas, and increased fee collection efforts. The NIA concentrated its services and collection efforts in 
the politically more interesting upstream areas. In addition, Oorthuizen also finds no proof that financial autonomy induces downward accountability and argues that accountability needs to be understood from an historical perspective and a perspective that goes beyond the boundaries of an irrigation system.

These findings are difficult to explain for those who analyse resource management organisations as autonomous service provision entities. The reason is that they analyse them as separate units with clear boundaries and internal rules and incentives that dictate rational managerial responses to the idealised forces of state (final arbiter), market (dispersed competition), and society (democracy). My findings suggest that, to understand how the emerging opportunities of a new organisational model are appropriated, we cannot separate resource management from the wider and more enduring political and cultural relations of power, and the social and material relations in resource distribution.

Michael Moore (1989) identified a myth circulating about Taiwanese Irrigation Associations that explained their good performance as resulting from financial and electoral accountability. This popular myth can also be recognised in the way the Mexican WUAs are generally represented in resource management theories and policies. It postulates that WUAs' self-sufficiency and managerial performance are stimulated by their accountability to users operating through the two mechanisms of social control enshrined in the liberal doctrine: the ideal market model of 'dispersed competition' and the ideal of electoral democracy. The facts presented in this case run contrary to the myth. Like Moore, I find that the actual mechanisms for controlling management are more political than dispersed and democratic, and that they depend on the existence and balancing of concentrations of institutional power.

To understand the combinations of forces actually working in and on WUAs, and the impact that they have on their financial and managerial performance, conventional public-private and state-society dichotomies no longer suffice. Some differences in irrigation management under state agencies and WUAs are obvious, such as hierarchical structures and bureaucratic rules. However, this case points to less obvious similarities or continuities, for example rent seeking on different levels, a lack of accountability to water users, and free riding behaviour of irrigating farmers. Repetto (1986) and many experts and policy makers after him considered these as characteristic of public irrigation management, but in this case it appears that they are more widely dispersed. Therefore, the idealised organisational forms that correspond with conventional dichotomies between state, society and market can no longer explain the persistence of such phenomena and their effects. This requires an interpretative framework that anallyses the cultural and political nature of organisational power relations (accountability) and resource distribution practices (e.g. rent seeking), situated on a wider playing field.

In the WUA that I have studied, a political group effectively controls the resource arrangements and resource flows of the WUA, obtains and distributes significant rents and material benefits for its political purposes, resulting in a situation of 'unresponsive, unreliable and unequal service provision' (Repetto, 1986). This situation is sustained financially through a set of negotiated agreements that interlock the WUA in a:network of financial, institutional and political dependencies that transcend conventional 
boundaries between state, market and society. The group also sustains itself, whilst being largely unresponsive to its user constituency and the CNA, by maintaining or developing alliances with political actors, government institutions and state levels, such as the governorship, the party, the municipality, the peasant union and the bureaucracy. Bureaucratically, the WUA still comes under the government agency CNA, which delivers water, extracts fees, defines the organisational form and requirements, monitors and intervenes in its operation. Multiple political, institutional and economic actors and forces, social and material arrangements, thus constitute the wider playing field of the WUA in which power, finance and resources are unequally distributed and flow unevenly.

Another continuity identified is that WUAs, like former government agencies, do not possess effective sanctions to discipline farmers who take their irrigation turns before paying their fees (see Chapter 5). The WUA aims to become self-sufficient by seasonally charging land and crop-based fees to individual farmers before they receive their first irrigation turn. This system of cost recovery presupposes co-ordination mechanisms that are not automatically in place: local patterns of social control and accountability, technical and managerial control over water supply and demand, and timely fee collection (Moore, 1989). In addition, as water is a public good that flows almost continuously in the irrigation channels during the productive season, it remains practically impossible for WUAs to exclude fee defaulters or free riders.

Finally, bureaucratic appointments and transfers of personnel remain important means of political control, even when the federal state is retreating. Wade (1982) indicates that, in public irrigation management, staff transfer determination is the politician's basic weapon of control over the bureaucracy, and thus the lever of surplus extraction from the clients of the bureaucracy. In this case of WUA management, for involved politicians transfer is not so much a lever as a means of protecting their control over the organisation and particular politically motivated forms of resource extraction and allocation.

\section{Notes}

1 Part of this section is based on what Moore identifies as a myth about Taiwanese Irrigation Associations that can also be recognised in how the Mexican WUAs are generally represented (Moore, 1989).

${ }_{2}$ 'Esquema de las principales funciones de superoision en distritos de riego transferidos' (Outline of the principal functions of supervision in the transferred irrigation districts), CNA, Subdireccion General de Operacion, Gerencia de Distritos y Unidades de Riego, Subgerencia de Transferencia, 1998.

3 Land reform communities created after the Mexican Revolution of 1910 . Before the revision of Article 27 of the Constitution in 1992, ejido land belonged to the state, with a combination of community (ejido) and private (ejidatorio) usufruct. Ejido members are called ejidatarios.

4 Interview with former District Head of Secretaria de Agricultura Y Recursos Hidraulicos, Ministry of Agriculture and Water Resources (SARH) (28 July 1999).

${ }_{5}$ Instead of being the outcome of neutral market forces of supply and demand, the pricing of water is the result of largely non-transparent calculative procedures carried out by the CNA district. These are based on data submitted by the WUAs and the CNA district about programmed irrigated surfaces and financial budgets. The district presents the outcomes of the Hydraulic Committee to the four WUA presidents for approval. The presidents of the four modules, which are located apart from each other, hardly appear to negotiate collectively in this respect, except under the co-ordination of the District 
Head. The CNA determines the percentage of the CNA district budget that a module has to finance (see also Kloezen (2002). To determine the volumetric water price for a module, its programmed expenses plus the CNA-determined share of the district budget are divided over the module's programmed water volume (based on the programmed number of hectares and estimated water use per crop per hectare). This administrative procedure encounters the longstanding bureaucratic practice of programming a much larger irrigated surface for the Left Bark than that actually irrigated. Around 19,000 hectares are programmed, close to its designed command area, rather than the 10,500 hectares irrigated on average since 1982. This has been possible because of the ample availability of water provided by the diversion dam on the River Santiago, a favourable condition that two other modules do not enjoy. A larger programmed irrigated area in combination with relatively low costs for the allocation of water means a lower volumetric water price. Because the Left Bank irrigates by far the most hectares of all modules, it still pays the largest part of the CNA budget (see Appendix 6, Table 2, column 7). Nevertheless, by accepting this planning practice the CNA implicitly favours the Left Bank module. This is where political relations come into play.

- Mexican law prohibits the refusal of water to a crop after a first irrigation turn has been applied.

7 As opposed to the definitions that I have chosen, the District Chief referred in this case to 100 per cent self-sufficiency (autosuficiencia).

8 Much depends on the exact definition of self-sufficiency. Here I keep to Kloezen's definition: actual fee collection covers actual expenditure. This definition thus excludes revenues other than fee collection. Kloezen defines the fee collection rate as the actual over programmed fee collection (Kloezen, 2002:154).

In addition, the fees for different crops were not based on their estimated water consumption, which was particularly inexpensive to producers with rice and pasture ( 250 pesos), crops that consume infinitely more water than tobacco and beans ( 170 and 100 pesos). This favoured a select group of large politically and commercially favoured producers (see Chapter 6).

io Cutting the water to an individual farmer is practically impossible, as farmers can take water without permission and in the absence of the canalero. This is particularly easy with the much-used mobile pumps for sprinkler installations (see Chapter 5). Cutting the water to an entire sub-lateral canal will usually harm many other users and create much political unrest.

${ }_{11}$ Calculations based on data from the 'Segundo Informe de Actividades, Asociacion de Usuarios de la Unidad de Riego de la Margen Izquierda del Rto Santiago, A.C., Modulo 2, 1997-1998'.

12 For example, in Irrigation District 094 El Grullo (see van der Zaag, 1992), the WUA has a formal agreement with the local sugarcane refinery, thus ensuring the largest part of their fee recovery.

13 According to the concession title that was designed by the CNA and determines the conditions under which the irrigation module is transferred to the WUA.

${ }_{14}$ Title of bachelor, used to address (among others) a lawyer, and expressing respect.

15 Ritual co-parent.

16 A former government bank for the rural sector, which was not left unaffected by state disengagement policies under presidents Salinas and Zedillo.

17 Amounts of approximately US $\$ 31,250$ (loan), US $\$ 6,500$ US (CNA) and US $\$ 10,000$.

18 I present approximates, because in some cases I do not have the exact number, and a higher degree of exactness is not required for the reader to capture the general trends.

${ }_{19}$ Beans are traditionally hardly irrigated in this region that was formerly seasonally inundated. See Chapter 4.

20 Approximately US $\$ 15,000$.

21 Drug Enforcement Agency. At the beginning of my stay, this was a serious possibility that people considered when they wondered about my presence in the region. This is understandable in a region of intensive drug transportation, into which DEA agents have been known to penetrate. By this time, however, it had become a popular joke about me.

${ }_{22}$ This rate is not included in the data presented to the delegates, and it is not clear how exactly the CNA calculated it.

${ }^{23}$ The association's charters forbid him being re-elected as president.

${ }^{24}$ Ochoa has been succeeded by a senior civil engineer from the Ministry of Electricity who is from Nayarit, unlike Ochoa, and was responsible for the completion of the Aquamilpa Dam. This major project in the Sierra of Nayarit on the River Santiago includes a hydro-electrical plant that will provide electricity to Nayarit and several other states. As such he developed good relations with the governor. 


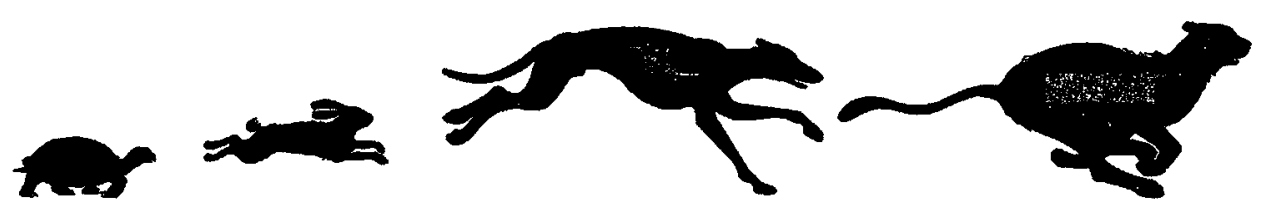




\title{
10 \\ The Success of a Policy Model: Irrigation management transfer in Mexico
}

\begin{abstract}
'I'm hopeful. I know there is a lot of ambition in Washington, obviously. But I hope the ambitious realize that they are more likely to succeed with success as opposed to failure.'
\end{abstract}

George W. Bush

Interview with Associated Press, January 18, 2001.

\section{1 Introduction}

Feel free to read this quote again! President Bush made this cryptic statement shortly after becoming the world's most senior policy maker. I remember feeling puzzled and at the same time intrigued, after reading it for the first time. The apparent self-reification in the president's 'secret to success' initially struck me as quite amusing, because it leads to a self-fulfilling prophecy. But when you further penetrate his words, they unveil a latent message to the ambitious policy makers of Washington: in order to succeed you require 'success'. I will argue that this is a cultural orientation that has become increasingly influential in international policy circles. Bush's motto serves as an excellent entrance to discuss the cultural construction and promotion of policy models in international policy networks. In this chapter, the Mexican policy model of Irrigation Management Transfer (IMT) will serve as an exemplary case to analyse this process.

As discussed in Chapters 2 and 3, water management in Mexico has been radically reformed in the past fifteen years under the influence of neo-liberal government policies. The creation of the Comision Nacional del Agua (CNA; National Water Commission) in 1989 and the transfer of government irrigation districts to Water Users' Associations (WUAs) (1989-present) exemplify this. Internationally, Mexico's Irrigation Management Transfer programme has been heralded as a 'success' and has drawn widespread attention because of its rapid implementation. Consequently, this example has been propagated as a model for other countries seeking to improve the performance of their public irrigation systems and cut burgeoning public expenditures (Groenfeldt, 1998).

From the beginning of the 1990s, the Mexican water reforms spearheaded an important shift for international development agencies from project-specific lending operations towards a sectoral investment approach aimed at supporting policy and institutional reforms in the recipient countries. As components of 'the Mexican success', the sectorwide approach and time-slice loans have become fashionable policy instruments. This shift in policy and aid strategies has coincided with the attempts of international institutions to redefine their role as knowledge brokers standing at the forefront of ideas, exemplified by the ambition of the World Bank to become 'the knowledge Bank' (McNeill, 2003). These combined developments have required multilateral funding and 
development agencies to think in terms of more sophisticated and increasingly internationalised exemplary models (Mosse, 2004) ${ }^{1}$. As a result, best practice scenarios, universal win-win situations (EDI, 1995), and success narratives have become increasingly popular in the international policy literature. Several of these international policy trends come together in the widely publicised success of the Mexican IMT policy model.

Policy discourse usually presents the 'success ${ }^{2}$ of a policy as a self-evident fact that basically explains its own diffusion. To evaluate critically this instrumental view of policy, I shall argue that the success of a policy model is only a success within the cultural and ideological understandings and practices of a policy network. Further, the chapter contends that success is the outcome of a cultural process of policy making that produces, promotes, and disseminates a policy model, i.e. a particular, stabilised interpretation of policy-related events that is used to generate similar policy in other parts of the world. By taking this cultural and constructivist perspective, the chapter tries to transcend the deadlock of instrumentality in conceptualising how policy works.

The El Grullo Irrigation District (094) in Jalisco was the first to be transferred to a water users' association in 1989. Although at international conferences the success of the Mexican IMT was being proclaimed, in this district nobody referred to success in a similar way. Without doubt the practice of irrigation management had changed significantly, but people differed about the extent to which these changes were beneficial to them. This often depended on their own position in the transfer process and vis-à-vis the local groups involved in the WUA. In everyday practice, the changes to organisational and managerial practices were much more complex than is usually discussed in policy documents.

Whilst opinions differed in the field, in the national (Mexico-City based) press there was a striking lack of coverage of the transfer. Very few independent academic sources or media discussed the matter in public ${ }^{3}$. This contrasted with the lively political debates in the media on the drastic legal reforms concerning the ownership of land (article 27 of the Constitution). The government bureaucracy, in particular the CNA, controlled the information that was released on the progress of the transfer, both inside and outside the country. The reports they issued on the success of the policy were part of the government campaign to promote the president's reforms, as is common in Mexico, but it also satisfied the international donors financing the reforms.

It struck me that policy documents on IMT and Participatory Irrigation Management (PIM) increasingly discussed and replicated the success of the Mexican case. Usually this was based on an extensive description of the procedures followed and the formal rules that came into effect, but there were very limited descriptions of actual management practices of WUAs or of broader policy outcomes. In conversation with a World Bank official during a PIM promotion event, I asked why he considered the Mexican case to be a success. He pondered and answered: 'because nobody denies that it is a success'. I thought that this was a very funny answer, but it also made me think. Perhaps the fact that nobody was challenging the success of the policy model at the international conferences organised to promote it was not so surprising; but how can such a forceful interpretation of the publicly unquestioned 'Mexican experience' emerge? 
Later in 1996, at an international policy meeting in Mexico, my attention was caught by the public effort made by CNA officials, irrigation experts and leaders of water users to reiterate the success of the Mexican transfer. Tellingly, distinguished Mexican and foreign irrigation engineers privately acknowledged the existence of problems with IMT and with some WUAs in terms of their long-term financial, infrastructural and organisational sustainability. However, this only emerged anecdotally and did not seem to change their overall views. Again, the strikingly persistent argumentation and the consistent public representation of the model as a success struck me, despite the information that problematised the model from my point of view. So, how could this come about?

The next section starts answering these questions by presenting a cultural and constructivist perspective on policy making to analyse how policy is produced, promoted and disseminated. This is followed by an outline of the policy network that generated a policy narrative framing the success of the Mexican IMT experience, which later evolved into a policy model. Section 3 presents the policy model in its own terms and shows how success is culturally produced. Subsequently, the same section contends that the Mexican policy model gained further credibility and exposure by being visualised through audio-visual technologies and performed at international policy events. Finally, section 4 draws the conclusions of this chapter.

\section{2 The Production and Promotion of a Policy Model}

\section{A cultural and constructivist perspective on policy}

The definition of success and the need for policy models are not self-evident, but depend on the view of policy to which one adheres. In the policy literature the dominant view understands policy as a rational, problem-solving process (Apthorpe, 1986; Shore and Wright, 1997; Stirrat, 2001). According to such an instrumental or linear model, all policies run through the successive phases of problem identification, policy formulation, implementation, and impact evaluation. Policy analysis is typically based on the description of a gap between a desired and an actual state of affairs. This tension induces a set of policy-engineered transformations with specified objectives to close the gap. As the political decision to pursue a policy is taken as a given, the usual concern of instrumental policy analysts is how to implement the policy, how to realise models in practice, and bring institutional reality in line with policy prescription (Mosse, 2004).

Within this instrumental approach underlying much of the policy literature on the Mexican IMT policy, the following set of positivist assumptions is common: there is an objectively knowable world, which is intelligible through the application of rational thought; reality consists of empirically verifiable facts, there to discover through scientific analysis, experimentation and hypothesis testing; these facts are systematically related through cause and effect relations; because the world 'out there' consists of systematically related facts, planned interventions with pre-designated results are possible (Stirrat, 2001). Within this epistemic framework, a problematic term like success is reified into an objective category. This implies that success can be measured with clear criteria and neutral methods by impartial researchers with universal theories. Policy 
analysis thus assumes that a coherent set of policy objectives can serve as the objectified criteria to evaluate policy outcomes. The success and dissemination of a policy model is believed in the end to be supported by empirical evidence. The instrumental view of policy making is problematic because of the artificial dichotomies it erects between policy design and implementation, and politics and bureaucracy. It is popular among politicians, bureaucrats, and experts, as it provides a useful rationale for legitimising their activities and task division.

In contrast to the instrumental view, a constructivist approach to policy making argues that the success of a policy is not simply an empirically verifiable and self-evident fact, whose diffusion and standardisation result from its own impetus (Latour, 1987). Success depends upon the stabilisation of a particular interpretation of events that explains the origin, implementation, and outcomes of a policy. The success of a policy is not simply inherent or given at the outset, but arises from the ability to continue recruiting support and so impose a growing coherence on those who argue about or oppose such an interpretation (Latour, 1996; Mosse, 2004; see also Chapter 2 and 3). The more interests and policy actors are tied up with the particular interpretation, the more stable and dominant the policy becomes. A stabilised interpretation of the origin, organisation, and outcomes of a policy becomes a policy model when it is used to validate and enforce the need for similar reforms in other places through a prescriptive set of guidelines for replicating its success. In the present context, the network of active supporters enrolled in the proliferation of a policy will be called a policy network ${ }^{5}$.

A policy is thus not finished after its political design. On the contrary, policy making is an ongoing process that transcends the artificial boundaries between politics, bureaucracy and impact evaluation. In my view, policy making includes not only politicians and technocrats, but also the officials, researchers, experts and consultants who play a role in the production, promotion and dissemination of a policy.

When we follow this approach, policy is not viewed as temporally fixed and a linear process that unilaterally orientates practice. Rather, policies are subject to a continuous process of cultural construction aiming to mobilise and maintain political consent among the epistemic communities to which they are directed and which they shape. An epistemic community is 'a network of professionals with recognised expertise and competence in a particular domain and an authoritative claim to policy-relevant knowledge within that domain' (Haas, 1992: 3). The trajectory of a policy model mobilises, unites, and circumscribes dispersed and diverse epistemic communities of policy makers, who become part of the policy network and increasingly share a number of cultural values, understandings, and practices. Success can become a powerful 'mobilising metaphor' in this process (Mosse, 2004), but only as an outcome of the eultural work of production, translation, and promotion of a policy model that manages to mobilise and maintain the support of an expanding policy network.

Therefore, this chapter reviews how the Mexican IMT model was culturally constructed and promoted by a policy network, with the aim to understand its capacity to enrol a range of epistemic communities and institutions that make policy. The chapter offers a retrospective perspective on the variety of cultural means, practices, and events through which the success of the Mexican experience was narrated, visualised, and performed. This will allow us to see how success is culturally represented with a view to rendering it 
appealing and worth pursuing to a target group of peers from other nations and organisations.

In my view, policy is represented and disseminated through a broad range of cultural means, practices and events, not only through language, discursive practices and textual resources (Apthorpe, 1986; Apthorpe and Gasper, 1996). The policy model is conveyed through policy documents and policy impact studies, but also through other cultural artefacts (Stirrat, 2001), practices and events, such as promotional videos, PowerPoint presentations and policy meetings, as I shall show. Analysing the model in this manner means it is not understood as an objective representation of reality. It is tailored to specific judgements of a target population of policy makers, donors, and experts who played a role in the cultural promotion and dissemination of the model.

To delimit my argument I shall summarise why the making of the model is also a profoundly political process with far-reaching macro-economic consequences (these issues are covered in greater depth in Chapters 2 and 3). Firstly, the Mexican transfer of irrigation districts was a politically contested process and its proclaimed success needs to be unpacked in relation to the social reality and everyday practices of different groups of water users and their disputed practices of resource distribution under WUAs. In making my argument I shall not discuss the impacts of IMT on the actual irrigation management practices, and I shall therefore refrain from qualifying IMT as either a success or a failure. Secondly, the IMT policy and its success also need to be understood as a product of an ongoing struggle between political and bureaucratic elites over control of the Mexican government bureaucracy, the irrigation districts and related financial flows. Thirdly, the political and financial pressure that international organisations impose co-determines why policy models are constructed, enforced and adopted by countries. However, although the development of my analysis inevitably involves a critical stance towards what individual authors have argued, no criticism of individuals and their motives, values and beliefs is implied.

Fourthly, the CNA was successful in achieving the resumption of international funding for water policy, which funding had been halted since the beginning of the 1980s. The loan supported its full irrigation and drainage programme, including the IMT programme (see Appendix 2). The World Bank changed from project-specific lending operations towards a sectoral investment approach aimed at supporting policy and institutional reforms in Mexico. Subsequently, the time-slice loan for 'sector-wide reforms' came to be considered as a success and was applied more broadly (World Bank, 2001). In Mexico the time-slice loan of US 1.2 billion financed approximately 85 per cent of irrigation and drainage construction (construction of irrigation infrastructure, rehabilitation, deferred maintenance, O\&M equipment), 13 per cent of other project actions, and 2 per cent of support actions, of which only 1 per cent for institutional development. Yet, through the Mexican policy model, this loan became publicly known. and was credited with generating institutional reform, a policy shift from a supply to a demand orientation, and from hardware to software. In fact, the loan resumed financing new construction and rehabilitation projects. A minute part of the economic capital invested in the Mexican irrigation sector generated huge symbolical capital for the reform package and resulted in the legitimation of what was basically a renewed investment in construction and rehabilitation. 
Besides the political and economic factors that drive policy processes, policy making is also a cultural process. The Mexican policy model was produced to appeal culturally, ideologically and aesthetically to particular epistemic communities in order to enrol them in the promotion and replication of the model. Its target audience consisted of a select trans-national elite of politicians, technocrats, irrigation experts, donor advisors, and other stakeholders that dominate policy making in political, financial, agricultural and hydraulic institutions across the world and who had to be brought on board to support the policy process. In these policy spheres, the disciplines of engineering, economics and law were particularly influential. The policy model thus reflected a number of generalised standards, understandings, and practices within the epistemic communities taken into consideration. Some examples are:

- Blueprint thinking, which assumes that a model is universally replicable when it is working successfully in one place, is influential within the engineering discipline.

- Designing standardised solutions for a large diversity of irrigation systems is common among planners, who operate through routinised bureaucracies.

- Selling success is a structural element of the donor world. Promises are made that within a limited time frame problems will be solved, and for this politicians and policy makers need successful models. The tendency is the flight forward: if one policy model does not work, jump to the next promise (Mollinga and Bolding, 2004).

- The instrumental character of policy models, i.e. the handy checklists they offer, and their apolitical nature, help policy makers to support their argument for politically difficult decisions (Kloezen, 2002).

President's Bush motto for this chapter defines success as an important cultural orientation of policy makers that has become increasingly influential in international political networks: to succeed you require success. This message makes an intuitive appeal to ambitious policy makers who read it as follows: you can succeed in your career by replicating or capitalising on earlier policy successes. The Mexican policy model accommodates such ambitions by offering guidelines to replicate its success. Policy makers to whose ideas, ambitions, and practices it appeals will try to jump on the bandwagon and attempt to replicate or imitate it. Those on the bandwagon generally find it difficult to resists replicating it in fields where it 'sort of' applies, without seeing the cost that this entails (McNeill, 2003).

\section{The policy network and the proliferation of the Mexican model}

The idea of an irrigation management transfer policy emerged from political and bureaucratic transformations spanning several decades, but only became viable in the late 1980s when the Mexican government faced a severe economic and political crisis (see Chapter 2). In 1976, the Secretaria de Agricultura y Recursos Hidráulicos (SARH) arose from a controversial fusion of the Secretaría de Recursos Hidráulicos (SRH; Ministry of Water Resources), a traditionally strong and affluent hydraulic bureaucracy, and the Ministry of Agriculture. At the end of the 1980s, a technocratic segment of water resource planners from the SRH supported the electoral campaign of the presidential candidate, Salinas de Gortari, and proposed a package of water reforms to him, among them the creation of an autonomous water agency and IMT. Through the reform package, these hydrocrats ${ }^{6}$ not only regained autonomy for the hydraulic bureaucracy with the CNA but also recovered control over the irrigation districts and achieved the 
resumption of international loans for the water sector - all of which had been lost to them as a result of the fusion?

Besides the necessary political support from the Mexican presidency, this group of hydrocrats gained support from several multilateral institutions in terms of funding and expertise on policy reform and water management organisation. From 1987 onwards, a succession of World Bank ${ }^{8}$ and FAO missions advised the Mexican government and the Ministry of Agriculture on how to reform their irrigation policies, providing extensive input into policy debates on reforms required for the resumption of international loans for the irrigation sector. At the end of 1991 the loan to reform the Mexican irrigation and drainage sector was approved. The CNA kept the World Bank and the FAO regularly informed and organised field visits to show the advances made with the transfer policy. Around this time the policy network emerged. Although the initial progress was slow, the process accelerated during the second half of 1991 and a switch was made from a gradual process to a 'fast track' implementation. By 1992, the speed and scale of the transfer and the improved levels of self-sufficiency surpassed the original plans and surprised the officials of the different institutions.

Senior officials of these different institutions started to point to the success of the Mexican policy at international policy meetings and to loan applicants. These are the roots of the policy network in which the 'Mexican success story' became defined and legitimated. The epistemic communities that originally constituted this policy network belonged to several aforementioned institutions, such as SARH/CNA, the World Bank (IBRD), IADB, and FAO, that shared a similar educational and technocratic background and set of ideological views and expert theories on irrigation management and the role of the state. These coinciding cultural and ideological understandings, values, and practices shaped the construction and promotion of the policy model.

The policy network generated and disseminated a policy narrative around the success of the Mexican IMT case that became dominant in the thinking on irrigation management and user participation for the following decade. The Mexican transfer experience as captured in the narrative started to serve as a crucial point of reference to promote, fund and research neo-liberal irrigation reforms in other third world countries. As a result, the policy model grew to consist of a standardised interpretation of the origin, organisation, and success of the Mexican transfer, inescapably leading to a prescriptive set of guidelines for replicating this successful policy in other countries.

From the beginning of the 1990s, the Mexican policy model gained currency. Promotional activities were organised and financed by the policy network. The success of IMT in Mexico was increasingly referred to at international irrigation policy meetings, in loan negotiations, and publicised through policy documents, research reports, and other means. The network also started to expand institutionally.

As from 1992, the policy network co-operated in organising an intensifying succession of international policy events and research conferences that contributed to the promotion of the Mexican model and the dissemination of its success (Economic Development Institute in Mexico, 1994/1995; Colegio de Postgraduados (CP)/International Irrigation Management Institute (IIMI, later IWMI characterised at some point by insiders as 'the 
Temple of Turnover') in Mexico 1996/1998; Turkey, 1996; Tokyo, 1997; IIMI/FAO in China, 1994; Thailand, 1996, etc.). A large stream of foreign policy makers, irrigation experts, and donor advisors were invited to Mexico to attend courses and conferences and see with their own eyes that transfer was actually taking place, and successfully. As an outcome of these events, the policy network produced and circulated an everincreasing flow of policy documents, conference papers, practitioners' manuals, audiovisual technologies, $\mathrm{CD}-\mathrm{ROMs}$, and internet applications, improving the exposure of the policy model among target populations of policy makers, irrigation experts, and donor consultants. The policy model thus became increasingly known, fashionable, and accepted among policy makers and their constituencies around the world.

Since Mexico had shown that IMT 'worked' and was 'successful', the Mexican policy model became to an increasing extent an 'obligatory passage point' for national policy makers who had to use its guidelines when designing their water sector policies and negotiating financial support with multilateral banks. As the model gained currency and achieved a dominant status within international policy arenas and donor organisations, financial and political pressures and incentives increasingly converged around IMT. A growing number of national governments from the developing world and their hydraulic bureaucracies began to consider IMT policies.

Initially, the policy network remained a rather dispersed network that lacked a clear centre. This changed halfway through the 1990s. Inspired by Mexico's 'exciting experiment', the Economic Development Institute (EDI), the educational arm of the World Bank, ${ }^{9}$ launched the establishment of the 'International Network on Participatory Irrigation Management' (INPIM) (Gorriz and Groenfeldt, 1995). This organisation for policy makers and irrigation experts institutionalised the production and promotion of IMT/PIM, in which the Mexican policy model played a major role. The network's mission is 'to facilitate PIM through the exchange of people, ideas and training materials' (Kloezen, 2002: 32). INPIM began to co-ordinate the various follow-up meetings in countries such as Turkey, Indonesia, India, Egypt, Morocco, Colombia, etc. that subsequently launched IMT policies.

Throughout the 1990s, the Mexican policy model showed itself to have an enormous evocative and mobilising power in terms of promoting IMT among policy makers, researchers, experts and financiers and their institutions around the world, which among other things contributed to:

- Changing international agendas for irrigation reform

- Aligning political will, bureaucratic and financial support for IMT policies

- Reproducing the IMT model via an expanding and consolidating policy network

- Reordering bureaucratic sources of power, finance, and expertise involved in irrigation.

Given its broad exposure and impact, a remarkably select number of people are responsible for the large body of literature on the Mexican IMT experience circulating within the policy network. Not more than around ten individuals have played a prominent role in producing, promoting and disseminating the 'unquestionable success' of the policy model (Garcés-Restrepo, 2001). In publications and at conferences, their names constantly recur and their careers have become inextricably linked with the 
Mexican policy model of IMT and PIM. Among this group of policy makers at least three epistemic communities can be identified as originating from the institutions that made up the policy network: senior CNA officials, international irrigation experts, donor officials and advisors:

The first epistemic community consists of senior Mexican hydrocrats who were closely involved in developing and implementing the transfer of irrigation districts as CNA officials at the beginning of the 1990s. A sub-division can be made between a group of planners and a group of irrigation engineers (see Chapter 3), who started and developed their career in the planning and operation departments of the hydraulic bureaucracy (SRH). Several of them became internationally respected engineers.

A second epistemic community consists of international experts who specialised in institutional reform policy and user participation in irrigation management and worked for different international institutions such as IWMI, International Food Policy Research Institute (IFPRI) and FAO (Kloezen, 2002). They have developed an expertise in researching, testing and reporting on the performance and impact of new institutional arrangements that can be applied by policy makers around the world. Most of their research output has contributed to the production and dissemination of a muchrepeated set of guidelines for successful transfer. As such they became promoters of the reforms and contributed to making the policy model, and in that sense they should be considered as policy makers.

The third epistemic community within this policy network is composed of World Bank, EDI officials, donor advisors, and consultants, who were closely involved in constructing, financing, and promoting the Mexican IMT model and have associated themselves with its success. Policy models that can illustrate early successes, like the Mexican case, are instrumental in achieving the political acceptance of reforms by national governments.

Although these three epistemic communities never constituted a collective, they shared a number of traits. Most had an irrigation-related PhD from a prestigious American university and dedicated an important part of their career to irrigation management, water planning and water user organisation. Further, they developed an international career undertaking consultancies, short-term or longer-term contracts for different multilateral organisations and became part of a trans-national class of technocrats, consultants and experts. In addition, the first two epistemic communities, predominantly consisting of engineers, played a most prominent role. Economy and law were two other influential disciplines.

Over time, the trajectory of the policy model mobilised and united these epistemic communities of trans-national policy makers. To an increasing extent their activities overlapped, paths crossed, and interrelations multiplied through multilateral institutions, conferences, professional associations, etc. Through these influences they increasingly shared and disseminated a number of cultural and ideological understandings, values, and practices associated with policy making, something that can be summarised as a cultural paradigm. They coincided in a number of professional and technocratic views and understandings regarding irrigation policy, the role of the government and irrigation performance assessment. This self-reinforcing congruence shaped the construction and 
promotion of the policy model and its acceptance and fashionability among peer communities and policy elites in relevant political, financial and hydraulic institutions around the world.

As an outcome of the momentum that the policy model gained, this select number of people became known as 'reformers, champions and experts'. In this prestigious role they increasingly functioned as a kind of cultural broker who mediated and performed the success of the model. Hence, they were asked to organise and were invited to international congresses and training seminars, where they reported on their experiences with the Mexican model and its lessons. Further, they co-produced a vast stream of promotional materials that conveyed the success of the policy model and set out the guidelines for successful IMT in different ways, such as consultancy reports, manuals, and PowerPoint presentations. Their promotional work helped to extend the model's scope among a target group of trans-national policy makers and mobilised political and financial support for $\mathbb{M M T}^{10}$.

As President Bush predicted, the success of the policy model was rewarded with all kinds of successes in other fields. Various sorts of opportunities for career advancement opened themselves up to these policy makers in the form of consultancies, contracts, trips, etc. These incentives and the prestige that they were personally awarded only confirmed their belief in the success of the IMT policy model. The model also contributed to the internationally favourable reputation of the Mexican government ('politically committed to reform') and the CNA ('catalytic institution'). Through their excellent reputation and continued cooperation, the CNA re-established high-level access to and achieved considerable leverage in the World Bank, which assisted them henceforth with acquiring new loans for the water sector. It is understandable that success thus gradually became a firm conviction of these policy makers and advocates, closely related to other positive cultural values that turn out to be self-reinforcing and rewarding in the public promotion of policies, such as optimism and enthusiasm. These policy makers became endowed with the optimism that the initial success of the policy model would automatically lead to more successes in other fields and places.

That policy makers tend to depict the outcomes of promoted policies as a success and learn to sustain this is not at all surprising. In cognitive psychology it is well established that people attribute success and failure in self-serving ways. Success tends to be attributed to one's owns actions, while failure is often attributed to external causes. This protects self-esteem and enhances public esteem. The position and career of senior managers and bureaucrats are often an outcome of previous policy successes. Throughout their institutional careers they experience well-advertised success as a resource of career advancement (Vaara, 2002). However, the enrolment of policy makers in the promotion and replication of a successful policy model is much more than the result of a psychological characteristic or strategic intent. Rather, I am arguing that they become part of an emergent and self-reinforcing cultural process. This accelerating dynamic can generate 'cascades of adoption' and 'institutional mimicry', very similar to fads in the business community and fashions in popular culture (Di Maggio and Powell, 1983; Strang and Macy, 2001). 


\subsection{The Success of the Mexican Model}

The policy model

According to the policy model, the Mexican government initiated the IMT programme at the end of the 1980s as a result of mounting budgetary pressures at a time of financial crisis in Mexico. Public management of the irrigation districts led to poor irrigation performance and decreasing levels of productivity because the government bureaucracy lacked the incentives and responsiveness to optimise management performance. Hence, the government adopted the policy of transferring the irrigation districts to water users out of necessity, because it simply lacked the funds to carry out basic management functions.

The Mexican government wanted water users to participate in the effort to bring the irrigation districts back to their formerly high levels of productivity. Participatory Irrigation Management can improve the productivity of irrigated agriculture, the sustainability of irrigation districts, while lowering costs for both the farmers and the government. PIM is therefore truly a win-win situation. Since the government was politically committed to effect the transfer and the policy objectives were clear from the beginning, the transfer process was made easier (EDI, 1995).

In 1989 the CNA was established as a sole water authority with a mandate to transfer management of the country's irrigation districts to WUAs. The CNA divided the irrigation districts into modules that were manageable from a hydraulic point of view. Then it began a promotional campaign to encourage water users within these modules to organise in WUAs, an organisational form that is recognised under Mexican law. To complete the process, the WUA receives a temporary concession for the use of the infrastructure and the machinery. The CNA subsequently has evolved into a provider of services to support farmers' own management effort (EDI, 1995).

The speed and magnitude of the transfer pleasantly surprised all involved, as the beginning had not been without difficulties. The CNA had to solve legal problems, organise the users in WUAs, convince them of the need for sharp fee increases, and deal with opposition (Palacios-Vélez, 1997). Initially the CNA organised discussions with leaders of farmer, producer and marketing associations, and later with the water users. Hundreds of meetings took place between the CNA and WUAs in which the terms of management transfer were negotiated. Major issues were the terms for the transfer of maintenance equipment, the rehabilitation of infrastructure before the transfer, and the increase in irrigation fees. The WUAs realised that in order to sustain the system, they had to raise irrigation fees and improve collection rates (Kloezen, 2002).

Firstly, the most productive irrigation districts, which were best organised and had the most enthusiastic farmers, were transferred. The most important criterion for selecting districts was the potential of the user organisation to become financially self-sufficient with users paying the fees of operation, maintenance and administration. The results of the newly established WUAs were very promising. They achieved self-sufficiency within a short time. In addition to financial autonomy, the organisation also had to become administratively self-sufficient and rely on its own staff rather than on CNA staff. The 
fact that the modules were designed as single infrastructural entities with clear physical and functional boundaries (Johnson, 1997a) enabled the WUAs to function as autonomous and special purpose organisations for irrigation management. The new irrigation institutions are more efficient and perform irrigation tasks better than bureaucratic organisations. Their structure of rules and incentives stimulates WUA managers to respond better to costs and benefits (Ostrom, 1992). The WUA leadership and staff are directly chosen and appointed by the water users and they also depend financially on them (Johnson, 1997a; Merrey, 1995; Vermillion, 1997). The key to success is accountability. WUAs act to contain the cost of water management while improving operational performance because it is in their direct interest to do so. Improved quality and cost efficiency of irrigation management will normally enhance the profitability of irrigated agriculture enough to offset the increased cost of irrigation to water users (Vermillion, 1997).

Water users agreed to take over operation and maintenance (O\&M) responsibilities, because they believed that a better job could be done with direct and full control over the revenues from fee collection. Despite initial difficulties, the process of transfer was carried out successfully. However, after the transfer of the modules to the WUAs, a new set of problems was detected, such as water rights and legal questions, financial selfsufficiency and investment requirements, operation and maintenance, environmental problems, and leadership problems. Broader socio-economic problems, economic crisis, water scarcity, or the speed with which the programme was implemented cause these 'second-generation problems'. The long-term success of the irrigation sector and the sustainability of the transferred districts would depend upon how the government, the CNA, and user organisations addressed such second-generation problems Johnson, 1997b; Johnson, 1997a; Palacios-Vélez, 1997; World Bank, 2001).

The IMT programme in Mexico, 'one of the largest and most ambitious programmes of management transfer' (Maldonado Rojas, 2000), is considered an 'unquestionable success' (Garcés-Restrepo, 2001). Clearly there are many conditions that are specific to Mexico, and therefore the Mexican case is not a blueprint that should be copied by other countries. It does, however, offer ideas that can be adapted to other countries. The trends are becoming universal in the irrigation sector: governments have overextended their reach beyond the point of efficient management and there are many benefits in harnessing the management potential of water users. In Mexico the paradigm of PIM is working well. What lessons does Mexico offer for replicating this kind of win-win situations? (EDI, 1995)

- First of all, strong government commitment to the IMT programme is required at the highest levels. Mexico's debt crisis in the 1980s fuelled government commitment to withdraw from management functions.

- Second, new management arrangements need to be grounded in a solid legal framework. Clearly defined ownership of water and other assets, rights and obligations have been important in successful irrigation management.

- Third, financial autonomy and self-sufficiency of WUAs is considered a fundamental prerequisite for effective user management (Palacios-Vélez, 1997; Vermillion, 1997). In Mexico, water users pay a fee prior to water delivery so that the financial basis of the organisation is secure. 
- In addition, other elements of the Mexican model that are deemed essential for success are a strategic training and promotion campaign to forge consensus among stakeholders (Palacios-Vélez, 1997; Vermillion and Sagardoy, 1999) and the need for promoters and 'champions' who mobilise support within the government agency (Groenfeldt 1998).

The more these key enabling factors are present in an IMT programme, the more likely IMT is to be successful and WUAs to be sustainable and effective (Vermillion and Sagardoy, 1999).

\section{Reviewing the model}

In line with most policy makers, the policy model subscribes to an instrumental model of policy, which views policy making as a problem-solving activity that follows a linear logic of successive temporal events. (See The Production and Promotion of a Policy Model above.) The model presents the IMT policy as the only obvious solution to the objectively identifiable problems of the Mexican irrigation sector. This policy then manages to transform the original state of affairs of government-managed disorder into a new equilibrium of user management, which is repeatedly classified in terms of success. From the Mexican experience, a set of lessons and explanations are derived. The characteristic elements that are believed to have caused success are then interpreted as generalised conditions or determinants for 'successful IMT' (Vermillion and Sagardoy, 1999), 'winwin situations' (EDI, 1995), or even 'effective water governance' (Rogers, 2002). Further, the policy literature presents the emergence of worldwide interest in the Mexican model and its partial replication in other countries as a spontaneous process that naturally follows from its success.

The Mexican policy model is structured as a black box that inevitably leads to a successful transfer. The set of lessons and guidelines inferred from the Mexican case are positivist and prescriptive templates for knowing and acting upon the world (Stirrat, 2001). This forces national policy makers who also aspire to achieve successful transfer in their country along a route of 'obligatory passage points' or marks that identify with the Mexican success (Latour, 1987). To follow this scenario seems the only rational thing to do. The byroads or shortcuts are systematically closed off, because they are prone to failure.

The policy model is prescriptive, because it sets out what inescapably ought to be done and what stands to reason, rather than providing informative and descriptive accounts of actual practices or outcomes 'telling it as it is' (Apthorpe, 1986; Apthorpe and Gasper, 1996). For example, IMT in Mexico is couched in terms of an unavoidable and logical response of the Mexican government in economic crisis to counter the threat of decreasing cost recovery, irrigation investment and deteriorating irrigation infrastructure. Similarly, the model has a normative orientation and focuses on the extensive explanation of the official procedures followed and the formal rules that came into effect. The limited empirical description of actual processes of transfer and user management practices is usually selective and biased, and tends to confirm the central propositions of the model. As a result, the empirical evidence provided follows and reaffirms the ideas and theories, in short the cultural paradigm, that underlie the IMT policy model. The 
lessons and guidelines for other countries to follow perfect the prescriptive and normative character of the model.

The policy model is strengthened by appeals to objectivity, neutrality and rationality, which confer on it legitimacy and authority. For instance, the presentation of quantitative data suggests objectivity. The model also reifies an area of expertise, with the effect that it appeals to experts from particular epistemic communities and excludes laymen. For example, the frequent use of acronyms (IMT, PIM, IWMI, CNA, etc.) and technical jargon works to place the policy model in the wider field of expertise and official institutions, whilst making it less transparent to outsiders. Institutional sources that are cited grant the document legitimacy and an official status, e.g. the World Bank (Stirrat, 2001).

The transfer process and user management are de-politicised by the policy model, because it ignores how the policy was politically contested in different irrigated regions and quarters of Mexican society, and excludes the conflictive aspects of daily management and resource distribution in WUAs. This obscures the (un)intended policy outcomes and political side-effects of the IMT policy, such as the renewed autonomy for the hydraulic bureaucracy and the politicisation of WUAs, which could potentially falsify the model (Ferguson, 1990). (See also Chapter 2 and 3.)

What is most striking is the asymmetrical use of the labels of 'success' and 'failure'. Prior to IMT, the failure of public irrigation policies and irrigation systems is the norm and success the exception, whereas after IMT success prevails and failure is hardly ever reported. When problematic aspects such as insufficient fee recovery or deferred maintenance are discussed, they are explained by external factors and called 'secondgeneration problems'. They are presented as temporary threats to an inherently successful transfer, rather than serious indications of partial failure or structural problems. This subtle rhetorical technique acts in conjunction with the employment of asymmetrical standards of evidence. Transfer and user management are 'innocent until proven guilty', whereas government management is 'guilty until proven innocent' (Wade, 1996). Such devices make it almost impossible to falsify and refute the model or deny its success.

The main thrust of the model is that the success or failure of the Mexican IMT programme can be assessed with a straightforward set of criteria (the policy objectives) by impartial researchers with neutral methods and unproblematic theories. In contrast to such a view, I shall show that a clear and coherent set of objective criteria for assessing the success the IMT policy that is shared by both policy makers and researchers is lacking. It is not at all so clear what is really meant by success, and this varies according to the circumstances. Specified claims of success are usually only partially validated by straightforward empirical evidence about the realised objectives, improved irrigation management practices, or the long-term outcomes of the policy. To back this claim, I shall briefly review the four objectives that are generally mentioned for IMT and the evidence provided for their successful attainment ${ }^{11}$ :

First of all, there is a general consensus in the policy literature that the Mexican government transferred its irrigation districts for financial reasons. The objective was to 
reduce public expenditure on irrigation management, as it had become too large a financial burden. A higher degree of cost recovery among the water users in irrigation districts should bring about this public investment reduction (Espinosa de León and Trava, 1992; Gorriz et al., 1995; Johnson, 1997a; Trava-Manzanilla, 1994). In fact, the public expenditure on irrigation was reduced (Johnson, 1997a), though the degree of this reduction is debated. While some argue that annual government subsidies fell from US\$40 million in 1989 to zero by 1993 (Vermillion, 1997), others claim that the government subsidies reduced from eighty per cent to only twenty-five per cent in just five years (Palacios-Vélez, 2000). Nevertheless, there are few data available on the impact of transfer and other neo-liberal policies on overall government expenditure in the water or agricultural sectors (Vermillion, 1997).

There is also general agreement that the WUAs improved the recovery of O\&M costs, and achieved a high degree of self-sufficiency and financial autonomy within a few years of initiation (Garcés-Restrepo, 2001; Johnson, 1997a; Kloezen, 2002; Palacios-Vélez, 1998). Fee collection rates rose from only 15 per cent before transfer to 80 to 100 per cent afterward. By the second year they are usually above 80 percent, and after a few years around 100 percent in the majority of modules (Gorriz et al., 1995; Johnson, 1997a). The IMT programme and the resulting increase in irrigation fees have permitted the irrigation districts to improve their self-sufficiency from thirty-seven per cent in 1991 to eighty per cent in 1994 (Johnson, 1997b).

A second concern from which the transfer emerged was the need to ensure long-term infrastructural sustainability. The increased cost recovery and self-sufficiency of WUAs would solve the problems of lack of funds for required maintenance (Johnson, 1997a). Despite the improved cost recovery under WUAs, it is uncertain what this means for the long-term viability of the WUAs, particularly their infrastructural viability (Kloezen, 2002; Palacios-Vélez, 1997). In Chapter 10 I show that financial self-sufficiency of the WUA does not at all automatically imply the infrastructural viability of a module. Likewise, an impact study of the Colegio de Postgraduados demonstrated that in many WUAs the fee recovery was insufficient to cover total management costs (including O\&M) (Palacios-Vélez, 1994b). WUAs indicated that they cut back on the maintenance programme when there was a lack of fee recovery. Another concern is the increase of deferred maintenance, because the annual fee increase does not keep up with monetary inflation (Kloezen, 2002; Palacios-Vélez, 1997). WUAs and CNA staff revealed that the actual fee levels were less than half of what they felt they should levy to manage the modules at optimum level (Kloezen, 2002: 152). Another concern is that the wages of CNA personnel operating the sources of water (e.g. a dam) and the primary canals are only partly paid by the WUAs, which means that their budgets are not really selfsufficient (Johnson, 1997b). The initial high degree of financial self-sufficiency of WUAs is thus hard to maintain, and it is questionable what self-sufficiency really means when it does not secure adequate investment in (deferred) maintenance, let alone the rehabilitation of infrastructure. Of course, these problems are bound to be more serious outside the select number of commercial districts partly rehabilitated as part of the international loan. In conclusion, the empirical evidence with regard to financial objectives is significant, but difficult to judge from a longer time perspective. There remain many uncertainties about what this implies for the overall viability of the irrigation districts in the long run, particularly infrastructural viability. 
A third objective of the Mexican government was to bring the irrigation districts back to their formerly high levels of productivity by making water users co-responsible for the operation and maintenance of the system (Gorriz et al., 1995; Groenfeldt, 1998; Vermillion and Sagardoy, 1999). The irrigation districts should retake their leading role as productive zones in the agricultural sector and increase agricultural production ${ }^{12}$. However, to date MMT has not had a major impact on crop production (Johnson, 1997a). Kloezen does not find convincing evidence of agricultural and economic productivity improvements either (Kloezen, 2002). Several other authors admit that the causal relationship between management transfer and productivity increases is not so direct as for financial viability. So far, impact research in Mexico has shown no significant increase in area irrigated, cropping intensity, yields before and after transfer, or gross economic returns (Johnson, 1997a; Palacios-Vélez, 1997; Vermillion, 1997).

A fourth objective was to improve and sustain system performance and to increase efficiency of water use. There is little evidence of such an improvement, as two IWMI impact studies show. For Alto Río Lerma (011) in Central Mexico, Kloezen (2002) comes to similar findings as my own study. He concludes that WUA management has not improved water distribution, according to performance measurement of water application (relative water supply). He found a considerable continuity in allocation and distribution practices before and after IMT. According to Kloezen, the most positive impact of IMT has been the improvement in maintenance services, especially at the lower system level. However, it is uncertain whether this has solved the deferred maintenance problem and whether it is sustainable in the long run. In addition, Kloezen considers the provision of non-irrigation related services by WUAs as a positive effect of IMT. Unlike Kloezen, another IWMI study on the Lagunera District in North Mexico does make claims about success (Levine et al., 1998). In spite of its practical limitations which prevent the study from concluding about management performance improvements or changes in the hydraulic performance of the system, data still suggest that the combination of CNA and the transferred modules has been generally successful in managing their water operations. The facts that 'policies are taken seriously', 'management can and does implement the policies', and head/tail problems are lacking, are presented as evidence of the effectiveness of module water management in terms of O\&M improvement.

The empirical evidence to support the success of IMT on the basis of the abovementioned criteria is often partial and inconclusive. Reduced government expenditure, improved fee collection rates and maintenance services are undoubtedly important partial arguments for claiming that the IMT policy has had positive outcomes. However, the reported outcomes on productivity, management performance and infrastructural sustainability do not offer conclusive evidence. In a similar vein, Hales (1999) observes that evidence provided on the link between decentralisation and organisational performance is usually somewhat equivocal and he suggests that although decentralisation does generate a stronger concern with financial performance (and its measurement), it is not clear whether this concern translates into performance outcomes. The question remains as to whether realising short-term financial objectives is sufficient evidence to claim a successful reform in terms of achieving more sustainable and productive irrigation districts in the long run. Nonetheless, the lack of clarity about what is really meant by success and the ambiguous evidence have not in any way 
prevented or corrected the celebration of the Mexican model and the multiplication of references to its success. Impact studies rather tend to report selectively on the positive and neutral outcomes of IMT. To conclude, we cannot consider success to be a verifiable claim that is validated with straightforward empirical evidence by neutral researchers. The Mexican policy model is only a success within the specific cultural and ideological understandings and practices of the policy network that has produced and promoted it.

Interestingly, Vermillion and Sagardoy (1999) arrive at similar conclusions when they review a large body of impact studies from around the world. They argue that the adoption of irrigation management policies is probably not informed by validated expectations about enhanced performance, but rather by government's financial constraints. Vermillion and Sagardoy disqualify much of the reported research findings as a basis for generalisation or broad conclusions, because of a lack of quality and comparability of data and research methods. However, they do not home in on the recurring tendency to report positive impacts and guidelines for success. Yet, they come very close to an explanation when they observe the following biases in impact research:

- the selection of favourable sites

- a reliance on secondary government data, leading to overestimation of performance levels

- the tendency to report the perspectives of stake holders in the outcome of transfer

- the possibility that many authors are promoters of the reforms (Vermillion and Sagardoy, 1999).

These conclusions are reinforced by a similar observation of Hales (1999) that authors who have written about radical decentralisation do so more as advocates than detached observers. It follows that the success of the Mexican IMT policy is construed through a set of culturally and ideologically biased practices that are shared and reproduced in a policy network.

\section{The cultural production of success}

The presentation of empirical evidence regarding the impacts of IMT is part and parcel of the cultural production of success. In this section I present a number of the cultural, aesthetic and ideological understandings, biases, and practices that are commonly used to validate and convey the success of the Mexican model. These serve to mobilise potential support for the model among targeted populations of policy makers in favour of reforms that are promoted by the policy network. By making an appeal to particular predominating cultural understandings, the policy model becomes credible, imaginable, forceful and replicable among epistemic communities of influential policy makers. Below, five typical ways of validating and representing success are discussed: firstly, the celebration of the speed and scale of reforms; secondly, the ambivalence about means and objectives; thirdly, the biased use of positive and quantitative data; fourthly, prescriptive evidence; fifthly, idealisations of actual practices associated with policy, theory and discipline.

Firstly, the speed and magnitude of the transfer as indicators of success are central to the policy model. From the second half of 1991 onwards, a 'fast track' was followed, which meant that the policy was carried out much faster and on a broader scale than originally 
planned in the time-slice loan agreements with the World Bank in 1991 (see Chapter 3). Within a relatively short period of less than a presidential term of six years, the majority of irrigation districts in the country were transferred. This became a source of international status and prestige among policy makers ${ }^{13}$. The number of WUAs organised, the hectares transferred, the number of meetings convened are presented as evidence of success. Observers were also pleased that the WUAs demonstrated their ability to manage the modules, even the larger ones (Johnson, 1997a). The fact that they actually 'worked' was seen as a sign of success.

Nevertheless, although the speed and scale of IMT is undoubtedly an impressive result for policy makers, it says little about actual policy outcomes. They do not guarantee positive impacts. The impact of fast and efficient implementation could just as easily be detrimental. Moreover, there were good reasons to opt for the gradual process of policy implementation that was originally planned, as many irrigation districts were believed not to be ready for various reasons (Castro, 1995; World-Bank, 1991). Hence, the accelerated speed of the transfer is mentioned as a cause for second-generation problems (Palacios-Vélez, 1997; World Bank, 2001) ${ }^{14}$. Thus, while the tempo and magnitude of reforms may even have a negative impact on policy outcomes, nevertheless they create a certain prestige and status and nurture certain cultural standards for measuring success among ambitious bureaucrats, managers, and politicians. Hales (1999) also concludes that evidence of the increasing spread and popularity of new organisational forms cannot be considered as reliable evidence of their liberating effects, given that their adoption is as much prone to fashion, or expectations of institutional environments, as to considerations of effectiveness.

Secondly, the ambivalence about the hierarchy of means and objectives of a policy in some cases produces self-validating arguments. For example, attaining a high degree of self-sufficiency is defined both as a requirement for, as well as the evidence of, successful transfer. The means of a policy become ends in themselves. This implies that the implementation of a policy according to plan already makes it a success. A similar type of self-fulfilling prophecy occurs when the participation of water users is taken both as a means and as an objective of transfer.

Thirdly, the presentation of positive quantitative evidence in connection with performance indicators validates the central message of success in different ways. Policy documents and impact studies tend to focus selectively on positive and neutral policy outcomes that are interpreted in a favourable manner. Policy makers and experts generally prefer to demonstrate the impact of IMT with quantitative 'facts and figures', because they appeal to positivist concerns of objectivity, neutrality and preciseness and confer authority (Stirrat, 2001; Wade, 1996). Another reason for this bias is an increasing call in the development field for 'evidence-based decision making' and controls over decisions and performance, in what has been called the 'audit society' (McNeill, 2003). However, surprisingly firm, anecdotal, or normative conclusions are based on limited performance data, non-transparent survey techniques and questionable research methods. In most cases the data sets originate from the CNA and other sources within the policy network and are often difficult to check for reliability. In the absence of the presentation of significant data, statements such as 'results show...' or 'data suggest...' validate strong positive qualifications, such as that WUAs are managed 'well' or 
'successfully'. In the absence of reliable measurement, surveys among water users ${ }^{15}$ are another way of validating the improvement of irrigation management performance. For example, a survey carried out in four districts indicates that eighty per cent of the interviewed farmers think water management by WUAs has permitted an improvement in agricultural production (Palacios-Vélez, 1997: 31). Furthermore, the absence of negative impacts is presented as a positive outcome, a powerful rhetorical technique. When it is clear that an increase of yields in Alto Río Lerma cannot be attributed to the transfer, the fact that it did not result in yield declines is taken to be a positive outcome (Garcés-Restrepo, 2001).

Fourthly, in policy and impact studies, policy, theory, and empirical evidence on policy outcomes and organisational practices are often mutually validating (Mosse, 1999; Palmer-Jones, 1995). The model is usually validated by neo-institutional theories on 'crafting institutions for self-governing irrigation systems' (Ostrom, 1992). This body of theory advances the essential role of water users in the design of successful irrigation management arrangements. A classic example of how policy, theory and empirical evidence can mutually validate each other is when user participation is presented as '...a way of bringing irrigation management into line with proven management theory' (Groenfeldt and Sun, 1997). The automatic connection that is made here between certain policies and success is telling. Below I present a number of examples and show how policy, theory, and disciplinary images of an ideal order validate the idea of success.

In policy documents it is common to idealise actual user management in line with policy prescriptions. They often take the view that organisational practices correspond with formal rules (see Chapter 5). This rule conformity is then identified as an indicator of success, independent of outcomes. When water management institutions are evaluated in this manner, success becomes self-fulfilling, defined in terms of the prescription of the model itself (Mosse, 1999). However, in practice rules are not always followed and, if they are, this does not necessarily assure positive outcomes. An example is the idea that Mexican water users pay their irrigation fees to the WUA before the first irrigation turn of the season. The conclusion follows that this ensures high fee collection rates, because farmers need to pay their fee before receiving any water Johnson, 1997a; Palacios-Vélez, 1997; Vermillion, 1997). This is an understandable misconception, based on a rule formulated by the CNA in the by-laws of the WUA. However, it is not a generalised custom. In Chapter $10 \mathrm{I}$ have shown that fee default is still a serious problem for WUAs. Many WUAs are still confronted with the practical difficulties of refusing irrigation turns to defaulting water users ${ }^{16}$.

Another manner in which policy prescription shapes the production of empirical evidence is that qualitative evidence on improved WUA management or beneficial policy outcomes frequently contain a prescription in them. Outcomes or actual practices are rhetorically framed in the light of new objectives or future interventions. The latter need to be fulfilled in order to achieve desired outcomes and to make the success complete. Long-term success is just within reach, it seems, provided that a range of additional interventions are carried out, as the following quote illustrates. As a result, it is complicated to evaluate actual management practices, because of the expectations of future success that are evoked: 


\begin{abstract}
'With increased O\&M budgets including more funds for maintenance, and more responsive staff, the transfer program has created a situation that is much more sustainable than the situation in the irrigated sector prior to transfer. For long-term sustainability, there are additional changes that are required to ensure the program is sustainable over time. The system of water fees needs to be changed.... They also need to shift to a system where the module collects a fixed amount ... as well as a volumetric fee....' (Johnson, 1997a: 28)
\end{abstract}

In addition, the reference to theoretical or disciplinary ideas about 'best practices' also triggers the idealisation of organisational practices. These ideas are appealing and seem factual to the targeted audience because they refer to certain commonsensical theoretical understandings in the dominant disciplines of economy, engineering and law. An example is the emergence of 'support systems' among WUAs (Garcés-Restrepo, 2001). Originally, this was never an objective of transfer and is sometimes questioned as an appropriate objective. Nevertheless, the fact that WUAs are taking over responsibilities previously provided by government agencies, such as agricultural extension services, technical assistance, legal matters and training programmes, is seen as part of their success. This idea about success seems to originate in the fact that neo-institutional economics identifies the provision of external support services as a requirement for sustaining management organisations (Kloezen, 2002).

A third way in which policy documents evoke success and so appeal to policy makers and experts is to call upon certain disciplinary images of an idealised order. Such images allude to cultural myths, acquired tastes and dreams of utter control among epistemic communities and within policy circles (Chambers, 1988; Law, 1994). An example is the concept of volumetric water pricing to which the policy literature on the Mexican model refers (Gorriz et al., 1995; Johnson, 1997a; Plusquellec et al., 1994). The power of the concept lies in the future potential that international epistemic communities of hydrocrats, irrigation experts and donor officials attribute to it. The idea of simultaneously delivering, measuring, and pricing the water per volume counts as a rational and modern form of irrigation that promises to materialise efficient water use, exact cost recovery and increased net farm income (Gorriz et al., 1995; Johnson, 1997a; Plusquellec et al., 1994; Repetto, 1986; Vos, 2002). In an ideal hydraulic system of volumetric water control, users request water and are charged for the volume delivered at their intake. This creates a financial incentive not to apply more water than strictly needed. This potential solution to both technical and economic inefficiencies of water distribution is considered to be the desirable way forward. However, the approval that this idea evokes in the engineering and economic disciplines is more evident than its practicality on the ground. For most medium and large-scale irrigation districts in Mexico, it remains a promise and is not practical at all. The required infrastructure for volumetric delivery and measurement is not in place, or does not function as such. Moore (1989) argues that worldwide there are few cases documented of actual volumetric water pricing in large-scale gravity irrigation systems with many small farmers in developing countries (Bolding et al., 1995; Moore, 1989) ${ }^{17}$.

Another image of idealised order stems from the emphasis on the creation of a supportive legal framework. However, in Mexico the National Water Law of 1992 was 
more an outcome of the initial process of transfer and the experience gained during this period than a precondition to the transfer (see Chapter 3).

\section{Visualisation of the model}

The policy network has produced and distributed a large stream of cultural artefacts to promote IMT. Besides policy documents and other textual resources, audio-visual technologies, computer software and Internet applications have increased the persuasiveness and visibility of the policy model. These technologies circulated and increased the exposure of the model among target populations of politicians, technocrats, irrigation experts, and donor consultants. Once saved on disk or cassette, the model can easily and rapidly circulate by fax, electronic mail, and the Internet, making heavy suitcases with policy documents redundant (Latour, 1999). This sort of technology visualises the policy model through a number of appealing digitalised images of the Mexican experience, and thus allows increasingly large audiences to personally observe the model as something concrete and imagine similarly successful scenarios for other countries.

For example, a video production with the telling title 'Participatory Irrigation Management: Seeing is Believing' was co-produced by the EDI and the CNA and presented to foreign policy makers and experts to promote the Mexican case and its lessons (EDI, 1995). With the rapidly alternating pictures, it is possible to present very graphic contrasts of the situation before and after IMT, therefore powerfully demonstrating its success. Selected pictures effectively stand for the larger promises and symbolise the idealised orders that IMT must fulfil: waving wheat implies productive irrigated agriculture; modern irrigation technologies stand for efficient irrigation; computers suggest transparency; and modern, light machinery demonstrates improved maintenance. In practice, however, these images are idealisations of actual managerial practices. Nevertheless, these carefully produced sets of images effectively evoke a sensation of success among audiences.

Another example comes from a presentation of two World Bank/EDI officials who were promoting the benefits of PIM. In a PowerPoint presentation they showed different national cases of irrigation reforms, among which Turkey, Mexico and the Philippines. These countries were represented by strongly contrasting images of moving animals: from a speeding cheetah to a slowly creeping tortoise. The Mexican model was characterised as a 'Big Bang' and as innovative. I was impressed by the combined power of these words and images and amused by how this graphic contrast instantly identified the speedy with the successful. Also the audience had to laugh, but at the same time they were left dazzled and speechless by these crude but persuasive presentational devices. Nobody had the presence of mind to counter this powerful imagery with Aesop's fable of the hare and the tortoise.

\section{The cultural performance of success in policy events}

As mentioned earlier, the emergence of foreign interest in the Mexican model was not a spontaneous process, but the result of a concerted promotional effort within an emerging policy network. 
These international policy events are analysed here as cultural performances that represent the success of the IMT model (Munro, 1999). They were carefully targeted, structured and arranged in order to appeal to a target group of key policy makers and persuade them to join in with 'the universal trend' to IMT/PIM. These events comprised intensive personal encounters with key policy makers during which the success of the Mexican model was performed through a mixture of formal sessions, study tours, and field visits to pilot areas. The effects of such encounters were substantial. The events proved enormously effective not only in terms of promoting and disseminating the policy model, but also in consolidating and expanding the policy network.

The excitement, inspiration and altered opinions produced in policy makers resulted in a shift in policy agendas of several countries. As the slogan goes, 'Seeing is Belieoing' (EDI, 1995; Groenfeldt, 1998):

'Bringing policy makers into contact with PIM cases can be a powerful ingredient in swaying long-held opinions. Study tours, if carefully arranged and the right people are involved, can make dramatic differences in the outlooks of individual officials. During a one-year period (19921993) when Turkey was considering an ambitious programme of accelerated IMT, nearly 50 senior officials visited Mexico (largely with World Bank financing) to see for themselves what a transfer programme looks like. Those visits have been credited with imparting both lessons as well as confidence that resulted in the government adopting a dramatic transfer programme in 1993.' (Groenfeldt, 1998: 22)

In the Turkish case mentioned in this quote, teams of political and administrative leaders and bureaucratic officials were carefully targeted to participate in these visits. This resulted in the Turkish government adopting an ambitious and speedy PIM programme (Groenfeldt, 1998).

In February 1995, the EDI and the CNA jointly organised the aforementioned PIM training seminar of a week in Mexico (Gorriz and Groenfeldt, 1995). The audience consisted of national policy makers from India, Pakistan, Morocco, Egypt, Indonesia and World Bank task managers working in different regions of the world. The objectives of the seminar in Mexico were to learn and understand the Mexican experience and to study it as a case of best practice in PIM. Several elements were important in the promotion of the Mexican model:

First of all, senior officials of authoritative institutions presented the policy model. The presentation of the Director of the EDI informed the participants about what the World Bank was expecting from countries in terms of future loans for the irrigation sector. Several CNA officials presented their views in their publicly acknowledged roles of reformers, or what later became known as 'champions'. Of course, the performance of these authoritative and respected senior figures added to the weight of the message conveyed. For the policy network, the group of Mexican 'reformers' turned out to be very instrumental in the promotion of the policy model. These public performances of reformers appeal to policy makers, experts and donors and can genuinely energise and incite an audience to take a model on as an exemplar. 
Secondly, the success of the policy model was demonstrated by visits to privileged pilot areas. The districts first transferred in Mexico were also the most productive, commercial, and best organised. They had the most potential to become self-sufficient and thus had 'higher chances of success' (Castro, 1995; Vermillion and Sagardoy, 1999). The CNA started to organise Mexican study tours for water users' representatives and farmer leaders from other regions to these pilot areas in order to promote the transfer, and these significantly contributed to its acceleration. In this manner, the 'early successes' generated more support for the programme and facilitated the later and more difficult transfers (Vermillion and Sagardoy, 1999) ${ }^{18}$. At a later stage, the policy network brought the transfer in Mexico to the attention of foreign policy makers, World Bank officials, irrigation experts, by bringing them to these pilot areas. These privileged areas were believed to be typical for irrigation in Mexico (Gorriz and Groenfeldt, 1995). Foreign visitors had the tendency to generalise selective findings and to infer lessons for the country as a whole. The effect was that foreign policy makers departed from the field with the favourable image of the Mexican irrigation transfer as a broadly successful policy that would facilitate more modern, commercial and productive irrigation.

Pilot projects are universally performed as a success in international policy networks. Chambers (1988) argues that these 'islands of salvation' are usually unrepresentative, unlikely to be replicated and project certain myths in development. Nonetheless, they are much visited, quoted, and believed by policy-making officials, and thus have significant impacts. Chambers illustrates beautifully that the success of pilot projects is usually based on the selection of favourable conditions, preferential treatment, exceptional resources, and high-level official concern for success. This special attention makes it difficult to draw practical conclusions. He argues that the repetitive short visits of officials and researchers give rise to insights of uniform superficiality. A succession of visitors meets the same farmers, and they tell them similar things. What farmers say can be slanted, false, or rehearsed in advance. Visitors do not have the time to crosscheck findings, question biases, or perceive costs that offset the benefits that they are shown. They depart to their conferences where they repeat to each other their common misconceptions. A belief can gain currency that an approach is replicable and should be included in policy and plans (Chambers, 1988). In a similar vein, Mosse argues that the exceptional allocations of human and financial resources put into well-publicised pilot projects, together with the agency needs for good news stories, can conspire and give a misleading picture of the performance of the WUAs on a longer term, larger scale, and on closer examination (Mosse, 1999).

Thirdly, the succession of consecutive seminar elements worked somewhat like a funnel. The participants were taken from field visits and presentations of the guidelines for successful transfer, towards the formulation of national action plans. The policy makers' positive excitement and inconsequential enthusiasm about the possible prospects of IMT for their country produced by the field visits and the presentations was skilfully channelled into commitment towards the desired policy reforms. At that moment 'handy check lists' of lessons from Mexico were convenient in activating the inspired policy makers and found them in a favourable disposition to work on the basis of these ideas. The guidelines were incorporated and adapted by teams of national policy makers to the specific situation of their country. The seminar in Mexico was followed by national 
seminars and workshops in each country to finalise, implement, and evaluate national PIM action plans.

\subsection{Conclusions}

President Bush's intriguing statement at the start of this chapter is a metaphor for a cultural orientation that is influential in international policy making. It points to the strong belief of policy makers that it is possible to replicate and capitalise on earlier successes. Although such a conviction might not correspond with the actual practice of policy interventions, it can be hugely powerful in the production and proliferation of policy models, best practices, and win-win situations, as well as in mobilising support for the international policy networks that sustain them.

Following these insights, this chapter argued that the production and promotion of the Mexican policy model of IMT was a profoundly cultural undertaking. In addition, it illustrated how a policy network propagated the success of the Mexican case through a range of cultural means, practices, and events. As a result of these efforts, the model succeeded in predominating in the debates on irrigation reform. In retrospect, the policy network contributed to reordering political and bureaucratic power relations and domains of expertise. Further, it helped to redistribute financial resource flows to multilateral agencies and national governments engaged with irrigation. Alongside the neo-liberal political and economic forces that were exerted on policy makers to reform their irrigation policies and that effectuate such changes, I have suggested that there is also a cultural process at work that penetrates institutions and mobilises officials to take on and replicate policy models.

The dominant status acquired by the Mexican model in the irrigation world was the outcome of the policy network's concerted effort to sustain it. The institutional capacity to produce and circulate a stream of cultural artefacts, such as policy documents and videos that conveyed the message of success to an increasing audience, was crucial. In addition, during international policy events the Mexican model was performed to convince influential policy makers. By means of this variety of cultural practices the success of the Mexican experience was narrated, validated, visualised, and performed. Such activities made it credible and appealing to an ever-larger group of trans-national policy makers and acquired their support.

This chapter has pointed to the importance of analysing the cultural and ideological processes of policy making in contemporary international policy networks to understand how and why certain policies are pursued and become a success. Until recently, the role of multilateral agencies and that of national bureaucracies and policy-making elites in governing such processes has not been studied much. I propose that a cultural and constructivist perspective on policy making would be suitable to take on this challenge. An interesting line of research that follows from this is the ethnographic study of policy in the making. Such an anthropology of the policy process would look at the performative and imaginative dimensions of policy making and analyse it as an ongoing process of cultural representation that takes place through a variety of social and material 
means. It requires the development of new analytical devices and methodological tools, for which I have provided some initial ideas.

\section{Notes}

1 The ideas I use from this article are drawn from a draft with provisional page numbers. This draft paper was presented at the Advanced Research Seminar of CERES, Wageningen (8 May, 2003). It's title was: 'Re-presenting Development: Reflections on the Ethnography of Aid Policy and Practice'.

2 In this chapter the term 'success' is used so frequently, that using quotation marks every single time would be irritating. The reader is kindly requested to imagine them every time the term is used and not to take its meaning for granted.

3 Those in academic and research institutions that held more informed views of what was happening in the field were often bureaucratically or ideologically tied to the CNA.

${ }_{4}$ The World Bank initiated the approach to participatory irrigation management (PIM), at a later stage institutionalised through an International Network on PIM (INPIM). The Mexican model became known as an international policy model for IMT or 'Participatory Irrigation Management' (PIM). These two institutional labels refer to the same policy, though the first indicates the process and the second the desired outcome (Gorriz et al., 1995; Groenfeldt, 1998). Henceforth, I shall mainly refer to IMT, but also imply PIM.

5 For other uses of the concept of policy network see: Sutton, 1999; Teichman, 1995.

- This term is a contraction of hydraulic bureaucrats or technocrats and is used here to refer to engineers working in water bureaucracies.

7 The CNA came under the jurisdiction of the SARH from 1989-94. Since 1994 it has come under the Ministry of Environment, Natural Resources and Fisheries.

- The World Bank experimented with a time-slice loan financing a government's full irrigation, drainage and flood control sector programme for a specified number of years. For the World Bank this was an important innovation compared to traditional project loans, as it provided more scope for policy dialogue and made it possible to reassess investment priorities and redirect financial flows.

- EDI provides most external training for the World Bank on high priority policy issues.

10 On several occasions these officials have warned against exaggerated expectations from replicating the Mexican model in other parts of the world and point to the specific conditions in which the policy worked in Mexico. Notwithstanding this, the policy network persisted in asking them to explain the Mexican model at policy conferences.

11 Vermillion and Sagardoy consider management transfer to be successful if it saves the government money, improves the cost-efficiency of O\&M, and maintains or increases the productivity of irrigated agriculture, and achieves financial and infrastructural sustainability (Vermillion and Sagardoy, 1999). Other objectives that are mentioned are to reduce the number of public employees in the irrigation districts (Johnson, 1997b), and the participation of water users in irrigation management through financially autonomous and administratively independent bodies (Poder-Ejecutivo-Federal, 1989: 77).

${ }_{12}$ This appears from a contribution of Dr Trava in the electronic forum on IMT of the FAO (September 2001): $T$ think we have spent a lot of time talking about the different ways to approach IMT (or PIM) or to develop the needed actions to make the program successful but in the meanwhile we have lost some perspective on what the overall idea is all about. The overall and basic idea in the end is to achieve a productive (socially and economically speaking) agricultural sector'.

13 Between 1990 and 1994 the CNA transferred nearly 2.5 million hectares, roughly three-quarters of the total irrigated surface in Mexico (CNA, 1994). See also the section on the visualisation of the model below.

${ }_{14}$ It is very likely that the international celebration of the Mexican policy model and the prestige it created for the political regime and the CNA reinforced this trend of acceleration (see Chapter 3 ).

15 These surveys are often strongly biased and a questionable basis for making statements about the quality of maintenance. It is not uncommon for questionnaires to be administered by canaleros (people in charge of distributing water at the field level), or other people who can be identified with the WUA, the bureaucracy, or the government in general. This, the strongly biased questions, and the context in which they are asked, are all likely to lead to tendentious responses.

16 After a first irrigation turn, it is forbidden by Mexican law subsequently to refuse water to the crop. 
17 For an exception, see Vos, 2002.

18 These privileged districts became pilot areas for international missions organised by the policy network. Initially, the CNA wanted to demonstrate the preliminary successes, i.e. the advances with the transfer policy. This was important for settling and executing the loan agreement. See Chapter 3. 


\section{Conclusions}

\subsection{The Practice of User Management and Outcomes of IMT}

The advocates of decentralisation and neo-institutional theory predicted that irrigation management transfer (IMT) would systematically reduce public irrigation expenditure; achieve financial self-sufficiency, managerial autonomy and accountability; and improve infrastructural sustainability, irrigation management performance and productivity. Nevertheless, the case study of the Left Bank irrigation system shows that IMT has produced an ambiguous set of changes and continuities. This becomes evident in the comparison of the theory with the practice and outcomes of IMT:

One of the major objectives of the Mexican government in initiating IMT was the reduction of public investment in irrigation management. The transfer of management of the irrigation system and a subsequently higher degree of cost recovery by water users' associations (WUAs) brought about this public reduction in irrigation expenditure. Since IMT, fee collection rates have risen. The Left Bank WUA improved the recovery of operation and maintenance (O\&M) costs and achieved a high degree of self-sufficiency within a few years of initiation. However, in spite of the policy objectives, IMT has not led to complete self-sufficiency and the concern exists that this problem will persist or even become worse. In addition, institutional efforts to increase fee collection have interlocked the WUA into a network of new dependencies on the agro-industry, subsidy providers and producer elites that challenges the meaning of 'financial autonomy' and its automatic connection with improved performance (see Chapter 9).

Despite the improved cost recovery of the WUA, it is uncertain what this means for its long-term viability and infrastructural sustainability. High financial self-sufficiency on the part of the WUA does not at all automatically imply the infrastructural viability of a module. In Chapter $7 \mathrm{I}$ have argued that maintenance is a particularly useful entry point to analyse the functioning and viability of irrigation systems. Maintenance improvements are undeniable, but they are selective and exclude particular areas and producer groups in the tail-end, as they fall outside the political constituency of the group in control of the WUA. The partial improvement can mainly be attributed to an increased and more adequate machine capacity, longer working days, and direct control over budgets and revenues for maintenance. However, because these machines are also a scarce and highly strategic asset for which there is high demand and a variety of uses in and around irrigation systems, their use is very intensive, which leads to breakdowns and high repair costs. Further, the question is whether the partially improved maintenance can be sustained in the longer run, given the frequent disrepair of the machinery and the continuing deterioration of the infrastructure. Deferred maintenance increases, because the annual fee increase does not keep up with monetary inflation. A high degree of selfsufficiency therefore does not secure adequate investment in (deferred) maintenance. It can also not reverse the fact that a major rehabilitation has never taken place before or after the transfer, something that will become a problem in the longer run. 
There is also little evidence of an improvement in system performance and an increase in efficiency of water use. WUA management has not significantly improved water distribution. Admittedly, the improvement in maintenance services seems to have led to a higher responsiveness of irrigation services to farmers' water demands, particularly in the neglected downstream areas. For the rest, there exists considerable continuity in allocation and distribution practices before and after IMT. This continuity lies in the persistence of a service relation in which a professional group of canaleros (people in charge of distributing water at the field level) and largely unmodified social and technological arrangements mediate between the irrigation institution and the irrigating constituency.

Further, this study has not found evidence of agricultural and economic productivity improvements as a result of IMT. It has shown no significant increase in area irrigated, cropping intensity, yields, or gross economic returns. Of course, this is partly related to the crisis in agriculture, and particularly to the decline of tobacco production in Nayarit over the last decade and a half, but that still does not validate a causal connection between IMT and a productivity increase. Finally, in contrast to the participatory policy rhetoric, a low level of direct participation on the part of water users and their representative delegates occurs in the WUA. This is upheld by the finding in this study that the formal financial and elective accountability relations that theory and policy assume are generally weak in practice.

Hence, on the Left Bank, IMT did not produce an unambiguous pattern of improvements. Reduced government expenditure, improved fee collection rates and maintenance services are undoubtedly important partial arguments for claiming that the IMT policy has had positive outcomes. However, the reported outcomes on selfsufficiency, water distribution, productivity, and infrastructural sustainability are neutral to negative. The doubt remains as to whether realising short-term financial objectives guarantees sustainable and productive irrigation districts in the long run. The most cynical interpretation, which does insufficient justice to the achievements of the policy, is that IMT, stripped to its core, means a decentralisation of the costs and problems of public irrigation management and a more effective centralisation and accumulation of revenues in the hydraulic bureaucracy.

In this thesis I have explained the above-described ambiguous pattern as follows. A local political group occupied the principal functions in the WUA and used it as a platform. Through the WUA, the group mobilised a variety of resources, personnel and facilities to organise a political campaign with the aim of launching its president onto the municipal peasant committee, CMC. From the WUA, the group distributes favours and privileged access to strategic resources to politically influential actors and producer groups in order to canvass financial and political support and build an electoral coalition. In this manner, they have expanded their support base in order to establish themselves politically in the municipal capital and possibly within the state government. Access to the WUA as the platform from which the group acts thus enables the organisation of a campaign and the cultural performance of a series of election events, and this results in an electoral victory and the career advancement of the WUA president. 
Hence, the transfer of irrigation management has opened up new opportunities for local groups to advance their political project and new paths for political ascension by opening up to them organisational control over local resources. This affects the way in which public resources are managed, but also generates new locations of power in the rural political landscape of a region. My contention is not that IMT has generally led to the use of WUAs as political platforms, the political appropriation of its resources, or that the influence of politics over irrigation management is necessarily always detrimental. However, my argument is that these are phenomena occurring much more broadly than is currently acknowledged, and this substantially affects the outcomes of IMT. Later in this chapter I will therefore argue that, in this respect, the Left Bank WUA is not at all an isolated case.

\subsection{Discrepancy Between the Policy's Proclaimed Success and its Practice}

The most remarkable feature of the IMT policy is the immense contrast between its nationally and internationally acclaimed success as a policy model and its ambiguous results and politically contested practice in Mexico's irrigation districts (see also Chapter 10). In a similar fashion, Pollitt (1995) argues that, in spite of the broadly proclaimed success of New Public Management (NPM) reforms, the underpinnings of their reputation are actually quite fragile. The paradox is that while the NPM doctrine insists that public services must invest much more heavily in the currency of measurable outputs, some fundamental aspects of NPM reforms themselves appear to have remained almost immune to such requirements. The limited existing evaluations are almost uniformly positive. Hence, despite its general call for evaluation, there have been relatively few broad-scope evaluations of NPM policies with an adequate set of methodologies. However, what explains this discrepancy between the policy rhetoric and the practice of transfer?

Firstly, it is the result of 'escape hatches' between political decision making and bureaucratic implementation or technical irrigation management, through which policy makers can avoid responsibility (Clay and Schaffer, 1984). Policy analysis is typically based on the description of a gap between a desired and an actual state of affairs, or between theory and practice. This tension induces the necessity for a set of policyengineered interventions with specified objectives to close the gap. The Mexican policy model is therefore structured as a black box that transforms a government-managed disorder into a new equilibrium of user management, which inevitably leads to success.

Secondly, this discrepancy occurs because policy making sets out what inescapably ought to be done and what stands to reason, rather than providing informative and descriptive accounts of actual practices or outcomes 'telling it as it is' (Apthorpe, 1986; Apthorpe and Gasper, 1996). The limited empirical description of actual processes of transfer and user management practices is usually selective and biased, and tends to confirm the central propositions of the model. The adoption of policies is usually also not informed by validated expectations about enhanced performance, but enhanced through other practices and performances. Hence, policy models are generally poor analytical tools for understanding actual organisational practices, events and effects, on the one hand, and the making and proliferation of policy, on the other. 
Thirdly, many policy approaches work to conceal the political nature of governing public infrastructure and natural resource management, for example by conceiving decentralisation as a way of providing an enabling environment for effective service provision, which is understood as an essentially technical task. A particularly effective aspect of neo-liberal policy discourse, as exemplified in the case of IMT, is the way in which it de-politicises what is actually to a large extent a painful cost-cutting operation. The discourse glorifies those policies and its advocates in a language and an imagery that are full of a kind of heroic euphoria: 'rolling back the state', 'champions of reform', 'strong government commitment', 'win-win situations', 'self-sufficiency', and 'the fast track of policy implementation'. The use of this discourse and imagery is closely linked to the celebration of success. It obscures several things that could potentially falsify the model, for example the politically contested nature of the IMT policy, the renewed autonomy for the hydraulic bureaucracy as an outcome of IMT and a prolonged bureaucratic struggle, and the political use of the WUAs and their resources.

Success is therefore not a verifiable claim that is systematically validated with straightforward empirical evidence by neutral researchers. Instead, as argued in Chapter 10 , the success of a policy model is only a success within the cultural and ideological understandings and practices of researchers within a wider policy network. This makes it hard to refute the model or deny its success. It burdens one with the immense task of falsifying the work of a whole policy network whose coherence rests on this idea.

An interesting understanding of the discrepancy results when I apply James Ferguson's (1990) argument about the development discourse in Lesotho to the IMT policy discourse: Policy making institutions generate their own form of discourse, and this discourse simultaneously constructs 'the irrigation sector' as a particular kind of object of knowledge and creates a structure of knowledge around that object. Policies are then organised on the basis of this structure of knowledge, and, although they fail on their own terms, they have regular effects that include the expansion and entrenchment of bureaucratic state power, side by side with the projection of economic and social life that denies 'politics' and suspends its effects. The network of institutions that make irrigation policy thus works as an 'anti-politics machine' that places political realities out of view but performs, almost unnoticed, the pre-eminently political operation of the expansion and entrenchment of bureaucratic state power (Ferguson, 1990: xiv). Hence, policy discourses have both institutional effects (maintaining relations of power) and ideological effects (de-politicisation). The institutional side effects of the IMT policy, such as the concentration of bureaucratic powers and resource flows under a single water authority (see Chapter 2), are whisked out of sight through technical discourses that naturalise poor irrigation performance under public management, objectify irrigation reform as an inevitable response to economic crisis, and de-politicise user management.

Although this reading is a very convincing interpretation of the discrepancy between success and the political practice of irrigation policy and management, there are three differences with how I approached this question, which Mosse (2003) handily sums up for me: Firstly, Ferguson takes the failure of development interventions as self-evident, whereas it is success that is clearly at the centre of this case. Secondly, he does not go beyond the instrumentality of policy but merely substitutes the stated policy goals with a set of real, unintended ends or effects, and the instrumental rationality of policy with the 
anonymous automaticity of the machine. Thirdly, his view does not do justice to the complexity of policy making as an institutional practice and its relation to actual irrigation management, nor to the creativity and skill involved in negotiating the effectuation of user management and the making of models, which requires the enrolment of a multiplicity of interests, points of view, intentions and strategies (Mosse, 2004).

Ferguson fails to examine the way in which a policy discourse becomes embodied and at the same time contested through concrete social and material practices, all of which influence how the policy develops, is sustained, and produces various, sometimes contradictory, outcomes. This requires the study of the processes through which the social behaviour of real life actors in connection with the organisations, resources and technologies at stake actually change or is reproduced in relation to the policy process and other ongoing processes. In this thesis I have explored such interconnected processes not only by studying the articulation of reforms (Chapter 2), the engineering of a policy package (Chapter 3), and the making of a policy model (Chapter 10), but also by documenting what the policy discourse actually means at the daily level of irrigation management by means of an organisational ethnography of a WUA (Chapters 4 to 9).

Studying the making both of policy and of organisation creates remarkable insights into the complex connections between policy and practice. For example, originally the policy discourse indicated a concern regarding the lack of infrastructural viability of irrigation districts as one of the main reasons behind IMT (see Chapter 2). Chapter 3 indicates how the IMT policy only really became practical through a policy package made up of particular technologies of governance developed by the Comision Nacional del Agua (CNA). In combination with increasing political and financial pressure and a selective distribution of resources, this contributed to reducing and removing resistance to the transfer, and consequently led to the acceleration of the transfer process. It is very likely that the international celebration of the Mexican policy model and the prestige it created for the political regime and the CNA also reinforced this trend of acceleration (see Chapter 3). However, the fast track of policy implementation did not unambiguously contribute to infrastructural viability of the irrigation districts (see Chapter 10), since it led to a skewed distribution of rehabilitation and maintenance resources. The districts that were later transferred after this acceleration, often less modern and more in need of rehabilitation, did not receive the same resources for rehabilitation as the already historically privileged, more modem and better maintained, and earlier transferred districts, that are mainly located in the North and Northwest of Mexico (see Chapter 3). This has led to the paradox that, on the one hand, the fast track of policy implementation was interpreted as a sign of success, whereas in practice it produced reverse effects for the infrastructural viability of all irrigation districts in Mexico.

On the Left Bank and probably in other districts that were transferred at a later stage, this pattern resulted in an emphasis on new maintenance machinery for solving the problem of deferred maintenance. This machinery played an important role in convincing selected local leaders to accept the transfer that they had initially resisted (see Chapter 4). Subsequently, the machinery became a source of conflict between those leaders and a political tool for the group that took charge of the WUA. This intimately affected the further organisational course of the WUA. In addition, it influenced the way 
in which the machinery especially improved maintenance in the central part of the irrigation district that belonged to the political constituency of the leading group in the WUA and partially excluded the tail-end section from such benefits (Chapter 7). These contradictory outcomes canniot be sufficiently explained by looking at the institutional and ideological effects of the IMT policy discourse. What is required is the study of the social and material practices that make up actual policy and organisational processes.

Hence, perhaps rather surprisingly, but with a touch of irony, I concur with the viewpoint that the Mexican IMT model is a success! However, it is based on very different grounds than might be expected and is a choice that reveals the political nature of success. I take success not as reflecting an unambiguous improvement in practice, process or outcomes on the ground, but rather for what its policy model achieved nationally and internationally: Throughout the 1990s, the policy model has had an enormous evocative and mobilising power in terms of promoting IMT/PIM (participatory irrigation management) among policy makers, researchers, experts and financiers and their institutions around the world. Retrospectively, the policy model has an impressive record in terms of playing a key role in the resumption of loans for the hydraulic bureaucracy, reordering bureaucratic sources and flows of power, finance, and expertise involved in irrigation, exemplified in the reconstitution of a hydraulic bureaucracy and the formation of an international policy network promoting IMT/PIM policies. This again contributed to changing international agendas for irrigation reform, aligning political will, bureaucratic and financial support for such policies, and so on. By means of a range of practices, means and events, the IMT policy model was culturally constructed in a way that made it convincing, credible, imaginable and appealing to an ever-larger group of trans-national policy makers, to bring them and their institutions together and mobilise their support, funding and expertise.

\subsection{The Political Opportunities Opened Up by Neo-liberal Policy}

Irrigation management transfer, like other neo-liberal policies that affect control over public resources, creates new political opportunities, platforms and patterns of political ascendancy. My organisational ethnography has specifically demonstrated how the Left Bank WUA became entangled in the regional politics of the state of Nayarit and how its personnel, facilities and resources were mobilised for the purpose of an election campaign in culturally and historically specific ways. It has not been my idea to argue that the Left Bank is a typical case representative of all other WUAs in Mexico. Instead, through this case study I have developed an original perspective on the organisation of resource politics and a sensitivity for its cultural aspects that allows me to look at similar cases and developments through a distinct lens and thus create insights that are relevant far beyond the boundaries of this case. Below I will indicate why the Left Bank is not an isolated case, firstly by identifying similar cases of WUAs in the literature, and secondly by identifying comparable phenomena that occur in the Mexican countryside as a response to neo-liberal policies of state disengagement.

The following authors observe similar phenomena occurring in WUAs to those which I have documented, although they vary from my perspective in three ways. Firstly, the first two authors use a rather mechanical state-centred model of state-society interactions 
dominated by particular corporatist and political relations, and this dictates which actors they see as empowered by the transfer and how this transforms the existing political landscape. Secondly, they do not fully analyse the implications for resource allocation. The third author does to some extent, but fails to review the political impact. Thirdly, the lack of a cultural perspective in the work of these authors seems to preclude identifying a possible diversity of outcomes.

According to Torregrosa Armentia (1998), the transfer of irrigation districts to WUAs has generated power lacunae that become potential areas for the reconstitution of lost power and former strength. Traditional political groups and corporatist factions, that were removed and lost power as a consequence of neo-liberal government policies, see these new power lacunae and will try to reconstitute their control over the users in the irrigation districts and their negotiation space vis-à-vis public institutions. In a broad review of socio-economic and political changes in nine large-scale transferred districts, Torregrosa Armentia takes the perspective of the diminishing power of traditional corporatist organisations as her starting point. She observes that the weakening of the ejido as an institution and the corporately organised ejido commissioners make these social-political factions search for their reinsertion and reproduction in other environments of local, regional and national influence, such as for example municipal presidencies, Sanidad Vegetal, and WUAs. For these groups, it means the reconstitution of their power space by means of clientelistic allocation and distribution of resources associated with the administration, distribution and control of water for agricultural production. Several of these groups have succeeded in consolidating themselves on the boards of directors of WUAs, supported by their federal corporatist networks, and reconstituting their political power through the control of water. The consequence is that water users distrust the WUAs and have withdrawn from participation because they do not feel represented by them. The danger that Torregrosa Armentia sees is that in the medium term these spaces will become the usufruct of a small fraction of producers, and not the spaces of interest representation and participation in decision making for the larger collective of water users. One of the specific cases to which she refers is the irrigation district at the Coast of Hermosillo (051) in North-western Sonora (Torregrosa Armentia 1998: 238). She observes that the management of the WUAs is completely interwoven with a major producer association (Asociacion de Agricultores del Norte de Sonora). The tasks and functions of the WUAs are not clearly delimited, and therefore there is no separation between water management and production, the board members are the same, the locality and infrastructure are shared, and the provision of marketing inputs and loans is integrated (Torregrosa, 1998).

The findings of Vargas Velázquez et al. (2000) also bolster my case. They identify the WUAs as privileged and contested political spaces for negotiation with government institutions and for the advancement of candidates to electoral positions. The WUAs have become an alternative space of intermediary power between the government and the users. Moreover, the WUAs constitute a privileged space of negotiation, from which producer groups can demand resources and programmes for the rural sector from government institutions, and from which their management have increased their influence and their local political networks. The main political parties, Partido Reoolucionario Institucional (PRI: Institutional Revolutionary Party), Partido de la Reoolución Democrática (PRD: Party of the Democratic Revolution) and Partido Acción 
Nacional (PAN: National Action Party) made systematic attempts to take possession of the leading positions on the boards of the WUAs, to use these public spaces as political platforms to launch candidates for local or federal positions of popular election. These parties attempted to control or influence the WUA boards, as the water that they control is the most important agricultural input in the region. Hence, WUAs have become politically contested spaces that can be used for the advancement of political careers.

From the perspective of state-farmer relations, the authors review the transfer of the large-scale Alto Río Lerma irrigation district (011) to ten WUAs, which together have formed an overarching society of limited liability (SRL). They show that the new WUAs have gained ground and a certain degree of autonomy and helped to eliminate the traditional hegemony of corporatist organisations and their form of representation of peasant interests. The old corporatist organisations were not functional to the state anymore, as it needed to integrate new actors, such as rural producers with a capacity to compete on the market, agro-industrial companies, and local PRI committee members. For the government and for rural producers, the corporatist organisations were no longer the privileged interlocutors for resource allocation and political representation in irrigation districts and at present there exist multiple producer organisations that do not operate along corporatist lines (Vargas Velázquez et al., 2000). With the transfer of irrigation management, another organisational form of rural producers is added to the spectrum of organisations that represent the interests of irrigating peasants and rural producers vis-à-vis government institutions. This implies a rearrangement of forces and a readjustment of the forms of intermediation between the state and rural producers (Vargas Velázquez et al., 2000). For the leadership of a WUA, these emergent organisational spaces open up access to new political constituencies, administrative resource flows, government programmes, infrastructure, and strategic assets such as machinery.

According to the authors of this study, the importance of the modules as a political space was most evident in two of the four modules analysed: Abasolo and Salvatierra, where conflicts emerged between different groups supported by political parties to gain control over the positions on the WUAs' boards or to replace the current board. In the case of Salvatierra, a member of the board of the WUA successfully launched himself as a candidate for the local municipal presidency for the PRD. What was thought to be essential by an informed government official was the political use of a wide network of relations with local organisations, such as ejido unions, agricultural associations and societies of rural production that could be co-ordinated and accessed from the WUA. Further, the WUA gained a central role in the organisation and provision of additional services to users, such as fertilisers, machines, and the levelling of land. Kloezen also reports on the political struggles within the Salvatierra WUA, where the WUA president from a well-to-do family with connections in the PRI had gained political leverage in the town of Salvatierra because his brother became mayor (Kloezen, 2002: 130-131). At the end of 1995 , when his term ended his position was increasingly challenged by political accusations of financial mismanagement and corruption. Although he received support from within the PRI and the CNC (national peasant committee), he was forced to accept one of his critics as vice-president and general manager. At a later stage, the vicepresident succeeded him as president and successfully used the WUA as a political platform to win the elections for mayor of Salvatierra (Vargas Velázquez et al., 2000). 
Monsalvo Velázquez (1999) concludes, with respect to WUAs in the Alto Río Lerma (010) and the Laguna Districts (017), that in many cases land and water resources are concentrating in the hands of a person or a company that controls and starts to demand 'cuota de poder' (power quota) in the political field.

Palacios Vélez (1997) also observes some cases in which those occupying positions on the board use the WUA as a springboard to political positions. He refers to one case in particular in Valle de Banderas on the Southern Coast of Nayarit. According to representatives of this association, WUA funds were used for a political campaign. Such actions disrupted O\&M and threatened the very existence of the association. A group of water users requested an independent investigation, because the former president of the WUA used this position to launch himself as municipal president of the neighbouring town. Because of the funds that he diverted, he left the WUA with a large debt ${ }^{3}$. Nevertheless, the CNA state representative did not intervene. There was the danger that as municipal president the president of the WUA would put pressure on the state government to transfer him (see also Chapter 9). This type of investigation should not too easily be understood as a sign of accountability, but rather as a weapon of a competing alliance for organising support to remove the sitting board and occupy the vacated positions. Hence they are often triggered as part of a struggle for power and spoils (cf. Wade, 1982: 310).

By reviewing comparable processes of state disengagement in resource management that took place in the region and in Mexico, we can also see that neo-liberal policy creates political contest over, and use of, organisational spaces and resources and that this is not specific to IMT. Snyder (1999) argues that, by vacating institutionalised policy domains, neo-liberal reforms give political incumbents opportunities to expand their authority and support bases. In an article about the deregulation of the Mexican coffee market and the dismantling of the state-owned enterprise Inmecafe, he shows that this triggered politically motivated institution building, driven not by technical or market exigencies but by ambitious exigencies looking to control these policy areas vacated by state downsizing. The distributive effects of this policy generated powerful incentives for political action. The possibility to distribute favours, privileged access, and individual exceptions to rules, similar to that which I have described in the preceding chapters, generates resources by which to govern, build political support and compete for power (Snyder, 1999: 177). These kinds of political processes also emerged in similar cases of decentralisation in agricultural institutions in Nayarit. For example, Chapter 8 highlights the political role of ARIC in Nayarit that emerged after the dismantling of the parastatal, Tabamex. As a tobacco producers' organisation, ARIC became an important financier of the electoral campaigns of PRI candidates for the governorship. In addition, it enjoyed political influence in many tobacco-producing ejidos and municipalities and was occasionally allocated, by the PRI, the political post of deputy in these regions on the coast of Nayarit. From the situational analysis in that chapter it also became evident that a relatively new organisation like Sanidad Vegetal, entrusted with the former government task of crop hygiene, is involved in the political struggle between producer organisations and the political control of the state government over the marketing of large quantities of beans, shattering all promises and hopes of free trade. 
For several decades now, the corporatist peasant organisations have no longer been the privileged interlocutors for resource allocation and the political representation of rural producers vis-à-vis government institutions, the agro-industrial enterprises and other forces. As a result of a retreat of the state apparatus and a decline in corporatism, we see the upsurge of a range of new forms of power and authority. At present, there exist multiple organisations that represent demands and forms of participation that do not operate along corporatist lines (Vargas Velázquez et al., 2000). Like other types of producer organisations, WUAs occupy the institutionalised policy domains that neoliberal reforms have vacated, they constitute new spaces to represent producers, and they acquire control over an organisational and physical network for resource allocation.

The political and producer elite groups that frequently come to dominate these user organisations are in a favourable position to appropriate these resources by generating and sustaining political support among electoral constituencies. Under such circumstances, these political incumbents are able to convert a WUA into a platform that enables an alternative pattern of political ascendancy. As a result, the WUAs become public institutions that are uniquely placed to articulate positions of power and political affiliation, provide opportunities to challenge authority, and canvass political support (Mosse, 1999: 326). In addition, the WUAs appear to have a remarkable potential to coordinate the wider network of rural organisations and concentrate, control and allocate resource flows, facilities and services that are essential to irrigated agriculture. Further, the organisation of irrigation districts and water users and the concentration of resources and power are subsumed under the direct or more distant control of the hydraulic bureaucracy. This provided a basis for its reconstitution and its autonomy from the agricultural and the environmental bureaucracy (see Chapters 2 and 3 ).

Hence, WUAs are a crucial case for studying the powerful entanglements of resource allocation, producer organisation, bureaucracy and politics. Furthermore, they are a convergence point for a form of heterogeneous control over people, resources, and infrastructure, which is not necessarily located within the state, but also does not singularly represent market forces or civil society. To understand such interconnections, it is necessary to transcend conventional state-centred models, public-private and statesociety dichotomies.

When the wider pattern of outcomes that these authors observe is reviewed, it is not so evident that one particular type of political actor will necessarily appropriate the new organisational spaces vacated by IMT and other decentralisation policies - corporatist groups, political parties, former government officials, agro-industrial enterprises, ejidos, producer associations, or possibly alliances between such groups? And it is also uncertain for how long such groups or alliances can control these organisations and how far-reaching their influence will become over politics and the reconstitution of the rural political landscape. This depends on many factors and requires further research.

Again, a policy like IMT does not produce a homogeneous but a diverse pattern of outcomes, as Long and van der Ploeg have argued (Long and van der Ploeg, 1989). Central and often overlooked elements in the realisation of such uneven outcomes are the structural discontinuities or interfaces between for example policy makers and farmers (Long, 2001), the heterogeneity in political culture between regions (Rubin, 
1990), and the nature of local social organisation and how it links with regional and national centres of power (Enge and Whiteford, 1989). This is not to reify culture, power or politics as unchangeable and inescapable realities, cast in concrete or fixed in genes, but to acknowledge the persistance of political and cultural patterns in human behaviour, as well as the differentiation and heterogeneity in relations of power. The political opportunities that IMT opens up are appropriated and the WUA's resources mobilised by political actors who pursue a rational strategy to gain power and wield authority. They do so, however, according to culturally and historically specific ways, not according to the universal rational behaviour that the neo-institutional theory underlying the IMT model presumes.

\subsection{An International Workshop}

Several of my findings and their analytical interpretation were confirmed during an international workshop on drainage organised by the World Bank at the end of 2002. I attended the presentation of one of the senior CNA officials, who had been closely involved in the actual initiation and organisation of the transfer. As a civil engineer, he was part of the influential team of planners that managed the CNA during its first presidential term under the Ministry of Agriculture, SARH. Before his presentation, in the corridors he confirmed his own role in deciding upon the transfer and stated that they had come up with the idea, which President Salinas subsequently 'bought' (see Chapter 2). He recalled that the whole project had been very difficult, but that they had had very good results.

In relation to the Alto Río Lerma district (011), the former CNA official remarked that it was an example for the rest of the country, because of the hundreds of meetings that had been organised to convince the users about transfer. The decision was finally made at a meeting with all the top leaders of various parties - there were even representatives of the Communist Party there. It was clear to the leaders that the CNA were in favour of transfer. An old man asked him whether this meant that they would be able to dismiss canaleros. He confirmed this and the leader responded by saying that, if that were true, he would immediately sign. The official immediately walked towards this person and asked him to sign a paper. In the end, the leaders approved the transfer, in spite of the fact that they also had to accept a large fee increase (see Chapter 3).

Although the official's PowerPoint presentation concerned a research project on drainage, the audience of international officials, consultants and researchers had a great interest in knowing about the IMT experience, and it became evident that the Mexican model was still thought of as relevant to contemporary water management issues (see Chapter 10). There was a perceptible respect among the audience for the fact that the official stood at the base of this policy. One of those attending asked the former CNA official what the main 'drivers' were behind the political will for the transfer in Mexico. He responded that there were several: to start with, 'the looe and care for our country and the irrigation systems'. He explained that the irrigation systems were destroyed when the CNA fell under the Ministry of Agriculture. The way to solve this was to transfer the districts and to give the WUAs autonomy and their own resources (see Chapter 2). Irrigation was behind other sectors in this respect. The banks and CFE (Comisión Federal 
de Electricidad: Federal Electricity Commission) were already privatised, but in the irrigation districts they still had more than 40,000 canaleros. After the transfer this number was reduced to 4,000. 'Imagine the problems when we had negotiations with the trade unions', he remarked. People laughed. Another important driver was selfsufficiency. For this the size of the WUA was important. They have to be of a certain size, the largest are 20,000 hectares and the average is around 5,000 hectares. He reminded the audience that the WUAs are service providers or enterprises: they have to collect charges (see Chapter 9).

The former CNA official was of the opinion that currently the transfer is of great importance to the country and its agriculture to further develop. At the moment, the producers think that water is the most important resource. At the beginning they thought the machines the most important, the offices, the infrastructure, the canals and the dams, but now they think water is the most valuable (see also Chapter 7). He concluded that nowadays it is more important to become president of a WUA than a member of the congress or a mayor (see Chapter 8). Later in the meeting he stated that the present second-generation problems of the transfer were transparency and accountability.

This workshop was a highlight that illustrated the importance of several analytical interpretations with regard to the IMT policy process. In the first place, it underlined the contemporary relevance of cultural performance by policy makers (reformers, champions) at international workshops in promoting the success of the IMT model. Even if the former CNA official had not intended to speak about the policy model, his international and informed audience of experts would have asked it of him. This shows that the momentum of the model transcends individual intentions. However, the former official was willing to shed light on his role in the process, as it generates a fair amount of personal prestige. Secondly, there is the political nature of the execution of the IMT policy, as evidenced by the negotiations with selected leaderships of political parties, farmers and trade unions (see Chapter 3). Thirdly, there is the powerful political role of the WUAs in the rural political landscape (see Chapter 8). Fourthly, there is the apolitical nature of his concepts of WUAs as service-providing enterprises (see Chapter 8) and water as a productive resource for agriculture (see Chapters 5 and 6). This stands in stark contrast to his own descriptions of WUAs as politically powerful entities that consider water, machines, offices and infrastructure to be strategic resources. The second-generation problems of transparency and accountability are signalled but not explained in the official's discussion. Yet, they become intelligible in a perspective that acknowledges the political potential of WUAs and the resources that they control and the cultural performance of transparency and accountability (See Chapter 9). Fifthly, there is the way in which, according to the official's interpretation, the political power of the WUAs even becomes evidence of the success of the IMT policy (see Chapter 10).

\subsection{The Ethnography of Irrigation, Policy and Organisation}

Colloquially it is often said that the study of irrigation has moved from concrete hardware to the human software. A shift in attention that may be needed to progress further in that direction may be from the formal and normative to the variety of actual 
social and material practices that constitute and are tied up with irrigation. The ethnographic study of policy in the making brings out the behavioural, unofficial and unintended aspects in policy making. Ethnographic and social anthropological perspectives also permit us to look at the performative and imaginative dimensions of policy making and analyse it as an ongoing process of cultural representation that takes place through a variety of social and material means. The use of ethnographic methods to study organisation and policy is nowadays advocated from various sources (e.g. Grillo and Stirrat, 1997; Mosse, 2004; Shore and Wright, 1997; Strathern, 2000). This study thus hopes to show the value of such an approach and provide some initial ideas for the development of new analytical devices and methodological tools oriented to this purpose.

\section{Notes}

In the history of 'transformation' policies, such as land reform or participatory 'community development', it has not been unusual for the costs and problems of development to be foisted upon local people, that is without them showing much willingness to take on certain responsibilities. In this way the state reduces the costs to itself. Hence, decentralisation under neo-liberal measures is only the most recent case of this kind (I thank Norman Long for making this point).

2 Land reform communities created after the Mexican Revolution of 1910. Before the revision of Article 27 of the Constitution in 1992, ejido land belonged to the state, with a combination of community (ejido) and private (ejidatorio) usufruct. Ejido members are called ejidatarios.

3 Interview with ex-CNA official, 21" of May 1999. 


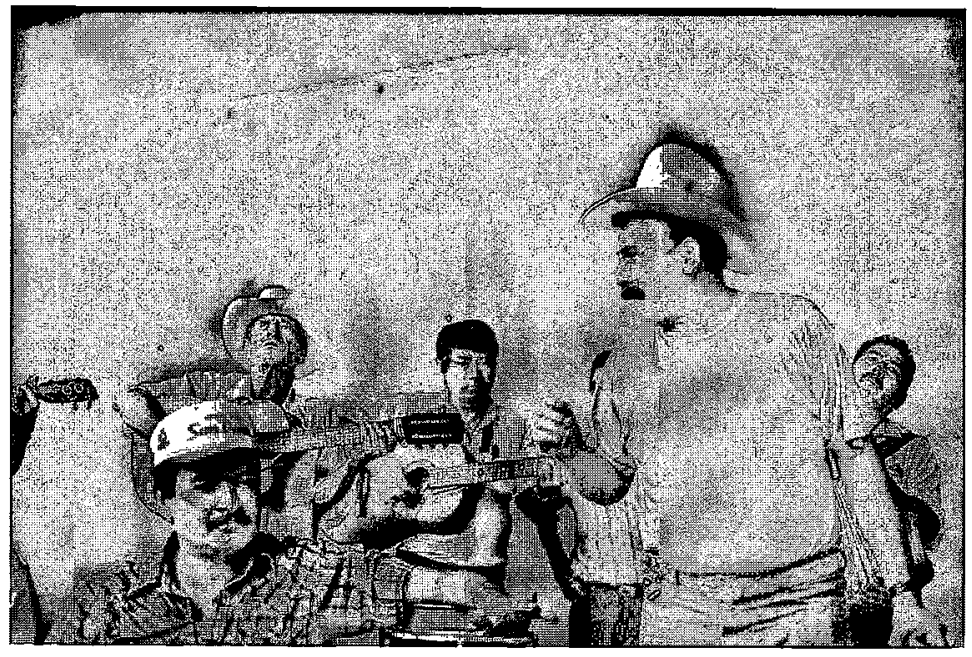

Photo 26 A song in the cantina 


\section{Epilogue on the Culture and Politics of the Gold Coast}

I close this book with an epilogue that provides an open perspective on the political culture of my research location: the Northern Coast of Nayarit:

The history of the Northem Coast of Nayarit has been intimately interwoven with the production of tobacco. During the nineteen fifties and part of the sixties, the region experienced a real boom in agriculture, and tobacco in particular was a most profitable crop. People used to call it: oro verde (green gold). In this period the northern coast received its glorious name: $L a$ Costa de Oro (The Gold Coast). The national and multinational tobacco companies mainly worked with medium and large-scale producers, who became the most prosperous farmers in Nayarit. Nowadays, after the nationalisation of tobacco production in the 1970s and the dismantling of the parastatal, Tabamex, the popular recollection of the period during which the Northern Coast of Nayarit was called 'the Gold Coast' is still in the minds of many ejidatarios in the region, especially now that tobacco is no longer such a profitable crop and only provides them with a meagre subsistence that means misery to most of them. 'Now it's not even the Copper Coast', people tend to exclaim. With pleasure, tobacco producers recall the days when a tobacco producer with four hectares was able to buy a brand new pick-up after his annual payment. When people want to express how much money was earned in those days, they tell you that the cantinas in the region were packed at the time that the companies paid out. Modest ejidatarios contracted mariachi groups that playe $\mathrm{d}$ all night long for them, whilst they were drinking, until they fell asleep at their table. Politicians from Nayarit also like to refer to this collective mythical past of the Northern Coast. It corresponds with age-old visions of the abundance in this region (see Chapter 4) and also holds a promise for the future.

An experienced official of the former Secretaria de Recursos Hidrálicos (SRH: Ministry of Water Resources) also recalls that people used to earn large amounts of money, but that many people used their money foolishly, spending it in the cantinas on beer and music. The producers who saved money in those years are now rich. According to this official, the rest are as badly off as before. Shortly after this conversation I talked about the same matter with two ejidatarios whom I knew from the coast. I remarked that this period of great affluence was not so noticeable anymore. One of the two, who is relatively well to do, protested that some people improved their houses and conditions and that this could still be seen nowadays. The other ejidatario, who worked for the first man, said nothing. He only smiled. When I looked at him for an answer, he silently responded by making two meaningful gestures. The first was with his right hand extending both thumb and little finger outwards, whilst pointing the thumb downwards to his mouth. This is Mexican sign language for drinking. For the second gesture, he took up a dance position with both arms, holding one behind the lady's back and pushing the other up in the air. He finished it off by loosely shaking his shoulders and, whilst we broke into laughter, we understood that the lady was not his wife.

It is also no coincidence that people currently often remember those prosperous days when they are together drinking. This evokes a collective sensation of grandeur and extreme pleasure, often leading to more drinking. At such a moment many people are 
proud of this preference and like to expose it. This creates a sense of liberty and heroism. A popular traditional song that best represents this powerful and dramatic sentiment is called: 'Mi gusto es...' (my liking is...). The tenor of this song that is sung by a male singer who is accompanied by loud festive brass music goes something like this:

'My liking is...'

'Who will take it away from me?'

'Only God in heaven will take it away from me'
(Unspecified, left open to imagination)

(Nobody, of course, or perhaps...)

(Well ok, that is in a different league)

The song then introduces a pretty young lady and love, but in the end she also has to understand that even if they threaten to shoot him:

\section{'Mi gusto es...'}

Most great politicians with clout in the region are past masters at incorporating and putting to political use this set of popular recollections among ejidatarios and cultural preferences of people more generally on the Northern Coast of Nayarit. I am especially thinking of two electoral scenes in which the performance of such cultural competencies became very evident: first, the campaign for the municipal peasant organisation of Santiago Ixcuintla in 1998 described in Chapter 8; second, a campaign event of the candidate governor for the opposition, entrepreneur Echeverría Dominguez, in his hometown Santiago Ixcuintla, opportunely organised during its annual festivities. Only a few months after the death of the PRI patriarch, Don Emilio, all hell broke loose in the regional PRI, and divisions emerged over his succession. One of his most senior protégés, the influential and affluent old guard Priista Echeverría Dominguez, saw his way blocked to the governorship and left the PRI. He forged an alliance with a diverse range of opposition parties, most importantly the PAN, PRD and PT (Partido de Trabajo: Labour Party), and won the elections for governor in 1999. A few months before that:

Imagine a nocturnal carnival with bandas (musical groups) playing all along the colourfully lit main street of Santiago Ixcuintla. Cheerful and energetic people crowd the streets. The air is filled with music, dance and hormones, and the beer flows. As the candidate, Echeverría leads a procession followed by his supporters through the main street greeting the drinking and dancing crowds that cheer him on. One after another banda that Echeverría passes with his procession immediately stops what it is singing and starts playing his campaign song: 'Mi gusto es...' It is a reflection of his excellent preparation and financial means. People in the audience sing the song enthusiastically with him. The climax of the evening approaches when the candidate governor accepts a can of beer from a woman in the crowd. Fortunately, the beer is of the brand Modelo that 
Echeverria as entrepreneur distributes in Nayarit. The woman invites him to dance with movements that shake the stout fundaments of her body. Echeverría accepts, puts the beer can on his head and balances it whilst he dances with her. The people around shout and applaud in approval. This is electoral propaganda and commercial advertisement at the same time. Using this sort of populism that he has learned in the PRI, he beats this party on its home ground.

A few blocks back, the PRI celebrates its own party with music and drink. I see the PRI candidate, Lucas Vallarta, who is also from Santiago, sitting at a long table and talking to some old acquaintances. However, it appears that the PRI has not the money to contract the best bands and the enthusiasm of the audience is notably less than in the place I have just left. At the comer of the street, I spot Nuñez with a companion. He greets me more enthusiastically than he usually does and appears a bit lost. I notice that he is pretty drunk already. He becomes very melancholic and reminds me that he has always been there to help me. I am his friend. It is really a sad melancholy, caused by his bleak career prospects, it seems. His patrons, Felix Torres and Pérez, have not been chosen as the official PRI candidates for the governorship and the mayorship of Santiago, respectively. Felix Torres has already swapped the PRI for the PT, but Pérez chose to support the PRI candidate, Vallarta. Pérez' name is mentioned as Minister of Agriculture and at a later stage, in a final attempt to capture votes for the PRI, Vallarta even promises at a campaign meeting that he will make the Left Bank a separate municipality (see Chapter 4).

Nuñez' future, however, is not clear. Although his name was initially mentioned for mayor, deputy and other important posts, he now has to settle for a minor post in the municipality - this in spite of the fact that he organised several protests, occupations, and mobilisations, and media opposition to ARIC on behalf of the peasant sector. Although he has some other options, not one of them is secure. Nuñez recently sold his land to his brother and therefore requires a new source of income. In the euphoria after his electoral victory at the $\mathrm{CMC}$, his political ambitions surpassed and conflicted with those of his patron Pérez, which resulted in a row between them. Pérez temporarily withdrew his support and since then Nuñez has been leading a more solitary political course. Although he will be president of the CMC for another two years, everybody knows that there is nothing more there. His term as president of the ejido of Solorceño has ended, and the new president has threatened to start an investigation into his period in office. Nuñez' term in the WUA is also coming to an end, and, worse, criticism of his performance is increasing. Guttiérez and Diego have already been removed under accusations based on an investigation into managerial affairs at the association. While the celebrations continue around us, Nuñez recalls that he still needs to talk to somebody. He takes his leave of me and vanishes into the crowd.

In July 1999 Echeverria wins the elections for the governorship, and most municipalities and congress seats are won by his alliance of opposition parties. Pérez' group is one of the big losers. A few months later they also lose the WUA elections. The electoral loss of the PRI and the resulting political changes in Nayarit strengthen the formation of an alliance that is organised behind the scenes among dissatisfied ejido delegates, WUA employees and CNA officials. It runs its own list of candidates and wins the elections. A new board of directors is installed at the end of my fieldwork period. The latter 
developments indicate that the influence of irrigation is by no means all determining in regional politics, but rather that larger political processes influence the management of irrigation systems.

This exploratory account includes elements of the regional history and the political, electoral and cultural practices that proved to be important in my ethnography of organisation. It shows that particular materials, preferences and ideas are mobilised in the cultural performance of election campaigns. Conspicuously, alcohol serves as an electoral elixir that brings together people and catches their votes in what is called constructive drinking (Douglas, 1987), wet politics (Fallaw, 2003), or the politics of enjoyment (de Vries, 2002). Further, elections are publicly celebrated in a way that engages an audience of prospective voters with music and through the sensual play of bodies in dance. Furthermore, the building of electoral support also occurs through identification with the joint glory of regional myths, collective recollections of tobacco and prosperity; and ultimately, the sentiments shared through a song. 


\section{References}

Aboites, L. (1998) El Agua de la Nación: Una Historia Politica de México (1888-1946). Mexico City: CIESAS.

Adler Lomnitz, L. (1994) Redes Sociales, Cultura y Poder: Ensayos de Antropología Latinoamericana. México: Facultad Latinoamericana de Ciencias Sociales.

Aitken, R. (1999) 'Localizing Politics: Cardenismo, the Mexican State and Local Politics in Contemporary Michoacán'. PhD dissertation, Leiden University.

Apthorpe, R. (1986) 'Development Policy Discourse', Public Administration and Deoelopment 6: 377-89.

Apthorpe, R. and D. Gasper (1996) Arguing Deoelopment Policy: Frames and Discourses. London: Cass.

Arce, A. (1993) Negotiating Agricultural Deoelopment: Entanglements of Bureaucrats and Rural Producers in Western Mexico. Wageningen Studies in Sociology no. 34, Wageningen: Agricultural University Wageningen.

Arce, A. (1994) Regulating or Creating Development Diversity?: Cases and Reflections on Languages of Development', paper presented at the workshop Languages of Development, Berkeley, California (October 1994).

Ascher, W. (1999) Why Gooernments Waste Natural Resources: Policy Failures in Deoeloping Countries. Baltimore and London: The Johns Hopkins University Press.

Auyero, J. (2000) 'The Logic of Clientelism in Argentina: An Ethnographic Account', Latin American Research Review 35 (3): 55-81.

Bartra, R. (1975) Caciquismo y Poder Político en México. México: Siglo XXI.

Baumard, P. (1999) Tacit Knowledge in Organizations. London: Sage.

Beetham, D. (1987) Bureaucracy: Concepts in Social Thought. Minneapolis: University of Minnesota Press.

Beezley, W. H., C. E. Martin and W. E. French (1994) Rituals of Rule, Rituals of Resistance: Public Celebrations and Popular Culture in Mexico. Wilmington: Scholarly Resources.

Boissevain, J. (1974) Friends of Friends: Networks, Manipulators and Coalitions. Oxford: Basil Blackwell.

Bolding, A., P. P. Mollinga and K. v. Straaten (1995) 'Modules for Modernisation: Colonial Irrigation in India and the Technological Dimension of Agrarian Change', Journal of Deoelopment Studies 31(6): 805-44.

Bos, M. G., D. H. Murray-Rust, D. J. Merrey, H. G. Johnson and W. B. Snellen (1994)

'Methodologies for Assessing Performance of Irrigation and Drainage Management', Irrigation and Drainage Systems 7: 231-261.

Bottrall, A. (1981a) 'Improving Canal Management', Water Supply and Management, 5: 67-79.

Bottrall, A. (1981b) 'Comparative Study of the Management and Organization of Irrigation Projects', World Bank Staff Working Paper no. 458, Washington, D.C: World Bank.

Bourdieu, P. (1977) Outline of a Theory of Practice. Cambridge: Cambridge University Press.

Bourdieu, P. (1984) Distinction. London: Routledge and Kegan Paul.

Brewer, J. D., R. Sakthivadel and K. V. Raju (1997) Water Distribution Rules and Water Distribution Performance: A Case Study in the Tambraparani Irrigation System', 
IIMI Research Report 12. Colombo, Sri Lanka: International Irrigation Management Institute.

Buras, N. (1983) 'Water Resources Planning in Mexico: The First National Water Plan', paper presented at the Second U.S.-Mexico Conference on the Regional Impacts of U.S.-Mexico Economic Relations: Challenges and Opportunities. Tuscon, Arizona (25-27 May).

Burgess, R.G. (1984) In the Field: An Introduction to Field Research. Contemporary Social Research 8, London: Routledge.

Callon, M. and J. Law (1995) 'Agency and the Hybrid Colletif', South Atlantic Quarterly, 94 (2): 481-507.

Camp, R.A. (1999) Politics in Mexico: The Decline of Authoritarianism. New York and Oxford: Oxford University Press.

Castañeda, J.G. (1999) La Herencia: Arqueología de la Sucesión Presidencial en México. Mexico City: Extra Alfaguara.

Castro, J. E. (1995) 'Decentralization and Modernization in Mexico: The Management of Water Services', Natural Resources Journal 35: 461-87.

Centeno, M. A. (1994) Democracy within Reason: Technocratic Reoolution in Mexico. Pennsylvania: Pennsylvania State University Press.

Clay, E. and B. Schaffer (1984) 'Room for Manoeuvre: The Premise of Public Policy', in E. Clay and B. Schaffer (eds) Room for Manoeure. An Exploration of Public Policy in Agriculture and Rural Development, pp. 1-13. Heinemann studies in Development and Society. London: Heinemann Educational Books.

CNA (1990) 'Water Policies and Strategies'. Mexico City: CNA.

CNA (1991a). Programa de Transferencia de los Distritos de Riego a los Usuarios. Noviembre 1991'. Mexico City: CNA.

CNA (1991b) 'Transferencia de los Distritos de Riego a los Usuarios. Abril 1991'. Mexico City: CNA.

CNA (1991c) Instructivo para la Transferencia de los Distritos de Riego a los Usarios (versión preliminar)'. Mexico City: CNA.

CNA (1992) "Terminos de Referencia y Especificaciones que Integran el Documento del Distrito de Riego No. 043, "Estado de Nayarit", El Cual Será Transferido a los Usuarios'. Tepic: CNA.

CNA (1994a) Transferencia de los Distritos de Riego en México. Mexico City: CNA.

CNA (1994b) 'Informe 1989-1994'. Mexico City: CNA.

CNA/SARH (1992) Crónicas del Agua: Los Distritos de Riego Guasave y Río Fuerte, Sin. Y Delicias, Chih. En Manos de los Productors. México: CNA/SARH.

Contreras Valdez, J. M. (2001) Reparto de Tierras en Nayarit: Un Proceso de Ruptura y Continuidad. México: Instituto Nacional de Estudios Históricos de la Revolución Mexicana.

Cook, L. M., K. J. Middlebrook and J. M. Horcasitas (1994). 'The Politics of Economic Restructuring in Mexico: Actors, Sequencing and Coalitions Change', in L. M. Cook, K.J. Middlebroook and J. M. Horcasitas (eds) The Politics of Economic Restructuring in Mexico: State-Society Relations and Regime Change in Mexico. San Diego: La Jolla: Center for U.S.- American Studies, University of California.

Cornelius, W., A. Craig and J. Fox (1994) Transforming State-Society Relations in Mexico: The National Solidarity Strategy. San Diego: Center for US-Mexico Studies, University of California. 
Cornish, G. (1998) Modern Iirrigation Technologies for Smallholders in Developing Countries. London: Intermediate Technology Publications.

Cummings, R.G. (1974) Interbasin Water Transfers: A Case Study in Mexico. Baltimore: Johns Hopkins Press.

Cummings, R.G., V. Brajer, J.W. McFarland, J. Trava and M.T. El-Ashry (1989)

Waterworks: Improoing Irrigation Management in Mexican Agriculture. Washington,

D.C: World Resources Institute.

Dealy, G. C. (1992) The Latin Americans: Spirit and Ethos. Boulder: Westview Press.

Demmers, J. (1998) 'Friends and Bitter Enemies: Politics and Neoliberal Reform in Yucatán, Mexico'. Amsterdam: Thela.

Diario Oficial (1946) Ley de Riegos. Mexico City: Diario Oficial.

Diario Oficial (1972) Ley Federal de Aguas. Mexico City: Diario Oficial.

Di Maggio, P. and W. Powell (1983) 'The Iron Cage Revisited: Institutional Isomorphism and Collective Rationality in Organizational Fields', American Sociological Review 48: 147-60.

Douglas, M. (1987) Constructive Drinking: Perspectives on Drink from Anthropology. Cambridge: Cambridge University Press.

Durán, J.M. (1988) Hacia una Agricultura Industrial? México 1940-1980. Guadalajara: Universidad de Guadalajara.

EDI (1995) 'Participatory Irrigation Management: Seeing is believing', .Video-tape. Washington: World Bank.

Enge, K. and S. Whiteford (1989) The Keepers of Water and Earth: Mexican Rural Social Organization and Irrigation. Austin: University of Texas Press.

Engstrand, I. H. W. (1993) San Blas de Nayarit. México: El Colegio de Jalisco.

Espinosa de León, E. (1994) Transferencia de los Distritos de Riego: Libro Blanco General'. Mexico City: CNA.

Espinosa de León, E. (1998) 'La Transferencia de los Distritos de Riego a las Asociaciones de Usuarios', in Proceedings of the First International Seminar on Integrated Water Use (August 1998). Part I. Article 2-13. Chapingo: Universidad Autonomo Chapingo. Espinosa de León, E. and J.L. Trava (1992) 'Transferencia de los Distritos de Riego a los Usuarios', paper presented at the Tercera Conferencia Regional Panamericana, Mazatlán, Sinaloa: ICID (November 1992).

Fallaw, B. (2002) 'Dry Law, Wet Politics', Latin American Research Review 37 (2): 37-64.

Ferguson, J. (1990) The Anti-Politics Machine: 'Development', Depoliticization, and Bureaucratic Power in Lesotho. Cambridge: Cambridge University Press.

Ferguson, J. (1998). "Trans-national Topographies of Power: Beyond "The State"and "Civil Society" in the Study of African Politics', in H. S. Marcussen and S. Arnfred (eds) Concepts and Metaphors: Ideologies, Narratives and Myths in Deoelopment Discourse, Roskilde: Roskilde University.

Fisher, G. (1953) Directed Cultural Change in Nayarit, Mexico: Analysis of a Pilot Project in Basic Education: Tulane University.

Foucault, M. (1977) Discipline and Punish: The Birth of the Prison. London: Penguin books. Fox, J. (1992) The Politics of Food in Mexico. Ithaca, New York: Cornell University Press. Friedman, T. (1975) There is No Such Thing as a Free Lunch. La Salle: Open Court.

Fuente, J. de la and H. Mackinlay (1994). 'El Movimiento Campesino y las Políticas de Concertación y Desincorporación de las Empresas Paraestatales: 1989-1994', in M. Bassols (eds) Campo y Ciudad en una Era de Transición, pp. 105-146. México: Departamento de Sociologia, UAM-Iztapalapa. 
Garces Restrepo, C. and D. Vermillion (1995) 'Irrigation Management Transfer in Colombia: Assessment of Seven Transferred Districts', in S.H. Johnson, D.L. Vermillion and J.L. Sagardoy (eds) Irrigation Management Transfer: Selected Papers from the International Conference on Irrigation Management Transfer, Wuhan, China, 2024 September 1994, pp. 413-424. Rome: IIMI/FAO.

Garcés Restrepo, C. (2001) 'TMT Case Study Mexico: Irrigation Management Devolution in Mexico', paper available for the International E-mail Conference on Irrigation Management Transfer, June-October 2001) online at: http://www.fao.org./landandwater/aglw/waterinstitutions.

Garza Toledo, E. de la (1994). 'The Restructuring of State-Labor Relations in Mexico', in L. M. Cook, K. J. Middlebrook and J. M. Horcasitas (eds) The Politics of Economic Restructuring: State-Society Relations and Regime Change in Mexico. La Jolla: Center for U.S.-Mexican Studies, University of California, San Diego.

Gascón Mercado, J. (1988) Tabaco: Testimonio de una Lucha Campesina. Tepic: Universidad Autonoma de Nayarit.

Gascón Mercado, A. (1997) Aután.

Gates, M. (1988) 'Codifying Marginality: The Evolution of Mexican Agricultural Policy and its Impact on the Peasantry', Journal of Latin American Studies, 20: 277-311.

Gledhill, J. (1994) Power and its Disguises: Anthropological Perspectives on Politics. Boulder, CO: Pluto Press.

Gluckman, M. (1958) Analysis of a Social Situation in Modern Zululand. Manchester: Manchester Universtiy Press.

González, H. (1998) 'Las Asociaciones Locales de Productores frente al Centralismo y a la Discontinuidad de la Política Agrícola del Estado Mexicano', Estudios Sociológicos XVI (48): 689 - 709.

González Villareal, F. (1982a) 'Agua y Desarrollo: Documento de Profundidad'. Mexico City: IEPES.

González Villareal, F. (1982b) 'La Infraestructura Hidráulica de México', in Consulta Popular en las Reuniones Nacionales, Agua y Desarrollo, pp. 20-21. Mexico City: IEPES.

Gordillo de Anda, G. (1988) Campesinos al Asalto del Cielo, de la Expropriación Estatal a la Apropriación Campesina. Mexico City: Siglo XXI.

Gorriz, C. M. and D. Groenfeldt (1995) Proceedings of the International Seminar on Participatory Irrigation Management, Mexico, February 8-15, 1995. Washington, D.C.: Economic Development Institute of the World Bank.

Gorriz, C. M., A. Subramanian and J. Simas (1995) 'Irrigation Management Transfer in Mexico: Process and Progress', World Bank Technical Paper, no. 292. Washington, D.C.: World Bank.

Greenberg, M. H. (1970) Bureaucracy and Deoelopment: A Mexican Case Study. Lexington, MA: Heath Lexington Books.

Grillo, R. D. and R. L. Stirrat (1997) Discourses of Development: Anthropological Perspectives. Oxford: Berg.

Grindle M.S. (1977) Bureaucrats, Peasants and Politicians in Mexico: A Case-Study in Policy. Berkeley: University of California Press.

Grindle M.S. (1980) Politics and Policy Implementation in the Third World. New Jersey: Princeton University Press.

Grindle, M.S. (1996) Challenging the State: Crisis and Innovation in Latin America and Africa. Cambridge: Cambridge University Press. 
Groenfeldt, D. (1998) Handbook on Participatory Irrigation Management. Washington, D.C.: The Economic Development Institute of the World Bank.

Groenfeldt, D., and P. Sun (1997). 'Demand Management of Irrigation Systems Through Users' Participation.' In M. Kay, T. Franks and L. E. D. Smith (eds) Water: Economics, Management, and Demand, pp. 304-311. London: Chapman Hall.

Gupta, A. (1995) 'Blurred Boundaries: The Discourse of Corruption, the Culture of Politics, and the Imagined State', American Ethnologist 22 (2): 375-402.

Gusterson, H. (1997) 'Studying Up Revisited', Political and Legal Anthropology Reoiew, 20(1): 114-19.

Haas, P. (1992) 'Epistemic Communities and International Policy Coordination', International Organization 46(1): 1-36.

Hales, C. (1999) 'Leading Horses to Water? The Impact of Decentralization of Managerial Behaviour', Journal of Management Studies 36(6): 831-52.

Handelman, D. (1990) Models and Mirrors: Towards an Anthropology of Public Events. Cambridge: Cambridge University Press.

Hernández Rodríquez, R. (1997) 'Los Grupos Políticos en Mexico: Una Revisión Teórica', Estudios Sociológicos 15(45): 691-739.

Herrera Toledo, C. (1997) 'National Water Master Planning in Mexico', in A.K. Biswas (ed), National Water Master Plans for Deoeloping Countries, pp. 8-53. New Delhi: Oxford University Press.

Horst, L. (1990) Interactions between Technical Infrastructure and Management, Irrigation Management Network Paper 90/3b. ODI/mMI.

Huppert, W. (1989) Situation Conformity and Seroice Orientation in Irrigation Management: Basic Concepts. Eschborn: Deutsche Gesellschaft für Technische Zusammenarbeit (GTZ).

Huppert, W., M. Svendsen and D. L. Vermillion (2001) Governing Maintenance Provision in Irrigation: A Guide to Institutionally Viable Maintenance Strategies. Wiesbaden: GTZ. Hutchins, E. (1995) Cognition in the Wild. Cambridge: MIT Press.

Ibargüengoita, J. (1991) La Casa de Usted y Otros Viajes. México: Joaquín Mortiz.

IEPES (1982) Tema Agua. Documento de Referencia. Grupos de Trabajo para la Elaboración del Plan de Gobierno 1982-1988'. Mexico City: IEPES.

IEPES (1987) 'Dialogo Nacional. El Agua: Recurso Vital'. Mexico City: IEPES.

IEPES (1988) 'Perfiles del Programa de Gobierno 1988-1994. Agua: Recurso Vital'. Mexico City: IEPES.

IMTA (undated) 'Organizacion y Administracion'. Jiutepec, México: IMTA.

IMTA (1992) Imagen Corporativa de la CNA en Distritos de Riego'. Jiutepec, México: IMTA.

INEGI (1998) 'Estadísticas del Medio Ambiente, Mexico, 1997'. Aguascalientes: INEGI.

Jáuregui, J., M. Huschick, H. Itriago and A. I. García-Torres (1980) Tabamex: Un Caso de Integración Vertical de la Agricultura. México: Editorial Nueva Imagen.

Johnson, S.H., D. Vermillion, M. Svendsen, W. Xinyuan, Z. Xiying and M. Xuesen (1995) Institutional Management and Performance Changes in Two Irrigation Districts: Case Study from Hebei Province, PR China', in S.H. Johnson, D.L. Vermillion and J.L. Sagardoy (eds). Irrigation Management Transfer: Selected Papers from the International Conference on Irrigation Management Transfer, Wuhan, China, 20-24 September 1994, pp. 133-156. Rome: IMI/FAO. 
Johnson III, S.H. (1997a) 'Irrigation Management Transfer in Mexico: A Strategy to Achieve Irrigation District Sustainability'. IIMI Research Report no. 16, Colombo, Sri Lanka: IIMI.

Johnson III, S.H. (1997b) 'Trigation Management Transfer: Decentralizing Public Irrigation in Mexico', Water International, 22(3): 159-67.

Johnson, R. W. and H. P. Minis (1996) Toward Democratic Decentralization: Approaches to Promoting Good Governance. Research Triangle Institute.

Juarez Guitron, M. (1991) 'Caracteristicas Principales y la Operación del Distrito de Riego 043, Estado de Nayarit'. Thesis to acquire the title of agronomist, Universidad Autonoma de Nayarit, Escuala Superior de Agricultura.

Kaufman Purcell, S. (1981) 'Mexico: Clientelism, Corporatism and Political Stability', in S. N. Eisenstadt and R. Lemarchand (eds) Political Clientelism, Patronage and Deoelopment. Beverley Hills; London: Sage.

Keller, J. and R. D. Bliesner (1990) Sprinkle and Trickle Irrigation. New York: Van Nostrand Reinhold.

Klesner, J. L. (1997) 'Political Change in Mexico: Institutions and Identity', Latin American Research Review 32 (2): 184-200.

Kloezen, W.H., C. Garcés-Restrepo and S.H. Johnson III (1997) 'Impact Assessment of Irrigation Management Transfer in the Alto Rio Lerma Irrigation District, Mexico'. IIMI Research Report no. 15, Colombo, Sri Lanka: IIMI.

Kloezen, W. H. (2002) 'Accounting for Water: Institutional Viability and Impacts of Market-oriented Irrigation Interventions in Central Mexico'. PhD Dissertation, Wageningen University.

Kortelainen, J. (1999) 'The River as an Actor-Network: The Finnish Forest Industry Utilization of Lake and River Systems', Geoforum 30 (3): 235-247.

Latour, B. (1987) Science in Action: How to Follow Scientists and Engineers through Society. Milton Keynes: Open University Press.

Latour, B. (1992) 'Where are the Missing Massess? The Sociology of a Few Mundane Artifacts', in W. Bijker and J. Law (eds) Shaping Technology-Building Society: Studies in Sociotechnical Change, pp. 225-259, Cambridge MA: MIT Press.

Latour, B. (1996) Aramis or the Love of Technology. Cambridge: Harvard University Press.

Latour, B. (1999) Pandora's Hope: Essays on the Reality of Science Studies. Cambridge: Harvard University Press.

Law, J. (1994) Organizing Modernity. Oxford: Blackwell Publishers.

Law, J. and M. Akrich (1994) 'On Customers and Costs - a Story from Public-Sector Science', Science in Context 7 (3): 539-561.

Levine, G. and Garces-Restrepo, C. (1995) 'Observaciones desde Afuera: Una Mirada a Sistemas de Riego Transferidos en México', in E. Palacios-Vélez, A. Exebio-Garcia, E. Rubiños-Panta, E. Mejía-Saenz and J. Durán-Barios (eds) Memorias del Seminario Internacional sobre Transferencia de Sistemas de Riego, pp. 101-112. Ciudad Obregon, México: El Colegio de Postgraduados, IIMI, Instituto Nacional de Investigaciones Forestales y Agropecuarias.

Levine, G., A. Cruz Galvan and D. Garcia (1998) Performance of Two Transferred Modules in the Lagunera Region: Water Relations. Colombo: International Water Management Institute.

Limón, J. E. (1989) 'Carne, Carnales, and the Carnivalesque: Bakhtinian Batos, Disorder, and Narrative Discourses', American Ethnologist 16 (3): 471-486. 
Lipsky, M. (1980) Street-Level Bureaucracy: Dilemmas of the Indioidual in Public Service. New York: Russel Sage.

Lomnitz, L. A. (1977) Networks and Marginality: Life in a Mexican Shantytown. New York: Academic Press.

Long, N. (1979) 'Multiple Enterprise in the Central Highlands of Peru', in S.M. Greenfield, A. Strickon, R. T. Aubey (eds) Entrepreneurs in Cultural Context, pp.123158. Albuquerque: University of New Mexico Press.

Long, N. (ed) (1989) Encounters at the Interface: A Perspective on Social Discontinuities in Rural Deoelopment. Wageningen: Wageningen Agricultural University.

Long, N. (2001) Deoelopment Sociology: Actor Perspectives. London: Routledge.

Long, N. and J.D. van der Ploeg (1989) 'De-mythologizing Planned Intervention: An Actor Perspective. Sociologia Ruralis 29 (4): 249-72.

Long, N. and J.D. van der Ploeg (1995) 'Reflections on Agency, Ordering the Future and Planning', in G. Frerks and J. den Ouden (eds) In Search of the Middle Ground: Essays on the Sociology of Planned Deoelopment. Wageningen, Wageningen Agricultural University.

Maldonado Rojas, T. (2000) Transferencia de Sistemas de Riego a los Usuarios en Países de América Latina y el Caribe. Santiago de Chile: FAO.

Martínez, T. (1988) Los Campesinos y el Estado en México. Montecillo, Colegio de Postgraduados.

McNeill, D. (2003) 'The Use and Abuse of Ideas in Multilateral Development Institutions', paper presented at the Intensive Researcher Training Seminar on Global Governance and Development, Bornholm, Denmark (2-4 June 2003).

Mehta, L. (2000) Water for the Twenty-First Century: Challenges and Misconceptions. Brighton: Institute of Development Studies.

Meinzen-Dick, R, R. Reidinger and A. Manzardo (1995) Participation in Irrigation. Washington: World Bank.

Menchaca, J.C.M. and M.L. Torregrosa (1995) 'Social Aspects of Irrigation District Transfer', in S.H. Johnson, D.L. Vermillion and J.L. Sagardoy (eds) Irrigation Management Transfer: Selected Papers from the International Conference on Irrigation Management Transfer, Wuhan, China, 20-24 September 1994, pp. 413-424. Rome: IMI/FAO.

Merrey, D.J. (1995) 'Institutional design principles for accountability on large irrigation systems', in S.H. Johnson, D.L. Vermillion and J.L. Sagardoy (eds) Irrigation Management Transfer: Selected Papers from the International Conference on Irrigation Management Transfer, Wuhan, China, 20-24 September 1994, pp. 47-58, Rome: IIMI/FAO.

Mestre, E. (1997) 'Integrated Approach to River Basin Management: Lerma-Chapala Case Study - Attributions and Experiences in Water Management in Mexico', Water International, 22(3): 140-52.

Michael, M. (2000) Reconnecting Culture, Technology and Nature: From Society to Heterogeneity. London: Routledge.

Miller, P. and N. Rose (1992) 'Political Power beyond the State: Problematics of Government', British Joumal of Sociology 43 (2): 174-201.

Miller, P. and A. Hopwood (eds) (1994) Accounting as a Social and Institutional Practice. Cambridge: Cambridge University Press.

Mitchell, J.C. (1983) 'Case Situation Analysis', The Sociological Reoiew 31: 187-211. 
Mollinga, P. (1992) 'The Study of Irrigation: A Theoretical Approach', unpublished lecture for the Zimwesi Research Group. Wageningen Agricultural University.

Mollinga, P.P. (1998) 'On the Waterfront: Water Distribution, Technology and Agrarian Change in a South Indian Canal Irrigation System'. PhD Dissertation, Wageningen University.

Mollinga, P. P. (2001) 'Water and Politics: Levels, Rational Choice and South Indian Canal Irrigation', Futures 33: 733-752.

Mollinga, P. P. and A. Bolding (eds) (2004) The Politics of Irrigation Reform: Contested Policy Formulation and Implementation in Asia, Africa and Latin America. London: Ashgate.

Monsalvo Velázquez, G. (1999) Sostenibilidad Institucional de las Asociaciones de Riego en México. Colombo: International Water Management Institute.

Moore, M. (1981) 'The Sociology of Irrigation Management in Sri Lanka', Water Supply and Management, 5: 117-133.

Moore, M. (1989) 'The Fruits and Fallacies of Neoliberalism: The Case of Irrigation Policy', World Deoelopment 17(11): 1733-50.

Mosse, D. (1997) 'The Symbolic Making of a Common Property Resource: History, Ecology and Locality in a Tank-irrigated Landscape in South India', Development and Change 28 (3): 467-504.

Mosse, D. (1999) 'Colonial and Contemporary Ideologies of "Community Management": The Case of Tank Irrigation Development in South India', Modern Asian Studies 33(2): 303-38.

Mosse, D. (2004) 'Good Policy is Unimplementable? Reflections on the Ethnography of Aid Policy and Practice', Development and Change 35 (4).

Munro, R. (1999) 'The Cultural Performance of Control', Organization Studies 20(4): 61940.

Nader, Laura (1972) 'Up the Anthropologist - Perspectives Gained from Studying Up', in D.H. Hymes (ed.) Reinoenting Anthropology, pp. 284-311. New York: Pantheon Books.

Nava Salcedo, J. M. (1997) Recursos Hidáulicos de Nayarit. México: CNA, SEP and SEMARNAP.

Nuijten, M. (1998) 'In the Name of the Land: Organization, Transnationalism, and the Culture of the State in a Mexican Ejido'. PhD dissertation, Wageningen Agricultural University.

Nuijten, M. (2003) Power, Community and the State: The Political Anthropology of Organisation in Mexico. London: Pluto.

Oorthuizen, J. (2003) Water, Works and Wages: The Everyday Politics of Irrigation Management Reform in the Philippines. New Delhi: Orient Longman.

Oorthuizen, J. and W. H. Kloezen (1995) 'The Other Side of the Coin: A Case Study on the Impact of Financial Autonomy on Irrigation Management Performance in the Phillipines', Irrigation and Drainage Systems 9: 15-37.

Orive Alba, A. (1970) La Irrigación en México. Mexico City: Editorial Grijalbo.

Ostrom, E. (1990) Gooerning the Commons: The Evolution of Institutions for Collective Action. Cambridge: Cambridge University Press.

Ostrom, E. (1992) Crafting Institutions for Self-Governing Irrigation Systems. San Francisco: ICS.

Ostrom, E., L. Schroeder and S. Wynne (1993) Institutional Incentioes and Sustainable Deoelopment: Infrastructure Policies in Deoelopment. Boulder: Westview Press. 
Pacheco, L. C. (1990) Nayarit. México: Centro de Investigaciones Interdisciplinarias en Humanidades, Universidad Nacional Autonónoma de México.

Palacios Vélez, E. (1992) The Mexican Experience In Irrigation Districts Transfer to their Users. México: IMTA.

Palacios Vélez, E. (1993) Diagnostico sobre la Administracion de los Modulos Operados por las Asociaciones de Usuarios, Montecillo: Colegio de Postgraduados.

Palacios Vélez, E. (1994) La Agricultura de Riego en México. Mexico City: FAO/CNA.

Palacios-Vélez, E. (1994b) 'El Desempeño de las Asociaciones de Usuarios en la Operación y Mantenimiento de los Distritos de Riego', in E. Palacios-Vélez, A. Exebio-Garcia, E. Rubiños-Panta, E. Mejia-Saenz and J. Durán-Barios (eds) Memorias del Seminario Internacional sobre Transferencia de Sistemas de Riego, pp. 11318. Ciudad Obregon, México: El Colegio de Postgraduados, IIMI, Instituto Nacional de Investigaciones Forestales y Agropecuarias.

Palacios-Vélez, E. (1995) Terformance of Water Users Associations in the Operation and Maintenance of Irrigation Districts in Mexico', in S.H. Johnson, D.L. Vermillion and J.L. Sagardoy (eds) Irrigation Management Transfer: Selected Papers from the International Conference on Irrigation Management Transfer, Wuhan, China, 20-24 September 1994, pp. 403-412. Rome: IIMI/FAO.

Palacios, E. (1996) El Agua: Recurso para el Futuro de México. Marco Legal e Institucional del Agua, Herramienta Indispensable para la Gestion Adecuada de los Recursos Hidráulicos, Montecillo: Colegio de Postgraduados.

Palacios-Vélez, E. (1997) Benefits and Second Generation Problems of Irrigation Management Transfer in Mexico, EDI Participatory Irrigation Management Case Studies Series. Cali, Columbia: EDI, World Bank.

Palacios-Vélez, E. (1998) 'Problemas de Segunda Generación que tienen las Asociaciones de Usuarios del Agua'. Montecillo: Colegio de Postgraduados.

Palacios-Vélez, E. (2000). 'Benefits and Second-Generation Problems of Irrigation Management Transfer in Mexico', in M. Svendsen and David Groenfeldt (eds) Case Studies in Participatory Irrigation Management, pp. 3-26. Washington, D.C.: World Bank Institute.

Palmer-Jones (1995) 'Water Markets and Water Management in South Asia', paper presented at the International Conference on The Political Economy of Water in South East Asia, Joint Committee on South Asia Social Research Council, American Council of Learned Societies, and Madras Institute of Development Studies, (5-8 January, 1995).

Pansters, W. (2000) 'Politics, Culture and the State: Explaining the Mexican Regime', European Review of Latin American and Caribbean Studies 68: 77-82.

Parkin, D. (1990) 'Eastern Africa: The View from the Office and the Voice from the Field', in R. Fardon (ed) Localizing Strategies: Regional Traditions of Ethnographic Writing. Edinburgh: Scottish Academic Press.

Parkin, D., L. Caplan and H. Fisher (eds) (1996) The Politics of Cultural Performance. Oxford: Berghahn Books.

Paz, O. (1994) El Laberinto de la Soledad. México: Fondo de Cultura Económica.

Peña, G. de la (1986) 'Poder Local, Poder Regional: Perspectivas Socio-antropológicas', in J. Padua and A. Vanneph (eds) Poder Local, Poder Regional. México: El Colegio de México/CEMCA.

Pérez-González, J. (1894) Ensayo Estadistico Y Geografico del Territorio de Tepic. 
Plusquellec, H., C. Burt and H. W. Wolter (1994) 'Modern Water Control in Irrigation: Concepts, Issues, and Applications', World Bank Technical Paper no. 246. Washington: World Bank.

Poder Ejecutivo Federal (1989) Plan Nacional de Desarrollo 1989-1994. México: Secretaría de Programación y Presupuesto.

Pollitt, Christopher, (1995) 'Justification by Works or by Faith? Evaluating the New Public Management' Evaluation, 1(2): 133-54.

PRI (1988) 'Los Retos de la Modernización: Agua y Desarrollo', Mexico City: PRI.

Rap, E., P. Wester and L. N. Pérez-Prado (2004). 'The Politics of Creating Commitment:

Irrigation Reforms and the Reconstitution of the Hydraulic Bureaucracy in Mexico', in P. P. Mollinga and A. Bolding (eds) The Politics of Irrigation Reform: Contested Policy Formulation and Implementation in Asia, Africa and Latin America, pp. 57-94. London: Ashgate.

Reed, M.I. (1992) The Sociology of Organizations: Themes, Perspectives and Prospects. New York: Harvester Wheatsheaf.

Repetto, R. (1986) 'Skimming the Water: Rent-seeking and the Performance of Public Irrigation Systems', World Resources Institute Research Report no. 4, Washington, D.C.: World Resources Institute.

Richards, P. (1985) Indigenous Agricultural Reoolution: Ecology and Food Production in West Africa. London: Unwin Hyman.

Roep, D. (2000) 'Vernieuwend Werken: Sporen van Vermogen en Onvermogen: Een Socio-materiële Studie over Vernieuwing in de Landbouw Uitgewerkt voor de Westelijke Veenweidegebieden'. PhD Dissertation, Wageningen University.

Rogers, P. and A. W. Hall (2003) Effective Water Governance, TEC Background Paper no. 7. Stockholm: Global Water Partnership.

Rogers, P. (2002) 'Water Governance in Latin America and the Caribbean', draft for presentation at the Inter American Development Bank's Annual Meeting. Fortaleza, Brazil: Inter American Development Bank.

Rubin, J.W. (1997) Decentering the Regime: Ethnicity, Radicalism, and Democracy in Juchitán, Mexico. Durham, NC: Duke University Press.

Samstad, J. G. (2002) 'Corporatism and Democratic Transition: State and Labor During the Salinas and Zedillo Administrations', Latin American Politics and Society 44 (4): 128.

Sánchez, Martin (1998) 'La Primera Transferencia: Gestión y Administración Federal del Agua en México', in P. Avila-García (ed), Agua, Medio Ambiente y Desarrollo en México, pp. 139-146, Zamora: Colegio de Michoacán.

SAyF (1929) Ley de Aguas de Propiedad Nacional. Mexico City: SAyF.

SARH (1981) Plan Nacional Hidráulico. Mexico City: SARH.

SARH (1985) 'Programa Nacional de Uso Pleno de la Obra Agrohidraulica: Unidad de Riego de la Margen Izquierda del Río Santiago, Nayarit', Tepic: Secretaría de Agricultura y Recursos Hidráulicos.

SARH (1991) Programa Nacional de Aprovechamiento del Agua. 1991-1994. Mexico City: SARH.

Schön, D. A. (1983) The Reflectioe Practitioner: How Professionals Think in Action. New York: Basic Books.

Shore, C. and S. Wright (1997) Anthropology of Policy: Critical Perspectives on Governance and Power. London: Routledge. 
Small, L.E. and I. Carruthers (1991) Farmer-financed Irrigation: The Economics of Reform. Cambridge: Cambridge University Press.

Small, L. E. and M. Svendsen (1992) A Framework for Assessing Irrigation Management Performance, Working Papers on Irrigation Performance 1. Washington: IFPRI.

Smith, B. (1985) Decentralisation: The Territorial Dimension of the State. London: George Allen \& Unwin.

Snyder, R. (1999) 'After Neoliberalism: The Politics of Reregulation in Mexico', World Politics 51 (Januari 1999): 173-204.

Spaeth, E. B. (1999). 'What a Laywer Needs to Learn', in R. J. Sternberg and J. A. Horvath (eds) Tacit Knowledge in Professional Practice; Researcher and Practitioner Perspectives. Mahwah, New Yersey: Lawrence Erlbaum Associates.

Sparrow, J. (1998) Knowledge in Organizations: Access to Thinking at Work. London: Sage. SRH (1948) 'Informe de Classificación de "Gran Visión de la Zona de Riego del Rio Santiago, Nayarit'. Tepic: Secretaría de Recursos Hidráulicos.

SRH (1971) Rehabilitación y Ampliación del Distrito de Riego: Estudio de Factibilidad. México: Secretaría de Recursos Hidráulicos.

SRH (1975) Plan Nacional Hidrálico. Mexico City: SRH.

SRH (1976) Politica Hidráulica en México: Pasado, Presente y Futuro. Mexico City: SRH.

SRH (undated) 'Presa Derivadora "Amado Nervo": Rehabilitación y Ampliación de la

Zona de Riego Margen Izquierda del Rio Santiago, Nayarit': Secretaría de Recursos Hidráulicos.

Stanford, L. (1993) "The "Organization" of Mexican Agriculture: Conflicts and Compromises', Latin American Research Review, 28(1): 188-201.

Sternberg, R. J. and J. A. Horvath (1999) Tacit Knowledge in Professional Practice: Researcher and Practitioner Perspectives. Mahwah, NJ: Lawrence Erlbaum.

Stirrat, R. L. (2001) 'Cultures of Consultancy', Critique of Anthropology 20(1): 31-46.

Strang, D. and M. W. Macy (2001) 'In Search of Excellence: Fads, Success Stories, and Adaptive Emulation', American Journal of Sociology 107(1): 147-82.

Strathern, M. (2000) Audit Cultures: Anthropological Studies in Accountability, Ethics, and the Academy. London: Routledge.

Sutton, R. (1999) 'The Policy Process: An Overview', Working Paper 118. London: ODI. Svendsen, M. (1993) The Impact of Financial Autonomy on Irrigation System Performance in The Philippines', World Deoelopment 21 (6): 989-1005.

Svendsen, M. and D. Vermillion (1995) Lessons from Management Transfer in the Columbia Basin Project', in S.H. Johnson, D.L. Vermillion and J.L. Sagardoy (eds) Irrigation Management Transfer: Selected Papers from the International Conference on Irrigation Management Transfer, Wuhan, China, 20-24 September 1994, pp. 343-358. Rome: IIMI/FAO.

Sijbrandij, P. (1989) 'Irrigation and Human Organization: Searching for the Meaning of Maintenance in a Government-Managed Irrigation System in Western Mexico', MSc. thesis. Wageningen: Wageningen Agricultural University.

Sijbrandij, P. and P. van der Zaag (1993) 'Canal Maintenance: A Key to Restructuring Irrigation Management', Irrigation and Drainage Systems 7: 189-204.

Teichman, J. A. (1995) Prizatization and Political Change in Mexico. Pittsburgh: University of Pittsburgh Press.

Teichman, J. A. (1997) 'Neoliberalism and the Transformation of Mexican Authoritarianism', Mexican Studies 13 (1): 121-147. 
Thompson, M. (1997) 'The Politics of Cultural Performance', American Anthropologist 99 (2).

Torregrosa Armentia, M. L. (1998) 'Modernización del Campo y Crisis de las Identidades Sociales Tradicionales en México: Un Estudio del los Distritos de Riego'. PhD Dissertation, El Colegio de México.

Torres Espinosa, E. (1999) Bureaucracy and Politics in Mexico: The Case of the Secretariat of Programming and Budget. Aldershot: Ashgate.

Trava Manzanilla, J.L. (1994) Transfer of Management of Irrigation Districts to WUAs in Mexico', in Indicatioe Action Plan and Proceedings of the National Seminar on Farmers Participation in Irrigation Management. Aurangabad, Maharashtra: Water and Land Management Institute.

Uphoff, N., P. Ramamurthy and R. Steiner (1991) Managing Irrigation: Analyzing and Improoing the Performance of Bureaucracies. New Delhi: Sage.

Uphoff, N. (1992) Learning from Gal Oya: Possibilities for Participatory Deoelopment and Post-Newtonian Social Science. Ithaca: Cornell University Press.

Vaara, E. (2002) 'On the Discursive Construction of Success/Failure in Narratives of Post-merger Integration', Organization Studies 23(2): 211-48.

Vargas Velázquez, S. (1996) 'Las Grandes Tendencias Históricas de la Agricultura de Riego', in R. Melville and F. Peña (eds), Apropiacion y Usos del Agua: Nueoas Lineas de Investigación, pp. 31-50. Chapingo: Universidad de Chapingo.

Vargas Velázquez, S., D. Murillo Licea, R. Romero Pérez, and E. López Ramírez (2000) 'Cambios en la Gestión del Agua en la Cuenca Lerma Chapala y la Representación de los Usuarios de Riego en el Consejo de Cuenca', unpublished working document. Jiutepec, México: IMTA.

Velsen, J. van (1967) 'The Extended-Case Method and Situational Analysis', in A. L. Epstein (ed.) The Craft of Social Anthropology. London: Tavistock.

Vermillion, D. (1991) The Turnover and Self Management of Irrigation Institutions in Developing Countries: A Discussion Paper for the New Programme of IIMI. Colombo: International Irrigation Management Institute.

Vermillion, D.L. and Johnson S.H. (1995) 'Globalization of Irrigation Management Transfer: A Summary of Ideas and Experiences from the Wuhan Conference', in S.H. Johnson, D.L. Vermillion and J.L. Sagardoy (eds) Irrigation Management Transfer: Selected Papers from the International Conference on Irrigation Management Transfer, Wuhan, China, 20-24 September 1994, pp. 1-14. Rome: IIMI/FAO.

Vermillion, D. L. (1997) Impacts of Irrigation Management Transfer: A Reoiew of the Evidence, IMI Research Report 11. Colombo: IMMI.

Vermillion, D. L. and J. A. Sagardoy (1999) Transfer of Irrigation Management Services: Guidelines. Rome: FAO.

Vincent, L. F. (1997) Irrigation as a Technology, Irrigation as a Resource: A Sociotechnical Approach to Irrigation. Wageningen: Wageningen Agricultural University.

Vos, J. M. C. (2002) 'Metric Matters: The Performance and Organisation of Volumetric Water Control in Large-Scale Irrigation in the North Coast of Peru'. PhD Dissertation, Wageningen University.

Vries, P. de (1992) Unruly Clients: A Study of how Bureaucrats Try and Fail to Transform Gatekeepers, Communists and Preachers into Ideal Beneficiaries'. PhD dissertation, Wageningen: Wageningen Agricultural University.

Vries, P. de (2002) 'Vanishing Mediators: Enjoyment as a Political Factor in Western Mexico', American Ethnologist 29 (4): 901-927. 
Wade, R. (1978) 'Water Supply as an Instrument of Agricultural Policy: A Case Study', Economic and Political Weekly, 13(12): A9-13.

Wade, R. (1982) 'The System of Administrative and Political Corruption: Canal Irrigation in South India', Journal of Deoelopment Studies, 18(3): 287-328.

Wade, R. (1988) Village Republics: Economic Conditions for Collectioe Action in South India. Cambridge: Cambridge University Press.

Wade, R. and D. Seckler (1990) 'Priority Issues in the Management of Irrigation Systems', in R.K. Sampath and R.A. Young (eds), Social, Economic and Institutional Issues in Third World Irrigation Management, pp. 13-29. Boulder: Westview Press.

Wade, R. (1996) 'Japan, the World Bank, and the Art of Paradigm Maintenance: The East Asian Miracle in Political Perspective', New Left Reoiew 217 (May/June): 3-36.

Wester, P., G. Cornish and J. J. Ramírez-Calderón (2000) Determinación de las Prioridades de Mantenimiento en los Sistemas de Riego Transferidos: La Aplicación del Procedimiento Marlin en el Distrito de Riego Alto Río Lerma, México. Colombo: IWMI.

Wionczek, M.S. (1982) 'La Aportación de la Política Hidráulica entre 1925 y 1970 a la Actual Crisis Agrícola Mexicana', Comercio Exterior, 32(4): 394-409.

Wolf, E. (1966) 'Kinship, Friendship and Patron-Client Relations in Complex Societies', in M. Banton (ed.) The Antropology of Complex Societies, pp. 1-22. London: Tavistock.

Wood, G. (1985) 'The Politics of Development Policy Labelling', Deoelopment and Change 16: 347-373.

World Bank (1983a) 'Mexico Irrigation Subsector Survey - First Stage. Improvement of Operating Efficiencies in Existing Irrigation Systems. Volume I - Main Findings', Report no. 4516-ME. Washington D.C: World Bank.

World Bank (1983b) 'Mexico Irrigation Subsector Survey - First Stage. Improvement of Operating Efficiencies in Existing Irrigation Systems. Volume II - Annexes', Report no. 4516-ME. Washington D.C: World Bank.

World Bank (1991) 'Mexico. Irrigation and Drainage Sector Project. Staff Appraisal Report', Report no. 9779-ME. Washington D.C: World Bank.

World Bank (2001) 'Mexico. Irrigation and Drainage Sector Project (Loan 3419-ME). Implementation Completion Report', Report no. 22165. Washington D.C: World Bank.

WUA (1998) 'Segundo Informe de Actividades, Asociación de Usuarios de la Unidad de Riego de la Margen Izquierda del Río Santiago, A.C., Modulo 2, 1997-1998'. Villa Hidalgo: Left Bank WUA.

WUA (1999) Tercero Informe de Actividades, Asociación de Usuarios de la Unidad de Riego de la Margen Izquierda del Río Santiago, A.C., Modulo 2, 1998-1999'. Villa Hidalgo: Left Bank WUA.

Yanow, D. (1988) Tackling the Implementation Problem: Epistemological Issues in Implementation Research', in D.J. Palumbo and D.J. Calista (eds). Implementation and the Policy Process: Opening Up the Black Box, pp. 213-227. New York and London: Greenwood Press.

Zaag, P. van der (1992) Chicanery at the Canal: Changing Practice in Irrigation Management in Western Mexico, CEDLA Latin American Studies, no. 65, Amsterdam: Centrum voor Studie en Documentatie van Latijns Amerika.

Zaag, P. van der, A. Bolding, and E. Manzungu (2001) 'Water-networks and the Actor: The Case of the Save River Catchment, Zimbabwe', in P. Hebinck and G. Verschoor (eds) Resonances and Dissonances in Deoelopment: Actors, Networks and Cultural Reportoires, pp. 257-79. Assen: Royal Van Gorcum. 


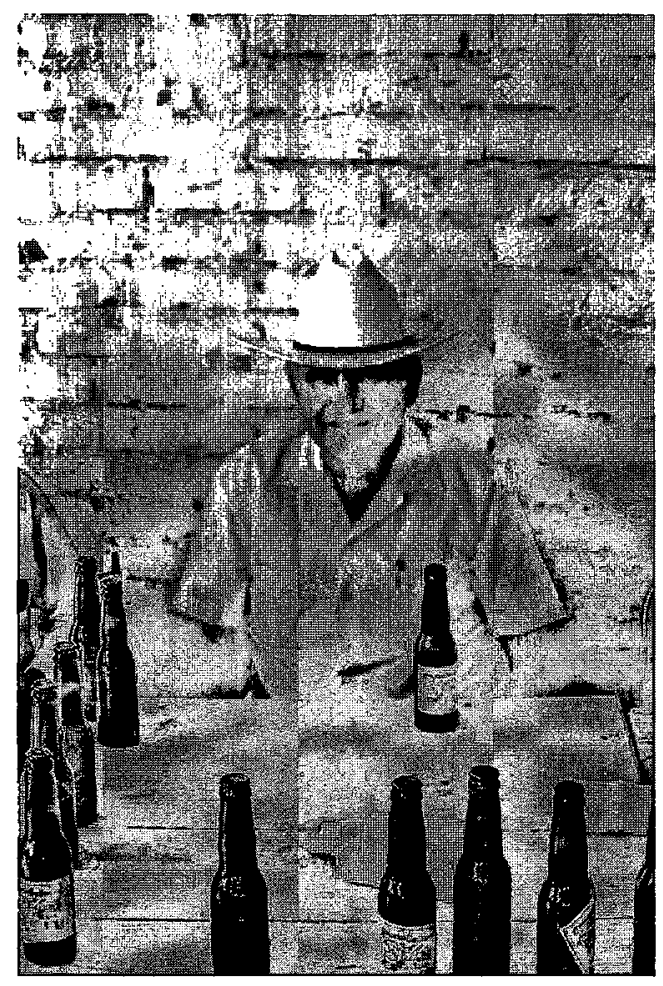

Photo 27 A water user

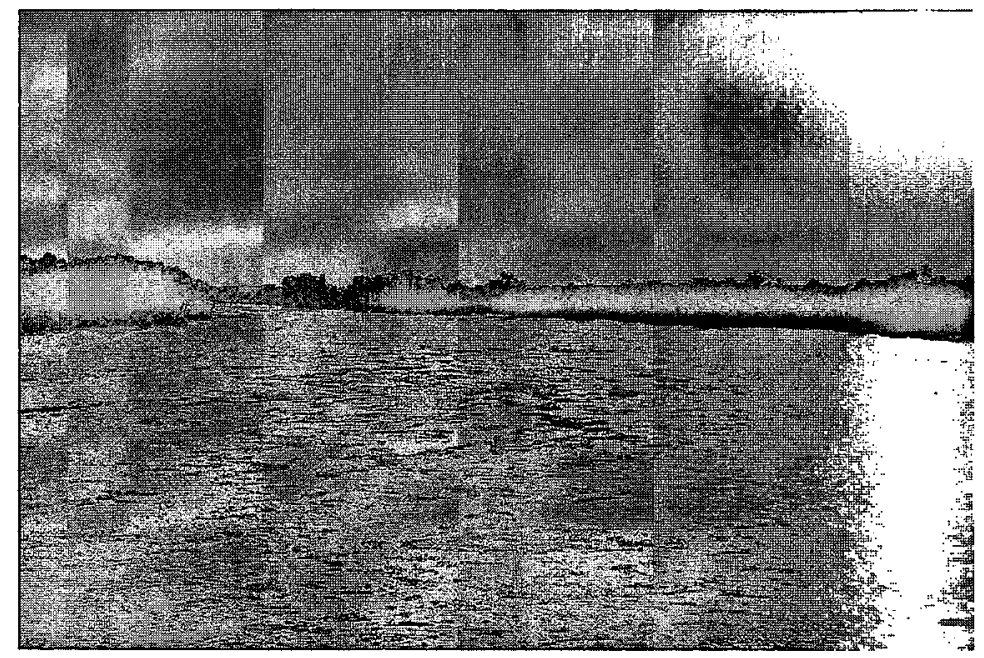

Photo 28 The Great River of Santiago turning towards the Pacific Ocean 


\section{Appendices}

\section{Appendix 1: Plan Nacional Hidráulico}

In 1973, the Mexican Government, the World Bank and the UNDP signed a tripartite agreement to develop a National Water Plan by 1975 (Herrera Toledo, 1996). For this purpose, the World Bank created a special office in Mexico with four permanent staff members to assist in the formulation and evaluation of policy ideas and to advise on policy decisions (Buras, 1983). The SRH created a special plan commission as a semiindependent body under the Under Ministry of Planning to organise a multidisciplinary study group to produce the plan. Dr. González Villareal, a civil engineer in the Faculty of Engineering of the UNAM, was appointed as the General Co-ordinator of the study group. He put together a team of young, dedicated and specialised professionals for this purpose, who became his close collaborators.' The staff of the plan commission was divided over national and regional planning groups, in which foreign resident advisers of the World Bank also participated (Herrera Toledo, 1996). They generated an impressive set of studies on land and water resources and their use at both the river basin and national level. These studies attempted to match estimates of future water demands by the domestic, industrial and agricultural sectors with estimated future supplies and specified alternative courses of action for meeting the projected shortfalls (Cummings et al., 1989; Herrera Toledo, 1996).

In an evaluation of the first National Water Plan, Buras ${ }^{2}$ (1983) points out that at the start the PNH study group had a 'definite engineering orientation' with relatively little input from economic, agronomic or social disciplines. He states that the first PNH started as a super-project in hydraulic engineering and that solutions to the discrepancies in water availability were initially sought in the construction of inter-basin transfers and the expansion of irrigation. ${ }^{3}$ Cummings (1974) mentions that the Mexican government considered the Sistema Hidraulico Interconectado del Noroeste (SHINO: Northwestern Interconnected Hydraulic System), an ambitious plan to expand the irrigated area in the arid Northwest by a massive inter-basin transfer of water from the south. However, several studies showed the technical and financial unfeasibility of this plan (Buras, 1983). ${ }^{4}$

Although the first PNH had a clear construction bias and this bias did not fully disappear in subsequent revisions, the perspective of the study group on water resources was significantly broadened, amongst other things due to the integration of the foreign advisers. The $\mathrm{PNH}$ opened up space for the formation of a team of water planners and enabled them to write plans and studies concerning water resource management. They

\footnotetext{
According to Grindle (1977), senior bureaucrats use their appointive powers to build loyal and efficient teams, called equipos.

2 Buras was appointed to the Advisory Council of the PNH as a foreign expert on water resource planning and thus intimately involved.

3 It was calculated that it was necessary to double the area under irrigation, to 10 million ha, by 2000 (SRH, 1975; Herrera-Toledo, 1996).

4 It is remarkable that, in spite of this, SHINO was continued and given a strong push forward during the SARH era (CNA, 1994b). This illustrates the continued construction bias of the hydraulic bureaucracy.
} 
developed policy ideas and gained experiences that departed from the traditional construction bias of the hydraulic bureaucracy, more specifically of groups within the Under Ministry of Construction and their network of beneficiaries. Ex-staff of the plan confirm that the influence of World Bank advisors on the development of policy ideas was important. This is not surprising, because it was an explicit intention of the Mexican government to incorporate such advice in policy decisions. The World Bank was thus intimately involved in putting certain policy issues on the agenda and further developing them into concrete options. 


\section{Appendix 2: Details of World Bank Lending History from 1982}

In 1982, the World Bank had stopped lending to Mexico as a response to the moratorium on payments of foreign debt principal declared by the Mexican government in August 1982. To assess future investment priorities, the World Bank carried out a review of the irrigation sector towards the end of 1982. In line with international debates on irrigation management (Bottrall 1981), the review concluded that Mexico needed to shift from the construction of new irrigation systems to improving the management and efficiency in existing systems. To do so, the report made three recommendations:

'First, (...) [a]s it is not in the interest of farmers to observe a run-down in the irrigation infrastructure, an across-the-board increase in water charges would ease the budget constraints which are the biggest obstacle to adequate maintenance. (...) Second, (...) in order to achieve a fair water pricing system acceptable to farmers (...) a program of repair and upgrading of existing systems needs to be undertaken in most Districts. (...) Third, (...) if users are to be increasingly responsible for irrigation financing then their role in decision making will need to be increased $(. . .)^{\prime}$. (World Bank, 1983a:17-18)

The report goes on to recommend the bulk sale of water by the government to users' associations in the districts, who would then sell and distribute the water to its members, citing the successful use of this system in the Río Yaqui irrigation district. Although transfer is not mentioned as such in the report, it is striking to see how its recommendations strongly coincide with the core of the IMT programme in the 1990s. The 1983 report signified an important shift in the Bank's agenda for the irrigation sector in Mexico, which the hydrocracy needed to accommodate to obtain desperately needed external funding. In late 1987 and early 1988, the Bank sent several missions to Mexico to discuss possible future loans to support IMT and broader reforms in the water sector. At one of the national meetings on water held during Salinas' election campaign, Salinas asked Dr. González Villareal his opinion on the risks of transferring irrigation districts to the users. His answer is illuminating:

The transfer of irrigation districts to users was already an established policy of this administration [of de la Madrid], which has encountered some difficulties. (...) Those of the Northwest and North of the country are prepared to start taking on their own administration. As a matter of fact, in the Río Yaqui irrigation district users already nearly completely manage the maintenance, administration, payment and delivery of water. (...) In a new programme that will be financed with international credit, called 'modernisation of the irrigation districts', a subsequent phase after the original construction of the districts is proposed, consisting of the bulk delivery of water to the users and an administration run by them (...). However, in the districts in the centre of the country (...) we believe that the process has to be more gradual. First, some rehabilitation and public investment will be needed, before a first phase of organising users, if the process is to be effective'. (IEPES, 1987:7; my translation) 
Apparently, discussions with the World Bank concerning transfer had reached such an advanced stage that Dr. González Villareal felt confident enough to announce publicly to Salinas that international loans for IMT would be forthcoming. In 1988 and 1989, the Bank sent eight missions to Mexico as part of the loan identification phase of what was to become the Irrigation and Drainage Sector Project, with a pre-appraisal mission visiting Mexico in April 1990. Extensive discussions were held with Dr. Ramos and his team concerning the loan, with emphasis placed on the need to change the water law and reduce government subsidies to the irrigation districts to zero. The Bank was very eager to ensure the success of IMT and assigned top expertise and adequate resources to assist the CNA. Nonetheless, it was only in February 1991 that the appraisal mission went to Mexico, and only in December 1991 was the loan approved by the board of the World Bank, to become effective in June 1992. 


\section{Appendix 3: The Pre-1989 Technologies of Governance and the IMT Package}

According to Palacios Vélez (1993), Río Mayo was one of the first districts in which transfer was initiated. Here, a modernisation programme consisting of canal lining and plot levelling was carried out during the 1980s as part of one of the few World Bank loans to the SARH during that period. SARH engineers told water users that the district would be handed over to the users after it was modernised. The impression was created that the SARH was testing how the transfer could be organised and that the district would be used as a model for other districts to follow. In August of 1986 the then Minister of Agriculture, Eduardo Pesqueira-Olea, announced at a meeting in Los Mochis in Sinaloa that 'steps are being taken to transfer to organised farmers the operational management of the irrigation districts, so that every peso that is paid in water fees will be invested in the same district' (El Financiero, 19 August 1986). This suggests that transfer initiatives on the ground were well underway in 1986. Based on instructions received from SARH headquarters at the start of 1988, the Río Mayo district office began to organise WUAs that would become responsible for the operation and maintenance of the infrastructure. A CNA official remembers:

There was little demand for transfer. A group of users in the Northwest was motivated, in Rio Mayo, because it is close to Rio Yaqui, where the users were already managing the secondary canals. In Mayo they started to organise the associations, but when we arrioed with the lawyers [in 1989], it was said that it could not be done that easily, to carry out a series of changes. Also in Sinaloa some things were initiated. The users supported by the SARH did this. But when the CNA was created, the decision was taken that it definitely had to be done.

Another important transfer initiative occurred in the El Grullo irrigation district, which strongly contributed to the definition of key characteristics of the IMT programme. User involvement was not new to the El Grullo district, as a team of SARH engineers had experimented with a water user commission from 1980 to 1983 to counter the interests of a local sugarcane lobby (van der Zaag, 1992). The same team of engineers had transferred the La Barca irrigation district to a WUA in 1985, apparently for the first in Mexico since the water boards of the 1940s (see Chapter 2). Maintenance tasks were handed over to this user organisation. This experiment attracted serious interest on the national and international level. This informal group of engineers had studied at the University of Guadalajara in the early 1970s. They were led by Engineer Velazco, their professor, who was head of the SARH office in the state of Jalisco in the late 1980s.

In May 1987, Velazco instructed the El Grullo District Head to put water users in charge of the maintenance tasks in the district (van der Zaag, 1992). User representatives did not accept this proposal, apparently because it was not very concrete at the time. In February 1988, the same District Head informed user representatives that the SARH had a new policy of decentralising its functions to farmer organisations. He proposed the creation of a WUA and stated that he was authorised to hand over machinery for maintenance tasks. Although the El Grullo District Head was not in favour of transfer, during the first months of 1988 district officials went to the ejidos to explain that the SARH could not maintain the district efficiently and that a WUA could do it better. Delegates were chosen in each ejido and by the private farmers. In May 1988, the 
founding assembly of the WUA was held in the presence of the senior SARH official who had given the instructions to form the WUA, and a working group was formed to draft internal regulations. In November 1988, the regulations were accepted and the association's board was chosen (van der Zaag, 1992).

At the beginning of 1989, a new District Head was appointed by the SARH. This engineer had been part of Velazco's team in the 1980s. With this tract record, he was fully in favour of transfer and gave a strong impetus to it by handing over maintenance machinery to the newly formed WUA and removing the district engineers who had resisted transfer. The association started to train new personnel, carried out large-scale maintenance in the district, and received visits from national SARH officials and the governor of Jalisco. In September 1989, a new district head arrived to become responsible for the newly formed El Grullo irrigation district, which had recently come under the control of the CNA. The removed, resistant engineers were reinstated in their posts, but in the new CNA district office. They appropriated the WUA as their own initiative and changed its regulations to curtail the board's influence and bring it under control of the CNA. They also slowed down the process of transfer by delaying the transfer of the operation of the irrigation district. The SARH engineers of the 'Guadalajara group' were removed and were denied any credit for their work vis-à-vis the outside world. In CNA documents on transfer, El Grullo is presented as a CNA pilot project, deleting all references to the pre-CNA phase and the SARH involvement. This fits in with the larger bureaucratic struggle of the CNA to become autonomous from the larger SARH bureaucracy as discussed in Chapter 1.

5 According to Palacios 'one of the first actions of the CNA was to re-establish the independent administration of the irrigation districts' (1996:35). The CNA regained control over the Irrigation Districts in September 1989, when the separation between the Irrigation Districts and the Rural Development Districts that existed before 1985 was re-established. 


\section{Appendix 4: Steps Involved in First Phase of Transfer Progamme}

Diagnosis: To initiate transfer in an irrigation district, a thorough study is made of the district by the Mexican Institute of Water Technology (IMTA) and the CNA to assess the feasibility of transfer and to identify possible problems and solutions. Descriptions and recommendations are made about the operational, maintenance and administrative situation in the irrigation district and the condition of the infrastructure and machinery. On the basis of information provided by the CNA District Head and district staff, the expenses and time required for rehabilitation and deferred maintenance are estimated. Surveys are used to evaluate the willingness of users to participate in the transfer process.

Promotion: After the diagnosis, a vast number of meetings are held with ejidatarios and private farmers to present the transfer programme, explain its objectives and determine the boundaries of modules. This is carried out by the CNA with the help of companies of promoters. During this step, water delegates (delegados de agua), ostensibly elected by all farmers, are appointed by the CNA to represent 'the users' in the assembly of delegates.

To constitute a WUA: After the boundaries of the modules have been determined and the user delegates chosen, the CNA and the IMT promotion team help the delegates to form a WUA. This entails drawing up the charter of the WUA, obtaining the relevant approvals from various government agencies, constituting the WUA as a civil association and drafting the Concession Title and its annexes according to formats provided by the CNA. The annexes are a set of technical documents that contain basic information on the district and the module, a working methodology for different activities, and corresponding instructions.

Acceptance of commitments: When the necessary legal and technical documentation is ready, it is time for the WUA to sign an agreement of acceptance of commitments. The WUA manifests its acceptance of the conditions of transfer, its willingness and ability to take over the management of the module, and its commitment to increasing fee levels and maintaining them to accomplish self-sufficiency. The latter is generally considered as the main criterion for transfer. The CNA promises to execute deferred maintenance over a period of one or several years and formulates a plan for the rehabilitation and modernisation of the irrigation district to be co-financed by the WUA.

Concession Title: The Title of Concession of Water and for the Use of Hydraulic Infrastructure is a comprehensive legal document that is assembled based on the prepared documents and handed over by the CNA to the WUA. It stipulates the legal framework in which it is embedded, all essential data on the module, and the conditions under which the transfer takes place. In addition, the rights and obligations of both the WUA and the CNA are detailed, and the technical annexes and legal instruments mentioned earlier are included.

Physical transfer of the module: During an official ceremony, the Concession Title is handed over to the WUA. Meanwhile, the district personnel of the CNA are restructured, followed by a phased reduction of personnel. 
Parallel operation: For a period of generally six months after the transfer, the CNA manages the modules in co-operation with the WUAs. The CNA trains the new WUA personnel with specific programmes on Operation, Maintenance, Irrigation and Drainage, and Administration. After this stage, the transfer process is completed and the WUAs become fully responsible for the management of the modules. 


\section{Appendix 5: Nayarit}

Nayarit is one of the smallest states of the Mexican Republic. The name Nayarit is given to pre-Columbian clay figurines that are found in the vicinity. The state is located on the Western coast that faces the Pacific Ocean (see Map 5). Only in 1917 after the Mexican Revolution it became independent from the much larger state of Jalisco, that borders it to the south and the east. The state consists of four geograhical regions. The north eastern part of the state is dominated by the Sierra Madre Occidental, a mostly wild and rugged mountain range descending from the United States along the Western coast. The inhospitable Sierra del Nayar is the home to the Huichol and Cora people, indigeneous groups that are famous for having resisted the colonization of their mountaineous region up to 200 years after the Spanish Conquest. These mountains, like in many parts of Latin-America, served as their hiding place suffering from the attacks of the Spaniards during the colonial period. This remained to be so until the past century when civil wars were striking the country.

The adjoining south central part of Nayarit is a plateau situated between $900-1500$ meters above sea level that bears clear traces of a volcanic origin. On the northern end of this plateau lies the provincial town and state capital of Tepic. Tepic is the commercial and political center of the state, that has further benefited from agroindustry and differerent services. During the last decades it has expanded rapidly due to a relatively late process of urbanization in a state where the economy for a long time remained largely depended on agriculture. Today Tepic has a quarter of the almost 1 million inhabitants of Nayarit. A large refinery in the center of town explain the waving sugarcane fields around the town.

The Southern Coast of Nayarit is a narrow strip of coastal plain separated from the central plateau by western spurs that advance from the Sierra, most eager to reach the Ocean, it seems, at which they never quite succeed. The river Ameca that has shaped and nurtured the valley of Bahia de Banderas, a town, and an irrigation module, separates Nayarit from Jalisco. The nearby town of Puerta Vallarta became a puplar resort for national and international tourism that grew explosively since the 1970 s and extended its influence along the coastline into Nayarit. 


\section{Appendix 6: Financial Data}

Table 5 Historical overview financial balance of the Left Bank module (in Mexican pesos)

\begin{tabular}{|l|rrrrr|}
\hline Revenues & $1993-1994$ & $1994-1995$ & $1995-1996$ & $1996-1997$ & $1997-1998$ \\
\hline 1. Fee collection & $1,026,303$ & $1,083,085$ & $1,262,363$ & $1,318,400$ & $1,769,726$ \\
2. Rehabilitation levy & & & & & 190,453 \\
3. Other revenues & 407,958 & 504,292 & 372,504 & 358,512 & 16,103 \\
4. Total Revenues & $1,434,261$ & $1,587,376$ & $1,634,868$ & $1,676,912$ & $1,976,282$ \\
\hline Expenses & & & & & \\
\hline 6. Administration & 139,568 & 149,894 & 227,752 & 258,618 & 311,282 \\
7. Operation & 174,227 & 199,514 & 233,869 & 381,774 & 393,378 \\
8. Maintenance & 436,981 & 524,499 & 690,852 & $1,012,835$ & $1,122,084$ \\
9. Payment CNA & 251,424 & 264,491 & 316,776 & 329,000 & 270,119 \\
10. Other costs & 3,816 & 6,219 & 3,794 & 3,669 & 1,561 \\
11. Total Expenditure & $1,006,017$ & $1,144,618$ & $1,473,043$ & $1,985,896$ & $2,098,424$ \\
\hline Total (11-4) & 428,244 & 442,758 & 161,824 & $-308,984$ & $-122,142$ \\
\hline 12. Adm. share (6/11) & 14 & 13 & 15 & 13 & 15 \\
13. Op. share (7/11) & 17 & 17 & 16 & 19 & 19 \\
13. Maint. share (8/11) & 43 & 46 & 47 & 51 & 53 \\
14. CNA share (9/11) & 25 & 23 & 22 & 17 & 13 \\
\hline Self-sufticlency \%(11/1) & 102 & 95 & 86 & 66 & 84 \\
\hline
\end{tabular}

Source: Data derived from annual reports of the Left Bank Association ('Informes de Actioidades, Asociación de Usuarios de la Unidad de Riego de la Margen Izquierda del Rfo Santiago, A.C., Modulo 2, 1993-1999'). 
Table 6 Historical analysis of irrigation service fee recovery in the Left Bank's module and its payment for 'water in blocks' to the CNA-District (in Mexican pesos)

\begin{tabular}{|c|c|c|c|c|c|c|c|c|}
\hline & \multicolumn{3}{|c|}{ Left Bank } & \multicolumn{3}{|c|}{ CNADistrict } & \multirow{2}{*}{\begin{tabular}{|l|} 
LB's part \\
$7 .(3 / 6)(\%)$ \\
\end{tabular}} \\
\hline & & 1. Irr. surface (ha's) & 2. Fee collection & 3. Payment CNA (Mx \$) & 4. Tot. surface (ha's) & 5. Tot foes WUAs & 6. Revenues & \\
\hline \multirow{3}{*}{ 1989-1990 } & Programme & 17,595 & & $1,015,665$ & 28,822 & & $1,719,443$ & 59 \\
\hline & Realised & 6,208 & Not transferred yet & 358,355 & 17,452 & Not transferred yet & 955,645 & 37 \\
\hline & $\begin{array}{c}(\%) \\
\text { Programme }\end{array}$ & $\begin{array}{r}35 \\
17,694\end{array}$ & 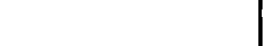 & $\begin{array}{r}35 \\
1,344,825\end{array}$ & $\begin{array}{r}61 \\
29,979\end{array}$ & & $\begin{array}{r}56 \\
2,276,685\end{array}$ & 59 \\
\hline \multirow[t]{2}{*}{ 1990-1991 } & Realised & 8.444 & Not transferred yet & 386,064 & 21,017 & Not transferred yet & $1,029,537$ & 37 \\
\hline & $\begin{array}{c}(\%) \\
\text { Programme }\end{array}$ & $\begin{array}{r}48 \\
17,800\end{array}$ & 777,542 & $1,881,150$ & $\begin{array}{r}70 \\
32.073\end{array}$ & $1,690,867$ & $\begin{array}{r}45 \\
3,448,370\end{array}$ & 55 \\
\hline \multirow[t]{2}{*}{ 1991-1992 } & Realised & 8,689 & 159,458 & 386,607 & 18,761 & 658,115 & $1,116,353$ & 35 \\
\hline & $\begin{array}{c}(\%) \\
\text { Programme }\end{array}$ & $\begin{array}{r}49 \\
18,014\end{array}$ & $\begin{array}{r}21 \\
788,720\end{array}$ & $\begin{array}{r}21 \\
1,774,620\end{array}$ & $\begin{array}{r}58 \\
32,766\end{array}$ & $\begin{array}{r}39 \\
1,882,770\end{array}$ & $\begin{array}{r}32 \\
3.523,870\end{array}$ & 50 \\
\hline \multirow[t]{3}{*}{ 1992-1993 } & Realised & 10,503 & 217,522 & 489,408 & 21,774 & 649,760 & $1,229,772$ & 40 \\
\hline & (\%) & 56 & & & & 35 & 35 & \\
\hline & Programme & 18,225 & $\begin{array}{r}1,849,273 \\
745,516\end{array}$ & 597,685 & $\begin{array}{l}33,902 \\
29,352\end{array}$ & $\begin{array}{l}4,521,606 \\
2586,892\end{array}$ & $\begin{array}{r}1,320,943 \\
778,303\end{array}$ & $\begin{array}{l}45 \\
29\end{array}$ \\
\hline \multirow{2}{*}{ 1993-1994 } & $\begin{array}{r}\text { Realised } \\
(\%)\end{array}$ & $\begin{array}{r}17,047 \\
94\end{array}$ & $\begin{array}{r}745,516 \\
40\end{array}$ & $\begin{array}{r}224,053 \\
37\end{array}$ & $\begin{array}{r}20,002 \\
87\end{array}$ & $\begin{array}{r}2,000,002 \\
57\end{array}$ & & \\
\hline & Programme & 19,911 & $1,765,809$ & 597,685 & 36,525 & $4,497,837$ & $1,185,673$ & 50 \\
\hline \multirow{2}{*}{ 1994-1995 } & Realised & $\begin{array}{r}14,658 \\
74\end{array}$ & $\begin{array}{r}871,727 \\
49\end{array}$ & $\begin{array}{r}288,881 \\
48\end{array}$ & $\begin{array}{r}27,767 \\
76\end{array}$ & $\begin{array}{r}3,180,099 \\
71\end{array}$ & 830,160 & 35 \\
\hline & Programme & 18,610 & $1,555,350$ & 518,450 & 34,231 & $4,377,177$ & $1,185,673$ & 44] \\
\hline \multirow[t]{3}{*}{ 1995-1996 } & Realised & 11,598 & 660,636 & 257,591 & 25,992 & $2,754,555$ & 830,160 & 31 \\
\hline & $(\%)$ & 62 & & & 76 & & & \\
\hline & Programme & 22,577 & $1,924,650$ & 329,001 & 40,124 & $5,680,278$ & $1,024,561$ & 32 \\
\hline \multirow[t]{2}{*}{ 1996-1997 } & Realised & 16,927 & $1,072,708$ & 329,000 & 32,272 & $4,257,950$ & $1,024,565$ & 32 \\
\hline & (\%) & 75 & 56 & 100 & 80 & 75 & 100 & \\
\hline
\end{tabular}

Source: CNA District, Tepic, 1998. 
346 The Success of a Policy Model

Table 7 Monthly overview of irrigation service fee collection 1997-1998 (in Mexican pesos)

\begin{tabular}{|l|rllllll|r|}
\hline & \multicolumn{1}{|c}{ Oct. } & Nov. & Doc. & Jan. & \multicolumn{1}{c|}{ Fob. } & Mar. & \multicolumn{1}{c|}{ Apr-Sep } & Total \\
\hline Progr. fee coll. & 166,104 & 254,604 & 529,098 & 235,104 & 206,604 & 268,404 & $1,030,837$ & $2,690,755$ \\
Real fee coll. & 111,173 & 410,172 & 451,091 & 262,290 & 57,386 & 107,993 & \\
Progr. expenses & 154,405 & 210,546 & 326,846 & 219,246 & 214,946 & 229,548 & $1,335,218$ & $1,400,105$ \\
Real expenses & 49,763 & 213,537 & 461,561 & 178,076 & 136,676 & 148,668 & $2,690,755$ \\
Balance at bank & 23,334 & 121,003 & 150,625 & 130,137 & - & - & $1,188,281$ \\
\hline
\end{tabular}

Source: Data distributed by the association during the second assembly 


\section{Summary}

This thesis studies the emergence, process and outcomes of the Mexican policy of Irrigation Management Transfer (IMT). Under the influence of neo-liberal government policies, the transfer of government-managed irrigation districts to water users' associations (WUAs) has radically changed irrigation management in Mexico during the past fifteen years. Internationally, Mexico's IMT programme has been heralded as a success and has drawn widespread attention because of its rapid implementation. Consequently, it has been propagated as a model for other countries seeking to improve the performance of their public irrigation systems and cut burgeoning public expenditures. This study firstly critically examines the emergence of this policy model and its proclaimed success. Secondly, it discusses the impacts this has on everyday irrigation management. The contribution of this thesis to the study of policy reform and irrigation management is that it consistently analyses them as political practices that are also expressive of the cultural dimension of human action and social ordering.

The thesis is the product of intensive fieldwork carried out between 1997 and 1999. The first stage concerned a detailed organisation study of the WUA that is called the Left Bank of the River Santiago and is located on the Northern Coast of Nayarit in Western Mexico. The second stage of my research covered the entire life cycle of the IMT policy, from its earliest roots until its international celebration as a policy model. From the beginning, the ethnography of an organisation and the study of policy were basically intertwined throughout my research journey, although the emphasis shifted towards the latter.

On the one hand, the thesis offers a comprehensive analysis of the contemporary history of the IMT policy. It traces the idea of transfer back to its bureaucratic roots and reviews how the idea gained political commitment as the consequence of a prolonged bureaucratic struggle. This shows that the IMT policy has a fascinating history that it is tied up with the past and the future of the hydraulic bureaucracy (involved with hydraulic resources and water management). The formerly influential and autonomous Ministry of Water Resources lost its autonomy and its control over the irrigation districts in Mexico when it was merged halfway the 1970s with the agricultural bureaucracy (responsible for the agricultural sector). At the end of the 1980s, the IMT policy played an important role in the reconstitution of the hydraulic bureaucracy in the Comision Nacional del Agua (CNA: National Water Commission), which regained autonomy and control over the irrigation districts.

Initially, the effectuation of the policy was a contested process and the thesis shows how the assembling of a policy package responded to this. The actual policy package with which senior officials, called hydrocrats in this thesis, had to effectuate the transfer was experimented with, resisted and adapted significantly. After some time, this led to a standardisation of the package that worked to include and direct favourable leaderships and exclude resisting or uncontrollable elements. In the end, this contributed to an unforeseen acceleration in the pace of transfer in Mexico and an increasing control of the CNA over the process. Hence, I argue that, contrary to what is generally expected, IMT 
in Mexico did not lead to a withdrawal of the state from irrigation, but served to reorder and strengthen bureaucratic control over irrigation management from a distance.

On the other hand, this book takes a close look at the everyday organisational practices that have emerged in a WUA around the strategic resources of water, maintenance machinery and irrigation fees. It shows how a political group based in a WUA maintains a network of political and institutional relations by controlling this set of resources. A detailed understanding of everyday water use practices is established through two contrasting case studies of canaleros in water distribution. These cases investigate the role of the canalero in relation to the operational arrangements with which he deals in his daily work and his social position vis-à-vis the WUA management. The first of the two cases shows how a canalero's work is shaped, not by a set of rules, but by his frequent interactions with sprinkler irrigation and small-scale tobacco producers and the fact that he has rather distant relations with his superiors. This is used to falsify the neoinstitutional assumption that water distribution in particular, and organisational practices in general, are governed by a system of agreed rules and incentives. The second case study presents the case of a canalero who is a client to the political group that is in control of the WUA and performs an important role in a network of large-scale rice producers that irrigate using the surface irrigation method. By focusing on the role that this client plays in the distribution of various material and cultural resource flows, I illustrate that it is essential in the reproduction of the political group. This case addresses the need to revise simple sociological models of patron-client relations in which the patron monopolises all the power and resources on which his clients depend.

Besides studying water use, the thesis emphasises that maintenance is a particularly useful entry point to analyse the transfer and functioning of irrigation systems. The analysis illustrates that machine use contributes not only to the improvement of maintenance performance, in line with formal performance objectives, but also to other social, material and political practices and performances that transcend and change what are conceived to be the boundaries and objectives of an irrigation system. The approach taken illustrates that the managerial group, through their connection with maintenance machinery and the works it enables, engages in multiple performances. When the thesis focuses on irrigation fees, it demonstrates that, in spite of the expectations, fee collection continues to be a problematic issue even under the organisation of water users. Although the WUA has found a way of partly overcoming the problem of fee default among irrigating farmers, by reaching financial agreements with federal subsidy providers and agro-industrial companies, this has not resolved it entirely. This serves to challenge the policy view that the WUAs have generally achieved financial autonomy as an outcome of IMT and that they are accountable, both financially and electorally, to the larger community of water users.

A situational analysis of an election rally is the starting point to illustrate the political nature of resource allocation, the WUA as a political platform, and the rally as a cultural performance. It is a central chapter that shows how the political group in control of the WUA draws for electoral purposes on the material resources that are discussed in the other chapters of the organisational ethnography. It also shows how the group mobilises these resources in a culturally specific way to build an alliance of support and engage an electoral audience. In this manner the organisation becomes a platform to further the 
careers of the group's proponents and their ascendancy to important posts in the regional government. This aspect of the book illustrates that the continuous political nature of IMT and the resource use practices that it generates, affect the outcomes of the policy. In addition, it focuses attention on the cultural aspects of irrigation management and politics.

Towards the end of the thesis, I focus on how the Mexican IMT policy became an international policy model that was propagated as a success. This exercise in combination with the findings from the organisational ethnography puts 'the success of the Mexican IMT model' between quotation marks. The thesis analyses the cultural process of policy making that has generated the Mexican IMT policy model and follows the practices, means and events through which it has achieved increasing transnational circulation and popularity. The argument is that the success of a policy model is only a success within the cultural and ideological understandings and practices of the policy network in which it is generated and disseminated. This aspect of the book results in the understanding that policy is political throughout its life cycle and that policy making is a continuous and profoundly cultural undertaking. 


\section{Resumen}

Esta tesis estudia la aparición, proceso y resultados de la política mexicana de la Transferencia del Manejo de Riego (TMR). Bajo la influencia de políticas neo-liberales de gobierno, la transferencia de distritos de riego manejados por el gobiemo a las asociaciones de usuarios del agua (AUA) ha cambiado radicalmente el manejo de riego en México durante los pasados quince años. Internacionalmente, el programa de TMR de México ha sido anunciado como un éxito y ha llamado la atención general debido a su rápida realización. Por consiguiente, ha sido propagado como un modelo para otros países que procuran mejorar el desempeño de sus sistemas públicos de riego y recortar sus costos. Este estudio en primer lugar examina críticamente la aparición de este y su éxito proclamado. En segundo lugar, habla de los impactos que este modelo tiene sobre el manejo cotidiano del riego. La contribución de esta tesis al estudio de la reforma política y de manejo de riego consiste en que consistentemente los analiza como prácticas políticas que también expresan la dimensión cultural de acción humana y el ordenamiento social.

La tesis es el producto del trabajo de campo intensivo realizado entre 1997 y 1999. La primera etapa se enfocó en un estudio detallado de la organización de la AUA llamada Margen Izquierda del Río Santiago, sobre la Costa Norte de Nayarit en el Occidente de México. En la segunda etapa de mi investigación estudié el ciclo de vida de la política del TMR, desde sus orígenes más tempranos hasta su celebración internacional como un modelo de política. Desde el principio, la etnografía de una organización y el estudio de la política ligada a ella fue entretejida en todas las partes de mi jornada de investigación, aunque posteriormente el énfasis lo desplacé hacia lo segundo.

Por una parte, la tesis ofrece un análisis extenso de la historia contemporánea de la política de TMR. Mi tesis rastrea la idea de transferencia hasta sus raíces burocráticas y revisa cómo con esta idea se obtuvo el compromiso político para su puesta en marcha como consecuencia de de una lucha burocrática prolongada. La tesis muestra que la política de la TMR tiene una historia fascinante que esta ligada al pasado y al futuro de la burocracia hidráulica (involucrada con recursos hidráulicos). La Secretaría de Recursos Hidráulicos (SRH) anteriormente influyente y autónoma, perdió su autonomía y control sobre los distritos de riego en México cuando se fusionó en los años 1970s con la burocracia agrícola (a cargo del sector de agricultura). Hacia el final de los años 1980s, la política de la TMR desempeñó un papel importante en la reconstitución de la burocracia hidráulica en la Comisión Nacional del Agua (CNA), la cual recobró la autonomía y obtuvo el control sobre los distritos de riego.

Inicialmente, el cumplimiento de la política fue un proceso impugnado, y la tesis muestra cómo el ensamblado de un paquete de políticas respondió a esta lucha. El paquete de políticas con el que los funcionarios de riego de más alto rango (hidrócratos) tenían que realizar la transferencia fue experimentado, resistido y se adaptó considerablemente. Después de algún tiempo, este proceso condujo a una estandarización del paquete de trabajo que permitió incluir y utilizar liderazgos favorables y excluir elementos de resistencia o incontrolables. Al final, esto contribuyó a una aceleración imprevista en el ritmo de transferencia en México y a un control creciente de la CNA sobre el proceso. 
Aquí, argumento que, contrario a lo que generalmente se cree, la TMR en México no llevó a un retiro del estado de los asuntos de riego, sino sirvió para reordenar y fortalecer el control burocrático a distancia sobre el manejo del riego.

Por otra parte, en este libro muestro observaciones cercanas de las prácticas diarias de organización que han emergido en una AUA en torno a los recursos estratégicos de agua, maquinaria de conservación y pagos de riego. Muestro como un grupo político basado en una AUA mantiene una red de relaciones políticas e institucionales controlando este juego de recursos. Una comprensión detallada de las prácticas cotidianas de uso del agua se establece a través de los contrastes entre dos estudios de caso de canaleros distribuidores de agua. Estos casos investigan el papel del canalero con relación a las disposiciones operacionales con las que trata en su trabajo diario y, su posición social vis-à-vis la dirección de la AUA.

El primero de los dos casos muestra como se moldea el trabajo del canalero, no a través de una serie de reglas, sino a través de sus frecuentes interacciones con productores de tabaco a pequeña escala con prácticas de riego por aspersión y, aunado al hecho de que el canalero mantiene relaciones más bien distantes con sus superiores. Esto es utilizado para combatir la asunción neo-institucional de que la distribución del agua en particular, y las prácticas organizativas en general, están gobernadas por un sistema de reglas acordadas y de incentivos. El segundo estudio de caso presenta a un canalero que es cliente del grupo político que esta en control de la AUA y realiza un papel importante en una red de productores de arroz en gran escala que riegan a través del método de riego por superficie. Enfocándome en el papel que este cliente juega en la distribución de flujos de recursos materiales y culturales, ilustro que esto es esencial en la reproducción del grupo político. Este caso cubre la necesidad de revisar modelos sociológicos simples de relaciones patrón-cliente en las que el patrón monopoliza el poder y recursos sobre los cuales sus clientes dependen.

Además de estudiar el uso del agua, la tesis enfatiza que el mantenimiento es un punto de entrada particularmente útil para analizar la transferencia y el funcionamiento de sistemas de riego. El análisis ilustra que el uso de maquinaria contribuye no sólo a mejorar el desempeño del mantenimiento, de acuerdo a objetivos de desempeño formales, sino que también contribuye a otras prácticas y 'performances' sociales, materiales, políticas e interpretaciones que trascienden y cambian lo que se imaginaban limites y objetivos de un sistema de riego. La aproximación utilizada ilustra que el grupo directivo, por su unión con la maquinaria de conservación y los trabajos que permite realizar, se involucra en múltiple 'performances'. Cuando la tesis se enfoca en el pago de cuotas de riego demuestra que, a pesar de las expectativas, la colección de cuotas continúa siendo un asunto problemático inclusive bajo la organización de usuarios del agua. Aunque la AUA haya encontrado una forma de superar parcialmente el problema de la omisión de pagos entre agricultores que riegan a través de acuerdos financieros con proveedores de subsidios federales y compañías agro-industriales, el asunto no se ha resuelto por completo. Este punto sirve para retar la visión política de que las AUAs han generalmente alcanzado autonomía financiera como resultado de la TMR y que ellas son las responsables, tanto financieramente como electoralmente, ante la gran comunidad de usuarios de agua. 
Un análisis situacional de una campaña electoral es el punto de partida para ilustrar la naturaleza política de la asignación de recursos, de la AUA como plataforma política y, de la campaña electoral como desempeño cultural. Este (análisis) es un capítulo central que muestra como el grupo político en control de la AUA utiliza para propósitos electorales los recursos materiales, mismos que se presentan y discuten en los otros capítulos de la etnografía de la organización. También muestra cómo el grupo moviliza estos recursos en una forma culturalmente específica para construir una alianza de apoyo y ganar una audiencia de electores. En esta manera la organización se convierte en una plataforma para fomentar la carrera de los candidatos por el grupo y su ascenso a puestos importantes en el gobierno regional. Este aspecto del libro ilustra que la naturaleza continuamente política de la TMR y las prácticas de uso de recursos que genera, afectan los resultados de la política. Además, esto enfoca la atención sobre los aspectos culturales del manejo del riego y de la política.

Hacia el fin de esta tesis, me concentro en cómo la política mexicana de la TMR se convirtió en un modelo internacional de política que fue propagado como un éxito. Este ejercicio en combinación con los hallazgos de la etnografía de la organización pone 'el éxito del modelo mexicano de la TMR' entre comillas. La tesis analiza el proceso cultural de hacer política (policy making) que ha generado el modelo mexicano de la TMR y sigue las prácticas, significados y eventos a través de los cuales ha alcanzado una circulación transnacional y una popularidad creciente. El argumento es que el éxito de un modelo de política es sólo un éxito dentro de la comprensión ideológica, cultural y de las prácticas de la red política (policy network) en la que se ha generado y diseminado. Este aspecto del libro resulta en la comprensión de que la política (policy) de TMR es política (political) a través de todo su ciclo de vida y de que el hacer política es una continua y profunda tarea cultural. 


\section{Samenvatting}

Dit boek bestudeert het ontstaan, het proces en de uitkomsten van Irrigation Management Transfer in Mexico (IMT; Irrigatie Management Overdracht). Onder invloed van neoliberaal overheidsbeleid heeft de overdracht van de door de overheid beheerde irrigatiesystemen aan Water Users' Associations (WUAs; watergebruikers' organisaties), het irrigatie management in Mexico radicaal veranderd. Het Mexicaanse IMT beleid trok internationaal de aandacht vanwege haar snelle implementatie en werd uitgeroepen tot een succes. Als gevolg hiervan werd het een model voor andere landen die trachtten om de performance (prestatie) van hun irrigatie systemen te verbeteren en de publieke uitgaven terug te brengen. Deze studie onderzoekt enerzijds het ontstaan van dit beleidsmodel en haar verkondigde succes op een kritische wijze. Anderzijds bestudeert ze de gevolgen die dit heeft voor het alledaagse irrigatie management. De bijdrage van dit boek aan de studie van beleidshervorming en irrigatie management is dat het deze consistent analyseert als politieke praktijken die ook uitdrukking geven aan de culturele dimensie van menselijke actie en sociale ordening.

Dit proefschrift is het product van intensief veldwerk dat werd uitgevoerd tussen 1997 en 1999. De eerste fase betrof een gedetailleerde studie van één WUA op de linkeroever van de Santiago rivier aan de Noordelijke kust van Nayarit in West Mexico. Het tweede deel van mijn onderzoek dekte de gehele levenscyclus van het IMT beleidsmodel. Vanaf het begin waren de etnografie van organisatie en de studie van beleid vervlochten in mijn onderzoek, ook al verschoof de nadruk in de loop van de tijd van het eerste naar het laatste.

Aan de ene kant biedt dit proefschrift een grondige analyse van de eigentijdse geschiedenis van het IMT beleid. Het gaat op zoek naar de bureaucratische wortels van het idee van overdracht en beschrijft hoe het idee aan politieke steun won als gevolg van een lange bureaucratische strijd. Dit toont dat het IMT beleid een fascinerende geschiedenis heeft die verbonden is met het verleden en de toekomst van de hydraulische bureaucratie (verantwoordelijk voor hydraulische werken en water management). Het voorheen invloedrijke en autonome Ministerie van Waterstaat (Water Resources) verloor haar autonomie en de controle over de irrigatie districten in Mexico, toen het half jaren 70 gefuseerd werd met de agrarische bureaucratie (verantwoordelijk voor de landbouw). Aan het eind van de jaren 80 speelde het IMT beleid een belangrijke rol in het wederom oprichten van een hydraulische bureaucratie in de vorm van de Comisión Nacional del Agua (CNA; Nationale Water Commissie), welke autonomie en controle over de irrigatie districten herwon.

In aanvang was de toepassing van het beleid een omstreden proces en dit proefschrift toont hoe de samenstelling van het beleidspakket dit reflecteert. Het concrete beleidspakket waarmee de hoge functionarissen (hydrocraten) de overdracht uitvoerden, was onderwerp van experimenten, ondervond weerstand en als veranderde als gevolg hiervan van samenstelling. Na verloop van tijd leidde dit tot een standaardisatie van het beleidspakket, wat toestond dat gunstig gestemde leiders werden geïncorporeerd en gestuurd, terwijl het verzet en de oncontroleerbare elementen werden buitengesloten. Uiteindelijk droeg dit bij tot een onvoorziene versnelling in de overdracht van irrigatie 
districten en een toenemende controle van het CNA over dit proces. Daarom beargumenteer $\mathrm{ik}$, in tegenstelling tot wat er algemeen verwacht werd, dat IMT niet leidde tot een terugtrekking van de staat uit de irrigatie, maar diende ter herordening en versterking van de bureaucratische controle over irrigatie management op een afstand.

Aan de andere kant ontwikkelt dit boek een nadere kijk op de alledaagse organisatie praktijken die zijn ontstaan in een WUA rondom de strategische middelen: water, machines voor onderhoud en irrigatie belastingen (irrigation fees). Dit laat zien hoe een politieke groep vanuit een WUA een netwerk van politieke en institutionele relaties onderhoudt door het controleren van deze hulpbronnen. Een gedetailleerd begrip van water verdelingspraktijken wordt bereikt door twee contrasterende case studies van canaleros die verantwoordelijk zijn voor de dagelijkse waterverdeling. Deze cases onderzoeken de rol van de canalero in relatie tot de operationele arrangementen waar hij in zijn dagelijkse werk mee te maken heeft en zijn sociale positie vis-à-vis het management van de WUA. De eerste van de twee cases laat zien hoe het werk van een canalero wordt gevormd, niet door een stel regels, maar door zijn regelmatige interactie met kleinschalige tabaksboeren die sprinkler irrigatie bedrijven, alsmede de afstandelijke relatie die hij heeft met zijn superieuren. Deze case wordt gebruikt om de neoinstitutionele aanname te problematiseren dat waterverdeling in het bijzonder en organisatie praktijken in het algemeen worden gestuurd door een stel overeengekomen regels en prikkels. De tweede case studie presenteert de situatie van een canalero die cliënt is van de politieke groep die de WUA controleert. Deze vervult een belangrijke rol in een netwerk van grootschalige rijstproducenten die irrigeren door middel van oppervlakte irrigatie. Door te focussen op de rol die deze cliënt speelt in het verdelen van verschillende materiële en culturele hulpbronnen, illustreer $i k$ dat deze essentieel is in de reproductie van de politieke groep. Deze case toont de noodzaak aan voor het herzien van eenvoudige sociologische modellen van patroon-cliënt verhoudingen te herzien, waarbij de patroon alle macht en middelen monopoliseert waar zijn cliënten afhankelijk van zijn.

Naast het besturen van watergebruik, benadrukt dit proefschrift dat het onderhoud een bijzonder geschikte ingang is voor het analyseren van de overdracht en het functioneren van irrigatie systemen. De analyse laat zien dat machine gebruik niet alleen bijdraagt aan de verbetering van het onderhoud, in overeenstemming met performance doelstellingen, maar ook aan andere sociale, materiële en politieke praktijken en verrichtingen, die wat als de grenzen en doelstellingen van het irrigatie systeem gezien worden overstijgen en veranderen. De gekozen benadering illustreert dat het management van de WUA door de connecties die zij met onderhoudsmachines maakt, betrokken is bij meerdere verrichtingen (performances). Wanneer het proefschrift zich richt op irrigatie belastingen, laat het zien dat in tegenstelling tot de verwachtingen, de inning daarvan nog steeds een probleem is, zelfs onder de organisatie van water gebruikers. Hoewel de WUA een manier gevonden heeft om het probleem van belastingontduiking onder irrigerende boeren gedeeltelijk te omzeilen door financiële overeenkomsten met federale subsidiegevers en agro-industriële bedrijven, heeft dit het probleem lang niet in het geheel opgelost. Dit dient om het beleidstandpunt te problematiseren dat als gevolg van IMT de WUAs over het algemeen financiële autonomie hebben bereikt en dat ze zowel financieel als electoraal verantwoording schuldig zijn aan de water gebruikers. 
Een situationele analyse van een verkiezingsbijeenkomst is het uitgangspunt om de politieke aard van de verdeling van hulpbronnen, de WUA als een politiek platform en de bijeenkomst als een culturele performance te demonstreren. Dit laat zien hoe de politieke groep die controle heeft over de WUA, gebruik maakt van een variëteit aan materiële hulpbronnen voor electorale doeleinden. Het demonstreert ook dat deze hulpbronnen op een cultureel specifieke manier worden aangewend om een electoraal draagvlak te creëren en een publiek van stemmers te onderhouden. Hierdoor wordt de WUA als organisatie een platform voor het bevorderen van de carrières van politieke leiders en het verkrijgen van belangrijke posten in de regionale overheid. Dit aspect van het boek illustreert dat de politieke aard van IMT en het gebruik van hulpbronnen dat hieruit voortkomt de uitkomsten van het beleid beïnvloeden. Verder geeft het aandacht aan de culturele aspecten van irrigatie management en politiek.

Richting het eind van dit boek toon ik hoe het Mexicaanse IMT beleid zich tot een internationaal beleidsmodel ontwikkelde en gepropageerd werd als een succes. Dit perspectief op het beleid in combinatie met de bevindingen van de organisatie etnografie plaatst het succes van het Mexicaanse IMT beleidsmodel tussen aanhalingstekens. Het proefschrift analyseert het culturele proces van beleid maken en volgt de praktijken, middelen en gebeurtenissen waardoor het een toenemende transnationale circulatie en populariteit verkrijgt. Het argument is dat het succes van een beleidsmodel alleen een succes is binnen de culturele en ideologische begrippen en praktijken van een beleidsnetwerk, waarbinnen het geproduceerd en verspreid wordt. Hieruit volgt dat gedurende de gehele levenscyclus beleid politiek is en dat het proces van beleid maken een continu en intens culturele onderneming is. 


\section{Curriculum Vitae}

Edwin Rap was born on the $27^{\text {th }}$ of November 1968 in Steenwijk, The Netherlands. In 1987 he started his study Tropical Land and Water use (Tropische Cultuurtechniek) at the Wageningen University. During his study he followed a curriculum that specialised in philosophy of science, rural extension and development sociology. Research on knowledge transfer and learning processes in rural extension took him to Zambia. At the end of his study he carried out an organisational study of a Water Users' Association in Western Mexico, which introduced him to the theme of Irrigation Management Transfer in Mexico. In 1993 he graduated (MSc) with distinction (cum laude). In the years that followed, he worked for the Rural Extension group of the International Agricultural Centre (IAC), the Management of Agricultural Knowledge Systems (MAKS) course, and the Department of Rural Development Sociology of the Wageningen University. To further pursue his research interests; he subsequently wrote a research proposal for the Netherlands Foundation of Tropical Research (WOTRO). When the funding was awarded in 1997, he left for Mexico, where he carried out the fieldwork until 1999. In recent years he has written his thesis based on this fieldwork, presented papers at several international conferences, and was involved in the organisation of researchers' and network activities within the research school CERES and at the Department of Rural Development Sociology, where he was based. In 2003 he was connected for several months to the International Development Studies group of the Roskilde University in Denmark. His research interests include the ethnography of policy and organisation and political and material culture, with special reference to water management and resource allocation issues. 
Cover: A series of moving animals representing the speed and success of policy models (see Chapter 10) Cover design: Olivier Rijcken and Edwin Rap

Maps: Pim van Hengel

Photographs and lay-out: Edwin Rap

Language correction: Catherine O'Dea

Printed by: Pons \& Looyen b.v. 